Universidade de São Paulo

Escola de Engenharia de São Carlos

Departamento de Engenharia de Estruturas

\title{
VIGAS DE CONCRETO ARMADO COM TELAS SOLDADAS: ANÁLISE TEÓRICA E EXPERIMENTAL DA RESISTÊNCIA À FORÇA CORTANTE E DO CONTROLE DA FISSURAÇÃO
}

\author{
Reginaldo Carneiro da Silva
}

Tese apresentada à Escola de Engenharia de São Carlos, da Universidade de São Paulo, como parte dos requisitos para obtenção do título de Doutor em Engenharia de Estruturas.

ORIENTADOR: José Samuel Giongo

São Carlos -SP

2003 
Aos meus pais, meus primeiros mestres na vida. À minha esposa Letícia e aos meus filhos Matheus, Henrique e Natália, companheiros de jornada. 


\section{Agradecimentos}

A Deus, sempre presente ao meu lado.

Ao Prof. José Samuel Giongo pela orientação segura, ensinamentos, incentivo e amizade nesses anos de convivência.

Ao programa PICD/CAPES pela concessão de bolsa de estudos.

À Fundação de Amparo à Pesquisa do Estado de São Paulo, pelo financiamento do programa experimental.

Aos professores Ibrahim Shehata e João Bento de Hanai, pelas sugestões no Exame de Qualificação.

Aos técnicos do Laboratório de Estruturas, Amaury, Jorge, Mário, Mauri e Valdir e aos estagiários Fabiano, Matheus, Juliano e Waldemir pela dedicação na execução dos ensaios, sem o trabalho dos quais o programa experimental não teria sido desenvolvido.

Aos funcionários do Serviço de Marcenaria da EESC-USP.

À empresa GERDAU S. A., pela doação de materiais usados na pesquisa e ao Eng. João Batista Rodrigues da Silva do IBTS.

Ao Eng. Luís Vareda e ao Prof. Toshiaki Takeya, que dispensam comentários.

À Profa. Maria Ângela de Pace Almeida Prado Giongo.

Aos colegas e amigos da pós-graduação Romel, Rodrigo, Petrus, Humberto, Rita de Cássia, Fábio, Geraldo, Tatiana, Mônica, Adilson e Maiola.

Aos colegas e amigos do Setor de Estruturas do Departamento de Engenharia Civil da UFV, com os quais estarei compartilhando os conhecimentos adquiridos.

Ao Departamento de Engenharia Civil da Universidade Federal de Viçosa pela oportunidade concedida.

À bibliotecária Maria Nadir Minatel, pela orientação no trabalho de referências bibliográficas.

Aos funcionários Francisco, Sylvia, Rosi, Júnior e Masaki pela ajuda prestada durante a elaboração deste trabalho.

Aos demais funcionários e professores do Departamento de Engenharia de Estruturas da EESC-USP, que de alguma forma colaboraram para a execução do presente trabalho.

Ao meu irmão Sérgio que resolveu tudo em Viçosa durante minha ausência. 


\section{SUMÁRIO}

RESUMO

ABSTRACT

1 - INTRODUÇÃO

1.1 - GENERALIDADES 01

1.2 - OBJETIVOS 03

1.2.1 - OBJETIVO GERAL 03

1.2.2 - OBJETIVOS ESPECÍFICOS 03

1.4 - JUSTIFICATIVA 03

1.5 - APRESENTAÇÃO 05

2 - ARRANJOS DE ARMADURAS EM VIGAS

$\begin{array}{ll}2.1 \text { - PRELIMINARES } & 07\end{array}$

2.2 - ESTRIBOS VERTICAIS 07

2.3 - ARMADURA DE PELE 12

2.4 - TELAS SOLDADAS 16

2.5 - INDUSTRIALIZAÇÃO DAS ARMADURAS 20

2.5.1 - SISTEMA DE CORTE E DOBRA 22

2.5.2 - TELAS SOLDADAS 22

2.5.3 - VIGAS 23

3 - RESISTÊNCIA AO CISALHAMENTO 26

3.1 - MECANISMOS RESISTENTES À FORÇA CORTANTE 26

3.2 - FATORES QUE INFLUEM NA RESISTÊNCIA AO CISALHAMENTO 30

3.3 - MODOS DE RUÍNA 33

3.4 - DIMENSIONAMENTO DE ACORDO COM

NORMAS/PESQUISADORES 35

3.4.1 - PROJETO DE REVISÃO DA NBR 6118: 2001

3.4.1.1 - Generalidades 35

3.4.1.2 - Verificação do Estado Limite Último 36

3.4.1.3 - Modelo de cálculo I 36 
3.4.1.4 - Modelo de cálculo II 37

3.4.1.5 - Armadura mínima e espaçamentos 38

3.4.2 - CÓDIGO MODELO CEB-FIP (1990) 38

3.4.2.1 - Generalidades 38

3.4.2.2 - Condições para aplicação dos modelos 39

3.4.2.3 - Expressões para o dimensionamento 39

3.4.2.4 - Procedimento para verificação 43

3.4.2.5 - Determinação do ângulo $\theta$

3.4.2.6 - Distribuição dos estribos $\quad 44$

3.4.3 - ACI 318R (2002) 44

3.4.3.1 - Generalidades $\quad 44$

3.4.3.2 - Contribuição do concreto 45

3.4.3.3 - Dimensionamento da armadura transversal 45

3.4.3.4 - Armadura mínima e espaçamentos 46

3.4.4 - EUROCODE 2 (1992) 46

3.4.4.1 - Generalidades $\quad 46$

3.4.4.2 - Verificação da ruptura do concreto 47

3.4.4.3 - Verificação da necessidade de armadura transversal 47

3.4.4.4 - Cálculo da armadura transversal 48

3.4.4.5 - Armadura mínima e espaçamentos 49

3.4.5 - ZSUTTY (1968) 50

3.4.6 - NORMA ESPANHOLA EHE (1999) 51

3.4.6.1 - Generalidades 51

3.4.6.2 - Obtenção de $V_{u 1}$

3.4.6.3 - Obtenção de $V_{u 2}$

3.4.6.4 - Armadura mínima e espaçamentos $\quad 54$

3.5 - RESISTÊNCIA AO CISALHAMENTO EM VIGAS

COM TELAS SOLDADAS 55

4 - TEORIA DO CISALHAMENTO-ATRITO 58

4.1 - CONSIDERAÇÕES INICIAIS $\quad 58$

4.2 - TEORIA CLÁSSICA DO CISALHAMENTO-ATRITO 60 
4.3 - TEORIA DO CISALHAMENTO-ATRITO MODIFICADA 62

4.4 - VIGAS COM ESTRIBOS VERTICAIS 65

4.4.1 - COMENTÁRIOS INICIAIS 65

4.4.2 - HIPÓTESES BÁSICAS 66

4.4.3 - EQUAÇÕES INICIALMENTE PROPOSTAS 66

4.4.4 - EQUAÇÕES SIMPLIFICADAS 71

4.5 - FORMULAÇÃO PROPOSTA (VIGAS COM ESTRIBOS

VERTICAIS E ARMADURA LATERAL) 75

5 - FISSURAÇÃO

5.1 - CONSIDERAÇÕES INICIAIS

5.2 - A FISSURAÇÃO NO CONCRETO ARMADO 80

5.3 - MOMENTO DE FISSURAÇÃO 81

5.4 - ESTADO LIMITE DE FORMAÇÃO DE FISSURAS

DE CISALHAMENTO 81

5.5 - FISSURAS DE FLEXÃO 83

5.5.1 - CRITÉRIO DO PROJETO DE REVISÃO DA

NBR 6118: 2001

5.5.2 - CRITÉRIO DO EUROCODE 2 (1992) 85

5.5.3 - CRITÉRIO DA NORMA ESPANHOLA EHE (1999) 87

5.6 - FISSURAS DE CISALHAMENTO 89

5.6.1 - LEONHARDT (1979) ADAPTADA POR NOBRE (1992) 90

5.6.2 - CÓDIGO MODELO CEB-FIP (1978) 91

5.6.3 - NORMA ESPANHOLA EHE (1999) 92

6 - ESTUDOS EXPERIMENTAIS REALIZADOS POR OUTROS

PESQUISADORES $\quad 94$

6.1 - PRELIMINARES 94

6.2 - VIGAS COM ESTRIBOS VERTICAIS ABERTOS 94

6.3 - VIGAS COM ESTRIBOS VERTICAIS E ARMADURA DE PELE 97

6.4 - VIGAS ARMADAS COM TELAS SOLDADAS 108 
$\begin{array}{ll}7.1 \text { - CONSIDERAÇÕES INICIAIS } & 121\end{array}$

7.2 - MODELOS EXPERIMENTAIS 122

7.2.1 - DENOMINAÇÃO E PARÂMETROS ENVOLVIDOS 122

7.2.2 - DIMENSIONAMENTO DAS VIGAS 124

7.2.2.1 - Resistência à força cortante 124

7.2.2.2 - Resistência à flexão 125

7.2.2.3 - Ancoragem e distribuição na seção da armadura longitudinal 127

$\begin{array}{ll}\text { 7.2.3 - DETALHAMENTO DAS VIGAS } & 128\end{array}$

7.3 - MATERIAIS UTILIZADOS $\quad 142$

7.3.1 - FÔRMAS 142

7.3.2 - CONCRETO 147

$\begin{array}{ll}\text { 7.3.3 - ARMADURAS } & 150\end{array}$

7.3.3.1 - Barras de aço 150

7.3.3.2 - Telas soldadas 151

7.4 - EQUIPAMENTOS 152

7.5 - INSTRUMENTAÇÃO 155

7.5.1 - FORÇAS APLICADAS 155

7.5.2 - DESLOCAMENTOS VERTICAIS 155

7.5.3 - DEFORMAÇÕES ESPECÍFICAS NAS ARMADURAS 156

7.5.4 - DEFORMAÇÕES ESPECÍFICAS NO CONCRETO 162

7.5.5 - FISSURAÇÃO 163

7.6 - ESQUEMA DE ENSAIO 164

7.7 - EXECUÇÃO DOS ENSAIOS 165

7.7.1 - DESCRIÇÃO GERAL 165

7.7.1.1 - Montagem das fôrmas 165

7.7.1.2 - Montagem das armaduras 166

$\begin{array}{ll}\text { 7.7.1.3 - Concretagem } & 167\end{array}$

7.7.1.4 - Cura 168

7.7.1.5 - Aplicação do carregamento 168

7.7.2 - DESCRIÇÃO DE CADA SÉRIE 169

$\begin{array}{ll}\text { 7.7.2.1 - Série A1 } & 169\end{array}$ 
7.7.2.2 - Série B

169

7.7.2.3 - Série D

169

7.7.2.4 - Série A2

170

7.7.2.5 - Série $\mathrm{C}$

173

8 - RESULTADOS DOS ENSAIOS

174

8.1 - INTRODUÇÃO

174

8.2 - FORMAÇÃO E DESENVOLVIMENTO DAS FISSURAS

175

8.2.1 - SÉRIE A1

175

8.2.1.1 - VQ-0

175

8.2.1.2 - VQ-1

175

8.2.1.3 - VQ-2

176

8.2.1.4 - VQ-3

176

8.2.2 - SÉRIE B

179

8.2.2.1 - VQ-4

179

8.2.2.2 - VQ-5

179

8.2.2.3 - VQ-6

179

8.2.2.4 - VQ-1A

180

8.2.3 - SÉRIE D

182

8.2.3.1 - VQ-7

182

8.2.3.2 - VQ-8

182

8.2.3.3 - VQ-9

183

8.2.3.4 - VQ-10

183

8.2.4 - SÉRIE A2

186

8.2.4.1 - VS-0

186

8.2.4.2 - VS-1

186

8.2.4.3 - VS-2

186

8.2.4.4 - VS-3

187

8.2.5 - SÉRIE C

189

8.2.5.1 - VS-4

189

8.2.5.2 - VS-5

190

8.2.5.3 - VS-6

190

8.3 - FORÇAS E MODOS DE RUÍNA

192 
8.4 - DESLOCAMENTOS VERTICAIS 193

8.5 - DEFORMAÇÕES NA ARMADURA LONGITUDINAL 196

8.6 - DEFORMAÇÕES NO CONCRETO COMPRIMIDO 199

8.7 - DEFORMAÇÕES NOS ESTRIBOS VERTICAIS 202

8.8 - DEFORMAÇÕES NAS ARMADURAS LATERAIS 212

8.9 - ABERTURAS E ESPAÇAMENTOS DAS FISSURAS 219

9 - ANÁLISE DOS RESULTADOS 220

9.1 - PRELIMINARES 220

9.2 - FORÇA CORTANTE ÚLTIMA 220

9.2.1 - NORMAS TÉCNICAS E PESQUISADORES 220

9.2.2 - PROPOSTA DE SILVA, RITA C. (1999) 224

9.2.3 - FORMULAÇÃO PROPOSTA 226

9.3 - ANÁLISE DOS PARÂMETROS ENVOLVIDOS 228

9.3.1 - INFLUÊNCIA DA RESISTÊNCIA À COMPRESSÃO

DO CONCRETO 228

9.3.2 - INFLUÊNCIA DA ALTURA DA VIGA 230

9.3.3 - INFLUÊNCIA DA TAXA DE ARMADURA

LONGITUDINAL 231

9.3.4 - INFLUÊNCIA DA TAXA DE ARMADURA

TRANSVERSAL 231

9.3.5 - INFLUÊNCIA DA TAXA DE ARMADURA

LATERAL 232

9.3.6 - INFLUÊNCIA DO TIPO DE ANCORAGEM

DA TELA NA BORDA COMPRIMIDA 233

9.3.7 - ANÁLISE COMPARATIVA ARMADURA LATERAL (FIOS AMARRADOS X TELA SOLDADA) 235

9.4 - ESTADOS LIMITES DE SERVIÇO 235

9.4.1 - MOMENTO FLETOR DE FISSURAÇÃO 235

9.4.2 - FORÇA CORTANTE DE FISSURAÇÃO 236

9.4.3 - ABERTURAS DE FISSURAS DE CISALHAMENTO 237

9.4.3.1 - SÉRIE A1 237

9.4.3.2 - SÉRIE B 240 
9.5 - DEFORMAÇÕES NOS ESTRIBOS VERTICAIS E ARMADURAS LATERAIS

10 - CONCLUSÃ̃o

10.1 - CONSIDERAÇÕES INICIAIS

10.2 - FORÇA ÚLTIMA

10.3 - ESTADOS LIMITES DE SERVIÇO

10.4 - CONTINUIDADE DA PESQUISA

REFERÊNCIAS BIBLIOGRÁFICAS 


\section{RESUMO}

SILVA, R. C. (2003). Vigas de concreto armado com telas soldadas: análise teórica e experimental da resistência à força cortante e do controle da fissuração. São Carlos. 264 p. Tese (Doutorado) - Escola de Engenharia de São Carlos, Universidade de São Paulo, Brasil.

Este trabalho apresenta uma análise teórica e experimental do desempenho de vigas de concreto armado com telas soldadas com relação à resistência à força cortante e ao controle da fissuração. O programa experimental englobou cinco séries de vigas com variação dos seguintes parâmetros: largura e altura das vigas, taxa de armadura transversal, taxa de armadura lateral e tipo de ancoragem dos fios verticais da tela no bordo comprimido da viga. Os modelos experimentais foram constituídos por doze vigas VQ (15 x $40 \times 305)$, relação a/d $=2,78$ e sete vigas VS $(20 \times 70 \times 540), \mathrm{a} / \mathrm{d}=2,66$, ambas com seção $\mathrm{T}\left(b_{f}=50 \mathrm{~cm}\right.$ e $\left.h_{f}=10 \mathrm{~cm}\right)$. O esquema de ensaio foi de uma viga simplesmente apoiada, com duas forças concentradas aplicadas. A formulação proposta, elaborada com base na teoria do cisalhamento-atrito, considerando a contribuição da armadura lateral na resistência à força cortante, foi analisada mediante os resultados obtidos nos ensaios. Analisaram-se também as aberturas das fissuras de cisalhamento na alma. A contribuição da armadura lateral da tela soldada deve-se à alteração em dois mecanismos resistentes alternativos: aumento da parcela de engrenamento dos agregados afetada pelas menores aberturas das fissuras de cisalhamento na alma e pelo efeito de pino dos fios da armadura lateral nos pontos em que são interceptados pelas fissuras diagonais. De modo geral, as vigas armadas com telas soldadas apresentaram menores aberturas de fissuras de cisalhamento na alma, um panorama de fissuração mais sistemático e maior reserva de resistência nas proximidades do colapso.

Palavras-chave: vigas, concreto armado, tela soldada, força cortante, fissuração. 


\begin{abstract}
SILVA, R. C. (2003). Reinforced concrete beams with welded wire mesh: theoreticalexperimental analysis of the shear strength and the control of cracking. São Carlos. $264 \mathrm{p} . \mathrm{Ph}$. D. Thesis - School of Engineering of São Carlos, University of São Paulo, Brazil.
\end{abstract}

Keywords: beams, reinforced concrete, welded wire fabric, shear, cracking.

This work presents a theoretical-experimental analysis of performance shear design and cracking control in reinforced concrete beams with welded wire mesh. The experimental program consisted of five series of beams with variation of the following parameters: width and depth of the beam, transversal reinforcement ratio, lateral reinforcement ratio and type of stirrup anchorage in beam compression zone. The tested specimens comprised of twelve beams VQ (15 x 40 x 305), shear span-to-depth a/d = 2,78 and seven beams VS $(20 \times 70 \times 540), a / d=2,66$, both with $\mathrm{T}$ transversal section $\left(b_{f}=50 \mathrm{~cm} e h_{f}=10 \mathrm{~cm}\right)$. The test setup was a simply supported beam, with two concentrated forces applied. The proposed model was based on shear friction, which took account of the lateral reinforcement contribution on shear design. This model was compared with the test results. It was also studied the shear crack widths on the web beam. The lateral reinforcement contribution is provided by two alternative strength mechanisms: the increasing of portion agreggate interlock affected by smaller diagonal crack widths and the dowel effect of lateral reinforcement wires intercepted by diagonal plane failure. Generally, the welded wire fabric beams presented smaller inclined shear cracks, a better cracking configuration and higher strength reserve close to colapse. 


\section{1 \\ INTRODUÇÃO}

\section{1 - GENERALIDADES}

A construção civil responde por aproximadamente 15\% do P.I.B. (Produto Interno Bruto), gerando em torno de 15 milhões de empregos. Há pelo menos duas décadas, essa indústria tem encontrado dificuldades inerentes à realidade na qual se insere: grande déficit habitacional e de infra-estrutura urbana, financiamento insuficiente, exigência do cliente incompatível com o estágio tecnológico e baixa renda do possível comprador. Nos últimos anos ocorreram aumentos significativos nos preços dos materiais de construção (para citar apenas dois, cimento e aço). Os índices de variação de preços são quase sempre superiores aos índices setoriais, como INCC (Índice Nacional de Custos da Construção) ou CUB (Custo Unitário Básico). O custo da mão-de-obra também apresenta variações bem acima dos índices citados. Hoje pode-se afirmar que, simplificadamente, o custo da mão-de-obra representa em torno de $45 \%$ do custo final da obra.

Com uma concorrência acirrada e preços de venda praticados abaixo dos valores históricos, apresentam-se duas alternativas: piora da qualidade do produto ou investimento em racionalização do processo construtivo e aumento da produtividade da mão-de-obra. A 
primeira alternativa seria um contrasenso, ainda mais com as exigências atuais do Código de Defesa do Consumidor.

Antigamente, quase não se falava em treinamento e qualificação da mão-de-obra, porque esse item sempre foi considerado pouco relevante em relação ao custo final do empreendimento. Hoje em dia, para a sobrevivência do setor, os investimentos em racionalização da construção e aumento da produtividade da mão-de-obra são essenciais.

A industrialização da construção, que é uma tendência irreversível e traz como consequências custos mais baixos, menores prazos de entrega e melhoria da qualidade do produto, dentre outras vantagens, deve ser implantada com uma visão sistêmica, com uma mudança de paradigmas.

Algumas construtoras, nas principais cidades brasileiras, já possuem grande parte da mão-de-obra terceirizada, ou seja, funcionam verdadeiramente como indústrias: gerenciam os contratos, recebem as partes prontas e executam a montagem. Nesse contexto, deve-se enfatizar a importância da industrialização da produção das armaduras dos elementos estruturais de concreto armado.

A maioria das obras de concreto armado no Brasil ainda utiliza o processo convencional de preparação das armaduras dos elementos estruturais. Com a tendência de industrialização da construção, observa-se um crescente aumento da utilização do sistema de corte e dobra e de telas soldadas.

O sistema industrializado exige menor utilização de mão-de-obra, quase que elimina o desperdício de material, garante qualidade superior no corte e na dobra das barras de aço e rapidez de execução. Em alguns países, praticamente só se utiliza o sistema industrializado de preparação das armaduras.

As telas soldadas também podem ser utilizadas como estribos de vigas, de pilares e de outros elementos estruturais. Nesse caso, as mesmas seriam cortadas e dobradas para formarem as "gaiolas", acrescentando-se barras de aço adicionais (armaduras de flexão) posicionadas de acordo com o projeto. No Brasil, estima-se algo em torno de $4 \%$ de participação da tela soldada no mercado de aço, um percentual extremamente baixo em relação aos países mais desenvolvidos.

As telas soldadas não são comumente utilizadas como armaduras de vigas, salvo exceções (pré-moldados, por exemplo). Com a tendência à industrialização da construção civil, certamente serão utilizadas no futuro.

Esta pesquisa aborda as vigas de concreto armado com telas soldadas analisando-se a resistência à força cortante, considerando a contribuição da armadura lateral (fios 
longitudinais da tela soldada posicionados na lateral da viga), o controle da fissuração e a ancoragem dos fios verticais da tela (estribos) na borda comprimida da viga.

LOOV (1998) propõe uma formulação para o dimensionamento de vigas à força cortante tomando como base a teoria do cisalhamento-atrito. A formulação proposta pelo autor, que considerou a contribuição dos fios horizontais da tela na resistência à força cortante, foi validada pelos resultados dos ensaios feitos no programa experimental.

\section{2 - OBJETIVOS}

\subsection{1 - OBJETIVO GERAL}

Este trabalho pretende fornecer subsídios para o projeto de vigas de concreto armado com telas soldadas em relação à capacidade resistente e ao comportamento em serviço sob a ação de força cortante.

\subsection{2 - OBJETIVOS ESPECÍFICOS}

- Avaliar as rotinas de dimensionamento à força cortante em vigas de concreto armado e sua possível aplicação às vigas armadas com telas soldadas;

- propor formulação que considera a contribuição da armadura lateral na resistência à força cortante, utilizando a teoria do cisalhamento-atrito;

- validar a formulação proposta por meio dos resultados dos ensaios;

- analisar experimentalmente as aberturas de fissuras de cisalhamento em relação às expressões teóricas propostas;

- investigar a influência das telas soldadas no controle da fissuração da viga;

\section{3 - JUSTIFICATIVA}

Num futuro próximo, com a tendência à industrialização da construção, as vigas com telas soldadas poderão ser amplamente utilizadas, proporcionando melhor qualidade e maior rapidez de execução das estruturas de concreto armado. Assim sendo, o processo 
artesanal de produção dos estribos de vigas - corte, dobras e montagem - será substituído por um processo mais eficiente de montagem das armaduras.

Em relação à ancoragem dos fios verticais das telas na borda comprimida da viga, ensaios realizados por LEONHARDT \& WALTHER (1965) e MANSUR et al. (1986) indicam detalhes de ancoragem de difícil realização na prática, por exemplo: ganchos nas telas, posicionamento de dois fios longitudinais de mesmo diâmetro soldados pouco espaçados e utilização de um fio longitudinal soldado de maior diâmetro. Alguns desses detalhes trariam dificuldades ao processo de industrialização da produção de armaduras, tais como: maior número de dobras das telas, fios ou barras adicionais soldadas no local ou fabricação de telas específicas para vigas.

Normas atuais, como a norma canadense CSA-A23.3-94 (1994), o ACI 318R (2002) e o Projeto de Revisão da NBR 6118:2001 também indicam os mesmos detalhes de ancoragem.

Os autores citados analisaram o comportamento de vigas armadas com telas com um número pequeno de fios horizontais, com a finalidade apenas de manter os fios verticais corretamente posicionados. Eventualmente, foram colocados fios horizontais adicionais próximos da borda superior com a finalidade única de melhorar a ancoragem dos fios verticais. O objetivo principal foi analisar a industrialização da montagem das armaduras e suas implicações na segurança estrutural das vigas.

Os trabalhos sobre telas soldadas em vigas comentados na revisão bibliográfica analisam apenas a ancoragem da tela na borda comprimida e o controle da fissuração. Apenas os trabalhos referentes às vigas com armadura de pele, desenvolvidos na Universidade de Brasília, indicam um aumento na capacidade resistente à força cortante.

Como não há referências bibliográficas sobre a contribuição da armadura lateral na resistência à força cortante, procurou-se enfatizar esse tópico na análise teórica e no desenvolvimento do programa experimental.

Também foram consideradas alternativas de ancoragem no banzo comprimido da viga em uma série específica de ensaios.

Com relação aos Estados Limites de Serviço esperam-se menores valores de aberturas de fissuras, um panorama de fissuração mais próximo da fissuração sistemática, quando atuarem as solicitações tangenciais. 


\section{4 - APRESENTAÇÃO}

O trabalho foi dividido em capítulos referentes à revisão de literatura (capítulos $2 \mathrm{a}$ 6) e aqueles com descrição dos ensaios executados e análise dos resultados (capítulos 7 a $10)$.

\section{Cap. 1- Introdução}

Neste capítulo apresenta-se uma breve introdução e definição do tema da pesquisa, com os objetivos e justificativas, além da apresentação do conteúdo do trabalho.

\section{Cap. 2 - Arranjos de armaduras em vigas}

O capítulo contém a revisão bibliográfica sobre estribos verticais, armadura de pele, telas soldadas e industrialização da produção de armaduras para vigas.

\section{Cap. 3- Resistência ao cisalhamento}

No capítulo são apresentados comentários sobre os mecanismos resistentes e os fatores que influem na resistência à força cortante, além dos critérios de cálculo de algumas normas técnicas e pesquisadores.

\section{Cap. 4- Teoria do cisalhamento-atrito}

Apresenta-se a teoria do cisalhamento-atrito para vigas com estribos verticais e a formulação proposta pelo autor para a consideração da contribuição da armadura lateral na resistência à força cortante.

\section{Cap. 5 - Fissuração}

Este capítulo mostra as expressões teóricas para o cálculo da força cortante de fissuração e aberturas e espaçamentos de fissuras de flexão e de cisalhamento

\section{Cap. 6 - Estudos experimentais realizados por outros pesquisadores}

São comentados resumidamente no capítulo os resultados das pesquisas experimentais realizadas por outros pesquisadores. Foram abordadas vigas com estribos verticais abertos, vigas com estribos verticais e armadura de pele e vigas com telas soldadas.

\section{Cap. 7 - Programa experimental}


No capítulo sobre a pesquisa experimental desenvolvida, são descritos os modelos experimentais, os materiais utilizados, instrumentação, equipamentos e execução dos ensaios.

\section{Cap. 8 - Apresentação de resultados}

São apresentados os resultados obtidos nos ensaios por meio de gráficos, tabelas e fotografias.

\section{Cap. 9 - Análise de resultados}

Procede-se à análise e discussão dos resultados obtidos com o programa experimental, com o objetivo de subsidiar as conclusões do trabalho.

\section{Cap. 10 - Conclusão}

No capítulo são apresentadas as principais conclusões sobre a pesquisa desenvolvida, além de algumas sugestões para a sua continuidade. 


\section{ARRANJOS DE ARMADURAS EM VIGAS}

\section{1 - PRELIMINARES}

Neste capítulo analisa-se o funcionamento estrutural dos arranjos de armaduras em vigas de concreto armado submetidas à força cortante. Comenta-se sobre os estribos verticais, a armadura de pele e as telas soldadas.

A industrialização das armaduras é abordada com ênfase nas vigas de concreto armado.

\section{2 - ESTRIBOS VERTICAIS}

A armadura comumente utilizada em vigas para resistir à força cortante são os estribos verticais que envolvem a armadura do banzo tracionado onde apóiam-se preferencialmente as diagonais comprimidas. Os estribos verticais garantem que as aberturas das fissuras permaneçam pequenas.

FUSCO (1994) mostra o funcionamento dos estribos na formação da treliça resistente à força cortante na Figura 2.1. No detalhe (I), nos cruzamentos dos estribos com a armadura longitudinal de tração, formam-se os nós do banzo tracionado da treliça, onde teoricamente se apóiam as diagonais comprimidas de concreto. No banzo comprimido da 
peça, os estribos se ancoram no próprio concreto, auxiliados pelas barras porta-estribos. $\mathrm{O}$ detalhe (II) mostra como são mobilizadas as tensões $\sigma_{\mathrm{s}}$ nas barras e de aderência $\tau_{\mathrm{b}}$ entre a armadura longitudinal de tração e o concreto das diagonais comprimidas, a fim de que a tensão $\sigma_{\mathrm{s}}$ dessa armadura longitudinal possa receber acréscimos $\Delta \sigma_{\mathrm{s}}$ ao longo da viga.

Ainda na Figura 2.1, no detalhe (III) mostra-se que as diagonais comprimidas têm um caráter tridimensional. Como os nós da treliça estão localizados junto aos ramos verticais dos estribos, as forças $R_{c \theta}$ das diagonais comprimidas também têm inclinação transversal. $O$ detalhe (III) mostra também que o ramo horizontal inferior do estribo não tem rigidez suficiente para que a diagonal comprimida de concreto se apóie inteiramente sobre ele, ao longo de todo o seu comprimento. A ligação da diagonal comprimida ao nó do banzo tracionado faz-se, portanto, parcialmente pelo apoio direto sobre os cruzamentos das barras longitudinais com os ramos horizontais dos estribos e, parcialmente, por aderência ao trecho terminal desses ramos verticais dos próprios estribos. O detalhe (IV) mostra que o ramo horizontal do estribo deve equilibrar os esforços de tração provocados pela inclinação transversal das diagonais comprimidas, além de permitir o apoio dessas diagonais às barras longitudinais intermediárias.

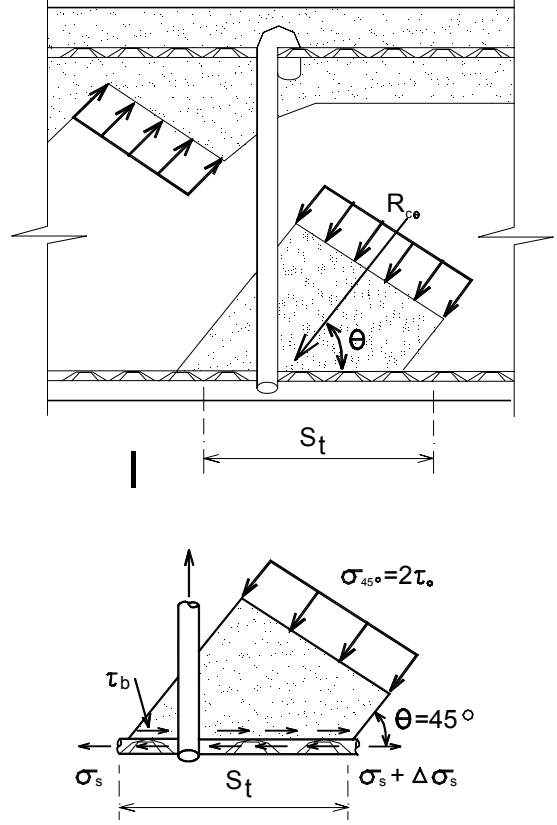

II

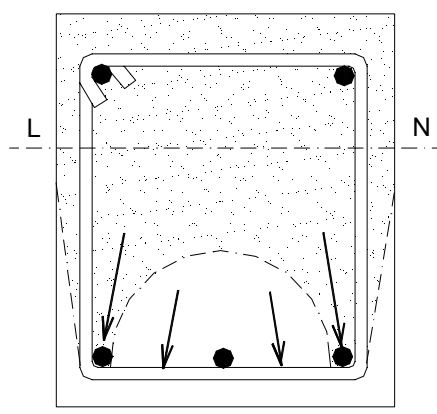

III

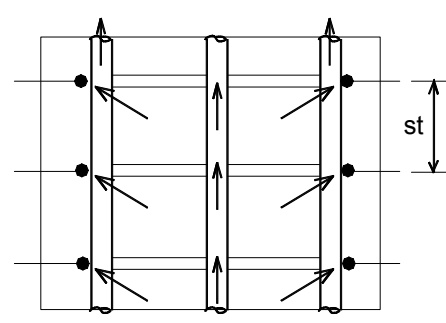

IV

Figura 2.1 - Funcionamento dos estribos (FUSCO, 1994). 
Na verdade, a inclinação transversal das diagonais comprimidas mostrada no detalhe III da Figura 2.1 não pode ocorrer na realidade porque o conjunto armaduras longitudinais estribos verticais forma uma chapa horizontal que aumenta a rigidez do banzo tracionado, uniformizando a distribuição das tensões de compressão no ramo horizontal do estribo.

Evidencia-se então a necessidade de que o estribo possua o ramo horizontal do lado do banzo tracionado da peça. Do lado do banzo comprimido, o ramo horizontal não é obrigatório, embora a sua presença seja recomendável.

A Figura 2.2 mostra que o acréscimo de força $\Delta \mathrm{R}_{\mathrm{st}}$, nas barras longitudinais afastadas do canto da viga, ocorre pela mobilização de forças em diagonais comprimidas situadas no plano da armadura de tração. Assim, os ramos horizontais dos estribos funcionam como armadura de costura na transmissão de esforços para essas barras.

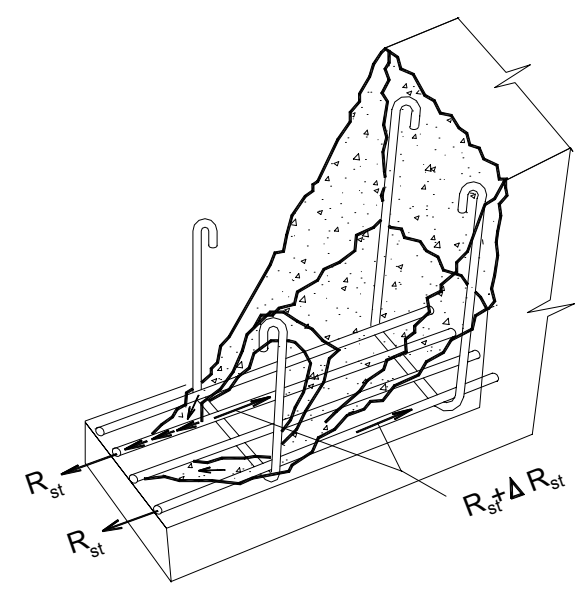

Figura 2.2 - Detalhe das diagonais comprimidas situadas no plano da armadura de tração, quando se utilizam barras longitudinais afastadas do canto da viga (FUSCO, 1994).

LEONHARDT \& MÖNNIG (1978b) apresentam diversas formas de estribos, como indicado na Figura 2.3. Para a ancoragem superior, o gancho voltado para dentro é o melhor (Figuras 2.3-a e 2.3-b), pois ganchos voltados para fora (Figuras 2.3-c e 2.3-d) exigem uma armadura transversal inferior da laje para absorver o empuxo ao vazio dos ganchos. Não há necessidade de usar estribos fechados (Figura 2.3-e), nem mesmo na região de momentos fletores negativos, se as armaduras das lajes forem contínuas (Figura 2.3-f). Todavia, no caso de vigas contínuas de seção retangular sem laje colaborante, os estribos devem envolver completamente a armadura sobre o apoio. As Figuras 2.3-g e 2.3-h mostram detalhes de estribos fechados para o caso de torção, engastamento de lajes no bordo ou cintamento de 
zonas comprimidas na flexão, fortemente solicitadas. Em vigas com almas muito delgadas, usualmente pré-moldadas, são suficientes estribos com um ramo como estribos em escada de marinheiro (Figura 2.3-i) ou em serpentina (Figura 2.3-k). Para vigas I a forma mostrada na Figura 2.3-1 permite fácil montagem.

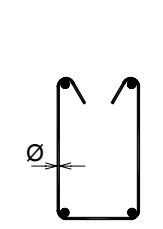

(a) $\geqslant 10 \varnothing$,

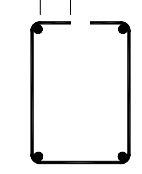

(b)

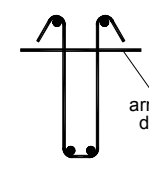

(c)

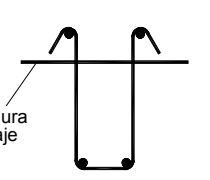

(d)

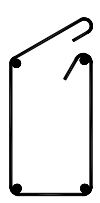

(e)

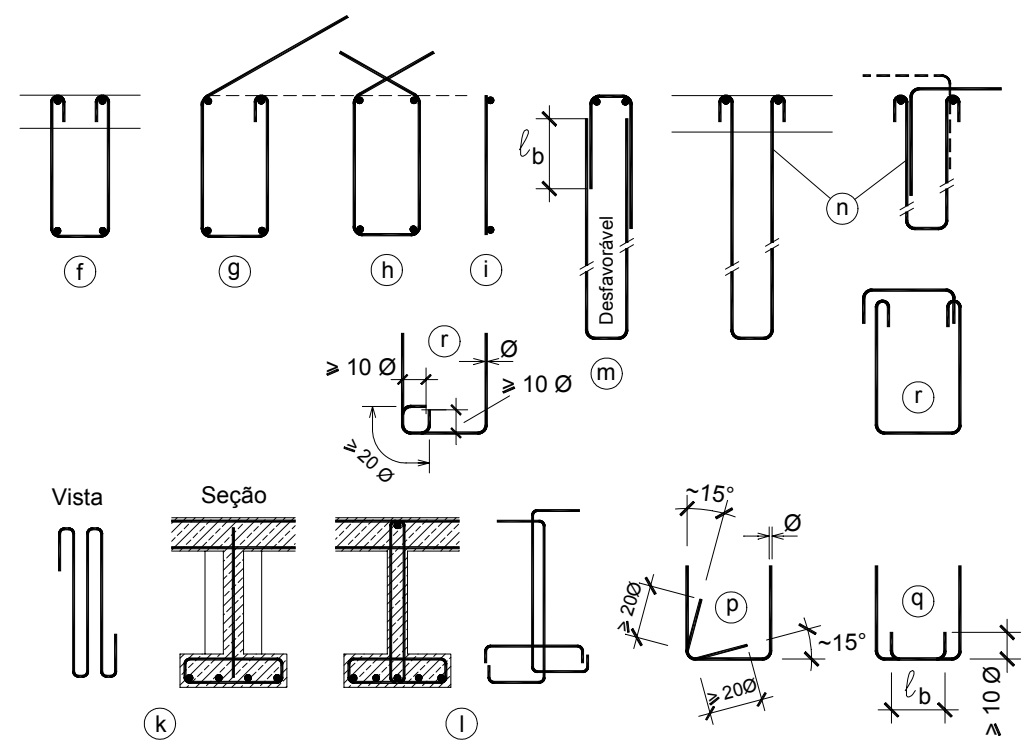

Figura 2.3 - Formas de estribos (LEONHARDT \& MONNIG, 1978b).

Em vigas altas, para facilitar a colocação da armadura longitudinal podem ser utilizados "estribos em chapéu" (Figura 2.3-m) que não têm um funcionamento favorável e exigem grandes comprimentos de traspasse $\ell_{\mathrm{b}}$. É melhor ancorar os estribos com ganchos para fora e apoiar as bielas de compressão na amadura da laje colaborante (Figura 2.3-n).

A Figura 2.4 mostra os arranjos básicos dos estribos: estribos fechados, estribos abertos com ou sem armadura suplementar de fechamento e os estribos duplos.

Segundo FUSCO (1994), em princípio os estribos abertos são tão eficientes quanto os estribos fechados. Em virtude do processo construtivo, quando se utilizam estribos abertos, o lado fechado é sempre colocado no fundo da fôrma. Se o lado aberto do estribo 
ficar situado no banzo tracionado da peça, então a armadura suplementar de fechamento será obrigatória.

No caso de vigas solicitadas à torção (vigas de marquises ou vigas nas quais lajes em balanço são engastadas) a utilização de estribos fechados é obrigatória.

O emprego de estribos fechados ou abertos com armadura suplementar de fechamento é uma decisão de projeto que também depende da montagem e da colocação das armaduras na fôrma. Em vigas armadas com telas soldadas, o formato em $\mathrm{U}$ aberto facilita não só o dobramento da tela como também o acréscimo de barras adicionais da armadura de flexão com as armaduras já posicionadas na fôrma.

Em projetos usuais de edifícios, a armadura suplementar de fechamento poderá ser constituída pelas barras da armadura negativa da laje colaborante.
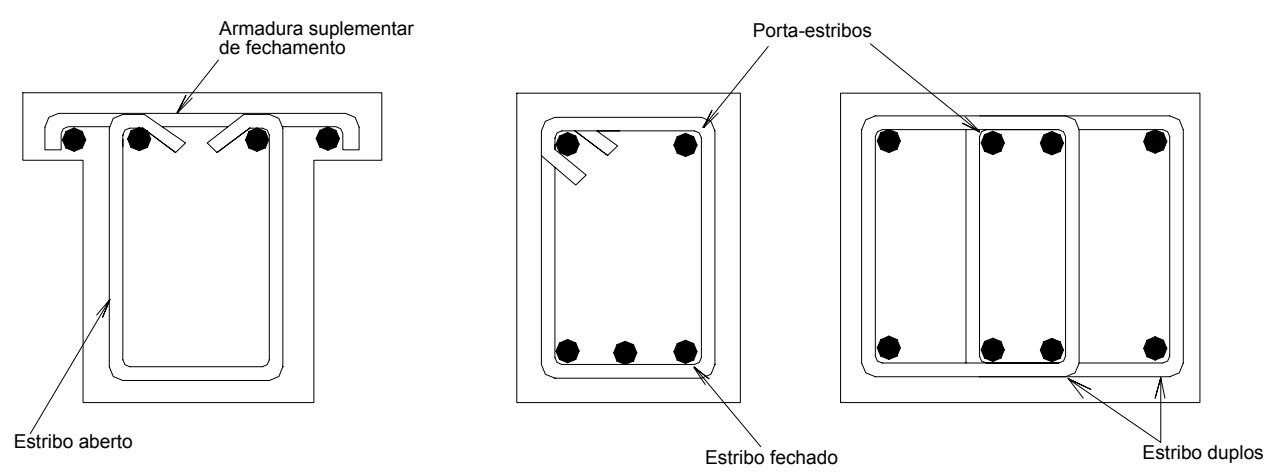

Figura 2.4 - Arranjos básicos dos estribos (FUSCO, 1994).

Segundo o Projeto de Revisão da NBR 6118: 2001, a armadura transversal pode ser constituída por estribos verticais que devem ser fechados por um ramo horizontal, envolvendo as barras da armadura longitudinal de tração, e ancorados na face oposta. Quando essa face também puder estar tracionada, o estribo deve ter o ramo horizontal nessa região, ou complementado por barra adicional.

\section{3 - ARMADURA DE PELE}

A tendência de fissuração do concreto submetido a tensões normais de tração exige a presença de barras da armadura que possam controlar essa fissuração. A ausência dessa 
armadura pode afetar a durabilidade da estrutura. A armadura de controle da fissuração tem a função de distribuir a fissuração, impedindo que se formem apenas umas poucas fissuras, muito espaçadas e de grande abertura.

$\mathrm{O}$ mecanismo pelo qual as peças de concreto armado podem ter alongamentos significativos, sem que apareçam fissuras visíveis é mostrado na Figura 2.5. A microfissuração interna impede que a abertura dessas fissuras junto à armadura aumente exageradamente, mesmo quando aparecem fissuras visíveis. Esse controle da fissuração visível é exercido até uma certa distância da barra de aço, que provoca a microfissuração do concreto em seu entorno.
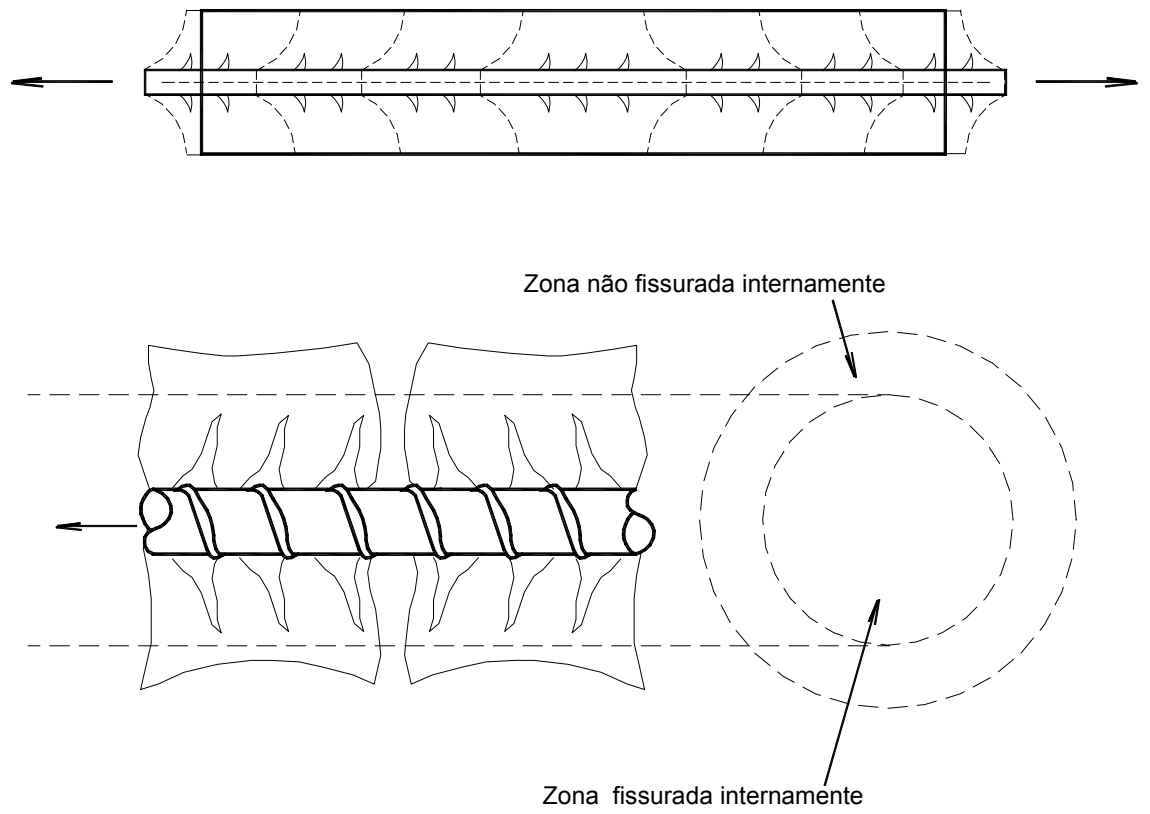

Figura 2.5 - Efeito da microfissuração (FUSCO, 1994).

Em almas de vigas altas a armadura tracionada, apenas, não é suficiente para limitar as fissuras de flexão na alma. A maioria das fissuras que se iniciam na borda tracionada desaparecem acima da armadura de tração; apenas uma em cada 3 ou 4 fissuras, propaga-se para cima, com aumento de abertura. Essa tendência à arborização das fissuras, que pode provocar o aumento da abertura das fissuras ao longo da altura da alma da viga, é ilustrada na Figura 2.6.

As armaduras de pele, como armadura auxiliar, têm a função de impedir uma fissuração superficial exagerada da peça, em condições normais de utilização. Cabe às armaduras principais de tração a absorção das forças de tração liberadas pelo concreto na região onde elas se situam. As armaduras de pele vão ter apenas função local de distribuição 
das fissuras e, portanto, não estão subordinadas às mesmas exigências que aquelas armaduras.

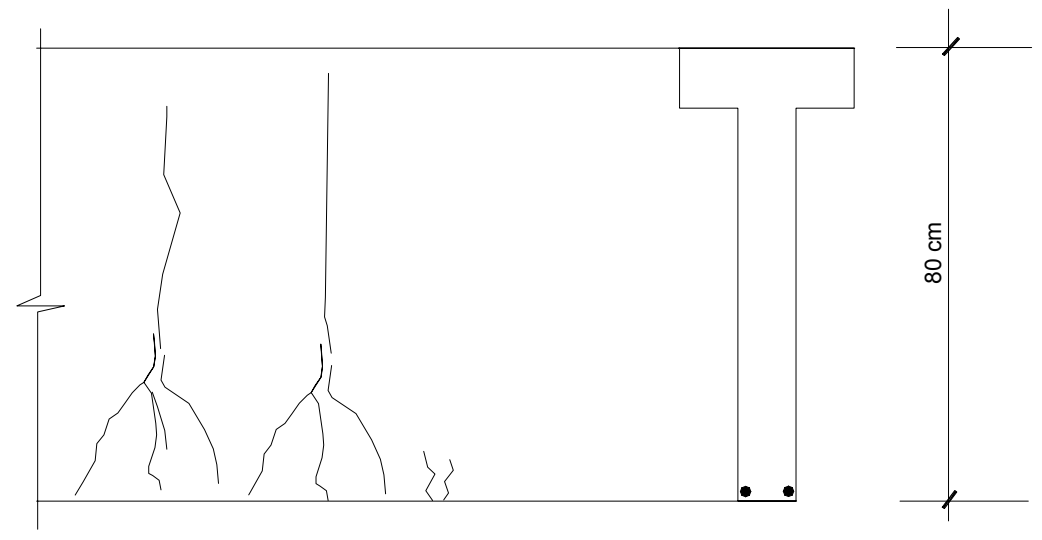

Figura 2.6 - Configuração das fissuras em vigas altas (FUSCO, 1994).

Analisando-se algumas normas técnicas, observam-se diferentes especificações para o cálculo e o arranjo das armaduras de pele.

A NBR 6118:1978 indica que "quando a altura útil da viga ultrapassar $60 \mathrm{~cm}$ e o aço da armadura de tração for CA-50 ou CA-60, deve dispor-se longitudinalmente e próxima a cada face lateral da viga, na zona tracionada, uma armadura de pele. Essa armadura, de aço com resistência igual ou superior à do aço da armadura de tração, deve ter, em cada face seção transversal igual a:

$$
A_{s, p e l e}=0,05 \% b_{w} \cdot h \quad(\text { por face })
$$

onde:

$\mathrm{b}_{\mathrm{w}}$ - largura da viga;

$\mathrm{h}$ - altura da viga.

$\mathrm{O}$ espaçamento entre as barras não deve ultrapassar $\mathrm{d} / 3$ e $30 \mathrm{~cm}$ e a barra mais próxima da armadura de tração deve distar mais de $6 \mathrm{~cm}$ e menos de $20 \mathrm{~cm}$ ”, como mostra a Figura 2.7. 


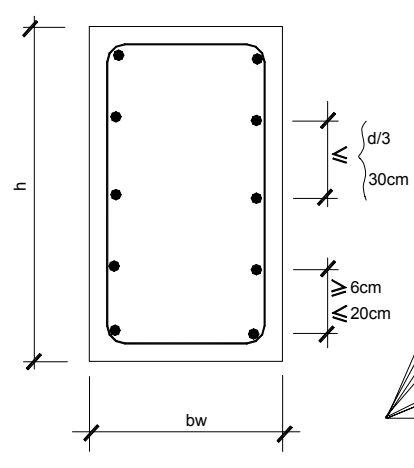

a) NBR 6118: 1978

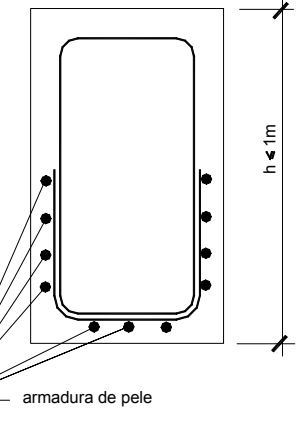

b) EUROCODE 2 (1992)

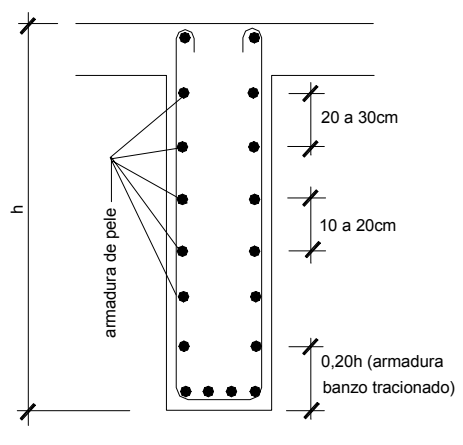

c) LEONHARDT \& MONNIG (1978b)

Figura 2.7 - Arranjos sugeridos para a armadura de pele (FIORIN,1998).

O Projeto de Revisão da NBR 6118: 2001 propõe que a armadura de pele em cada face da alma da viga será de:

$$
A_{s, p e l e}=0,10 \% b_{w} \cdot h \quad(\text { por face })
$$

Essa armadura deve ser composta por barras de alta aderência $\left(\eta_{1} \geq 2,25\right)$ de diâmetro não inferior ao do estribo e espaçamento não maior que $20 \mathrm{~cm}$. Caso se utilize barras de pequeno diâmetro $\phi<8,0 \mathrm{~mm}$, que não possuam alta aderência, deve-se dobrar essa quantidade de armadura. Dispensa-se a utilização dessa armadura em vigas com altura igual ou inferior a $60 \mathrm{~cm}$. Indica-se também que a armadura de pele deve ser disposta com espaçamento entre as barras igual ou inferior a d/3 e $30 \mathrm{~cm}$.

THOMAZ (1988) comenta que é comum aparecerem fissuras verticais à meia altura em vigas de pontes e viadutos de concreto armado. Essas fissuras ocorrem por insuficiência de armadura de pele. Na verdade, a área de armadura de pele recomendada pela NBR 6118: 1978 é insuficiente para vigas de grande porte.

Observa-se que o Projeto de Revisão da NBR 6118: 2001 indica o dobro da área de armadura de pele sugerido anteriormente. As prescrições praticamente coincidem em termos de disposição da armadura de pele e altura mínima da viga para a qual sua utilização é obrigatória. Lembra-se que a NBR 7187: 1988 já prescrevia para vigas de pontes exatamente esse valor proposto pelo Projeto de Revisão da NBR 6118: 2001. 
LEONHARDT \& MÖNNIG (1978b) sugerem armadura de pele em vigas altas com uma zona tracionada $\mathrm{d}-\mathrm{x}>50 \mathrm{~cm}$, cujas barras são distribuídas ao longo da alma da viga espaçadas de 10 a $20 \mathrm{~cm}$. Em vigas muito altas, o espaçamento entre as barras horizontais deve ser aumentado de baixo para cima (Figura 2.7-c). Considera-se como fazendo parte da armadura do banzo as barras localizadas dentro de uma altura de $0,2 \mathrm{~h}$, a partir da borda tracionada.

O ACI 318R (2002) indica que, quando a altura útil da viga excede $90 \mathrm{~cm}$, a armadura de pele deve ser uniformemente distribuída ao longo de ambas as faces da viga, em uma distância d/2 próximo da armadura de tração. A área dessa armadura a cada $30 \mathrm{~cm}$ de altura em cada lado da face deve ser:

$$
A_{s k} \geq 0,012(d-30)
$$

O máximo espaçamento da armadura de pele não deve exceder d/6 e $30 \mathrm{~cm}$.

Para o EUROCODE 2 (1992), em alguns casos, pode ser necessária a colocação de uma armadura de superfície ou para controlar a fissuração ou para garantir uma resistência adequada ao desprendimento do cobrimento do concreto. A armadura para controlar a fissuração deve ser utilizada em vigas com altura maior do que $100 \mathrm{~cm}$. Quando a armadura de flexão possui um diâmetro maior do que $32 \mathrm{~mm}$, deve-se também utilizar essa armadura, composta por uma malha ou barras de pequeno diâmetro, usualmente posicionada fora dos estribos, como indica a Figura 2.7-b. A área dessa armadura deve ser no mínimo igual a:

$$
A_{s, \text { surf }} \geq 0,01 A_{c t, e x t}
$$

onde:

$$
\begin{aligned}
& \mathrm{A}_{\mathrm{ct} \text { ext }} \text { - área de concreto tracionado, externa aos estribos; } \\
& \mathrm{A}_{\mathrm{s}, \text { surf }} \text { - área de armadura adicional na direção paralela à armadura de tração. }
\end{aligned}
$$

Entre os autores e normas citados anteriormente notam-se valores divergentes tanto para a área e espaçamento máximo da armadura de pele quanto para a altura da viga em que sua utilização é obrigatória. Os critérios adotados para o cálculo da quantidade dessa armadura são sempre de natureza empírica.

LÉPORE (1998) executou investigação experimental sobre o comportamento de vigas com armadura de pele, segundo os critérios da NBR 6118:1978, CEB-FIP(1990), NBR 
7187:1988 e EUROCODE 2 (1992). Os resultados obtidos indicaram melhor desempenho das vigas dimensionadas pelo critério da NBR 7187:1988, o que confirma a adequação das prescrições do Projeto de Revisão da NBR 6118:2001.

\section{4 - TELAS SOLDADAS}

As telas soldadas, utilizadas como armaduras de vigas, são cortadas e dobradas para formarem as "gaiolas", às quais são adicionadas barras discretas da armadura de flexão, posicionadas de acordo com o projeto. Os fios verticais das telas formarão os estribos verticais (armadura transversal) e os fios horizontais posicionados nas laterais das vigas formarão a armadura lateral. $\mathrm{O}$ dobramento das telas pode ser feito em mesas dobradeiras no próprio canteiro da obra ou em empresas especializadas no corte e dobra de aço.

Em relação à forma da tela depois de dobrada, o procedimento análogo ao utilizado para os estribos verticais fechados não é interessante do ponto de vista construtivo. Primeiro, porque quanto maior o número de pontos de dobra, maior o tempo de mão-de-obra. Segundo, com a "gaiola fechada", surgiriam dificuldades na colocação das barras soltas das armaduras de flexão por ocasião de seu posicionamento nas fôrmas das vigas. $\mathrm{O}$ formato da tela em "U" seria mais adequado, desde que se garanta a ancoragem dos fios verticais da tela no banzo comprimido. Além disso, em vigas contínuas com o lado aberto da tela situado no banzo superior deve-se dispor armadura suplementar de fechamento.

A Figura 2.8 ilustra passo-a-passo um esquema de dobramento de telas soldadas para utilização como armaduras em vigas.

No caso de vigas contínuas, as armaduras compostas pelas telas dobradas seriam fornecidas em comprimentos pré-determinados, permitindo a utilização de diferentes bitolas e/ou espaçamentos ao longo do comprimento da viga. 

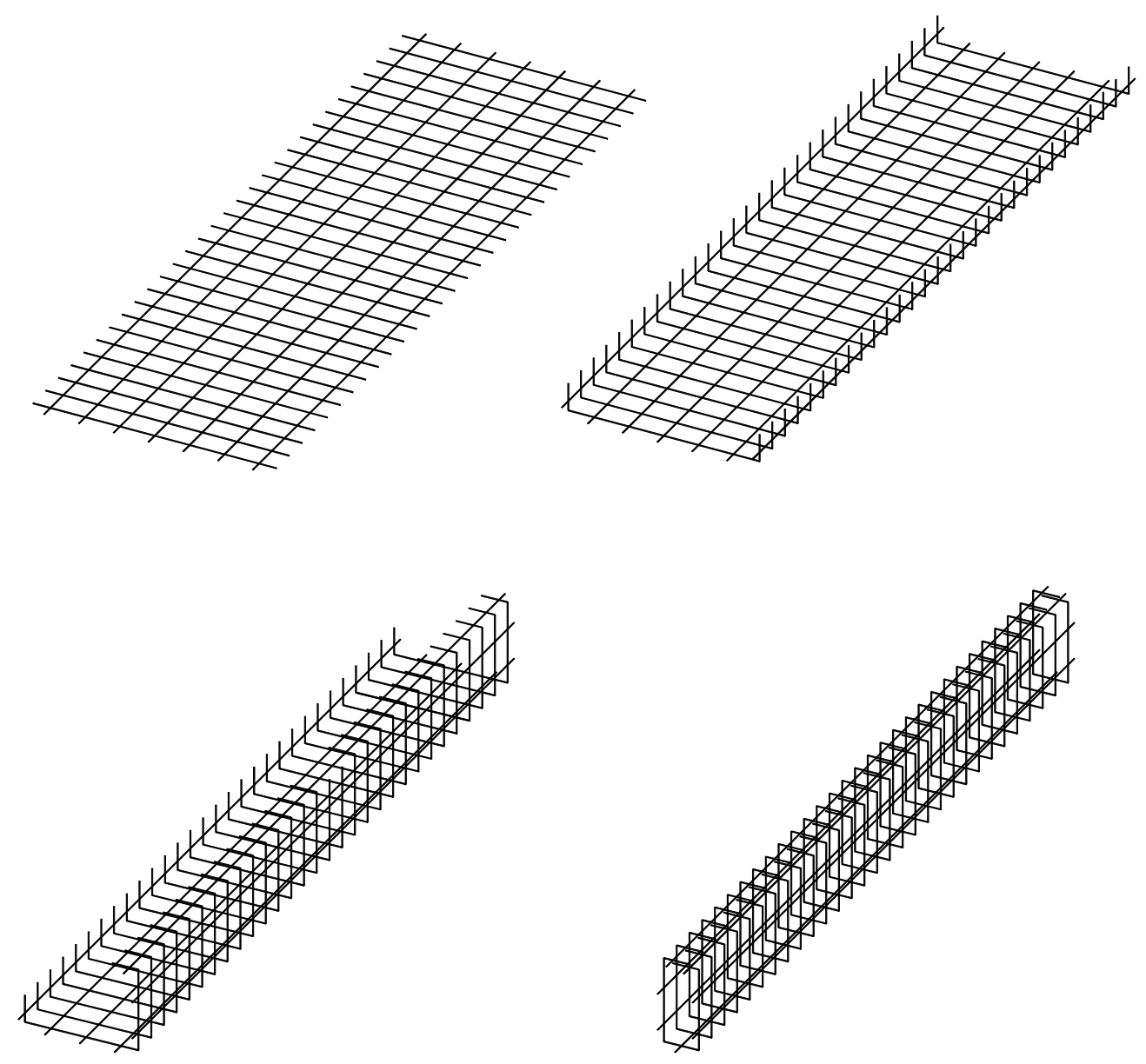

Figura 2.8 - Esquema de dobramento de telas soldadas para vigas.

A Figura 2.9 apresenta um detalhamento de vigas contínuas com telas soldadas e barras soltas da armadura de flexão, proposto pelo BOLETIM CEB-164 (1985). Observa-se que nas proximidades dos apoios utilizam-se telas em forma de U voltadas para baixo. Além disso, o lado aberto da tela em $\mathrm{U}$ é fechado pela armadura posicionada junto à face superior da laje. O FIB (1999) mostra que esta armadura pré-fabricada poderia ser facilmente colocada na fôrma, como mostrado nos cortes das seções transversais da Figura 2.9. 


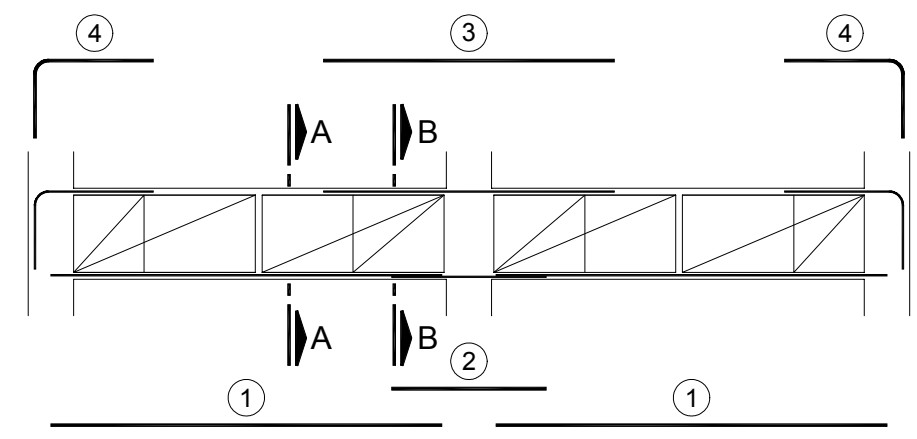

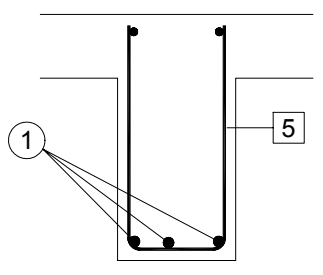

Seção A-A

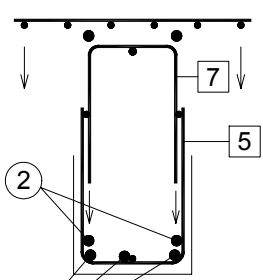

Seção B-B

Figura 2.9 - Detalhamento sugerido de vigas contínuas armadas com telas soldadas e barras discretas da armadura de flexão, BOLETIM CEB-164 (1985).

O ACI 318R (2002) apresenta prescrições para a ancoragem dos fios verticais de telas soldadas de barras lisas. Para cada lado da tela em forma de U, deve-se adotar uma das seguintes especificações (Figura 2.10):

- duas barras longitudinais espaçadas de $5 \mathrm{~cm}$ no topo do $\mathrm{U}$;

- uma barra longitudinal posicionada não mais que $\mathrm{d} / 4$ da borda comprimida e uma segunda barra mais próxima daquela borda e distante de no mínimo $5 \mathrm{~cm}$ da primeira. A segunda barra deve ser posicionada no ramo do estribo além da dobra ou na dobra cujo diâmetro $d_{b} \geq 8 \phi$.
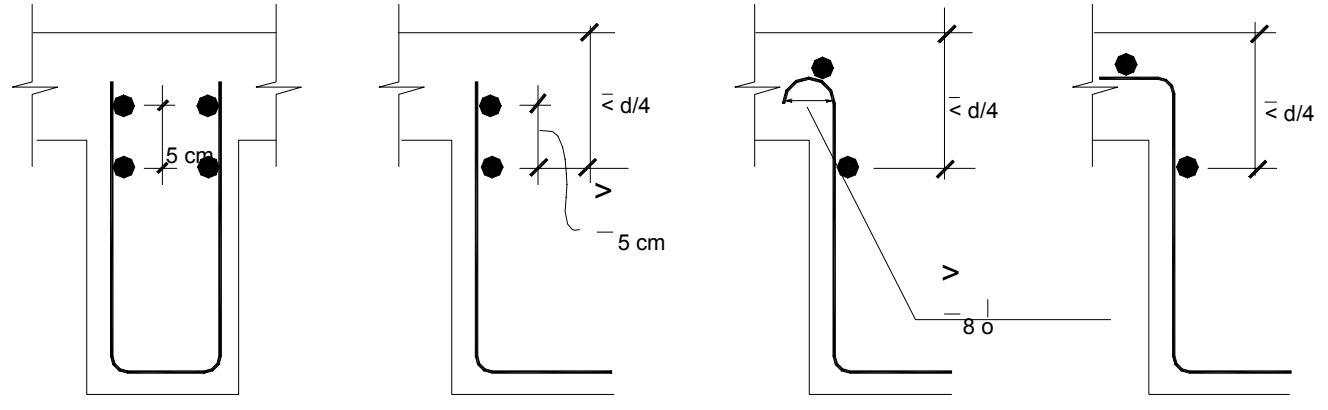

Figura 2.10 - Ancoragem na zona comprimida de estribos em U constituídos por telas soldadas de barras lisas (ACI 318R, 2002). 
O EUROCODE 2 (1992) indica que a ancoragem da armadura transversal deve ser executada por meio de ganchos ou barra transversal soldada (Figura 2.11):

- ganchos de $135^{\circ}$ : comprimento reto não menor do que $5 \phi$ ou $50 \mathrm{~mm}$;

- ganchos de $90^{\circ}$ : comprimento reto não menor do que $10 \phi$ ou $70 \mathrm{~mm}$;

- duas barras transversais soldadas (Figura 2.11-c);

- uma barra transversal soldada (Figura 2.11-d).

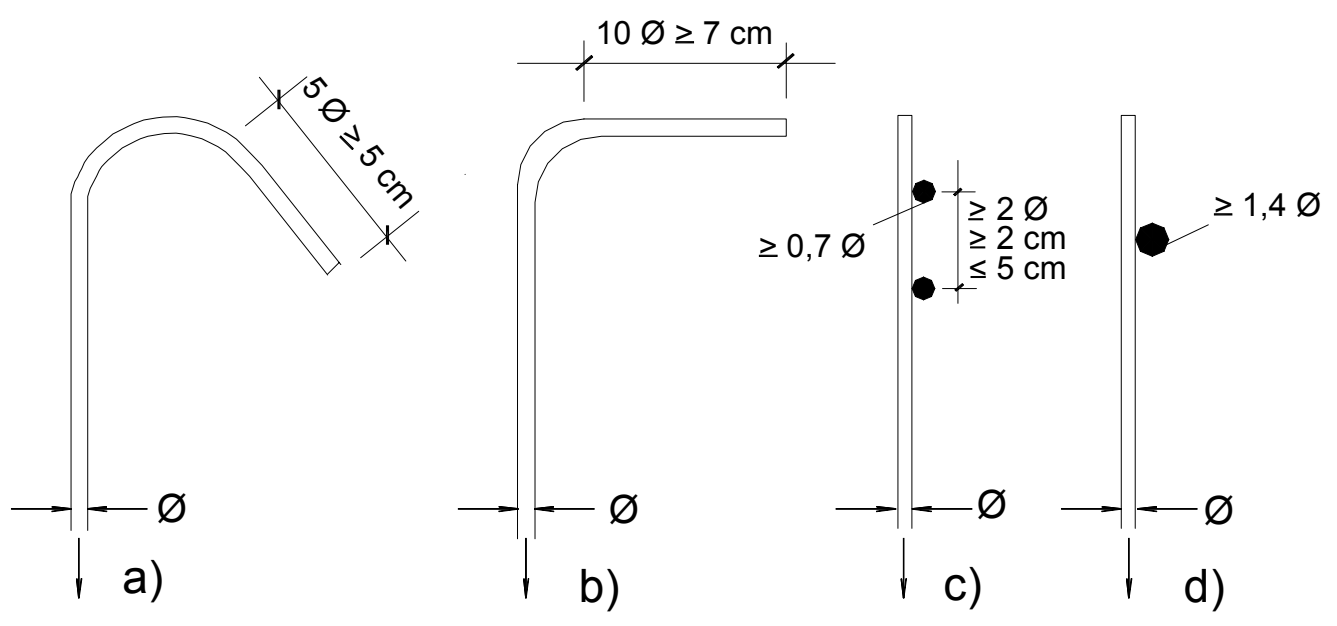

Figura 2.11 - Ancoragem de armadura transversal por meio de ganchos ou barras soldadas (EUROCODE 2, 1992).

Para a ancoragem dos fios verticais das telas no bordo comprimido da viga, o Projeto de Revisão da NBR 6118:2001, no item 9.4.6.2, sugere: "a ancoragem dos estribos, por meio de barras transversais soldadas, poderá ser constituída, com as restrições indicadas na Figura 2.12, por:

a) duas barras soldadas com diâmetro $\phi_{\mathrm{t}}>0,7 \phi$ para estribos constituídos por 1 ou 2 ramos;

b) uma barra soldada com diâmetro $\phi_{\mathrm{t}} \geq 1,4 \phi$, para estribos de 2 ramos;

desde que seja comprovada, por ensaio, a resistência ao cisalhamento da solda para uma força mínima de $A_{s} \cdot f_{y d}$, em que $A_{s} \cdot f_{y d}$ é a resistência da barra ancorada”. 


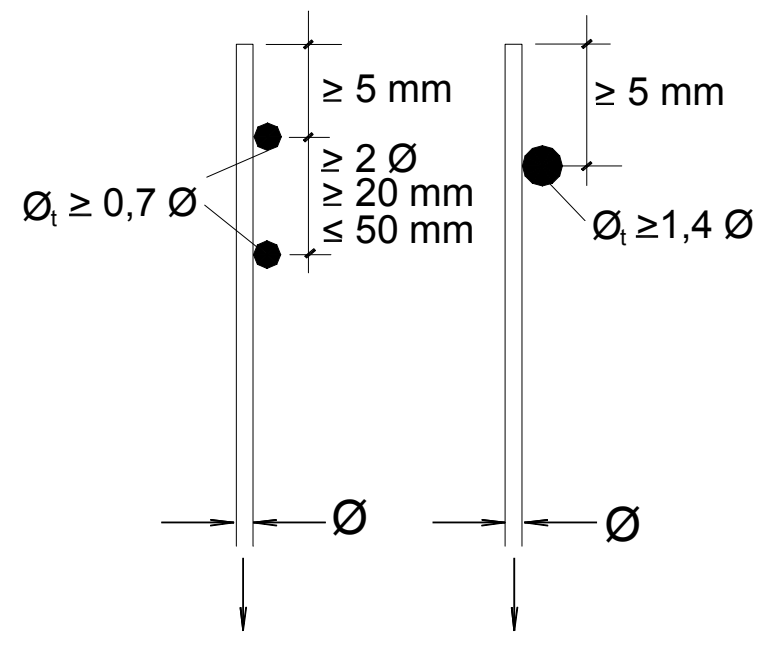

Figura 2.12 - Ancoragem de armadura transversal por meio de barras soldadas (Projeto de Revisão da NBR 6118: 2001).

O Projeto de Revisão da NBR 6118:2001 ainda propõe, no caso de estribos formados por telas soldadas, que o diâmetro mínimo pode ser reduzido de 5,0 mm para 4,2 $\mathrm{mm}$, desde que sejam tomadas precauções contra a corrosão dessa armadura.

MONTOYA et al. (2000) apresentam, como uma disposição eficaz para resistir à força cortante, uma malha ortogonal composta por estribos verticais e barras longitudinais. Prescreve, também, que as quantidades mecânicas sejam iguais em ambas as direções, isto é:

$$
\frac{A_{h}}{d}=\frac{A_{s 90}}{s}
$$

onde:

$\mathrm{A}_{\mathrm{h}}$ - área total das barras posicionadas em ambas as faces laterais da viga;

d - altura útil;

$\mathrm{A}_{\mathrm{s} 90}$ - área total de estribos verticais;

$\mathrm{s}$ - espaçamentos entre os estribos.

\section{5 - INDUSTRIALIZAÇÃO DAS ARMADURAS}

Com o aumento da competitividade e necessidade de redução de custos na indústria da construção civil, a industrialização parcial ou total do processo construtivo tornou-se fundamental para a sobrevivência das empresas do setor. A produtividade média do trabalhador brasileiro na construção civil gira em torno de 40 a 60 homens-hora por $\mathrm{m}^{2}$, 
enquanto nos Estados Unidos, por exemplo, situa-se entre 10 e 15 homens-hora por $\mathrm{m}^{2}$. Como o ganho médio por hora do trabalhador brasileiro na construção civil é sensivelmente menor do que o do trabalhador americano ou europeu, a modernização dos canteiros torna-se pouco atraente do ponto de vista estritamente financeiro. Entretanto, deve-se enfatizar que a racionalização é essencial para a rapidez de execução e a qualidade do produto final.

Observa-se uma crescente conscientização dos construtores na percepção das vantagens proporcionadas pela compra da obra em partes, ou seja, o material associado ao serviço necessário para a obtenção do produto final.

Nesse contexto se insere a industrialização da produção de armaduras para os elementos estruturais de concreto armado.

A maioria das obras de concreto armado no Brasil utiliza o processo convencional de preparação das armaduras para os elementos estruturais. Nesse processo, o aço é adquirido na forma de barras de seção circular com 12 metros de comprimento e armazenado no próprio canteiro. Posteriormente, as barras de aço são cortadas e dobradas para a produção das armaduras das lajes, vigas, pilares, etc. Esse processo apresenta as seguintes desvantagens:

- espaço físico no canteiro para armazenagem das barras e preparação das armaduras;

- as barras de aço podem ficar expostas às ações das intempéries;

- maior consumo de mão-de-obra no canteiro;

- perdas de material.

A construção de edifícios em terrenos com áreas limitadas, principalmente nas regiões centrais das grandes cidades, e a falta de uma lei de zoneamento que obrigue a adoção de afastamentos determinados para esses prédios costumam criar dificuldades para os construtores. Não há espaço disponível para o armazenamento adequado das barras de aço e para a preparação das armaduras ficando o transporte interno das barras bastante prejudicado.

A solução que se apresenta é utilizar os serviços de empresas especializadas em corte e dobra das barras de aço. Algumas dessas empresas são subsidiárias das principais siderúrgicas brasileiras. Com base no projeto estrutural e obedecendo o cronograma da obra, a empresa produz as peças necessárias e as entrega cortadas e dobradas, prontas para montar. O sistema de armaduras industrializadas exige menos mão-de-obra, quase que elimina o desperdício de material, garante qualidade e rapidez de execução. Em alguns países, praticamente só se utiliza esse sistema. As vendas de barras de aço pelo sistema 
industrializado de corte e dobra chegam a $20 \%$ do total comercializado para a construção formal com forte tendência de crescimento.

\subsection{1 - SISTEMA DE CORTE E DOBRA}

O sistema de corte e dobra de aço industrializa as etapas de preparação das armaduras anteriormente executadas artesanalmente no canteiro de obras. Nas centrais de armação as peças são executadas por equipamentos que garantem precisão no corte, dobras e formatos das armaduras. O sistema apresenta as seguintes vantagens:

- redução de custos com mão-de-obra no canteiro;

- ganho de espaço no canteiro com eliminação de bancadas e equipamentos;

- garantia de qualidade;

- redução de perdas;

- menor tempo de execução da obra;

- entrega na obra obedecendo cronograma.

\subsection{2 - TELAS SOLDADAS}

A NBR 7481:1990 define tela de aço soldada como armadura pré-fabricada, em forma de rede de malhas retangulares, constituída de fios de aço longitudinais e transversais, sobrepostos e soldados em todos os pontos de contato (nós), por resistência elétrica (caldeamento). A utilização de telas soldadas se dá em pisos industriais, pavimentos de concreto, lajes maciças, cortinas de contenção, reservatórios, piscinas, canais, elementos pré-moldados, etc.

Em relação à armadura convencional, as telas soldadas apresentam as seguintes vantagens, IBTS (1990):

- fornecimento em aço categoria CA-60 até a bitola de 10,0 mm;

- perda próxima de zero;

- eliminação de marcação na fôrma e amarração com arame recozido;

- ancoragem reta, por ação dos nós, IBTS (1996);

- aderência ao concreto se dá pela superfície dos fios e, principalmente, pela região dos nós soldados;

- espaçamentos entre fios rigorosamente uniformes, pois os fios são soldados em todos os pontos de cruzamento, resultando armação de qualidade superior;

- facilidade de inspeção e conferência na obra; 
- redução da mão-de-obra e tempo de execução.

Segundo GRIEZIC et al. (1994), o mercado de tela soldada no ano de 1989 correspondeu a 29\% na França e 50\% na Holanda. Estima-se que, no ano de 1999, o uso de tela soldada foi responsável por $48 \%$ do mercado na Alemanha. Em contrapartida, no Brasil, estima-se algo em torno de $4 \%$ do mercado, um percentual extremamente baixo em relação aos países mais desenvolvidos.

As telas soldadas produzidas no Brasil são especificadas pela NBR 7481: 1990, sendo o ensaio de resistência ao cisalhamento da junta soldada especificado pela NBR 5916: 1990. Nos EUA as telas soldadas são especificadas pelo ASTM A185/94, telas fabricadas com barras lisas e ASTM A497/95, barras nervuradas.

\subsection{3 - VIGAS}

O sistema de corte e dobra para vigas é bastante utilizado com as armaduras montadas entregues na obra. Para vigas de comprimentos maiores, as armaduras devem ser previamente montadas por trechos da viga, com os ajustes finais sendo feitos por ocasião de sua colocação na fôrma.

As telas soldadas também podem ser utilizadas em vigas e outros elementos estruturais.

A Figura 2.13 mostra a redução do custo de fabricação das armaduras em vigas quando se utiliza tela soldada. No caso A, barras retas e dobradas e estribos convencionais são usados. Ao se utilizar tela soldada dobrada como estribos (alternativa B) obtém-se uma redução no tempo de fabricação de cerca de $25 \%$, em comparação ao caso A. Para barras retas e tela soldada dobrada como armadura de cisalhamento (caso C), a quantidade de homens-hora reduz-se em torno de 50\%, em comparação ao caso A.

Atualmente no Brasil a produção de armaduras de vigas com telas soldadas não tem sido adotada, salvo exceções (pré-moldados, por exemplo). Com a tendência de industrialização da construção civil, certamente será utilizado no futuro.

A Figura 2.14 apresenta uma sequência de fotografias que ilustram o processo de corte, dobra e montagem das armaduras de uma viga com telas soldadas. 


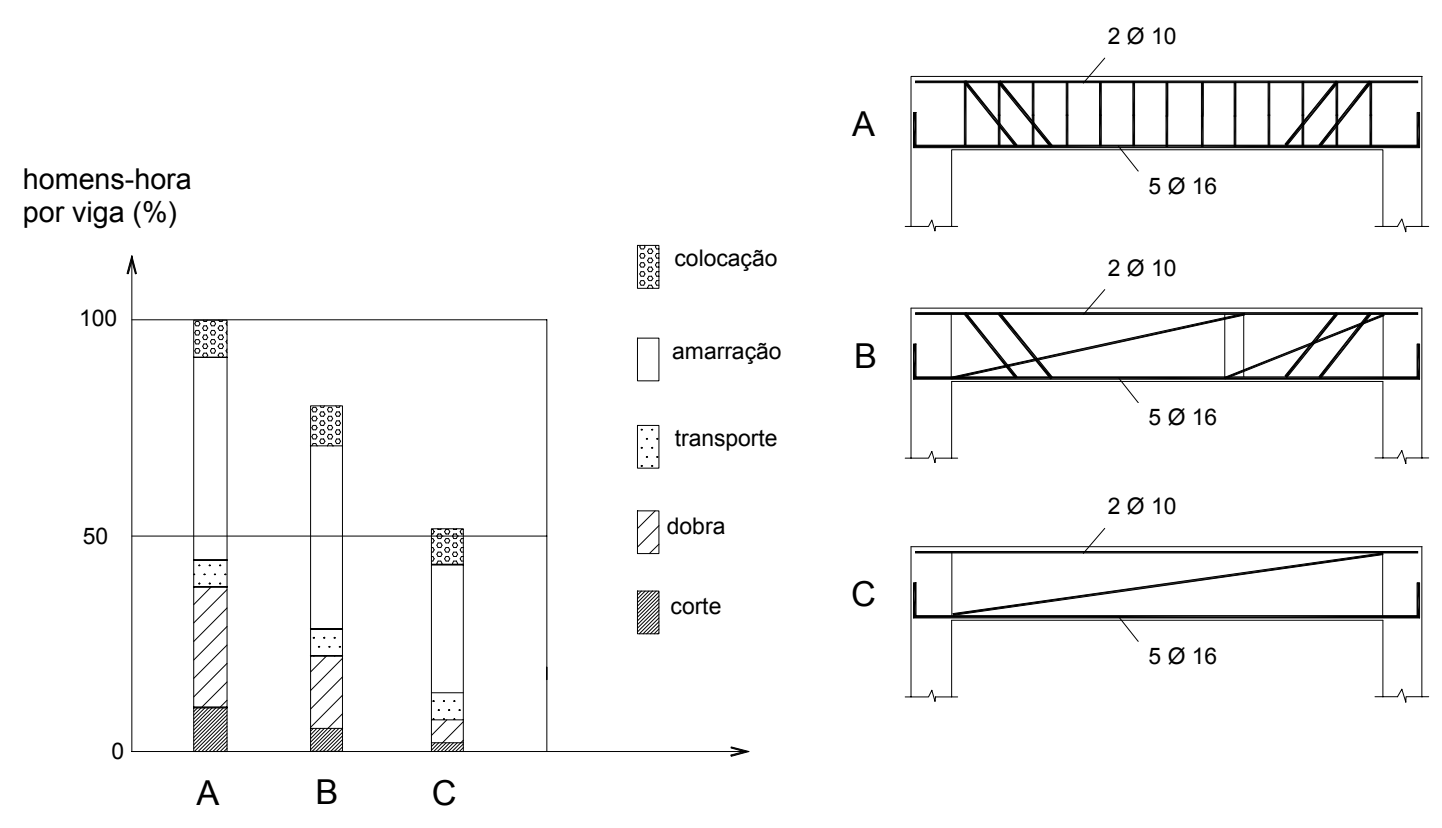

Figura 2.13 - Quantidade relativa de mão-de-obra para fabricação da armadura de uma viga, Boletim CEB 164 (1985).

Usualmente o custo do material tela soldada é superior ao das barras de aço. Quando se considera a economia na mão-de-obra proporcionada pelo uso da tela soldada, conclui-se que a utilização em vigas é economicamente viável. A intensa utilização da tela soldada em alguns países da Europa corrobora a afirmação anterior.

Em qualquer análise de custo deve-se considerar que, no Brasil, a mão-de-obra é mais barata e os equipamentos mais caros (em relação aos EUA e Europa). Os índices de economia na mão-de-obra mostrados na Figura 2.13 referem-se a países da Europa. Todavia, durante a montagem das armaduras das vigas com telas soldadas no Laboratório de Estruturas (LE -SET), foram anotados índices médios de economia em homens-hora por viga bastante próximos. 

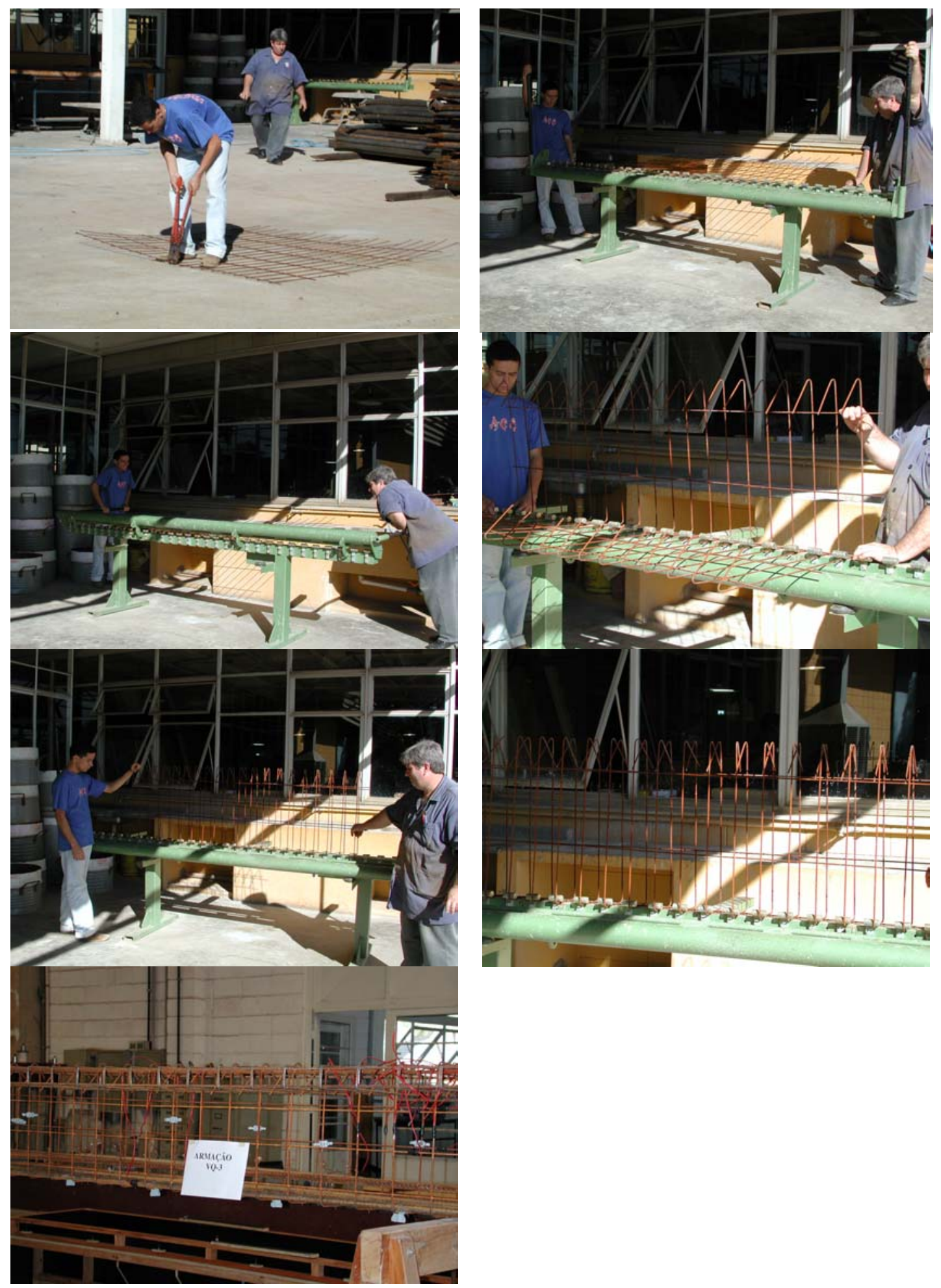

Figura 2.14 - Fotografias que ilustram o processo de corte, dobra e montagem das armaduras de uma viga com telas soldadas. 


\section{RESISTÊNCIA AO CISALHAMENTO}

\section{1 - MECANISMOS RESISTENTES À FORÇA CORTANTE}

Nos elementos estruturais de concreto armado submetidos à força cortante, além do modelo de treliça, outros mecanismos resistentes são responsáveis pela transmissão de esforços solicitantes de uma seção transversal a outra.

Mesmo em lajes usuais, nas quais não se utiliza armadura transversal, a contribuição quantitativa de cada um dos mecanismos resistentes alternativos ainda não está totalmente esclarecida. Em vigas de concreto armado, com a mobilização do modelo de treliça, a parcela de contribuição dos outros mecanismos resistentes diminui.

A resistência à força cortante no concreto armado ainda é objeto de inúmeros estudos teóricos e experimentais. A maioria das formulações utilizadas são baseadas em expressões empíricas ou semi-empíricas.

As principais normas técnicas ou códigos consideram a resistência de uma viga ao cisalhamento a partir de duas parcelas: a contribuição do concreto $\left(\mathrm{V}_{\mathrm{c}}\right)$ e a contribuição da armadura transversal $\left(\mathrm{V}_{\mathrm{s}}\right)$. Determina-se a "contribuição do concreto" empiricamente, representando a contribuição dos mecanismos resistentes alternativos. Para o dimensionamento da armadura transversal, utilizam-se os modelos de treliça.

Alguns autores consideraram o valor de $\mathrm{V}_{\mathrm{c}}$ igual à resistência de uma viga similar sem armadura transversal ou igual à força cortante que provoca a fissuração diagonal. $\mathrm{Na}$ 
realidade, observando-se os ensaios das vigas, comprova-se que a força última experimental $\left(\mathrm{V}_{\mathrm{u} \text { exp }}=\mathrm{V}_{\mathrm{c}}\right)$ de uma viga sem estribos verticais é um pouco maior que o valor da força cortante de fissuração $V_{\text {cr }}$ de uma viga similar com estribos verticais.

Os mecanismos resistentes à ação do esforço cortante, de uma seção de concreto armado (Figura 3.1) são os seguintes:

- resistência ao cisalhamento do banzo comprimido $\left(\mathrm{V}_{\mathrm{cz}}\right)$;

- engrenamento dos agregados entre superfícies do concreto numa fissura $\left(V_{\mathrm{a}}\right)$;

- efeito de pino da armadura longitudinal $\left(\mathrm{V}_{\mathrm{de}}\right)$;

- efeito de arco;

- resistência da armadura transversal $\left(\mathrm{V}_{\mathrm{s}}\right)$.

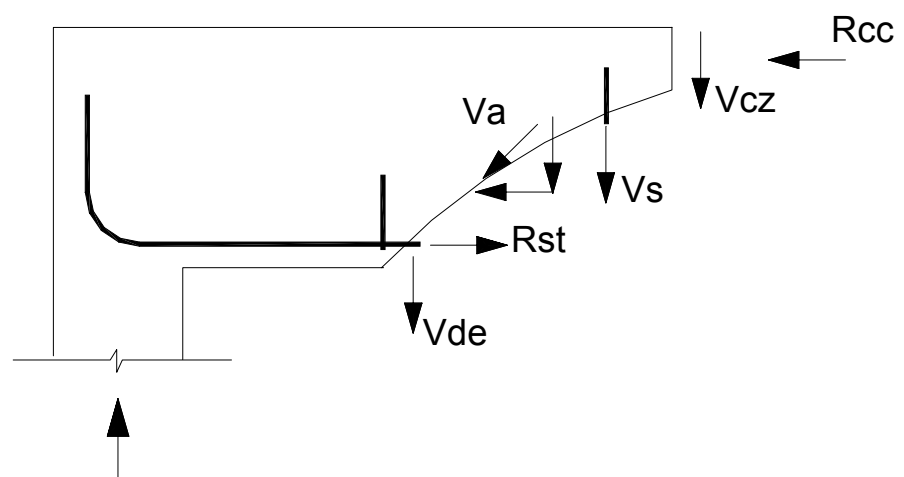

Figura 3.1 - Transferência de força cortante em vigas.

A Figura 3.2 mostra as parcelas de contribuição dos citados mecanismos, para uma viga sem armadura transversal, com a evolução do carregamento. Observa-se que, antes da fissuração, aproximadamente $50 \%$ da força cortante é transmitida pelo banzo comprimido. Com a fissuração da viga, esta contribuição é proporcionalmente reduzida, com o acréscimo das parcelas do engrenamento dos agregados e efeito de pino, até a ruptura.

LEONHARDT (1978) mostra que, em vigas com armadura transversal, a participação dos mecanismos alternativos pode ser apenas subsidiária. A Figura 3.3 mostra resultados de ensaios de vigas com seção transversal em $\mathrm{T}$, com a definição das parcelas de contribuição destes mecanismos. Grande parte da força cortante é transmitida pelo banzo comprimido e pela armadura transversal, com uma parcela minoritária atribuída ao engrenamento dos agregados e efeito de pino. 


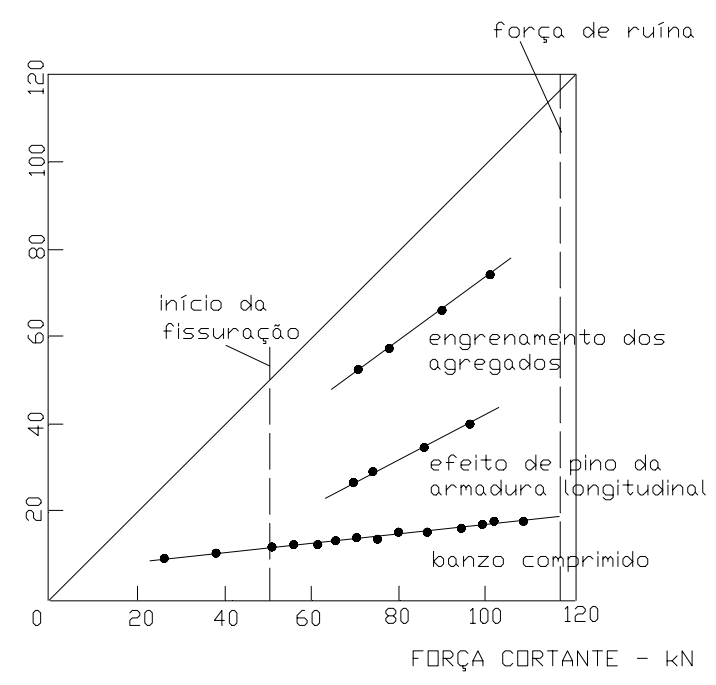

Figura 3.2 - Parcelas dos mecanismos resistentes em vigas sem armadura transversal (CHANA, 1987).

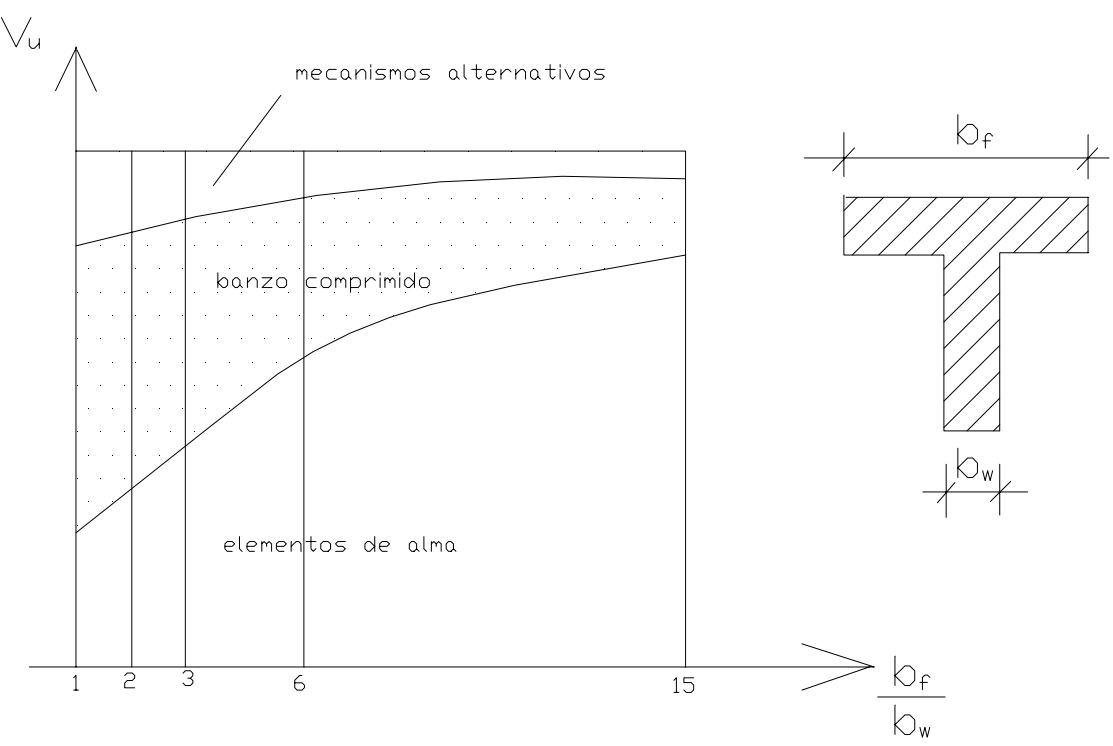

Figura 3.3 - Parcelas dos mecanismos resistentes em vigas com armadura transversal (LEONHARDT, 1978).

A transferência de força cortante por meio das tensões de cisalhamento no banzo comprimido ocorre nas vigas não-fissuradas ou em partes das mesmas ainda não-fissuradas de modo similar ao de um material homogêneo resistente à tração.

Pelo efeito de arco as ações atuantes são transferidas diretamente aos apoios da viga. Este efeito não se constitui num mecanismo de transmissão de tensões de cisalhamento de 
uma seção a outra de uma viga, todavia pode reduzir as parcelas de contribuição dos outros mecanismos resistentes.

$\mathrm{O}$ efeito de pino representa uma parcela da força cortante absorvida pelas barras longitudinais, que funcionam como pinos de ligação que solidarizam os diferentes trechos da viga separados pelas fissuras (Figura 3.4). Numerosos pesquisadores têm investigado experimentalmente este efeito, apesar das dificuldades ocasionadas pelo grande número de variáveis a serem consideradas. A rigidez das barras longitudinais e a área de concreto entre elas influenciam o efeito de pino.

JELIC et al. (1999) apresentaram um resumo das principais expressões empíricas para o cálculo da parcela referente ao efeito de pino da armadura longitudinal. OLIVEIRA et al. (2001) propuseram um programa de ensaios com o objetivo de quantificar a porcentagem de força cortante resistida pelo efeito de pino.

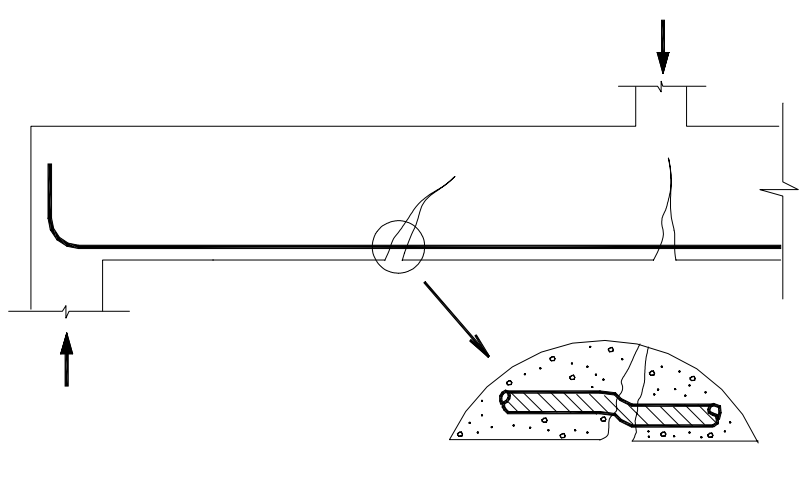

Efeito de pino

Figura 3.4 - Efeito de pino da armadura longitudinal.

O engrenamento entre os agregados pode, simplificadamente, ser interpretado, como transmissão de tensões entre as duas faces de uma fissura, por meio de uma força de atrito entre elas. A eficiência do mecanismo depende, então, do grau de rugosidade das superfícies de fissuração e da força normal existente entre essas faces. Com o aumento da abertura da fissura, esta força decresce, pois a intensidade do contato entre faces tende a diminuir.

Assim, a transferência de força cortante pela interface das fissuras torna-se possível pelo engrenamento dos agregados e, no caso de vigas com armadura transversal, também pelo efeito de pino da armadura transversal.

Dentre outros, os trabalhos de CHANA (1987), BAZANT \& SUN (1987), REAGAN (1993) e a coletânea do BOLETIM CEB-126 (1978) analisam também os mecanismos resistentes.

Inúmeros parâmetros influenciam as parcelas de cada um dos mecanismos resistentes. Como os parâmetros são inter-relacionados, torna-se difícil quantificar com 
precisão estas parcelas. Em vigas com armadura transversal constituída por estribos, deve-se analisar ainda as vantagens indiretas desta armadura nos outros mecanismos resistentes, FURLAN JR. (1995):

- banzo comprimido $\rightarrow$ confinamento do concreto e limitação do avanço das fissuras de cisalhamento;

- efeito de pino $\rightarrow$ maior proteção e suporte da armadura longitudinal e aumento na resistência ao fendilhamento;

- atrito nas fissuras $\rightarrow$ limitação da abertura e espaçamento das fissuras.

\section{2 - FATORES QUE INFLUEM NA RESISTÊNCIA AO CISALHAMENTO}

A resistência ao cisalhamento das vigas pode ser afetada por inúmeros fatores que influenciam os mecanismos resistentes. LEONHARDT (1965) admite a existência de 20 destes fatores sendo que para alguns deles não há conhecimento suficiente de sua influência. MORENO JR. (1996) apresenta um resumo dos principais fatores indicados em trabalhos de alguns importantes pesquisadores.

Os principais fatores são:

- dimensões e forma da seção transversal;

- armadura longitudinal: taxa, cortes ou dobramento e resistência ao escoamento;

- armadura transversal: taxa, tipo, espaçamento, resistência ao escoamento;

- resistência à compressão do concreto;

- moldagem e cura do concreto;

- granulometria do concreto;

- relação a/d;

- carregamento: tipo e maneira de aplicação.

Espera-se, considerando as análises teóricas realizadas por outros pesquisadores, um aumento na resistência à força cortante com o aumento da resistência à compressão do concreto. Entretanto, observou-se que esse aumento não mais ocorreria a partir de certo limite de resistência à compressão do concreto. TAYLOR (1978) justificou esse comportamento em função do agregado graúdo utilizado. Em vigas com concreto de alta 
resistência à compressão, mas com agregado graúdo de baixa resistência à compressão, as fissuras tornam-se pouco rugosas, diminuindo a parcela de engrenamento dos agregados.

LEONHARDT (1978), além de outros pesquisadores, obteve resultados de ensaios que indicaram que a capacidade resistente à força cortante diminui consideravelmente com o aumento da altura h da seção.

Em relação à influência da largura da mesa colaborante em seções T, PLACAS \& REGAN (1971) chegaram aos resultados indicados na Figura 3.5, onde as vigas com menor largura de mesa têm menor capacidade resistente ao cisalhamento.

É importante enfatizar ainda que centenas de ensaios já realizados para o estudo da capacidade resistente ao cisalhamento foram executados com vigas de seção retangular.

Segundo MORENO JR (1996), para uma taxa de armadura longitudinal abaixo de um valor limite (entre $1,2 \%$ e $1,5 \%$ ) a resistência ao cisalhamento caía significativamente. Com a diminuição da taxa de armadura longitudinal, haveria uma maior abertura das fissuras que reduziria o efeito de engrenamento dos agregados e, conseqüentemente, a resistência ao cisalhamento da viga.

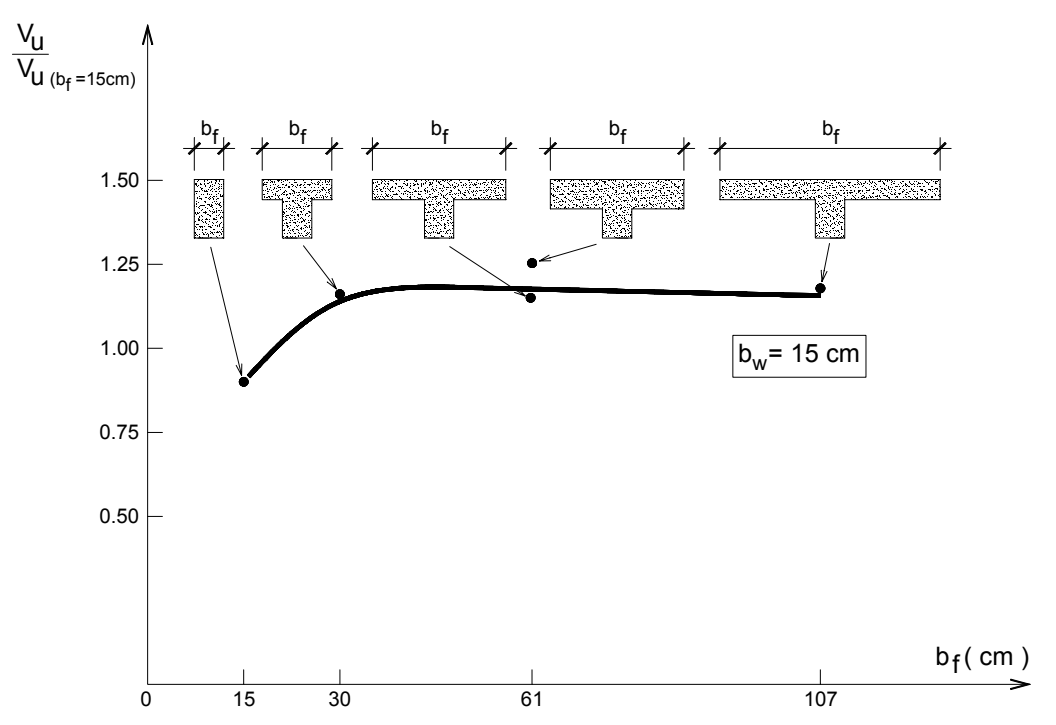

Figura 3.5 - Influência da largura da mesa na capacidade resistente ao cisalhamento, LEONHARDT \& MÖNNIG (1978a).

LEONHARDT \& MÖNNIG (1978b) mostram que os estribos, verticais ou inclinados, são mais eficientes que as barras dobradas, tanto em relação ao carregamento último quanto à abertura de fissuras, Figura 3.6. 


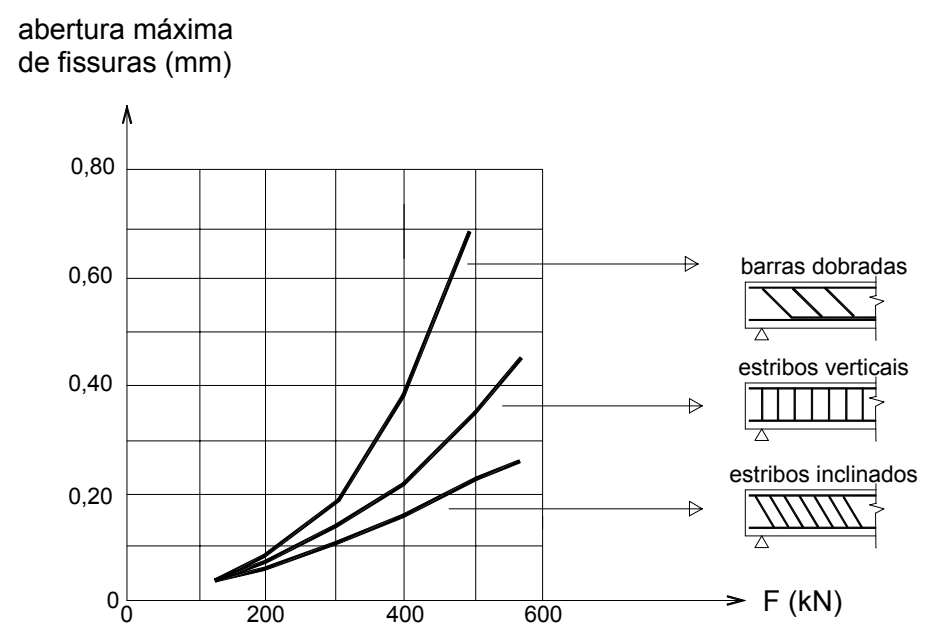

Figura 3.6 - Abertura máxima das fissuras em função do tipo de armadura transversal.

A capacidade resistente à força cortante seria diretamente proporcional à tensão de escoamento da armadura transversal se a ruína por força cortante fosse causada somente pelo escoamento da armadura. Entretanto, esta tensão de escoamento tem sido limitada pela maioria das normas e códigos atuais. Justifica-se esta limitação principalmente pela prevenção de aberturas excessivas para as fissuras inclinadas.

Com todos os outros parâmetros constantes, obtém-se um acréscimo na resistência ao cisalhamento da viga com o aumento da taxa de armadura transversal. O limite máximo para essa taxa seria imposto pela resistência à compressão das diagonais.

A relação a/d ou $\mathrm{M} /(\mathrm{V} . \mathrm{d})$ é outro parâmetro muito importante na resistência ao cisalhamento de uma viga. Mantidos os outros parâmetros constantes, esperar-se-ia uma mesma capacidade resistente com a variação de a, pois o esforço cortante máximo no apoio independeria de a. Todavia, este fato não foi comprovado experimentalmente como mostra a Figura 3.7. Nesta figura observa-se uma menor capacidade resistente para uma relação a/d em torno de 3. Cabe observar que essa influência na resistência ao cisalhamento foi comprovada em vigas ensaiadas sem armadura transversal.

CASTRO (1997) apresentou um estudo paramétrico sobre a resistência à força cortante em vigas de concreto armado. Foram analisados 409 ensaios de vigas, com e sem estribos, com a resistência à compressão variando entre $18 \mathrm{MPa}$ e $130 \mathrm{MPa}$, relação a/d de 0,5 a 8,0 , taxa de armadura longitudinal de $0,5 \%$ a $7,0 \%$ e taxa de armadura transversal de 0 a $2,64 \%$. 


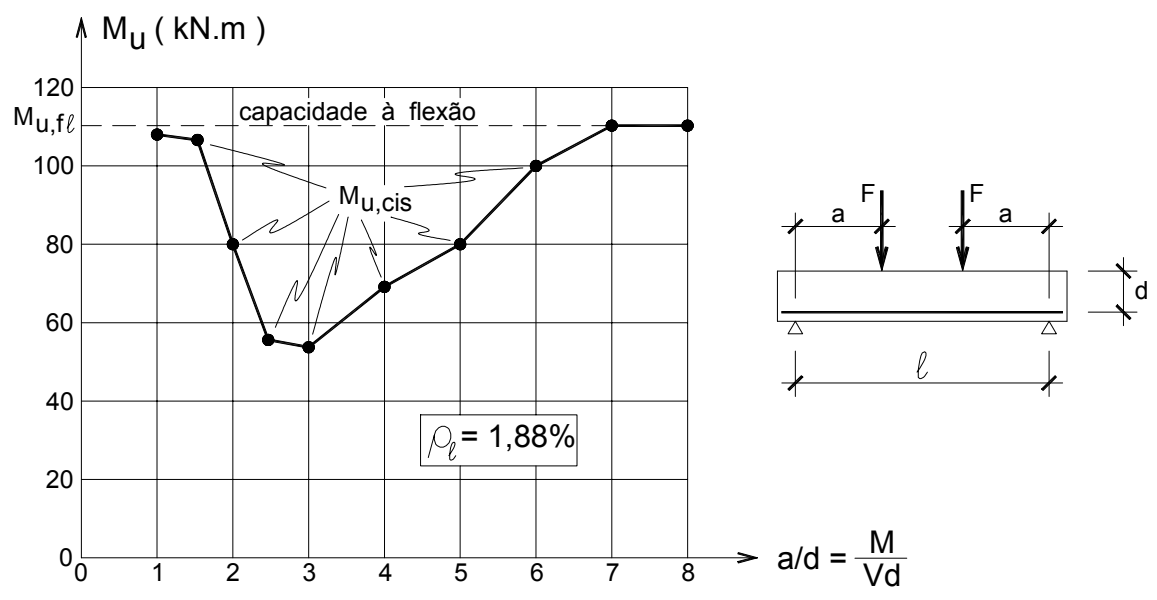

Figura 3.7 - Influência da relação a/d na resistência ao cisalhamento de uma viga, LEONHARDT \& MÖNNIG (1978a).

\section{3 - MODOS DE RUÍNA}

O modo de ruína ao cisalhamento por força cortante varia muito dependendo da geometria, dimensões dos elementos estruturais e da força aplicada.

A Tabela 3.1 apresenta os modos de ruína típicos em elementos sem armaduras transversais efetivas, ilustrados na Figura 3.8.

Tabela 3.1 - Modos de ruína em elementos sem armaduras transversais efetivas, FUSCO (1984).

\begin{tabular}{|c|c|c|}
\hline Modo de ruína & Descrição & Aspecto \\
\hline $\begin{array}{c}\text { tração diagonal no } \\
\text { concreto }\end{array}$ & $\begin{array}{c}\text { elemento sem armadura } \\
\text { transversal }\end{array}$ & Figura 3.8-a \\
\hline tração diagonal no \\
concreto & $\begin{array}{c}\text { elemento com espaçamento } \\
\text { excessivo da armadura } \\
\text { transversal }\end{array}$ & Figura 3.8-b \\
& & \\
\hline
\end{tabular}




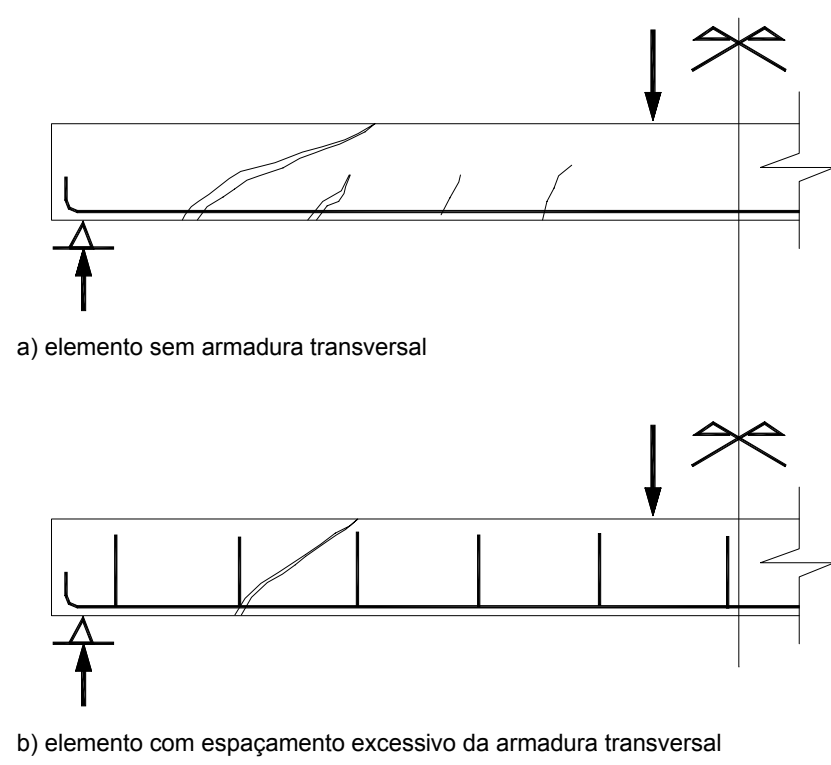

Figura 3.8 - Aspecto dos modos de ruína em elementos sem armaduras transversais efetivas.

A Tabela 3.2 apresenta os modos de ruína típicos em elementos com armaduras transversais efetivas, ilustrados na Figura 3.9.

Tabela 3.2 - Modos de ruína em elementos com armaduras transversais, FUSCO (1984).

\begin{tabular}{|c|c|c|}
\hline Modo de ruína & Descrição & Aspecto \\
\hline cortante-compressão & $\begin{array}{c}\text { esmagamento da biela } \\
\text { comprimida junto ao apoio }\end{array}$ & Figura 3.9-a \\
\hline cortante-tração & $\begin{array}{c}\text { ruptura da armadura } \\
\text { transversal por tração }\end{array}$ & Figura 3.9-b \\
\hline cortante-flexão & $\begin{array}{c}\text { interação momento } \\
\text { fletor/cortante, a fissura } \\
\text { diagonal avança e corta o } \\
\text { banzo comprimido da peça }\end{array}$ & Figura 3.9-c \\
\hline flexão da armadura & $\begin{array}{c}\text { rompimento da armadura de } \\
\text { flexão }\end{array}$ & Figura 3.9-d \\
\hline romgitudinal & por esgotamento da & \\
aço-concreto & capacidade de aderência & \\
\hline
\end{tabular}




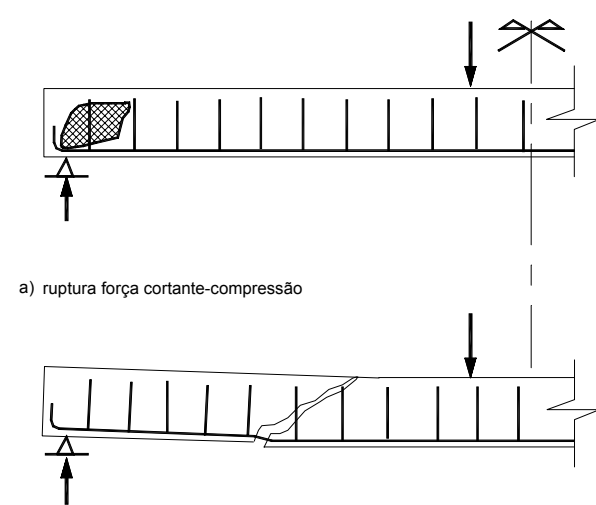

b) ruptura força cortante-tração

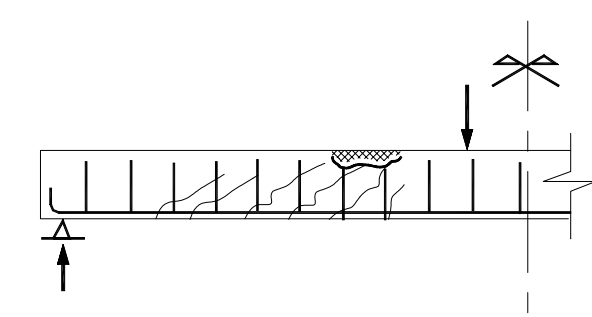

c) ruptura força cortante-flexão

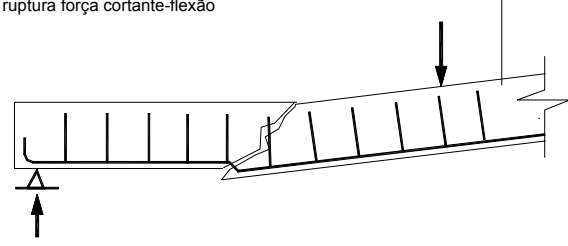

d) ruptura por flexão da armadura longitudinal de tração

Figura 3.9 - Aspecto dos modos de ruína em elementos com armaduras transversais efetivas.

\section{4 - DIMENSIONAMENTO DE ACORDO COM NORMAS/PESQUISADORES}

\subsection{1 - PROJETO DE REVISÃO DA NBR 6118:2001}

\subsubsection{1 - Generalidades}

A verificação da segurança de peças fletidas pressupõe a analogia com modelo em treliça, de banzos paralelos, associado a mecanismos resistentes complementares desenvolvidos no interior da peça e traduzidos por uma componente adicional $\mathrm{V}_{\mathrm{c}}$. As verificações são feitas em termos de forças atuantes nas diagonais comprimidas de concreto e armadura transversal e não mais nas tensões. Admitem-se dois modelos de cálculos alternativos:

-modelo I: admite as diagonais de compressão inclinadas de $\theta=45^{\circ}$ em relação ao eixo longitudinal da peça, e em que $\mathrm{V}_{\mathrm{c}}$ é suposto de valor constante;

-modelo II: adota essas diagonais com inclinação diferente de $45^{\circ}$, arbitrada livremente no intervalo $30^{\circ} \leq \theta \leq 45^{\circ}$. Nesse caso, considera-se a parcela $V_{c}$ com valores que diminuem com o aumento da força cortante. 
As condições relativas aos esforços solicitantes, reduções nos esforços cortantes para seções próximas aos apoios e peças de altura variável, foram mantidas como indicadas na NBR 6118: 1978.

\subsubsection{2 - Verificação do Estado Limite Último}

A resistência da peça, em uma determinada seção transversal é satisfatória quando verificadas simultaneamente as seguintes condições:

$$
\begin{aligned}
& V_{S d}<V_{R d 2} \\
& V_{S d}<V_{R d 3}=V_{c}+V_{s w}
\end{aligned}
$$

em que:

$V_{S d}$ - força cortante solicitante de cálculo, na seção;

$V_{R d 2}$ - força cortante resistente de cálculo, relativa à ruína das diagonais comprimidas de concreto;

$V_{R d 3}=V_{c}+V_{s w}$, sendo $V_{c}$ a parcela de força cortante absorvida por mecanismos complementares ao de treliça e $V_{s w}$ a parcela absorvida pela armadura transversal.

\subsubsection{3 - Modelo de cálculo I}

No modelo de cálculo I, a resistência da peça é assegurada pela verificação da compressão diagonal no concreto, com a expressão:

$$
V_{R d 2}=0,27 \alpha_{v} \cdot f_{c d} \cdot b_{w} \cdot d, \operatorname{com} \alpha_{v}=\left(1-f_{c k} / 250\right), f_{c k} \text { em MPa }
$$

e, pelo cálculo da armadura transversal, dada por:

$$
V_{s w}=\left(A_{s w} / s\right) 0,9 d \cdot f_{y w d}(\operatorname{sen} \alpha+\cos \alpha)
$$

em que:

$$
f_{y w d} \leq 435 \mathrm{MPa}
$$


$V_{c}=0$ nas peças tracionadas quando a linha neutra se situa fora da seção;

$V_{c}=V_{c o}$ na flexão simples e na flexo-tração com a linha neutra cortando a seção;

$V_{c}=\left(V_{c o}+V_{c o} \cdot M_{o} / M_{S d, \max }\right) \leq 2 V_{c o}$ na flexo-compressão com

$$
V_{c o}=0,6 f_{c t d} \cdot b_{w} \cdot d
$$

sendo,

$M_{o}$ - momento fletor que anula a tensão normal de compressão na borda da seção;

$M_{S d, \text { max }}$ - momento fletor de cálculo máximo no trecho em análise;

$$
\begin{aligned}
& f_{c t d}=f_{c t k, \text { inf }} / \gamma_{c}, \text { sendo } f_{c t k, \text { inf }}=0,7 f_{c t m} \mathrm{e} \\
& f_{c t m}=0,3 f_{c k}^{2 / 3}\left(f_{c k} \text { em MPa }\right)
\end{aligned}
$$

\subsubsection{4 - Modelo de cálculo II}

Quando é utilizado o modelo de cálculo II, a resistência da peça é assegurada pela verificação da compressão diagonal no concreto, com a expressão:

$$
V_{R d 2}=0,54 \alpha_{v} \cdot f_{c d} \cdot b_{w} \cdot d \cdot \operatorname{sen}^{2} \theta(\cot g \alpha+\cot g \theta)
$$

e, pelo cálculo da armadura transversal, dado por

$$
V_{s w}=\left(A_{s w} / s\right) 0,9 d \cdot f_{y w d}(\cot g \alpha+\cot g \theta) \operatorname{sen} \alpha
$$

sendo:

$f_{y w d} \leq 435 \mathrm{MPa}$;

$V_{c}=0$ em peças tracionadas quando a linha neutra se situa fora da seção;

$V_{c}=V_{c 1}$ na flexão simples e na flexo-tração com a linha neutra cortando a seção;

$V_{c}=\left(V_{c 1}+V_{c 1} \cdot M_{o} / M_{S d, \max }\right) \leq 2 V_{c 1}$ na flexo-compressão com

$V_{c 1}=V_{c o}$ quando $V_{d}=V_{c o} \mathrm{e}$

$V_{c 1}=0$ quando $V_{d}=V_{R d 2}$ 
interpolando-se linearmente para valores intermediários.

\subsubsection{5 - Armadura mínima e espaçamentos}

Todos os elementos lineares fletidos, submetidos à ação de força cortante, devem ter uma armadura transversal mínima constituída por estribos, com taxa geométrica dada por:

$$
\rho_{s w}=\frac{A_{s w}}{b_{w} \cdot s \cdot \operatorname{sen} \alpha} \geq 0,2 \frac{f_{c t m}}{f_{y w k}}
$$

O espaçamento mínimo entre estribos, medido segundo o eixo longitudinal da peça, deve ser suficiente para permitir a passagem do vibrador, garantindo um bom adensamento do concreto. $\mathrm{O}$ espaçamento máximo deve atender às seguintes condições:

- se $V_{d} \leq 0,67 V_{R d 2}$, então $s_{\max } 0,6 d \leq 300 \mathrm{~mm}$;

- se $V_{d}>0,67 V_{R d 2}$, então $s_{\max } 0,3 d \leq 200 \mathrm{~mm}$.

\subsection{2 - CÓDIGO MODELO CEB-FIP (1990)}

\subsubsection{1 - Generalidades}

O Código Modelo CEB-FIP (1990) adota o modelo da treliça generalizada para o dimensionamento à força cortante. Para o dimensionamento da armadura transversal, indicam-se duas verificações de ações atuantes e esforços resistentes : nas bielas diagonais e nos tirantes da armadura transversal. Para a otimização da distribuição das barras da armadura longitudinal, também propõem-se duas verificações de ações atuantes e esforços resistentes: no banzo tracionado e no banzo comprimido.

O modelo fundamental de um trecho típico da alma de uma viga é mostrado na Figura 3.8. O braço de alavanca $\mathrm{z}$ e altura $\mathrm{x}$ da zona comprimida, em um trecho no qual os momentos fletores mantêm o mesmo sinal, podem ser considerados iguais aos valores na seção de momento fletor $\mathrm{M}_{\mathrm{d}}$ máximo. 


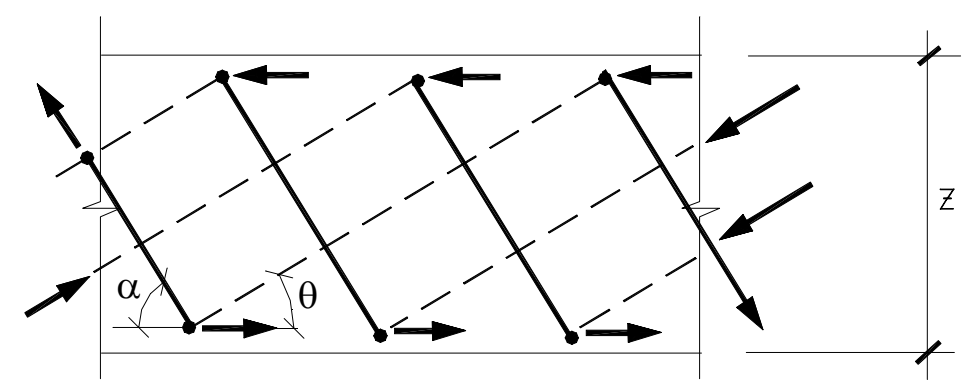

Figura 3.8 - Modelo fundamental da alma (CEB-FIP, 1990)

\subsubsection{2 - Condições para aplicação dos modelos}

A aplicação dos modelos está sujeita às seguintes condições:

a) a taxa mecânica de armadura transversal não deve ser menor que 0,2 , isto é:

$$
\begin{aligned}
& \omega_{s w}=A_{s w} \cdot f_{y w k} /\left(b_{w} \cdot s \cdot f_{c t m} \cdot \operatorname{sen} \alpha\right) \geq 0,2, \text { ou seja: } \\
& \frac{A_{s w}}{s} \geq 0,2 f_{c t m} \times \frac{b_{w} \cdot \operatorname{sen} \alpha}{f_{y w k}}
\end{aligned}
$$

com o objetivo de limitar a abertura da fissura de cisalhamento, e com $f_{c t m}$, que é a resistência média à tração, dada por:

$$
f_{c t m}=1,4\left(\frac{f_{c k}}{10}\right)^{2 / 3}
$$

b) a inclinação dos estribos em relação ao eixo da peça deve ser no mínimo $45^{\circ}$ e a das barras dobradas, no mínimo $30^{\circ}$;

c) o espaçamento entre os ramos dos estribos (em ambas as direções, longitudinal e transversal) não deve ser maior que $0,75 \mathrm{~d}$ ou $800 \mathrm{~mm}$;

d) a armadura de cisalhamento deve ser adequadamente ancorada nos banzos. 


\subsubsection{3 - Expressões para o dimensionamento}

a) Banzo tracionado

A força atuante no banzo tracionado é dada pela expressão:

$$
F_{s t}=\frac{\left|M_{d}\right|}{z}+\frac{N_{d}\left(z-z_{s}\right)}{z}+\frac{V_{d}}{2}(\operatorname{cotg} \theta-\operatorname{cotg} \alpha)
$$

onde:

$F_{S t}$ - força solicitante no banzo tracionado;

$\mathrm{M}_{\mathrm{d}}$ - momento fletor de cálculo;

$\mathrm{N}_{\mathrm{d}}$ - força axial, sendo positiva para tração e negativa para compressão;

$\mathrm{V}_{\mathrm{d}}$ - força cortante de cálculo;

$\mathrm{z}$ - braço de alavanca;

$\mathrm{Z}_{\mathrm{s}}$ - distância da linha de ação de $\mathrm{N}_{\mathrm{d}}$ ao centro de gravidade da armadura de tração;

$\theta$ - ângulo de inclinação das bielas com a horizontal;

$\alpha$ - ângulo de inclinação da armadura transversal.

No caso de ações aplicadas na face superior:

$F_{S t} \leq \frac{\left|M_{d, \max }\right|}{z}+\frac{N_{d}\left(z-z_{s}\right)}{z}$

A força resistente no banzo tracionado será dada por:

$$
F_{R t}=A_{s} \cdot f_{y d}
$$

onde:

$\mathrm{A}_{\mathrm{s}}$ - área da armadura longitudinal tracionada;

$\mathrm{f}_{\mathrm{yd}}$ - resistência ao escoamento do aço da armadura.

Verificação de segurança: $F_{S t} \leq F_{R t}$

b) Banzo comprimido

A força solicitante de cálculo no banzo comprimido da treliça é dada por:

$$
F_{S c}=\frac{\left|M_{d}\right|}{z}-\frac{N_{d} \cdot z_{s}}{z}-\frac{V_{d}}{2}(\operatorname{cotg} \theta-\operatorname{cotg} \alpha)
$$


onde:

$F_{S c}$ - força solicitante no banzo comprimido.

Na seção de momento máximo, para ação aplicada na face superior, tem-se:

$F_{S c}=\frac{\left|M_{d, \max }\right|}{z}-N_{d} \frac{z_{s}}{z}$

Para a força resistente do banzo comprimido, tem-se:

$$
F_{R c}=f_{c d 1} \cdot A_{c}+f_{y c d} \cdot A_{s c}
$$

em que:

$\mathrm{A}_{\mathrm{sc}}=$ área da armadura longitudinal comprimida;

$\mathrm{A}_{\mathrm{c}}=$ área da seção transversal do banzo comprimido;

$$
A_{c}=\left\{\begin{array}{l}
b_{w} \cdot x \\
b_{f} \cdot x \\
\left(b_{f}-b_{w}\right) h_{f}+b_{w} \cdot x
\end{array}\right.
$$

Para seção retangular, seção tê com a linha neutra cortando a mesa e seção tê com a linha neutra cortando a alma, respectivamente, sendo x a altura da linha neutra.

Verificação de segurança: $F_{S c} \leq F_{R c}$

c) Diagonal comprimida

A força solicitante de cálculo na diagonal comprimida (Figura 3.19) é expressa por:

$$
F_{S c w}=\frac{V_{d}}{\operatorname{sen} \theta}\left(\frac{\operatorname{cotg} \theta}{\operatorname{cotg} \theta+\operatorname{cotg} \alpha}\right)
$$

onde:

$F_{S c w}$ - resultante na diagonal comprimida das tensões atuantes no trecho z.cos $\theta$.

A força resistente à compressão da diagonal é dada por:

$$
F_{R c w}=f_{c d 2} \cdot b_{w} \cdot z \cdot \cos \theta
$$

Verificação de segurança: $F_{S c w} \leq F_{R c w}$ 


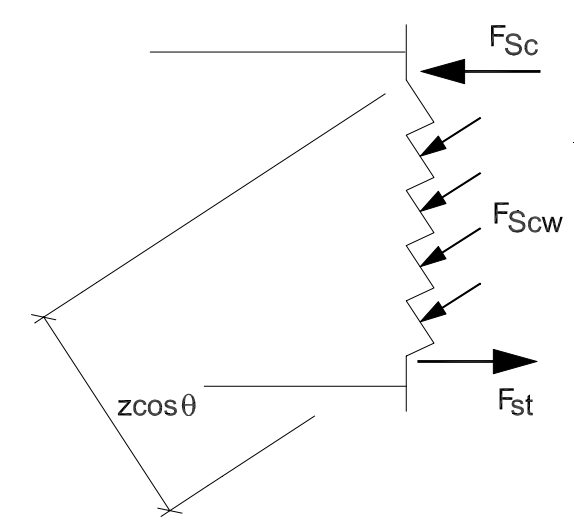

Figura 3.9 - Compressão na diagonal de concreto.

d) Tração na armadura transversal expressão:

A força solicitante de cálculo de tração na armadura transversal é dada pela

$$
F_{S t w}=\frac{V_{d}}{\operatorname{sen} \alpha}
$$

A força resistente de tração da armadura transversal é dada por:

$$
F_{R t w}=A_{s w} \frac{z(\operatorname{cotg} \theta+\operatorname{cotg} \alpha)}{s} f_{y w d}
$$

onde:

$F_{R t w}$ - força de tração resistente da armadura transversal;

$F_{S t w}$ - força resultante em um trecho $\mathrm{z}(\operatorname{cotg} \theta+\operatorname{cotg} \alpha)$ da armadura transversal; $\mathrm{s}$ - espaçamento dos estribos medido ao longo do eixo da peça.

Verificação de segurança: $F_{S t w} \leq F_{R t w}$

Para estribos verticais $\left(\alpha=90^{\circ}\right)$ :

$$
\frac{A_{s w}}{s}>\frac{V_{d}}{f_{y w d} \cdot z \cdot \operatorname{cotg} \theta}
$$




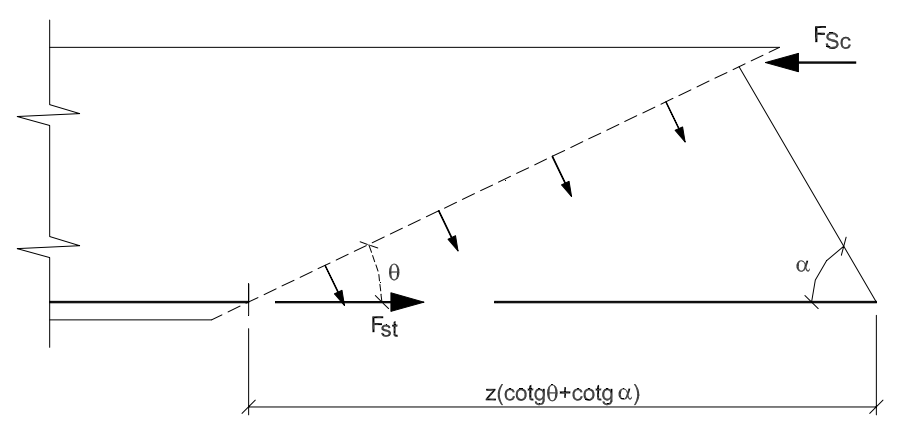

Figura 3.10 - Tração na armadura transversal.

\subsubsection{4 - Procedimento para verificação}

Para um trecho de viga no qual o momento fletor de cálculo permanece com o mesmo sinal e seção transversal constante, utiliza-se o seguinte procedimento para verificação:

a) A resistência do concreto na alma é verificada na seção de máxima força cortante.

b) A resistência da armadura transversal é verificada :

b.1) para o trecho que dista (z.cotg $\theta$ ) do eixo do apoio, nos casos de ações aplicadas na face superior;

b.2) para todo o trecho nos casos de ações aplicadas ao longo da altura ou na face inferior.

\subsubsection{5 - Determinação do ângulo $\theta$}

O ângulo $\theta$ entre as diagonais comprimidas e os banzos pode ser escolhido livremente no intervalo $\theta_{\min } \leq \theta \leq 45^{\circ}$. A escolha de um ângulo próximo a $45^{\circ}$ conduz a uma maior área de armadura transversal com baixas tensões nas diagonais. Por outro lado, podese diminuir a área de armadura transversal escolhendo um valor de $\theta$ próximo a $\theta_{\min }$. Entretanto, isso acarreta um acréscimo nas tensões nas diagonais comprimidas. Como essas tensões são verificadas diretamente, sugere-se a adoção de valores de $\theta$ os mais próximos possíveis de $\theta_{\min }$, desde que conduzam a tensões de compressão dentro dos limites.

\subsubsection{6 - Distribuição dos estribos}

O espaçamento máximo $s_{\max }$ entre as barras da armadura transversal é definido pelas seguintes condições: 


$$
\begin{aligned}
& \text { Se } \mathrm{F}_{\mathrm{Scw}} \leq \frac{1}{5} \mathrm{~F}_{\mathrm{Rcw}} \rightarrow \mathrm{s}_{\max }=0,7 \mathrm{~d}<300 \mathrm{~mm} \\
& \mathrm{~F}_{\mathrm{Scw}} \leq \frac{2}{3} \mathrm{~F}_{\mathrm{Rcw}} \rightarrow \mathrm{s}_{\max }=0,6 \mathrm{~d}<300 \mathrm{~mm} \\
& \mathrm{~F}_{\mathrm{Scw}}>\frac{2}{3} F_{R c w} \rightarrow \mathrm{s}_{\max }=0,3 \mathrm{~d}<200 \mathrm{~mm}
\end{aligned}
$$

\subsection{3 - ACI 318R (2002)}

\subsubsection{1 - Generalidades}

Segundo o ACI 318R (2002), para a verificação da segurança à força cortante procede-se à comparação entre a força solicitante de cálculo e a força cortante resistente na seção considerada. Assim, tem-se:

$$
V_{u} \leq \phi \cdot V_{n} e V_{n}=V_{c}+V_{s}
$$

em que:

$\mathrm{V}_{\mathrm{u}}$ - força cortante solicitante de cálculo;

$\mathrm{V}_{\mathrm{n}}$ - força cortante resistente da seção;

$\phi$ - coeficiente de redução da resistência ( $\phi=0,85$, no caso de cisalhamento);

$\mathrm{V}_{\mathrm{c}}$ - parcela da força cortante absorvida pelo concreto;

$\mathrm{V}_{\mathrm{s}}$ - parcela da força cortante absorvida pela armadura.

Admite-se a redução da força cortante solicitante, desde que não ocorra força concentrada próxima ao apoio, tomando-a igual à força cortante que atua na seção transversal que dista $\mathrm{d}$ da face do apoio.

\subsubsection{2 - Contribuição do concreto}

A parcela de força cortante absorvida pelo concreto, para seções submetidas à ação de força cortante, pode ser calculada pela expressão: 


$$
\mathrm{V}_{\mathrm{c}}=\left(\sqrt{f_{c}^{\prime}} / 6\right) b_{w} \cdot d
$$

sendo,

$\mathrm{f}_{\mathrm{c}}$ ' - resistência à compressão do concreto, definida a partir do quantil de $1 \%$, definida em VASCONCELOS \& GIAMMUSSO (1993).

$$
\sqrt{f_{c}^{\prime}} \leq 25 / 3 M P a
$$

Para seções em que atua momento fletor simultaneamente à ação de força cortante, tem-se:

$$
\mathrm{V}_{\mathrm{c}}=\left[\left(\sqrt{f_{c}^{\prime}}+120 \rho \cdot \frac{V_{u} \cdot d}{M_{u}}\right) / 7\right] b_{w} \cdot d \leq 0,30 \sqrt{f_{c}^{\prime}} \cdot b_{w} \cdot d
$$

em que:

$\rho=A_{s} / b_{w} \cdot d \quad$ e $\quad\left(V_{u} \cdot d / M_{u}\right) \leq 1,0 ;$

$\mathrm{M}_{\mathrm{u}}$-momento fletor solicitante de cálculo que ocorre simultaneamente na seção considerada; $\rho$ - taxa de armadura longitudinal.

\subsubsection{3 - Dimensionamento da armadura transversal}

A resultante das tensões de tração absorvida pela armadura, no caso de estribos verticais, pode ser obtida pela expressão:

$$
\mathrm{V}_{\mathrm{s}}=\frac{A_{v} \cdot f_{y} \cdot d}{s} \leq\left(2 \sqrt{f_{c}^{\prime}} / 3\right) b_{w} \cdot d
$$

em que:

$\mathrm{A}_{\mathrm{v}}$ - área da armadura transversal;

$\mathrm{s}$ - espaçamento entre os estribos;

$\mathrm{f}_{\mathrm{y}}$ - resistência de escoamento da armadura, não se adotando valores maiores que $400 \mathrm{MPa}$;

Assim, $\mathrm{V}_{\mathrm{u}}=\phi . \mathrm{V}_{\mathrm{n}} \rightarrow \mathrm{V}_{\mathrm{n}}=\mathrm{V}_{\mathrm{u}} / \phi$

Como $V_{n}=V_{c}+V_{s} \rightarrow V_{s}=V_{n}-V_{c}$, com o valor de $V_{s}$, tem-se: 


$$
\frac{A_{v}}{s}=\frac{V_{s}}{f_{y} . d} \cdot 100 \quad\left(\mathrm{~cm}^{2} / \mathrm{m}\right)
$$

\subsubsection{4 - Armadura mínima e espaçamentos}

A área de armadura transversal mínima é obtida por:

$$
\frac{A_{v, \text { min }}}{s}=\frac{b_{w}}{3 f_{y}}\left(\mathrm{~cm}^{2} / \mathrm{m}\right)
$$

com $b_{w}$ em mm.

O espaçamento máximo não deve ser maior do que a metade da altura útil (d), porém, nunca maior do que $60 \mathrm{~cm}$.

Quando $\mathrm{V}_{\mathrm{s}}>\left(\sqrt{f_{c}^{\prime}} / 3\right) b_{w} \cdot d$, os espaçamentos acima deverão ser reduzidos à metade.

\subsection{4 - EUROCODE 2 (1992)}

\subsubsection{1 - Generalidades}

Segundo o EUROCODE 2 (1992), a verificação da segurança de elementos fletidos também baseia-se na treliça de Mörsch, comparando-se forças atuantes e resistentes nas diagonais de concreto e armadura transversal. As forças resistentes consideradas são as seguintes:

$V_{R d 1}$ - força cortante resistente do elemento sem armadura transversal;

$V_{R d 2}$ - força cortante máxima que pode ser resistida sem o esmagamento das diagonais comprimidas de concreto;

$V_{R d 3}$ - força cortante que pode ser absorvida pelo elemento com armadura transversal.

A força cortante considerada na seção próxima ao apoio é a atuante na seção que dista $\mathrm{d}$ da face do apoio. 


\subsubsection{2 - Verificação da ruptura do concreto}

$$
V_{S d}<V_{R d 2}=\left(0,50 \cdot f_{c d}\right) b_{w} \cdot 0,9 d(1+\cot g \alpha)
$$

sendo,

$$
\mathrm{v}=\left(0,7-f_{c k} / 200\right) \geq 0,5\left(f_{c k} \text { em } M P a\right)
$$

\subsubsection{3 - Verificação da necessidade de armadura transversal}

Quando a força solicitante de cálculo for menor do que o valor limite $V_{R d 1}$, deve-se determinar a área de armadura mínima.

$$
V_{R d 1}=\left[\tau_{R d} \cdot k\left(1,2+40 \rho_{\ell}\right)\right] b_{w} \cdot d
$$

em que:

$\tau_{R d}$ - tensão resistente devido aos mecanismos internos;

$k$ - constante que considera a contribuição da armadura longitudinal na resistência ao esforço cortante;

$\rho_{\ell}$ - taxa geométrica da armadura longitudinal;

$\mathrm{b}_{\mathrm{w}}$ - largura da viga;

$\mathrm{d}$ - altura útil da viga.

Os termos mostrados na expressão são dados por:

$$
\begin{gathered}
\tau_{R d}=\frac{0,25 f_{c t k, 5 \%}}{\gamma_{c}} \\
\rho_{\ell}=\frac{A_{s \ell}}{b_{w} \cdot d} \leq 0,02
\end{gathered}
$$

sendo,

$\gamma_{c}$ - coeficiente de segurança $\left(\gamma_{c}=1,5\right)$;

$\mathrm{A}_{\mathrm{s} \ell}=$ área da armadura longitudinal tracionada; 
$f_{c t k, 5 \%}$ - resistência característica à tração do concreto, assegurando-se que pelo menos $95 \%$ dos corpos-de-prova rompidos apresentem tensão de ruptura superior a esta.

Os valores de k são dados por:

$\mathrm{k}=1$ para peça onde mais que $50 \%$ da armadura inferior é reduzida nos apoios;

$\mathrm{k}=1,6-\mathrm{d} \geq 1$ ( $\mathrm{d}$ em metros), nos outros casos;

O EUROCODE 2 (1992) fornece os valores de $\tau_{R d}$ em função da classe do concreto, conforme a Tabela 3.3 abaixo.

Tabela 3.3 - Valores de $\tau_{R d}$ para diferentes classes de concreto

\begin{tabular}{|l|l|l|l|l|l|l|l|}
\hline $\begin{array}{l}\text { Classe do } \\
\text { Concreto }\end{array}$ & $\mathrm{C} 20$ & $\mathrm{C} 25$ & $\mathrm{C} 30$ & $\mathrm{C} 35$ & $\mathrm{C} 40$ & $\mathrm{C} 45$ & $\mathrm{C} 50$ \\
\hline$\tau_{R d}\left(\mathbf{N} / \mathbf{m m}^{\mathbf{2}}\right)$ & 0,26 & 0,30 & 0,34 & 0,37 & 0,41 & 0,44 & 0,48 \\
\hline
\end{tabular}

\subsubsection{4 - Cálculo da armadura transversal}

Quando $V_{S d}>V_{R d 1}$ há necessidade de se calcular a área da armadura transversal . A resistência ao cisalhamento da seção com armadura transversal é dada por:

$$
V_{S d}=V_{R d 3}=V_{c d}+V_{w d}
$$

em que:

$V_{c d}=V_{R d 1}$ - contribuição do concreto;

$V_{w d}$ - contribuição da armadura transversal, dada pela equação:

$$
V_{w d}=\left(A_{s w} / s\right) 0,9 d \cdot f_{y w d}
$$




\subsubsection{5 - Armadura mínima e espaçamentos}

Os valores das taxas de armadura mínima são mostrados na Tabela $3.4 \mathrm{em}$ função das resistências do concreto e do aço, sendo a taxa de armadura dada por:

$$
\rho_{w}=\frac{A_{s w}}{b_{w} . s \cdot \operatorname{sen} \alpha}
$$

Tabela 3.4 - Taxas mínimas $\rho_{\mathrm{w}}$ de armadura transversal (EUROCODE 2, 1992).

\begin{tabular}{|c|c|c|c|}
\hline Classe do concreto & \multicolumn{3}{|c|}{ Classe do aço } \\
\cline { 2 - 4 } & $\mathrm{S} 220$ & $\mathrm{~S} 400$ & $\mathrm{~S} 500$ \\
\hline $\mathrm{C} 12 / 15$ e C20/25 & 0,0016 & 0,0009 & 0,0007 \\
\hline $\mathrm{C} 25 / 30$ e C35/45 & 0,0024 & 0,0013 & 0,0011 \\
\hline $\mathrm{C} 40 / 50$ e C50/60 & 0,0030 & 0,0016 & 0,0013 \\
\hline
\end{tabular}

Obs.: Na Tabela 3.4, para a classe C20/25 o primeiro valor é a resistência obtida em corposde-prova cilíndricos e o segundo em corpos-de-prova cúbicos.

Os espaçamentos máximos entre os estribos dependem dos valores da força solicitante de cálculo $\left(V_{S d}\right)$ em relação à força cortante que provoca a ruptura das diagonais de concreto $\left(V_{R d 2}\right)$, segundo os valores dados abaixo:

$$
\begin{aligned}
& V_{S d} \leq(1 / 5) V_{R d 2} \rightarrow s_{\max }=0,8 d \leq 30 \mathrm{~cm} \\
& (1 / 5) V_{R d 2}<V_{S d} \leq(2 / 3) V_{R d 2} \rightarrow s_{\max }=0,6 d \leq 30 \mathrm{~cm} \\
& V_{S d}>(2 / 3) V_{R d 2} \rightarrow s_{\max }=0,3 d \leq 20 \mathrm{~cm}
\end{aligned}
$$

\subsection{5 - ZSUTTY (1968)}

Segundo ZSUTTY (1968), a capacidade resistente à força cortante de vigas de concreto armado, pode ser obtida pela expressão:

$$
V_{u}=\phi\left(V_{c}+V_{s}\right)
$$


onde:

$V_{u}$ - força cortante resistente da seção;

$V_{c}$ - parcela da força cortante absorvida pelo concreto;

$V_{s}$ - parcela da força cortante absorvida pela armadura;

$\phi$ - coeficiente de redução da resistência ( $\phi=0,85$, mesmo valor do ACI 318R (2002).

Em vigas esbeltas o colapso ocorre, geralmente, ao ser atingida a força que provoca a primeira fissura de cisalhamento. Em vigas curtas, por causa do efeito de arco, o colapso usualmente ocorre com forças aplicadas acima da força de fissuração diagonal. Assim, a parcela da força cortante absorvida pelo concreto é determinada pelas expressões seguintes, para vigas curtas $(a / d<2,5)$ ou vigas esbeltas $(a / d \geq 2,5)$ :

$$
\begin{array}{ll}
V_{c}=2,3 b_{w} \cdot d \sqrt[3]{f_{c k} \cdot \rho \cdot \frac{d}{a}} & (a / d \geq 2,5) \\
V_{c}=\left(\frac{2,5}{a / d}\right)\left(2,3 b_{w} \cdot d \sqrt[3]{f_{c k} \cdot \rho \cdot \frac{d}{a}}\right) & (a / d<2,5)
\end{array}
$$

sendo:

$V_{c}$ em N;

$b_{w}, d$ e a em $\mathrm{mm}$;

$f_{c k}$ em MPa;

$\rho=\frac{A_{s}}{b_{w} \cdot d}$

$\rho$ - taxa de armadura longitudinal.

A parcela de força cortante absorvida pela armadura transversal pode ser calculada pela expressão:

$$
V_{s}=\frac{A_{s w}}{s} \cdot f_{y w k} \cdot d
$$

em que:

$f_{y w k}$ - resistência característica de escoamento do aço da armadura transversal. 


\subsection{6 - NORMA ESPANHOLA EHE (1999)}

\subsubsection{1 - Generalidades}

As comprovações relativas ao Estado Limite de Esgotamento por Força Cortante são realizadas a partir da força cortante efetiva:

$$
V_{r d}=V_{d}+V_{p d}
$$

onde:

$V_{d}$ - força cortante de cálculo produzido pelas ações externas;

$V_{p d}$ - valor de cálculo da componente da força de protensão paralela a seção em estudo.

O Estado Limite de Esgotamento por Força Cortante pode ser atingido por esgotamento da resistência à compressão da alma ou esgotamento de sua resistência à tração, sendo necessárias duas verificações simultaneamente:

$$
\begin{aligned}
& V_{r d} \leq V_{u 1} \\
& V_{r d} \leq V_{u 2}
\end{aligned}
$$

em que:

$V_{u 1}$ - força cortante de esgotamento por compressão oblíqua na alma;

$V_{u 2}$ - força cortante de esgotamento por tração na alma.

A expressão (3.43) deve ser verificada na seção da face do apoio (e não no seu eixo) e a expressão (3.44) em uma seção que dista "d" da face do apoio direto.

\subsubsection{2 - Obtenção de $V_{u 1}$}

A força cortante de esgotamento por compressão oblíqua da alma pode ser obtida pela expressão: 


$$
V_{u 1}=K \cdot f_{1 c d} \cdot b_{0} \cdot d \frac{\cot g \theta+\cot g \alpha}{1+\cot g^{2} \theta}
$$

sendo:

$f_{1 c d}=0,60 f_{c d}$

$b_{0}$ - largura mínima do elemento;

$\mathrm{K}$ - coeficiente de redução por efeito de esforço axial;

$$
K=\frac{5}{3}\left(1+\frac{\sigma_{c d}^{\prime}}{f_{c d}}\right) \leq 1,00
$$

onde:

$\sigma_{c d}^{\prime}$ - tensão axial efetiva na seção (tração positiva);

$$
\sigma_{c d}^{\prime}=\frac{N_{d}}{A_{c}}
$$

$N_{d}$ - esforço axial de cálculo (tração positiva);

$A_{c}$ - área total da seção de concreto;

$\alpha$ - ângulo das armaduras com o eixo da peça;

$\theta$ - ângulo entre as diagonais de compressão do concreto e o eixo da peça, desde que esteja no intervalo $0,5 \leq \cot g \theta \leq 2,0$.

Para o caso usual em que $\theta=45^{\circ}$ e $\alpha=90^{\circ}$, tem-se:

$$
V_{u 1}=0,30 f_{c d} \cdot b_{0} \cdot d
$$

\subsubsection{3 - Obtenção de $V_{u 2}$}

a) Elementos sem armadura transversal

A força cortante de esgotamento por tração na alma é obtida pela expressão:

$$
\begin{gathered}
V_{u 2}=\left[0,12 \xi\left(100 \rho_{\ell} \cdot f_{c k}\right)^{1 / 3}-0,15 \sigma_{c d}^{\prime}\right] b_{0} \cdot d \\
\operatorname{com} f_{c k} \text { em } N / m^{2} \mathrm{e} \\
\xi=1+\sqrt{\frac{200}{d}}, \mathrm{~d} \mathrm{em} \mathrm{mm}
\end{gathered}
$$


$\rho_{\ell}$ - quantidade geométrica de armadura longitudinal tracionada, passiva e ativa aderente, ancorada a uma distância igual ou maior que d a partir da seção em estudo:

$$
\rho_{\ell}=\frac{A_{s}+A_{p} \frac{f_{y p}}{f_{y d}}}{b_{o} . d} \leq 0,02
$$

b) Elementos com armadura transversal

A força cortante de esgotamento por tração na alma é obtida pela expressão:

$$
V_{u 2}=V_{c u}+V_{s u}
$$

onde:

$V_{s u}$ - contribuição da armadura transversal na resistência à força cortante;

$$
V_{s u}=z \cdot \operatorname{sen} \alpha(\cot g \alpha+\cot g \theta) \sum A_{\alpha} \cdot f_{y \alpha, d}
$$

$A_{\alpha}$ - área por unidade de comprimento das armaduras inclinadas de um ângulo $\alpha$;

$f_{y \alpha, d}$ - resistência de cálculo da armadura $A_{\alpha}$;

$z$ - braço mecânico, $z=0,9 d$;

$V_{c u}$ - contribuição do concreto na resistência à força cortante;

$$
V_{c u}=\left[0,10 \xi\left(100 \rho_{\ell} \cdot f_{c k}\right)^{1 / 3}-0,15 \sigma_{c d}^{\prime}\right] b_{0} \cdot d \cdot \beta
$$

$\operatorname{com} f_{c k} \mathrm{em} \mathrm{N} / \mathrm{mm}^{2} \mathrm{e}$

$$
\begin{aligned}
& \beta=\frac{2 \cot g \theta-1}{2 \cot g \theta_{e}-1}, \text { se } 0,5 \leq \cot g \theta<\cot g \theta_{e} \\
& \beta=\frac{\cot g \theta-2}{\cot g \theta_{e}-2}, \text { se } \cot g \theta_{e} \leq \cot g \theta \leq 2,0
\end{aligned}
$$

$\theta_{e}$ - ângulo de referência da inclinação das fissuras, deduzido da expressão:

$$
\cot g \theta_{e}=\frac{\sqrt{f_{c t, m}^{2}-f_{c t, m}\left(\sigma_{x d}+\sigma_{y d}\right)+\sigma_{x d} \cdot \sigma_{y d}}}{f_{c t, m}-\sigma_{y d}}\left\{\begin{array}{l}
\geq 0,5 \\
\leq 2,0
\end{array}\right.
$$

$f_{c t, m}$ - resistência média à tração do concreto, considerada positiva; 
$\sigma_{x d}, \sigma_{y d}$ - tensões normais de cálculo, ao nível do centro de gravidade da seção, paralelas à diretriz da peça e ao esforço cortante, respectivamente. Estas tensões são obtidas a partir das ações de cálculo, incluindo a protensão, de acordo com a Teoria da Elasticidade supondo o concreto não-fissurado.

No caso freqüente de $\sigma_{y d}=0$, tem-se:

$$
\cot g \theta_{e}=\sqrt{1-\frac{\sigma_{x d}}{f_{c t, m}}}
$$

No caso usual de peças de concreto armado submetidas a flexão simples ou composta com $\alpha=90^{\circ} e \theta=\theta_{e}=45^{\circ}$, tem-se as seguintes expressões simplificadas:

$$
\begin{aligned}
& V_{c u}=0,10 \xi\left(100 \rho_{\ell} \cdot f_{c k}\right)^{1 / 3} b_{0} \cdot d \\
& V_{s u}=A_{90} \cdot f_{y 90, d} \cdot 0,90 d
\end{aligned}
$$

\subsubsection{4 - Armadura mínima e espaçamentos}

O espaçamento máximo entre as armaduras transversais deverá obedecer às condições seguintes para garantir um adequado confinamento do concreto submetido à compressão oblíqua:

$$
\begin{aligned}
& s_{t} \leq 0,80 \mathrm{~d} \leq 300 \mathrm{~mm}, \text { se } V_{r d} \leq \frac{1}{5} V_{u 1} \\
& s_{t} \leq 0,60 \mathrm{~d} \leq 300 \mathrm{~mm}, \text { se } \frac{1}{5} V_{u 1}<V_{r d} \leq \frac{2}{3} V_{u 1} \\
& s_{t} \leq 0,30 \mathrm{~d} \leq 200 \mathrm{~mm}, \text { se } V_{r d}>\frac{2}{3} V_{u 1}
\end{aligned}
$$

A quantidade mínima de armaduras transversais deve ser tal que atenda à relação:

$$
\sum \frac{A_{\alpha} \cdot f_{y \alpha, d}}{\operatorname{sen} \alpha} \geq 0,02 f_{c d} \cdot b_{o}
$$




\section{5 - RESISTÊNCIA AO CISALHAMENTO EM VIGAS COM TELAS SOLDADAS}

Não há referências bibliográficas sobre a consideração dos fios horizontais da tela soldada para absorver força cortante em vigas de concreto armado.

Com a utilização da tela soldada, as vigas tem uma armadura constituída por fios verticais formando os estribos e fios posicionados horizontalmente nas faces laterais. A maioria das normas considera essa armadura apenas no cálculo da capacidade resistente à torção. Atualmente, para o dimensionamento de vigas à força cortante com tela soldada, utilizam-se as expressões das normas citadas, ou seja, considerando a armadura transversal composta apenas pelos estribos verticais. A eventual contribuição dos fios horizontais da tela e da própria solda é desconsiderada nos cálculos.

AMARAL (1974) comentou que não havia pesquisas experimentais em número suficiente para permitir julgar-se a eficácia de uma armadura em malha para absorver as tensões resultantes do cisalhamento. Ensaios realizados com duas séries de vigas, algumas só com estribos verticais e outras com barras horizontais, além dos mesmos estribos, não mostraram qualquer variação nos esforços absorvidos pelos estribos, entre um caso e outro. Na Figura 3.11, com a superposição das curvas obtidas nas duas séries de ensaios, observa-se claramente que não houve variação na tensão $\sigma_{\mathrm{st}}$ dos estribos verticais.

TIETZ (1979) divulgou no Brasil, baseado em artigos publicados por pesquisadores russos, o uso de telas soldadas, posicionadas nas vigas, com os estribos abertos. Considerava-se a decomposição da força de tração inclinada a $45^{\circ}$ em iguais forças vertical e horizontal. Posteriormente, demonstrou-se que esta decomposição não tem realidade física. 


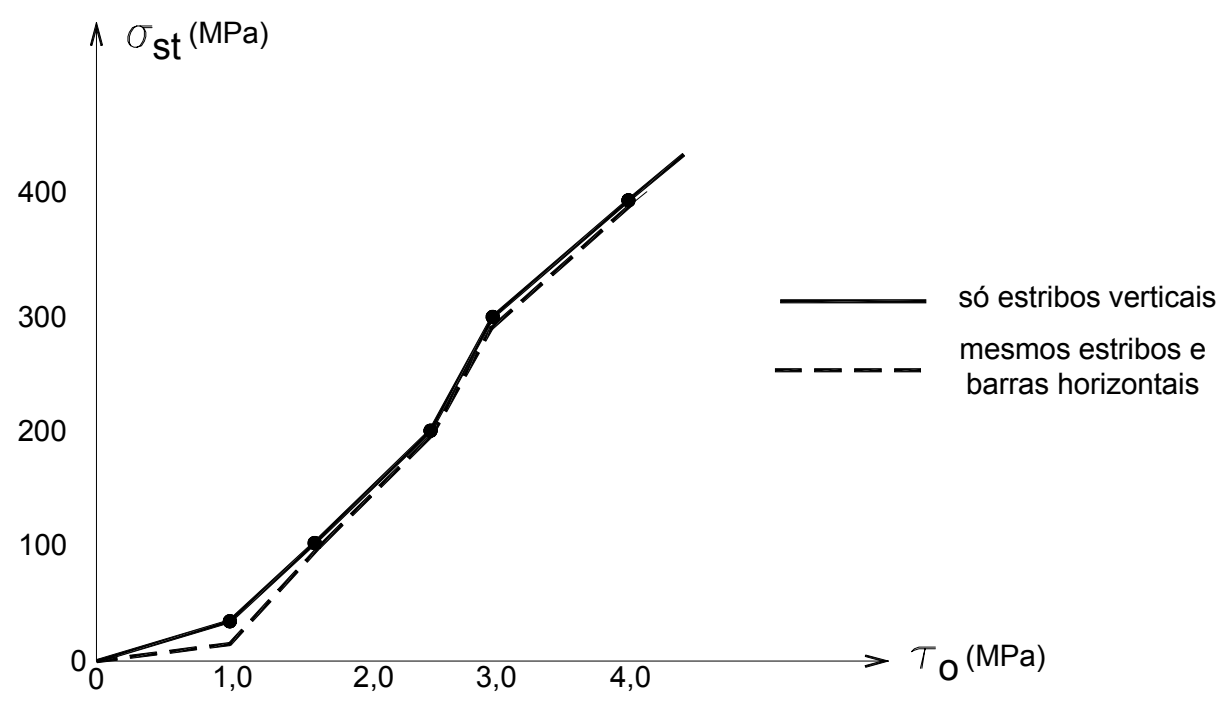

Figura 3.11 - Curvas de tensão nos estribos em ensaios de duas séries de vigas (AMARAL, 1974).

VASCONCELOS (2000) abordou a polêmica sobre o uso de telas soldadas como armadura de cisalhamento, citando como exemplo obra da década de 60 com vigas armadas com telas soldadas.

A pesquisa realizada objetivou analisar experimentalmente a contribuição dos fios horizontais das telas, em dois mecanismos resistentes alternativos. Esses mecanismos são o efeito de pino (acréscimo de fios horizontais) e o engrenamento dos agregados, cuja contribuição é tanto maior quanto menores forem as aberturas das fissuras de cisalhamento. Além dos fatores que influem na resistência à força cortante, já citados no item 3.2 para as vigas com estribos verticais, outros fatores devem ser acrescentados para as vigas com telas soldadas:

- armadura lateral: taxa, bitola, espaçamento e resistência de escoamento;

- tipo de ancoragem dos fios verticais da tela soldada na zona comprimida da viga;

- resistência dos nós soldados da tela.

Para as vigas com estribos verticais a interdependência dos fatores inicialmente citados sempre dificultou a análise dos resultados experimentais. Nas vigas com telas 
soldadas, nas quais pretende-se considerar a contribuição da armadura lateral, a dificuldade de análise e interpretação aumenta.

A utilização de armadura lateral nas proximidades dos apoios é sempre favorável porque proporciona maior confinamento da diagonal comprimida. Entretanto, no vão de corte, o modelo de treliça não é afetado, apenas os mecanismos resistentes alternativos. 


\section{TEORIA DO CISALHAMENTO- ATRITO}

\section{1 - CONSIDERAÇÕES INICIAIS}

A idéia básica da teoria do cisalhamento-atrito (shear-friction) consiste em localizar a provável fissura na região de transmissão da força cortante e posicionar uma armadura perpendicular ou inclinada em relação à fissura. Com o deslocamento relativo vertical de uma parte em relação à outra haverá uma tendência de separação entre estas partes. Como a superfície é irregular, ocorrerá então um deslocamento relativo horizontal que provocará tração na armadura que atravessa esta superfície. Por reação, a superfície de concreto estará comprimida. Esta força de compressão mobiliza tensões de atrito que possibilitam a transmissão da força cortante de uma parte para outra (Figura 4.1). O fenômeno lembra a transmissão de tensões tangenciais de um corpo para outro via atrito, estudado na Física Básica. 


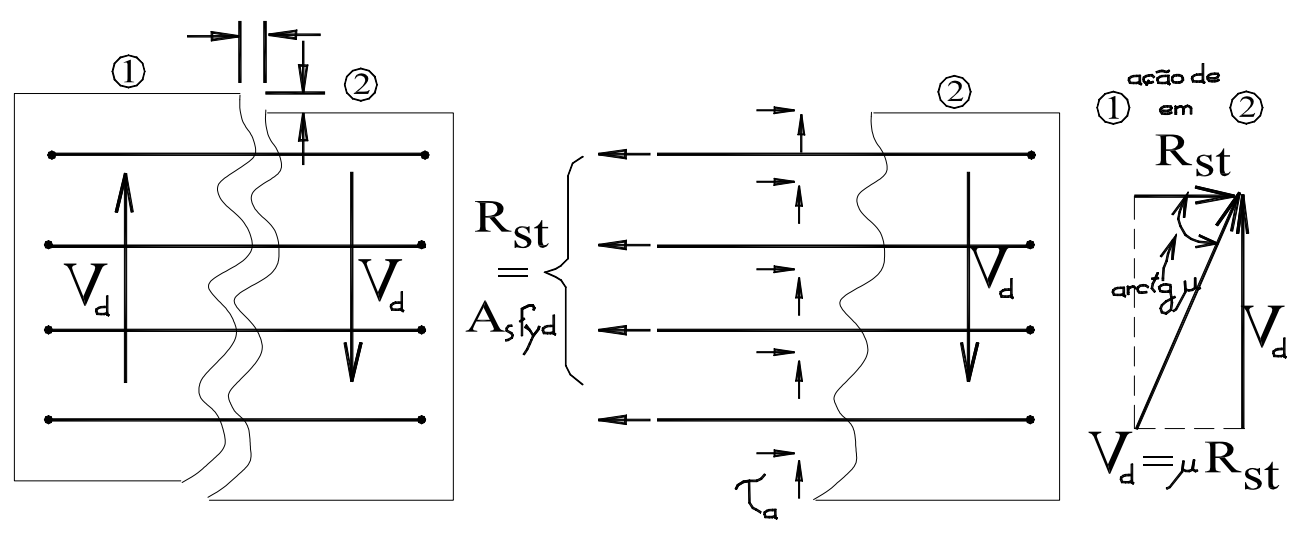

Figura 4.1 - Mecanismo do cisalhamento-atrito.

Inicialmente proposta para o dimensionamento de consolos muito curtos (baixas relações a/d), a teoria do cisalhamento-atrito supõe, a partir de ensaios, que ocorra ruptura por cisalhamento na interface consolo-pilar. No caso de outros elementos estruturais além dos consolos, a teoria supõe a transferência de tensões cisalhantes em um dado plano por meio de uma armadura distribuída que o atravessa. Tal plano pode ser o de uma provável fissura ou a interface de ligação entre dois concretos moldados em datas distintas (ou materiais diferentes).

Atualmente utiliza-se mais freqüentemente esta teoria para o dimensionamento de consolos muito curtos e ligações entre concreto pré-moldado e concreto moldado no local. MAST (1968) também apresenta exemplo de aplicação da teoria do cisalhamento-atrito (Figura 4.2) com armaduras atravessando fissuras nas proximidades de placas de apoio.

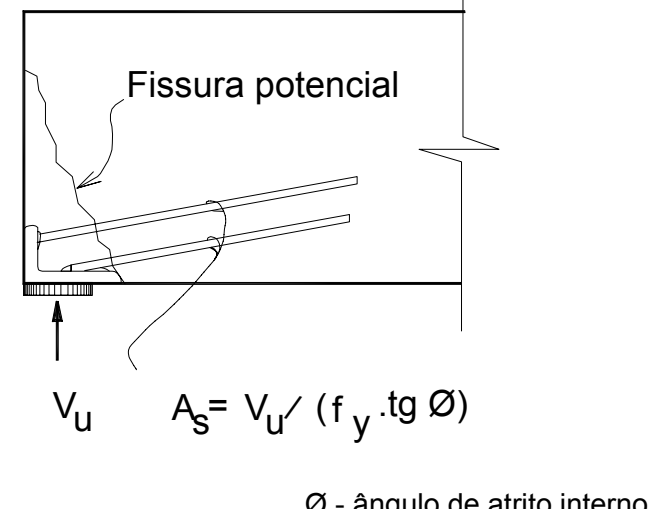

Figura 4.2 - Exemplo de aplicação da teoria do cisalhamento-atrito, além dos consolos muito curtos, MAST (1968). 
Segundo MAST (1968), para a aplicação da teoria do cisalhamento-atrito, devem ser observadas as seguintes restrições:

- a armadura deve ser adequadamente ancorada para ambos os lados da fissura;

- agindo uma força perpendicular nas ligações, além do esforço cortante, deve-se utilizar uma armadura adicional, além daquela obtida pela teoria do cisalhamentoatrito.

\section{2 - TEORIA CLÁSSICA DO CISALHAMENTO- ATRITO}

O conceito anteriormente apresentado de transmissão de tensões cisalhantes, com uma formulação simples acrescida de alguns critérios é denominada Teoria Clássica do Cisalhamento-Atrito.

Segundo o ACI 318R (2002), quando a armadura de cisalhamento-atrito é perpendicular ao plano da fissura potencial, tem-se:

$$
V_{n}=\mu \cdot A_{v f} \cdot f_{y}
$$

onde:

$V_{n}$-resistência ao cisalhamento-atrito;

$\mu$ - coeficiente de atrito;

$A_{v f}$ - área da armadura que atravessa a fissura potencial.

Quando a armadura de cisalhamento-atrito é inclinada em relação ao plano de cisalhamento, tal que ocorra tração na armadura utiliza-se a equação:

$$
V_{n}=\left(\mu \cdot \operatorname{sen} \alpha_{f}+\cos \alpha_{f}\right) A_{v f} \cdot f_{y}
$$

onde:

$\alpha_{f}$ - ângulo entre a armadura de cisalhamento-atrito e o plano de cisalhamento (Figura 4.3). 


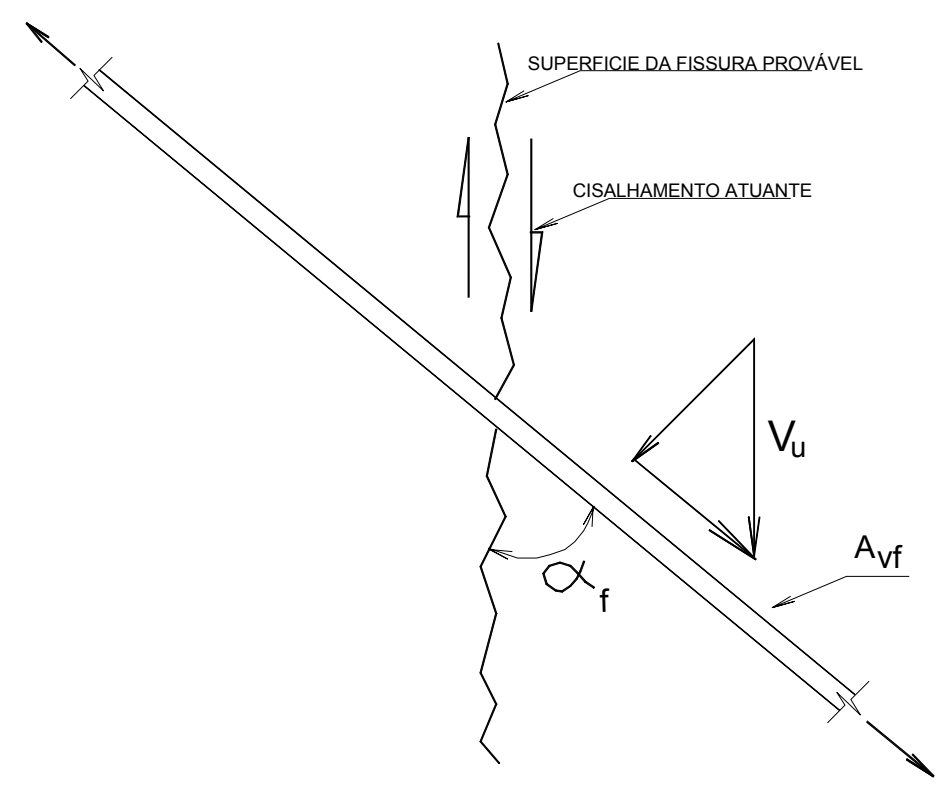

Figura 4.3 - Armadura de cisalhamento-atrito inclinada de um ângulo $\alpha_{f}$ em relação à fissura existente ou potencial (ACI 318R, 2002).

O coeficiente de atrito $\mu$ nas equações 4.1 e 4.2 vale:

$\mu=1,4$ para concreto lançado monoliticamente;

$\mu=1,0$ para concreto lançado sobre concreto endurecido com interface áspera;

$\mu=0,6$ para concreto lançado sobre concreto endurecido com interface lisa.

As recomendações do ACI 318R (2002) aplicam-se na transferência de cisalhamento por um dado plano, definido por:

- uma fissura existente ou potencial;

- uma interface entre materiais diferentes;

- uma interface entre dois concretos moldados em datas distintas.

As equações propostas pelo ACI 318 (1995) são válidas desde que algumas restrições sejam obedecidas:

$-\mathrm{f}_{\mathrm{y}} \leq 400 \mathrm{MPa}$

$-V_{n} \leq\left\{\begin{array}{l}0,2 f_{c}^{\prime} A_{c} \\ 5,5 A_{c}\end{array} \quad(e m N)\right.$ 


\section{3 - TEORIA DO CISALHAMENTO-ATRITO MODIFICADA}

A teoria do cisalhamento-atrito modificada introduz na equação linear, além do coeficiente de atrito, uma coesão aparente que são supostas independentes da resistência do concreto.

No caso em que a armadura é perpendicular ao plano da fissura potencial, a equação típica da teoria do cisalhamento-atrito modificado é dada por:

$$
\tau_{n}=\mu_{\bmod } \cdot \rho_{\text {lat }} \cdot f_{y}+c_{a}
$$

em que:

$$
\rho_{\text {lat }}=\frac{A_{v f}}{b \cdot d}
$$

onde:

$\mu_{\text {mod }}$ - coeficiente de atrito concreto-concreto modificado;

$\rho_{\text {lat }}$ - taxa de armadura de cisalhamento-atrito;

$c_{a}$ - coesão aparente;

$\tau_{n}-$ tensão resistente de atrito.

Pode-se trabalhar diretamente com a força resistente ao invés da tensão resistente, multiplicando-se a expressão (4.3) pela área resistente ao cisalhamento $A_{c}$ :

$$
\mathrm{V}_{\mathrm{n}}=\mu_{\mathrm{mod}} \cdot \mathrm{A}_{\mathrm{vf}} \cdot \mathrm{f}_{\mathrm{y}}+\mathrm{c}_{\mathrm{a}} \cdot \mathrm{A}_{\mathrm{c}}
$$

onde:

$$
A_{c} \cong b \cdot d
$$

Analogamente, quando a armadura é inclinada em relação ao plano de cisalhamento, tal que ocorra tração na armadura utiliza-se a equação:

$$
V_{n}=\left(\mu_{\bmod } \cdot \operatorname{sen} \alpha_{f}+\cos \alpha_{f}\right) A_{s f} \cdot f_{y}+c_{a} \cdot A_{c}
$$


Diversos pesquisadores procuraram determinar os valores do coeficiente de atrito e da coesão aparente, por meio de ensaios de cisalhamento direto e de consolos muito curtos. Para o coeficiente de atrito os resultados obtidos não variam consideravelmente mas a coesão aparente varia dependendo das condições iniciais da peça ensaiada: pré-fissuradas ou não. Nos elementos pré-fissurados, os ensaios mostram que há uma queda de resistência ao cisalhamento.

HERMANSEN \& COWAN (1974), a partir de ensaios com peças não-previamente fissuradas recomendaram $\mu_{\text {mod }}=0,8$ e $c_{a}=4,0 \mathrm{MPa}$. MATTOCK (1976) realizou ensaios com peças pré-fissuradas, tentando simular as situações reais, do lado da segurança e recomendou $c_{a}=2,75 \mathrm{MPa}$ para concretos de massa específica normal.

O ACI 318R (2002) apresenta as equações seguintes para os casos em que a armadura é perpendicular e inclinada, respectivamente, ao plano de cisalhamento:

$$
\begin{aligned}
& V_{n}=0,8 A_{v f} \cdot f_{y}+K_{1} \cdot A_{c} \\
& V_{n}=\left(0,8 \operatorname{sen} \alpha_{f}+\cos \alpha_{f}\right) A_{v f} \cdot f_{y}+K_{1} \cdot A_{c} \cdot \operatorname{sen}^{2} \alpha_{f}
\end{aligned}
$$

onde:

$K_{1}=2,75 M P a$, para concreto de massa específica normal;

$K_{1}=1,375 M P a$, para concreto leve.

$\mathrm{Na}$ equação (4.7) o primeiro termo representa a contribuição do atrito para a resistência de transferência de cisalhamento $(\mu=0,8)$. O segundo termo representa a soma da resistência ao cisalhamento das irregularidades nas faces das fissuras e do efeito de pino da armadura.

Para as equações anteriores serem válidas devem ser respeitadas as seguintes desigualdades:

$$
\rho_{\text {lat }} \cdot f_{y} \geq 1,375 \mathrm{MPa} \quad \text { ou } \quad\left(\rho_{\text {lat }} \cdot f_{y}\right) \operatorname{sen} \alpha_{f} \geq 1,375 \mathrm{MPa}
$$

WALRAVEN et al. (1987) publicaram um importante estudo que mostrou a importância da influência da resistência do concreto e da história do carregamento na resistência de cisalhamento-atrito nos elementos de concreto armado. Os autores analisaram 
resultados de 88 ensaios de cisalhamento direto executados por diferentes pesquisadores em modelos pré-fissurados, sugerindo a seguinte equação:

$$
\tau_{n}=0,878 f_{c}^{0,406}\left(\rho_{\text {lat }} f_{y}\right)^{0,167 f_{c}^{0,303}}
$$

onde:

$$
\tau_{n}=V_{n} / b \cdot d
$$

e a expressão é aplicável dentro dos limites:

$$
0,7<\rho_{\text {lat }} \cdot f_{y}<10 \mathrm{MPa} \quad \text { e } \quad 17,5<f_{c}<65 \mathrm{MPa}
$$

MACHADO (1998) propõe um novo modelo de teoria do cisalhamento-atrito modificado linear, considerando a variação do coeficiente de atrito e da coesão com a resistência do concreto. A partir de uma análise de resultados de ensaios e após análise numérica foram propostas as seguintes expressões:

$$
\begin{aligned}
& \tau_{n}=\mu_{\mathrm{var}} \cdot \rho_{\text {lat }} \cdot f_{y}+c_{\mathrm{var}} \\
& \mu_{\mathrm{var}}=0,073+0,023 f_{c}\left(f_{c} \text { em } M P a\right) \\
& c_{\mathrm{var}}=2,40+0,016 f_{c}
\end{aligned}
$$

Para os consolos muito curtos com formas usuais estas expressões são admitidas válidas para os limites:

$$
1,0 \mathrm{MPa} \leq \rho_{\text {lat }} \cdot f_{y} \leq 10 \mathrm{MPa} \mathrm{e} \quad 15 \mathrm{MPa} \leq f_{c} \leq 50 \mathrm{MPa}
$$

A comprovação experimental das expressões propostas é feita em duas etapas: primeiro, a partir de resultados de ensaios com corpos-de-prova para cisalhamento direto (push-off) e em seguida com resultados de ensaios de consolos com geometria e arranjos de armaduras usuais. 


\section{4 - VIGAS COM ESTRIBOS VERTICAIS}

\subsection{1 - COMENTÁRIOS INICIAIS}

Os modelos de treliça (ou bielas e tirantes) são comumente utilizados para o dimensionamento à força cortante em vigas de concreto armado. Como compreende-se facilmente o funcionamento de uma treliça, esses modelos parecem adequados e lógicos.

Todavia, LOOV (2000) critica a utilização dos modelos de treliça que têm sido generalizados e modificados para representar corretamente os resultados de ensaios. O problema básico é que assume-se que um dos possíveis tipos de ruptura é a ruína à compressão das bielas inclinadas de concreto. Se isto fosse verdadeiro, esperaria-se que a resistência ao cisalhamento das vigas aumentasse com a resistência do concreto, o que não é o caso. Discute-se o efeito das tensões e deformações na resistência das bielas de concreto, o que pode ser irrelevante porque a ruptura ocorre pela transferência de tensões por meio das fissuras.

Assim, LOOV (1998) propõe um novo modelo de cálculo ao cisalhamento que apresenta concordância razoável com a configuração fissurada na iminência do colapso. A Figura 4.4 mostra o modelo baseado em planos de falhas e blocos rígidos, similar aos planos de falhas nos estudos geológicos de placas tectônicas.

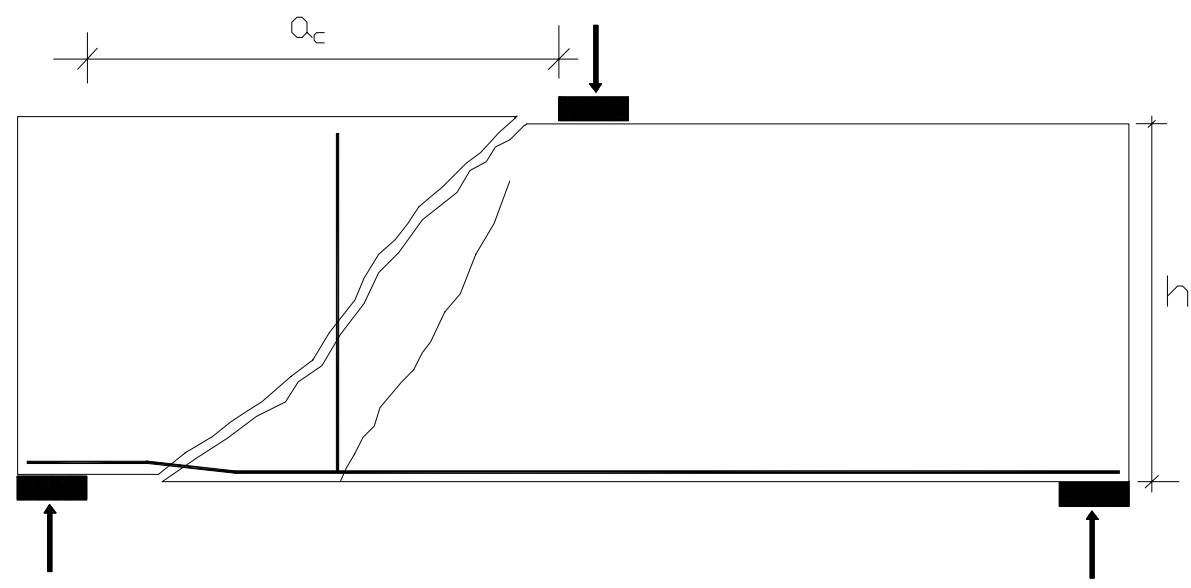

Figura 4.4 -Modelo de bloco rígido (LOOV, 2000). 


\subsection{2 - HIPÓTESES BÁSICAS}

$\mathrm{O}$ procedimento proposto para o dimensionamento à força cortante baseia-se em hipóteses simplificadoras. As hipóteses básicas são as seguintes:

a) considera-se o concreto pré-fissurado, ou seja, o concreto não resiste à tração. Dispensa-se assim o cálculo das tensões nas diagonais tracionadas. (Em pesquisas, pode ser necessário considerar o concreto não-fissurado para justificar resultados conservativos obtidos em ensaios);

b) assume-se que a resistência do plano menos resistente é a resistência ao cisalhamento, desde que os outros planos sejam mais resistentes, não é necessário verificá-los;

c) forças cortantes são limitadas àquelas que não causarão ruptura à compressão do concreto. Evita-se assim o cálculo das tensões e deformações na direção das diagonais comprimidas. Este limite ainda deverá ser estabelecido mas é maior que o limite imposto pelo método simplificado da norma canadense CSA-A23.3 (1994);

d) supõe-se que as barras de aço dos estribos que interceptam o plano de ruptura estejam em escoamento. Isto não é correto para estribos interceptados por fissuras nas extremidades. Para superar este problema, utiliza-se o comprimento efetivo do estribo para considerar sua ancoragem de extremidade.

\subsection{3 - EQUAÇÕES INICIALMENTE PROPOSTAS}

LOOV (1998) apresentou uma proposta inicial de utilização da teoria do cisalhamento-atrito no dimensionamento à força cortante de vigas. A dúvida que surge é "a teoria do cisalhamento-atrito poderia ser utilizada para prever a resistência ao cisalhamento em vigas que possuem inúmeras posições de fissuras potenciais ao longo das quais o escorregamento pode ocorrer?"

A equação que será considerada como base para esta discussão é a seguinte:

$$
\tau=k\left(\sigma \cdot f_{c}^{\prime}\right)^{1 / 2}
$$


onde:

$\tau$ - tensão de cisalhamento média no plano potencial de ruptura ao cisalhamento;

$k$ - fator determinado experimentalmente que relaciona a resistência ao cisalhamento com a tensão normal;

$\sigma$ - tensão normal média no plano potencial de ruptura ao cisalhamento;

$f_{c}^{\prime}$ - resistência à compressão do concreto.

A Figura 4.5 mostra como esta equação confronta com os resultados de vários ensaios de arrancamento ("push-off"). Com base nesses ensaios, o valor de k =0,6 é conservativo para seções não-fissuradas mas contra a segurança para seções fissuradas. Assim, o valor $\mathrm{k}=0,6$ é provavelmente apropriado para vigas, porque os possíveis planos de cisalhamento podem estar fissurados ao longo de parcela de seu comprimento, mas nãofissurado na zona comprimida.

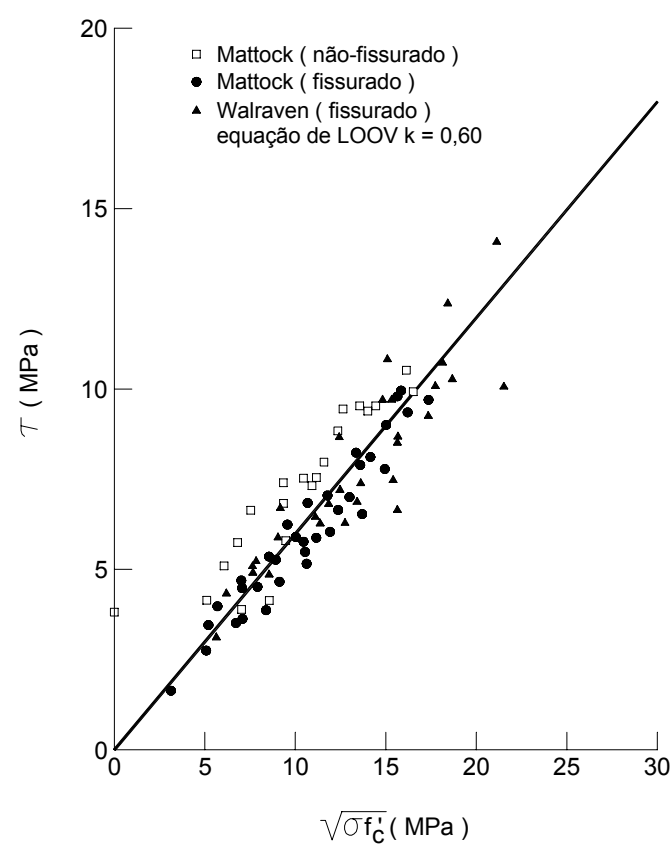

Figura 4.5 -Resultados de ensaios de arrancamento "push-off' (LOOV, 2000).

Para o plano inclinado mostrado na Figura 4.6, tem-se:

$$
\begin{gathered}
\tau=\frac{S}{A} \\
\sigma=\frac{R}{A}
\end{gathered}
$$




$$
A=\left(b_{w} \cdot h\right) / \operatorname{sen} \theta
$$

em que:

$S$ - força de cisalhamento no plano potencial de ruptura ao cisalhamento;

$R$ - força normal atuando no plano potencial de ruptura ao cisalhamento;

$A$ - área do plano potencial de ruptura ao cisalhamento.

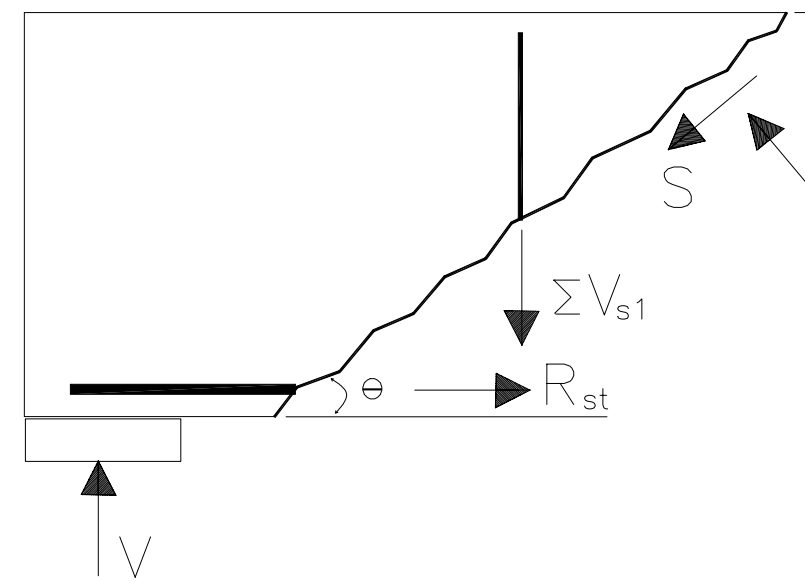

Figura 4.6 - Diagrama de corpo livre para uma viga com estribos verticais (LOOV, 1998).

Substituindo-se as equações 4.13 e 4.14 em 4.12, obtém-se:

$$
\begin{aligned}
& \frac{S}{A}=k \cdot\left(\frac{R}{A} \cdot f_{c}^{\prime}\right)^{1 / 2}=k \cdot\left(A^{2} \cdot \frac{R}{A} \cdot f_{c}^{\prime}\right)^{1 / 2} \\
& S=k \cdot\left(R \cdot f_{c}^{\prime} \cdot A\right)^{1 / 2}
\end{aligned}
$$

Os valores de R e S são determinados por equilíbrio de forças, conforme a Figura 4.6:

$$
\begin{aligned}
& R=R_{s t} \cdot \operatorname{sen} \theta-\left(V-\sum V_{s 1}\right) \cos \theta \\
& S=R_{s t} \cdot \cos \theta+\left(V-\sum V_{s 1}\right) \operatorname{sen} \theta
\end{aligned}
$$


Como mostrado em LOOV (1998), as expressões 4.17 e 4.18 podem ser combinadas com a expressão 4.16 com o intuito de se determinar uma equação geral da resistência ao cisalhamento:

$V=0,5 k^{2} C\left[\sqrt{\frac{R_{s t}}{0,25 k^{2} C}+\cot g^{2} \theta}-\cot g \theta\right]\left(1+\cot g^{2} \theta\right)-R_{s t} \cdot \cot g \theta+\sum V_{s}$

sendo:

$V$ - resistência ao cisalhamento;

$R_{s t}$ - força de tração na armadura longitudinal;

$V_{s 1}$ - força de tração em um estribo;

$\sum V_{s 1}$ - somatório das forças de tração nos estribos que interceptam o plano potencial de ruptura;

$\theta$ - ângulo entre o eixo longitudinal e o plano potencial de ruptura ao cisalhamento da viga;

$C=f_{c}^{\prime} \cdot b_{w} \cdot h$

$C$ - força limite no concreto da alma em função da altura h.

Embora à primeira vista a equação 4.19 pareça extremamente complexa, sua solução para quaisquer valores de $\theta, C, R_{s t} e \sum V_{s 1}$ é imediata. Utilizando-se esta equação, qualquer viga com um espaçamento arbitrário de estribos pode ser analisada determinandose a resistência ao longo de um número suficiente de possíveis planos de ruptura. A resistência é então simplesmente a menor de todas as resistências encontradas ao longo dos diferentes planos. Utilizando-se uma rotina ou programa computacional podem ser obtidas soluções para qualquer viga.

Deve-se ressaltar que a equação geral 4.19 de cisalhamento-atrito é mais adequada como um procedimento de pesquisa do que para projeto.

Como a componente perpendicular ao plano de ruptura, $R_{s t} \cdot \operatorname{sen} \theta$, aumenta a força $R$ e a componente paralela ao plano, $R_{s t} \cdot \cos \theta$, aumenta a força $S$, que deve ser resistida pelo concreto, é possível que a resistência máxima ao cisalhamento ocorra antes que a armadura longitudinal atinja os limites impostos pela aderência ou resistência ao escoamento. 
A Figura 4.7 mostra graficamente a variação da resistência de cisalhamento-atrito baseada na equação 4.19 e a resistência à flexão com o aumento da força de tração na armadura longitudinal. $\mathrm{O}$ ponto $\mathrm{A}$ corresponde à resistência ao escoamento da armadura. $\mathrm{A}$ resistência ao cisalhamento neste ponto é menor que no ponto B correspondente ao pico da curva de resistência ao cisalhamento. Quando $R_{s t}$ tem um valor pequeno a capacidade resistente ao cisalhamento aumenta com a força de tração na armadura longitudinal e então diminui se $R_{s t}$ excede $\left(R_{s t}\right)_{\text {opt }}$ que corresponde à máxima resistência ao cisalhamento. $\mathrm{O}$ ponto B pode ser determinado igualando-se a zero a derivada de $V$ em relação a $R_{s t}$ :

$$
\frac{\partial V}{\partial R_{s t}}=\frac{1+\cot g^{2} \theta}{\left(\frac{R_{s t}}{0,25 k^{2} \cdot C}+\cot g^{2} \theta\right)^{1 / 2}}-\cot g \theta=0
$$

A equação anterior pode ser rearranjada e simplificada, obtendo-se:

$$
\left(R_{\text {st }}\right)_{\text {opt }}=0,25 k^{2} \cdot C\left(1+\sec ^{2} \theta\right)
$$

Figura 4.7 - Efeito da variação da força de tração na armadura longitudinal na capacidade resistente ao cisalhamento (LOOV, 1998).

Se uma força de tração maior do que $\left(R_{s t}\right)_{\text {opt }}$ é necessária, então o ponto de interesse é o ponto $\mathrm{C}$, no qual as resistências ao cisalhamento e à flexão são iguais e a resistência ao 
cisalhamento será menor do que o valor de pico. Embora esta possível interação entre cisalhamento e flexão requeiram investigação adicional, o uso de $\left(R_{s t}\right)_{o p t}$ é apropriado quando a capacidade resistente à flexão não é reduzida. Na verdade, a resistência ao cisalhamento não é fortemente afetada com a variação de $R_{s t}$ em relação a $\left(R_{s t}\right)_{o p t}$. Por esta razão, parece razoável considerar $\left(R_{s t}\right)_{\text {opt }}$ nas equações desenvolvidas, desde que o valor de $k$ seja calibrado para compensar a natureza de limite superior dessas equações.

\subsection{4 - EQUAÇÕES SIMPLIFICADAS}

Substituindo-se a equação 4.21 em 4.19, obtém-se:

$$
V=0,25 k^{2} \cdot C \cdot \operatorname{tg} \theta+n \cdot V_{s 1}
$$

Observando-se os possíveis planos de ruptura ao cisalhamento ilustrados na Figura 4.8, tem-se:

$$
\begin{aligned}
& \operatorname{tg} \theta=\frac{d_{e v}}{m \cdot s} \\
& n=m-1 \\
& d_{e v}=h-\left(2 c+4 \phi_{t}\right)
\end{aligned}
$$

onde:

$m$ - número de espaços atravessados pelo plano de ruptura;

$n$ - número de estribos interceptados pelo plano de ruptura;

$d_{e v}$ - comprimento efetivo do estribo;

$c$ - cobrimento das armaduras;

$\phi_{t}$ - diâmetro do estribo. 


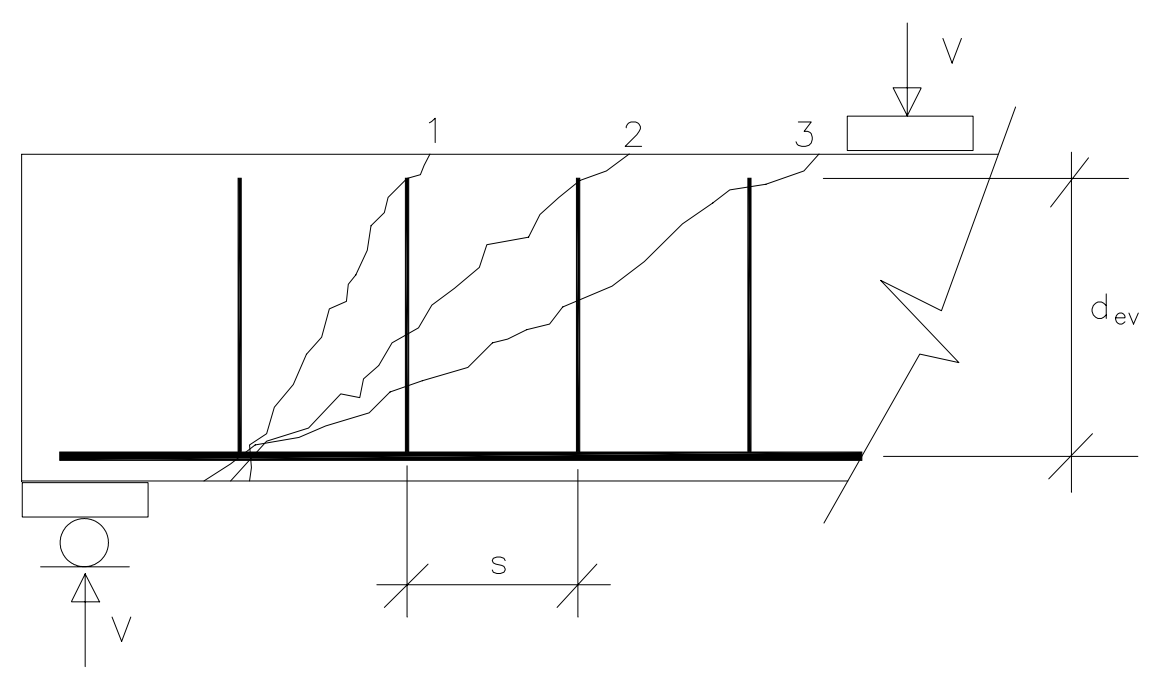

Figura 4.8 - Possíveis planos de ruptura ao cisalhamento (LOOV \& PENG, 1998).

Analisando mais detalhadamente a Figura 4.8, pode-se comentar sobre os três planos de ruptura ao cisalhamento apresentados. O plano de ruptura 1 se estende a partir da extremidade inferior do primeiro estribo até o topo do segundo, não interceptando nenhum estribo. Assim, sua resistência depende somente da armadura longitudinal e do concreto. Este poderia proporcionar um critério para obtenção do espaçamento máximo de estribos, o qual não é afetado pela resistência do estribo e é a equação determinante quando estribos mais resistentes são usados. No caso de estribos menos resistentes os planos críticos de ruptura passam a ser os planos 2 e 3. Nesses planos a resistência do concreto é reduzida como resultado do ângulo mais horizontal, todavia a resistência ao cisalhamento total é aumentada por 1 ou 2 estribos respectivamente. Em todos os casos o ângulo e, portanto, a resistência, são afetados pelo comprimento efetivo dos estribos $d_{e v}$ e o espaçamento dos estribos $s$.

Substituindo-se a equação 4.23 em 4.22, obtém-se:

$$
V=0,25 k^{2} \cdot C \cdot \frac{d_{e v}}{m \cdot s}+n \cdot V_{s 1}
$$

\section{a) Resistência ao longo do plano de ruptura que desvia dos estribos}

A resistência do plano de ruptura 1 da Figura 4.8 depende da armadura longitudinal e do ângulo $\theta$, mas não é afetado pela resistência do estribo. Tomando-se $m=1 \mathrm{e}$, conseqüentemente $n=m-1=0$ na equação 4.26 , tem-se: 


$$
V=0,25 k^{2} \cdot C \cdot \frac{d_{e v}}{s}
$$

Esta equação determina a resistência ao cisalhamento limitada pela resistência ao longo de uma fissura potencial que desvia de todos os estribos.

\section{b) Resistência ao longo do plano de ruptura que intercepta os estribos}

Extendendo-se a equação geral para incluir os estribos, a resistência ao cisalhamento ao longo de um plano de ruptura que atravessa $m$ espaços e intercepta $n$ estribos, é dada pela equação 4.26 :

$$
V=0,25 k^{2} \cdot C \cdot \frac{d_{e v}}{m \cdot s}+n \cdot V_{s 1}
$$

Um limite inferior pode ser encontrado assumindo-se $m$ na equação 4.26 como uma função contínua. Assim, pode-se calcular a derivada de $V$ em relação a $m$ e igualar a zero:

$$
\frac{\partial V}{\partial m} \approx-0,25 k^{2} \cdot C \cdot \frac{d_{e v}}{m^{2} \cdot s}+V_{s 1}=0
$$

Obtém-se então uma expressão para $m$, ou seja, o número de espaços referentes à seção menos resistente, que pode ser usada para determinar o ângulo do plano de ruptura e a resistência ao cisalhamento para um espaçamento definido dos estribos:

$$
m=\left(\frac{0,25 k^{2} \cdot C}{V_{s 1}} \cdot \frac{d_{e v}}{s}\right)^{1 / 2}
$$

Se o valor de $m$ da equação 4.28 é inserido na expressão 4.26, a equação contínua de cisalhamento-atrito finalmente torna-se:

$$
V=0,25 k^{2} \cdot C \cdot \frac{d_{e v}}{m \cdot s}+(m-1) \cdot V_{s 1}
$$




$$
\begin{aligned}
& V=0,25 k^{2} \cdot C \cdot \frac{d_{e v}}{\left(\frac{0,25 k^{2} \cdot C}{V_{s 1}} \cdot \frac{d_{e v}}{s}\right)^{1 / 2} \cdot s}+\left(\frac{0,25 k^{2} \cdot C}{V_{s 1}} \cdot \frac{d_{e v}}{s}\right)^{1 / 2} \cdot V_{s 1}-V_{s 1} \\
& V=\left(\frac{0,25 k^{2} \cdot C}{V_{s 1}} \cdot \frac{d_{e v}}{s}\right)^{1 / 2} \cdot 2 V_{s 1}-V_{s 1} \\
& V=k\left(V_{s 1} \cdot C \cdot \frac{d_{e v}}{s}\right)^{1 / 2}-V_{s 1} \\
& V=k \sqrt{V_{s 1} \cdot C \cdot \frac{d_{e v}}{s}}-V_{s 1}
\end{aligned}
$$

Deve-se enfatizar nesta equação que o valor de $V_{s 1}$ é realmente subtraído, porque isto leva em conta que nenhum estribo é interceptado até que $m>1$. A equação 4.29 é uma equação para projeto adequada para a determinação da resistência ao cisalhamento de vigas com espaçamentos regulares de estribos.

Alguns fatores como a resistência do concreto e a altura da viga influenciam o valor do coeficiente experimental $k$. Valores de $k$ entre 0,5 e 0,6 ajustam-se muito bem a resultados de ensaios para concreto de resistência usual. Em alguns trabalhos publicados, KRISKI \& LOOV (1996) e LOOV \& TOZSER (1999), são analisados resultados do valor $k$ obtidos experimentalmente, além de outros obtidos por diversos pesquisadores.

LOOV \& PENG (1998) estudaram o efeito da resistência do concreto no coeficiente $k$. Resultados experimentais obtidos, combinados com resultados de outros pesquisadores, mostraram que, para um intervalo mais amplo de resistências do concreto, há um aumento menor da capacidade resistente ao cisalhamento quando a resistência do concreto aumenta. A equação obtida experimentalmente é apresentada abaixo:

$$
k=2,1\left(f_{c}^{\prime}\right)^{-0,4}
$$

Em SILVA \& GIONGO (2002b) são analisados resultados iniciais de ensaios de vigas sem e com estribos verticais dimensionadas pela teoria do cisalhamento-atrito. 


\section{5 - FORMULAÇÃO PROPOSTA (VIGAS COM ESTRIBOS VERTICAIS E ARMADURA LATERAL)}

Para vigas com telas soldadas (estribos verticais e armadura lateral) propõe-se um modelo de cálculo que considera a contribuição da armadura lateral na resistência à força cortante. Este modelo é bastante semelhante àquele mostrado no item 4.4.3 para vigas com estribos verticais.

As hipóteses básicas adotadas, além daquelas do item 4.4.2, são as seguintes:

a) todas as barras da armadura lateral, exceto as barras porta-estribos, contribuem subsidiariamente para a resistência à força cortante;

b) supõe-se que todas as barras da armadura lateral, interceptadas pelo plano de ruptura, estejam em escoamento;

c) para os estribos verticais valem as hipóteses do item 4.4.2.

Para a dedução das equações, são utilizadas as expressões seguintes, já apresentadas no item 4.4.3:

$$
S=k \cdot\left(R \cdot f_{c}^{\prime} \cdot A\right)^{1 / 2}
$$

Os valores de R e S são determinados por equilíbrio de forças, conforme a Figura 4.9:

$$
\begin{aligned}
& R=\left(R_{s t}+\sum R_{s, l a t}\right) \operatorname{sen} \theta-\left(V-\sum V_{s 1}\right) \cos \theta \\
& S=\left(R_{s t}+\sum R_{s, l a t}\right) \cos \theta-\left(V-\sum V_{s 1}\right) \operatorname{sen} \theta
\end{aligned}
$$




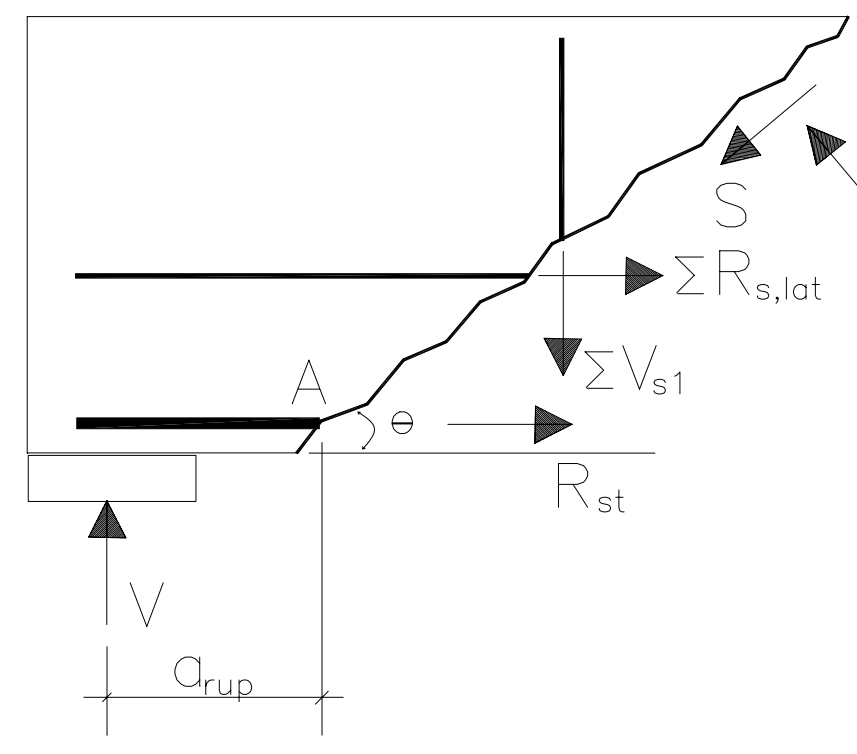

Figura 4.9 - Diagrama de corpo livre para uma viga com estribos verticais e armadura lateral.

Substituindo-se as equações 4.31 e 4.32 na expressão 4.16, obtém-se:

$V=0,5 k^{2} C\left[\sqrt{\frac{R_{s t}+\sum R_{s, l a t}}{0,25 k^{2} C}+\cot g^{2} \theta}-\cot g \theta\right]\left(1+\cot g^{2} \theta\right)-\left(R_{s t}+\sum R_{s, l a t}\right) \cot g \theta+\sum V_{s 1}$

sendo:

$V$ - resistência ao cisalhamento;

$\sum R_{s, l a t}$ - somatório da força de tração na armadura lateral;

$R_{s t}$ - força de tração na armadura longitudinal;

$V_{s 1}$ - força de tração em um estribo;

$\sum V_{s 1}$ - somatório das forças de tração nos estribos que interceptam o plano potencial de ruptura;

$\theta$ - ângulo entre o eixo longitudinal e o plano potencial de ruptura ao cisalhamento da viga;

Para uma viga com um espaçamento definido de estribos verticais e uma armadura lateral composta por fios ou barras distribuídos ao longo de sua altura, utiliza-se a equação 4.33 para se determinar a resistência à força cortante ao longo de possíveis planos de ruptura. 
A resistência à força cortante é a menor de todas as resistências encontradas ao longo dos diferentes planos de ruptura.

Fazendo o equilíbrio de momentos em torno do ponto A da Figura 4.9, obtém-se:

$$
V \cdot a_{r u p}+\sum V_{s 1} \cdot \frac{d}{2 \operatorname{tg} \theta}+\sum R_{s, l a t} \cdot \frac{d}{2}-R \cdot \frac{d}{2 \operatorname{sen} \theta}=0
$$

onde:

$a_{r u p}$ - distância entre o eixo do apoio e o ponto A.

Multiplicando-se a expressão anterior pela relação (2/d), tem-se:

$$
\begin{aligned}
& \frac{R}{\operatorname{sen} \theta}=V \cdot a_{r u p} \cdot \frac{2}{d}+\sum V_{s 1} \cdot \cot g \theta+\sum R_{s, l a t} \\
& \frac{R}{\operatorname{sen} \theta}=\left(V-\sum V_{s 1}\right)\left(\frac{2 a_{r u p}}{d}\right)+\sum V_{s 1}\left(\cot g \theta+\frac{2 a_{r u p}}{d}\right)+\sum R_{s, l a t}
\end{aligned}
$$

Adotando-se:

$$
\lambda=\frac{2 a_{\text {rup }}}{d}
$$

sendo:

$\lambda$ - coeficiente auxiliar adimensional.

$$
R=\left(V-\sum V_{s 1}\right) \cdot \lambda \cdot \operatorname{sen} \theta+\sum V_{s 1} \cdot \operatorname{sen} \theta(\cot g \theta+\lambda)+\sum R_{s, l a t} \cdot \operatorname{sen} \theta
$$

Substituindo-se as equações 4.35 e 4.32 na expressão 4.16, obtém-se:

$$
\begin{aligned}
& V=\left\{\lambda+\operatorname{sen} \theta \sqrt{\frac{\lambda^{2}}{\operatorname{sen}^{2} \theta}-\frac{\lambda \cdot \cot g \theta\left(R_{s t}+\sum R_{s, l a t}\right)}{0,25 k^{2} C}+\frac{\sum V_{s 1}(\cot g \theta+\lambda)}{0,25 k^{2} C}+\frac{\sum R_{s, l a t}}{0,25 k^{2} C}}\right\} \times \\
& \times\left\{0,5 k^{2} C\left(1+\cot g^{2} \theta\right)\right\}-\left(R_{s t}+\sum R_{s, l a t}\right) \cot g \theta+\sum V_{s 1}
\end{aligned}
$$

O ponto de máxima resistência à força cortante em função de $R_{s t}$ pode ser obtido derivando-se a equação 4.36 em relação a $R_{s t}$ e igualando-se a zero: 


$$
\begin{aligned}
& \frac{\partial V}{\partial R_{s t}}=0 \\
& \left(R_{s t}\right)_{o p t}=\frac{1}{\lambda \cdot \cot g \theta}\left[(1-\lambda \cdot \cot g \theta) \sum R_{s, l a t}+(\lambda+\cot g \theta) \sum V_{s 1}\right]
\end{aligned}
$$

O valor de $\left(R_{s t}\right)_{o p t}$ calculado pela expressão 4.37 será utilizado na equação 4.33 para se determinar a resistência ao cisalhamento da viga levando-se em conta a contribuição da armadura lateral.

A formulação apresentada pode ser aperfeiçoada, tendo em vista os seguintes aspectos:

- não foi obtida uma expressão para o cálculo teórico do ângulo $\theta$ de inclinação do plano potencial de ruptura;

- não se dispõe de uma expressão para o cálculo teórico de $a_{r u p}$.

Mesmo assim, as equações 4.33 e 4.37 podem ser consideradas adequadas para uma investigação experimental preliminar sobre o assunto em questão. 


\section{FISSURAÇÃO}

\section{1 - CONSIDERAÇÕES INICIAIS}

O concreto apresenta baixa resistência à tração, o que provoca o aparecimento de fissuras mesmo sob pequenas solicitações nas regiões tracionadas.

No projeto de elementos estruturais deve-se proceder à verificação dos Estados Limites de Serviço como os Estados Limites de Formação de Fissuras e de Fissuração Inaceitável, em função da utilização e desempenho requeridos para o elemento estrutural (Projeto de Revisão da NBR 6118:2001).

O presente capítulo apresenta as expressões para o cálculo do espaçamento entre fissuras e aberturas de fissuras que serão utilizadas na análise dos resultados do programa experimental.

Diversos pesquisadores têm apresentado resultados de investigações sobre fissuras de flexão em vigas. Entretanto, poucos trabalhos sobre fissuras de cisalhamento são encontrados.

A presente pesquisa enfoca com mais ênfase o Estado Limite de Formação de Fissuras de Cisalhamento e as aberturas de fissuras de cisalhamento. Espera-se que, com a utilização de telas soldadas, a fissuração seja caracterizada por menores aberturas de fissuras, com uma distribuição mais uniforme e menores espaçamentos entre fissuras. 


\section{2 - A FISSURAÇÃO NO CONCRETO ARMADO}

A fissuração nos elementos estruturais de concreto armado é causada pela baixa resistência à tração do concreto. Apesar de indesejável, o fenômeno da fissuração é natural (dentro de certos limites) no concreto armado.

O controle da fissuração é importante para a segurança estrutural em serviço, condições de funcionalidade e estética (aparência), desempenho (durabilidade, impermeabilidade, etc.). Deve-se garantir, no projeto, que as fissuras que venham a ocorrer apresentem aberturas menores do que os limites estabelecidos considerados nocivos.

Pequenas aberturas de fissuras, mesmo sem colocar em risco a durabilidade da estrutura, podem provocar alarme nos usuários leigos pelo efeito psicológico. Assim, a abertura máxima das fissuras, sem prejudicar a estética ou causar preocupação nos usuários depende da posição, profundidade, finalidade da estrutura, distância do observador, etc.

As fissuras podem ser divididas em fissuras não-produzidas por esforços solicitantes e fissuras produzidas por solicitações causadas pelas ações atuantes. As fissuras produzidas pelas ações podem ser divididas em:

- fissuras de separação: ocorrem na tração simples ou com pequena excentricidade de força (Figura 5.1-a);

- fissuras de flexão: são fissuras perpendiculares à armadura de flexão, causadas pelas tensões de tração na flexão (Figura 5.1-b);

- fissuras de cisalhamento: são fissuras inclinadas em relação ao eixo da peça, causadas pelas tensões de tração provocadas pela força cortante (Figura 5.1-c);

a)

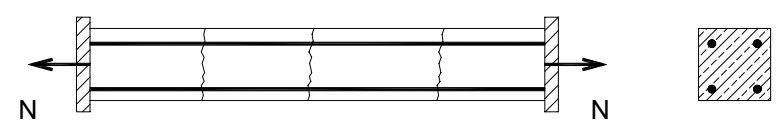

b)

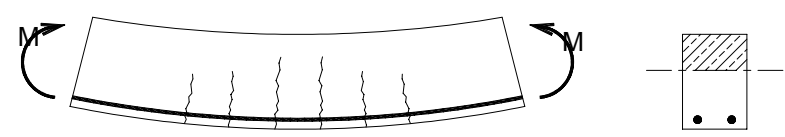

c)

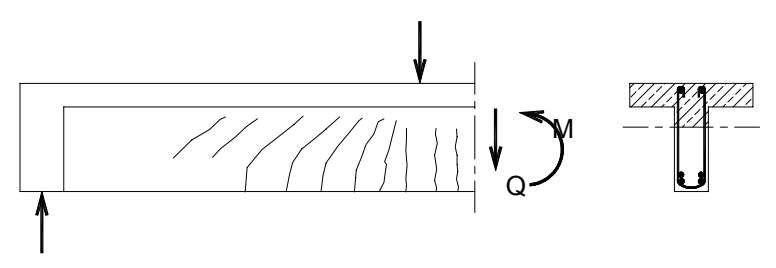

Figura 5.1 - Tipos de fissuras provocadas por solicitações causadas pelas ações. 
Como mostra BURMAN (1981), as teorias e expressões adiante apresentadas descrevem o fenômeno da fissuração para condições idealizadas. Estas condições raramente se encontram na prática e até mesmo no laboratório, sendo diversos os fatores que interferem nesse comportamento. Dentre estes, pode-se citar a retração que é responsável pela criação de um estado de tensões internas, geralmente de maior intensidade junto às armaduras. Essas tensões iniciais provocam o aparecimento de fissuras internas ou externas, que interferem no comportamento posterior do conjunto concreto-barras da armadura quando atuam as ações externas.

\section{3 - MOMENTO DE FISSURAÇÃO}

Pelo Projeto de Revisão da NBR 6118: 2001, o momento de fissuração pode ser calculado pela seguinte expressão aproximada, considerando as hipóteses do Estádio I, com a tensão na fibra mais tracionada obtida pelas expressões deduzidas com as hipóteses da Mecânica Clássica:

$$
M_{r}=\frac{\alpha \cdot f_{c t} \cdot I_{o}}{y_{t}}
$$

onde:

$I_{o}$ - momento de inércia da seção bruta de concreto;

$y_{t}$ - distância do centro de gravidade à fibra mais tracionada;

$f_{c t}$ - resistência à tração direta do concreto, com o quantil apropriado a cada verificação particular;

sendo:

$\alpha=1,2$ para seções T ou duplo T;

$\alpha=1,5$ para seções retangulares.

\section{4 - ESTADO LIMITE DE FORMAÇÃO DE FISSURAS DE CISALHAMENTO}

As fissuras de cisalhamento surgem por conta das tensões principais de tração, inclinadas, causadas por força cortante e se desenvolvem obliquamente em relação ao eixo 
da barra, como mostra LEONHARDT (1979). Estas fissuras causadas pela força cortante podem se desenvolver a partir de fissuras de flexão ou começar na alma.

A determinação do valor da força cortante que provoca o início da formação das fissuras de cisalhamento pode ser feita por expressões empíricas propostas por alguns pesquisadores ou normas técnicas. Uma das propostas da presente pesquisa é analisar comparativamente as aberturas destas fissuras em vigas armadas com estribos verticais e em vigas armadas com telas soldadas.

O Código Modelo CEB-FIP (1990) indica que, na ausência de um cálculo mais preciso, a força cortante que causa a fissuração pode ser estimada por:

$$
V_{c r}=0,15\left(3 d / a_{v}\right)^{1 / 3} \xi\left(100 \rho \cdot f_{c k}\right)^{1 / 3} b_{r e d} \cdot d
$$

em que:

$a_{v}$ - distância da ação principal até o apoio;

$\xi=1+\sqrt{200 / d}, \mathrm{~d}$ em mm;

$\rho=A_{s} /\left(b_{w} \cdot d\right)$, taxa de armadura de tração ancorada no apoio;

$\left(3 d / a_{v}\right)^{1 / 3}$ - expressão empírica que leva em conta a influência da compressão transversal devido às ações e reações de apoio;

$b_{r e d}=b-\eta \sum \phi$, largura da alma reduzida;

sendo:

$b$ - largura da alma;

$\sum \phi$ - soma dos diâmetros das bainhas que alojam os cabos de protensão;

$\eta=0,5$ ou 1,2 , para bainhas preenchidas com microconcreto ou não.

O ACI 318R (2002) enfatiza nos comentários a diferença entre fissuras de cisalhamento na alma e fissuras de flexão-cisalhamento. As fissuras de cisalhamento na alma iniciam-se quando as tensões principais de tração excedem a resistência à tração do concreto. As fissuras de flexão-cisalhamento iniciam-se pelas fissuras de flexão e se desenvolvem quando o cisalhamento combinado e as tensões de tração excedem a resistência à tração do concreto. A Figura 5.2 mostra estes dois tipos de fissuras em uma viga contínua. 


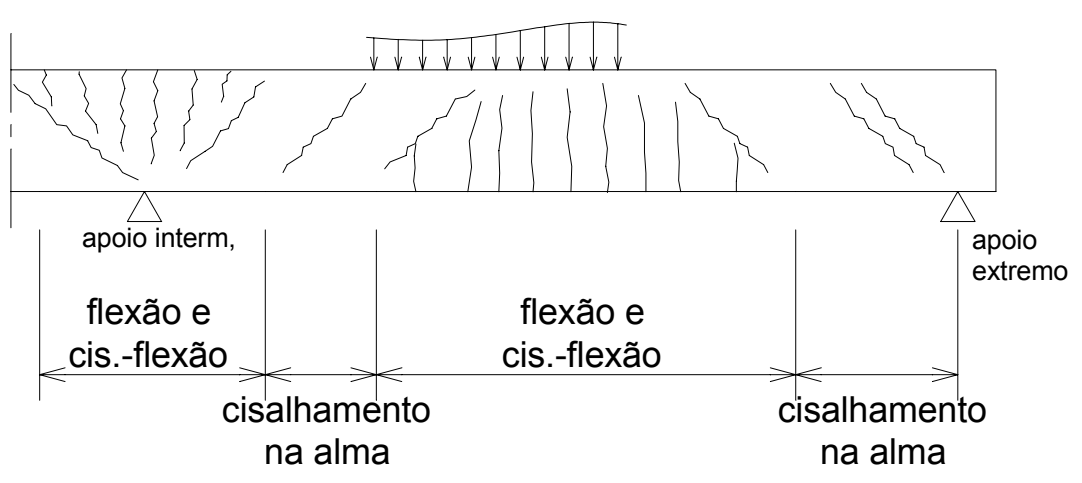

Figura 5.2 - Tipos de fissuras em vigas contínuas de concreto armado.

A expressão indicada pelo ACI 318R (2002) para o cálculo da força cortante que inicia a formação de fissuras de cisalhamento na alma é indicada a seguir:

$$
V_{c w}=0,3\left(\sqrt{f_{c}^{\prime}}\right) b_{w} \cdot d
$$

onde:

$V_{c w}$ - força cortante resistida pelo concreto quando a fissuração diagonal resulta de tensões principais de tração excessivas na alma; $f_{c}^{\prime}$ em MPa e $b_{w}$ e $d$ em mm.

\section{5 - FISSURAS DE FLEX̃̃O}

\subsection{1 - CRITÉRIO DO PROJETO DE REVISÃO DA NBR 6118: 2001}

Segundo o Projeto de Revisão da NBR 6118: 2001, para o caso de edifícios usuais, pode ser adotado $0,3 \mathrm{~mm}$ como máximo valor da abertura de fissura para as classes de agressividade II a IV. Para classe de agressividade I esse valor pode ser adotado igual a 0,4 $\mathrm{mm}$.

Permite-se o controle da fissuração sem a verificação da abertura de fissuras ou por meio da limitação da abertura estimada das fissuras.

Para o controle da fissuração sem a avaliação das aberturas das fissuras, determinadas condições de cobrimento, diâmetro e taxa de armadura devem ser respeitadas. Admite-se que a estrutura terá um bom desempenho (aberturas máximas esperadas da ordem de $0,3 \mathrm{~mm}$ e $0,2 \mathrm{~mm}$ para elementos estruturais de concreto armado e de concreto 
protendido, respectivamente) quando as restrições da Tabela 5.1 forem atendidas. Essas restrições referem-se ao diâmetro e ao espaçamento máximo entre barras, observados os valores das áreas de armaduras mínimas indicadas. Na Tabela 5.1, a tensão $\sigma_{s}$ deve ser determinada no Estádio II.

Tabela 5.1 - Valores máximos de diâmetro e espaçamento para barras de alta aderência.

\begin{tabular}{|c|c|c|c|c|}
\hline \multirow{3}{*}{$\begin{array}{c}\text { Tensão na } \\
\text { barra }\left(\sigma_{s}\right) \\
(\mathrm{MPa})\end{array}$} & \multicolumn{4}{|c|}{ Valores máximos } \\
\hline & \multicolumn{2}{|c|}{ concreto sem armaduras ativas } & \multicolumn{2}{|c|}{ concreto com armaduras ativas } \\
\hline & $\phi_{\max }(\mathrm{mm})$ & $\mathrm{S}_{\max }(\mathrm{cm})$ & $\phi_{\max }(\mathrm{mm})$ & $\mathrm{S}_{\max }(\mathrm{cm})$ \\
\hline 160 & 32 & 30 & 25 & 20 \\
\hline 200 & 25 & 25 & 16 & 15 \\
\hline 240 & 20 & 20 & 12,5 & 10 \\
\hline 280 & 12,5 & 15 & 8 & 5 \\
\hline 320 & 10 & 10 & --- & --- \\
\hline 360 & 8 & 6 & --- & --- \\
\hline
\end{tabular}

Para a verificação do Estado Limite de Aberturas de Fissuras por meio da limitação das aberturas de fissuras, avaliam-se as aberturas de fissuras e os valores obtidos são comparados aos valores limites.

A grandeza das aberturas de fissuras $\omega$, determinada para cada parte da região de envolvimento, será dada pela menor dentre aquelas obtidas pelas duas expressões que seguem.

$$
\begin{aligned}
& w_{k}=\frac{\phi}{12,5 \eta_{i}} \cdot \frac{\sigma_{s}}{E_{s}} \cdot\left(\frac{4}{\rho_{r}}+45\right) \\
& w_{k}=\frac{\phi}{12,5 \eta_{i}} \cdot \frac{\sigma_{s}}{E_{s}} \cdot \frac{3 \sigma_{s}}{f_{c t m}}
\end{aligned}
$$

em que:

$\phi$ - diâmetro da barra que protege a região de envolvimento considerada;

$\eta_{i}$ - coeficiente de conformação superficial da armadura;

$\sigma_{s}$ - tensão de tração no CG da armadura considerada, calculada no Estádio II;

$E_{s}$ - módulo de elasticidade do aço;

$f_{c t m}=0,3 f_{c k}^{2 / 3}$ - resistência média do concreto à tração;

$\rho_{r}=A_{s} / A_{c r}$ - taxa de armadura passiva em relação à área da região de envolvimento. 
O cálculo no Estádio II pode ser feito considerando-se a relação $\alpha_{e}$ entre os módulos de elasticidade do aço e do concreto igual a 15.

Para cada elemento ou grupo de elementos da armadura, que controlam a fissuração da peça, será considerada uma área de concreto de envolvimento $A_{c r}$, constituída por um retângulo cujos lados não distam mais de $7 \phi$ do contorno do elemento da armadura (Figura $5.3)$.

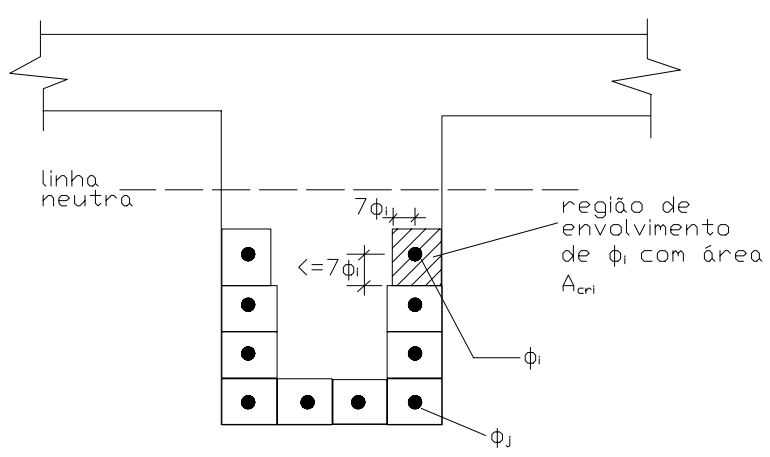

Figura 5.3 - Área de concreto de envolvimento da armadura $\left(A_{c r}\right)$.

A dedução das expressões propostas pelo Projeto de Revisão da NBR 6118: 2001 podem ser encontradas em MOLLICA JR. (1986) ou PAES (1994). A expressão 5.4 (formação sistemática de fissuras) é obtida pela Teoria Básica da Fissuração e a expressão 5.5 (formação não-sistemática de fissuras) pela Teoria da Dupla Ancoragem.

\subsection{2 - CRITÉRIO DO EUROCODE 2 (1992)}

A abertura da fissura de flexão é obtida da relação:

$$
w_{k}=\beta \cdot s_{r m} \cdot \varepsilon_{s m}
$$

onde:

$\beta$ - coeficiente que relaciona a abertura média da fissura ao valor de projeto; no caso de fissuração induzida por ação de força $\beta=1,7$;

$s_{r m}$ - espaçamento médio final das fissuras;

$\varepsilon_{s m}$ - deformação específica média sob a combinação de ações relevantes; 


$$
\varepsilon_{s m}=\frac{\sigma_{s}}{E_{s}}\left[1-\beta_{1} \cdot \beta_{2}\left(\frac{\sigma_{s r}}{\sigma_{s}}\right)^{2}\right]
$$

sendo:

$\sigma_{s}$ - tensão na armadura de tração calculada na seção fissurada;

$\sigma_{s r}$ - tensão na armadura de tração calculada para a ação que causa a primeira fissura;

$\beta_{1}$ - coeficiente que leva em conta as propriedades de aderência das barras;

$$
\beta_{1}=\left\{\begin{array}{l}
1,0 \text { para barras de alta aderência } \\
0,5 \text { para barras lisas }
\end{array}\right.
$$

$\beta_{2}$ - coeficiente que leva em conta a duração da ação ou se a ação é cíclica;

$$
\beta_{2}=\left\{\begin{array}{l}
1,0 \text { para ações de curta duração } \\
0,5 \text { para ações de longa duração ou cíclicas }
\end{array}\right.
$$

Para elementos sujeitos somente a deformações impostas, $\sigma_{s}$ pode ser tomado igual a $\sigma_{s r}$;

O espaçamento médio final das fissuras para elementos submetidos à flexão ou tração simples pode ser calculado pela expressão:

$$
S_{r m}=50+0,25 k_{1} \cdot k_{2} \cdot \frac{\phi}{\rho_{r}} \quad(\mathrm{em} \mathrm{mm})
$$

em que:

$\phi$ - diâmetro da barra em mm; no caso de uso de barras de diferentes bitolas na mesma seção, pode-se adotar um diâmetro médio;

$k_{1}$ - coeficiente que leva em conta as propriedades de aderência das barras;

$$
k_{1}=\left\{\begin{array}{l}
0,8 \\
1,6
\end{array}\right. \text { para barras de alta aderência ou lisas, respectivamente; }
$$

$k_{2}$ - coeficiente que leva em conta a forma do diagrama de deformações na seção; para flexão $k_{2}=0,5$;

$\rho_{r}$ - taxa de armadura efetiva;

$$
\rho_{r}=\frac{A_{s}}{A_{c, e f f}}
$$

onde: 
$A_{c, \text { eff }}$ - área de concreto efetiva, mostrada esquematicamente na Figura 5.4.

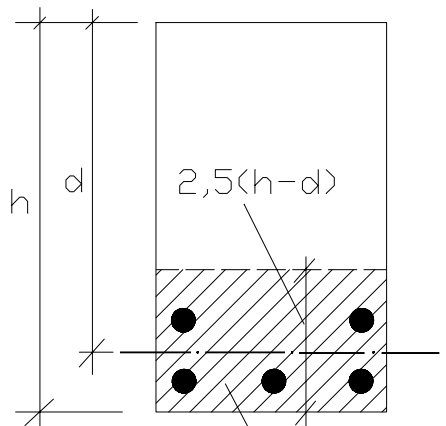

Figura 5.4 - Área de concreto efetiva para o caso de vigas $\left(A_{c, \text { eff }}\right)$.

O EUROCODE 2 (1992) também apresenta tabelas de limites de espaçamentos e diâmetros das barras para o caso em que não se procede ao cálculo das aberturas de fissuras conforme apresentado. Todavia, os valores apresentados são bastante semelhantes àqueles mostrados na Tabela 5.1 do item 5.5.1.

\subsection{3 - CRITÉRIO DA NORMA ESPANHOLA EHE (1999)}

A abertura característica da fissura será calculada pela seguinte expressão:

$$
\begin{aligned}
& w_{k}=\beta \cdot s_{m} \cdot \varepsilon_{s m} \\
& s_{m}=2 c+0,2 s+0,4 k_{1} \cdot \frac{\phi \cdot A_{c, e f i c a z}}{A_{s}} \\
& \varepsilon_{s m}=\frac{\sigma_{s}}{E_{s}}\left[1-k_{2}\left(\frac{\sigma_{s r}}{\sigma_{s}}\right)^{2}\right] \geq 0,4 \frac{\sigma_{s}}{E_{s}}
\end{aligned}
$$

onde:

$\beta$ - coeficiente que relaciona a abertura média da fissura com o valor característico (1,3 para fissuração produzida somente por ações indiretas e 1,7 nos outros casos);

$s_{m}$ - separação média das fissuras (em mm);

$\varepsilon_{s m}$ - deformação média das armaduras, levando em conta a colaboração do concreto entre fissuras;

$c$ - cobrimento do concreto;

$s$ - distância entre barras longitudinais; se $s>15 \phi$, adotar-se-á $s=15 \phi$; 
$k_{1}$ - coeficiente que representa a influência do diagrama de tensões de tração na seção;

$$
k_{1}=\frac{\varepsilon_{1}+\varepsilon_{2}}{8 \varepsilon_{1}}
$$

sendo:

$\varepsilon_{1} e \varepsilon_{2}$ - deformações máximas e mínimas calculadas na seção fissurada, nos limites da zona tracionada (Figura 5.5);

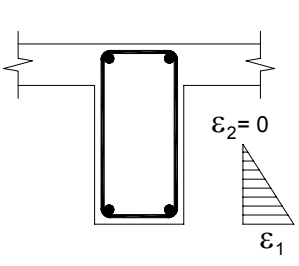

FLEXÃO SIMPLES $\mathrm{k}_{1}=0,125$

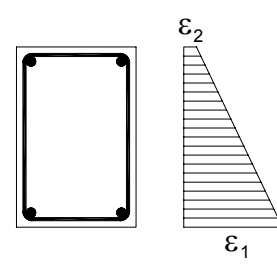

TRAÇÃO COMPOSTA $0,125<\mathrm{k}_{1}<0,250$

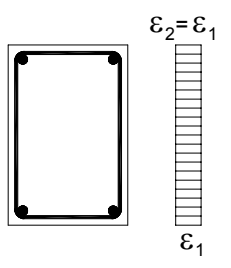

TRAÇÃO SIMPLES $\mathrm{k}_{1}=0,250$

Figura 5.5 - Deformações máximas e mínimas na região tracionada, segundo a norma espanhola EHE (1999).

$\phi$ - diâmetro da armadura tracionada de maior bitola ou diâmetro equivalente para grupo de barras;

$A_{c, \text { eficaz }}$ - área de concreto, definida na Figura 5.6, onde as barras tracionadas influem de forma efetiva na abertura das fissuras;

$A_{s}$ - área total das armaduras situadas na área $A_{c, \text { eficaz }}$;

$\sigma_{s}$ - tensão de serviço da armadura passiva na hipótese de seção fissurada;

$k_{2}$ - coeficiente de valor 1,0 para os casos de ações instantâneas não-repetidas e 0,5 para os casos restantes;

$\sigma_{s r}$ - tensão da armadura na seção fissurada no instante em que se fissura o concreto. 

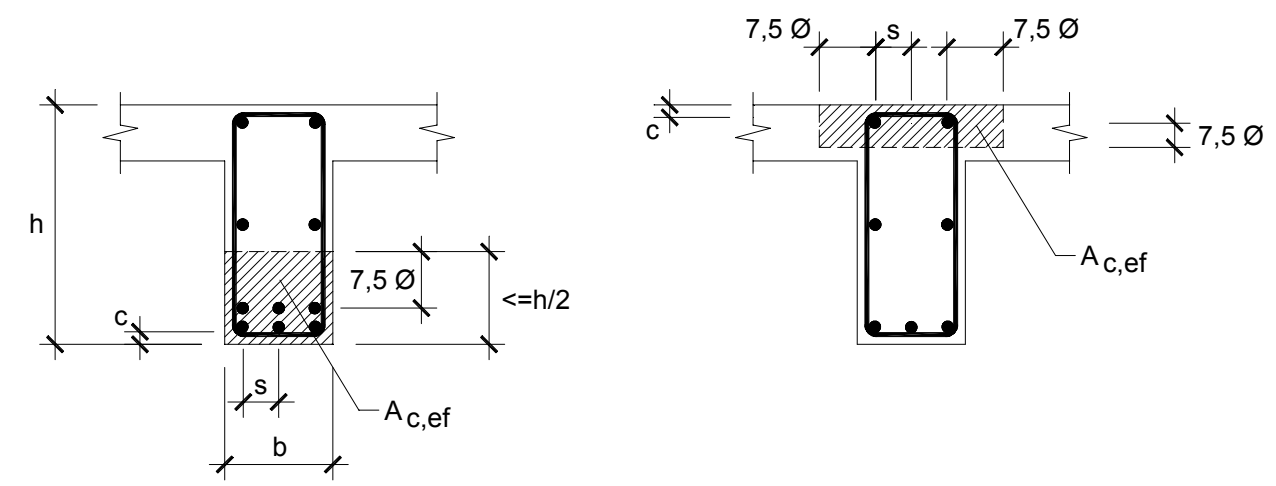

Figura 5.6 - Cálculo de $A_{c, e f i c a z}$, segundo a norma espanhola EHE (1999).

sendo:

$$
\begin{gathered}
\sigma_{s r}=\frac{M_{\text {fiss }}}{0,8 d \cdot A_{s}} \\
\sigma_{s}=\frac{M_{k}}{0,8 d \cdot A_{s}}
\end{gathered}
$$

$M_{\text {fiss }}$ - momento de fissuração;

$M_{k}$ - momento fletor para o qual se procede à verificação do Estado Limite de Fissuração.

\section{6 - FISSURAS DE CISALHAMENTO}

LEONHARDT (1979) comentava que poucos trabalhos continham resultados de ensaios relativos a aberturas de fissuras quando a direção da armadura desvia-se da direção das tensões principais de tração. Assim, no caso de estribos verticais, estes cruzam as fissuras não perpendicularmente, mas sim obliquamente como mostra a Figura 5.7. Deste modo, a abertura das fissuras geralmente aumenta.

Figura 5.7 - Fissuras de cisalhamento interceptadas por estribos verticais. 


\subsection{1 - LEONHARDT (1979) ADAPTADA POR NOBRE (1992)}

LEONHARDT (1979) sugeria, provisoriamente, os seguintes coeficientes $k_{\theta}$ que devem ser multiplicados pelo valor das aberturas de fissuras:

$$
\theta=\left\{\begin{array}{l}
15^{\circ} \rightarrow k_{\theta}=1,0 \\
45^{\circ} \rightarrow k_{\theta}=2,0
\end{array}\right.
$$

interpolando-se linearmente para valores intermediários.

Os estribos verticais cruzam as fissuras de cisalhamento em ângulos que variam entre $45^{\circ}$ e $60^{\circ}$, o que conduz à abertura de fissuras maiores que no caso de cruzamento ortogonal. Para ações variáveis totais, conforme LEONHARDT (1979), com estribos verticais é difícil manter as fissuras com pequena abertura e melhores resultados são obtidos em almas delgadas do que em almas espessas.

NOBRE (1992) apresentou expressões, com base na treliça generalizada, para o cálculo das tensões nos estribos e do ângulo de inclinação das bielas comprimidas:

$$
\begin{aligned}
& \sigma_{t t}=\frac{\tau_{d}}{\rho_{w}} \\
& \operatorname{tg} \theta=\frac{0,87 \tau_{d} \cdot b_{w} \cdot d}{V_{d}}
\end{aligned}
$$

onde:

$\sigma_{t t}$ - tensão na armadura transversal de acordo com a treliça generalizada; $\rho_{w}$ - taxa de armadura transversal.

Com base nas deduções e expressões mostradas em NOBRE (1992), as aberturas das fissuras de cisalhamento podem ser estimadas pelas relações que seguem:

- Fissuração Sistemática

$$
\begin{aligned}
& w_{w}=k_{\theta} \cdot w_{m}=k_{\theta} \cdot s_{w} \cdot \frac{\sigma_{s m}}{E_{s}} \\
& s_{w}=1,5\left(c+\frac{\phi}{2}\right)+0,16 \cdot \frac{\phi}{\rho_{r}}
\end{aligned}
$$

Como, para efeito de simplificação, LEONHARDT (1979) adotava:

$$
\sigma_{s m}=0,8 \sigma_{t t}
$$




$$
\begin{aligned}
\sigma_{s m} & =0,8 \frac{\tau_{d}}{\rho_{w}} \\
w_{w} & =\frac{0,8 k_{\theta}}{E_{s}} \cdot \frac{\tau_{d}}{\rho_{w}}\left[1,5\left(c+\frac{\phi_{w}}{2}\right)+0,16 \frac{\phi_{w}}{\rho_{r w}}\right]
\end{aligned}
$$

onde:

$\rho_{r w}$ - taxa de armadura transversal em relação à área crítica para cada barra.

- Fissuração Não-sistemática

$$
\begin{aligned}
& s_{w}^{\prime}=0,256 \cdot \frac{\phi \cdot \tau_{d}}{\rho_{w} \cdot f_{t}} \\
& w_{w}=0,41 k_{\theta} \cdot \frac{\phi}{f_{t}} \cdot \frac{\tau_{d}^{2}}{E_{s} \cdot \rho_{w}^{2}}
\end{aligned}
$$

\subsection{2 - CÓDIGO MODELO CEB-FIP (1978)}

THOMAZ (1988) comentava que a formulação proposta pelo Código Modelo CEBFIP (1978) para a avaliação das aberturas das fissuras inclinadas era adequada.

O Código Modelo CEB-FIP (1978) apresenta uma formulação para a avaliação das aberturas das fissuras de cisalhamento que é mostrada a seguir:

$$
w_{k}=1,7 k_{w} \cdot w_{m}
$$

em que:

$k_{w}$ - coeficiente que leva em conta a inclinação do estribo;

$k_{w}=\left\{\begin{array}{l}1,2 \text { para } \alpha=90^{\circ}, \text { estribos verticais } \\ 0,8 \text { para } \alpha=45^{\circ} \text { a } 60^{\circ}, \text { estribos inclinados }\end{array}\right.$

sendo:

$$
\begin{aligned}
& w_{m}=s_{r m} \cdot \varepsilon_{s m} \\
& \varepsilon_{s m}=\frac{\sigma_{s}}{E_{s}}\left[1-\left(\frac{V_{c d}}{V_{s d}}\right)^{2}\right] \geq 0,4 \frac{\sigma_{s}}{E_{s}}
\end{aligned}
$$

onde: 
$V_{c d}=V_{c r}$ calculado pela expressão (5.2);

$V_{s d}$ - esforço cortante atuante;

$$
\begin{aligned}
& \sigma_{s}=\frac{V_{s d}-V_{c d}}{b_{w} \cdot d \cdot \rho_{w}} \cdot \frac{1}{\operatorname{sen} \alpha(\operatorname{sen} \alpha+\cos \alpha)} \geq 40 M P a \\
& s_{r m}=2\left(c+\frac{s_{w}}{10}\right)+k_{1} \cdot k_{2} \cdot \frac{\phi_{w}}{\rho_{r}} \leq \frac{d-x}{\operatorname{sen} \alpha}
\end{aligned}
$$

em que:

$k_{1}$ - coeficiente de aderência;

$k_{1}=\left\{\begin{array}{l}0,4 \text { para barras de alta aderência } \\ 0,8 \text { para barras lisas }\end{array}\right.$

$k_{2}$ - coeficiente que leva em conta a influência da forma do diagrama de tensões;

$k_{2}=0,25$, valor adotado considerando um diagrama uniforme de tensões, pois o CEB não esclarece como interpretar este coeficiente no caso de fissuras de cisalhamento;

$$
\rho_{r w}=\frac{a_{s w}}{A_{c w, e f}}
$$

$a_{s w}$ - área de um ramo do estribo vertical (Figura 5.8);

$A_{c w, e f}$ - área efetiva de concreto para os estribos, como indica a Figura 5.8.

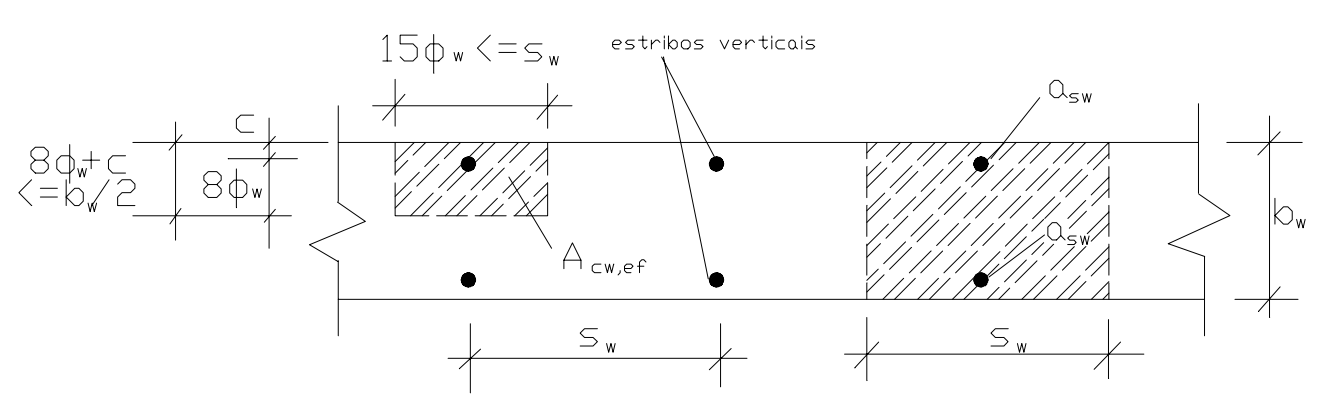

Figura 5.8 - Área efetiva de concreto para os estribos verticais.

\subsection{3 - NORMA ESPANHOLA EHE (1999)}

Segundo a Norma Espanhola EHE (1999), pode-se considerar que a fissuração causada por força cortante é adequadamente controlada sempre que os espaçamentos dos estribos verticais indicados na Tabela 5.2 sejam obedecidos. A recomendação é idêntica à do EC-2 (1992), ou seja, dispensa-se a verificação quando a viga não requer armadura 
transversal $\left(V_{r d}<V_{c u}\right)$ ou quando $\left(V_{r d}<3 V_{c u}\right)$, pois a viga não desenvolverá, em serviço, fissuras de cisalhamento.

Tabela 5.2 - Espaçamentos dos estribos verticais em vigas para controle da fissuração por força cortante, EHE (1999).

\begin{tabular}{|c|c|}
\hline$\frac{\left(V_{r d}-3 V_{c u}\right)}{\rho_{w} \cdot b_{w} \cdot d}$ & $\begin{array}{c}\text { Espaçamento dos } \\
\text { estribos } \\
\left(s_{t}\right)\end{array}$ \\
\hline$\left(N / \mathrm{mm}^{2}\right)$ & $(\mathrm{mm})$ \\
\hline$<50$ & 300 \\
\hline 75 & 200 \\
\hline 100 & 150 \\
\hline 150 & 100 \\
\hline 200 & 50 \\
\hline
\end{tabular}




\section{ESTUDOS EXPERIMENTAIS REALIZADOS POR OUTROS PESQUISADORES}

\section{1 - PRELIMINARES}

Este capítulo apresenta descrição sucinta de pesquisas experimentais desenvolvidas por outros pesquisadores sobre vigas com estribos verticais abertos, vigas com estribos verticais e armadura de pele (fios horizontais amarrados nos estribos) e vigas armadas com telas soldadas.

As pesquisas de ADORNO (1996), CABRAL (1998), ADORNO (1999), SILVA, Rita C. (1999) e MARTINS (2000) abordam as vigas com estribos verticais e armadura de pele.

Os trabalhos de LEONHARDT \& WALTHER (1965), TAYLOR \& EL-HAMMASI (1980), MANSUR et al. (1986), MANSUR et al. (1987), GRIEZIC et al. (1994) e LIN \& PERNG (1998) referem-se às vigas com telas soldadas.

\section{2 - VIGAS COM ESTRIBOS VERTICAIS ABERTOS}

ANDERSON \& RAMIREZ (1989) realizaram uma investigação experimental com 12 vigas de concreto armado (dimensões $20 \mathrm{~cm} \times 50 \mathrm{~cm}$ ), ensaiadas até a ruína com o detalhamento dos estribos como parâmetro variável. A Figura 6.1 mostra os vários tipos de arranjos de estribos verticais, fechados ou abertos, utilizados nas vigas. 

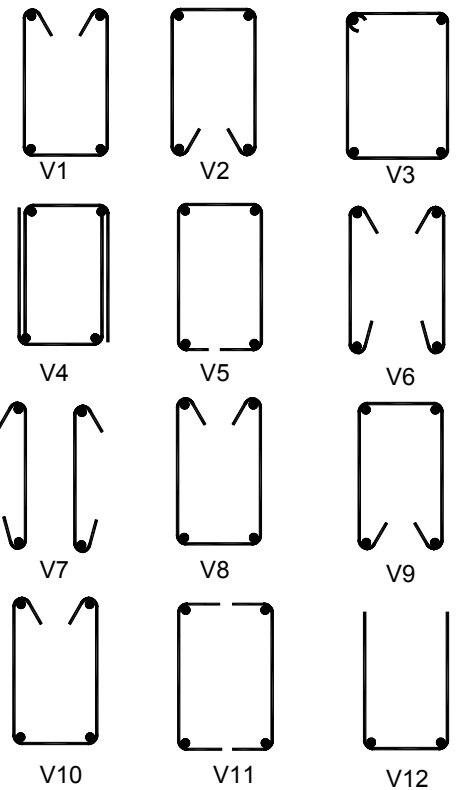

Figura 6.1 - Detalhamento dos estribos verticais das vigas ensaiadas por ANDERSON \& RAMIREZ (1989).

A Tabela 6.1 apresenta os resultados dos ensaios e modos de ruína das vigas.

Pela análise dos resultados as vigas V1 e V10, com estribos verticais abertos e extremidades ancoradas por ganchos de acordo com o ACI 318M (1995), comportaram-se satisfatoriamente. Na viga V8, com o mesmo tipo de detalhe, foram utilizadas barras longitudinais junto à face superior de bitolas menores. A diferença na força cortante última entre as vigas V8 e V10 foi causada pela resistência da zona comprimida não-fissurada. A penetração das fissuras de cisalhamento dentro da zona comprimida pela flexão aumentou as tensões na armadura longitudinal de compressão. Na viga V8, com barras comprimidas de bitolas menores, este aumento na tensão conduziu à flambagem dessas barras.

$\mathrm{Na}$ viga $\mathrm{V} 12$ as extremidades dos estribos em $\mathrm{U}$ foram ancoradas na zona comprimida apenas por ancoragem reta, o que conduziu a uma ruptura prematura, causada pela ancoragem inadequada do estribo da seção crítica.

Assim, as principais conclusões deste trabalho são as seguintes:

- evitar o uso de estribos verticais de apenas um ramo;

- as extremidades de estribos em U devem ser ancoradas por meio de ganchos dobrados para dentro da zona comprimida;

- evitar a ancoragem de estribos em U por meio apenas de um comprimento reto. 
Tabela 6.1 - Resultados dos ensaios e modos de ruptura das vigas V1 a V12, ANDERSON \& RAMIREZ (1989).

\begin{tabular}{|c|c|c|c|c|c|}
\hline Viga & $\begin{array}{c}\mathbf{f}_{\mathbf{c}} \\
\mathbf{( M P a )}\end{array}$ & $\begin{array}{c}\mathbf{V}_{\mathbf{u}, \mathbf{e x p}} \\
\mathbf{( k N )}\end{array}$ & $\begin{array}{c}\mathbf{V}_{\mathbf{u}, \mathbf{A C I}} \\
\mathbf{( k N )}\end{array}$ & $\mathbf{V}_{\mathbf{u}, \mathbf{e x p}} / \mathbf{V}_{\mathbf{u}, \mathbf{A C I}}$ & $\begin{array}{c}\text { Modo de } \\
\text { ruína }\end{array}$ \\
\hline V1 & 39,0 & 478,6 & 347,4 & 1,38 & V-FL \\
\hline V2 & 41,4 & 489,8 & 350,1 & 1,40 & V-FL \\
\hline V3 & 42,8 & 511,1 & 351,4 & 1,45 & V-FL \\
\hline V4 & 27,5 & 439,9 & 334,1 & 1,32 & flexão \\
\hline V5 & 28,7 & 426,6 & 335,4 & 1,27 & V-FL \\
\hline V6 & 29,6 & 368,8 & 336,7 & 1,10 & V-FL \\
\hline V7 & 32,1 & 391,0 & 339,4 & 1,15 & V-FL \\
\hline V8 & 33,9 & 360,0 & 341,6 & 1,05 & V-FL \\
& & & & & V-FL \\
\hline V9 & 34,4 & 395,5 & 342,5 & 1,16 & V-FL \\
\hline V10 & 31,0 & 386,6 & 338,1 & 1,14 & V-FL \\
\hline V11 & 32,3 & 368,8 & 339,8 & 1,09 & V-FL (anc. estr.) \\
\hline V12 & 33,2 & 331,0 & 341,2 & 0,97 & \\
\hline
\end{tabular}

onde: V-FL - força cortante-flexão

TOMPOS \& FROSCH (2002) ensaiaram 06 vigas de concreto armado, variando-se além das dimensões e taxa de armadura longitudinal, o tipo de ancoragem dos estribos verticais no banzo comprimido. A inclinação da fissura principal de cisalhamento influenciou a contribuição da armadura transversal na resistência à força cortante. $\mathrm{O}$ ângulo da fissura de cisalhamento determinou o número de estribos interceptados pelas fissuras e se o estribo interceptado é efetivo. Para estribos abertos em U, sem ganchos de extremidade, a fissura pode interceptar o estribo em um ponto, próximo da borda comprimida, a partir do qual a ancoragem reta não funciona. 


\section{3 - VIGAS COM ESTRIBOS VERTICAIS E ARMADURA DE PELE}

CLÍMACO \& ADORNO (1995) analisaram a influência da variação da taxa de armadura transversal sobre a contribuição da armadura de pele na capacidade resistente ao cisalhamento na flexão, por meio do ensaio de onze vigas de concreto armado. As vigas possuíam seção retangular $(15 \mathrm{~cm}$ x $30 \mathrm{~cm})$, comprimento total de $300 \mathrm{~cm}$, vão livre de 240 cm e valores da relação a/d iguais a 1,9 (V8A e V9A) e 2,4 (demais vigas).

A Figura 6.2 mostra o detalhamento de algumas das vigas ensaiadas. Para o par de vigas V8A e V9A tem-se a viga V8A com armadura transversal composta por estribos verticais e a outra viga V9A idêntica na armadura de flexão e estribos, porém com duas barras de mesma bitola dos estribos como armadura de pele. Essas duas barras eram dispostas uma em cada face da viga, posicionadas à meia altura da seção.

Nas vigas V14A a V17A utilizou-se armadura de compressão composta por 03 barras de $10 \mathrm{~mm}$ de diâmetro.

A Tabela 6.2 apresenta os resultados dos ensaios de todas as vigas, com as forças últimas (experimental e teórica) e os modos de ruína. Na maioria das vigas utilizaram-se 3 barras de $16 \mathrm{~mm}$ como armadura longitudinal de tração, exceto em V12A e V13A com 4 barras de $16 \mathrm{~mm}$.

Dentre as onze vigas ensaiadas, a maioria teve ruína por flexão, exceto V17A e V18A, que apresentaram colapso por cisalhamento. Observa-se que os acréscimos de força última nas vigas com barras longitudinais horizontais variaram de $0,3 \%$ a $43 \%$, sendo que todas atingiram a ruína com força superior às das vigas apenas com estribos, exceto V13A.

Notou-se também que a utilização de armadura de compressão (V14A a V17A) pouco influenciou a força última. 
N3 - $2 \varnothing 6,3$
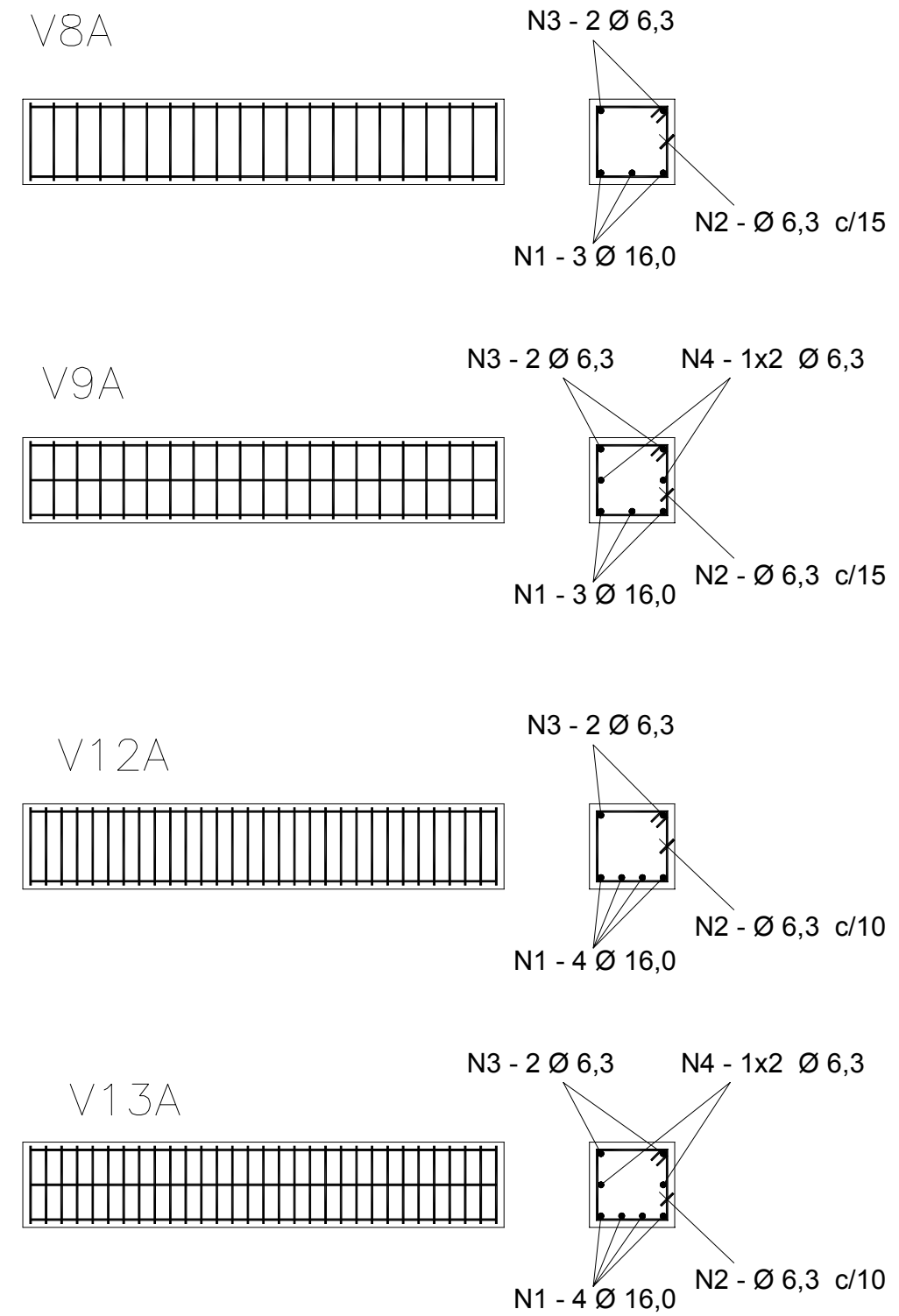

Figura 6.2 - Detalhamento de algumas das vigas ensaiadas por ADORNO (1996).

O aumento expressivo na capacidade resistente ao cisalhamento com o uso de barras horizontais nas vigas com baixa taxa de armadura transversal não ocorreu nas vigas com maiores taxas, pois as mesmas tiveram ruína por flexão. Mesmo assim, manteve-se a tendência de resultados mais altos para vigas com armadura de pele. 
Tabela 6.2 - Resultados das vigas ensaiadas por ADORNO (1996).

\begin{tabular}{|c|c|c|c|c|c|c|c|c|}
\hline \multirow[b]{2}{*}{ Viga } & \multirow{2}{*}{$\begin{array}{c}\mathbf{f}_{\mathrm{c}} \\
(\mathbf{M P a})\end{array}$} & \multicolumn{2}{|c|}{ Armaduras } & \multicolumn{2}{|c|}{$\mathrm{V}_{\mathrm{u} \text {,teor }}(\mathrm{kN})$} & \multirow{2}{*}{\begin{tabular}{|l}
$V_{u, \exp }$ \\
$(k N)$
\end{tabular}} & \multirow{2}{*}{$\begin{array}{l}\mathbf{V}_{\mathbf{u}, \mathbf{e x p}} / \\
\mathbf{V}_{\mathbf{u}, \text { teor }}\end{array}$} & \multirow{2}{*}{$\begin{array}{l}\text { Modo } \\
\text { de } \\
\text { ruína }\end{array}$} \\
\hline & & estribos & pele & flexão & cisalh. & & & \\
\hline V8A & 30,0 & $\phi 6,3 \mathrm{c} / 15$ & --- & 320 & 180 & 335 & 1,86 & flexão \\
\hline V9A & 29,4 & $\phi 6,3 \mathrm{c} / 15$ & $1 \times 2 \phi 6,3$ & 320 & 178 & 372 & 2,09 & flexão \\
\hline V10A & 28,0 & $\phi 8,0 \mathrm{c} / 20$ & --- & 250 & 182 & 278 & 1,53 & flexão \\
\hline V11A & 27,5 & $\phi 8,0 \mathrm{c} / 20$ & $1 \times 2 \phi 8,0$ & 248 & 182 & 397 & 2,18 & flexão \\
\hline $\mathrm{V} 12 \mathrm{~A}$ & 31,0 & $\phi 6,3 \mathrm{c} / 10$ & --- & 320 & 240 & 290 & 1,21 & flexão \\
\hline V13A & 29,0 & $\phi 6,3 \mathrm{c} / 10$ & $1 \times 2 \phi 6,3$ & 314 & 238 & 282 & 1,18 & flexão \\
\hline V14A & 23,5 & $\phi 6,3 \mathrm{c} / 15$ & --- & 262 & 172 & 233 & 1,35 & flexão \\
\hline V15A & 25,0 & $\phi 6,3 \mathrm{c} / 15$ & $1 \times 2 \phi 6,3$ & 264 & 174 & 241 & 1,39 & flexão \\
\hline V16A & 23,0 & $\phi 8,0 \mathrm{c} / 20$ & --- & 260 & 178 & 224 & 1,26 & flexão \\
\hline V17A & 24,5 & $\phi 8,0 \mathrm{c} / 20$ & $1 \times 2 \phi 8,0$ & 262 & 178 & 233 & 1,31 & cis-t \\
\hline V18A & 25,0 & $\phi 6,3 \mathrm{c} / 15$ & --- & 244 & 174 & 208 & 1,20 & cis-c \\
\hline
\end{tabular}

onde:

cis-c - cisalhamento-compressão e cis-t - cisalhamento-tração

CABRAL \& NAGATO (1999) analisaram cinco vigas de concreto armado, mostradas na Figura 6.3. Todas as vigas possuíam as mesmas dimensões $(15 \mathrm{~cm} \times 30 \mathrm{~cm})$ e a mesma armadura longitudinal de flexão, mas cada uma com um arranjo diferente de armaduras. O objetivo dos ensaios foi analisar a influência dos estribos verticais, das barras horizontais laterais, do efeito de pino da armadura longitudinal e do engrenamento dos agregados na resistência à força cortante.

A Tabela 6.3 apresenta os arranjos de armaduras utilizados, as forças de fissuração diagonal e últimas experimentais e o tipo de ruína. A viga V1 não tinha armadura transversal no vão de corte, V2 tinha apenas barras horizontais laterais, V3 tinha apenas estribos verticais e V4 combinava estribos verticais e barras horizontais laterais. A viga V5 tinha duas placas metálicas verticais no vão de corte, lubrificadas, com o objetivo de eliminar a parcela da força cortante resistida pela zona comprimida de concreto e deixarem atuantes apenas as parcelas de efeito de pino e engrenamento dos agregados. 
Tabela 6.3 - Armaduras, forças de fissuração diagonal e última e tipo de ruína das vigas ensaiadas por CABRAL (1998).

\begin{tabular}{|c|c|c|c|c|}
\hline Viga & Armaduras & $\begin{array}{c}\mathbf{V}_{\mathbf{c r}} \\
(\mathbf{k N})\end{array}$ & $\begin{array}{c}\mathbf{V}_{\mathbf{u}, \mathbf{e x p}} \\
(\mathbf{k N})\end{array}$ & $\begin{array}{c}\text { Tipo de } \\
\text { ruína }\end{array}$ \\
\hline V1 & arm. long. flexão & 60 & 78,3 & cis-t \\
\hline V2 & +barras hor. laterais & 60 & 103,7 & cis-t \\
\hline V3 & +estribos verticais & 60 & 195,2 & flexão \\
\hline V4 & $\begin{array}{c}\text { +estribos verticais } \\
\text { +barras hor. laterais }\end{array}$ & 60 & 208,5 & flexão \\
\hline V5 & arm. long. flexão & 45 & 78,2 & cis-t \\
\hline
\end{tabular}

A viga V5 apresentou um problema construtivo, porque durante a concretagem houve penetração parcial de nata de cimento entre as chapas, criando um espaço não previsto entre elas. Não se conseguiu, portanto, eliminar a resistência à força cortante da zona comprimida de concreto.

As principais conclusões resultantes deste trabalho foram:

- a armadura composta por barras horizontais laterais colocada nas vigas V2 e V4 aumentou a rigidez à flexão das vigas, conduzindo a deslocamentos menores do que nas vigas V1 e V3;

- a armadura composta por barras horizontais laterais da viga V2 controlou a abertura da fissura diagonal, levando a viga a suportar uma força cortante última cerca de $32 \%$ superior ao da viga $\mathrm{V} 1$;

- não ficou evidenciado o aumento da capacidade resistente à força cortante da viga com armadura transversal quando se adicionou as barras horizontais laterais (V4 rompeu com uma força cerca de $7 \%$ superior à de V3);

- o ensaio da viga V5 ficou prejudicado pelo não funcionamento das chapas metálicas como previsto, por falha de execução, mas indicou que a resistência à força cortante provida pelo efeito de pino e pelo engrenamento dos agregados é bastante significativa. 

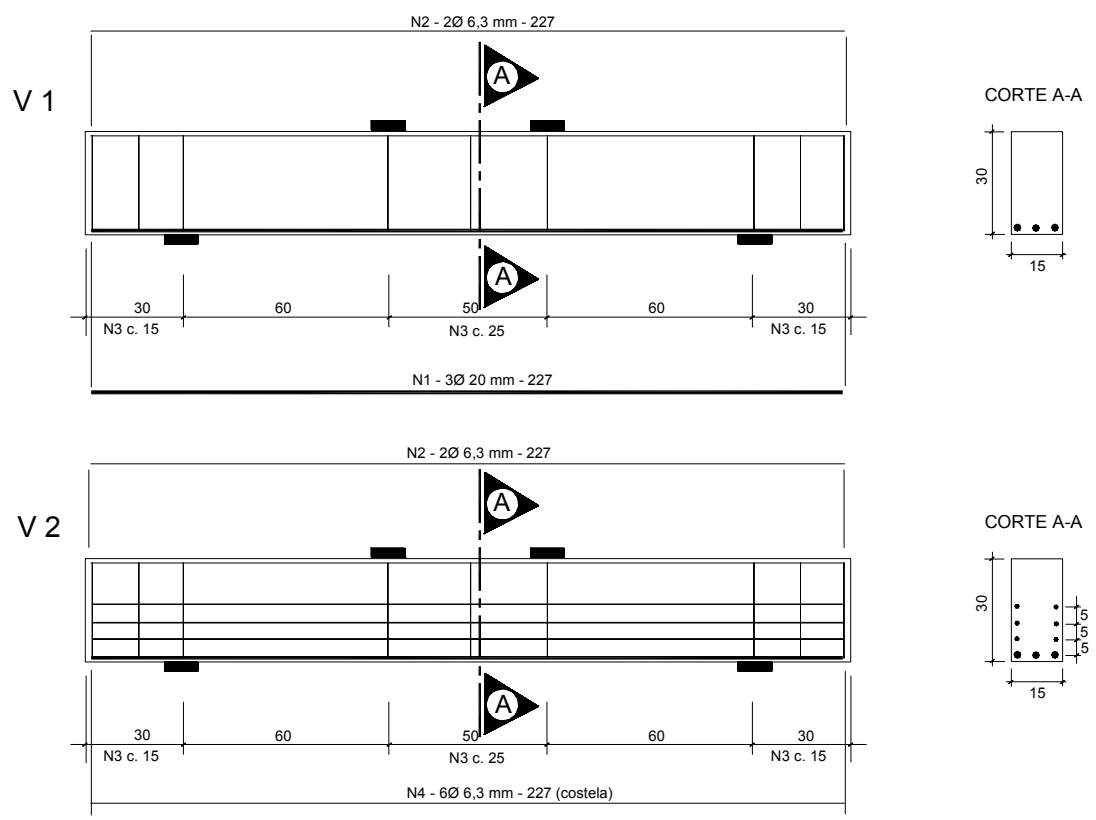

$\mathrm{N} 1-3 \varnothing 20 \mathrm{~mm}-227$
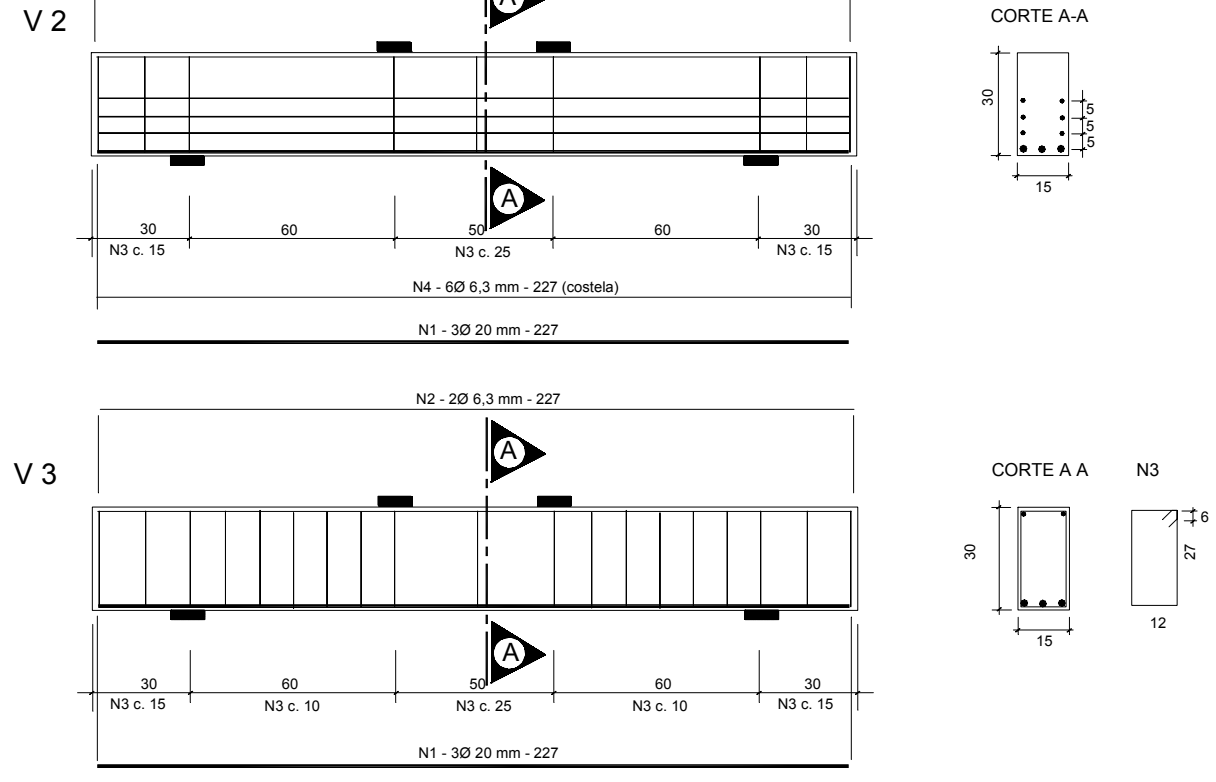

15
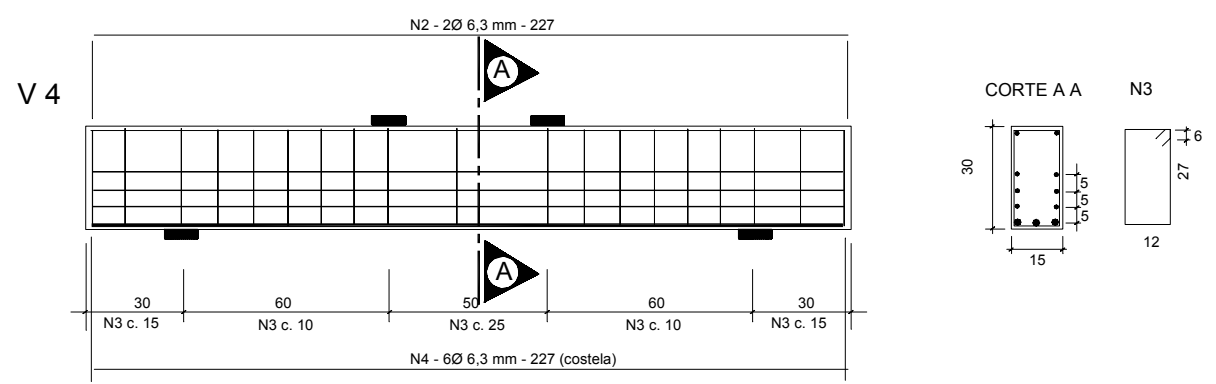

$\mathrm{N} 1-3 \varnothing 20 \mathrm{~mm}-227$

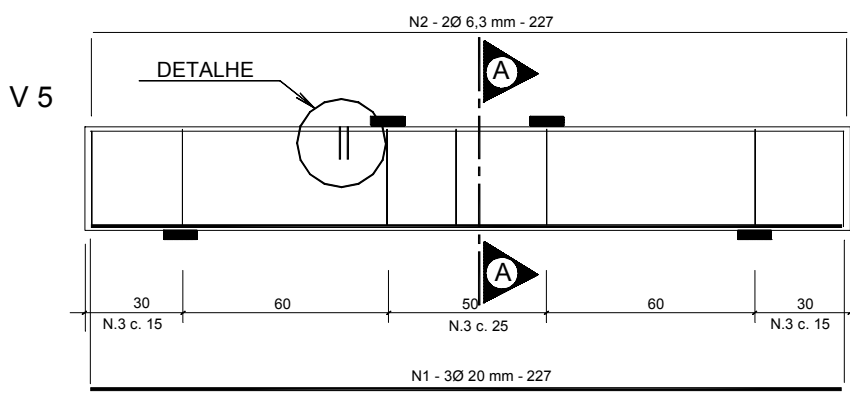

CORTE A A

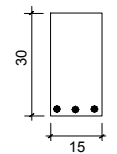

Figura 6.3 - Armaduras das vigas ensaiadas por CABRAL (1998). 
SILVA \& CLÍMACO (2000) estudaram oito vigas de concreto armado de seção T, tendo também como parâmetro variável a taxa de armadura transversal. As vigas tinham largura de alma $b_{w}=15 \mathrm{~cm}$, altura $\mathrm{h}=30 \mathrm{~cm}$, largura de mesa $b_{\mathrm{f}}=50 \mathrm{~cm}$ e relação $\mathrm{a} / \mathrm{d}=2,4$. As taxas de armadura transversal adotada foram $0,28 \%$ (V1,V2,V7 e V8), 0,35\% (V3 e V4) e $0,42 \%$ (V5 e V6).

A Figura 6.4 mostra o detalhamento das armaduras de algumas vigas ensaiadas por SILVA, Rita C. (1999).

Para o par de vigas V1 e V2, a viga V1 era armada convencionalmente, apenas com estribos verticais e a viga V2 possuía adicionalmente uma armadura composta por barras horizontais laterais, em cada face da viga, também com diâmetro igual ao do estribo. As vigas restantes, mostradas na Tabela 6.4, juntamente com os resultados dos ensaios, seguiam o mesmo esquema do par V1-V2.
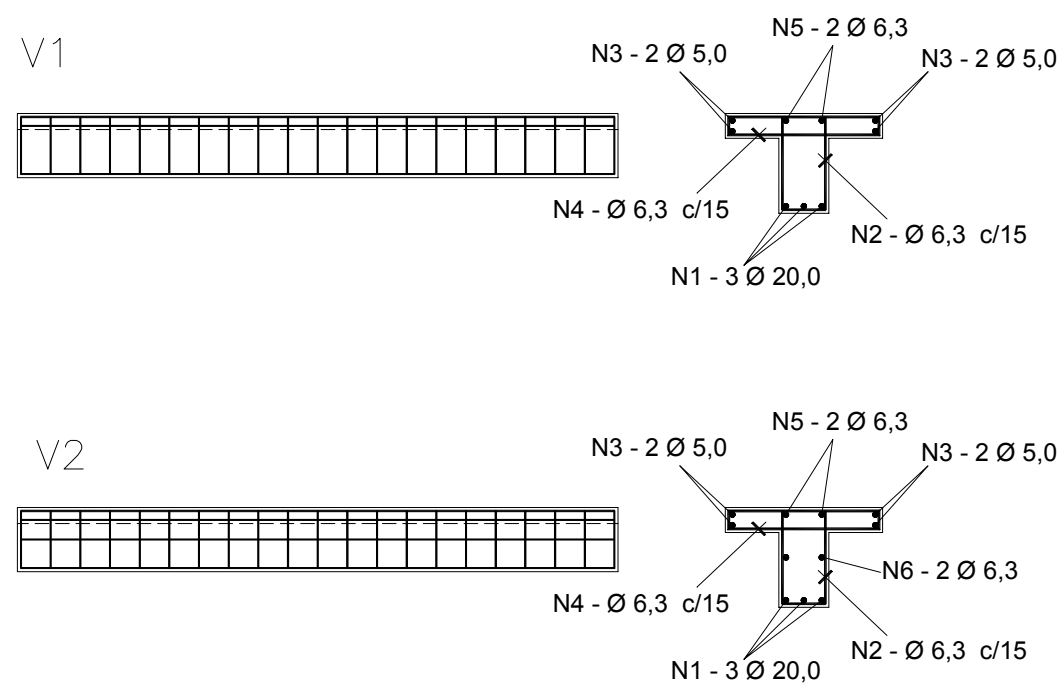

Figura 6.4 - Detalhamento de algumas vigas ensaiadas por SILVA, Rita C. (1999).

Com a utilização da seção $\mathrm{T}$, todas as vigas tiveram colapso por cisalhamento, com predominância do modo de ruína por cisalhamento-tração. Observa-se que as vigas com barras horizontais laterais apresentaram forças últimas superiores (de 4,0\% a 11,7\%) às das vigas armadas apenas com estribos verticais, exceto a viga V8. 
Tabela 6.4 - Resultados das vigas ensaiadas por SILVA, Rita C. (1999).

\begin{tabular}{|c|c|c|c|c|c|c|c|}
\hline \multirow[b]{2}{*}{ Viga } & \multirow{2}{*}{$\begin{array}{c}\mathbf{f}_{\mathrm{c}} \\
(\mathbf{M P a})\end{array}$} & \multicolumn{2}{|c|}{ Armaduras } & \multirow{2}{*}{$\begin{array}{c}\mathbf{V}_{\mathrm{u}, \text { teor }} \\
(\mathbf{k N})\end{array}$} & \multirow{2}{*}{$\begin{array}{l}V_{\mathrm{u}, \exp } \\
(\mathrm{kN})\end{array}$} & \multirow{2}{*}{$\begin{array}{l}\mathbf{V}_{\mathbf{u}, \exp } / \\
\mathbf{V}_{\mathbf{u}, \text { teor }}\end{array}$} & \multirow{2}{*}{$\begin{array}{c}\text { Modo } \\
\text { de } \\
\text { ruína }\end{array}$} \\
\hline & & estribos & pele & & & & \\
\hline V1 & 22,5 & $\phi 6,3 \mathrm{c} / 15$ & --- & 79 & 180 & 2,28 & cis-t \\
\hline V2 & 25,5 & $\phi 6,3 \mathrm{c} / 15$ & $1 \times 2 \phi 6,3$ & 79 & 201 & 2,51 & $\mathrm{~b}$ \\
\hline V3 & 25,3 & $\phi 6,3 \mathrm{c} / 12,5$ & --- & 92 & 191 & 2,08 & $\mathrm{~b}$ \\
\hline V4 & 26,7 & $\phi 6,3 \mathrm{c} / 12,5$ & $1 \times 2 \phi 6,3$ & 92 & 205 & 2,23 & cis-t \\
\hline V5 & 20,5 & $\phi 6,3 \mathrm{c} / 10$ & --- & 109 & 198 & 1,82 & cis-t \\
\hline V6 & 21,1 & $\phi 6,3 \mathrm{c} / 10$ & $1 \times 2 \phi 6,3$ & 109 & 206 & 1,89 & $\mathrm{~b}$ \\
\hline V7 & 22,0 & $\phi 6,3 \mathrm{c} / 15$ & --- & 79 & 178 & 2,25 & cis-t \\
\hline V8 & 22,0 & $\phi 6,3 \mathrm{c} / 15$ & $1 \times 2 \phi 6,3$ & 79 & 167 & 2,11 & cis- $t$ \\
\hline
\end{tabular}

onde:

cis- $\mathrm{t}$ - cisalhamento-tração, $\mathrm{b}$ - esmagamento de biela.

O trabalho propôs uma formulação inspirada na abordagem de MONTOYA et al. (2000) sobre a eficácia do uso de uma malha ortogonal (combinação de estribos verticais e armadura lateral) na resistência às tensões de tração oriundas da força cortante. Prescreve-se que as quantidades mecânicas dessas armaduras sejam iguais:

$$
\frac{A_{h}}{d}=\frac{A_{s 90}}{s}
$$

em que:

$A_{s 90} / s$ - área de estribos verticais por unidade de comprimento ao longo da viga;

$A_{h}$ - área das barras da armadura lateral, distribuída uniformemente ao longo da altura na zona tracionada.

Introduziu-se o conceito de área equivalente de armadura transversal $\left(\mathrm{A}_{\mathrm{sw}, \mathrm{eq}}\right)$, que consistia na soma da área de estribos com a área de armadura de pele na altura da viga $\left(\mathrm{A}_{\mathrm{h}} / \mathrm{d}\right)$, de acordo com a expressão:

$$
A_{s w, e q}=\frac{A_{s 90}}{s}+\frac{A_{h}}{d}
$$


onde:

$A_{s w, e q}$ - área equivalente de estribos por unidade de comprimento da viga.

Podia-se então estimar os valores de força última, tomando-se a área $A_{s w, e q}$ ao invés da área efetiva de estribos, seguindo-se as demais prescrições da NBR 6118:1978. A comparação dos valores experimentais obtidos com os estimados pela formulação proposta mostrou-se bastante satisfatória em números.

Entretanto, há uma inconsistência teórica na proposta de somar a área existente de estribos com a área de armadura de pele. Quando a viga não possui estribos verticais $\left(\mathrm{A}_{\mathrm{s} 90} / \mathrm{s}=0\right)$, mas possui armadura de pele $\left(\mathrm{A}_{\mathrm{h}} / \mathrm{d} \neq 0\right)$ o valor de $A_{s w, e q}$ é diferente de zero. Isso indica que a armadura de pele "substitui" os estribos verticais, o que é incongruente, analisando-se o comportamento da viga e não apenas números obtidos nos ensaios.

Em prosseguimento às investigações experimentais anteriores, ADORNO et al. (2000) ensaiaram dezesseis vigas de concreto armado (quatorze de seção T e duas de seção retangular), com valores da relação a/d iguais a 1,5;2,5 e 3,0. Nos ensaios variaram-se também a quantidade e posição das barras horizontais laterais.

Todas as vigas possuíam $6 \phi 16,0 \mathrm{~mm}$ como armadura de flexão e $\phi$ 5,0 c/ 14 como armadura transversal, exceto as vigas V3 e V4 $\operatorname{com} \phi 12,5 \mathrm{c} / 6$.

A Figura 6.5 apresenta o detalhamento de algumas destas vigas e a Tabela 6.5 mostra os parâmetros utilizados em todas as vigas, como também os resultados dos ensaios. $\mathrm{Na}$ Tabela 6.5 a posição da barra horizontal lateral é indicada como $\mathrm{h} / 2$ para a metade da altura e $\mathrm{h} / 3$ para o terço inferior ou superior da altura.

Com a utilização de barras horizontais laterais de mesmo diâmetro dos estribos na viga $\mathrm{V} 6$, a tensão última aumentou apenas $7 \%$ em relação à viga $\mathrm{V} 5$. Na viga $\mathrm{V} 9$, com diâmetro das barras horizontais laterais superior ao dos estribos, a tensão de cisalhamento última foi $24 \%$ superior à da viga V5. 
Tabela 6.5 - Armaduras e resultados de todas as vigas ensaiadas por ADORNO et al. (2000).

\begin{tabular}{|c|c|c|c|c|c|c|c|}
\hline Viga & $\begin{array}{c}\mathbf{f}_{\mathbf{c}} \\
\mathbf{( M P a )}\end{array}$ & Seção & $\mathbf{a} / \mathbf{d}$ & $\begin{array}{c}\text { Armadura } \\
\text { de pele }\end{array}$ & Posição & $\begin{array}{c}\mathbf{V}_{\mathbf{u}, \mathbf{e x p}} / \\
\mathbf{V}_{\text {u,teor }}\end{array}$ & $\begin{array}{c}\text { Modo de } \\
\text { ruína }\end{array}$ \\
\hline V1 & 70,2 & $\mathrm{~T}$ & 1,5 & --- & --- & 4,03 & flexão \\
\hline V2 & 50,5 & $\mathrm{~T}$ & 2,5 & --- & --- & 2,63 & flexão \\
\hline V3 & 69,0 & $\mathrm{~T}$ & 1,5 & --- & --- & 1,19 & flexão \\
\hline V4 & 50,5 & $\mathrm{~T}$ & 2,5 & --- & --- & 1,08 & flexão \\
\hline V5 & 57,5 & $\mathrm{~T}$ & 3,0 & --- & --- & 1,84 & cis-t \\
\hline V6 & 59,1 & $\mathrm{~T}$ & 3,0 & $1 \times 2 \phi 5,0$ & $\mathrm{~h} / 2$ & 2,01 & cis-t \\
\hline V7 & 48,2 & Ret. & 3,0 & --- & --- & 1,41 & cis-t \\
\hline V8 & 48,2 & Ret. & 3,0 & $1 \times 2 \phi 5,0$ & $\mathrm{~h} / 2$ & 1,86 & flexão \\
\hline V9 & 48,1 & $\mathrm{~T}$ & 3,0 & $1 \times 2 \phi 8,0$ & $\mathrm{~h} / 2$ & 2,23 & cis-t \\
\hline V10 & 51,5 & $\mathrm{~T}$ & 3,0 & $1 \times 2 \phi 8,0$ & $\mathrm{~h} / 3$ inf. & 2,41 & cis-t \\
\hline V10a & 49,7 & $\mathrm{~T}$ & 3,0 & $1 \times 2 \phi 10,0$ & $\mathrm{~h} / 3$ inf. & 2,42 & cis-t \\
\hline V10b & 49,7 & $\mathrm{~T}$ & 3,0 & $1 \times 2 \phi 12,5$ & $\mathrm{~h} / 3$ inf. & 2,04 & cis-t \\
\hline V11 & 48,1 & $\mathrm{~T}$ & 3,0 & $2 \times 2 \phi 8,0$ & $\mathrm{~h} / 2 \mathrm{e} \mathrm{h} / 3$ inf. & 2,36 & cis-t \\
\hline V11a & 48,4 & $\mathrm{~T}$ & 3,0 & $2 \times 2 \phi 10,0$ & $\mathrm{~h} / 2 \mathrm{e} \mathrm{h} / 3$ inf. & 2,44 & cis-t \\
\hline V11b & 48,4 & $\mathrm{~T}$ & 3,0 & $2 \times 2 \phi 12,5$ & $\mathrm{~h} / 2 \mathrm{e} \mathrm{h} / 3$ inf. & 2,27 & cis-t \\
\hline V12 & 51,5 & $\mathrm{~T}$ & 3,0 & $2 \times 2 \phi 8,0$ & $\mathrm{~h} / 2 \mathrm{e} \mathrm{h/3} \mathrm{sup.}$ & 2,36 & cis-t \\
\hline
\end{tabular}

Comparando-se a viga V10, com alteração da posição da armadura de pele, do meio da altura para o terço inferior da seção, com a viga V9, houve aumento de apenas 7\% na tensão última. O aumento na bitola da armadura de pele nas vigas V10a e V10b também não alterou substancialmente os resultados.

As vigas com o acréscimo de mais uma barra lateral em cada face da viga (V11 e V12) também tiveram a tensão de cisalhamento última pouco alterada.

Finalmente, pelos resultados do programa experimental, ficou evidenciada a contribuição da armadura de pele, com aumento de até 38\% na força última, para vigas com relação $\mathrm{a} / \mathrm{d}=3,0$. As barras horizontais laterais influenciam também o modo de ruína, como nas vigas V7 e V8 de seção retangular que atingiram o colapso por cisalhamento-tração (V7) e flexão (V8). 

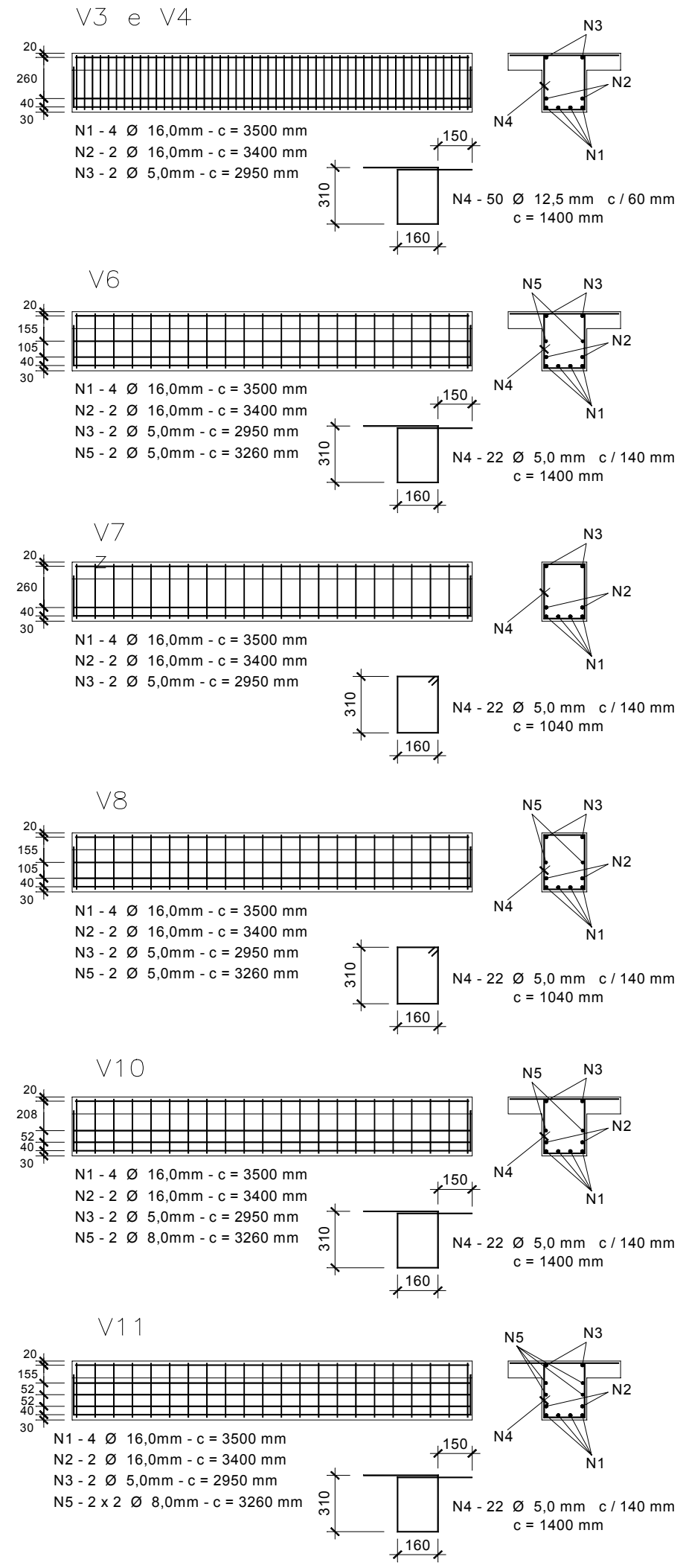

Figura 6.5 - Detalhamento de algumas vigas de ADORNO et al. (2000). 
MARTINS et al. (2000) analisaram experimentalmente a utilização de barras da armadura lateral como armadura de reforço à força cortante em vigas retangulares de concreto armado. A Figura 6.6 mostra o esquema do ensaio e os detalhes das armaduras das vigas. As vigas possuíam seção transversal de $150 \mathrm{~mm}$ x $300 \mathrm{~mm}$, altura útil d = $270 \mathrm{~mm}$, distância entre eixos dos apoios igual a $2400 \mathrm{~mm}$ e relação a/d =2,4. Todas as vigas foram projetadas com área insuficiente de armadura transversal. Na primeira etapa do ensaio, as vigas foram solicitadas até o aparecimento da primeira fissura de cisalhamento na alma. Então, a força aplicada foi retirada para executar o reforço com barras longitudinais laterais $\left(\phi_{\text {lat }}=\phi_{t}\right)$ posicionadas em sulcos perfurados na superfície do concreto e, posteriormente, preenchidos com argamassa de reparo.
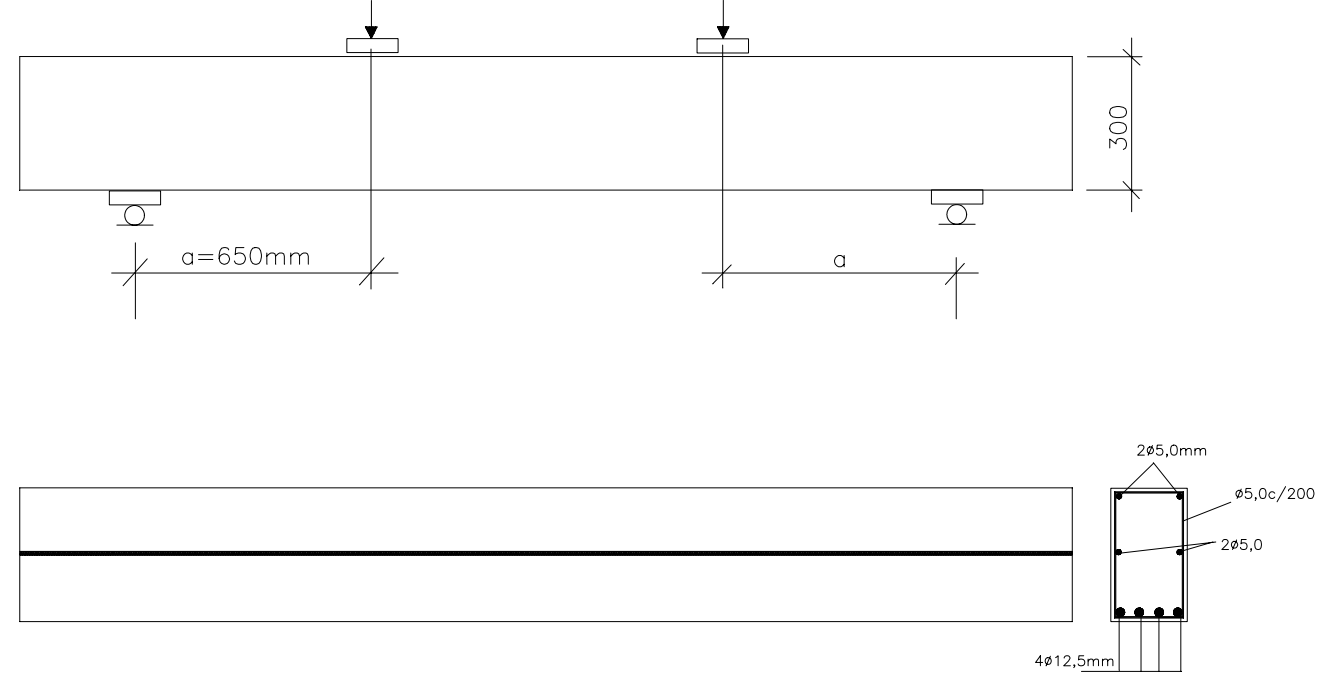

Figura 6.6 - Esquema do ensaio e armaduras das vigas ensaiadas por MARTINS et al. (2000).

Como indica a Tabela 6.6, nas vigas B1 a B4 as barras laterais foram colocadas externamente aos estribos e fixadas ao concreto com grampos de aço e coladas com resina époxi. Para as vigas B10, B11, B12, B15 e B17 as barras laterais foram colocadas internamente aos estribos e a viga B8 (viga de controle) foi originalmente concretada com a armadura lateral. 
Tabela 6.6 - Resultados dos ensaios das vigas reforçadas à força cortante de MARTINS et al. (2000).

\begin{tabular}{|c|c|c|c|c|c|}
\hline \multirow{2}{*}{ Vigas } & $A_{s w, e q}$ & $V_{u, \exp }$ & $V_{u, \text { teo }}^{*}$ & $V_{u, \exp } / V_{u, \text { teo }}^{*}$ & \multirow{2}{*}{ Observações } \\
\cline { 2 - 4 } & $\mathbf{( \mathbf { c m } ^ { 2 } / \mathbf { m } )}$ & $\mathbf{( k N )}$ & $\mathbf{( k N )}$ & & \\
\hline B1 & 3,44 & 84,2 & 78,2 & 1,08 & reparo (ext.) \\
\hline B2 & 3,44 & 86,1 & 78,3 & 1,10 & reparo (ext.) \\
\hline B3 & 3,44 & 87,7 & 78,1 & 1,12 & reparo (ext.) \\
\hline B4 & 3,44 & 85,0 & 78,3 & 1,09 & reparo (ext.) \\
\hline B8 & 3,44 & 98,0 & 73,5 & 1,33 & controle \\
\hline B10 & 3,44 & 100,0 & 72,6 & 1,38 & reparo (int.) \\
\hline B11 & 3,44 & 87,5 & 72,5 & 1,21 & reparo (int.) \\
\hline B12 & 3,44 & 75,5 & 70,9 & 1,06 & reparo (int.) \\
\hline B15 & 3,44 & 107,5 & 70,0 & 1,54 & reparo (int.) \\
\hline B17 & 3,44 & 108,5 & 71,8 & 1,51 & reparo (int.) \\
\hline
\end{tabular}

onde:

$V_{u, t e o}^{*}$ - força última teórica calculada pelas prescrições da NBR 6118 (1978), usando o valor de $A_{s w, e q}$ obtido pela expressão proposta por SILVA, Rita C. (1999).

As relações $V_{u, \exp } / V_{u, \text { teo }}^{*}$ variaram entre 1,06 e 1,54, o que mostra a eficiência do reforço proposto. As vigas reforçadas com barras laterais internas apresentaram melhor desempenho, entretanto a montagem com barras laterais externas é mais exequível e mais barata.

\section{4 - VIGAS ARMADAS COM TELAS SOLDADAS}

LEONHARDT \& WALTHER (1965) publicaram resultados de pesquisa experimental abordando vigas com telas soldadas. No trabalho foi enfatizado o comportamento da ancoragem dos estribos no banzo comprimido. 
Os ensaios foram executados em vigas de seção $T$, relação $a / d=3,33$, com as dimensões mostradas na Figura 6.7, que apresenta também o esquema de aplicação de forças utilizado.
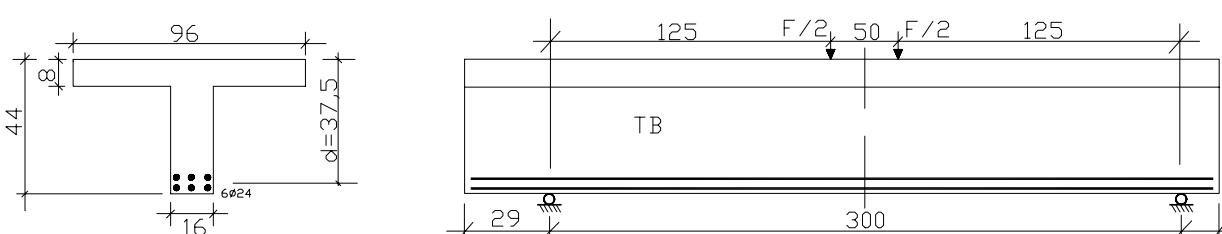

Figura 6.7 - Dimensões da seção transversal e esquema de aplicação de forças das vigas $T$, LEONHARDT \& WALTHER (1965).

A Figura 6.8 mostra a armação utilizada nas vigas TB1 a TB10. A ancoragem dos estribos na zona comprimida variou da seguinte forma:

- Grupo I: estribos abertos com barra soldada na parte superior (Figura 6.9-a);

- Grupo II: estribos com ganchos abertos (Figura 6.9-b);

- Grupo III: estribos com ganchos e $\mathrm{d}_{\mathrm{b}}=25 \mathrm{~mm}$ (Figura 6.9-c).

Em cada grupo variou-se o grau de armação ao cisalhamento. Nos grupos I e III foram variados o diâmetro e o espaçamento dos estribos. No grupo III as barras laterais adicionais de $10 \mathrm{~mm}$ foram posicionadas em toda a viga ou na metade esquerda $(29 \mathrm{~cm}$ de balanço) ou direita (14,5 cm de balanço) da viga. A Tabela 6.7 apresenta os dados das vigas de ensaio. 
Grupo III

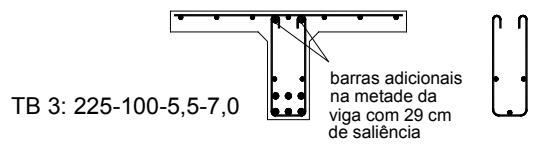

Grupo I
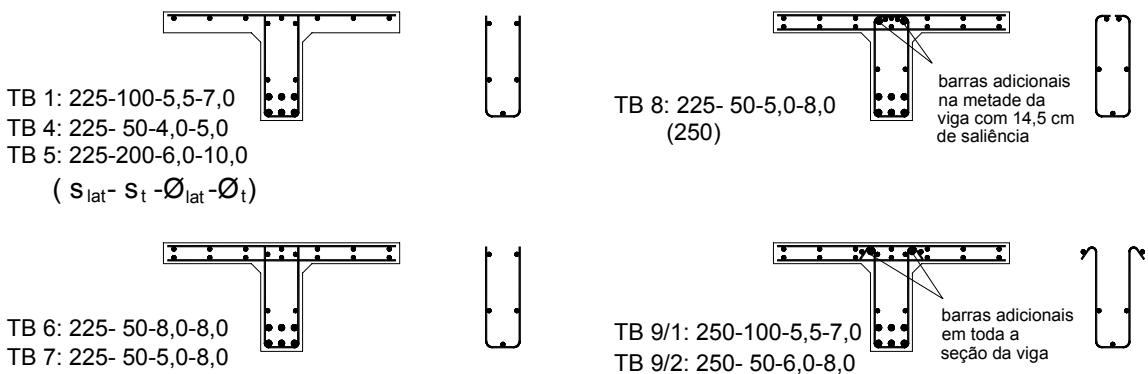

4: $225-50-4,0-5,0$

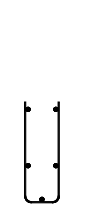

(250)

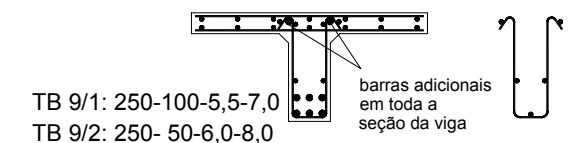

Grupo II

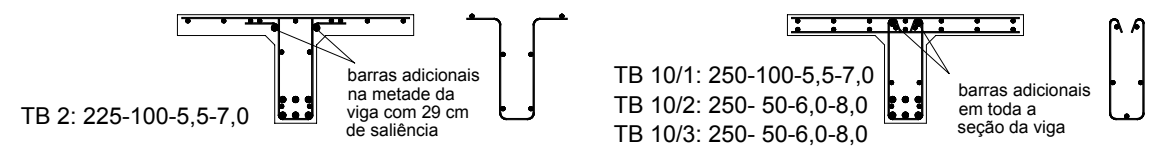

Figura 6.8 - Armaduras utilizadas nas vigas TB1 a TB10, LEONHARDT \& WALTHER (1965).

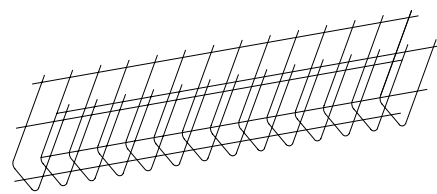

TB 1

a)
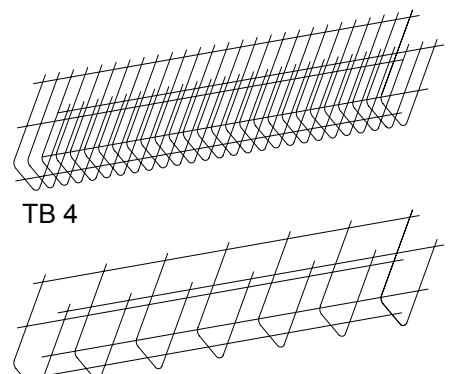

TB 5

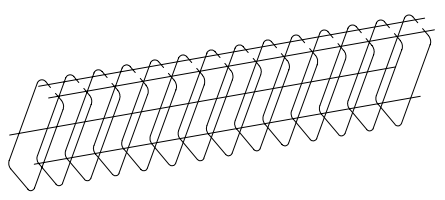

TB 8

c)

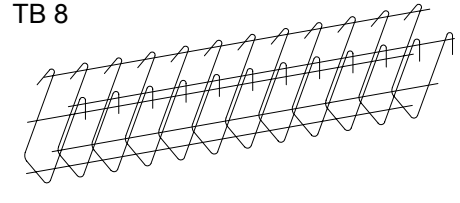

TB $9 / 2$

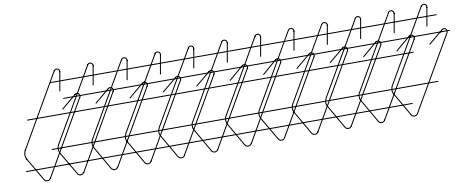

TB 10/2

b)

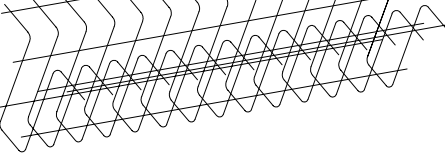

TB 2

Figura 6.9 - Detalhes das armaduras das vigas: a) TB1, TB4 e TB5; b) TB2; c) TB8, TB9/2 e TB 10/2, LEONHARDT \& WALTHER (1965). 
Tabela 6.7 - Dados principais das vigas de ensaio (tipos de ancoragem, armaduras transversal, lateral e barras adicionais).

\begin{tabular}{|c|c|c|c|c|c|c|c|}
\hline \multirow[b]{2}{*}{ Grupo } & \multirow[b]{2}{*}{ Vigas } & \multirow{2}{*}{$\begin{array}{l}\text { Ancoragem } \\
\text { dos estribos }\end{array}$} & $\phi_{\mathbf{t}}$ & $s_{t}$ & $\phi_{\text {lat }}$ & $\mathbf{S}_{\text {lat }}$ & \multirow{2}{*}{$\begin{array}{c}\text { Barras } \\
\text { adicionais }\end{array}$} \\
\hline & & & $\overline{(\mathrm{mm})}$ & $\overline{(\mathrm{mm})}$ & $\overline{(\mathrm{mm})}$ & $(\mathbf{m m})$ & \\
\hline \multirow{5}{*}{ I } & TB1 & \multirow{5}{*}{$\begin{array}{c}\text { estribos } \\
\text { abertos } \\
\text { (com barra } \\
\text { soldada } \\
\text { superior) }\end{array}$} & 7,0 & 100 & 5,5 & 225 & --- \\
\hline & TB4 & & 5,0 & 50 & 4,0 & 225 & --- \\
\hline & TB5 & & 10,0 & 200 & 6,0 & 225 & --- \\
\hline & TB6 & & 8,0 & 50 & 8,0 & 225 & --- \\
\hline & TB7 & & 8,0 & 50 & 5,0 & 225 & --- \\
\hline II & TB2 & $\begin{array}{c}\text { estribos c/ } \\
\text { ganchos } \\
\text { abertos }\end{array}$ & 7,0 & 100 & 5,5 & 225 & $\begin{array}{l}\text { metade da } \\
\text { viga c/ bal. } \\
\text { de } 29 \mathrm{~cm}\end{array}$ \\
\hline \multirow{7}{*}{ III } & TB3 & \multirow{7}{*}{$\begin{array}{l}\text { estribos c/ } \\
\text { ganchos }\end{array}$} & 7,0 & 100 & 5,5 & 225 & idem \\
\hline & TB9/1 & & 7,0 & 100 & 5,5 & 250 & toda a viga \\
\hline & TB10/1 & & 7,0 & 100 & 5,5 & 250 & toda a viga \\
\hline & TB8 & & 8,0 & 50 & 5,0 & $\begin{array}{l}225 / \\
250\end{array}$ & $\begin{array}{l}\text { metade da } \\
\text { viga } \mathrm{c} / \mathrm{bal} \\
\text { de } 14,5 \mathrm{~cm}\end{array}$ \\
\hline & TB9/2 & & 8,0 & 50 & 6,0 & 250 & toda a viga \\
\hline & TB10/2 & & 8,0 & 50 & 6,0 & 250 & toda a viga \\
\hline & TB10/3 & & 8,0 & 50 & 6,0 & 250 & toda a viga \\
\hline
\end{tabular}

A Tabela 6.8 indica os resultados dos ensaios e as causas da ruína.

A viga TB2 (grupo II) rompeu prematuramente após o aparecimento de uma fissura na ligação alma/mesa, causada pelas forças de desvio das abas dos estribos com ganchos abertos. A viga TB8, com ganchos fechados a $90^{\circ}$, atingiu o colapso por flexão com comportamento adequado da ancoragem no bordo comprimido. 
Tabela 6.8 - Resultados dos ensaios (forças e modos de ruína).

\begin{tabular}{|c|c|c|c|c|c|}
\hline \multirow[b]{2}{*}{ Grupo } & \multirow[b]{2}{*}{ Vigas } & $\beta_{w}$ & $\mathbf{V}_{\text {cr }}$ & $\mathbf{V}_{\mathrm{u}, \mathrm{exp}}$ & \multirow[t]{2}{*}{ Causa da ruína } \\
\hline & & (MPa) & $(\mathbf{k N})$ & $(\mathrm{kN})$ & \\
\hline \multirow{5}{*}{ I } & TB1 & 21,0 & 14,5 & 295,5 & escoamento dos estribos \\
\hline & TB4 & 23,4 & 25,0 & 255,5 & \multirow{2}{*}{$\begin{array}{l}\text { falha de ancoragem } \\
\text { dos estribos }\end{array}$} \\
\hline & TB5 & 23,4 & 18,0 & 255,5 & \\
\hline & TB6 & 23,4 & 28,5 & 305,5 & \multirow{2}{*}{$\begin{array}{l}\text { falha de ancoragem } \\
\text { dos estribos }\end{array}$} \\
\hline & TB7 & 23,8 & 27,5 & 329,5 & \\
\hline II & TB2 & 21,0 & 20,0 & 244,5 & $\begin{array}{l}\text { ruptura da mesa } \\
\text { comprimida }\end{array}$ \\
\hline \multirow{7}{*}{ III } & TB3 & 20,8 & 25,0 & 255,5 & \multirow{3}{*}{$\begin{array}{c}\text { escorregamento da } \\
\text { ancoragem dos estribos }\end{array}$} \\
\hline & TB9/1 & 24,1 & 12,0 & 274,0 & \\
\hline & TB10/1 & 20,5 & 20,5 & 239,0 & \\
\hline & TB8 & 26,5 & 26,0 & 345,5 & flexão \\
\hline & TB9/2 & 24,1 & 19,0 & 287,0 & \multirow{3}{*}{$\begin{array}{c}\text { escorregamento da } \\
\text { ancoragem dos estribos }\end{array}$} \\
\hline & TB10/2 & 20,5 & 21,5 & 287,0 & \\
\hline & TB10/3 & 22,7 & 21,0 & 261,5 & \\
\hline
\end{tabular}

onde:

$\beta_{w}$ - resistência cúbica à compressão do concreto.

Com a constatação da influência significativa da ancoragem dos estribos na capacidade resistente ao cisalhamento, LEONHARDT \& WALTHER (1965) realizaram ensaios de arrancamento com o objetivo de verificar o comportamento de diferentes alternativas de ancoragem. Foram analisadas as ancoragens com ganchos fechados $\left(90^{\circ}, 135^{\circ}\right.$ e $180^{\circ}$ ) e ancoragens retas com barras longitudinais soldadas (uma ou duas barras). Como indica a Figura 6.10, foram relatadas as seguintes conclusões:

- alternativas para a ancoragem no bordo comprimido:

- barra longitudinal soldada na extremidade superior do estribo; para estribos com $\phi_{t} \geq 8 \mathrm{~mm}$ sugere-se utilizar duas barras justapostas ou distantes $5 \mathrm{~cm}$ uma da outra, desde que $\phi_{\text {lat }} \geq 0,8 \phi_{t}$;

- ganchos fechados com uma barra longitudinal posicionada abaixo ou atrás da dobra; 
- ganchos fechados de $180^{\circ}$, com $d_{b} \geq 5 \phi$ e barra longitudinal entrelaçada no gancho;

- diâmetro da curvatura dos pontos de dobra das telas $d_{b} \geq 5 \phi$;

- barras longitudinais soldadas não devem ser posicionadas nas dobras.

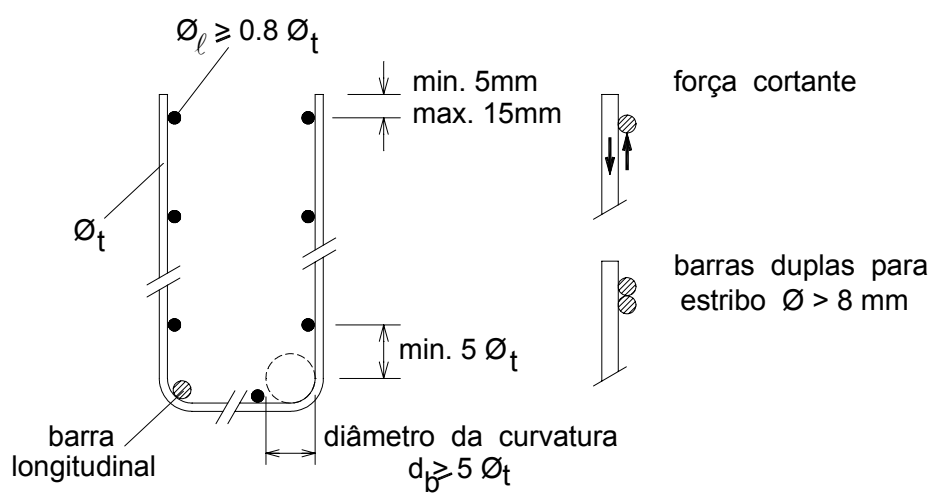

ancoragem com barra longitudinal soldada

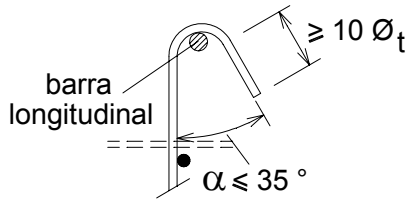

Ancoragem com ganchos para dentro ou para fora

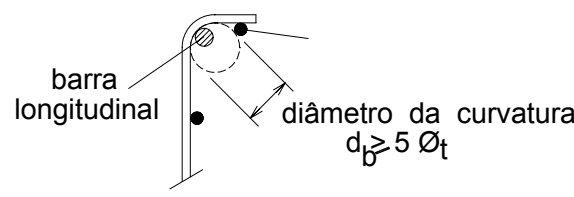

Ancoragem com ganchos inclinados e barra da tela

Figura 6.10 - Formas possíveis de ancoragem no bordo comprimido com telas soldadas, LEONHARDT \& WALTHER (1965).

TAYLOR \& EL-HAMMASI (1980) ensaiaram quinze vigas com dois arranjos diferentes de estribos verticais e três arranjos diferentes de telas soldadas com fios lisos. Os arranjos de estribos utilizados foram: um com o espaçamento máximo e outro com o diâmetro mínimo permitido.

Os arranjos de telas soldadas considerados foram: o primeiro com a mesma armadura transversal de diâmetro mínimo, mas com menor taxa de armadura composta por barras laterais; o segundo com maior taxa de armadura composta por barras laterais e o terceiro com espaçamentos mínimos nas duas direções.

A Figura 6.11 e a Tabela 6.9 mostram os detalhamentos e as características principais das vigas ensaiadas. 

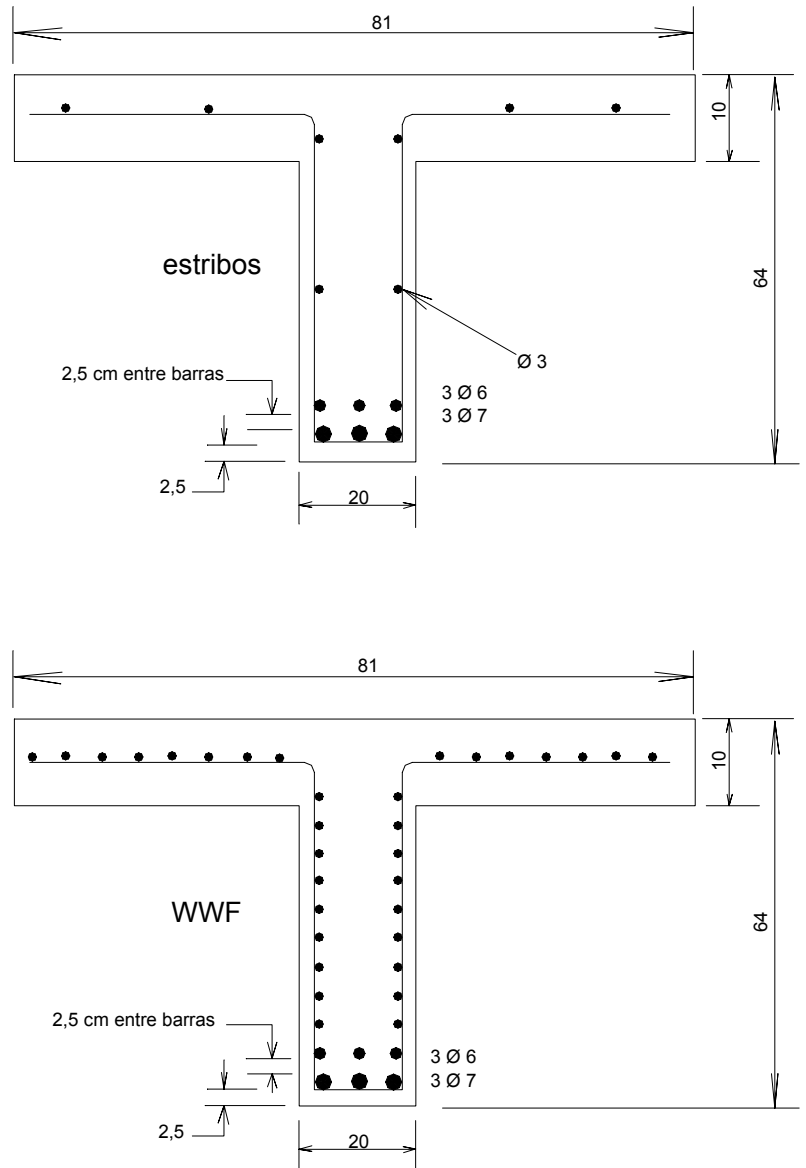

Figura `6.11 - Arranjos das armaduras das vigas com estribos ou telas soldadas ensaiadas por TAYLOR \& EL-HAMMASI (1980).

Os resultados dos ensaios mostraram que as vigas da série 6 tinham as menores aberturas de fissuras. As vigas da série 6 possuíam menor taxa de armadura transversal. Além disso, tanto as vigas da série 4 quanto as da série 5 tinham taxas maiores de armadura horizontal lateral que as da série 6 . Os autores consideram que haveria um limite superior absoluto para o espaçamento da armadura horizontal para que ela seja efetiva. As vigas da série 6 (bitolas e espaçamentos menores nas duas direções), embora com a menor resistência ao cisalhamento de todas as séries, absorveriam maiores forças em virtude de suas características de controle da fissuração.

Assim, para estas vigas a tela soldada mostrou-se adequada como armadura de cisalhamento e principalmente bastante eficaz no controle da fissuração. 
Tabela 6.9 - Armaduras utilizadas nas diferentes séries de vigas.

\begin{tabular}{|c|c|c|c|c|c|c|c|}
\hline Série & $\begin{array}{l}\text { Número } \\
\text { de vigas } \\
\text { ensaiadas }\end{array}$ & \begin{tabular}{|l} 
Estribos \\
ou Tela \\
Soldada
\end{tabular} & $\begin{array}{l}\text { Arm. } \\
\text { Transv. }\end{array}$ & $\begin{array}{l}\text { Arm. } \\
\text { Hor. } \\
\text { Lat. }\end{array}$ & $\begin{array}{l}\text { Espaç. } \\
\text { Vert. } \\
\text { (cm) }\end{array}$ & $\begin{array}{c}\mathbf{V}_{\mathrm{s}} \\
(\mathrm{kN})\end{array}$ & Objetivo \\
\hline 1 & 2 & --- & zero & --- & --- & 0 & obter $V_{c}$ \\
\hline 2 & 3 & estribos & $\begin{array}{c}\phi 4 \mathrm{c} / 30 \\
\left(1,29 \mathrm{~cm}^{2}\right)\end{array}$ & --- & --- & 245 & $\begin{array}{c}\text { espaç. máximo } \\
\text { pelo ACI }\end{array}$ \\
\hline 3 & 3 & estribos & $\begin{array}{c}\phi 3 \mathrm{c} / 23 \\
\left(0,71 \mathrm{~cm}^{2}\right)\end{array}$ & --- & --- & 178 & $\begin{array}{c}\text { mesma resist. } \\
\text { Série } 2 \text {, mas } \\
\text { com } \phi_{\min }\end{array}$ \\
\hline 4 & 2 & tela & $\begin{array}{c}\mathrm{W}_{11} \\
\left(0,71 \mathrm{~cm}^{2}\right)\end{array}$ & $\mathrm{W}_{2.5}$ & 5 & 205 & $\begin{array}{c}\text { mesma arm. } \\
\text { transv. série } 3 \\
\text { com }<\mathrm{A}_{\mathrm{s} \text {,lat }}\end{array}$ \\
\hline 5 & 3 & tela & $\begin{array}{c}\mathrm{W}_{11} \\
\left(0,71 \mathrm{~cm}^{2}\right)\end{array}$ & $\mathrm{W}_{11}$ & 5 & 205 & $\begin{array}{c}\text { mesma arm. } \\
\text { transv. série } 3 \\
\text { com }>\mathrm{A}_{\mathrm{s}, \text { lat }}\end{array}$ \\
\hline 6 & 2 & tela & $\begin{array}{c}\mathrm{W}_{1.4} \\
\left(0,09 \mathrm{~cm}^{2}\right)\end{array}$ & $\mathrm{W}_{1.4}$ & 4 & 156 & $\begin{array}{c}\text { espaç. mín. nas } \\
2 \text { direções }\end{array}$ \\
\hline
\end{tabular}

onde:

$\mathrm{W}_{11}$ - tela soldada com fios lisos com área de $0,11 \mathrm{in}^{2}=0,71 \mathrm{~cm}^{2}$, segundo WRI (1981).

MANSUR et al. (1986) ensaiaram quatro vigas com tela soldada dobrada em forma de U como armadura de cisalhamento. As vigas tinham dimensões de $20 \mathrm{~cm}$ x $50 \mathrm{~cm}$ e comprimento de $370 \mathrm{~cm}$. A Figura 6.12 mostra o esquema do ensaio (viga biapoiada com um balanço) com o objetivo de estudar o desempenho da ancoragem localizada nas zonas de compressão e tração da viga. Uma ou duas barras horizontais foram soldadas nas extremidades da tela em $\mathrm{U}$ para proporcionar a ancoragem necessária.

A Tabela 6.10 apresenta um resumo dos resultados dos ensaios das vigas. 

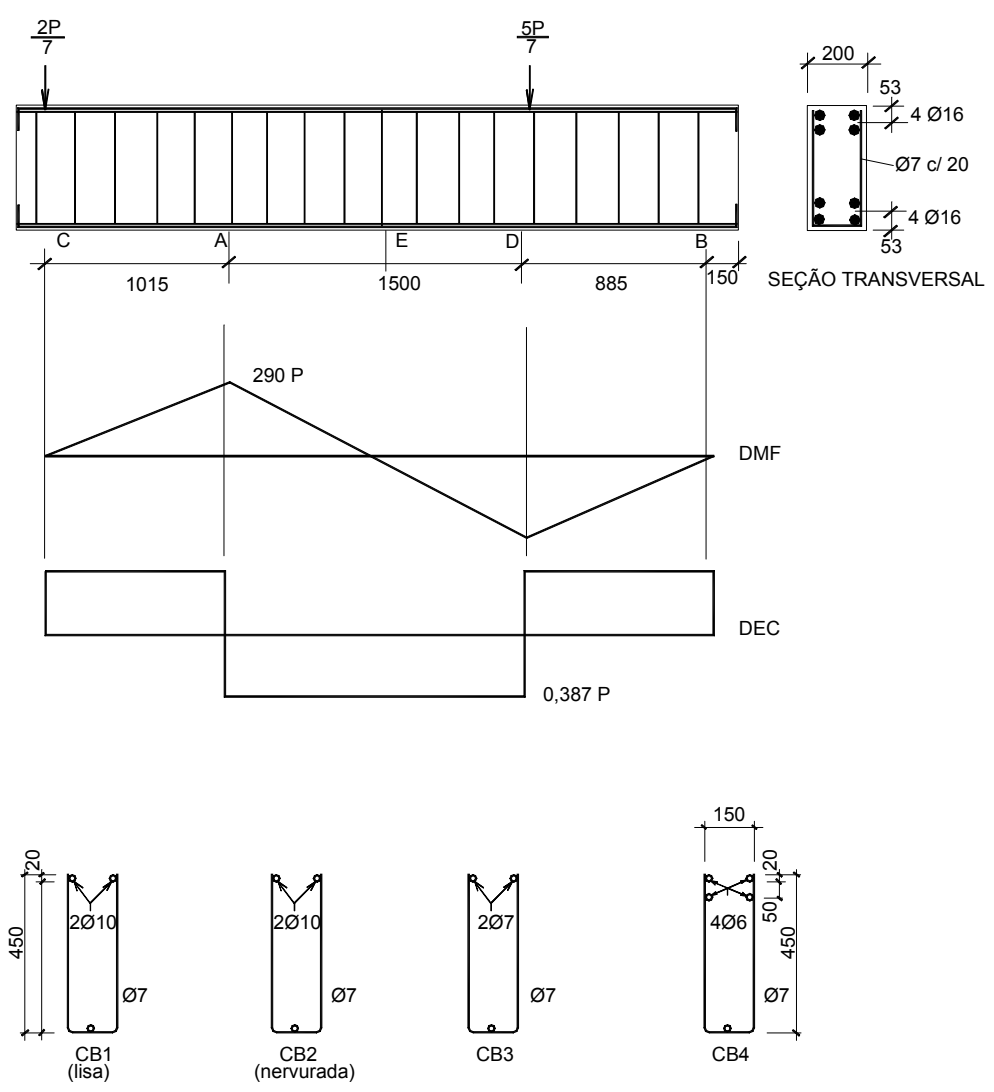

Figura 6.12 - Esquema do ensaio e detalhes das armaduras das vigas ensaiadas por MANSUR et al. (1986).

Tabela 6.10 - Resumo dos resultados dos ensaios das vigas e comparação com valores de projeto.

\begin{tabular}{|c|c|c|c|c|c|c|c|c|}
\hline Viga & $\begin{array}{c}\mathbf{f}_{\mathrm{cu}} \\
\left(\mathrm{N} / \mathrm{mm}^{2}\right. \\
)\end{array}$ & $\begin{array}{l}\mathrm{V}_{\mathrm{u}, \text { teor }} \\
(\mathrm{kN})\end{array}$ & $\begin{array}{l}V_{\text {serv }} \\
(\mathrm{kN})\end{array}$ & $\begin{array}{l}W_{\max } \\
(\mathbf{m m})\end{array}$ & $\begin{array}{c}V_{w=0,3, \exp } \\
(k N)\end{array}$ & $\begin{array}{c}\mathbf{V}_{\mathbf{w}=\mathbf{0}, \mathbf{3}, \mathbf{e x p}} \\
/ \\
\mathbf{V}_{\text {serv }}\end{array}$ & $\begin{array}{c}V_{u, \exp } \\
(k N)\end{array}$ & $\begin{array}{c}\mathbf{V}_{\mathbf{u}, \exp } \\
/ \\
\mathbf{V}_{\text {u,teor }}\end{array}$ \\
\hline CB1 & 26,4 & 134,4 & 84,0 & 0,25 & 95,5 & 1,14 & 209,8 & 1,56 \\
\hline CB2 & 26,4 & 134,4 & 84,0 & 0,09 & 135,4 & 1,61 & 235,5 & 1,75 \\
\hline CB3 & 27,9 & 136,1 & 85,1 & 0,04 & 129,9 & 1,53 & 231,5 & 1,70 \\
\hline CB4 & 27,9 & 136,1 & 85,1 & 0,07 & 127,2 & 1,50 & 243,6 & 1,79 \\
\hline
\end{tabular}

onde:

$\mathrm{V}_{\text {serv }}=\mathrm{V}_{\mathrm{u}, \text { teor }} / 1,6$. 
Pode-se observar que a relação $\mathrm{V}_{\mathrm{u} \text {,exp }} / \mathrm{V}_{\mathrm{u} \text {,eor }}$ para as vigas CB2, CB3 e CB4 varia de 1,70 a 1,79, com um valor médio de 1,75. Os resultados indicaram que os vários tipos de ancoragem praticamente não influenciaram a capacidade resistente das vigas.

As conclusões mais importantes deste trabalho são as que se seguem:

- a utilização de telas soldadas com barras nervuradas em vigas proporciona uma melhora significativa no controle da fissuração diagonal do que quando se utilizam telas soldadas com barras lisas;

- uma viga armada com tela soldada dobrada pode atingir a resistência última, desde que os fios verticais sejam ancorados adequadamente nas extremidades por fios transversais soldados de bitola adequada.

MANSUR et al. (1987) ensaiaram seis vigas de seção T com tela soldada de fios nervurados em forma de $\mathrm{U}$ como armadura de cisalhamento. Os principais parâmetros estudados foram o espaçamento dos estribos e a resistência do concreto. As vigas tinham largura da alma $b_{w}=20 \mathrm{~cm}$, largura de mesa $b_{f}=70 \mathrm{~cm}$ e altura $\mathrm{h}=50 \mathrm{~cm}$, como ilustrado na Figura 6.13.

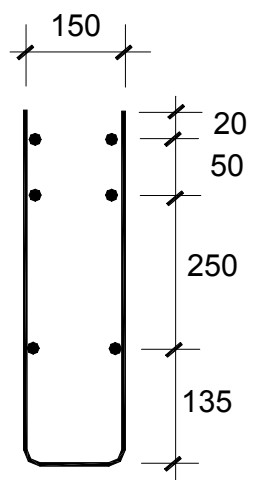

a) tela soldada dobrada

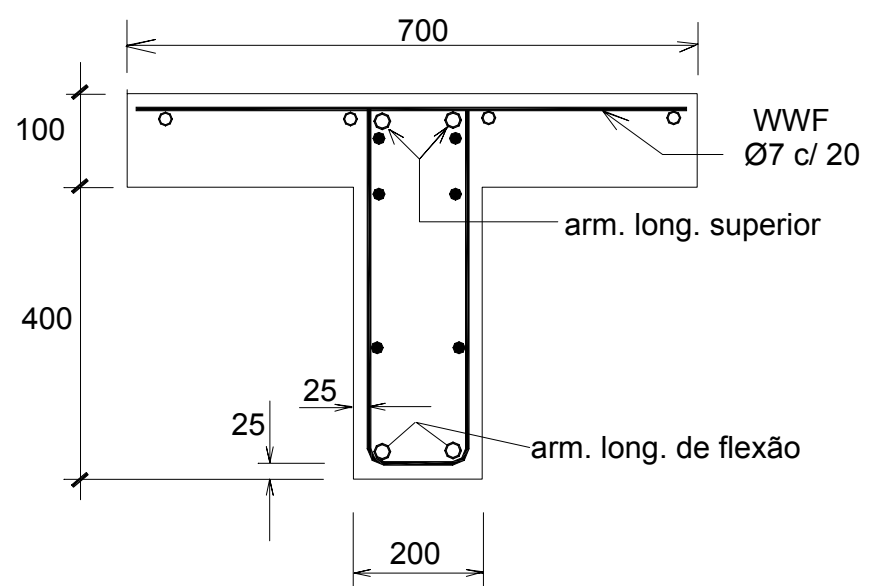

b) seção transversal das vigas

Figura 6.13 - Seção transversal das vigas e detalhes das armaduras, MANSUR et al. (1987).

A Tabela 6.11 apresenta os resultados das vigas ensaiadas. A armadura longitudinal utilizada foi $2 \phi 22$ e $1 \phi 20$ (vigas G e I) ou 4 ф 25 (vigas H e J). 
Tabela 6.11 - Resultados dos ensaios e detalhes das vigas.

\begin{tabular}{|c|c|c|c|c|c|c|c|c|}
\hline Viga & $\begin{array}{c}\mathbf{f}_{\mathrm{c}}^{\prime} \\
(\mathrm{MPa})\end{array}$ & $\begin{array}{l}\mathrm{V}_{\mathrm{u}, \text { teor }} \\
(\mathrm{kN})\end{array}$ & $\begin{array}{l}\mathrm{V}_{\text {serv }} \\
(\mathrm{kN})\end{array}$ & $\begin{array}{l}\mathbf{W}_{\max } \\
(\mathrm{mm})\end{array}$ & 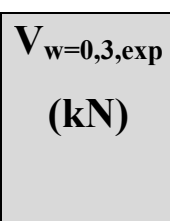 & $\begin{array}{c}\mathbf{V}_{\mathbf{w}=\mathbf{0 , 3}, \exp } \\
/ \\
\mathbf{V}_{\text {serv }}\end{array}$ & $\begin{array}{l}V_{u, \exp } \\
(k N)\end{array}$ & $\begin{array}{l}\mathbf{V}_{\mathrm{u}, \exp } / \\
\mathbf{V}_{\mathrm{u}, \text { teor }}\end{array}$ \\
\hline G1 & 23,4 & 159,2 & 93,7 & 0,15 & 133,4 & 1,42 & 260,0 & 1,63 \\
\hline G2 & 23,4 & 159,2 & 93,7 & 0,18 & 126,0 & 1,30 & 255,0 & 1,60 \\
\hline H1 & 23,6 & 230,1 & 135,4 & 0,15 & 195,0 & 1,44 & 342,0 & 1,49 \\
\hline $\mathrm{H} 2$ & 23,6 & 230,1 & 135,4 & 0,17 & 184,5 & 1,36 & 345,0 & 1,50 \\
\hline I & 35,2 & 175,2 & 103,1 & 0,12 & 151,8 & 1,47 & 249,0 & 1,42 \\
\hline $\mathrm{J}$ & 35,2 & 251,1 & 147,7 & 0,15 & 225,0 & 1,52 & 410,0 & 1,63 \\
\hline
\end{tabular}

onde:

$\mathrm{V}_{\text {serv }}=\mathrm{V}_{\mathrm{u}, \text { teor }} / 1,7$.

Observa-se que os valores da relação $\mathrm{V}_{\mathrm{u}, \exp } / \mathrm{V}_{\mathrm{u} \text {,teor }}$ variaram de 1,42 a 1,63, com um valor médio de 1,55, ou seja, todas as vigas apresentaram reserva de resistência. Os valores da relação $\mathrm{V}_{\mathrm{u}, \mathrm{w}=0,3} / \mathrm{V}_{\mathrm{u} \text {,serv }}$ indicam claramente que a tela soldada nervurada proporciona melhor controle da fissuração.

Além disso, um aumento na resistência do concreto $\left(\mathrm{de} \mathrm{f}_{\mathrm{c}}{ }^{\prime}=23,5 \mathrm{MPa}\right.$ nas vigas $\mathrm{G}$ e $\mathrm{H}$ para $\mathrm{f}_{\mathrm{c}}{ }^{\prime}=35,2 \mathrm{MPa}$ nas vigas I e J) melhora tanto o desempenho da ancoragem quanto o controle da fissuração.

GRIEZIC et al. (1994) ensaiaram duas vigas de seção T armadas com tela soldada nervurada dobrada em forma de U com barras de aço categoria 500. Para comparação ensaiaram também outras duas vigas de seção $\mathrm{T}$ armadas com estribos verticais com barras de aço categoria 400. As vigas tinham largura da alma $b_{w}=20 \mathrm{~cm}$, largura de mesa $b_{f}=80$ $\mathrm{cm}$ e altura $\mathrm{h}=40 \mathrm{~cm}$, como ilustrado nas Figuras 6.14 (vigas A500 e B500) e 6.15 (vigas A400 e B400). 

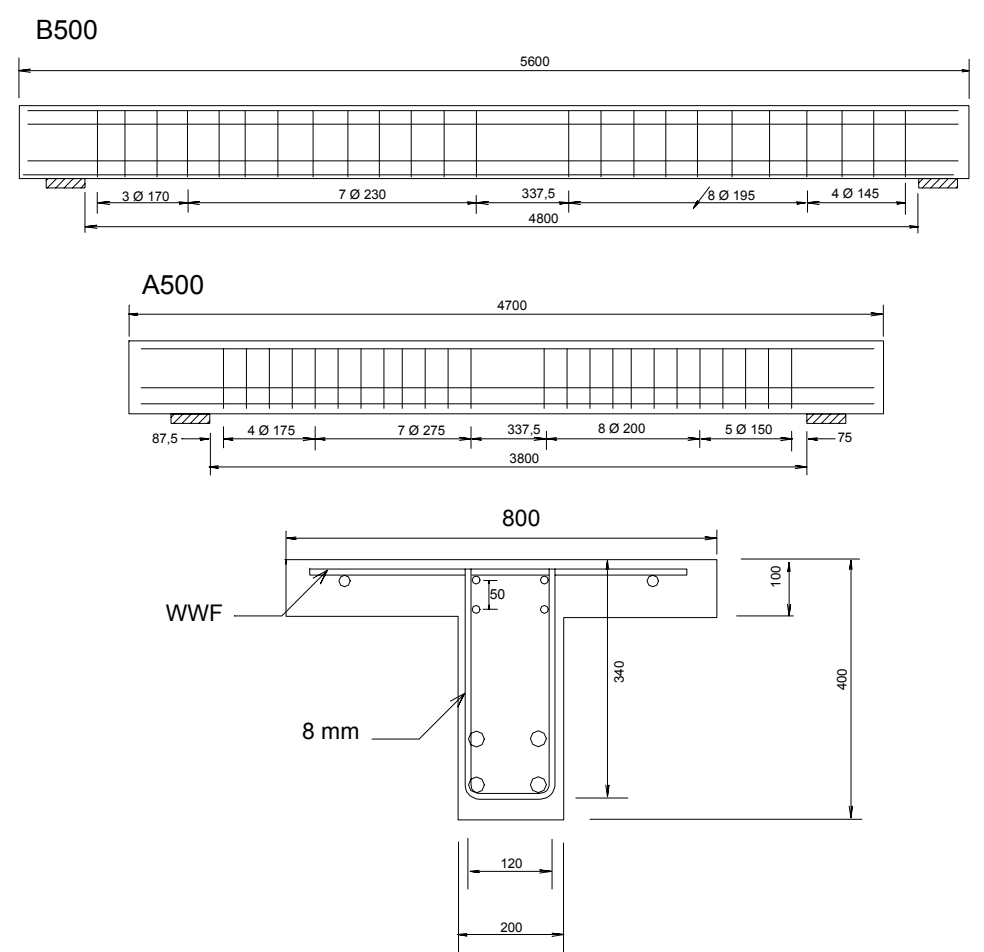

Figura 6.14 - Detalhes das armaduras das vigas A500 e B500, GRIEZIC et al. (1994).
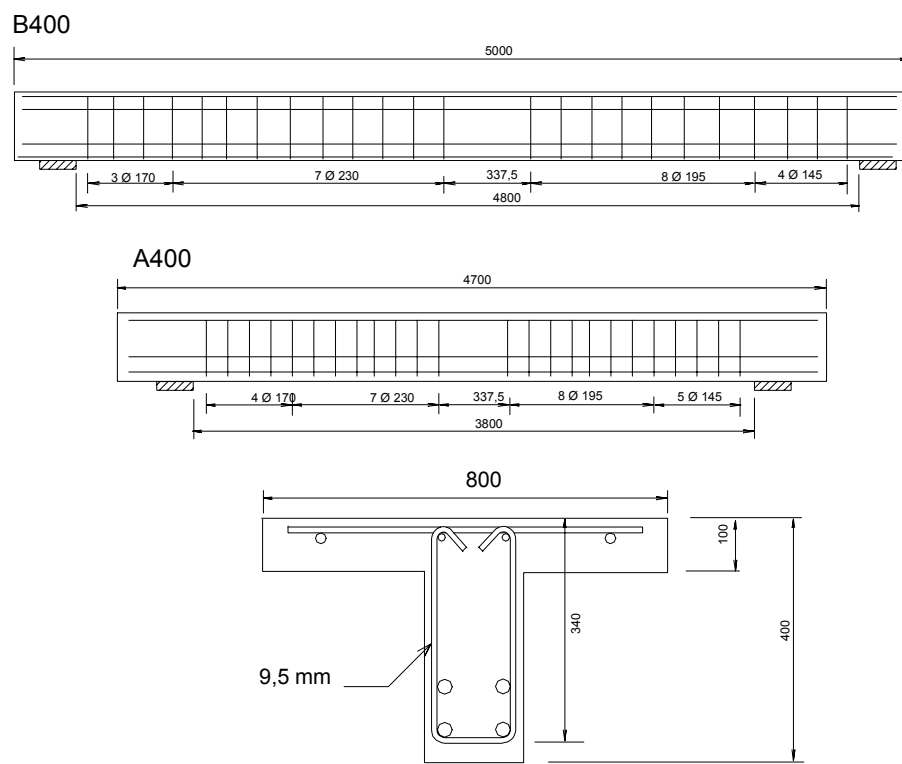

$\left|\begin{array}{c}120 \\ 200\end{array}\right|$

Figura 6.15 - Detalhes das armaduras das vigas A400 e B400, GRIEZIC et al. (1994). 
Alguns parâmetros das vigas e os resultados dos ensaios são mostrados na Tabela 6.12.

Tabela 6.12 - Resultados das vigas T ensaiadas por GRIEZIC et al. (1994).

\begin{tabular}{|c|c|c|c|c|c|}
\hline Viga & $\begin{array}{c}\mathbf{f}_{\mathbf{c}} \\
\mathbf{( M P a )}\end{array}$ & $\begin{array}{c}\text { Armadura } \\
\text { transversal }\end{array}$ & $\begin{array}{c}\mathbf{V}_{\mathbf{u}, \text { teor }} \\
(\mathbf{k N})\end{array}$ & $\begin{array}{c}\mathbf{V}_{\mathbf{u}, \mathbf{e x p}} \\
(\mathbf{k N})\end{array}$ & $\begin{array}{c}\mathbf{V}_{\mathbf{u}, \mathbf{e x p}} / \\
\mathbf{V}_{\mathbf{u}, \text { teor }}\end{array}$ \\
\hline A500 & 41 & tela soldada & 200 & 332 & 1,66 \\
\hline A400 & 39 & estribos abertos & 212 & 334 & 1,58 \\
\hline B500 & 41 & tela soldada & 162 & 291 & 1,80 \\
\hline B400 & 39 & estribos abertos & 169 & 272 & 1,61 \\
\hline
\end{tabular}

Estes ensaios, cujos resultados são mostrados na Tabela 6.12, resultaram nas seguintes conclusões:

- em serviço as aberturas das fissuras inclinadas de cisalhamento foram menores para as vigas armadas com telas soldadas nervuradas de aço categoria 500 do que para as vigas com estribos de aço categoria 400;

- a tensão de escoamento máxima do aço a ser utilizada em projeto é $\mathrm{f}_{\mathrm{y}}=400 \mathrm{MPa}$ (ACI). Este limite resulta em uma estimativa conservativa da resistência ao cisalhamento das vigas com telas de fios nervurados de aço categoria 500. Desde que a tela apresente ductilidade suficiente para redistribuir as deformações e evitar ruína frágil, sua resistência nominal de escoamento $\mathrm{f}_{\mathrm{y}}=500 \mathrm{MPa}$ poderia ser utilizada em projeto.

Alguns pesquisadores [ROBERTSON \& DURRANI (1987), XUAN et al. (1988), PINCHEIRA et al. (1989)] investigaram o desempenho de telas soldadas como armadura de cisalhamento em vigas $\mathrm{T}$ de concreto armado e protendido. Em geral, os resultados obtidos mostraram a eficiência da tela soldada como armadura transversal. 


\section{PROGRAMA EXPERIMENTAL}

\section{1 - CONSIDERAÇÕES INICIAIS}

Este programa experimental investigou o comportamento resistente de vigas de concreto armado solicitadas à força cortante e armadas com telas soldadas, considerando-se a contribuição dos fios horizontais da tela na resistência ao cisalhamento e no controle da fissuração por força cortante.

Os modelos experimentais foram 12 vigas VQ $(15 \times 40 \times 305)$ com relação $\mathrm{a} / \mathrm{d}=100 / 36=2,78$ e 07 vigas VS $(20 \times 70 \times 540)$ com relação $\mathrm{a} / \mathrm{d}=170 / 64=2,66$. Todas as vigas tinham seção T com largura de mesa $b_{f}=50 \mathrm{~cm}$ e altura $h_{f}=10 \mathrm{~cm}$, como mostra a Figura 7.1.

Apresenta-se a seguir um resumo das características geométricas dos modelos ensaiados:

- largura da viga: $b_{w}=15 \mathrm{~cm}$ (vigas VQ) ou $b_{w}=20 \mathrm{~cm}$ (vigas VS);

- altura útil da viga: $\mathrm{d}=36 \mathrm{~cm}$ (vigas $\mathrm{VQ}$ ) ou $\mathrm{d}=65 \mathrm{~cm}$ (vigas $\mathrm{VS}$ );

- relação a/d: 2,78 (vigas VQ) ou 2,66 (vigas VS);

- vigas de seção $T$ com relação entre a largura da mesa e da nervura $b_{f} / b_{w}$ igual a 3,33 (vigas VQ) ou 2,50 (vigas VS).

As dimensões adotadas para a seção transversal dos modelos ( $b=15$ e $20 \mathrm{~cm}$ e $\mathrm{h}=40$ e $70 \mathrm{~cm}$ ) englobaram valores usuais em vigas de concreto armado moldadas no local ( $\mathrm{b}=10 \mathrm{a}$ $20 \mathrm{~cm} \mathrm{e} \mathrm{h=40} \mathrm{a} 70 \mathrm{~cm}$ ). As justificativas para os valores adotados das relações a/d e $b_{\mathrm{f}} / \mathrm{b}_{\mathrm{w}}$ podem ser observadas nas Figuras 3.7 e 3.5, respectivamente. 


\section{2 - MODELOS EXPERIMENTAIS}

\subsection{1 - DENOMINAÇÃO E PARÂMETROS ENVOLVIDOS}

As vigas apresentavam diferentes arranjos de armaduras com parâmetros variáveis, de acordo com os objetivos desta investigação experimental. As vigas VQ possuíam dimensões 15 × 40 × 305 (em cm) e as vigas VS, dimensões 20 x 70 x 540 (em cm). Estas dimensões são bastante usuais na prática de projetos estruturais e, além disso, englobam tanto
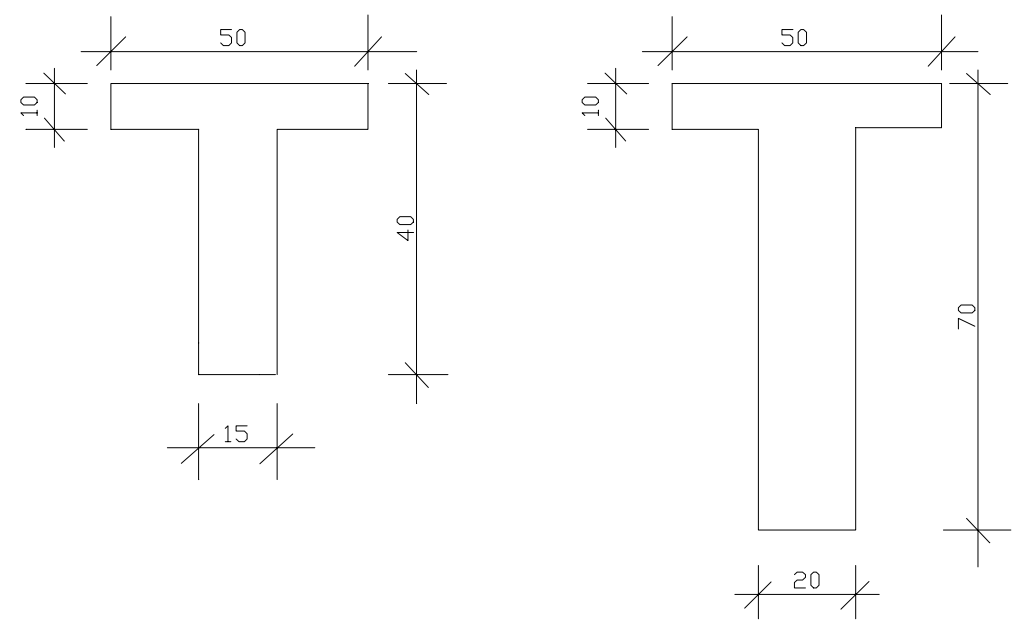

Figura 7.1 - Dimensões das vigas de ensaio VQ e VS.

as vigas com $\mathrm{d}>60 \mathrm{~cm}$, em que a armadura de pele é obrigatória, segundo o Projeto de Revisão da NBR 6118:2001, quanto as vigas de menor altura.

Os modelos experimentais foram agrupados em séries em função das dimensões da seção transversal, do arranjo das armaduras, dos parâmetros variáveis e dos objetivos dos ensaios de cada série. Optou-se pela utilização de concreto de resistência à compressão entre $25 \mathrm{MPa}$ e $40 \mathrm{MPa}$ aos 28 dias, por sua intensa aplicação em diferentes tipos de obras.

A Tabela 7.1 mostra, para cada série, a denominação e numeração das vigas, suas dimensões, seus parâmetros fixos e variáveis.

As vigas da série A1 foram as vigas VQ ( 15 x 40 x 305), sendo VQ-0 armada apenas com armadura longitudinal de flexão e VQ-1 com armadura transversal composta por estribos verticais. A viga VQ-2 possuía, além dessas duas armaduras, uma armadura lateral composta por fios amarrados nos estribos. A viga VQ-3 tinha, além da armadura longitudinal, uma tela soldada dobrada, formando os estribos e os fios posicionados na 
lateral da viga. As vigas da série A2, VS (20 x 70 x 540), foram armadas de modo análogo. Cabe comentar que as taxas de armadura lateral ( $\rho_{\text {lat }}$ ) foram iguais tanto em VQ-2 e VQ-3 quanto em VS-2 e VS-3.

As vigas da série B (VQ-4 a VQ-6), tiveram como parâmetro fixo a taxa de armadura lateral $\rho_{\text {lat }}$ e como parâmetro variável, a taxa de armadura transversal $\rho_{\mathrm{w}}$, variando-se o espaçamento horizontal dos fios verticais das telas soldadas.

As vigas da série D (VQ-7 a VQ-10) tinham as mesmas armaduras longitudinal, transversal e lateral da viga VQ-3, variando-se apenas o tipo de ancoragem dos fios verticais da tela soldada na borda comprimida da viga.

As vigas da série C (VS-4 a VS-6), tinham como parâmetro fixo a taxa de armadura transversal $\rho_{\mathrm{w}}$ e como parâmetro variável, a taxa de armadura lateral $\rho_{\text {lat }}$, variando-se o espaçamento vertical dos fios horizontais das telas soldadas.

Tabela 7.1 - Modelos experimentais de cada série.

\begin{tabular}{|c|c|c|c|c|c|}
\hline Série & Quant. & Vigas & $\begin{array}{c}\text { Dimensões (cm) } \\
\left(b_{w} \times h \times \ell_{o}\right)\end{array}$ & $\begin{array}{l}\text { Parâmetros } \\
\text { fixos }\end{array}$ & $\begin{array}{l}\text { Parâmetros } \\
\text { variáveis }\end{array}$ \\
\hline \multirow{4}{*}{ A 1} & \multirow{4}{*}{4} & VQ-0 & $15 \times 40 \times 305$ & $\rho_{\mathrm{w}}=0$ & \\
\hline & & VQ-1 & $15 \times 40 \times 305$ & $\rho_{\mathrm{w}}$ & $\rho_{\text {lat }}=0$ \\
\hline & & VQ-2 & $15 \times 40 \times 305$ & $\rho_{\mathrm{w}}$ e $\rho_{\text {lat }}$ & barras soltas \\
\hline & & VQ-3 & $15 \times 40 \times 305$ & $\rho_{\mathrm{w}} \mathrm{e} \rho_{\mathrm{lat}}$ & tela soldada \\
\hline \multirow{3}{*}{$\mathrm{B}$} & \multirow{3}{*}{3} & VQ-4 & $15 \times 40 \times 305$ & $\rho_{\text {lat }}$ & $\rho_{\mathrm{w}}$ \\
\hline & & VQ-5 & $15 \times 40 \times 305$ & $\rho_{\text {lat }}$ & $\rho_{\mathrm{w}}$ \\
\hline & & VQ-6 & $15 \times 40 \times 305$ & $\rho_{\text {lat }}$ & $\rho_{\mathrm{w}}$ \\
\hline \multirow{5}{*}{$\mathrm{D}$} & 1 & VQ-1A & $15 \times 40 \times 305$ & $\rho_{\mathrm{w}}$ & $\rho_{\mathrm{lat}}=0$ \\
\hline & \multirow{4}{*}{4} & VQ-7 & $15 \times 40 \times 305$ & $\rho_{\mathrm{w}} \mathrm{e} \rho_{\text {lat }}$ & \multirow{4}{*}{$\begin{array}{l}\text { ancoragem dos fios } \\
\text { verticais da tela } \\
\text { soldada no bordo } \\
\text { comprimido }\end{array}$} \\
\hline & & VQ-8 & $15 \times 40 \times 305$ & $\rho_{\mathrm{w}} \mathrm{e} \rho_{\text {lat }}$ & \\
\hline & & VQ-9 & $15 \times 40 \times 305$ & $\rho_{\mathrm{w}} \mathrm{e} \rho_{\text {lat }}$ & \\
\hline & & VQ-10 & $15 \times 40 \times 305$ & $\rho_{\mathrm{w}} \mathrm{e} \rho_{\text {lat }}$ & \\
\hline \multirow{4}{*}{$\mathrm{A} 2$} & \multirow{4}{*}{4} & VS-0 & $20 \times 70 \times 540$ & $\rho_{\mathrm{w}}=0$ & \\
\hline & & VS-1 & $20 \times 70 \times 540$ & $\rho_{\mathrm{w}}$ & $\rho_{\text {lat }}=0$ \\
\hline & & VS-2 & $20 \times 70 \times 540$ & $\rho_{\mathrm{w}} \mathrm{e} \rho_{\text {lat }}$ & barras soltas \\
\hline & & VS-3 & $20 \times 70 \times 540$ & $\rho_{\mathrm{w}} \mathrm{e} \rho_{\text {lat }}$ & tela soldada \\
\hline \multirow{3}{*}{$\mathrm{C}$} & \multirow{3}{*}{3} & VS-4 & $20 \times 70 \times 540$ & $\rho_{\mathrm{w}}$ & $\rho_{\text {lat }}$ \\
\hline & & VS-5 & $20 \times 70 \times 540$ & $\rho_{\mathrm{w}}$ & $\rho_{\text {lat }}$ \\
\hline & & VS-6 & $20 \times 70 \times 540$ & $\rho_{\mathrm{w}}$ & $\rho_{\text {lat }}$ \\
\hline
\end{tabular}

Observações: 
1 - Procurou-se utilizar concreto com resistência à compressão com pequena variabilidade dentro dos limites inicialmente estabelecidos. Todavia, para as vigas da série A2, a resistência à compressão do concreto ficou aquém da esperada;

2 - Na Tabela 7.1, têm-se:

$\rho_{\ell}-$ taxa de armadura longitudinal;

$\rho_{\mathrm{w}}-$ taxa de armadura transversal;

$\rho_{\text {lat }}-$ taxa de armadura lateral;

3 - Todas as vigas VQ possuíram a mesma taxa de armadura longitudinal possibilitando análise de resultados entre vigas de séries diferentes, como por exemplo, comparar os resultados da viga VQ-1 da série A1 com os resultados da viga VQ-6 da série B. As vigas VS também possuíam a mesma taxa de armadura longitudinal, porém diferente das vigas VQ.

\subsection{2 - DIMENSIONAMENTO DAS VIGAS}

\subsubsection{1 - Resistência à força cortante}

Para a determinação da resistência à força cortante os coeficientes de segurança foram considerados unitários. A resistência média à compressão do concreto foi inicialmente prevista em torno de $27 \mathrm{MPa}$ e o aço tipo CA-60, com resistência característica ao escoamento igual a $600 \mathrm{MPa}$ e módulo de elasticidade de $210.000 \mathrm{MPa}$.

Inicialmente, foi obtida a parcela $V_{c}$ das vigas VQ-0 e VS-0 sem armadura transversal. Em seguida, obtiveram-se as forças últimas dos outros modelos, adicionando-se a parcela $V_{s}$ da armadura transversal. Utilizaram-se as expressões propostas pelo Projeto de Revisão da NBR 6118:2001 e ZSUTTY (1968).

Analisando-se resultados das investigações experimentais de SILVA, Rita C. (1999) e SALLES NETO (2001), sobre resistência à força cortante em vigas de seção T, concluiu-se que a formulação proposta por ZSUTTY (1968) era a que mais se aproximava dos resultados experimentais.

Apresenta-se a Tabela 7.2 que contém os valores inicialmente calculados das parcelas $V_{c}$ e $V_{s}$ da resistência à força cortante, utilizando-se como armadura transversal das vigas VQ-1 e VS-1 estribos verticais perpendiculares ao eixo da peça. 
Tabela 7.2 - Capacidade resistente ao cisalhamento inicialmente prevista.

\begin{tabular}{|c|c|c|c|c|c|c|c|}
\hline \multirow{2}{*}{ Vigas } & \multicolumn{2}{|c|}{$V_{c}(k N)$} & \multirow{2}{*}{$A_{s w} / s\left(\mathrm{~cm}^{2} / m\right.$} & \multicolumn{2}{c|}{$V_{s}(k N)$} & \multicolumn{2}{c|}{$V_{u}(k N)$} \\
\cline { 2 - 3 } & NBR 6118 & Zsutty & & NBR 6118 & Zsutty & NBR 6118 & Zsutty \\
\cline { 5 - 8 } VQ-0 & 61,3 & 70,5 & --- & --- & --- & 61,3 & 70,5 \\
\hline VQ-1 & 61,3 & 70,5 & 2,8 & 54,4 & 60,5 & 115,7 & 131,0 \\
\hline VS-0 & 147,4 & 193,1 & --- & --- & --- & 147,4 & 193,1 \\
\hline VS-1 & 147,4 & 193,1 & 4,0 & 140,4 & 156,0 & 287,8 & 349,1 \\
\hline
\end{tabular}

\subsubsection{2 - Resistência à flexão}

A armadura de flexão foi dimensionada segundo as prescrições do Projeto de Revisão da NBR 6118: 2001, adotando-se coeficientes de segurança unitários. A resistência média à compressão do concreto, inicialmente prevista, foi de $27 \mathrm{MPa}$ e o aço, tipo CA-50, com resistência característica de escoamento igual a $500 \mathrm{MPa}$ e módulo de elasticidade de $210.000 \mathrm{MPa}$.

A viga foi considerada biapoiada, submetida a duas forças aplicadas simetricamente. Essas duas forças concentradas distavam $100 \mathrm{~cm}$ e $170 \mathrm{~cm}$ do apoio esquerdo das vigas VQ e VS, respectivamente.

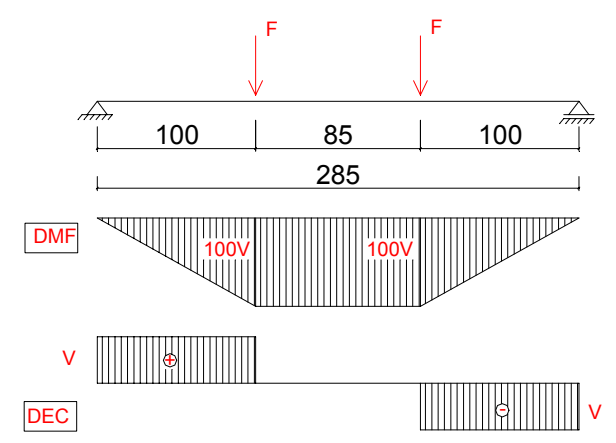

Figura 7.2 - Diagramas de esforços solicitantes das vigas VQ. 


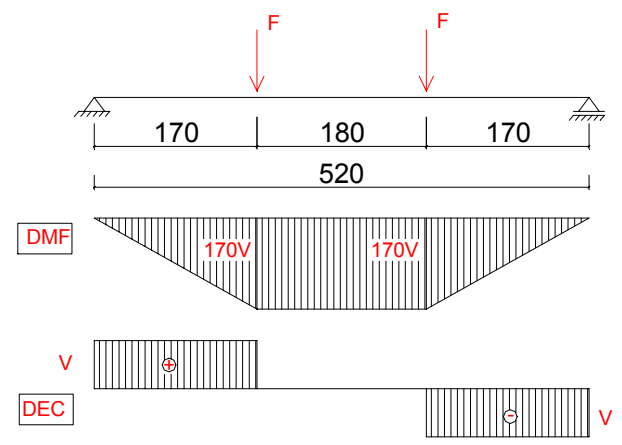

Figura 7.3 - Diagramas de esforços solicitantes das vigas VS.

Apresenta-se a Tabela 7.3 que mostra as armaduras de flexão calculada e efetiva. A armadura longitudinal foi calculada para a força última $V_{u}$ à força cortante e a seguir majorada para garantir que, nos ensaios, a ruína não ocorresse por flexão.

Tabela 7.3 - Dimensionamento inicial da armadura de flexão.

\begin{tabular}{|c|c|c|c|c|c|c|}
\hline Vigas & $\mathbf{F}(\mathbf{k N})$ & $\mathbf{M}(\mathbf{k N} . \mathbf{m})$ & $A_{s, \text { calc }}\left(\mathrm{cm}^{2}\right)$ & $A_{s, \text { efet }}\left(\mathrm{cm}^{2}\right)$ & $\phi$ & Majoração \\
\hline VQ-1 & 131,0 & 131,0 & 7,5 & 18,0 & $9 \phi 16$ & $+140 \%$ \\
\hline VS-1 & 349,1 & 593,5 & 19,5 & 44,1 & $14 \phi 20$ & $+126 \%$ \\
\hline
\end{tabular}

Justifica-se a grande majoração na área de armadura longitudinal em virtude de as forças últimas experimentais apresentarem-se superiores àquelas teoricamente previstas em investigações experimentais sobre resistência à força cortante. Apresenta-se a Tabela 7.4 com os valores das forças últimas previstas, para força cortante e momento fletor, recalculadas com a armadura longitudinal efetivamente adotada.

Tabela 7.4 - Capacidades resistentes previstas à flexão e ao cisalhamento (calculadas com a armadura longitudinal efetiva).

\begin{tabular}{|c|c|c|c|c|c|}
\hline \multirow{2}{*}{ Vigas } & $A_{s, \text { efet }}$ & $M_{u}$ & $P_{u, f l}$ & $V_{u, c i s}$ & $V_{u, c i s} / P_{u, f l}$ \\
\cline { 2 - 5 } & $\left(\mathrm{cm}^{2}\right)$ & $(k N . m)$ & $(k N)$ & $(k N)$ & \\
\hline VQ-1 & 18,0 & 291,6 & 291,6 & 131,0 & 0,45 \\
\hline VS-1 & 44,1 & $1.086,0$ & 638,8 & 349,1 & 0,55 \\
\hline
\end{tabular}


Assim, os modelos experimentais utilizados possuíam uma resistência à força cortante em torno de $50 \%$ da resistência à flexão, garantindo-se ruína por força cortantetração, com escoamento da armadura transversal.

Após a execução dos ensaios das vigas, as capacidades resistentes à força cortante foram recalculadas a partir dos valores experimentais da resistência à compressão do concreto e da resistência de escoamento do aço.

\subsubsection{3 - Ancoragem e distribuição na seção da armadura de flexão}

Mesmo com a utilização de grande quantidade de barras com elevado diâmetro nas armaduras longitudinais, optou-se pela ancoragem com gancho vertical a $90^{\circ}$. A ancoragem no apoio extremo foi verificada seguindo as recomendações do Projeto de Revisão da NBR 6118: 2001, como indica a Tabela 7.5. A ancoragem adequada do banzo tracionado preveniu eventual ruína por fendilhamento do concreto na região de ancoragem das barras.

Em SILVA \& GIONGO (2002c) analisa-se mais detalhadamente o comportamento estrutural da ancoragem no apoio extremo das vigas VQ.

Tabela 7.5 - Verificação da ancoragem no apoio extremo.

\begin{tabular}{|c|c|c|c|c|}
\hline \multirow{2}{*}{ Vigas } & $P_{u}$ & $R_{s t}$ & $A_{\text {s,nec.apoio }}$ & $\begin{array}{c}\text { Barras ancoradas } \\
\text { no apoio }\end{array}$ \\
\cline { 2 - 4 } & $(k N)$ & $(k N)$ & $\left(\mathrm{cm}^{2}\right)$ & \\
\hline VQ-1 & 291,6 & 197,0 & 4,5 & $4 \phi 16$ \\
\hline VS-1 & 638,8 & 476,5 & 10,3 & $6 \phi 20$ \\
\hline
\end{tabular}

Para um arranjo adequado das armaduras longitudinais na seção transversal optou-se pela utilização de feixes de 2 barras, como mostra a Figura 7.4.

As armaduras longitudinais $(9 \phi 16 \mathrm{~mm})$ das vigas VQ foram distribuídas na seção transversal em duas camadas. Na primeira camada foram posicionadas 6 barras compostas por 3 feixes de 2 barras e na segunda camada, 3 barras. As barras ancoradas no apoio (4 $\phi 16$ $\mathrm{mm}$ ) tinham ganchos de $90^{\circ}$. A Figura 7.5 mostra com mais detalhe a ancoragem das barras nos apoios extremos. Para os 2 feixes situados nas quinas dos estribos, 1 das 2 barras possuía gancho de $90^{\circ}$, enquanto para o feixe central as 2 barras possuíam ganchos em ângulo reto. 

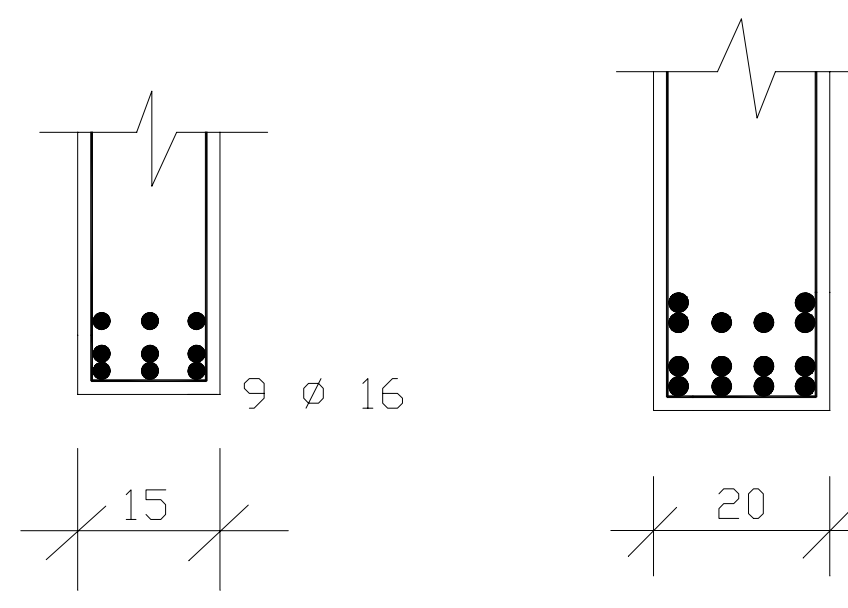

Figura 7.4 - Arranjos das armaduras longitudinais nas seções transversais das vigas VQ e VS.

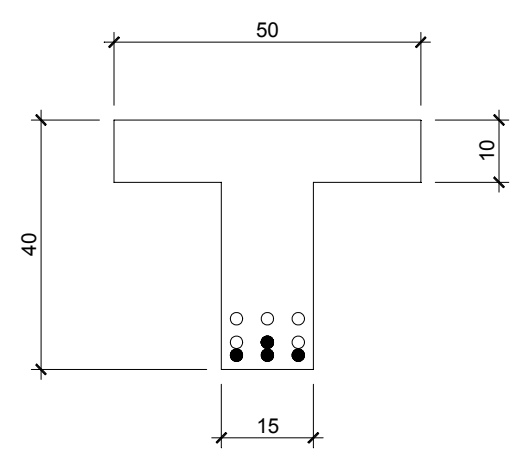

Figura 7.5 - Detalhes dos feixes das barras e da ancoragem nos apoios extremos com ganchos em ângulo reto nas vigas VQ.

\subsection{3 - DETALHAMENTO DAS VIGAS}

Neste item apresenta-se o detalhamento das armaduras de todos os modelos (Figuras 7.6 a 7.23$)$. 


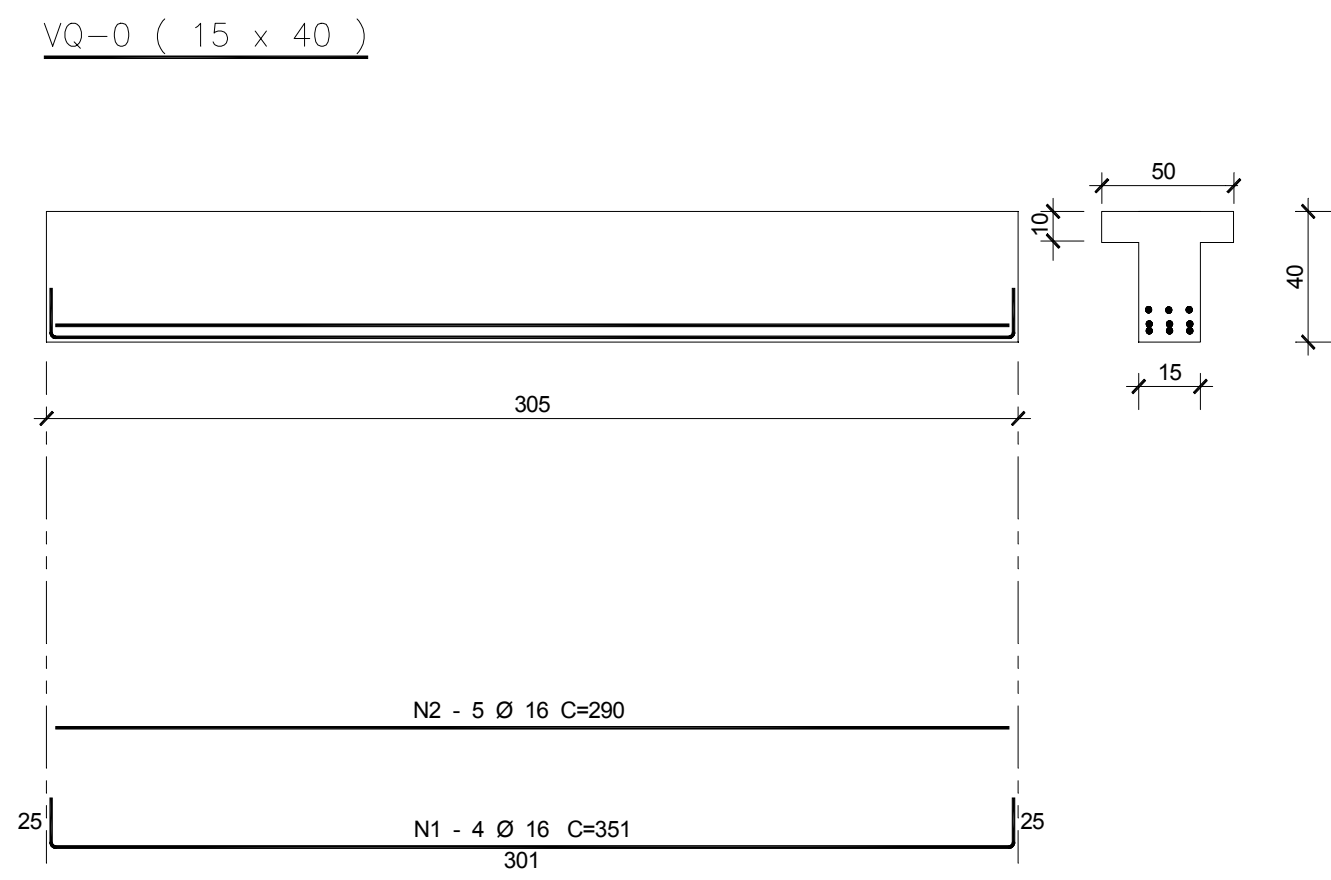

Figura 7.6 - Viga de ensaio VQ-0 da série A1.

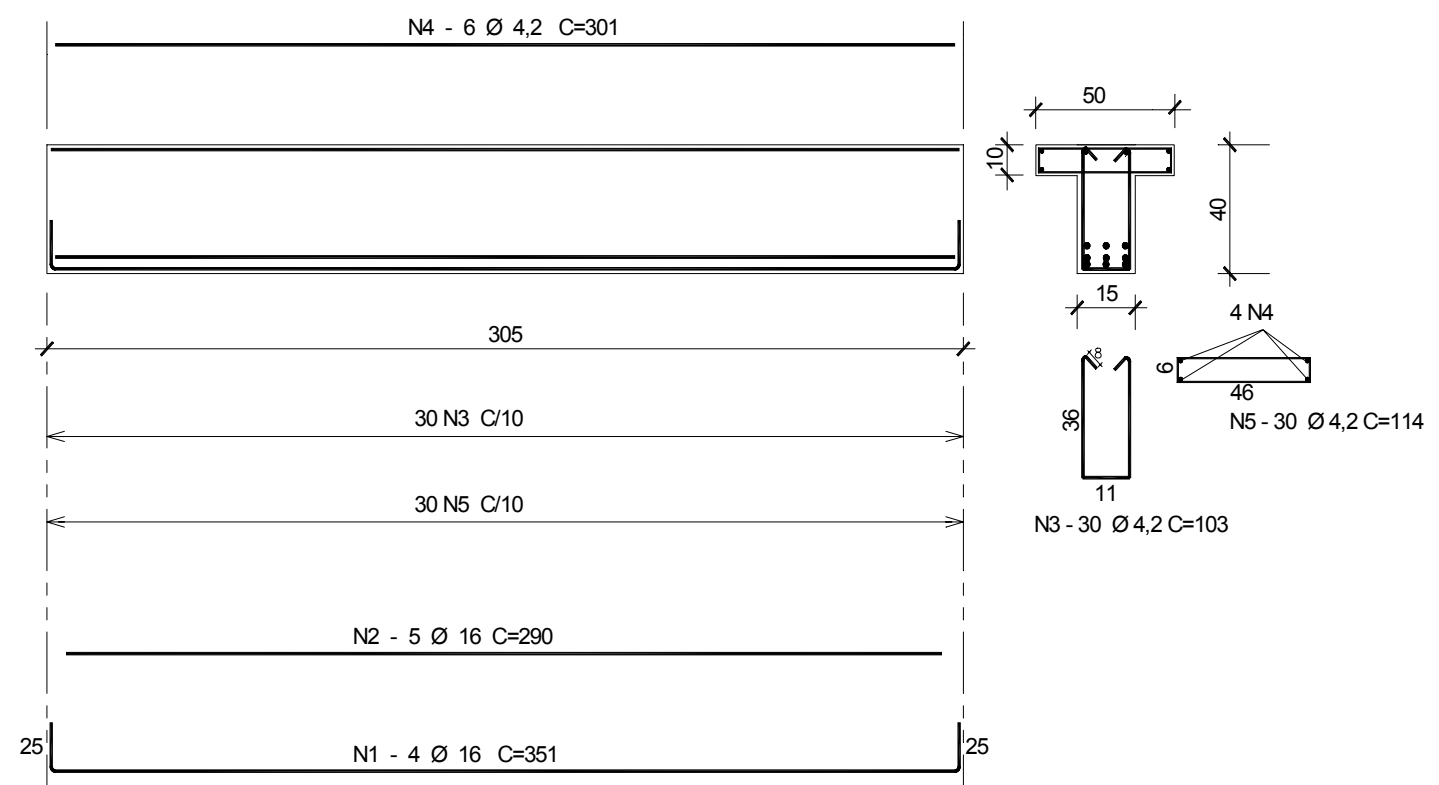

Figura 7.7 - Viga de ensaio VQ-1 da série A1. 


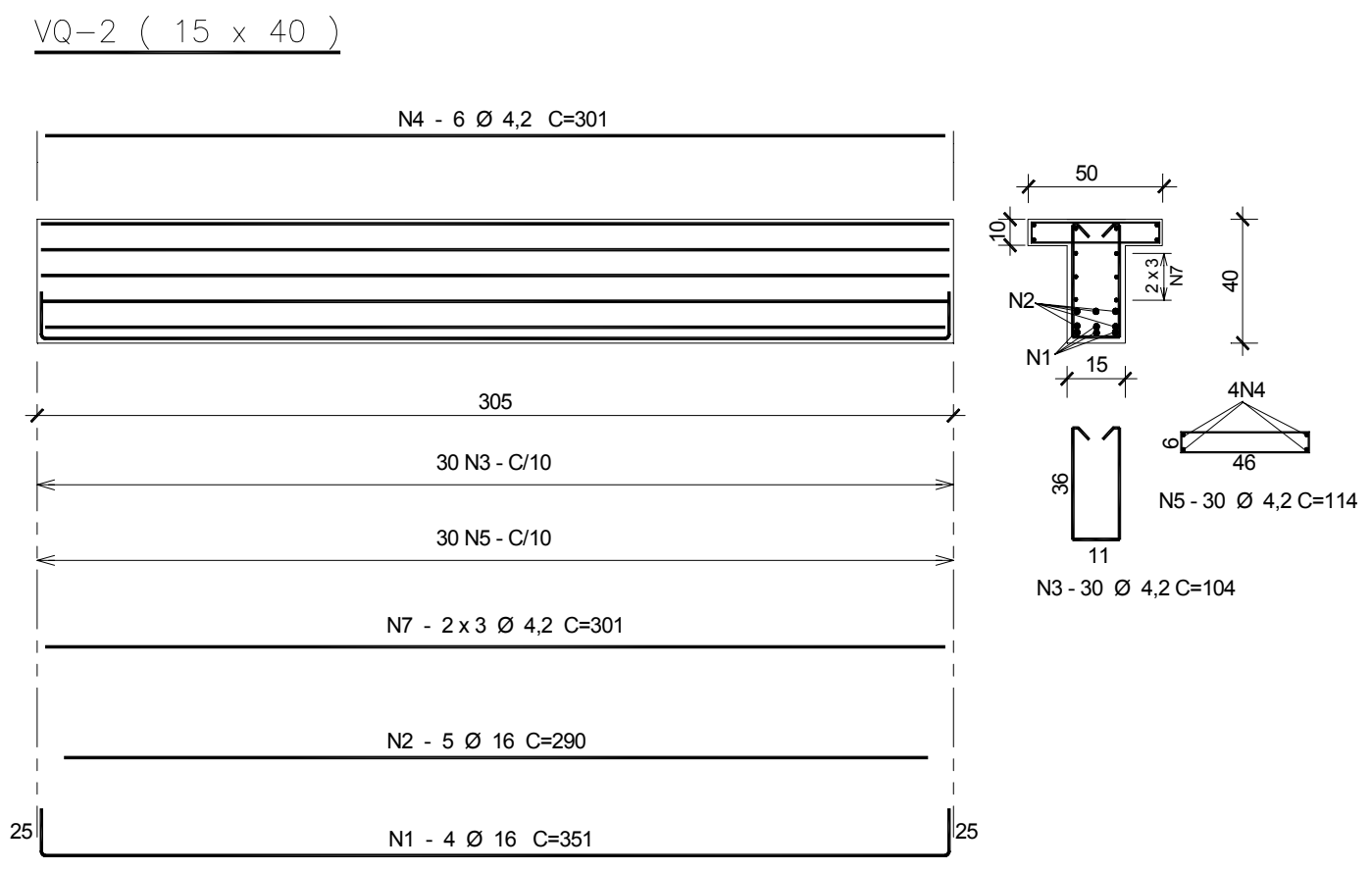

Figura 7.8 - Viga de ensaio VQ-2 da série A1.

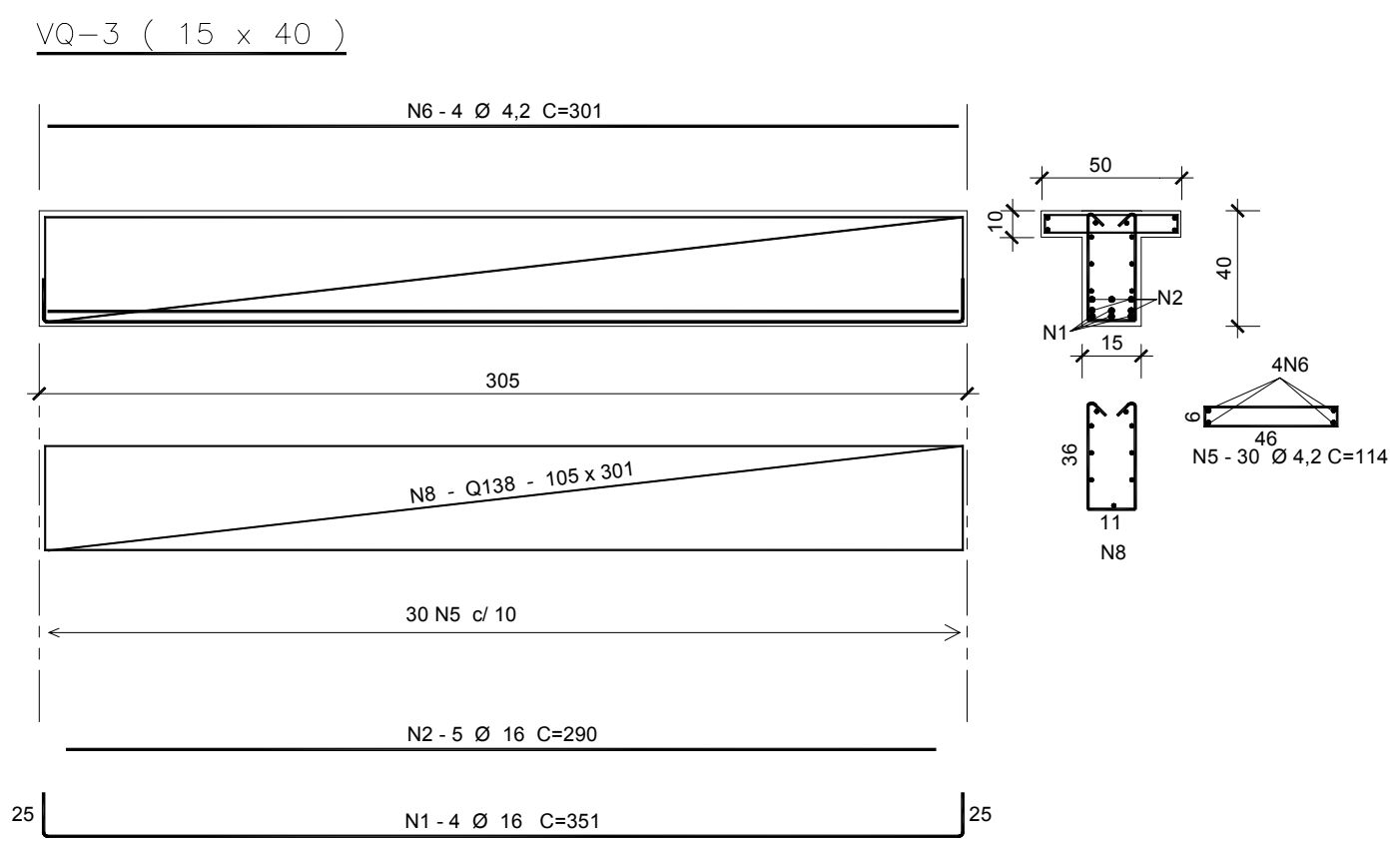

Figura 7.9 - Viga de ensaio VQ-3 da série A1. 


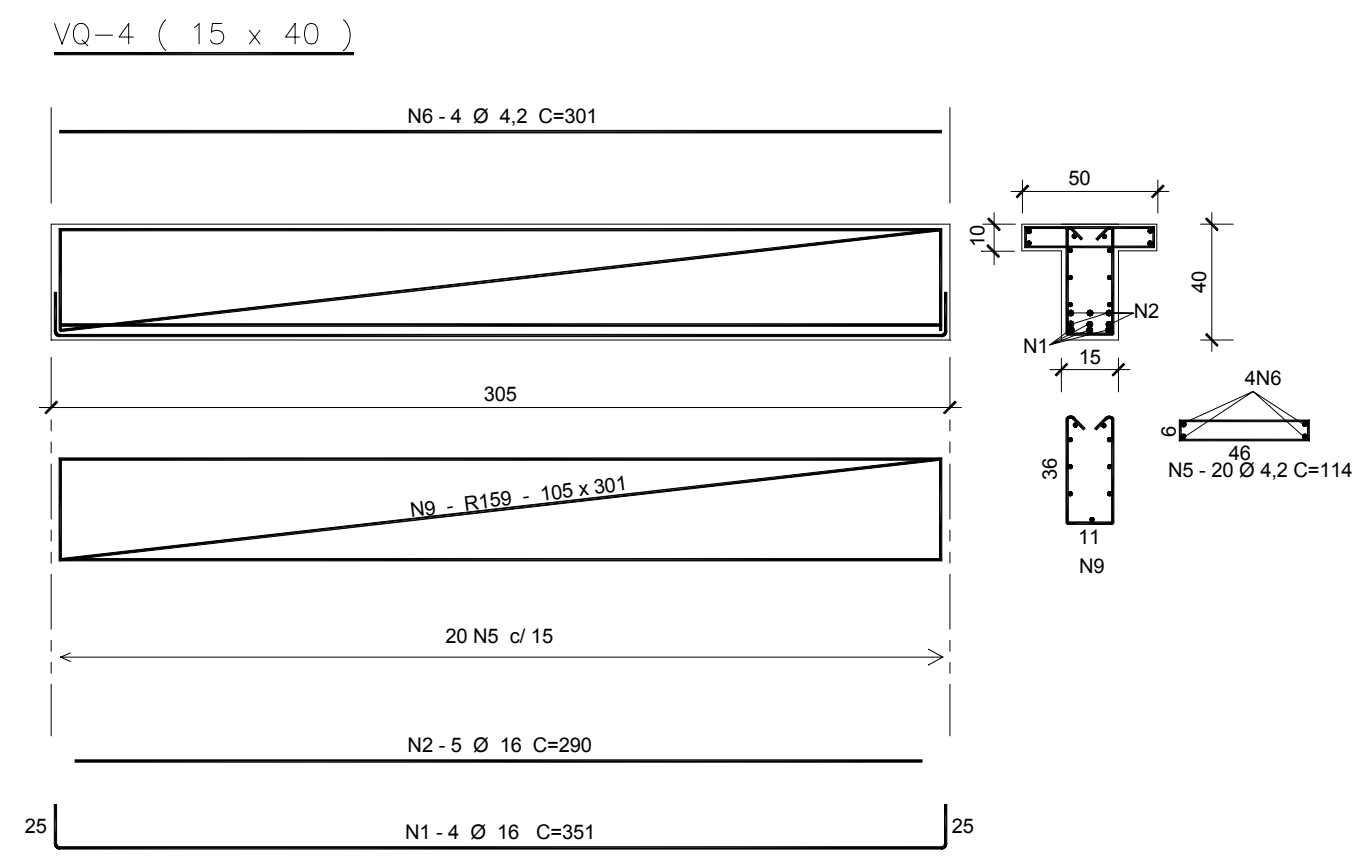

Figura 7.10 - Viga de ensaio VQ-4 da série B.

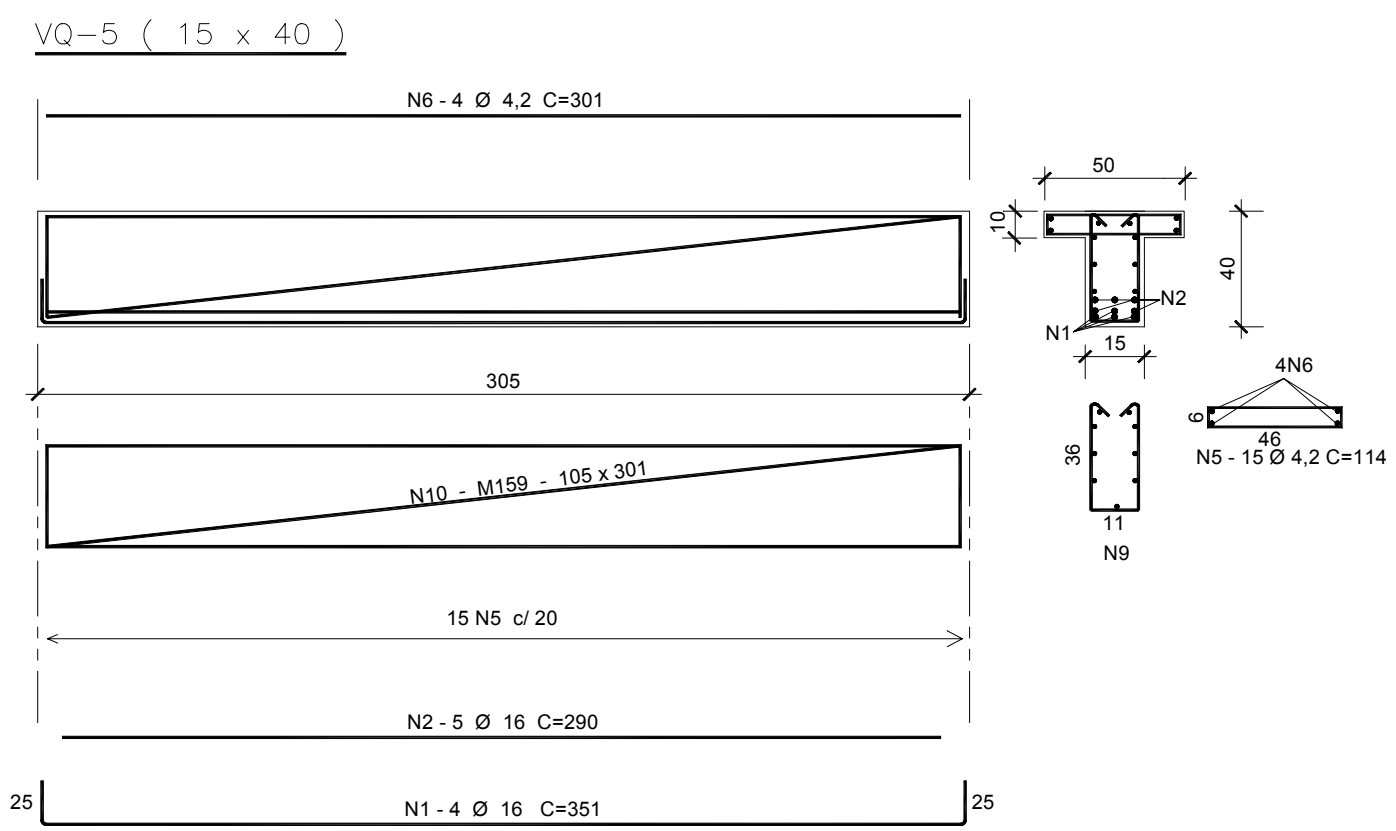

Figura 7.11 - Viga de ensaio VQ-5 da série B. 


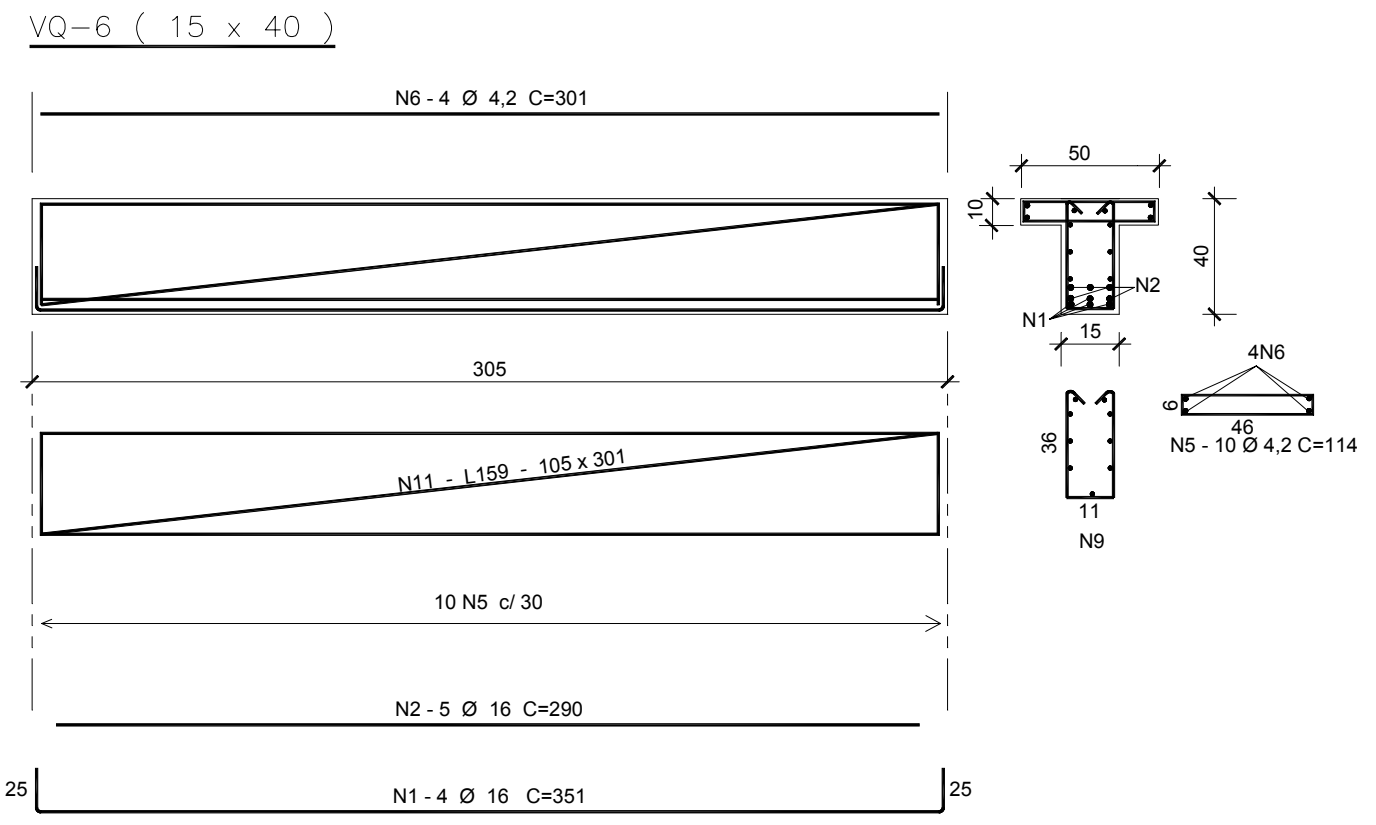

Figura 7.12 - Viga de ensaio VQ-6 da série B. 


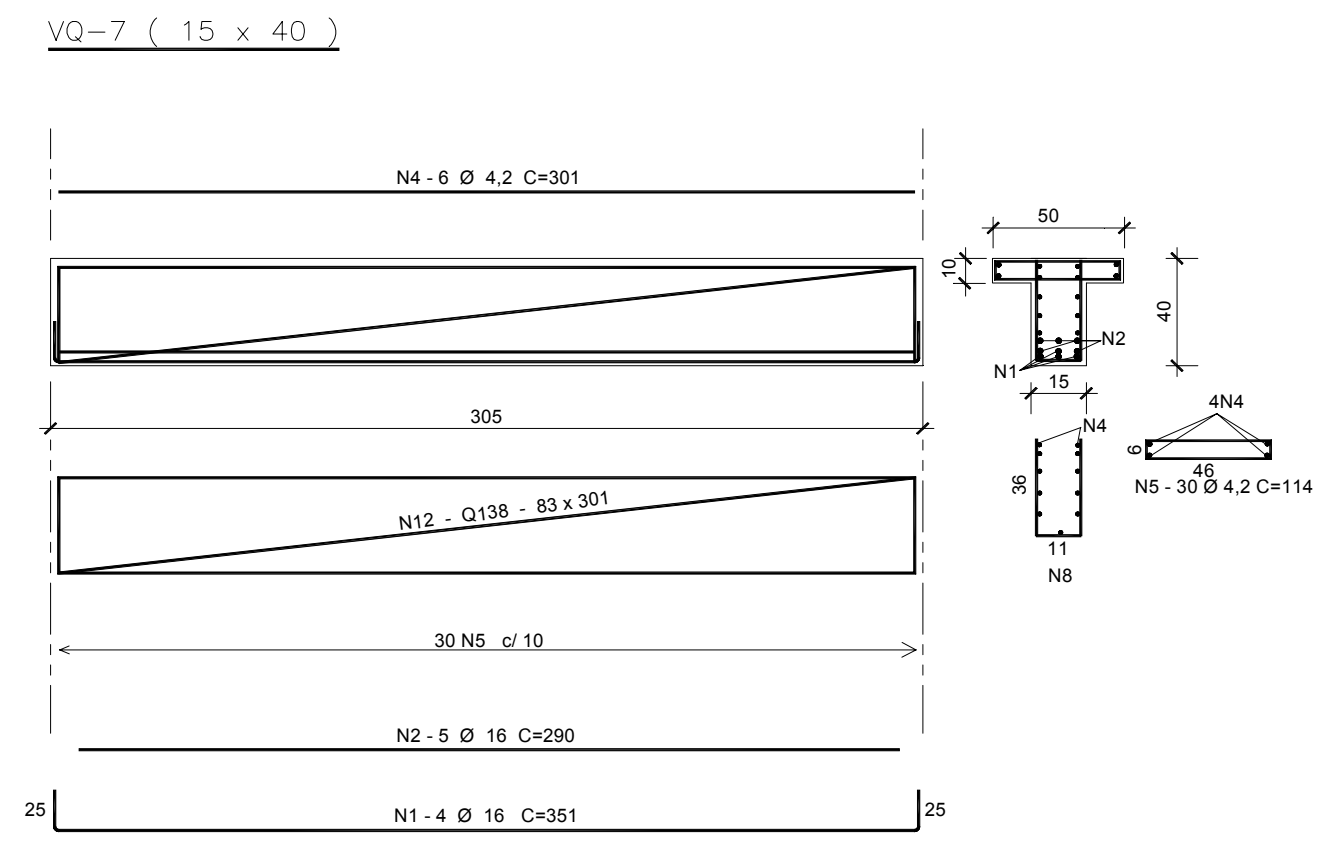

Figura 7.13 - Viga de ensaio VQ-7 da série D.

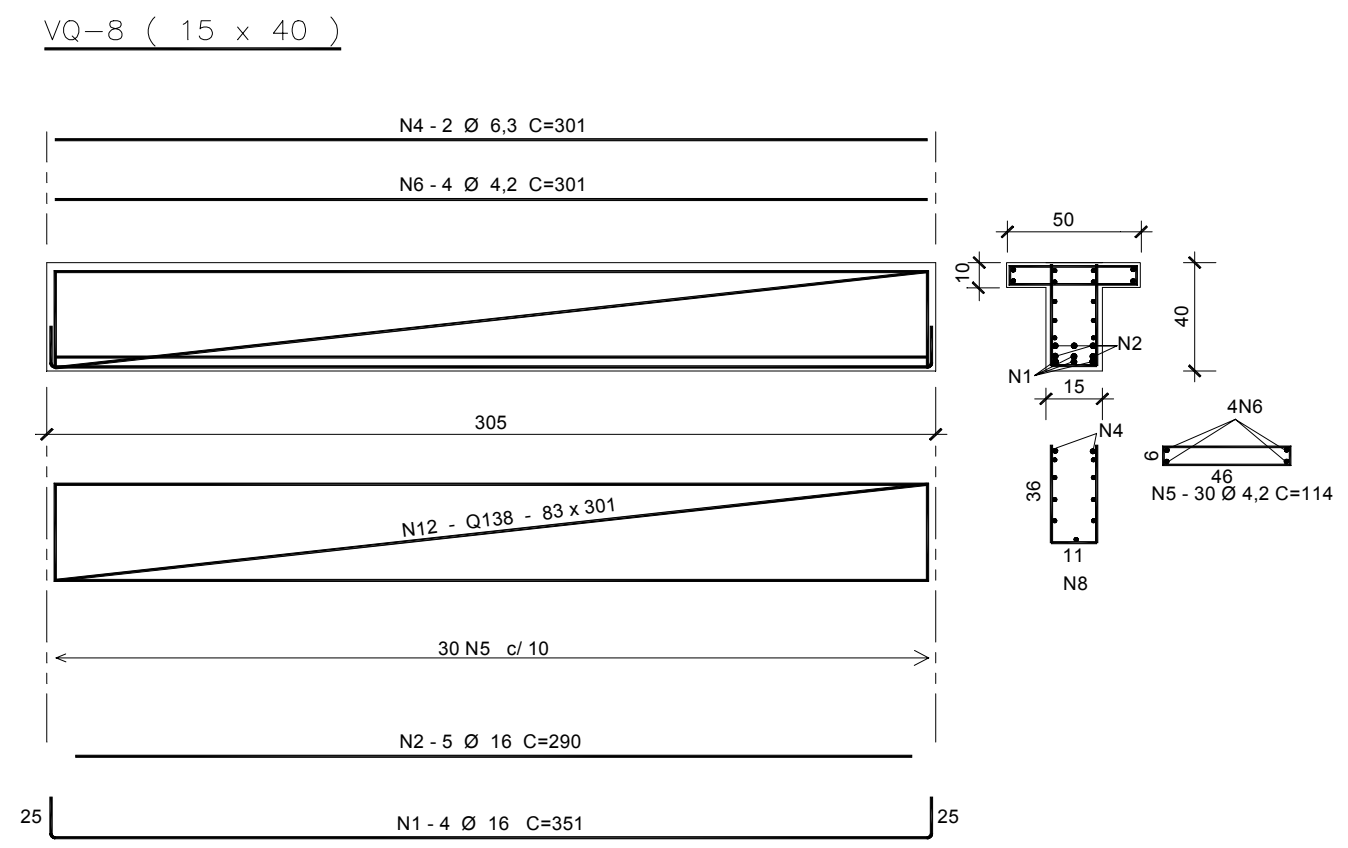

Figura 7.14 - Viga de ensaio VQ-8 da série D. 


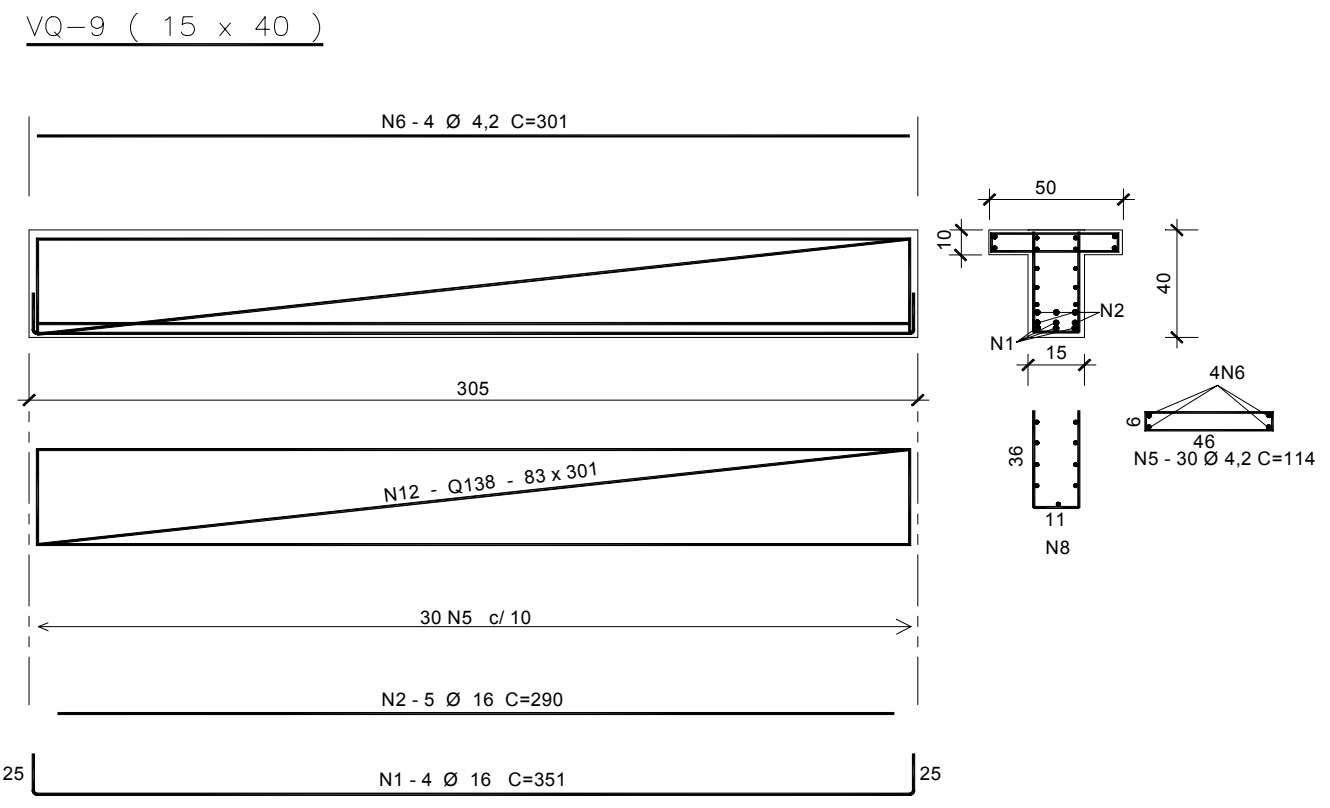

Figura 7.15 - Viga de ensaio VQ-9 da série D.

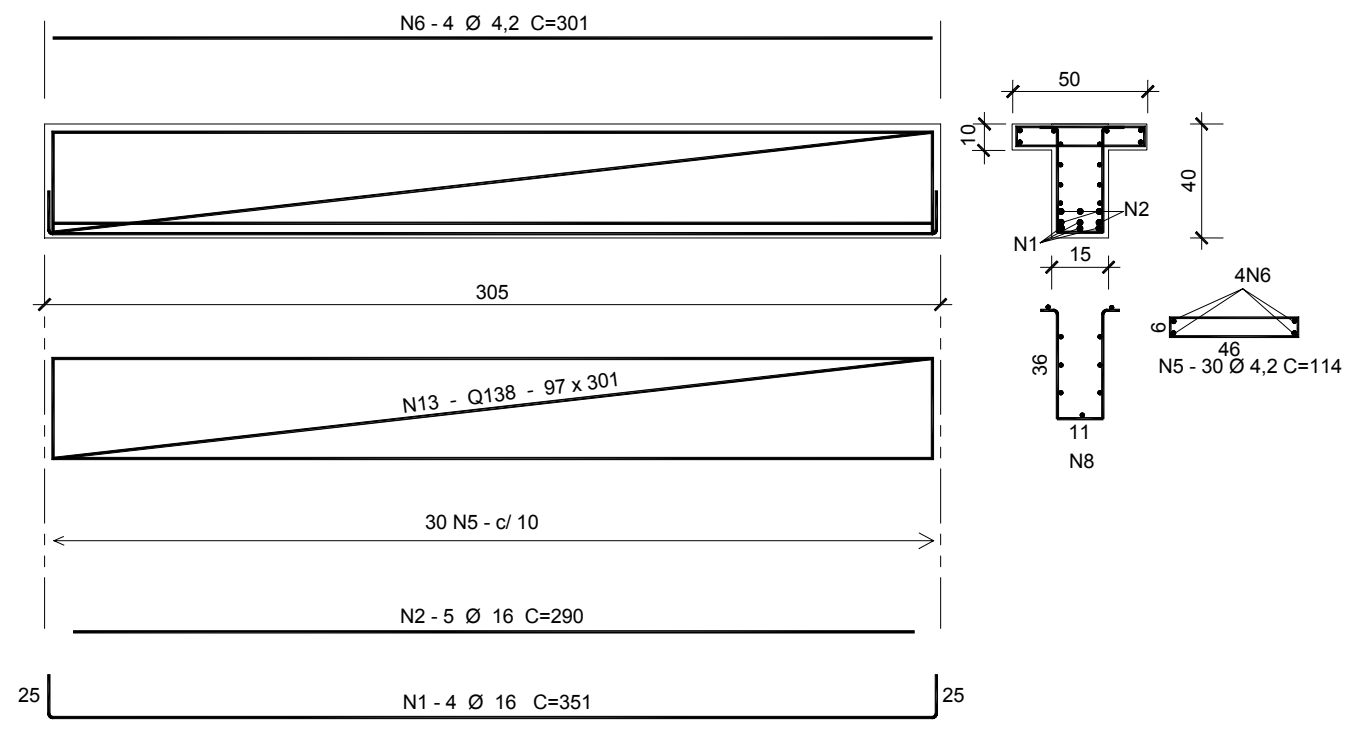

Figura 7.16 - Viga de ensaio VQ-10 da série D. 

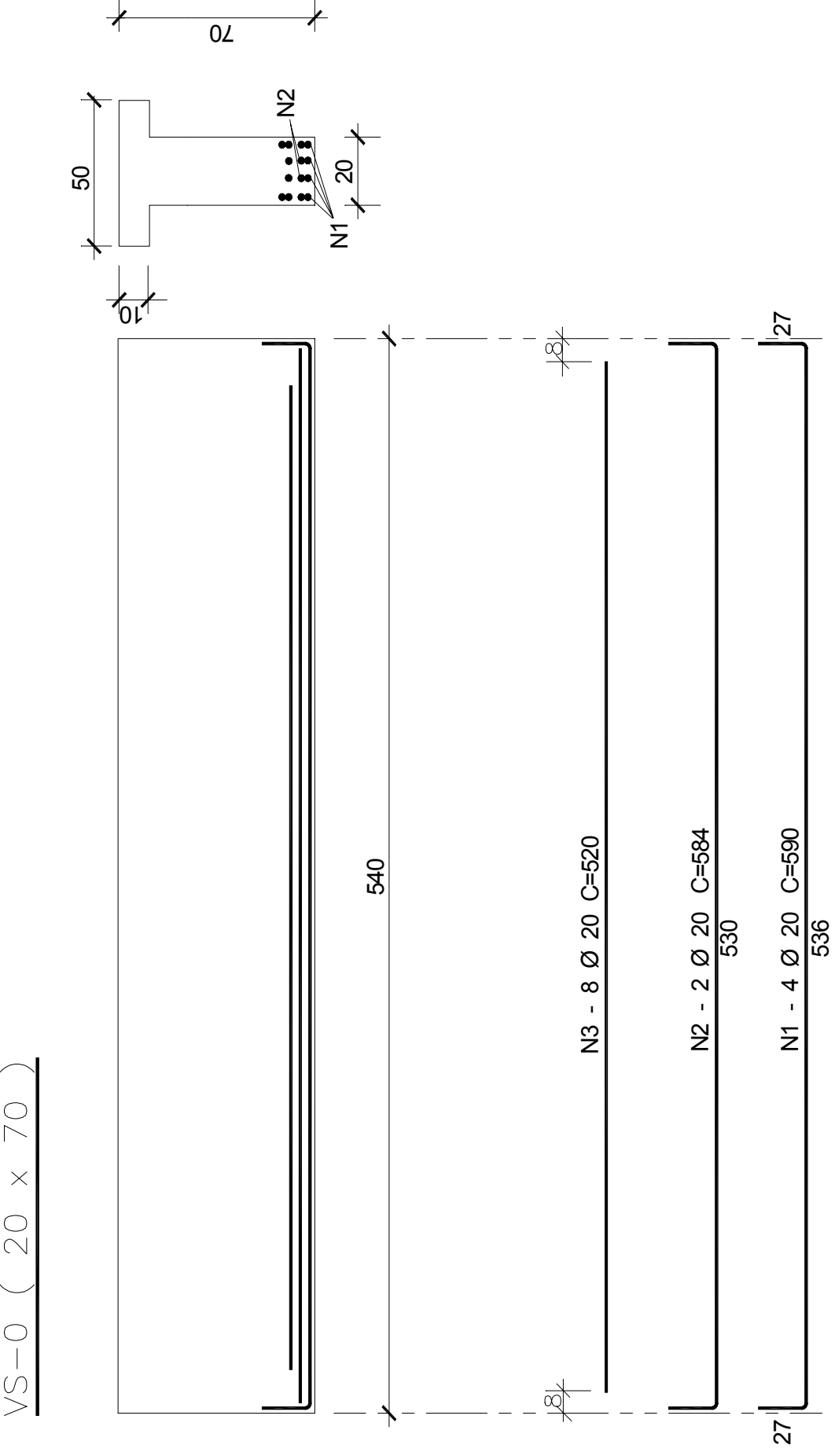

Figura 7.17 - Viga de ensaio VS-0 da série A2. 

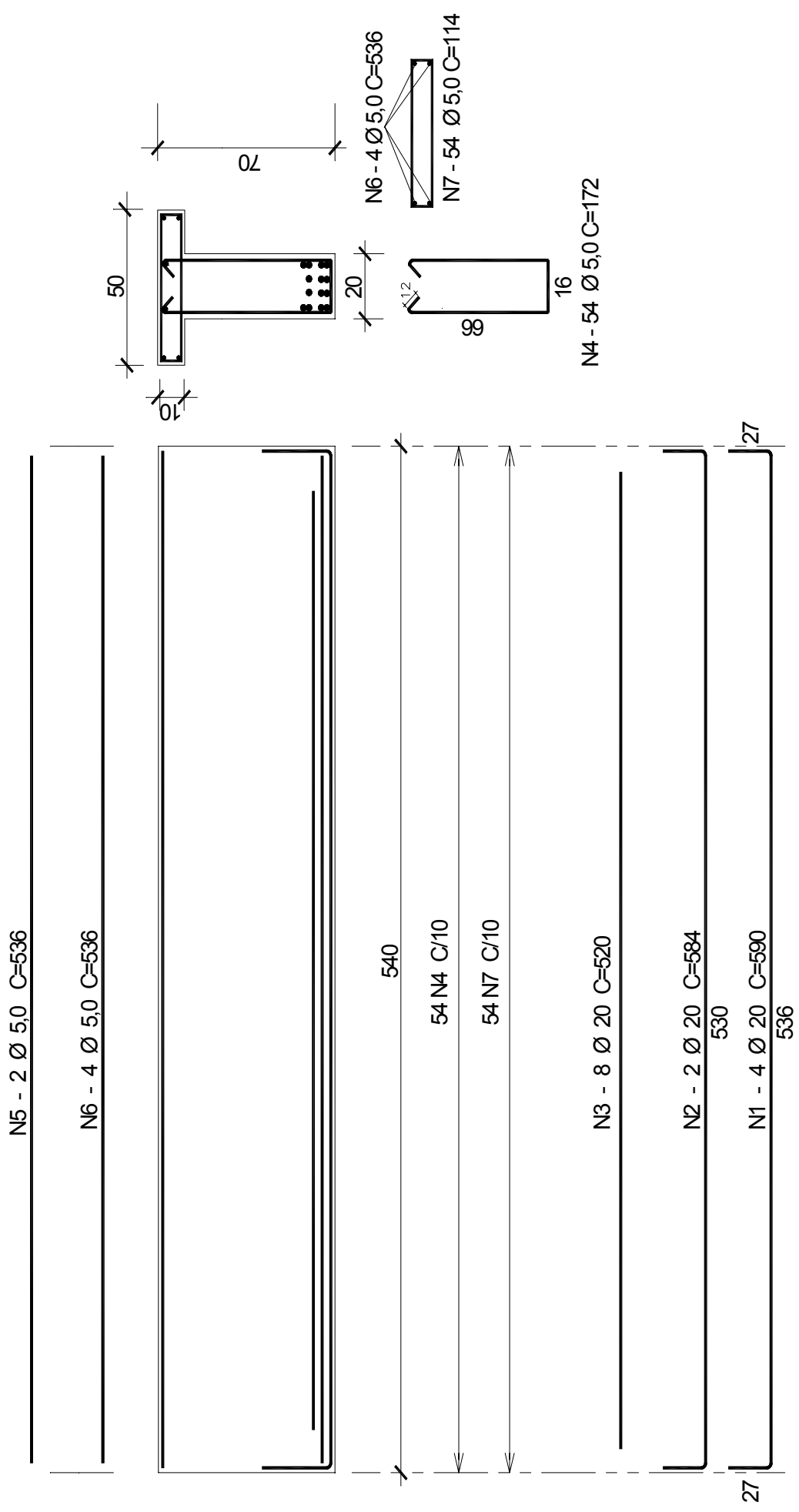

Figura 7.18 - Viga de ensaio VS-1 da série A2. 

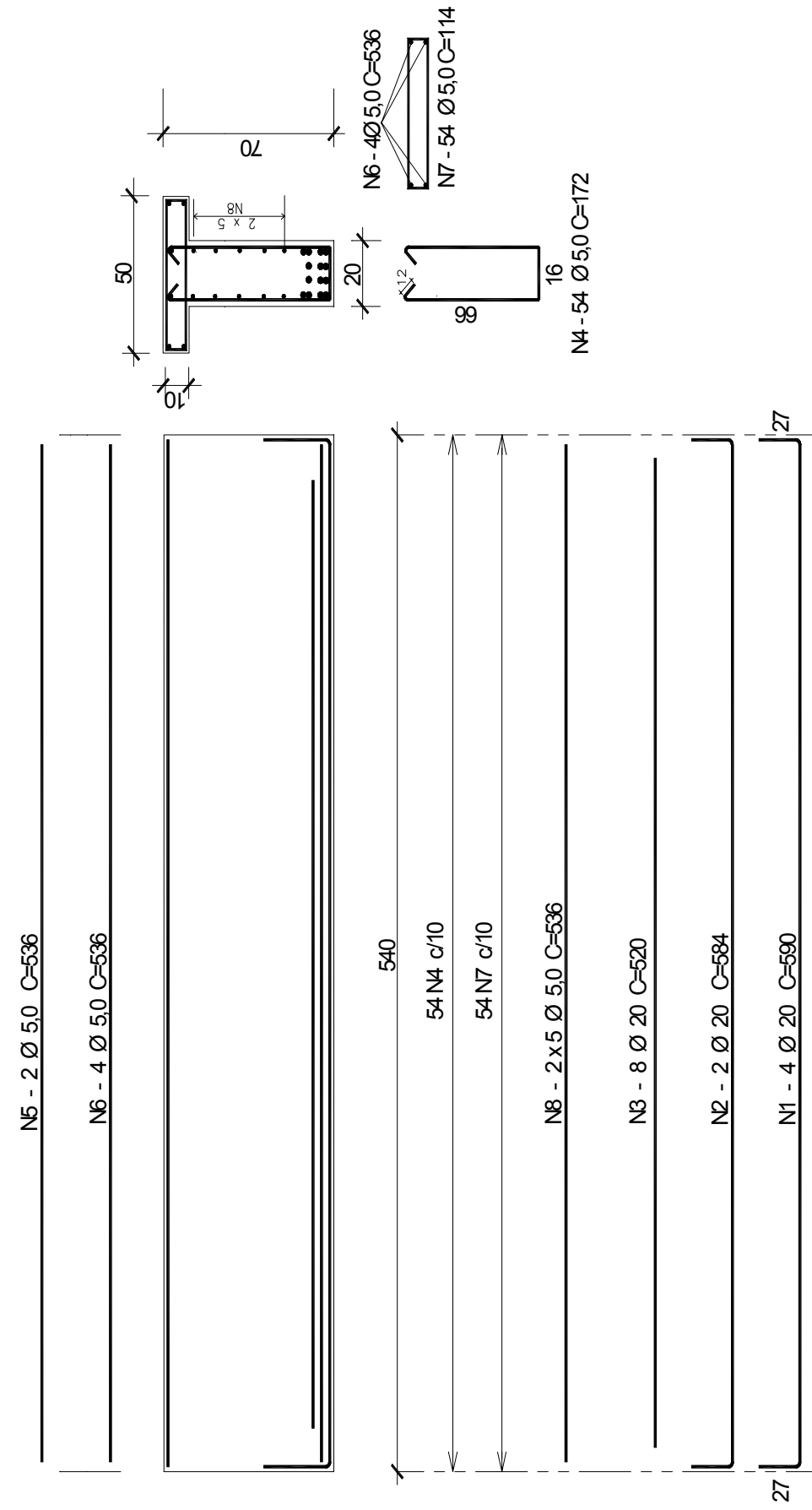

Figura 7.19 - Viga de ensaio VS-2 da série A2. 

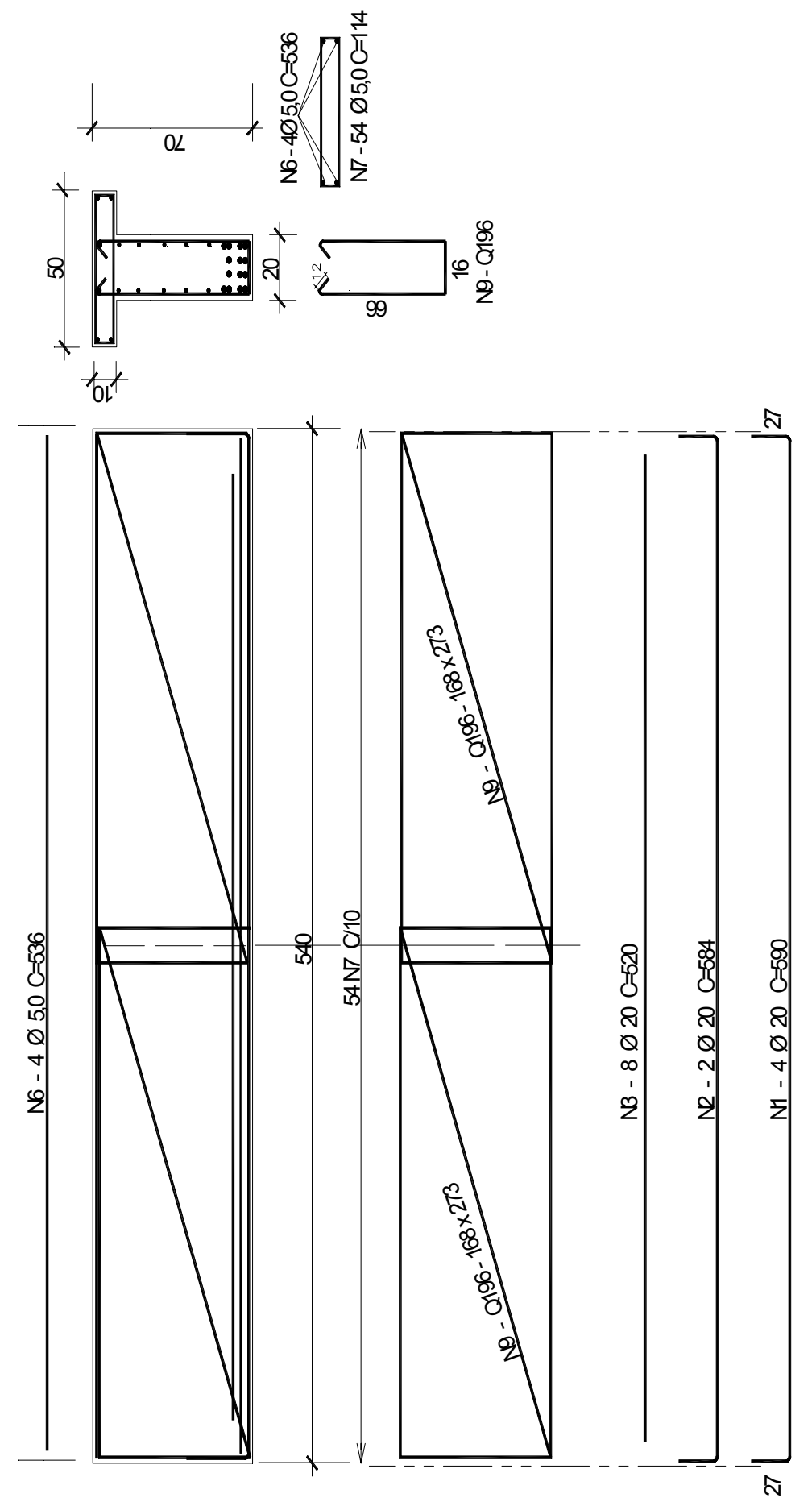

Figura 7.20 - Viga de ensaio VS-3 da série A2. 

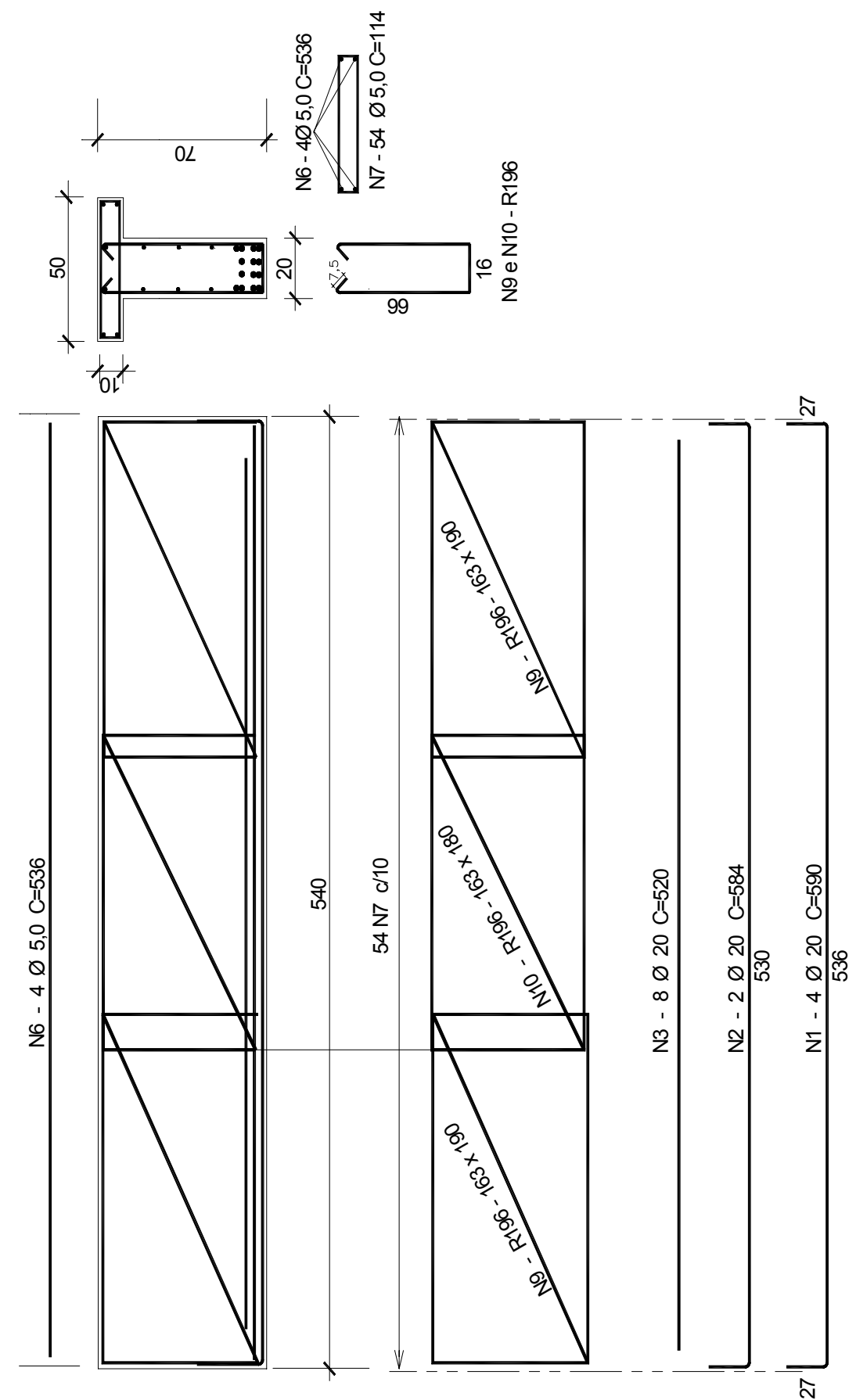

Figura 7.21 - Viga de ensaio VS-4 da série C. 

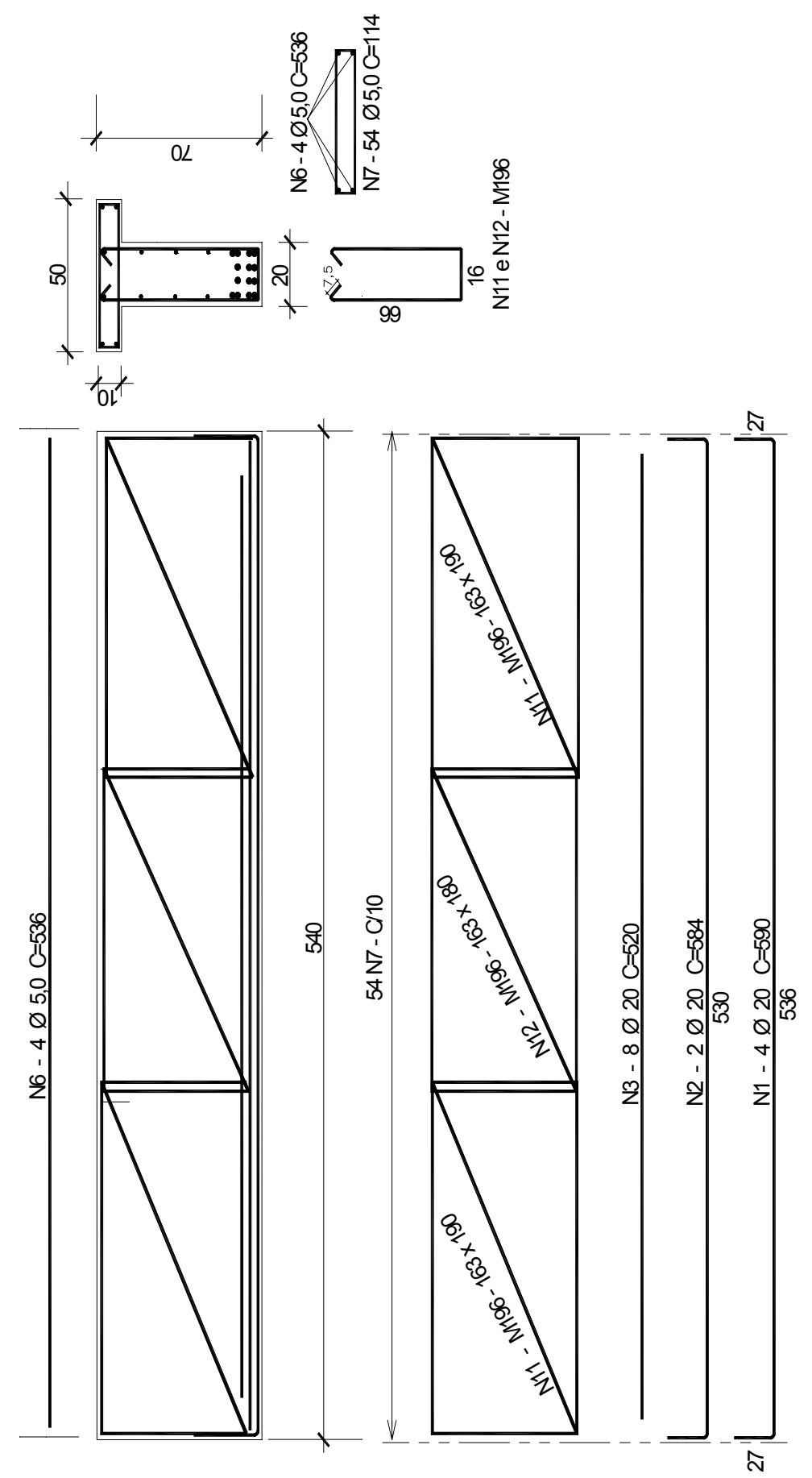

Figura 7.22 - Viga de ensaio VS-5 da série C. 


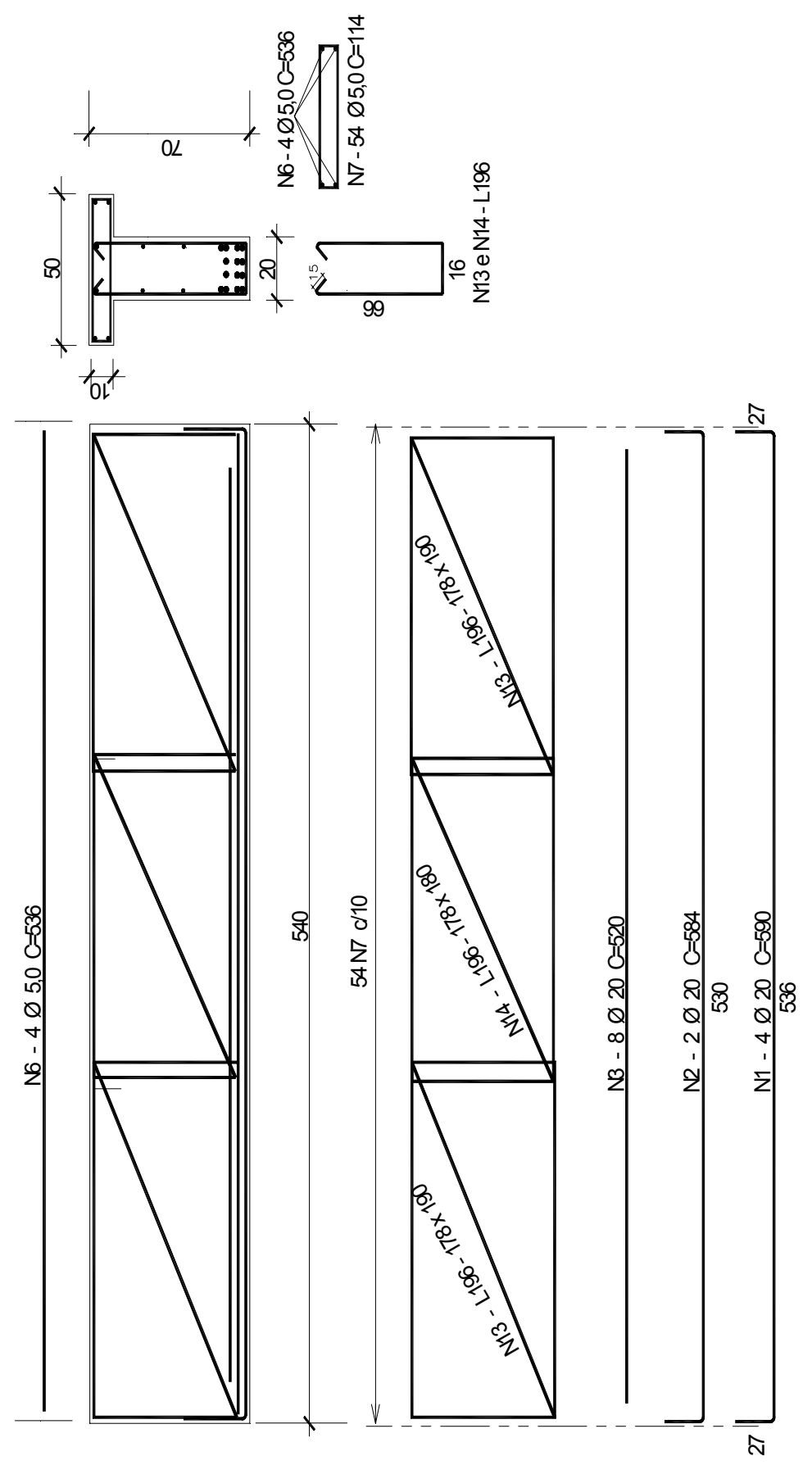

Figura 7.23 - Viga de ensaio VS-6 da série C. 


\section{3 - MATERIAIS UTILIZADOS}

\subsection{1 - FÔRMAS}

As fôrmas foram fabricadas com chapas de madeira compensada e sarrafos de pinho, considerando 04 conjuntos de fôrmas para as vigas VQ e 02 conjuntos para as vigas VS. A utilização de maior quantidade de fôrmas possibilitou a concretagem de 04 vigas VQ ou 02 vigas VS concomitantemente.

Os desenhos dos projetos das fôrmas para as vigas VQ estão nas Figuras 7.24a e $7.24 \mathrm{~b}$ e VS, Figuras $7.25 \mathrm{a}$ e $7.25 \mathrm{~b}$, respectivamente. 
VQ ( $15 \times 40 \times 305)-4$ Conjuntos

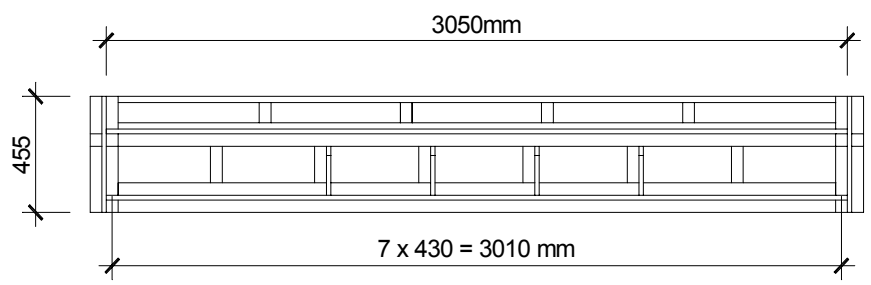

PEÇA LATERAL SUP. / INF. (8x)

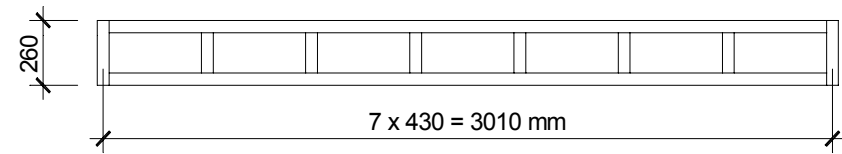

PEÇA DO FUNDO (4x)

$$
\text { 55 }
$$

CONJUNTO DE TRAVAMENTO

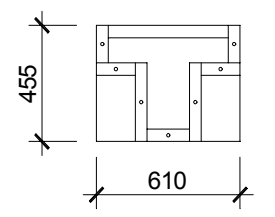

PEÇA EXTREMIDADE (8x)

\section{MATERIAIS}

- madeira compensada $15 \mathrm{~mm}$

- sarrafos $40 \times 40$

- madeira p/ travamento $50 \times 120$

- parafusos $1 / 4 \times 41 / 2 "$

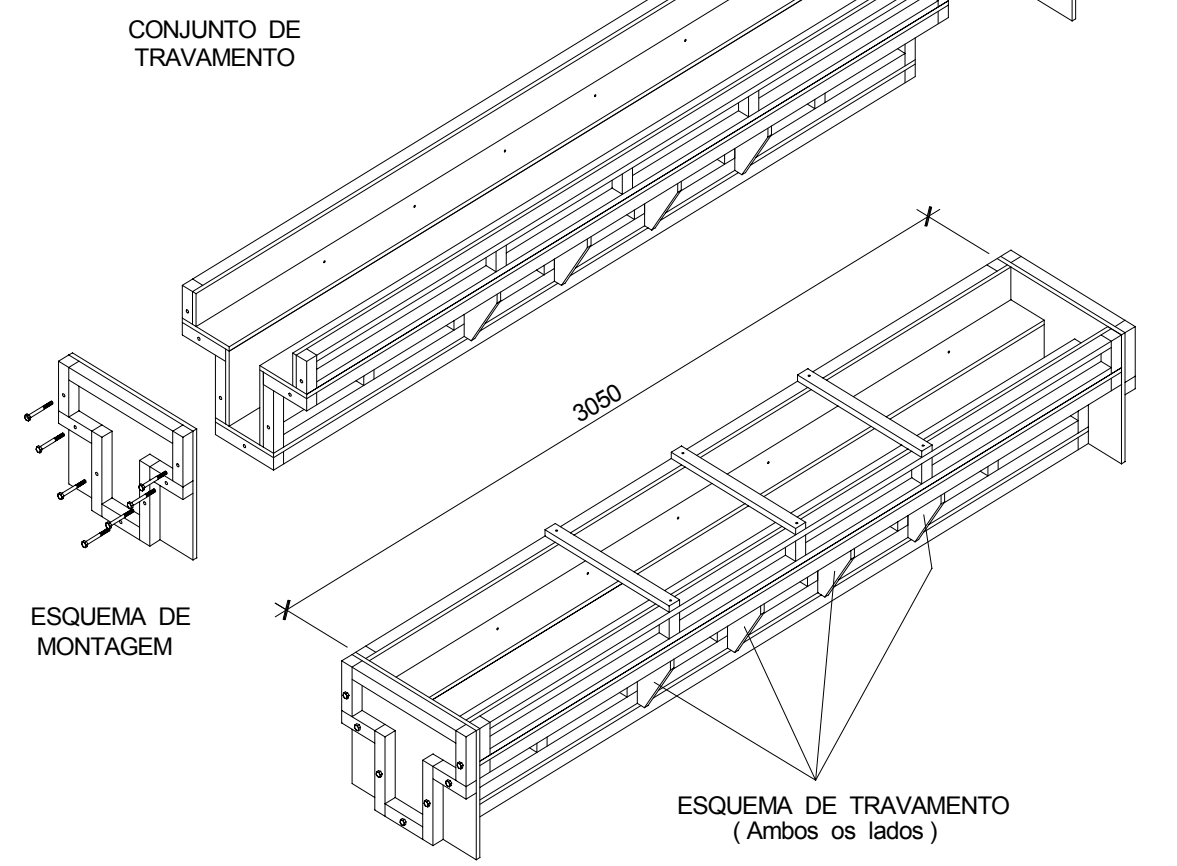

Figura 7.24a - Projeto das fôrmas das vigas VQ. 


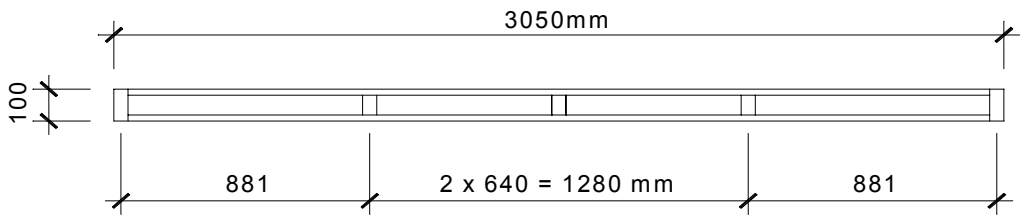

PEÇA LATERAL SUPERIOR $(8 \mathrm{x})$

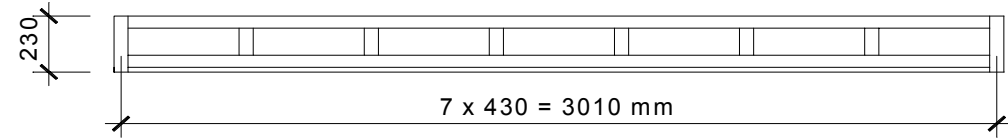

PEÇA LATERAL SUPERIOR $(8 x)$

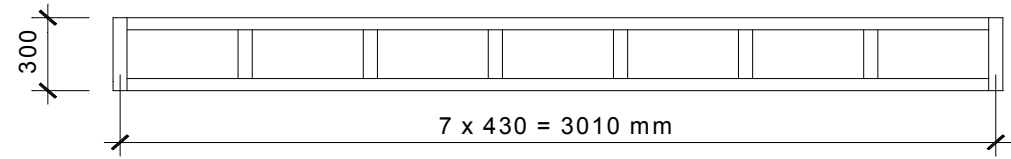

PEÇA LATERAL INFERIOR (8x)

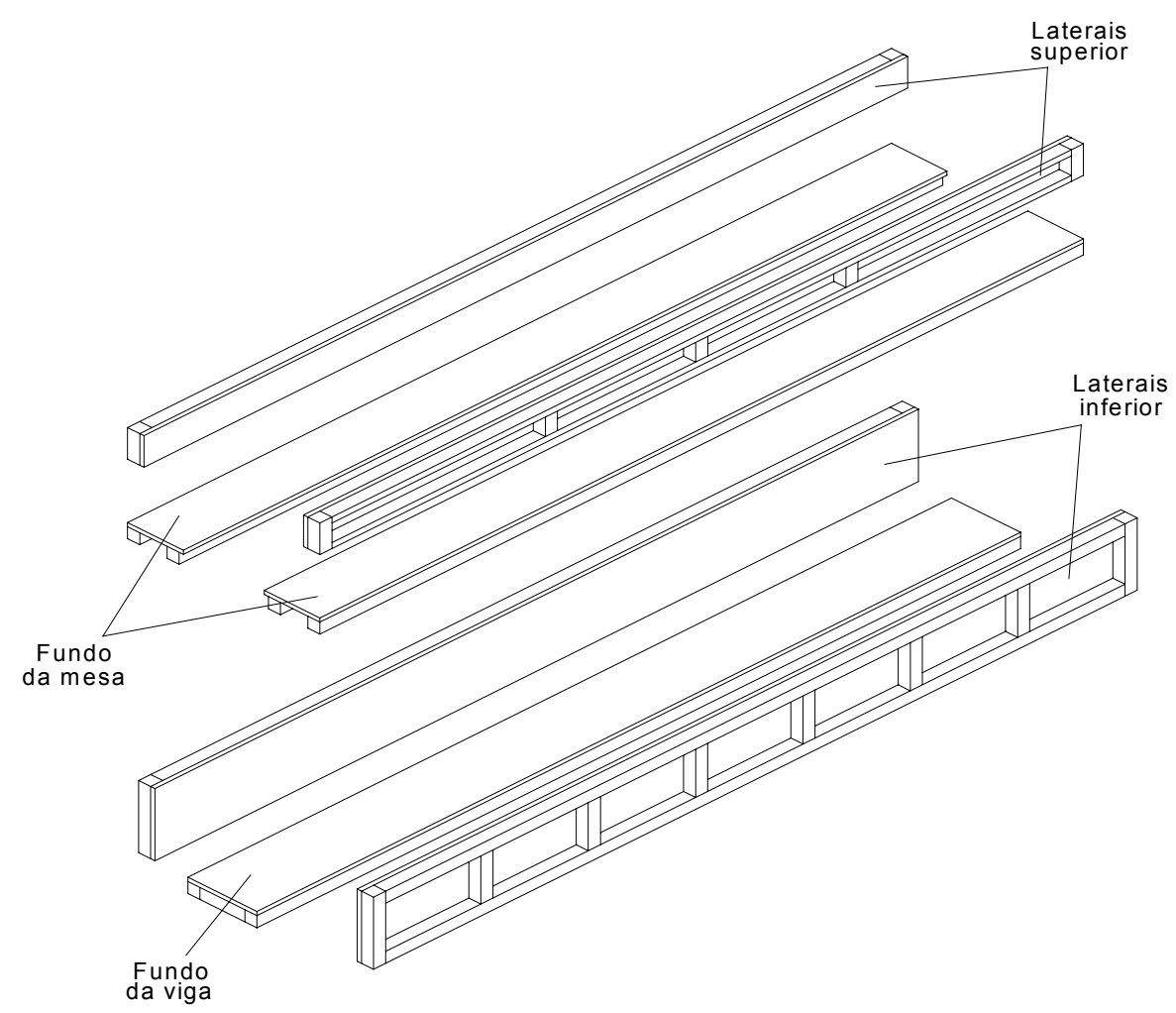

Figura 7.24b - Projeto das fôrmas das vigas VQ (cont.). 


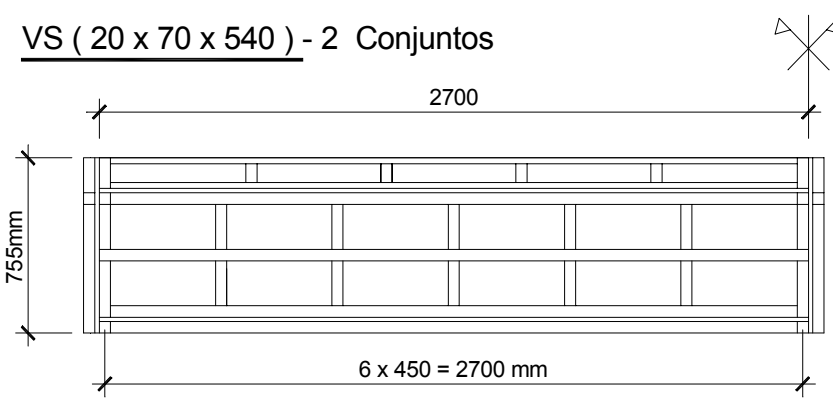

PEÇA LATERAL SUP. / INF. ( $8 \mathrm{x}$ )

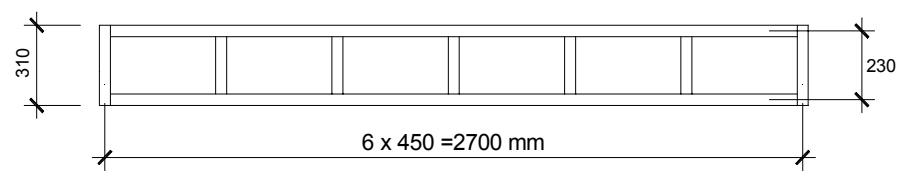

PEÇA DO FUNDO ( $4 \mathrm{x}$ )

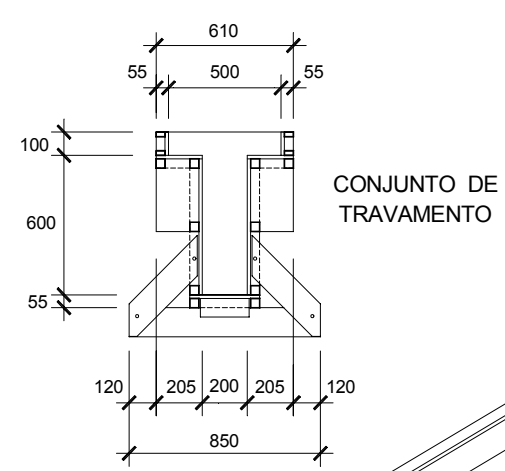

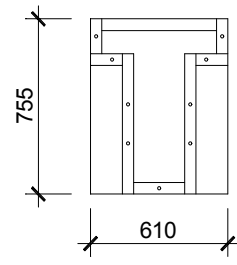

PEÇA EXTREMIDADE ( $2 x)$

MATERIAIS

- madeira compensada $15 \mathrm{~mm}$ - sarrafos $40 \times 40$ - sarrafos $20 \times 40$ madeira $\mathrm{p} /$ travamento $50 \times 120$ - parafusos 5/16 x 41/2"

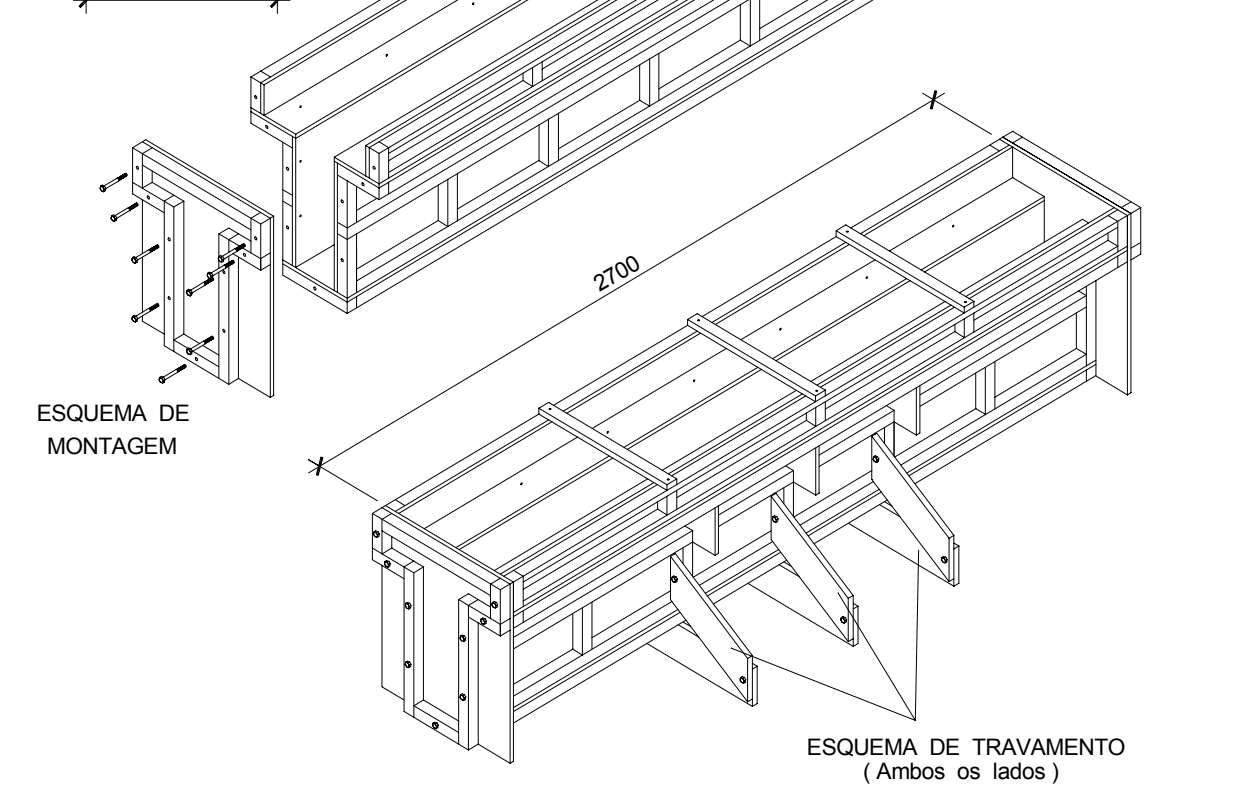

Figura 7.25a - Projeto das fôrmas das vigas VS. 


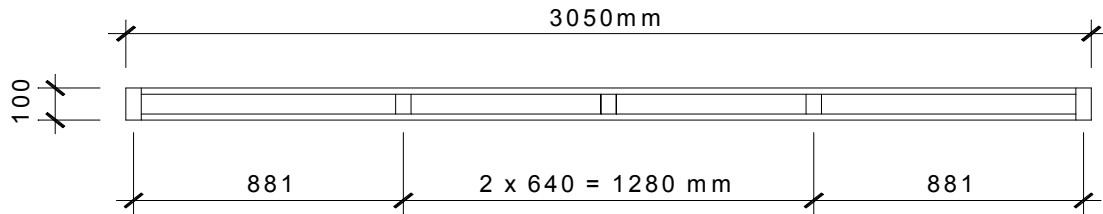

PEÇA LATERAL SUPERIOR (8x)

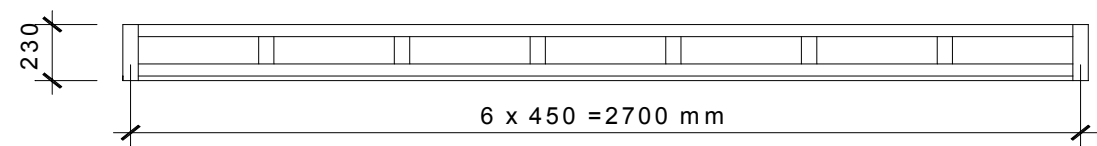

PEÇA LATERAL SUPERIOR (8x)

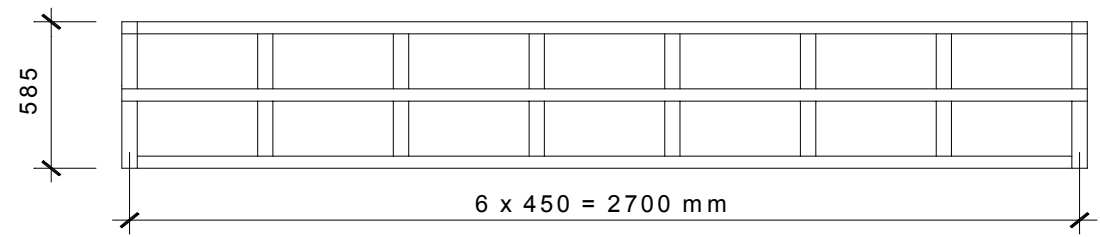

PEÇA LATERAL INFERIOR $(8 \mathrm{x})$

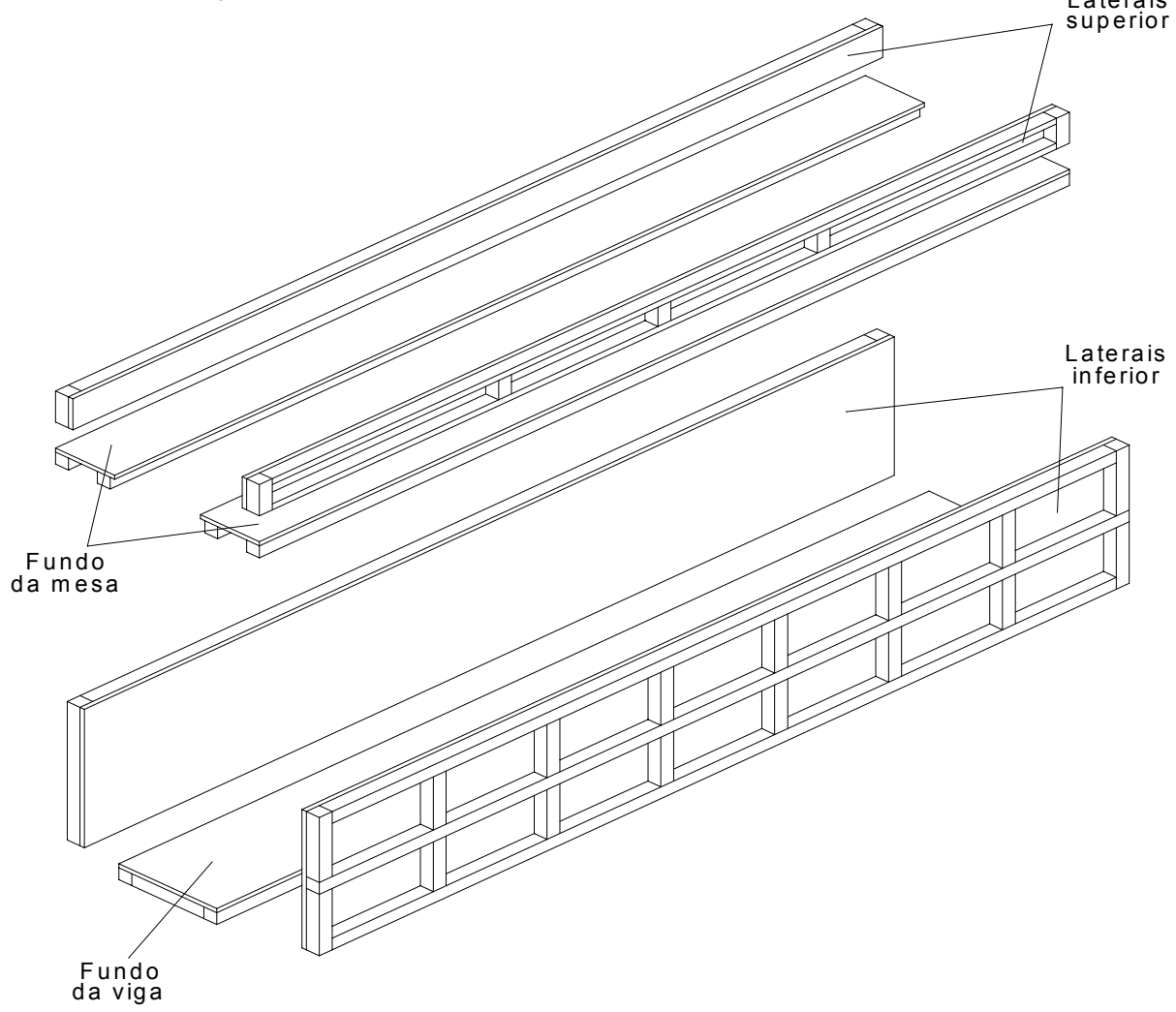

Figura 7.25b - Projeto das fôrmas das vigas VS (cont.). 


\subsection{2 - CONCRETO}

O concreto usinado utilizado na moldagem das vigas foi fornecido por empresa do ramo sediada na cidade de São Carlos - SP. Foi especificado concreto com resistência característica à compressão de $20 \mathrm{MPa}$ aos 28 dias de idade.

A Tabela 7.6 apresenta a composição do concreto fornecida pela empresa.

Tabela 7.6 - Composição por $m^{3}$ de concreto.

\begin{tabular}{|l|c|}
\hline \multicolumn{1}{|c|}{ Materiais } & Quantidade \\
\hline Cimento CP II F -32 & $298 \mathrm{~kg}$ \\
\hline Areia natural lavada & $803 \mathrm{~kg}$ \\
\hline Pedra britada $n^{\circ} 1$ & $1.114 \mathrm{~kg}$ \\
\hline Aditivo plastificante & 0,73 litros \\
\hline Água & 187 litros \\
\hline Relação água / cimento & $\mathbf{0 , 6 3}$ \\
\hline
\end{tabular}

Foram moldados, em todas as séries de vigas, de 12 a 16 corpos-de-prova cilíndricos de dimensões $15 \mathrm{~cm}$ x $30 \mathrm{~cm}$, com o objetivo de controlar as resistências à compressão e à tração do concreto segundo a NBR 5738:1984. A moldagem dos corpos-de-prova foi semelhante à das vigas com o lançamento manual do concreto e adensamento com vibrador de imersão ( $25 \mathrm{~mm}$ e $35 \mathrm{~mm}$ de diâmetro nos corpos-de-prova e vigas, respectivamente). No dia seguinte à concretagem, os mesmos foram desenformados e colocados na câmara úmida, onde foram mantidos até a data dos ensaios.

As resistências à compressão dos corpos-de-prova foram determinadas segundo a NBR 5739:1980 e a resistência à tração por compressão diametral, conforme a NBR 7222:1983. O Anexo A apresenta os resultados dos ensaios de resistências à compressão e à tração do concreto em todos os corpos-de-prova de todas as séries de ensaios. Os corpos-deprova foram ensaiados aos 07 , aos 28 dias e nas datas dos ensaios dos modelos. A princípio, os ensaios seriam executados aos 28 dias de idade. Entretanto, para compatibilização com o cronograma do Laboratório de Estruturas (LE), os ensaios foram efetivamente executados, dependendo da série, entre os 28 e os 48 dias de idade.

Observa-se na Tabela 7.7 que o abatimento do tronco de cone, medido segundo a NBR 7223:1982, variou muito de $40 \mathrm{~mm}$ a $126 \mathrm{~mm}$. 
Na verdade, a resistência do concreto obtida na série A1 foi bem acima da esperada, o que pode ser obervado na Tabela 7.9. Foi especificada à empresa fornecedora uma resistência característica à compressão de $20 \mathrm{MPa}$ aos 28 dias e um "slump" $=8 \pm 2 \mathrm{~cm}$. Como o valor do "slump test" obtido foi de $4 \mathrm{~cm}$ e os ensaios executados em data posterior à prevista, a resistência à compressão média $f_{c j}$ foi de $36,8 \mathrm{MPa}$ na data do ensaio.

$\mathrm{Na}$ concretagem das vigas da série A2 ocorreu o contrário, ou seja, um abatimento do tronco de cone de $126 \mathrm{~mm}$ e resistências aquém das esperadas.

$\mathrm{O}$ engenheiro da empresa fornecedora do concreto afirma que o mesmo traço foi utilizado em todas as séries de vigas. Como as concretagens ocorreram num intervalo de tempo de aproximadamente 12 meses (14/08/01 a 27/06/02), uma explicação plausível seria a variação das propriedades dos materiais componentes do concreto.

Tabela 7.7 -Datas de concretagem e abatimento do tronco de cone das séries de ensaios.

\begin{tabular}{|c|c|c|c|}
\hline Série & Vigas & $\begin{array}{c}\text { Data da } \\
\text { concretagem }\end{array}$ & $\begin{array}{l}\text { Abatimento do } \\
\text { tronco de cone } \\
(\mathrm{mm})\end{array}$ \\
\hline \multirow{4}{*}{ A1 } & VQ-0 & \multirow{4}{*}{$14 / 08 / 01$} & \multirow{4}{*}{40} \\
\hline & VQ-1 & & \\
\hline & VQ-2 & & \\
\hline & VQ-3 & & \\
\hline \multirow{4}{*}{ B } & VQ-4 & \multirow{4}{*}{$25 / 02 / 02$} & \multirow{4}{*}{40} \\
\hline & VQ-5 & & \\
\hline & VQ-6 & & \\
\hline & VQ-1A & & \\
\hline \multirow{4}{*}{$\mathrm{D}$} & VQ-7 & \multirow{4}{*}{$18 / 03 / 02$} & \multirow{4}{*}{69} \\
\hline & VQ-8 & & \\
\hline & VQ-9 & & \\
\hline & VQ-10 & & \\
\hline \multirow{4}{*}{$\mathrm{A} 2$} & VS-0 & \multirow{2}{*}{$11 / 04 / 02$} & \multirow[t]{2}{*}{126} \\
\hline & VS-2 & & \\
\hline & VS-1 & \multirow[t]{2}{*}{$08 / 05 / 02$} & \multirow[t]{2}{*}{119} \\
\hline & VS-3 & & \\
\hline \multirow{3}{*}{$\mathrm{C}$} & VS-4 & \multirow[t]{2}{*}{$05 / 06 / 02$} & \multirow[t]{2}{*}{52} \\
\hline & VS-5 & & \\
\hline & VS-6 & $27 / 06 / 02$ & 58 \\
\hline
\end{tabular}


Tabela 7.8 -Valores médios de resistência à compressão e à tração aos 28 dias de idade e nas datas dos ensaios.

\begin{tabular}{|c|c|c|c|c|c|}
\hline \multirow[t]{3}{*}{ Série } & \multirow[t]{2}{*}{ Idade } & \multicolumn{2}{|c|}{ Resistência à compressão } & \multicolumn{2}{|c|}{$\begin{array}{c}\text { Resistência à tração } \\
\text { indireta }\left(\mathbf{f}_{\mathrm{ct}, \mathrm{sp}}\right)\end{array}$} \\
\hline & & corpos-de-prova & média & corpos-de-prova & média \\
\hline & (dias) & \multicolumn{2}{|l|}{ (MPa) } & \multicolumn{2}{|l|}{ (MPa) } \\
\hline \multirow{8}{*}{ A1 } & \multirow{4}{*}{28} & 31,9 & \multirow{4}{*}{34,3} & 2,15 & \multirow[t]{3}{*}{2,10} \\
\hline & & 36,1 & & 2,05 & \\
\hline & & 36,4 & & & \\
\hline & & 32,9 & & & \\
\hline & \multirow{4}{*}{$45 / 48$} & 38,0 & \multirow{4}{*}{36,8} & 2,50 & \multirow[t]{2}{*}{2,70} \\
\hline & & 35,7 & & 2,85 & \\
\hline & & 36,4 & & & \\
\hline & & 37,1 & & & \\
\hline \multirow{8}{*}{ B } & \multirow{4}{*}{28} & 27,4 & \multirow{4}{*}{26,1} & 2,30 & \multirow[t]{2}{*}{2,35} \\
\hline & & 25,7 & & 2,40 & \\
\hline & & 26,0 & & & \\
\hline & & 25,1 & & & \\
\hline & \multirow{2}{*}{30} & 27,3 & \multirow{2}{*}{26,7} & --- & \multirow{2}{*}{---} \\
\hline & & 26,1 & & --- & \\
\hline & \multirow[t]{2}{*}{37} & 27,6 & \multirow[t]{2}{*}{27,1} & --- & \multirow[t]{2}{*}{---} \\
\hline & & 26,5 & & --- & \\
\hline \multirow{4}{*}{$\mathrm{D}$} & 28 & 25,5 & 26,4 & 2,20 & 2,25 \\
\hline & & 27,3 & & 2,30 & \\
\hline & $30 / 31$ & 29,2 & 28,2 & 2,45 & 2,50 \\
\hline & & 27,2 & & 2,55 & \\
\hline & $28 / 32$ & 18,6 & 18,6 & --- & --- \\
\hline A2 - 1 & & 18,6 & & --- & \\
\hline & & 18,5 & & 1,80 & \\
\hline & 35 & 18,3 & 18,5 & 1,80 & 1,75 \\
\hline & & 18,6 & & 1,65 & \\
\hline & 28 & 16,8 & 18,6 & --- & --- \\
\hline & & 20,3 & & --- & \\
\hline A2 - 2 & & 20,9 & & 1,75 & \\
\hline & 41 & 18,7 & 19,2 & 1,90 & 1,80 \\
\hline & & 17,7 & & 1,70 & \\
\hline & & 19,5 & & & \\
\hline & & 27,1 & & 2,50 & 2,35 \\
\hline$C-1$ & 28 & 26,6 & 26,2 & 2,15 & \\
\hline & & 26,1 & & & \\
\hline & & 24,9 & & & \\
\hline & & 20,4 & & 1,80 & \\
\hline$C-2$ & 28 & 22,1 & 22,1 & 2,05 & 2,00 \\
\hline & & 23,2 & & 2,20 & \\
\hline & & 22,6 & & 1,90 & \\
\hline
\end{tabular}


Tabela 7.9 -Valores de resistência à compressão e à tração do concreto das vigas.

\begin{tabular}{|c|c|c|c|c|c|}
\hline \multirow[t]{2}{*}{ Série } & \multirow[t]{2}{*}{ Vigas } & $\begin{array}{c}\text { Resistência à } \\
\text { compressão } \\
\text { média dos } \\
\text { corpos-de-prova }\end{array}$ & $\begin{array}{c}\text { Resistência à } \\
\text { compressão do } \\
\text { concreto } \\
\text { das vigas } \\
\end{array}$ & $\begin{array}{l}\text { Resistência à } \\
\text { tração indireta } \\
\qquad\left(\mathbf{f}_{\mathrm{ct}, \mathrm{sp}}\right)\end{array}$ & $\begin{array}{c}\text { Resistência } \\
\text { à tração } \\
\left(\mathbf{f}_{\mathrm{ct}}\right)\end{array}$ \\
\hline & & $(\mathrm{MPa})$ & (MPa) & (MPa) & (MPa) \\
\hline \multirow{4}{*}{$\mathrm{A} 1$} & VQ-0 & 36,8 & 36,8 & 2,70 & 2,45 \\
\hline & VQ-1 & 36,8 & 36,8 & 2,70 & 2,45 \\
\hline & VQ-2 & 36,8 & 36,8 & 2,70 & 2,45 \\
\hline & VQ-3 & 36,8 & 36,8 & 2,70 & 2,45 \\
\hline \multirow{4}{*}{ B } & VQ-4 & 26,7 & 25,4 & 2,35 & 2,10 \\
\hline & VQ-5 & 26,7 & 25,4 & 2,35 & 2,10 \\
\hline & VQ-6 & 27,1 & 25,8 & 2,35 & 2,10 \\
\hline & VQ-1A & 27,1 & 25,8 & 2,35 & 2,10 \\
\hline \multirow{4}{*}{$\mathrm{D}$} & VQ-7 & 26,4 & 25,1 & 2,25 & 2,05 \\
\hline & VQ-8 & 26,4 & 25,1 & 2,25 & 2,05 \\
\hline & VQ-9 & 28,2 & 26,8 & 2,50 & 2,25 \\
\hline & VQ-10 & 28,2 & 26,8 & 2,50 & 2,25 \\
\hline \multirow{4}{*}{$\mathrm{A} 2$} & VS-0 & 18,5 & 17,6 & 1,75 & 1,60 \\
\hline & VS-2 & 18,5 & 17,6 & 1,75 & 1,60 \\
\hline & VS-1 & 19,2 & 18,8 & 1,80 & 1,60 \\
\hline & VS-3 & 19,2 & 18,8 & 1,80 & 1,60 \\
\hline \multirow{3}{*}{$\mathrm{C}$} & VS-4 & 26,2 & 24,9 & 2,35 & 2,10 \\
\hline & VS-5 & 26,2 & 24,9 & 2,35 & 2,10 \\
\hline & VS-6 & 22,1 & 21,0 & 2,00 & 1,80 \\
\hline
\end{tabular}

Obs.:

1 - As resistências à compressão do concreto das vigas foram obtidas pela multiplicação da resistência à compressão média dos corpos-de-prova pelo coeficiente $\mathrm{k}_{\mathrm{mod}}=0,95$, exceto para as vigas da série $\mathrm{A} 1\left(k_{\mathrm{mod}}=1,05 \times 0,95 \cong 1,00\right)$ e $\mathrm{A} 2-2\left(k_{\text {mod }}=1,03 \times 0,95 \cong 0,98\right)$; $2-f_{c t}=0,90 f_{c t, s p}$.

\subsection{3 - ARMADURAS}

\subsubsection{1 - Barras de aço}

As barras de aço utilizadas como armaduras das vigas, especificadas pela NBR 7480: 1996, foram doadas pela Siderúrgica GERDAU e ensaiadas à tração na máquina INSTRON. Os fios de diâmetros nominais 4,2 $\mathrm{mm}$ e 5,0 $\mathrm{mm}$ foram instrumentados com extensômetro marca INSTRON, para medição das deformações das barras, com comprimento inicial de 50mm. A Tabela 7.10 apresenta as características dos aços utilizados nas armaduras das 
vigas, obtidas segundo a NBR 6152:1992. O diâmetro efetivo foi obtido a partir da massa de um comprimento conhecido adotando-se o valor de $7850 \mathrm{~kg} / \mathrm{m}^{3}$ para a massa específica.

Os fios de aço utilizados (diâmetros nominais de 4,2 $\mathrm{mm}$ e 5,0 $\mathrm{mm}$ ) são fios lisos de aço CA-60 (coeficiente de aderência $\eta_{\mathrm{b}}=1,0$ ).

Tabela 7.10 - Características das barras de aço.

\begin{tabular}{|c|c|c|c|c|c|}
\hline \multicolumn{2}{|c|}{ Diâmetro (mm) } & $\mathbf{f}_{\mathbf{y}}$ & $\boldsymbol{\varepsilon}_{\mathbf{y}}$ & $\mathbf{f}_{\mathbf{r}}$ & $\mathbf{E}_{\mathbf{s}}$ \\
\hline Nominal & Efetivo & $\mathbf{( M P a )}$ & $(\mathbf{m m} / \mathbf{m})$ & $(\mathbf{M P a})$ & $\mathbf{( M P a )}$ \\
\hline 4,2 & 4,19 & 751,96 & 5,61 & 818,83 & 208.310 \\
\hline 5,0 & 4,96 & 702,90 & 5,46 & 760,53 & 203.250 \\
\hline 16,0 & 16,07 & 582,45 & 2,83 & 712,05 & 205.950 \\
\hline 20,0 & 19,98 & 617,25 & 3,00 & 731,05 & 205.600 \\
\hline
\end{tabular}

\subsubsection{2 - Telas soldadas}

Nas vigas utilizaram-se telas soldadas (também doadas pela Siderúrgica GERDAU) e ensaiadas à tração no Laboratório de Madeiras e Estruturas de Madeiras (LAMEM) do Departamento de Engenharia de Estruturas - EESC/USP. Utilizou-se a máquina universal de ensaios DARTEC, servo-controlada, com capacidade de $100 \mathrm{kN}$, conectada a um computador que, por meio de software específico, gerenciava as operações do atuador e registrava automaticamente os valores de forças, deslocamentos e deformações. As medidas de deformações foram feitas em um comprimento de $25 \mathrm{~mm}$ na região central do corpo-deprova, com extensômetro elétrico do tipo "clip-gage" marca DARTEC, modelo EXA-50S. A Tabela 7.11 apresenta as características das telas soldadas utilizadas. As telas soldadas foram fabricadas com fios nervurados de aço CA-60 (coeficiente de aderência $\eta_{b}=1,5$ ).

Tabela 7.11 - Especificações e características das telas soldadas.

\begin{tabular}{|c|c|c|c|c|c|c|}
\hline \multicolumn{4}{|c|}{ Tela soldada } & $\mathbf{f}_{\mathbf{y}}$ & $\varepsilon_{\mathbf{y}}$ & $\mathbf{f}_{\mathbf{r}}$ \\
\hline Especificação & $\begin{array}{c}\text { Diâmetro } \\
(\mathbf{m m})\end{array}$ & $\begin{array}{c}\text { Espaçamento } \\
\text { long. (cm) }\end{array}$ & $\begin{array}{c}\text { Espaçamento } \\
\text { transv. (cm) }\end{array}$ & $\mathbf{( M P a )}$ & $\mathbf{( m m / \mathbf { m } )}$ & $\mathbf{( M P a )}$ \\
\hline Q138 & 4,2 & 10 & 10 & 744,00 & 5,63 & 796,50 \\
\hline R159 & 4,5 & 10 & 15 & 725,00 & 5,54 & 801,00 \\
\hline M159 & 4,5 & 10 & 20 & 669,50 & 5,27 & 725,50 \\
\hline L159 & 4,5 & 10 & 30 & 735,50 & 5,59 & 788,50 \\
\hline Q196 & 5,0 & 10 & 10 & 724,50 & 5,53 & 815,50 \\
\hline R196 & 5,0 & 10 & 15 & 746,50 & 5,64 & 829,00 \\
\hline M196 & 5,0 & 10 & 20 & 648,50 & 5,16 & 719,00 \\
\hline L196 & 5,0 & 10 & 30 & 680,00 & 5,32 & 752,00 \\
\hline
\end{tabular}




\section{4 - EQUIPAMENTOS}

Os pórticos de reação foram montados sobre a laje de reação do Laboratório de Estruturas (LE) do Departamento de Engenharia de Estruturas - EESC/USP, uma montagem para as vigas VQ e outra para as vigas VS. Em todos os ensaios, as vigas foram posicionadas no pórtico de reação com a mesa comprimida voltada para baixo, utilizando-se como apoios provisórios blocos de concreto. Os modelos foram apoiados em duas placas de neoprene e dois perfis metálicos de $200 \mathrm{~mm}$ de largura, que durante os ensaios transmitiam as forças aos pórticos que ficavam com suas barras tracionadas. Essas forças de tração eram absorvidas pela laje de reação na qual os tirantes foram parafusados.

$\mathrm{Na}$ montagem para as vigas $\mathrm{VQ}$, para distribuição das forças aplicadas foram utilizados dois perfis de seção I com dimensões $500 \mathrm{~mm}$ x $74 \mathrm{~mm}$. Os dois macacos hidráulicos foram posicionados diretamente sobre a laje de reação, ligados a duas células de carga e também ligados a uma bomba hidráulica elétrica marca ENERPAC, modelo 2038, com capacidade nominal de $70 \mathrm{MPa}$.

As Figuras 7.26 e 7.27 mostram a montagem para as vigas VQ.

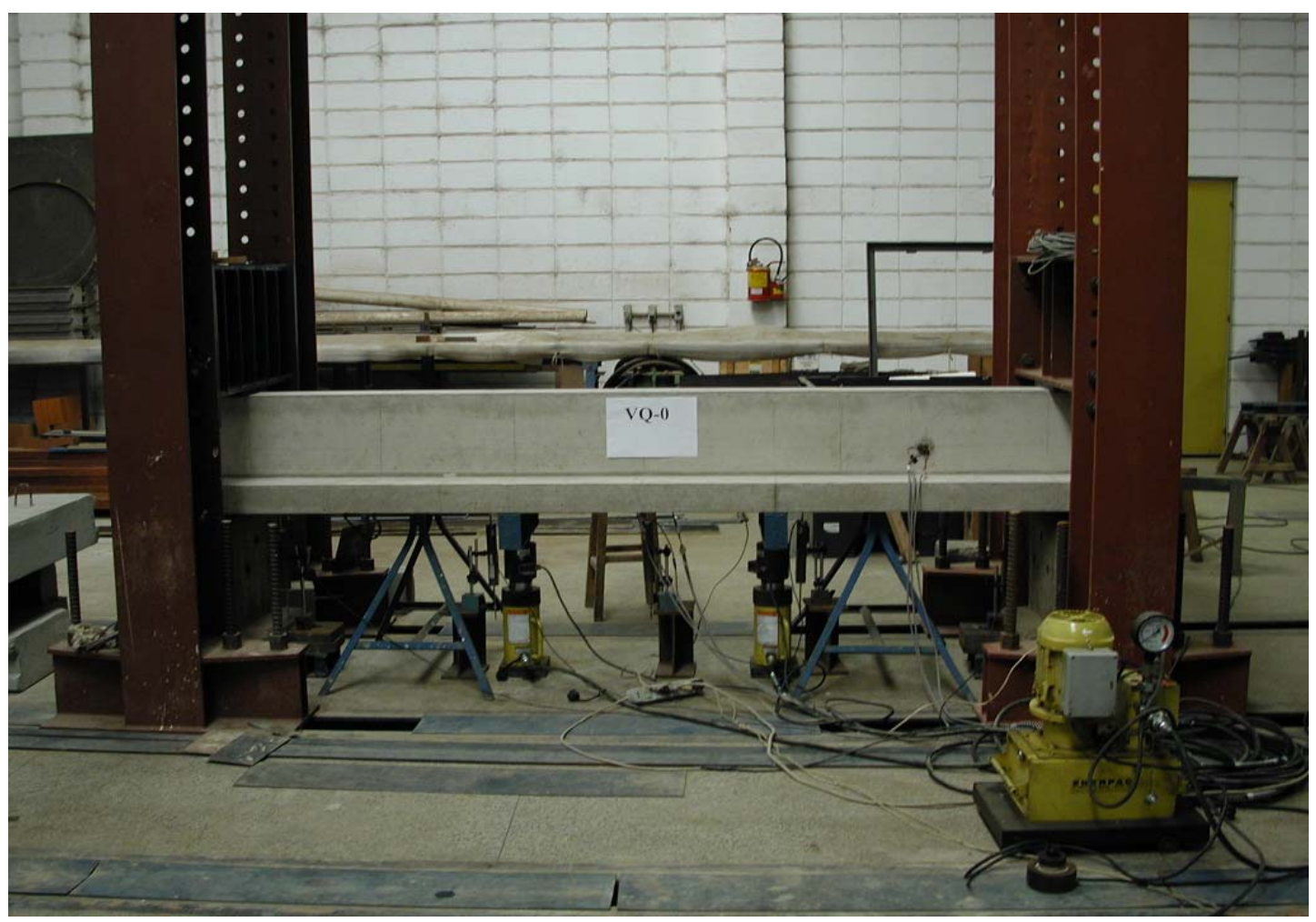

Figura 7.26 - Pórtico de reação montado para os ensaios das vigas VQ. 


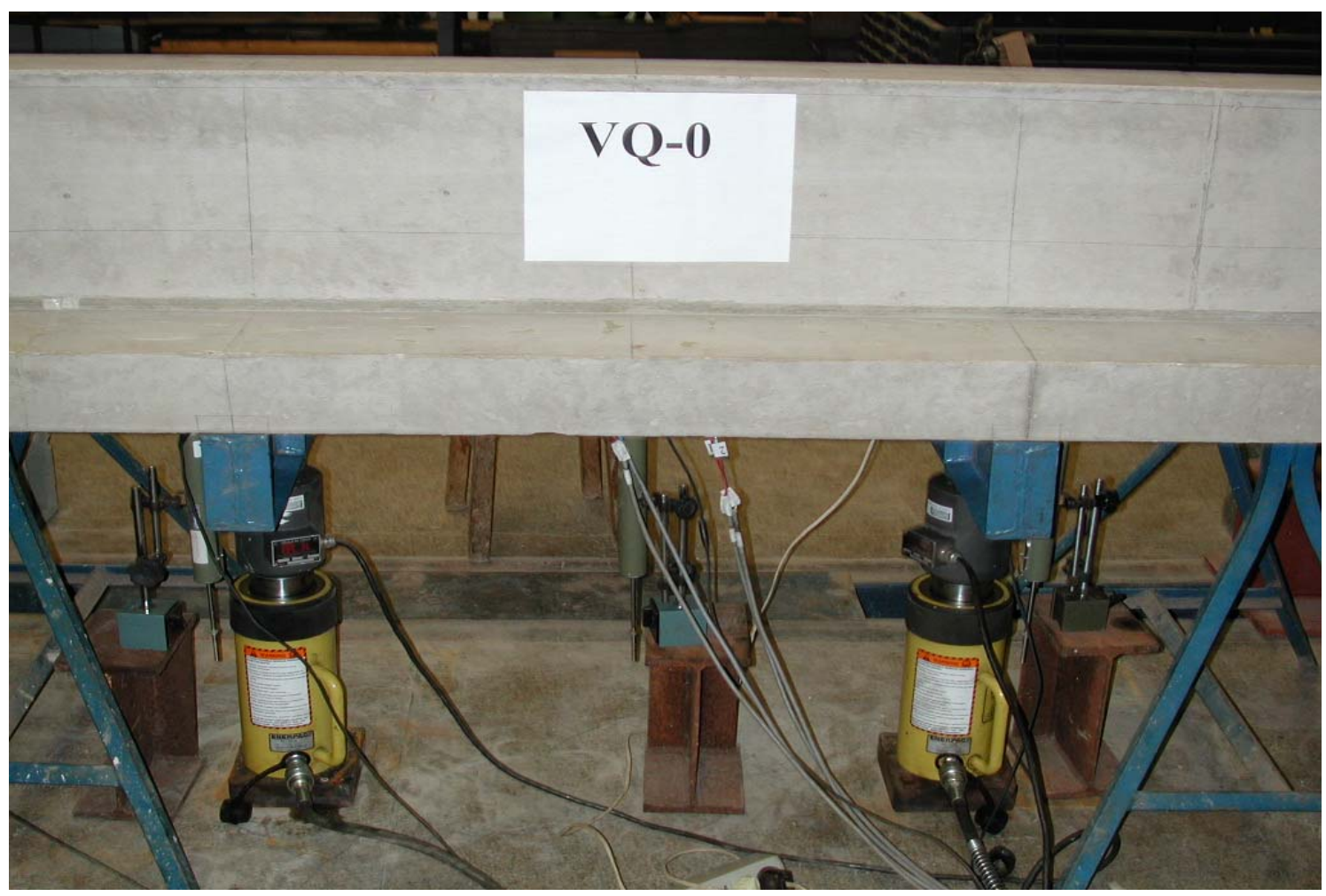

Figura 7.27 - Detalhe da montagem dos modelos para os ensaios das vigas VQ.

Na montagem dos ensaios para as vigas VS (Figura 7.29), para distribuição das forças aplicadas, foram utilizados dois perfis de seção I, soldados e justapostos, com comprimento de $650 \mathrm{~mm}$ e placas de aço com dimensões $170 \mathrm{~mm}$ x $170 \mathrm{~mm}$ x 25,4 mm (Figura 7.28). Além disso, foram utilizados apoios de neoprene fretado marca NEOPREX com dimensões $200 \mathrm{~mm}$ × $200 \mathrm{~mm}$ x $63 \mathrm{~mm}$. Utilizaram-se também cilindros hidráulicos ENERPAC com capacidade de $1000 \mathrm{kN}$ e células de carga SENSORTEC modelo TRK 100.
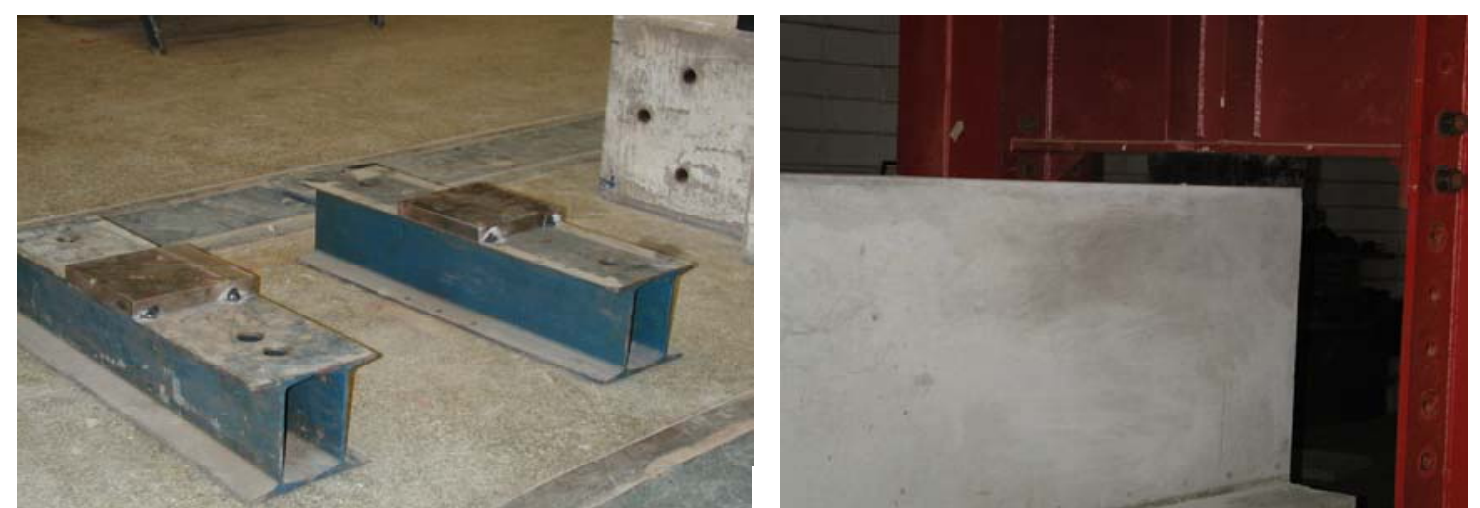

Figura 7.28 - Detalhes da placa de aço, dos perfis I justapostos e do apoio de neoprene fretado, utilizados nos ensaios das vigas VS. 


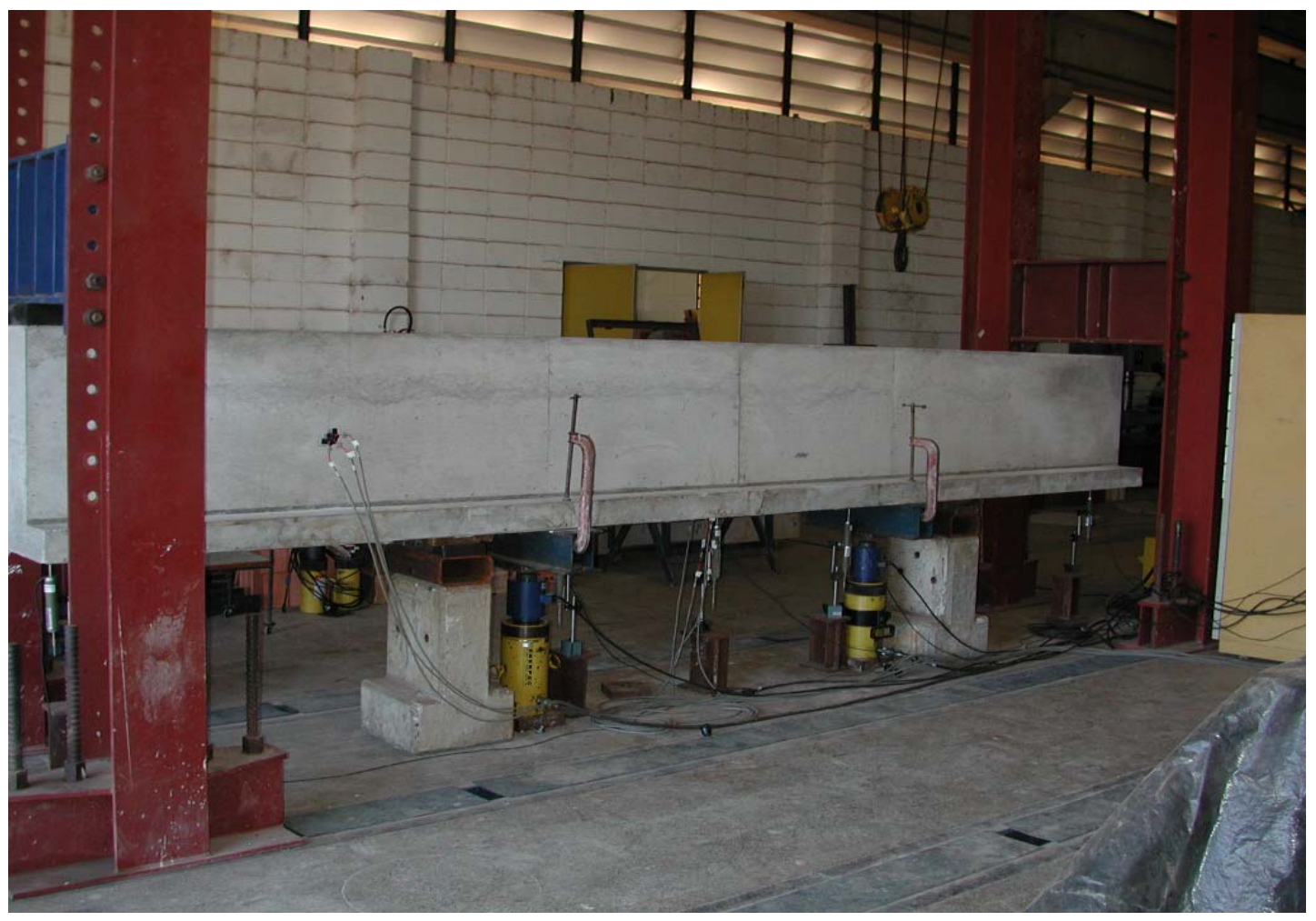

Figura 7.29 - Pórtico de reação montado para os ensaios das vigas VS.

Os equipamentos principais e os instrumentos de medição utilizados são relacionados a seguir:

a) sistema de aquisição de dados SYSTEM 4000 (Measurements Group), com capacidade para 120 canais, para aquisição automática das medidas de força, deformações e deslocamentos;

b) pórticos de reação metálicos, com uma montagem para as vigas VQ e outra para as vigas VS;

c) cilindros hidráulicos com capacidade nominal de $500 \mathrm{kN}$, marca ENERPAC, curso máximo de $150 \mathrm{~mm}$, para aplicação de força nos modelos VQ;

d) cilindros hidráulicos com capacidade nominal de $1000 \mathrm{kN}$, marca ENERPAC, curso máximo de $150 \mathrm{~mm}$, para aplicação de força nos modelos VS;

e) células de carga do tipo coluna, com capacidade nominal de $500 \mathrm{kN}$, modelo ELK, para medição da força aplicada nos modelos VQ;

f) células de carga do tipo coluna, com capacidade nominal de $1000 \mathrm{kN}$, marca SENSORTEC modelo TRK 100, para medição da força aplicada nos modelos VS;

g) transdutores de deslocamento marca KYOWA com sensibilidade 0,003 $\mathrm{mm}$ e curso máximo $100 \mathrm{~mm}$, para medição dos deslocamentos verticais da viga e dos apoios;

h) vibrador de imersão marca DYNAPAC com mangote de $35 \mathrm{~mm}$; 
i) bomba hidráulica elétrica marca ENERPAC modelo BER 2038, com capacidade nominal de $70 \mathrm{MPa}$;

j) máquina dobradeira de telas marca WEILLER modelo JR-6, com comprimento total de $300 \mathrm{~cm}$;

k) extensômetros elétricos de resistência ("strain gages"):

uniaxiais: marca KYOWA, para medição de deformações nas armaduras (modelos KFG-5-C1-120-11 e KFG-2N-C1-120-11) e no concreto ( modelo KFG-10-C1-120-11);

rosetas retangulares: marca KYOWA, modelo KFG-10-D17-120-11, para medição de deformações no concreto da alma;

1) lupa e microscópio com retículo graduado de $0,02 \mathrm{~mm}$ até $0,16 \mathrm{~mm}$, marca MITUTOYO, para observação das aberturas de fissuras;

m) régua comparadora do LNEC com graduação de $0,05 \mathrm{~mm}$ até $5 \mathrm{~mm}$, para observação das aberturas de fissuras;

n) aparelhos de apoio de neoprene fretado marca NEOPREX com dimensões $200 \mathrm{~mm}$ x 200 $\mathrm{mm} \times 63 \mathrm{~mm}$.

\section{5 - INSTRUMENTAÇÃO}

\subsection{1 - FORÇAS APLICADAS}

As forças aplicadas de baixo para cima foram medidas por células de carga indicadas no item anterior, instaladas em linhas com os macacos hidráulicos, como mostra a Figura 7.27 .

\subsection{2 - DESLOCAMENTOS VERTICAIS}

Os deslocamentos verticais foram monitorados no meio do vão (D3), na direção das duas forças aplicadas (D2 e D4) e nos apoios (D1 e D5). Todos os deslocamentos foram medidos com 5 transdutores de deslocamento marca KYOWA, com curso total de 50 ou 100 mm. A Figura 7.29 ilustra o posicionamento dos defletômetro durante os ensaios. 


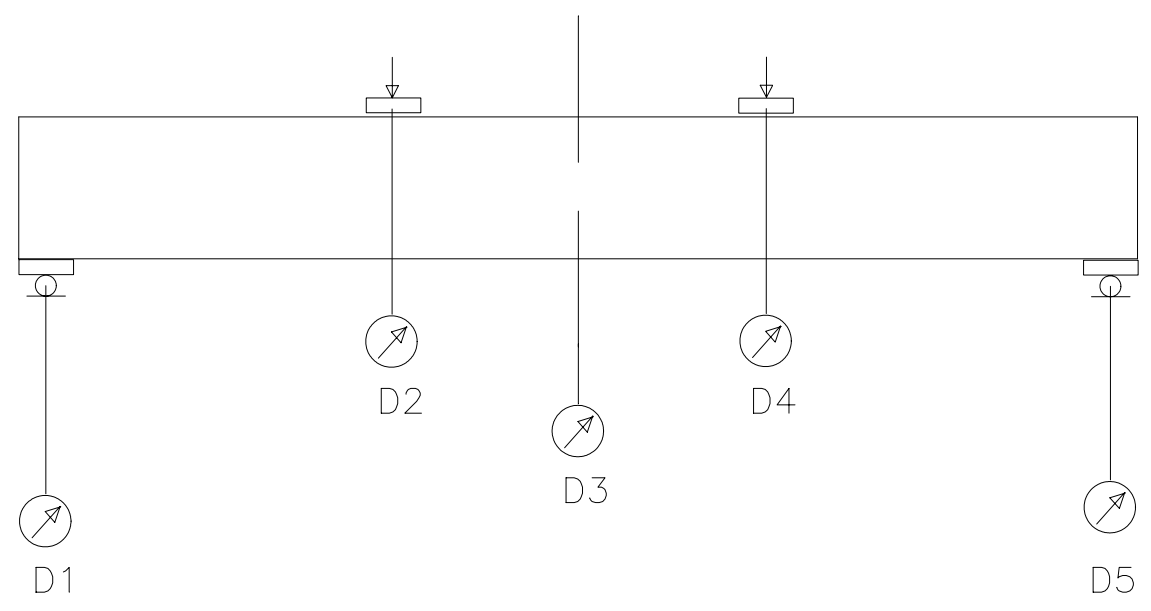

Figura 7.29 - Posicionamento dos defletômetros para os ensaios.

\subsection{3 - DEFORMAÇÕES ESPECÍFICAS NAS ARMADURAS}

As deformações específicas nas barras das armaduras foram medidas com extensômetros elétricos de resistência ("strain gages") tipos KFG-5-C1-120-11 e KFG-2NC1-120-11. Para cada série de vigas de ensaio utilizou-se uma instrumentação específica, com o intuito de propiciar análises de resultados dos modelos daquela série. As Figuras 7.30 a 7.34 apresentam os posicionamentos dos extensômetros nas barras das armaduras para todas as séries de ensaios. 

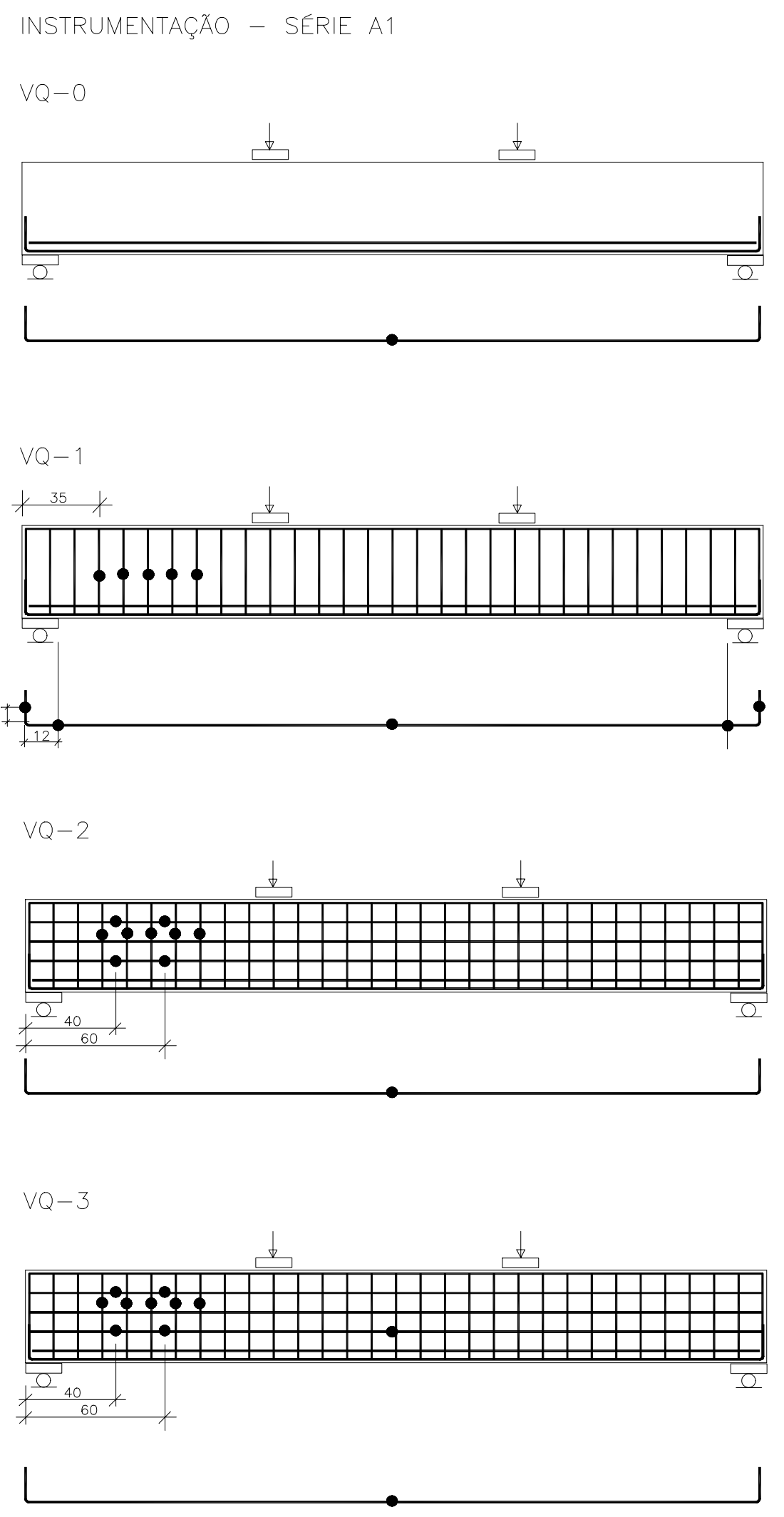

Figura 7.30 - Instrumentação das barras das armaduras (vigas de ensaio da série A1). 

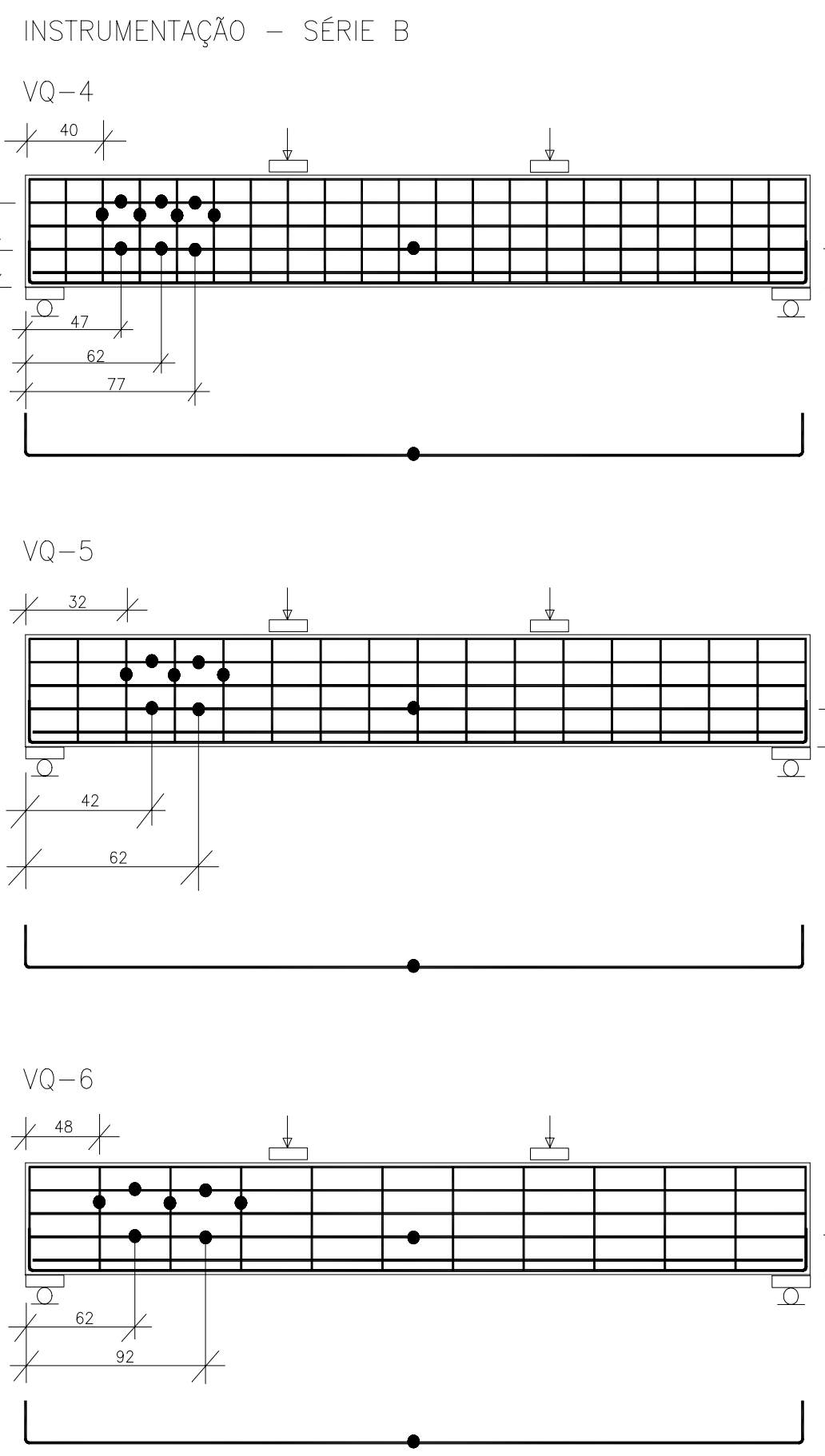

Figura 7.31 - Instrumentação das barras das armaduras (vigas de ensaio da série B). 

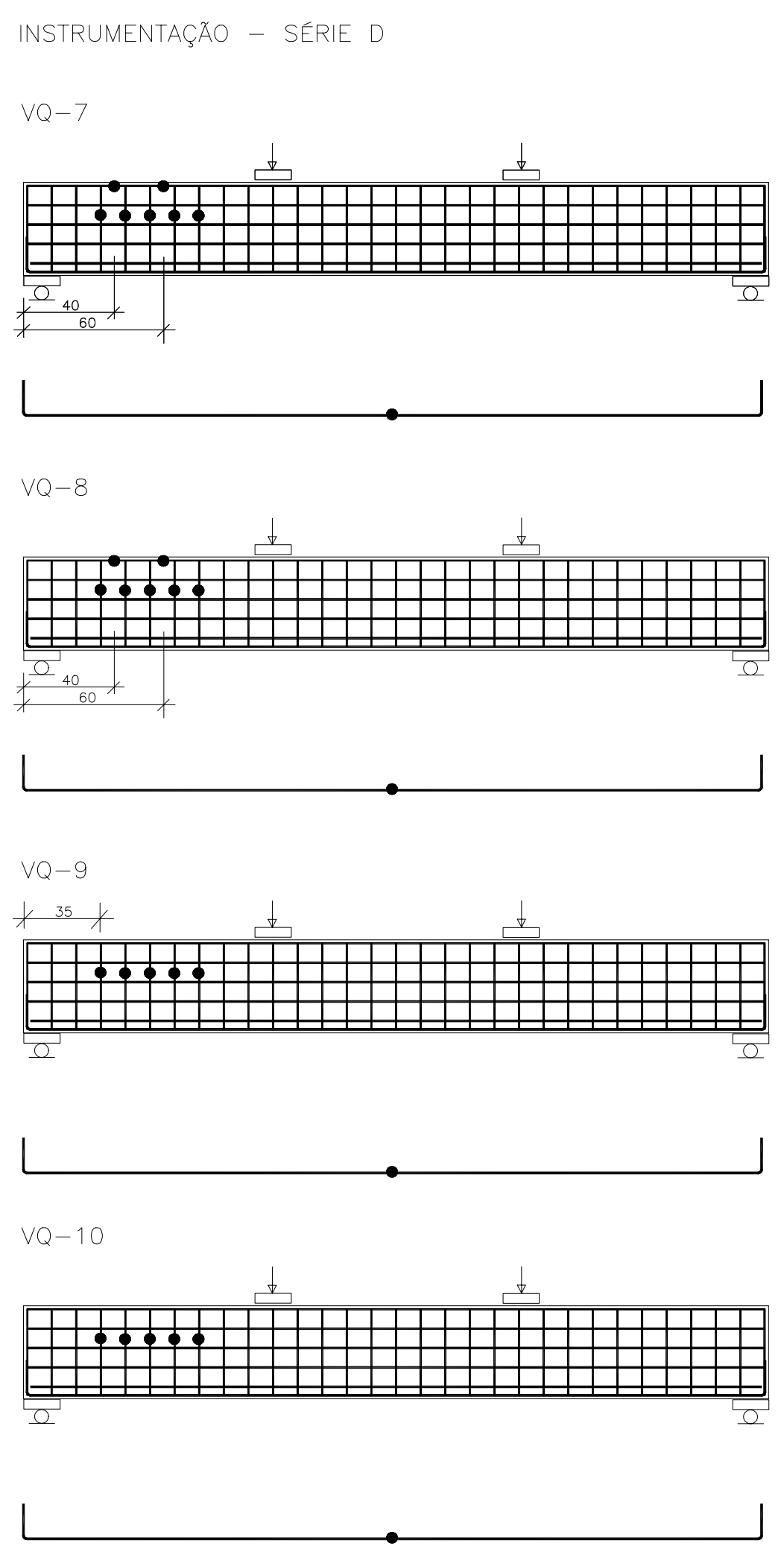

Figura 7.32 - Instrumentação das barras das armaduras (vigas de ensaio da série D). 

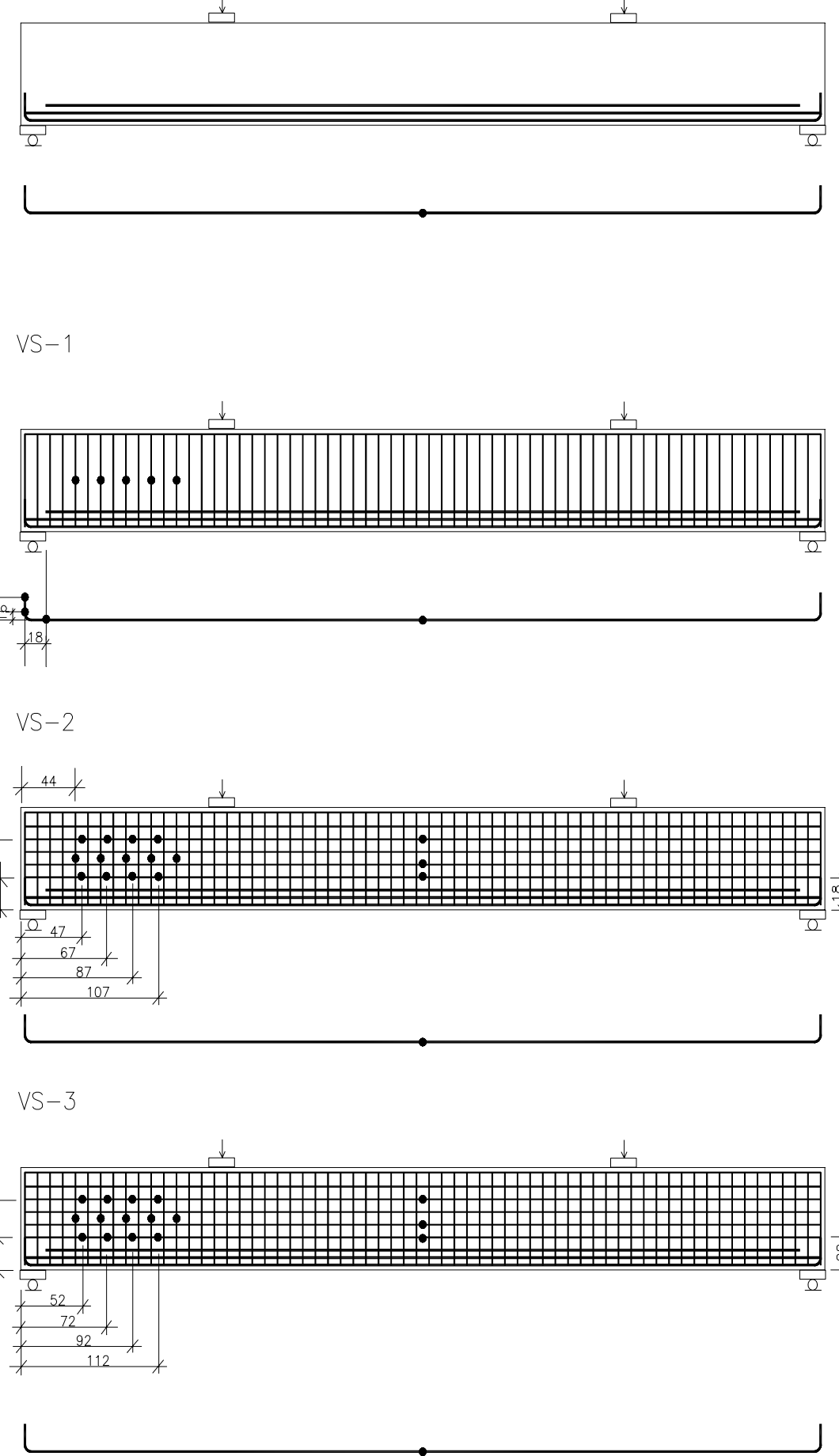

Figura 7.33 - Instrumentação das barras das armaduras (vigas de ensaio da série A2). 

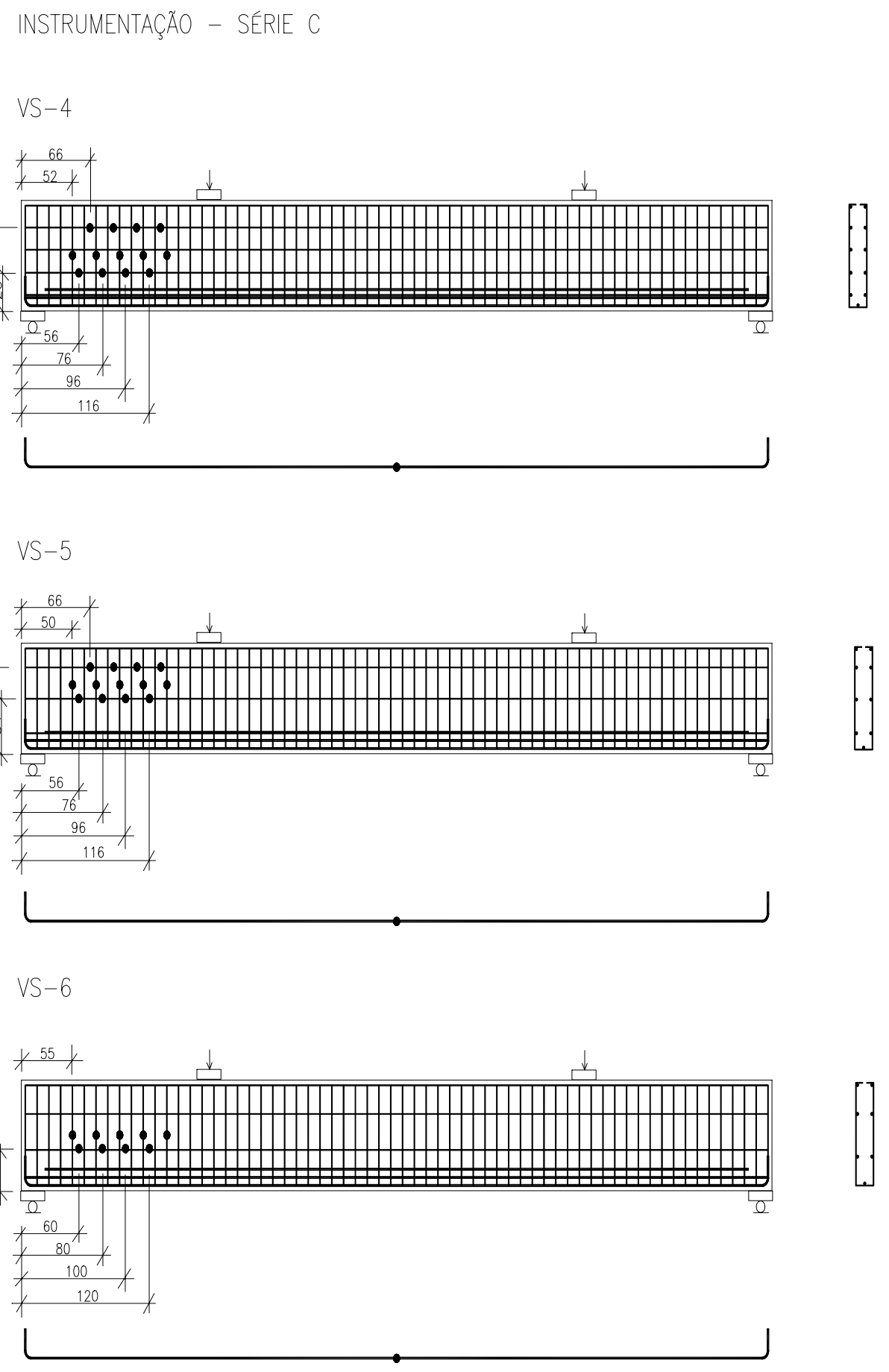

Figura 7.34 - Instrumentação das barras das armaduras (vigas de ensaio da série C). 
Em todos os modelos foram instrumentadas duas barras da armadura longitudinal de flexão no meio do vão. Apenas nos modelos VQ-1 e VS-1 foram colocados extensômetros no gancho vertical dessas barras com o intuito de verificar a adequada ancoragem no apoio extremo.

Nos fios horizontais das telas ou da armadura de pele foram posicionados 4 a 6 extensômetros no vão de corte e 1 ou 2 extensômetros no meio do vão, para os fios situados abaixo da linha neutra.

Para os fios verticais das telas ou dos estribos foram posicionados 3 a 5 extensômetros (de cada lado) no vão de corte, nos trechos mais solicitados pela força cortante, segundo indicações de FERNANDES (1992).

\subsection{4 - DEFORMAÇÕES ESPECÍFICAS NO CONCRETO}

As deformações no concreto comprimido foram medidas no meio do vão por extensômetros elétricos de resistência ("strain gages") modelo KFG-10-C1-120-11. As deformações no concreto das diagonais comprimidas foram medidas na metade da distância entre a força aplicada e o apoio, à meia altura da seção, utilizando rosetas retangulares, modelo KFG-10-D17-120-11. Como indica a Figura 7.35, foram utilizados 2 extensômetros na mesa comprimida e apenas uma roseta de um dos lados da seção.

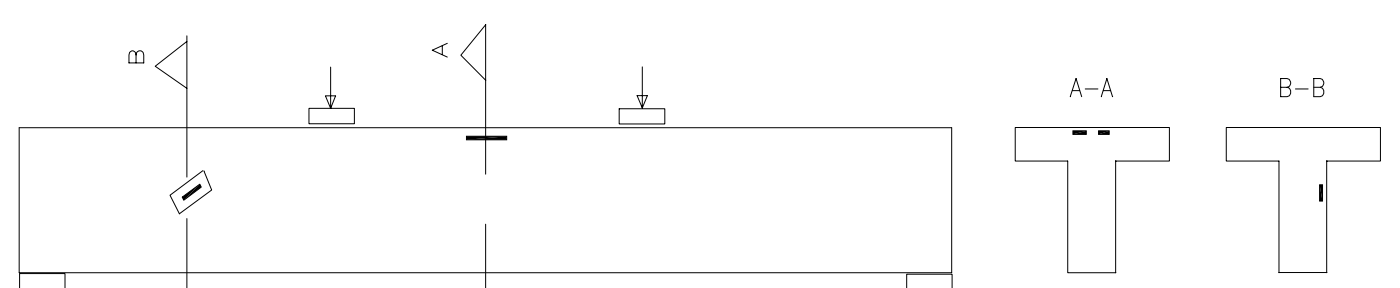

Figura 7.35 - Instrumentação do concreto. 


\subsection{5 - FISSURAÇÃO}

Para o acompanhamento da evolução da fissuração ao longo dos ensaios, o banzo tracionado e a alma foram divididos em três regiões A, B e C como pode ser visto na Figura 7.36 e a seguir descritas:

Região A: localiza-se entre o apoio esquerdo e a seção de aplicação da força concentrada esquerda. Essa região foi dividida ao meio em duas sub-regiões, A1 e A2, sendo a sub-região $\mathrm{A} 1$ à esquerda $\mathrm{e} \mathrm{A} 2$ à direita;

Região B: localiza-se entre as forças concentradas verticais, também dividida em sub-regiões B1 e B2;

Região C: localiza-se entre a seção de aplicação da força concentrada esquerda e o apoio esquerdo. Essa região também foi dividida ao meio em duas sub-regiões, $\mathrm{C} 1$ e C2, sendo a sub-região $\mathrm{C} 2$ à esquerda e $\mathrm{C} 1$ à direita.

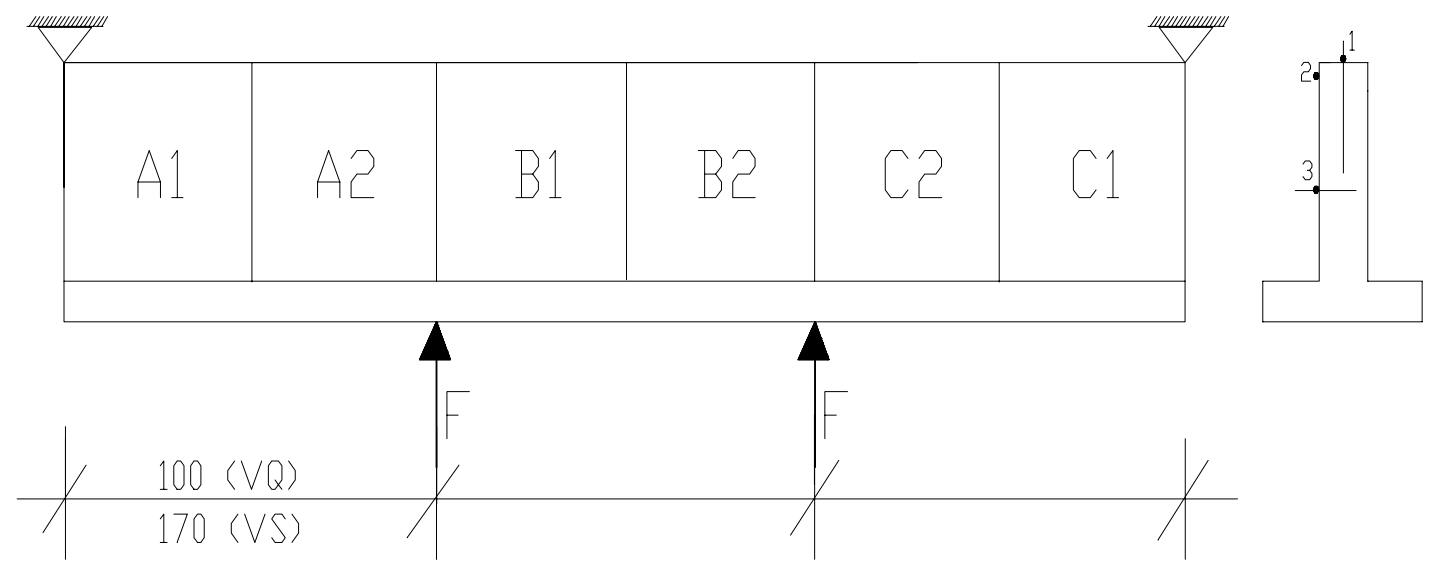

Figura 7.36 - Regiões e eixos longitudinais delimitados para a observação das fissuras.

Os espaçamentos entre fissuras foram medidos, após o término dos ensaios, ao longo dos seguintes eixos (Figura 7.36):

- eixo 1: posicionado na face tracionada da nervura, contido na interseção do plano médio da alma com o plano desta face;

- eixo 2: localizado na face lateral da nervura tracionada, que dista $3 \mathrm{~cm}$ do vértice da nervura; 
- eixo 3: posicionado na alma da viga, na interseção da face lateral com um plano horizontal que passa na metade da altura da viga.

\section{6 - ESQUEMA DE ENSAIO}

A montagem do ensaio considerou a viga simplesmente apoiada com duas forças concentradas simétricas. Essa montagem é usual nas investigações de viga com ruína por força cortante porque combina flexão pura (entre as forças aplicadas) e flexão simples com força cortante constante (entre as forças aplicadas e os apoios).

As Figuras 7.37 e 7.38 mostram o esquema de ensaio com aplicação das forças nas vigas VQ e VS, respectivamente.

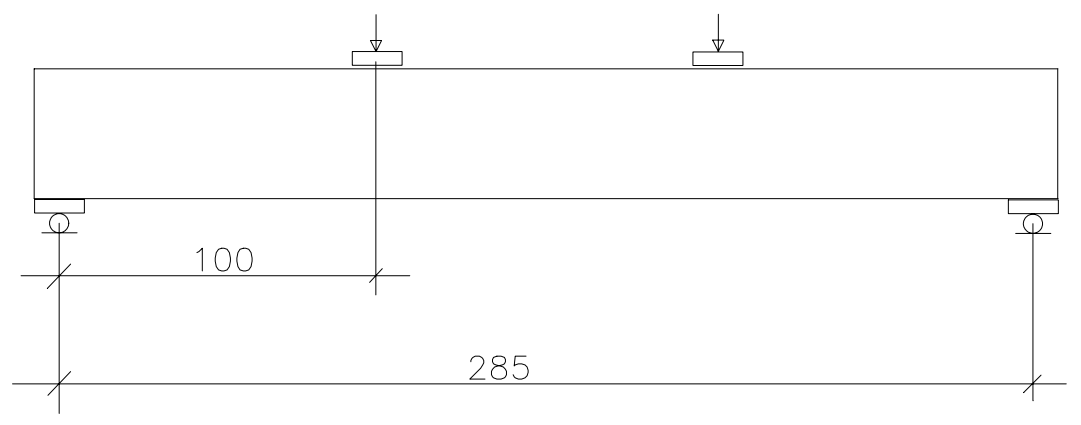

Figura 7.37 - Esquema de aplicação das forças para as vigas VQ.

Figura 7.38 - Esquema de aplicação das forças para as vigas VS. 
A Figura 7.39 mostra esquematicamente a montagem do ensaio. O sentido de aplicação das forças foi de baixo para cima.
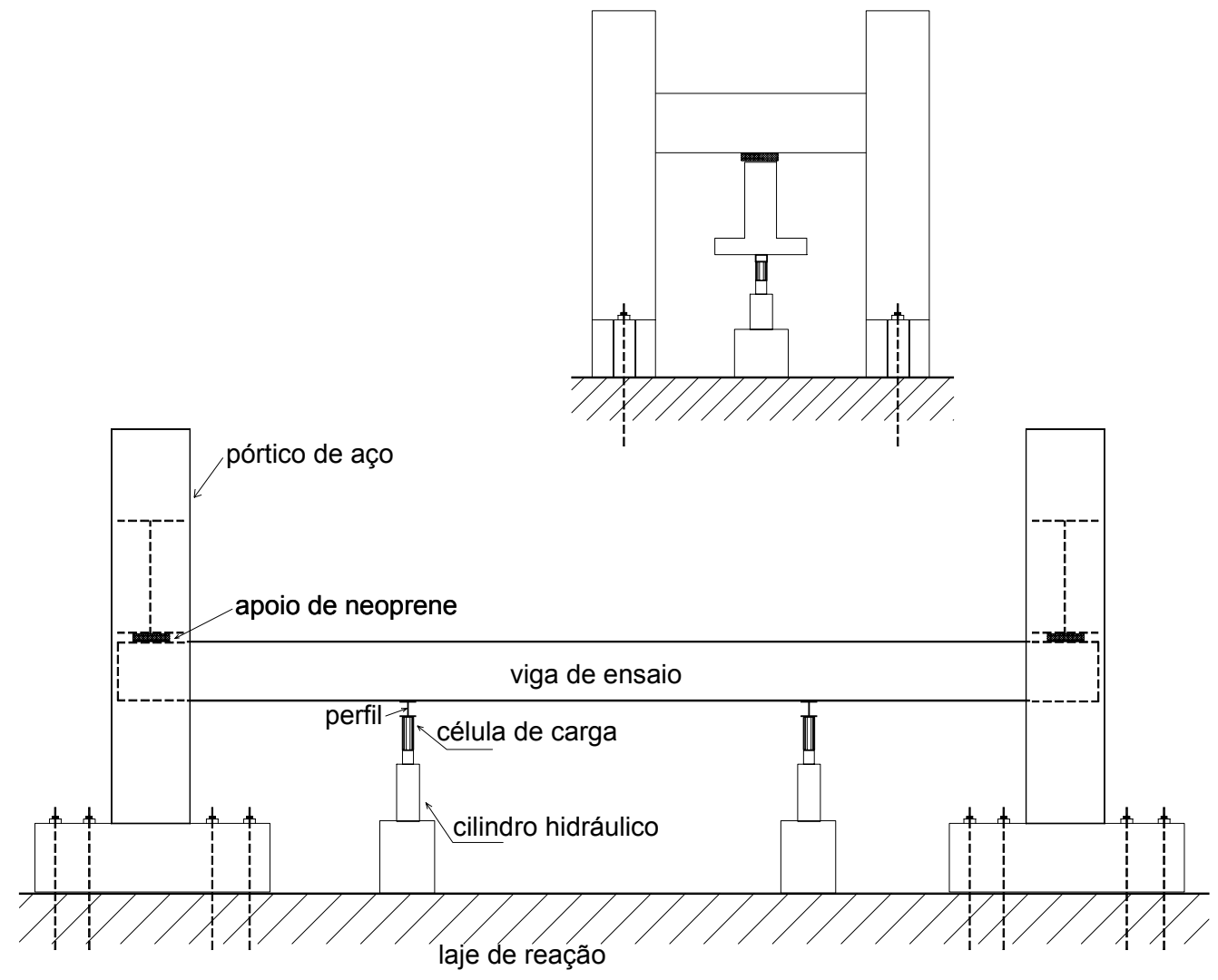

Figura 7.39 - Esquema do ensaio.

\section{7 - EXECUÇÃO DOS ENSAIOS}

\subsection{1 - DESCRIÇÃO GERAL}

\subsubsection{1 - Montagem das fôrmas}

Após a desforma das vigas procedia-se à limpeza cuidadosa dos painéis de fôrmas e aplicava-se uma demão de desmoldante para possibilitar novas reutilizações.

Os painéis de fôrmas eram parafusados de modo a facilitar a montagem e a desforma. Após a montagem, as fôrmas eram posicionadas no LE-SET, de modo a facilitar a concretagem por meio de caminhões betoneira. 

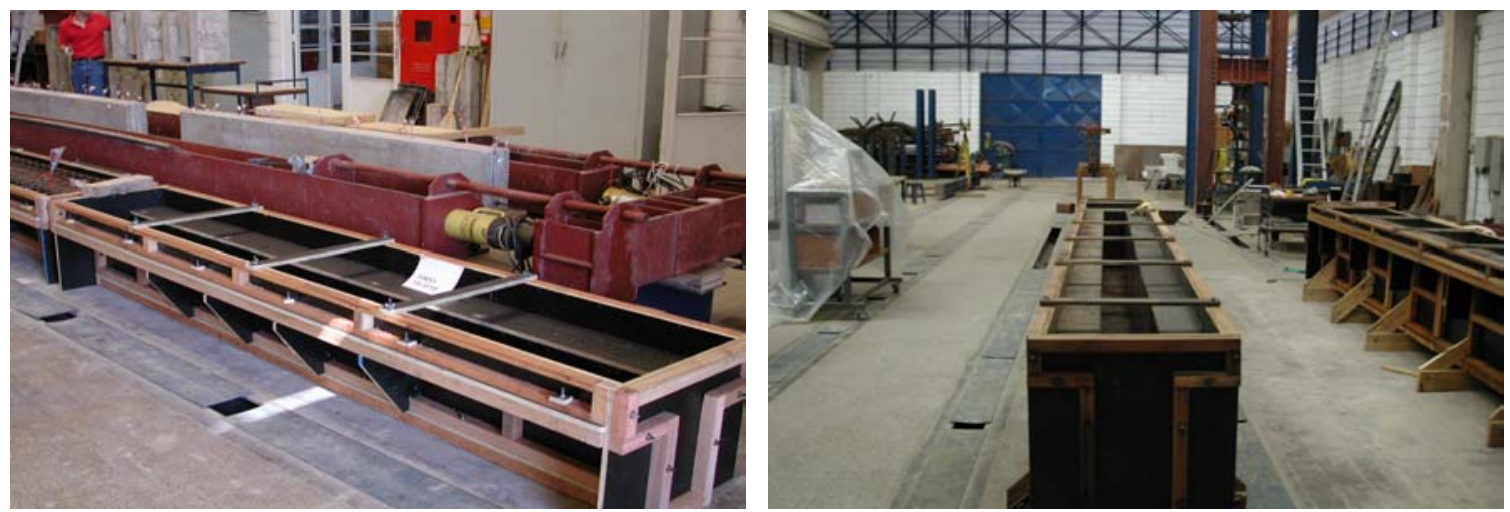

Figura 7.40 - Fôrmas das vigas VQ e VS.

\subsubsection{2 - Montagem das armaduras}

As barras de aço e telas soldadas, cortadas e dobradas, foram armazenadas no pátio do LE-SET. De acordo com a programação e andamento dos ensaios, as armaduras das vigas foram montadas.

As telas soldadas foram cortadas com tesoura de corte de fios e, em seguida, retificadas com pancadas de marreta de borracha, contra um plano. As telas foram dobradas em máquina dobradeira, modelo JR-6, com comprimento total de $300 \mathrm{~cm}$.

Para garantir o cobrimento especificado para as vigas, foram utilizados espaçadores plásticos da marca JERUELPLAST, modelos S20 e SL 20.

A Figura 7.41 mostra as armaduras das vigas VQ-3 e VS-6, prontas para a colocação na fôrma.
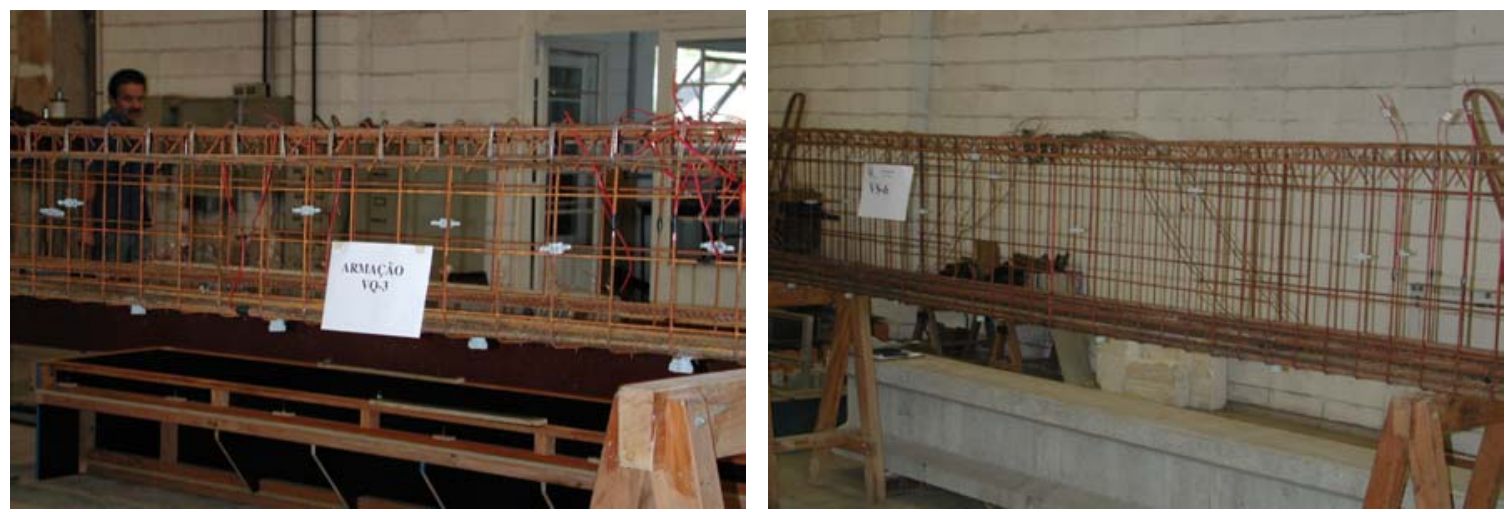

Figura 7.41 - Armaduras das vigas VQ-3 e VS-6. 


\subsubsection{3 - Concretagem}

Para possibilitar a entrega de um volume mínimo de concreto usinado $\left(1,5 \mathrm{~m}^{3}\right)$, foram concretadas simultaneamente quatro vigas das séries $\mathrm{A} 1, \mathrm{~B}$ e $\mathrm{D}$ ou duas vigas das séries A2 e C. Para o adensamento do concreto utilizou-se um vibrador de imersão, marca DYNAPAC, com mangotes de $35 \mathrm{~mm}$ (vigas VQ) ou $45 \mathrm{~mm}$ (vigas VS).

As Figuras 7.42 e 7.43 mostram a concretagem e o adensamento das vigas.
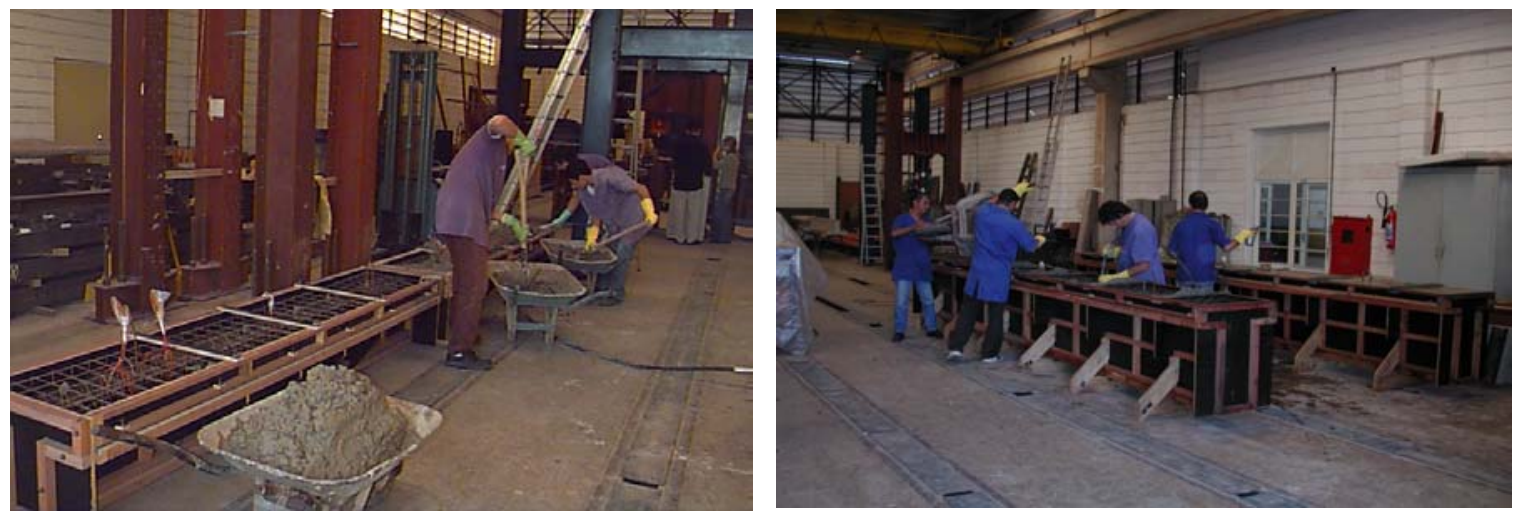

Figura 7.42 - Concretagem das vigas das séries A1 e A2.
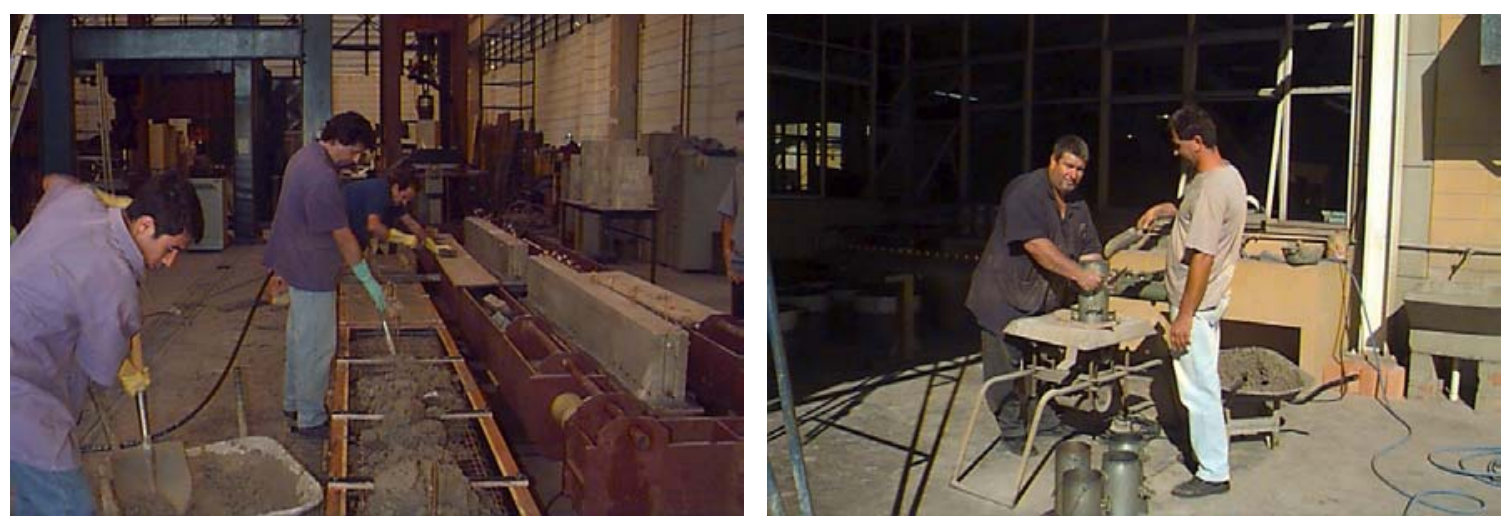

Figura 7.43 - Adensamento das vigas da série A1 e moldagem dos corpos-de-prova.

\subsubsection{4 - Cura}

As vigas concretadas foram submetidas a um período de cura de 07 dias, garantindo umidade adequada, utilizando-se espuma embebida em água. A desfôrma foi realizada após esses 07 dias de cura. 


\subsubsection{5 - Aplicação do carregamento}

Inicialmente, foi aplicada uma força com a finalidade de equilibrar o peso próprio da viga e dos equipamentos de ensaio $(3,6 \mathrm{kN}$ em cada macaco para as vigas VQ e $12 \mathrm{kN}$, para as vigas VS ) e assim desconsiderar seu valor nos cálculos.

Em seguida, foi aplicada uma força referente ao escorvamento da estrutura (aproximadamente $10 \%$ da força última). Após o descarregamento, iniciou-se a execução do ensaio propriamente dito.

Para a viga VQ-0 foram aplicados incrementos de $10 \mathrm{kN}$ no carregamento. Para as outras vigas VQ foram aplicados incrementos de $15 \mathrm{kN}$ até atingir a ruína. Em cada incremento de força foram feitas leituras de deformações e deslocamentos e estimativa dos valores das aberturas das fissuras. Para a viga VS-0, foram aplicados incrementos de $20 \mathrm{kN}$ no carregamento. Em todas as outras vigas VS foram utilizados incrementos de $30 \mathrm{kN}$ até atingir a ruína.

\subsection{2 - DESCRIÇÃO DE CADA SÉRIE}

\subsubsection{1 - Série A1}

As vigas da série A1, denominadas VQ-0, VQ-1, VQ-2 e VQ-3, foram moldadas em 14/08/2001. O abatimento do tronco de cone do concreto utilizado foi de $40 \mathrm{~mm}$, segundo a NBR 7223: 1982.

A desfôrma foi realizada em 21/08/2001 e os ensaios, entre os dias 26/09/2001 e $28 / 09 / 2001$

\subsubsection{2 - Série B}

As vigas da série $\mathrm{B}$, denominadas VQ-4, VQ-5 e VQ-6, foram concretadas em 25/02/2002. O abatimento do tronco de cone do concreto utilizado também foi de $40 \mathrm{~mm}$, segundo a NBR 7223: 1982. 
Simultaneamente à concretagem das vigas da série $\mathrm{B}$, concretou-se a viga VQ-1A, similar à viga VQ-1. Como a viga VQ-1 era uma viga de referência para a análise de resultados, considerou-se pertinente a moldagem de outro exemplar.

A desfôrma foi realizada em 05/03/2002 e os ensaios, entre os dias 27/03/2001 e $03 / 04 / 2002$

\subsubsection{3 - Série D}

As vigas da série D, denominadas VQ-7, VQ-8, VQ-9 e VQ-10, foram moldadas em 18/03/2002. O abatimento do tronco de cone do concreto utilizado foi de $69 \mathrm{~mm}$, segundo a NBR 7223: 1982.

A desfôrma foi realizada em 25/03/2002 e os ensaios, entre os dias 15/04/2002 e 18/04/2002.

A Tabela 7.12 apresenta um resumo das datas de concretagem e ensaio de todas as séries de vigas.

Tabela 7.12 - Datas de concretagem e ensaios de todas as séries de vigas.

\begin{tabular}{|c|c|c|c|c|}
\hline Série & Vigas & $\begin{array}{c}\text { Data da } \\
\text { concretagem }\end{array}$ & Data do ensaio & $\begin{array}{l}\text { Idade } \\
\text { (dias) }\end{array}$ \\
\hline \multirow{4}{*}{$\mathrm{A} 1$} & VQ-0 & \multirow{4}{*}{$14 / 08 / 01$} & $26 / 09 / 01$ & 43 \\
\hline & VQ-1 & & $27 / 09 / 01$ & 44 \\
\hline & VQ-2 & & $28 / 09 / 01$ & 45 \\
\hline & VQ-3 & & $01 / 10 / 01$ & 48 \\
\hline \multirow{4}{*}{ B } & VQ-4 & \multirow{4}{*}{$25 / 02 / 02$} & $27 / 03 / 02$ & 30 \\
\hline & VQ-5 & & $28 / 03 / 02$ & 31 \\
\hline & VQ-6 & & $01 / 04 / 02$ & 35 \\
\hline & VQ-1A & & $03 / 04 / 02$ & 37 \\
\hline \multirow{4}{*}{$\mathrm{D}$} & VQ-7 & \multirow{4}{*}{$18 / 03 / 02$} & $15 / 04 / 02$ & 28 \\
\hline & VQ-8 & & $16 / 04 / 02$ & 29 \\
\hline & VQ-9 & & $17 / 04 / 02$ & 30 \\
\hline & VQ-10 & & $18 / 04 / 02$ & 31 \\
\hline \multirow{4}{*}{ A2 } & VS-0 & \multirow[t]{2}{*}{$11 / 04 / 02$} & $15 / 05 / 02$ & 34 \\
\hline & VS-2 & & $17 / 05 / 02$ & 36 \\
\hline & VS-1 & \multirow[t]{2}{*}{$08 / 05 / 02$} & $17 / 06 / 02$ & 40 \\
\hline & VS-3 & & $18 / 06 / 02$ & 41 \\
\hline \multirow{3}{*}{$\mathrm{C}$} & VS-4 & \multirow[t]{2}{*}{$05 / 06 / 02$} & $04 / 07 / 02$ & 29 \\
\hline & VS-5 & & $03 / 07 / 02$ & 28 \\
\hline & VS-6 & $27 / 06 / 02$ & $25 / 07 / 02$ & 28 \\
\hline
\end{tabular}




\subsubsection{4 - Série A2}

As vigas da série A2, denominadas VS-0, VS-1, VS-2 e VS-3, foram concretadas em duas etapas.

Na primeira etapa da concretagem, em 11/04/2002, foram moldadas as vigas VS-0 e VS-2. O abatimento do tronco de cone do concreto utilizado foi de $126 \mathrm{~mm}$, segundo a NBR 7223: 1982 .

Durante a primeira concretagem, observou-se um pequeno abaulamento nas emendas dos painéis de fôrmas, porque a ligação entre os painéis não foi reforçada. Assim, houve um aumento no consumo de concreto inicialmente previsto e também um aumento na largura da viga na região central (de $20 \mathrm{~cm}$ para em torno de $22 \mathrm{~cm}$ ), o que causou a falta de uma pequena quantidade de concreto para a extremidade da mesa da viga VS-0, optando-se pelo preparo de $0,15 \mathrm{~m}^{3}$ de concreto em betoneira do LE-SET. Utilizou-se a dosagem de $25 \mathrm{MPa}$ aos 28 dias proposta por RAMOS (2001), mostrada na Tabela 7.13. Como a areia utilizada estava com alto teor de umidade e não houve disponibilidade de tempo para secagem, o concreto produzido no LE-SET apresentou praticamente as mesmas características ( "slump" e resistência à compressão) do concreto usinado, vide Anexo A.

Tabela 7.13 - Composição para $0,15 \mathrm{~m}^{3}$ de concreto.

\begin{tabular}{|l|c|}
\hline \multicolumn{1}{|c|}{ Materiais } & Quantidade \\
\hline Cimento CP II F -32 & $48 \mathrm{~kg}$ \\
\hline Areia natural lavada & $113 \mathrm{~kg}$ \\
\hline Pedra britada $n^{\circ} 1$ & $170,2 \mathrm{~kg}$ \\
\hline Água & 31,2 litros \\
\hline Relação água / cimento & $\mathbf{0 , 6 5}$ \\
\hline
\end{tabular}

Após a desmoldagem realizada em 19/04/2002, verificou-se a existência de vazios na extremidade inferior direita da viga VS-0, proveniente de deficiência no adensamento do concreto (ninho de concretagem). Durante o transporte interno com ponte rolante no LESET da viga VS-2, ocorreu um pequeno acidente que provocou danos localizados na mesa da viga VS-2.

Posteriormente, foram executados os dois reparos localizados nas vigas VS-0 e VS2, cujo procedimento de execução é apresentado a seguir: 
- limpeza do substrato: escarificação manual com escova de aço e aspersão com jato de ar;

- aplicação de pasta de cimento como ponte de aderência;

- preenchimento das cavidades com argamassa de reparo cuja dosagem é apresentada na Tabela 7.14, proposta por FAGURY \& LIBÓRIO (2002).

Tabela 7.14 - Dosagem da argamassa de reparo utilizada

\begin{tabular}{|l|c|}
\hline \multicolumn{1}{|c|}{.Materiais } & Dosagem \\
\hline Cimento ARI V - Plus & 1 \\
\hline Areia natural lavada & 2 \\
\hline Aditivo superplastificante REAX RX 3000 & $0,8 \%$ \\
\hline Relação água / cimento & $\mathbf{0 , 3 5}$ \\
\hline
\end{tabular}

As Figuras 7.44 e 7.45 mostram os reparos executados nas vigas VS-0 e VS-2, respectivamente.
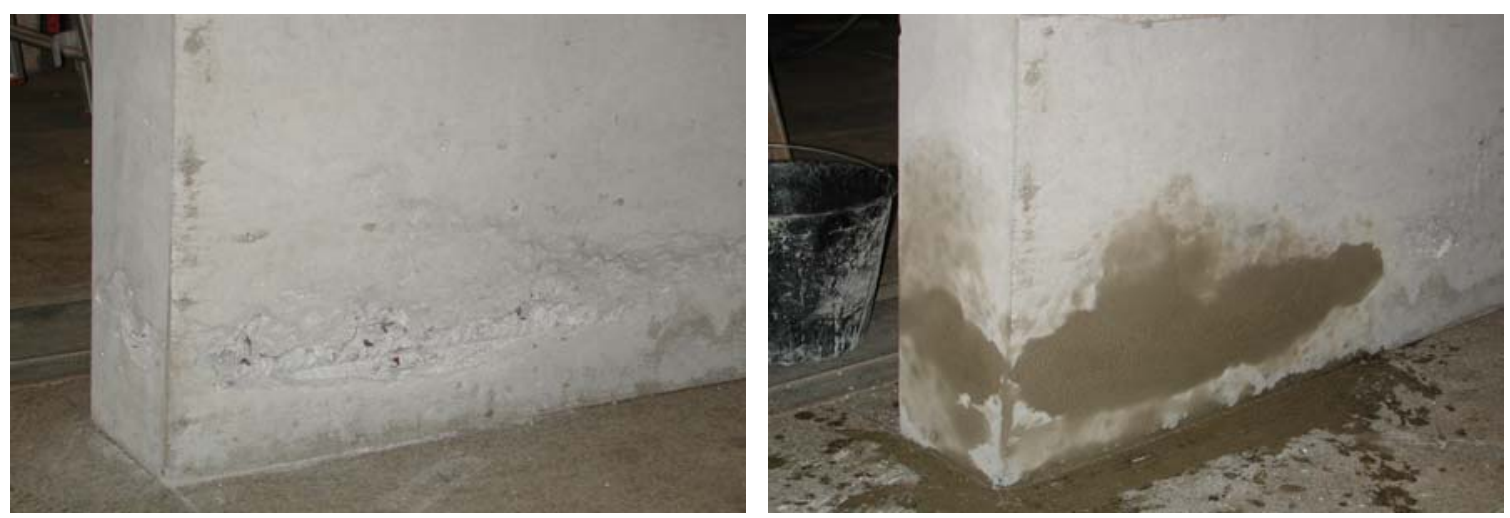

Figura 7.44 - Reparo localizado na viga VS-0 (antes e depois). 

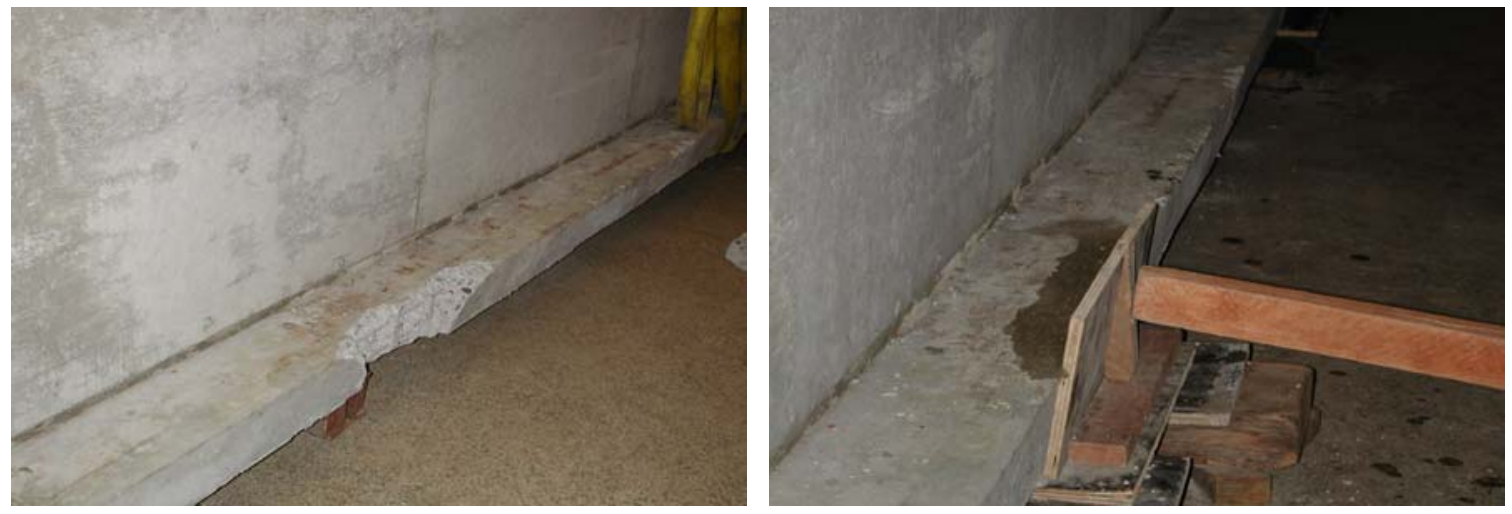

Figura 7.45 - Reparo localizado na viga VS-2 (antes e depois).

Os ensaios das vigas VS-0 e VS-2 foram realizados entre os dias 15/05/2002 e 17/05/2002.

A partir dos problemas ocorridos durante a concretagem dessas vigas, foi solicitado ao Serviço de Marcenaria da EESC/USP a execução de um reforço nas emendas dos painéis das fôrmas das vigas VS. As fôrmas foram então reforçadas com 05 tirantes de aço em cada viga, com barra rosqueada $\phi=5 / 16 "$. Esses serviços foram executados antes da concretagem seguinte.

Na segunda etapa da concretagem, em 08/05/2002, foram moldadas as vigas VS-1 e VS-3. O abatimento do tronco de cone do concreto utilizado foi de $119 \mathrm{~mm}$, segundo a NBR 7223:1982. A desfôrma foi realizada em 15/05/2002 e os ensaios, entre os dias 17/06/2002 e $18 / 06 / 2002$.

\subsubsection{5 - Série C}

As vigas da série C, denominadas VS-4, VS-5 e VS-6, foram também concretadas em duas etapas, por estarem disponíveis apenas dois conjuntos de fôrmas.

Na primeira concretagem, em 05/06/2002, foram moldadas as vigas VS-4 e VS-5. O abatimento do tronco de cone do concreto utilizado foi de $52 \mathrm{~mm}$, segundo a NBR 7223 : 1982. A desfôrma foi realizada em 12/06/2002 e os ensaios, entre os dias 03/07/2002 e 04/07/2002. Por causa das dificuldades encontradas na desfôrma da viga VS-4, ocorreu um dano no concreto da extremidade da mesa. Procedeu-se a um reparo, seguindo-se os mesmos procedimentos do item anterior. 
Na segunda moldagem, em 27/06/2002, foi concretada a viga VS-6. O abatimento do tronco de cone do concreto utilizado foi de $58 \mathrm{~mm}$, segundo a NBR 7223: 1982. A desfôrma foi realizada em 05/07/2002 e o ensaio, em 25/07/2002. 


\section{RESULTADOS DOS ENSAIOS}

\section{1 - INTRODUÇÃO}

Serão apresentados os resultados experimentais dos ensaios realizados nas vigas das séries $\mathrm{A} 1, \mathrm{~B}, \mathrm{D}, \mathrm{A} 2$ e C, abordando-se os seguintes tópicos:

$\triangleright$ formação e desenvolvimento das fissuras;

$\triangleright$ forças e modos de ruína;

$\triangleright$ deslocamentos verticais;

$\triangleright$ deformações na armadura de flexão;

$\triangleright$ deformações no concreto comprimido;

$\triangleright$ deformações nos fios dos estribos verticais;

$\triangleright$ deformações nos fios das armaduras laterais;

$\triangleright$ aberturas e espaçamentos das fissuras.

O programa experimental foi executado entre os dias 14/08/2001 (concretagem da série A1) e 27/06/2002 (ensaio da viga VS-6 da série C).

A evolução da fissuração, em todas as vigas ensaiadas, é apresentada no Anexo B. 


\section{2 - FORMAÇÃO E DESENVOLVIMENTO DAS FISSURAS}

\subsection{1 - SÉRIE A1}

\subsubsection{1 - VQ-0}

As primeiras fissuras visíveis na nervura tracionada da viga VQ-0 surgiram nas etapas de $40 \mathrm{kN}$ (eixo 1) e $60 \mathrm{kN}$ (eixo 2). As primeiras fissuras de cisalhamento na alma apareceram entre as etapas de 60 e $70 \mathrm{kN}$. Na etapa de $80 \mathrm{kN}$, essas fissuras já apresentavam grandes aberturas, caracterizando as proximidades da ruína.

A fissura de cisalhamento, que se apresentou inicialmente com maiores aberturas foi a da face dorsal do lado direito. Em seguida, as fissuras da face frontal, primeiro do lado direito e depois do lado esquerdo.

Com a aplicação da etapa de $90 \mathrm{kN}$, a fissura de cisalhamento do lado direito apresentou uma abertura estimada de $1,10 \mathrm{~mm}$, caracterizando a ruína da viga pela separação das partes pela fissura. A Figura 8.1 apresenta o panorama de fissuração nas proximidades do colapso.

\subsubsection{2 - VQ-1}

$\mathrm{Na}$ etapa de $45 \mathrm{kN}$, apareceram as primeiras fissuras da viga VQ-1 na nervura tracionada (eixo 1). Na etapa de $75 \mathrm{kN}$, apareceram as primeiras fissuras de cisalhamento na alma da viga. Essas fissuras apresentaram aberturas de até $0,30 \mathrm{~mm}$, a partir da etapa de 120 $\mathrm{kN}$.

Nas proximidades da ruína as fissuras de cisalhamento apresentaram grandes aberturas, caracterizando um colapso por força cortante-tração com escoamento da armadura transversal. A Figura 8.2 apresenta o panorama de fissuração nas proximidades da ruína. 


\subsubsection{3 - VQ-2}

As primeiras fissuras observadas na viga VQ-2 foram de flexão, na nervura tracionada (região B2) nas etapas de $45 \mathrm{kN}$ (eixo 1) e $60 \mathrm{kN}$ (eixo 2). As primeiras fissuras de cisalhamento na alma surgiram na etapa de $75 \mathrm{kN}$. Essas fissuras, a partir da etapa de 120 $\mathrm{kN}$, apresentaram aberturas de até $0,30 \mathrm{~mm}$.

Nas proximidades da ruína, as fissuras de cisalhamento também apresentaram grandes aberturas, caracterizando uma ruína por força cortante-tração com escoamento da armadura transversal. A Figura 8.3 apresenta o panorama de fissuração nas proximidades do colapso.

\subsubsection{4 - VQ-3}

$\mathrm{Na}$ etapa de $60 \mathrm{kN}$, surgiram as primeiras fissuras de flexão na nervura tracionada ( eixo 1) da viga VQ-3. As primeiras fissuras de cisalhamento na alma (região A2) surgiram na etapa de $75 \mathrm{kN}$, quando apareceram também inúmeras fissuras de flexão na nervura tracionada, tanto no eixo 1 quanto no eixo 2 . A partir da etapa de $165 \mathrm{kN}$, algumas fissuras de cisalhamento apresentaram aberturas de até $0,30 \mathrm{~mm}$.

Nas proximidades da ruína, as fissuras de cisalhamento também apresentaram grandes aberturas, caracterizando uma ruína por força cortante-tração com escoamento da armadura transversal. Após o escoamento dos estribos, a viga ainda suportou acréscimos de força, ocorrendo a ruptura de 3 estribos simultaneamente. A Figura 8.4 apresenta o panorama de fissuração nas proximidades do colapso. 


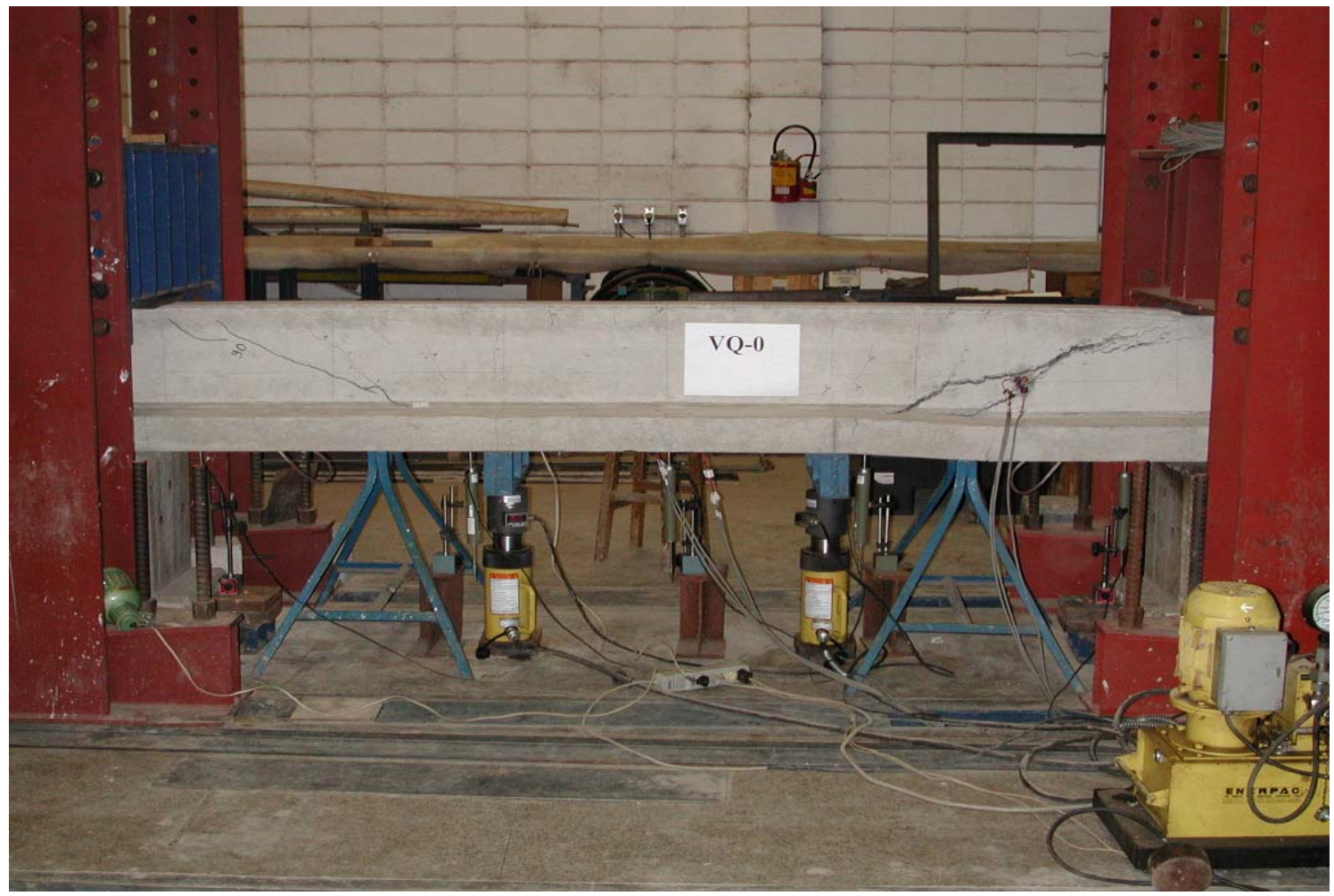

Figura 8.1 - Panorama de fissuração na viga VQ-0 na ruína.

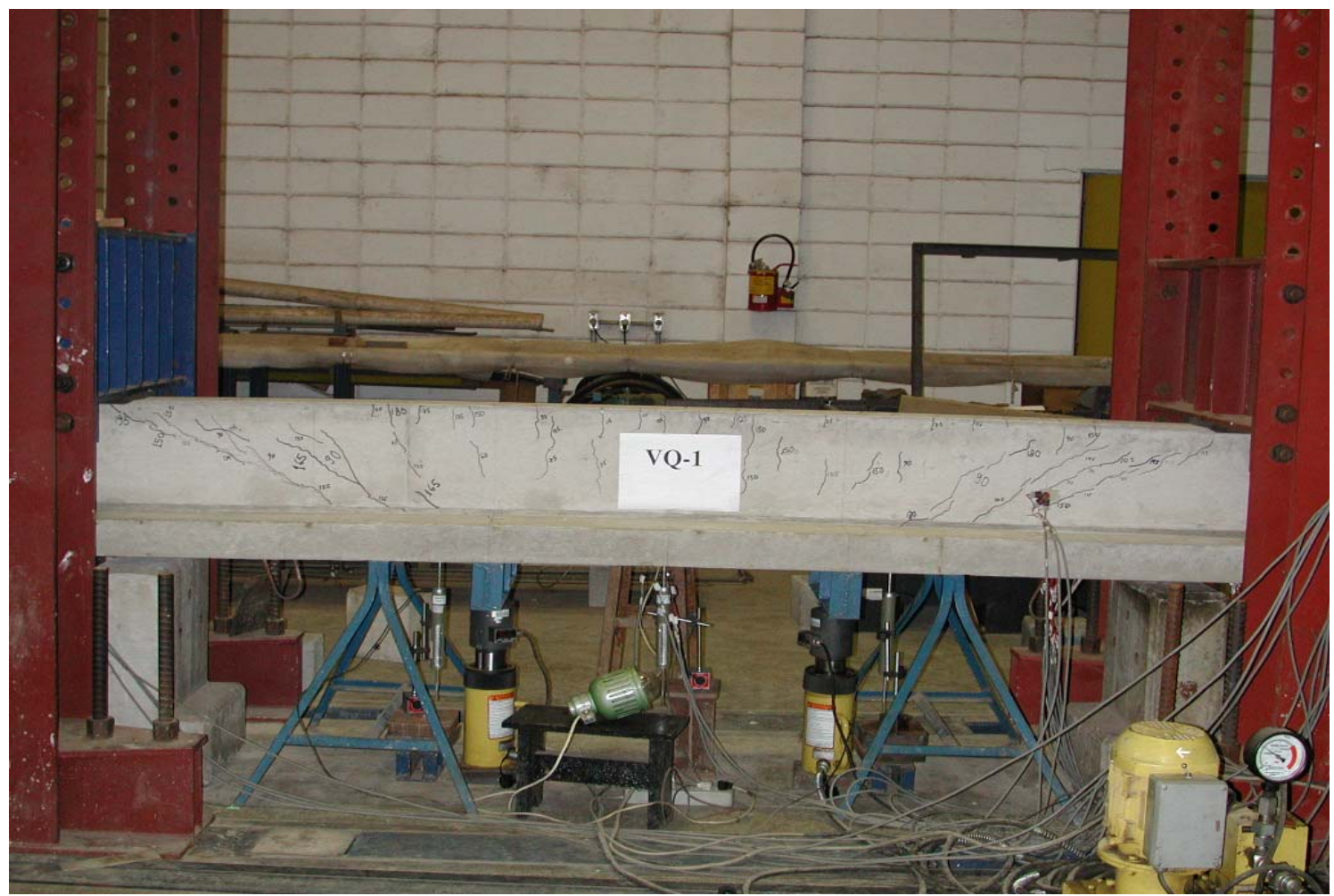

Figura 8.2 - Panorama de fissuração na viga VQ-1 nas proximidades da ruína. 


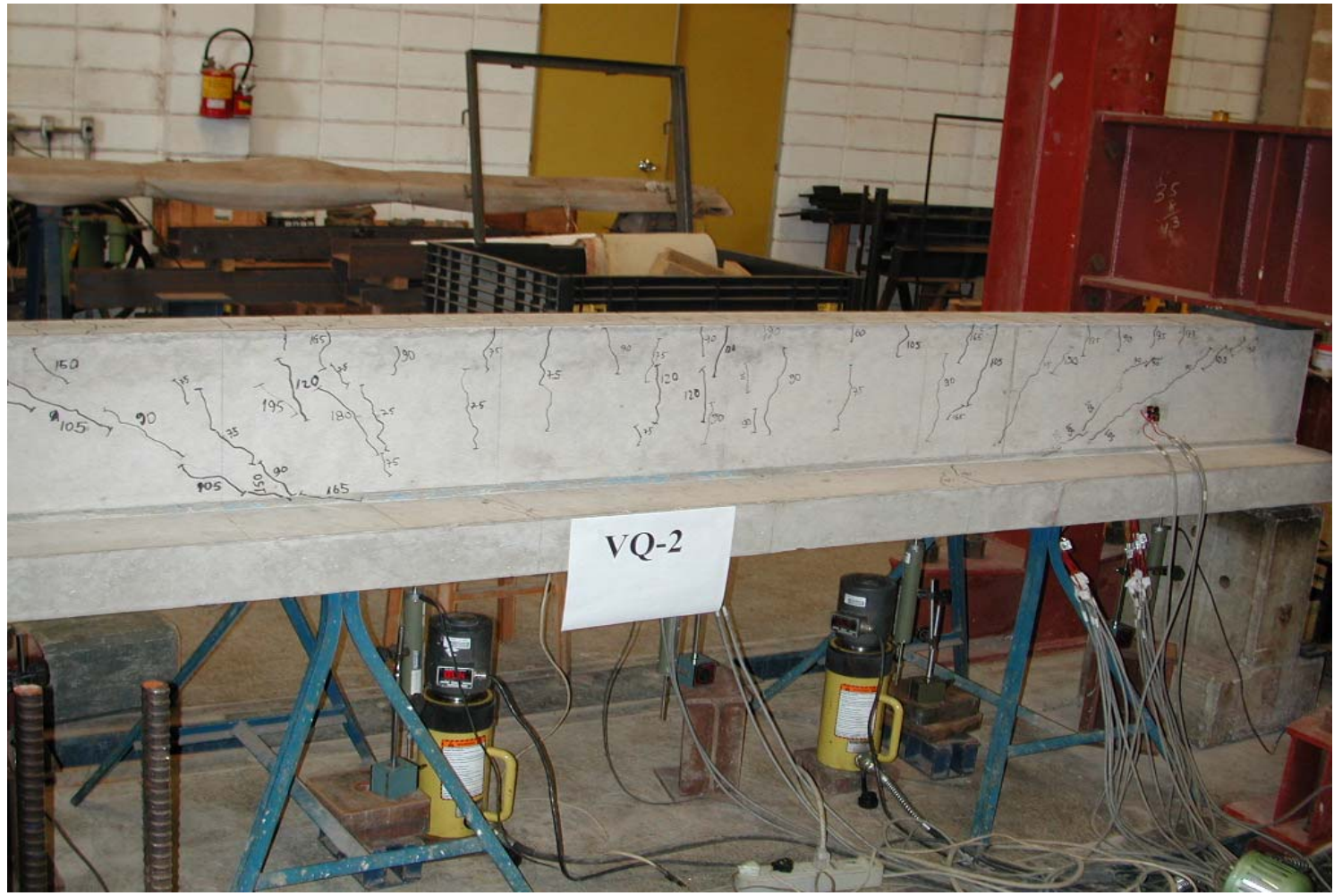

Figura 8.3 - Panorama de fissuração na viga VQ-2 nas proximidades da ruína.

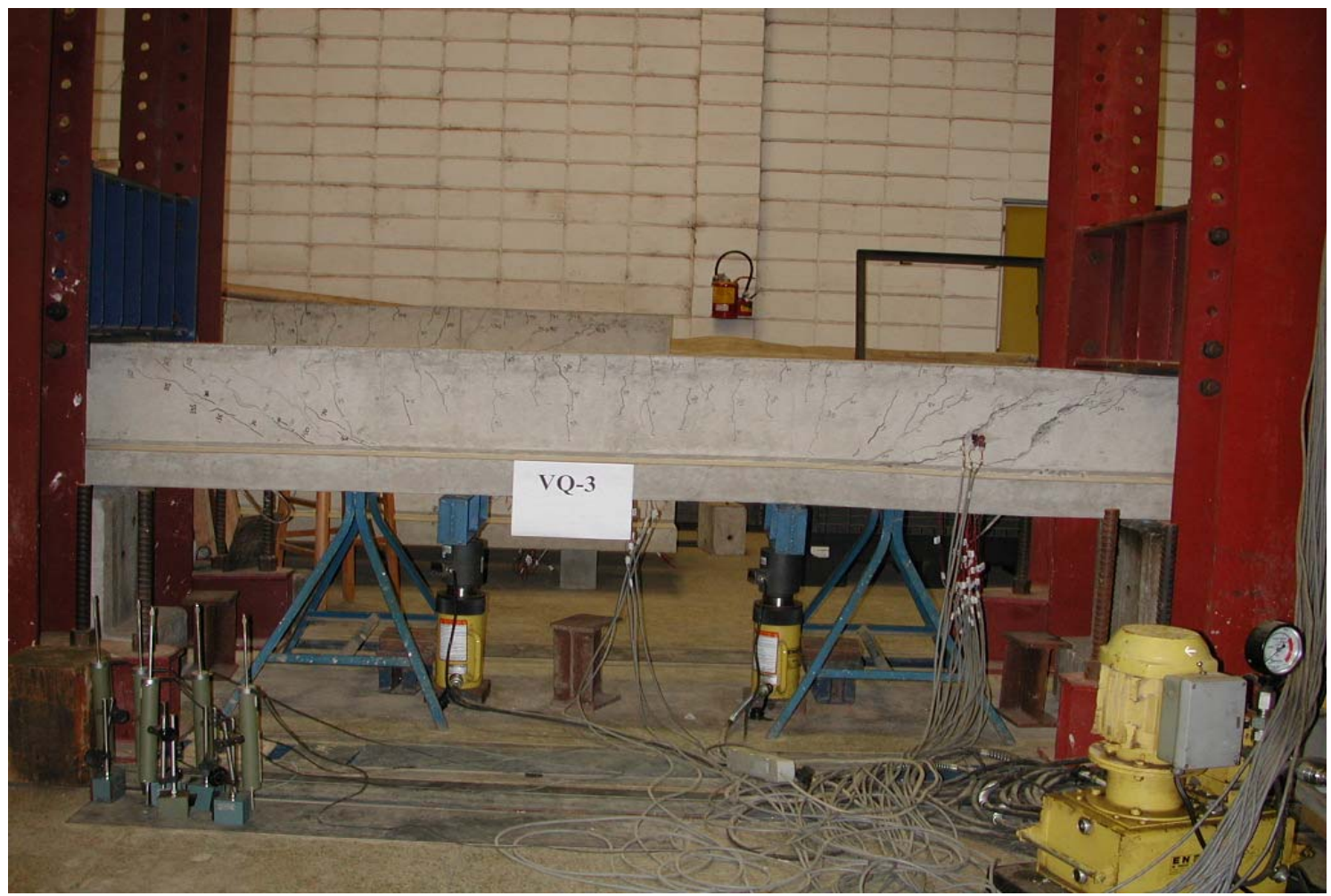

Figura 8.4 - Panorama de fissuração na viga VQ-3 após o colapso. 


\subsection{2 - SÉRIE B}

\subsubsection{1 - VQ-4}

As primeiras fissuras tanto na nervura tracionada quanto na alma da viga VQ-4 surgiram na etapa de $75 \mathrm{kN}$. A partir da etapa de $150 \mathrm{kN}$, as aberturas das fissuras de cisalhamento na alma, no vão de corte (regiões A1/C1 e A2/C2), apresentaram valores entre $0,30 \mathrm{~mm}$ e $0,40 \mathrm{~mm}$.

A ruína, por força cortante-tração, ocorreu do lado direito, onde os estribos não foram instrumentados. A Figura 8.5 apresenta o panorama de fissuração nas proximidades do colapso.

\subsubsection{2 - VQ-5}

$\mathrm{Na}$ etapa de $75 \mathrm{kN}$ também apareceram as primeiras fissuras na nervura tracionada e na alma da viga VQ-5. As fissuras de cisalhamento apresentaram aberturas de até $0,40 \mathrm{~mm}$, a partir da etapa de $135 \mathrm{kN}$.

Nas proximidades da ruína as fissuras de cisalhamento apresentaram grandes aberturas, caracterizando uma ruína por força cortante-tração com escoamento da armadura transversal. O colapso ocorreu do lado esquerdo, onde os estribos foram instrumentados. A Figura 8.6 apresenta o panorama de fissuração nas proximidades do colapso.

\subsubsection{3 - VQ-6}

As primeiras fissuras observadas na viga VQ-6 foram de flexão, na nervura tracionada, na etapa de $45 \mathrm{kN}$. As primeiras fissuras de cisalhamento na alma surgiram na etapa de $75 \mathrm{kN}$. Essas fissuras, a partir da etapa de $120 \mathrm{kN}$, apresentaram aberturas de até $0,35 \mathrm{~mm}$.

Nas proximidades da ruína as fissuras de cisalhamento também apresentavam grandes aberturas, caracterizando uma ruína por força cortante-tração com escoamento da armadura transversal. O colapso ocorreu do lado esquerdo, onde os estribos foram instrumentados. A Figura 8.7 apresenta o panorama de fissuração nas proximidades do colapso. 


\subsubsection{4 - VQ-1A}

Nas etapas de $45 \mathrm{kN}$ e $75 \mathrm{kN}$, apareceram as primeiras fissuras na nervura tracionada da viga VQ-1A, eixos 1 e 2 , respectivamente. Na etapa de $75 \mathrm{kN}$ também apareceram as primeiras fissuras de cisalhamento na alma da viga. Essas fissuras apresentaram aberturas de até $0,30 \mathrm{~mm}$, a partir da etapa de $150 \mathrm{kN}$.

Nas proximidades da ruína, que ocorreu do lado esquerdo (estribos instrumentados), as fissuras de cisalhamento apresentaram grandes aberturas caracterizando uma ruína por força cortante-tração com escoamento da armadura transversal (Figura 8.8).

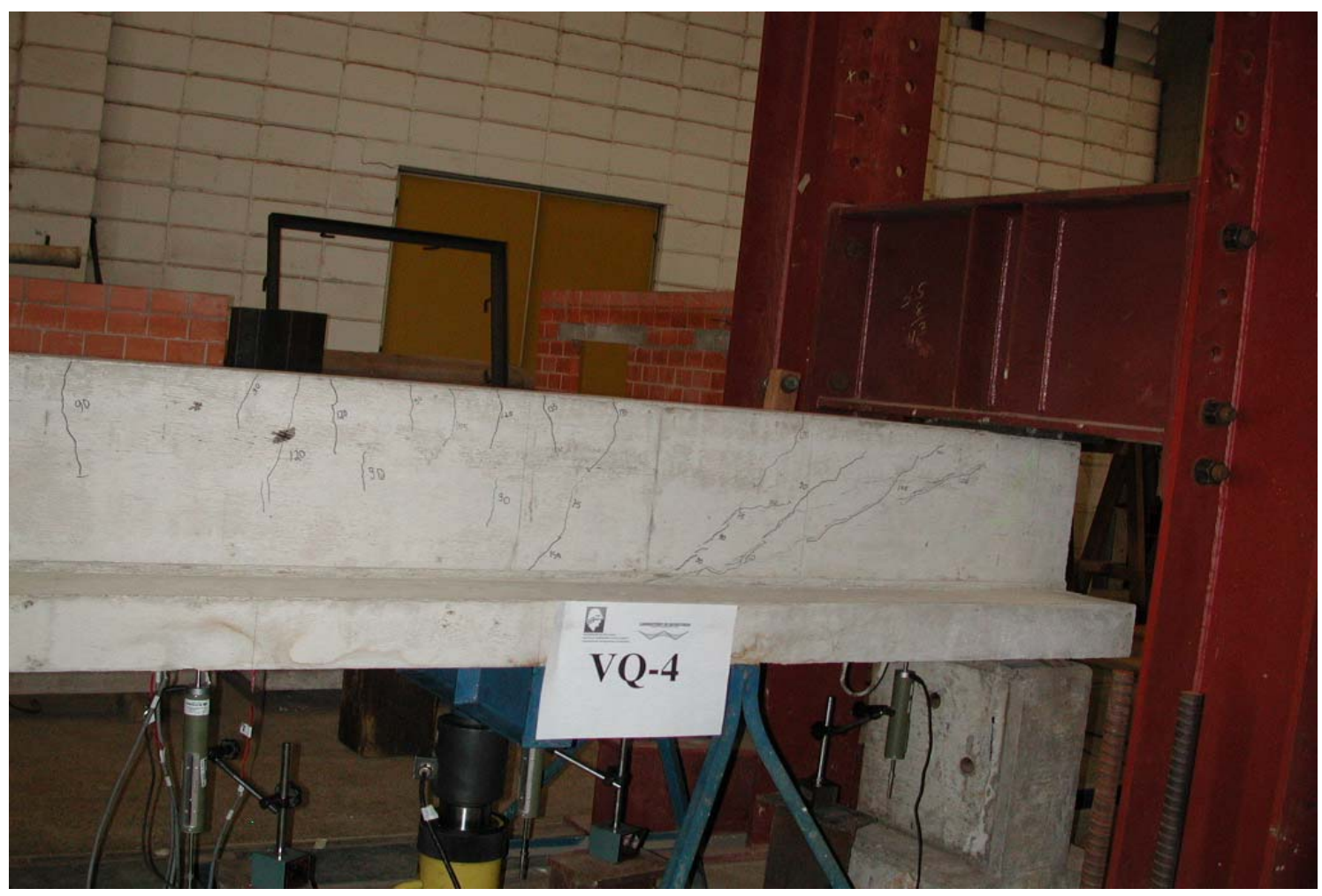

Figura 8.5 - Panorama de fissuração na viga VQ-4 nas proximidades da ruína. 


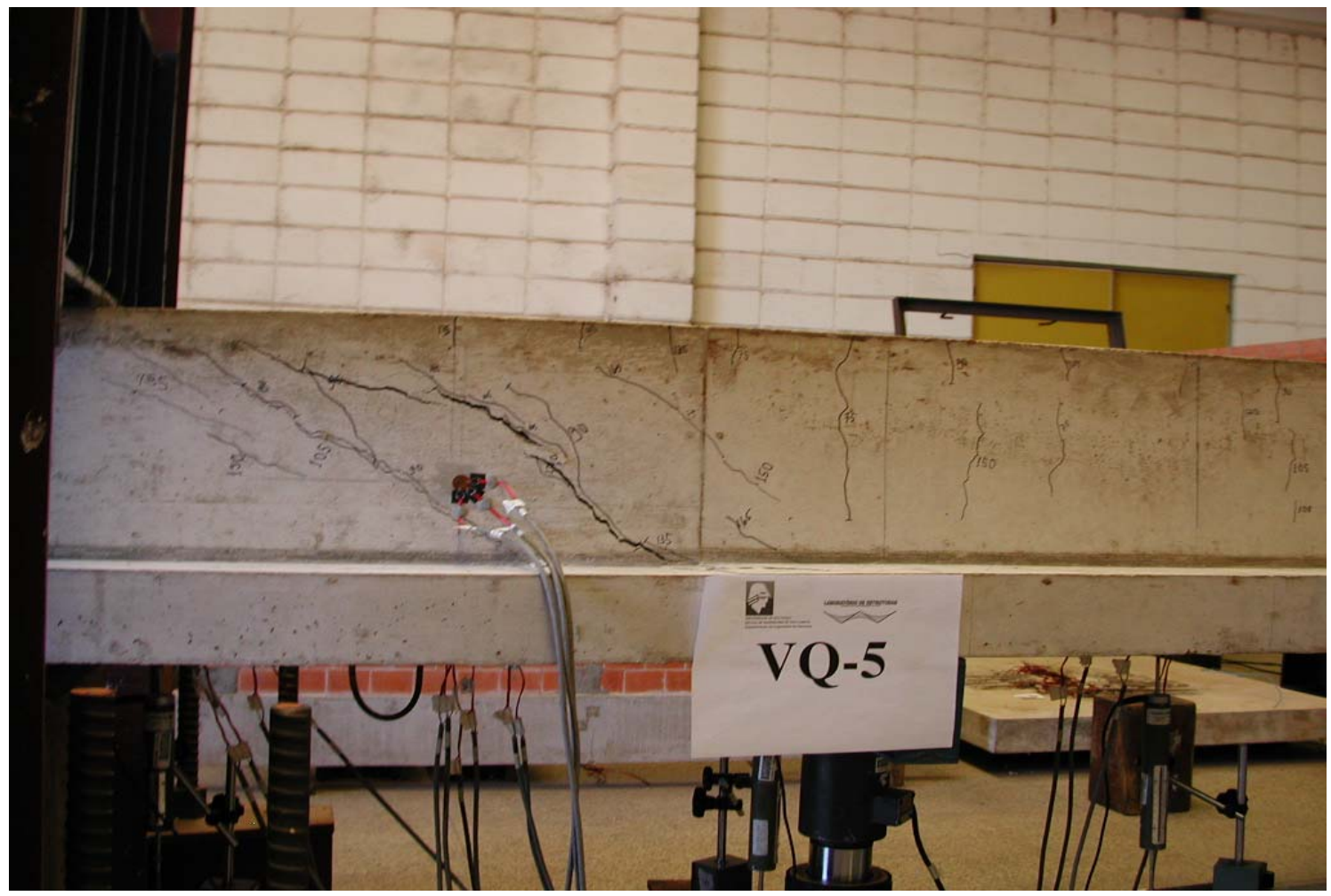

Figura 8.6 - Panorama de fissuração da viga VQ-5 na ruína.

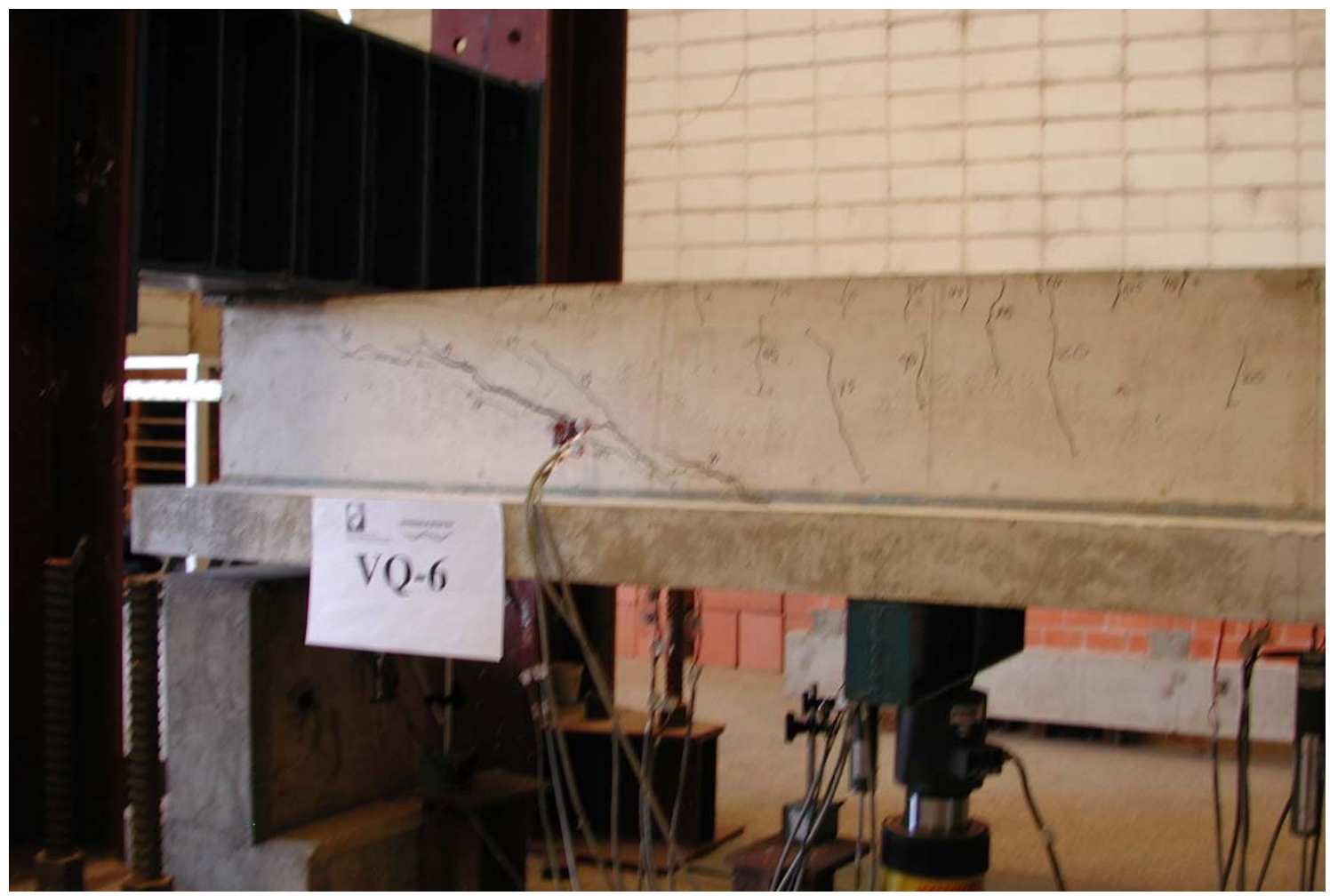

Figura 8.7 - Panorama de fissuração da viga VQ-6 na ruína. 


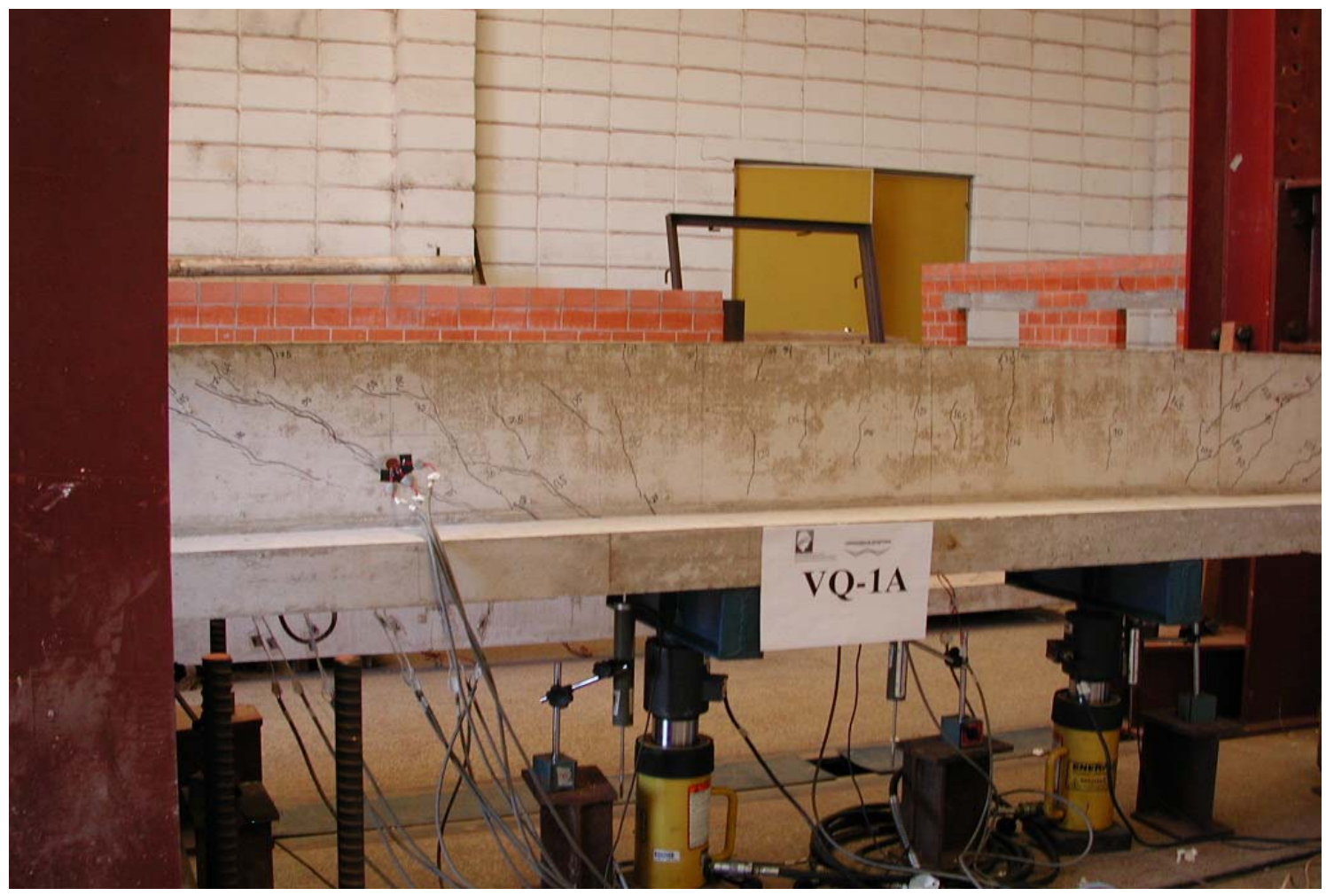

Figura 8.8 - Panorama de fissuração da viga VQ-1A após o colapso.

\subsection{3 - SÉRIE D}

\subsubsection{1 - VQ-7}

$\mathrm{Na}$ etapa de $60 \mathrm{kN}$ apareceram as primeiras fissuras na nervura tracionada e na etapa de $90 \mathrm{kN}$, as fissuras de cisalhamento na alma da viga VQ-7. As fissuras de cisalhamento apresentaram aberturas de até $0,30 \mathrm{~mm}$ a partir da etapa de $180 \mathrm{kN}$.

Nas proximidades da ruína as fissuras de cisalhamento apresentaram grandes aberturas, caracterizando uma ruína por força cortante-tração com escoamento da armadura transversal, que ocorreu do lado esquerdo (estribos instrumentados). A Figura 8.9 apresenta o panorama de fissuração nas proximidades do colapso.

\subsubsection{2 - VQ-8}

As primeiras fissuras na nervura tracionada e na alma da viga surgiram nas etapas de $75 \mathrm{kN}$ e $90 \mathrm{kN}$, respectivamente. A partir da etapa de $180 \mathrm{kN}$, as aberturas das fissuras de 
cisalhamento na alma, no vão de corte (regiões A1/C1 e A2/C2), apresentaram valores entre $0,16 \mathrm{~mm}$ e $0,25 \mathrm{~mm}$.

A ruína, por força cortante-tração, ocorreu do lado direito (estribos instrumentados). A Figura 8.10 apresenta o panorama de fissuração nas proximidades do colapso.

\subsubsection{3 - VQ-9}

As primeiras fissuras observadas na viga VQ-9 foram de flexão, na nervura tracionada, na etapa de $60 \mathrm{kN}$. As primeiras fissuras de cisalhamento na alma surgiram na etapa de $90 \mathrm{kN}$ e, a partir da etapa de $180 \mathrm{kN}$ as mesmas apresentaram aberturas de até 0,35 $\mathrm{mm}$.

Nas proximidades da ruína as fissuras de cisalhamento também apresentaram grandes aberturas, caracterizando uma ruína por força cortante-tração com escoamento da armadura transversal, que ocorreu do lado direito, onde os estribos não foram instrumentados. A Figura 8.11 apresenta o panorama de fissuração após o colapso.

\subsubsection{4 - VQ-10}

$\mathrm{Na}$ etapa de $45 \mathrm{kN}$ apareceram as primeiras fissuras na nervura tracionada e, na etapa de $75 \mathrm{kN}$, as fissuras de cisalhamento na alma da viga VQ-10. As fissuras de cisalhamento apresentaram aberturas de até $0,30 \mathrm{~mm}$ a partir da etapa de $165 \mathrm{kN}$.

A partir da etapa de $135 \mathrm{kN}$, o módulo de aquisição de dados deixou de funcionar, sendo então desconsideradas as leituras de deformações nas armaduras longitudinal e transversal. O colapso ocorreu do lado esquerdo, onde os estribos foram instrumentados. A Figura 8.12 apresenta o panorama de fissuração após a ruína. 


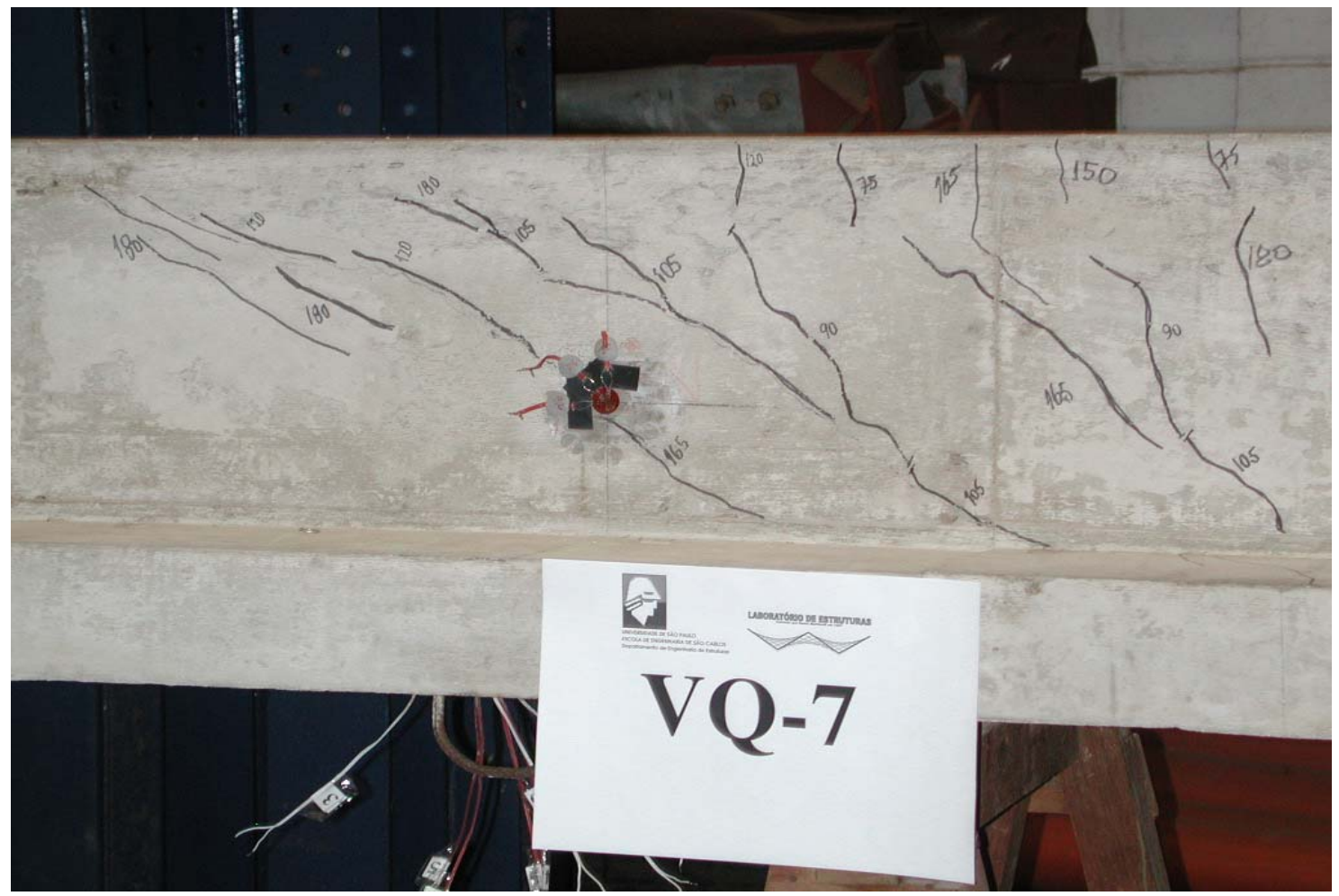

Figura 8.9 - Panorama de fissuração na viga VQ-7 nas proximidades da ruína.

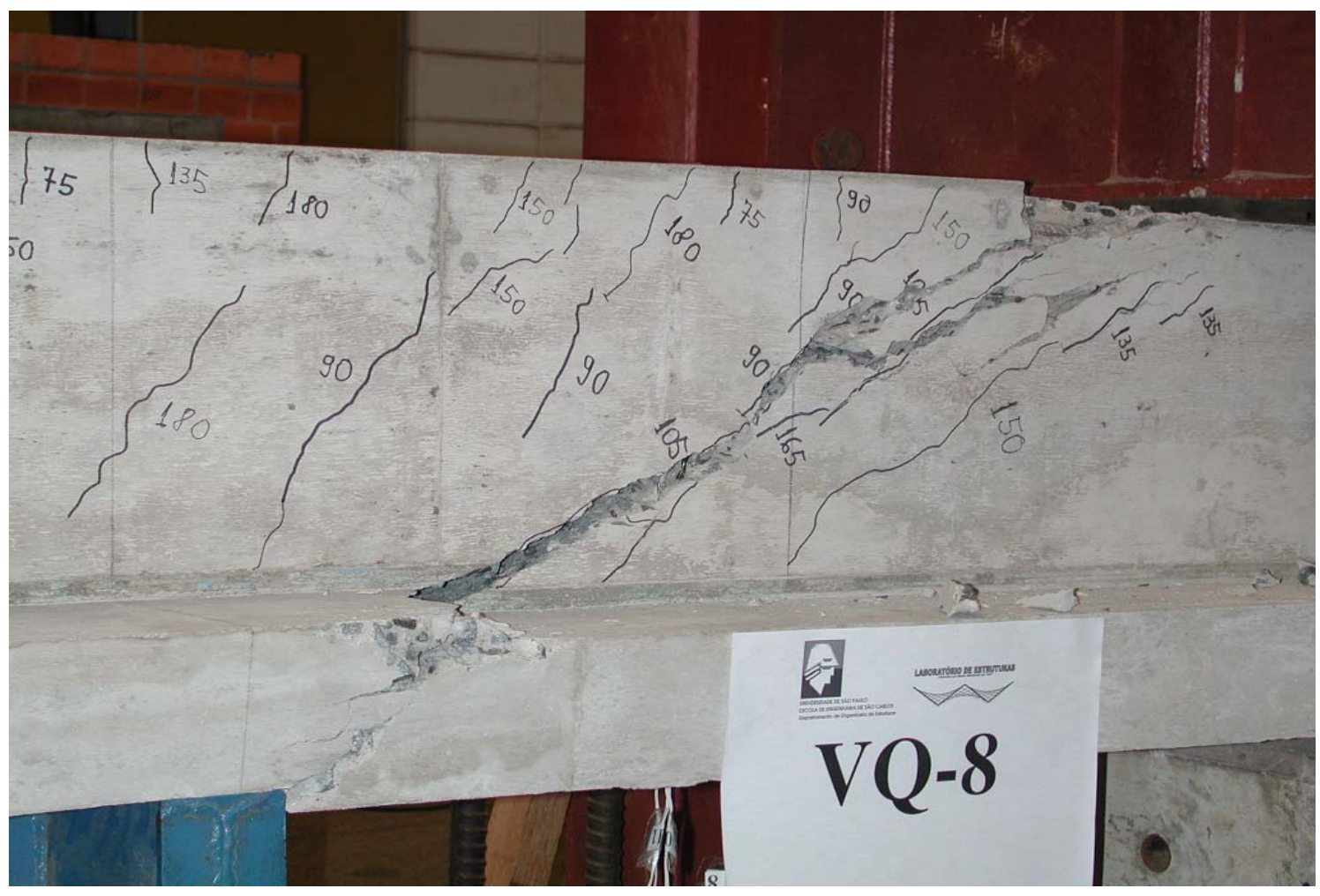

Figura 8.10 - Panorama de fissuração na viga VQ-8 após a ruína. 


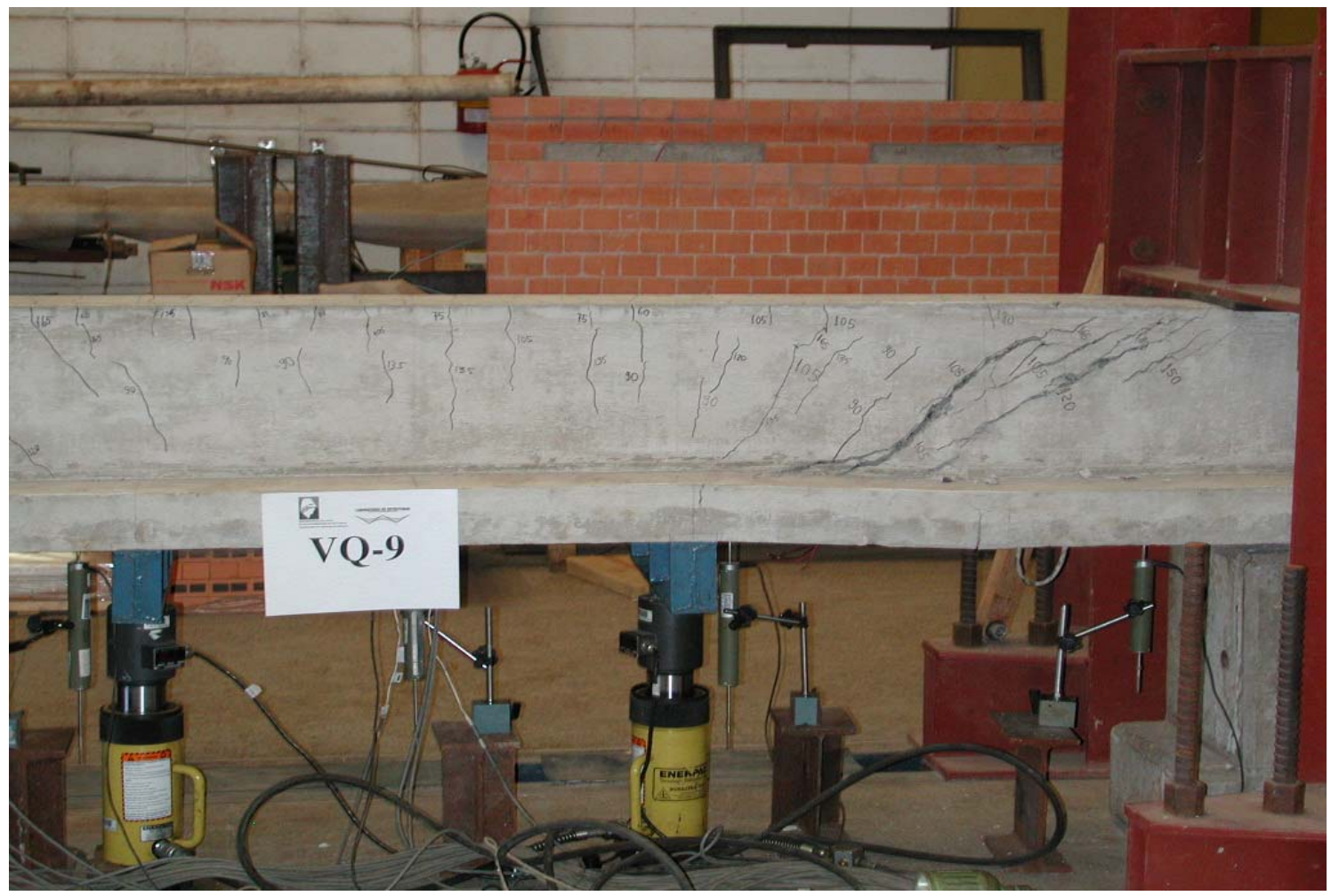

Figura 8.11 - Panorama de fissuração na viga VQ-9 após o colapso.

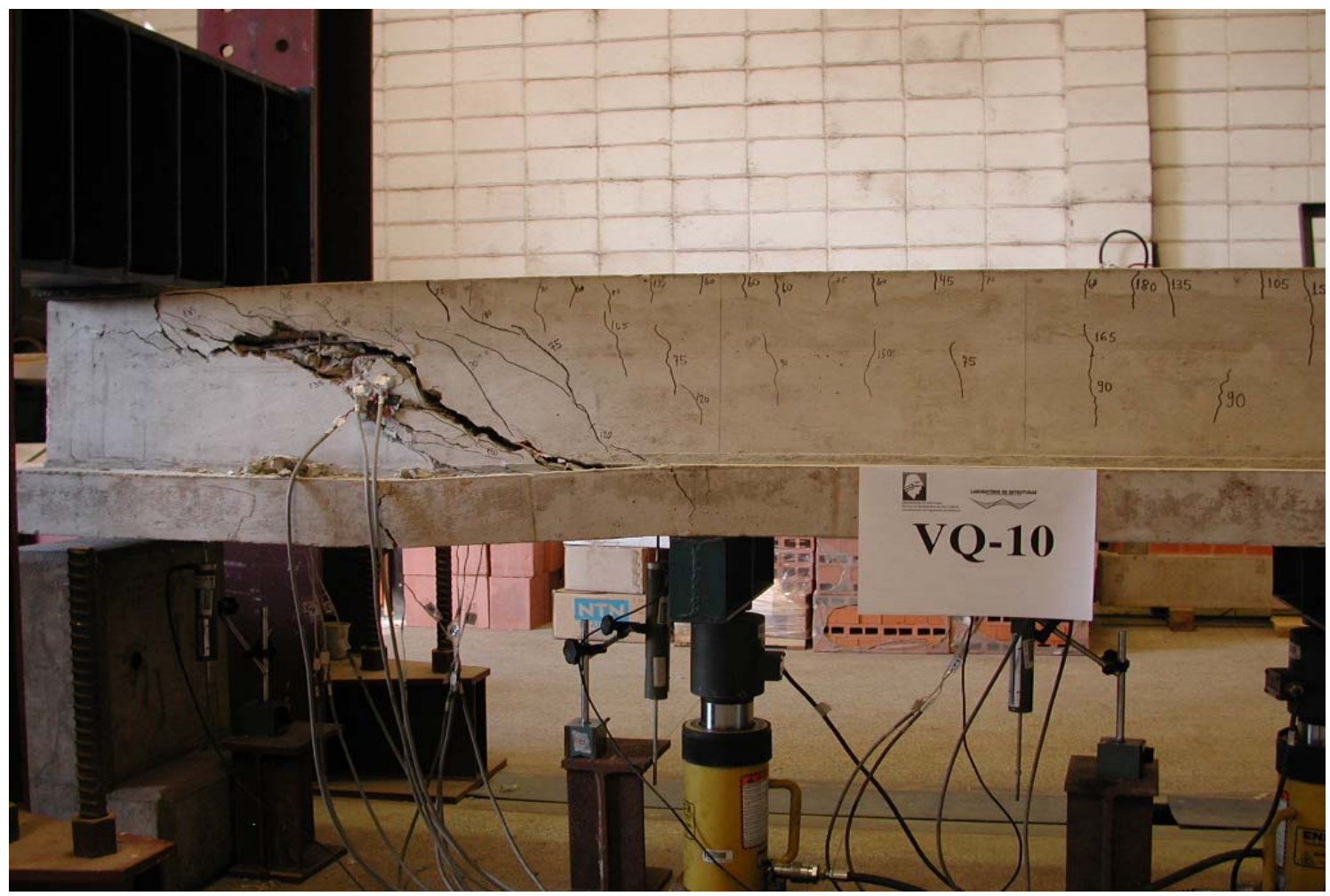

Figura 8.12 - Panorama de fissuração na viga VQ-10 após a ruína. 


\subsection{4 - SÉRIE A2}

\subsubsection{1 - VS-0}

As primeiras fissuras visíveis na nervura tracionada e na alma da viga VS-0 apareceram na etapa de $140 \mathrm{kN}$. Na etapa posterior a fissura de cisalhamento na alma causou a ruína brusca da viga, por tração diagonal, como pode ser observado na Figura 8.13.

É importante salientar que o reparo executado na zona tracionada não influenciou na ruína da viga. A fissura de cisalhamento atravessou toda a alma da viga antes de atingir a borda comprimida e a zona tracionada.

\subsubsection{2 - VS-1}

$\mathrm{Na}$ etapa de $150 \mathrm{kN}$ apareceram as primeiras fissuras visíveis na nervura tracionada e na alma da viga VS-1. As fissuras de cisalhamento apresentaram aberturas de até $0,20 \mathrm{~mm}$ a partir da etapa de $240 \mathrm{kN}$.

Nas proximidades da ruína as fissuras de cisalhamento apresentaram grandes aberturas, caracterizando uma ruína por força cortante-tração com escoamento da armadura transversal, que ocorreu do lado direito (estribos instrumentados). A Figura 8.14 apresenta o panorama de fissuração no colapso.

\subsubsection{3 - VS-2}

$\mathrm{Na}$ etapa de $150 \mathrm{kN}$ apareceram as primeiras fissuras visíveis na nervura tracionada e na alma da viga VS-2. As fissuras de cisalhamento apresentaram aberturas de até $0,20 \mathrm{~mm}$ a partir da etapa de $270 \mathrm{kN}$.

A ruína, por força cortante-tração, ocorreu do lado esquerdo da viga, onde os estribos foram instrumentados. A Figura 8.15 apresenta o panorama de fissuração no colapso. 


\subsubsection{4 - VS-3}

Durante o ensaio da viga VS-3 apareceram as primeiras fissuras na nervura tracionada na etapa de $150 \mathrm{kN}$ e, as fissuras de cisalhamento na alma da viga, na etapa de $120 \mathrm{kN}$. As fissuras de cisalhamento apresentaram aberturas de até $0,20 \mathrm{~mm}$ a partir da etapa de $270 \mathrm{kN}$.

O colapso ocorreu do lado esquerdo, onde os estribos foram instrumentados, com a ruptura de quatro estribos verticais. A Figura 8.16 apresenta o panorama de fissuração da viga VS-3 após a ruína.

Constatou-se, durante este ensaio, uma maior diferença entre os valores de forças aplicadas nos dois cilindros hidráulicos. Além disso, do lado esquerdo da viga (força aplicada menor), no instante do colapso, notou-se a separação das partes fissuradas, enquanto do lado direito, as fissuras de cisalhamento apresentaram aberturas bem menores.

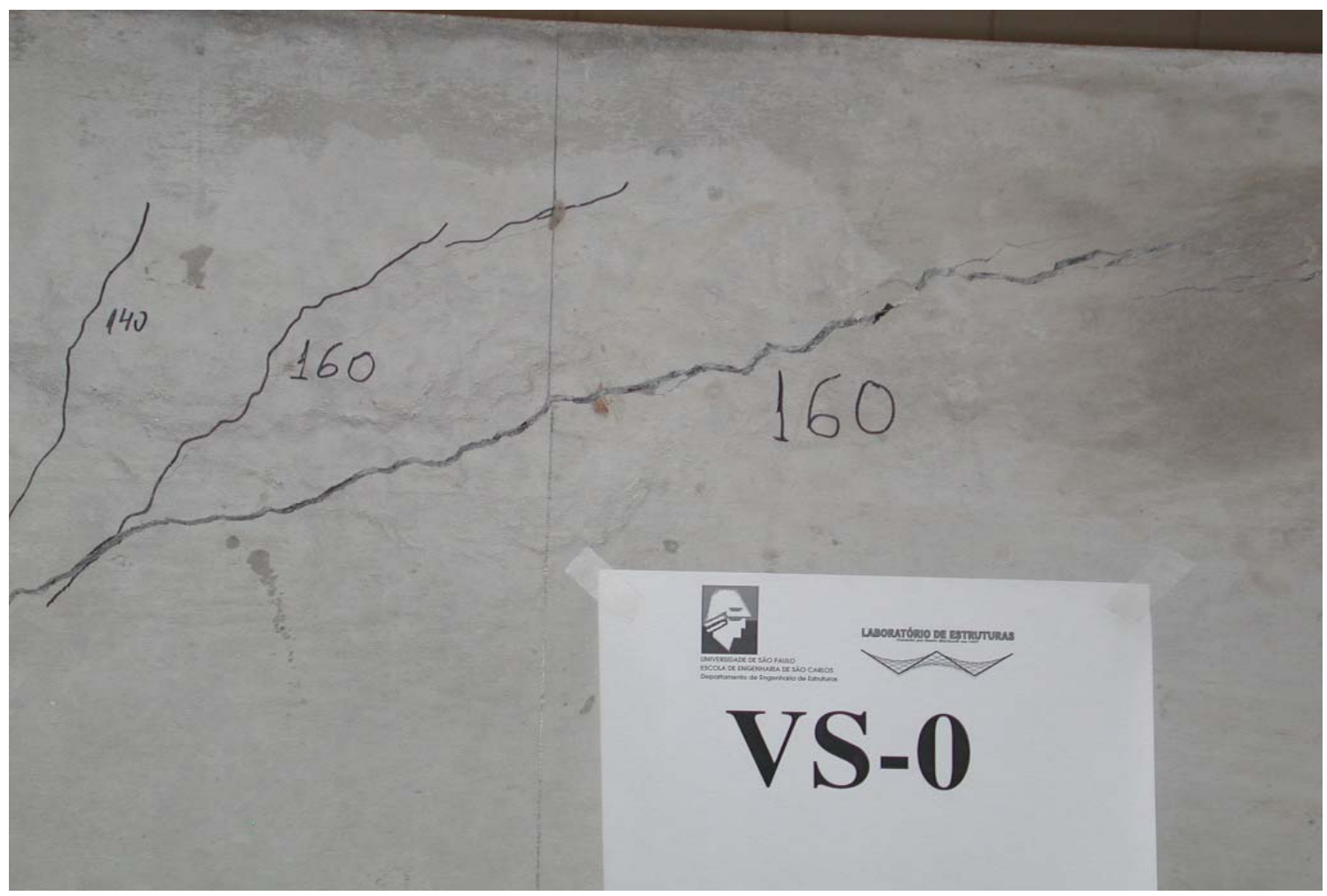

Figura 8.13 - Panorama de fissuração da viga VS-0 após a ruína. 


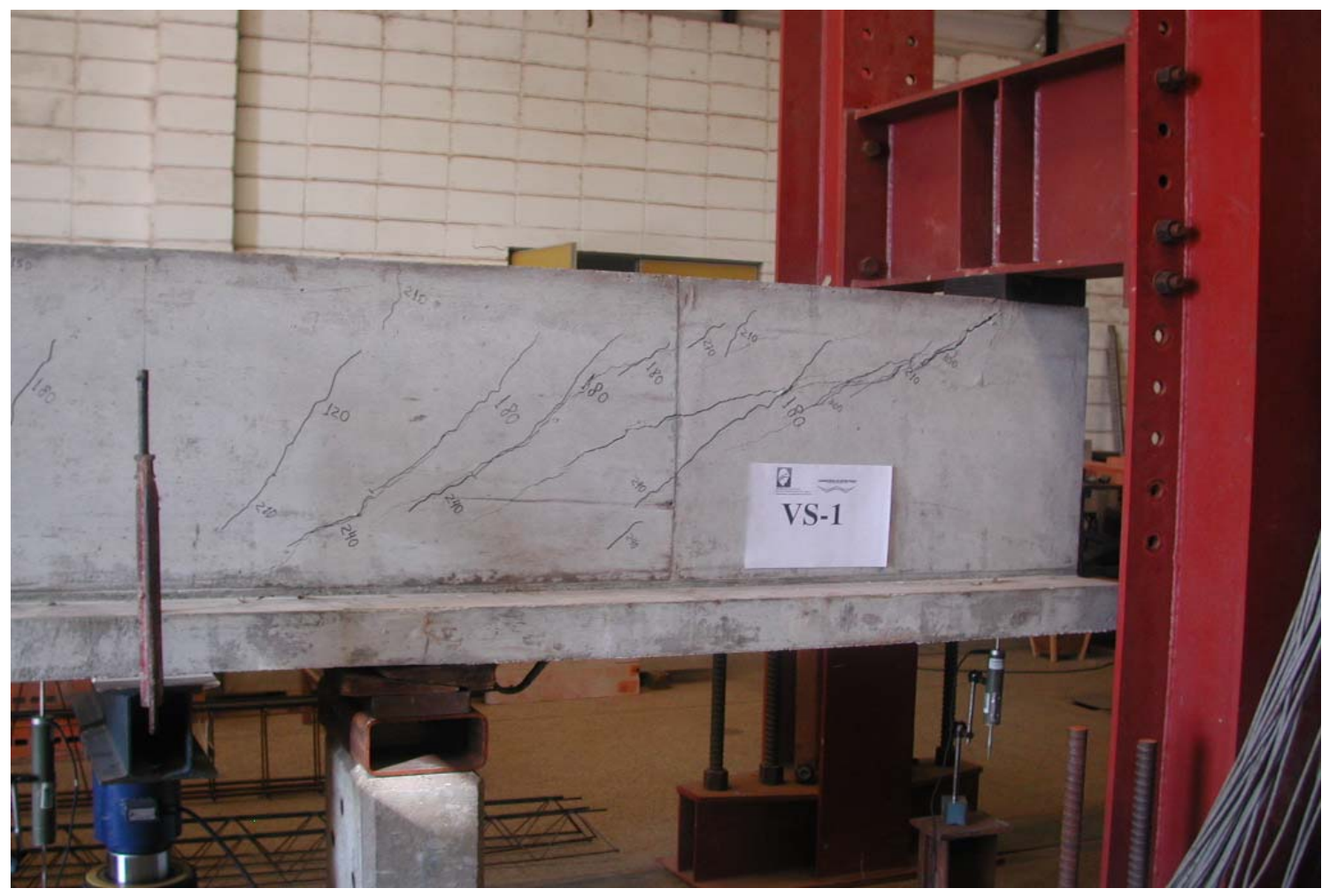

Figura 8.14 - Panorama de fissuração da viga VS-1 após a ruína.

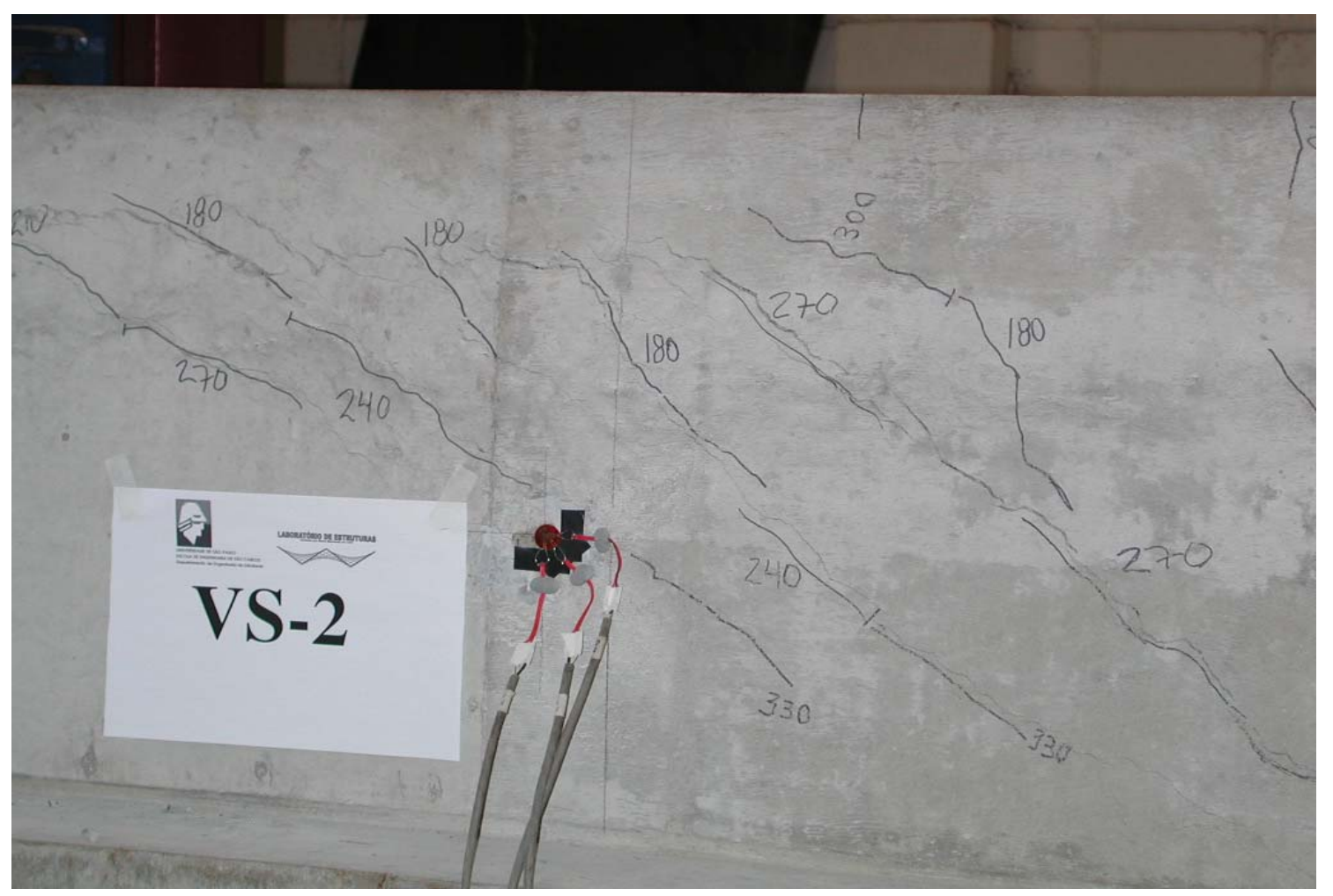

Figura 8.15 - Panorama de fissuração da viga VS-2 após a ruína. 


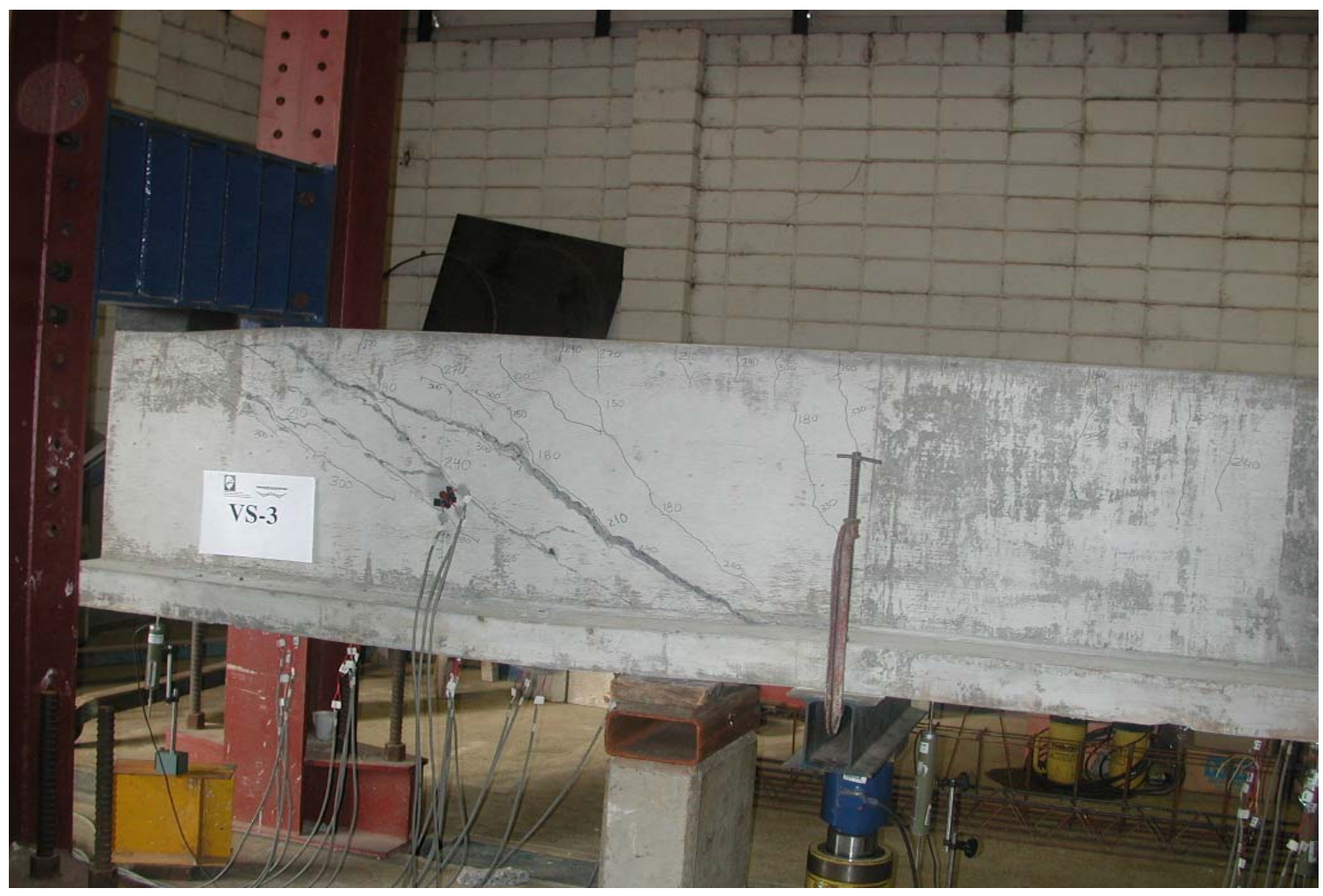

Figura 8.16 - Panorama de fissuração da viga VS-3 após a ruína.

\subsection{5 - SÉRIE C}

\subsubsection{1 - VS-4}

Durante o ensaio da viga VS-4 surgiram as primeiras fissuras na nervura tracionada e de cisalhamento na etapa de $150 \mathrm{kN}$. As fissuras de cisalhamento apresentaram aberturas de até $0,30 \mathrm{~mm}$ a partir da etapa de $330 \mathrm{kN}$.

O colapso ocorreu do lado esquerdo, onde os estribos não foram instrumentados, com a separação das partes da viga e com a ruptura de vários estribos verticais. A Figura 8.17 apresenta o panorama de fissuração na ruptura.

Observa-se que o reparo executado na extremidade direita da mesa comprimida em nada influenciou os resultados. 


\subsubsection{2 - VS-5}

$\mathrm{Na}$ etapa de $150 \mathrm{kN}$ apareceram as primeiras fissuras na nervura tracionada da viga VS-5 e, na etapa de $180 \mathrm{kN}$, as fissuras de cisalhamento. Essas fissuras de cisalhamento apresentavam aberturas de até $0,30 \mathrm{~mm}$ a partir da etapa de $330 \mathrm{kN}$.

O colapso ocorreu do lado direito (estribos instrumentados), com a ruptura de vários estribos verticais. A Figura 8.18 apresenta o panorama de fissuração na ruína.

\subsubsection{3 - VS-6}

Durante o ensaio da viga VS-6 apareceram as primeiras fissuras visíveis na nervura tracionada e de cisalhamento na alma, na etapa de $150 \mathrm{kN}$. As fissuras de cisalhamento apresentaram aberturas de até $0,30 \mathrm{~mm}$ a partir da etapa de $300 \mathrm{kN}$.

A ruína, por força cortante-tração, ocorreu do lado direito da viga (estribos instrumentados), com a separação das partes da viga pela fissura principal de cisalhamento. A Figura 8.19 apresenta o panorama de fissuração após o colapso.

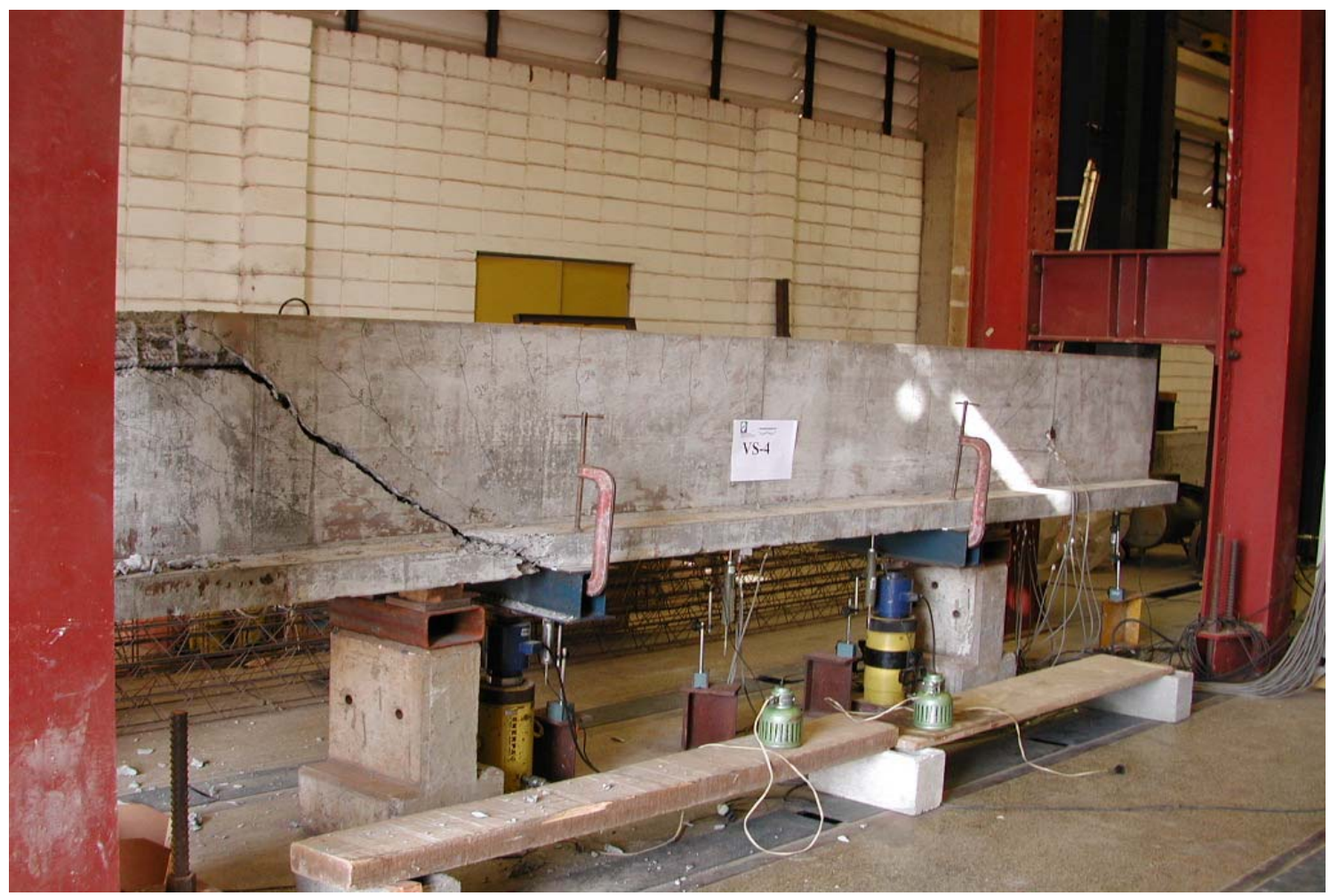

Figura 8.17 - Panorama de fissuração na viga VS-4 após a ruína. 


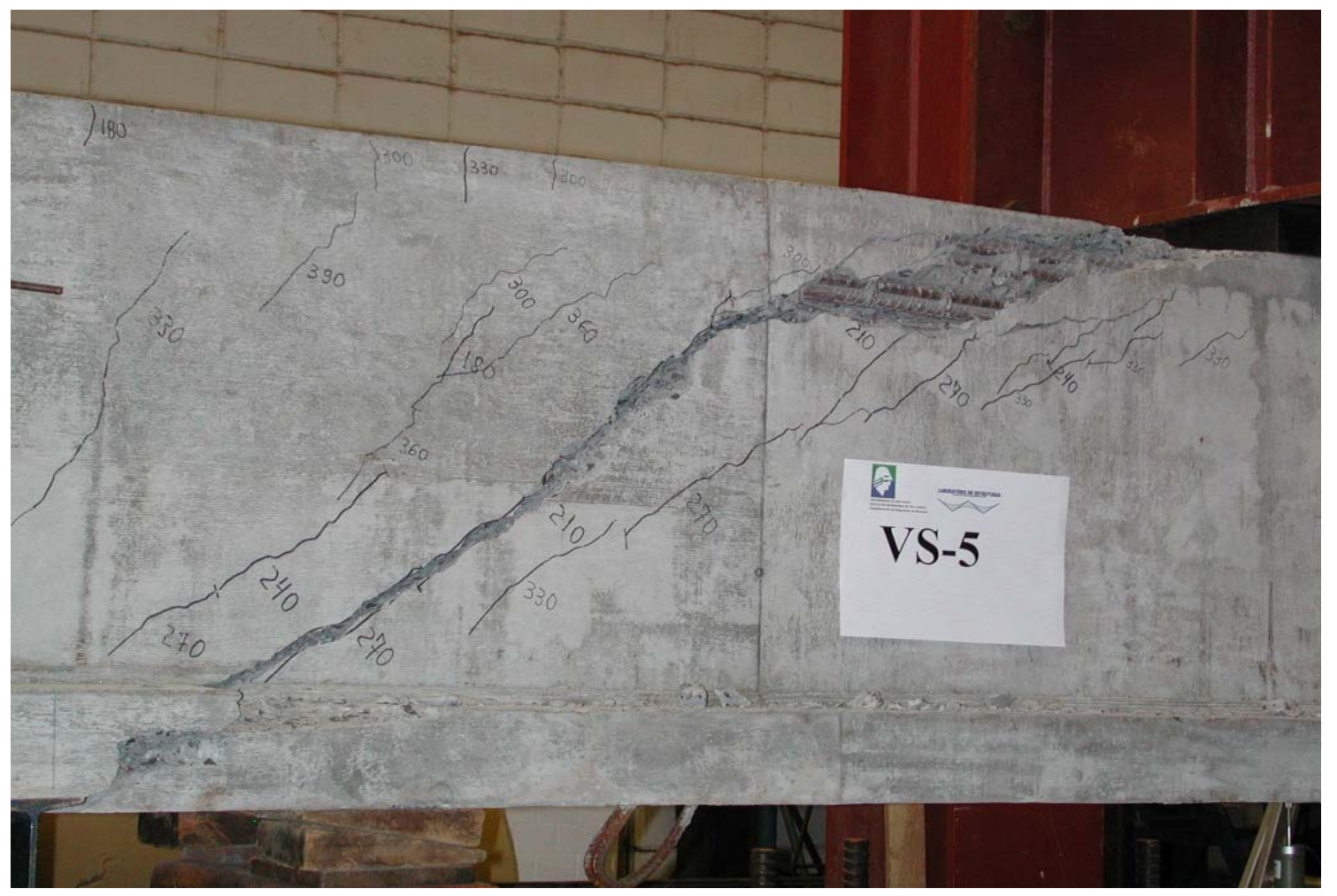

Figura 8.18 - Panorama de fissuração na viga VS-5 após a ruína.

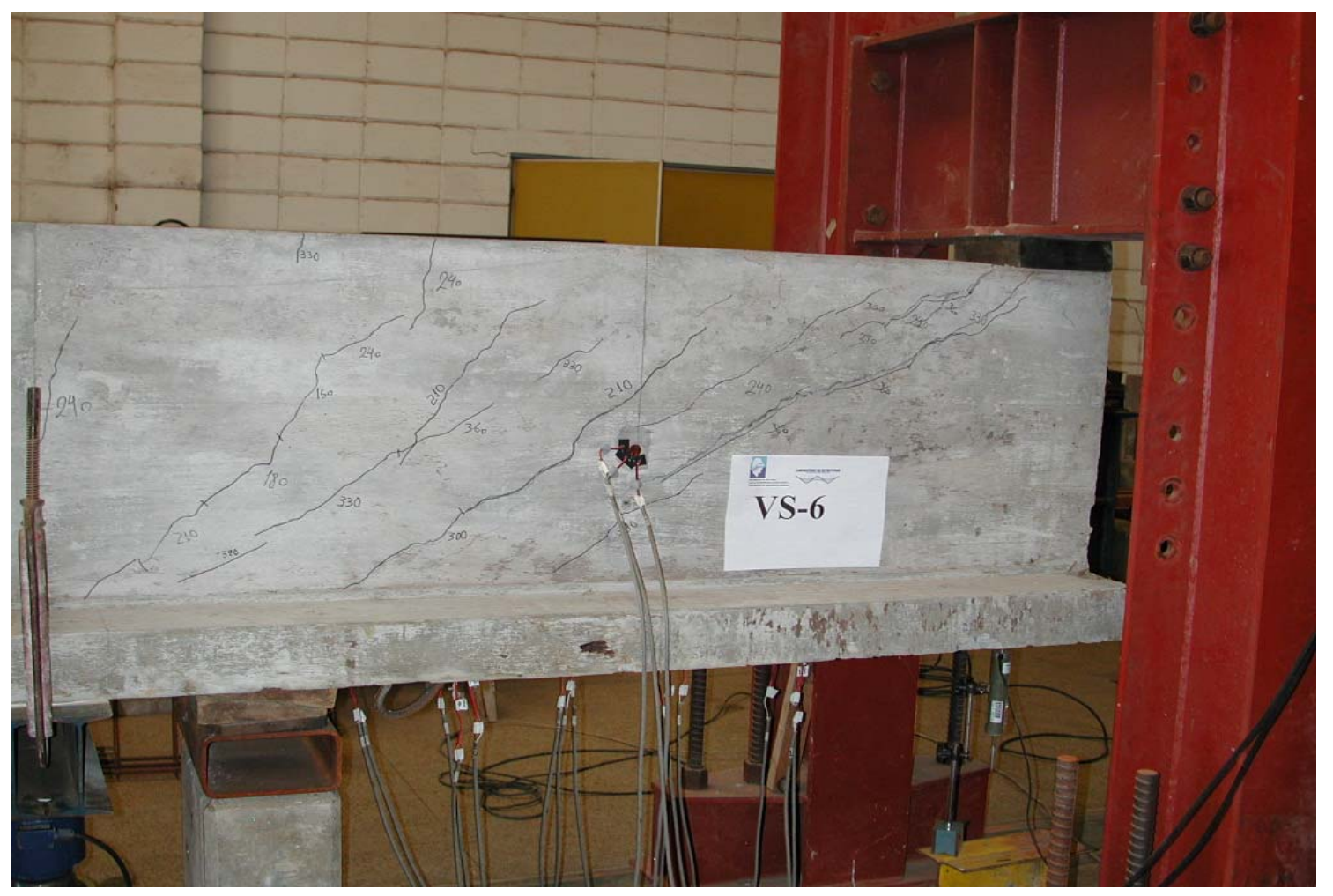

Figura 8.19 - Panorama de fissuração na viga VS-6 após a ruína. 


\section{3 - FORÇAS E MODOS DE RUÍNA}

Observa-se que, em todas as vigas ensaiadas, a ruína se deu por força cortante tração, variando a inclinação das fissuras de cisalhamento.

As vigas VQ-0 e VS-0, sem armadura transversal, apresentaram ruína por tração diagonal, com a formação da fissura principal de cisalhamento.

As vigas com armadura transversal, composta por estribos verticais, atingiram o colapso por força cortante-tração, com escoamento dos estribos e formação da fissura principal de cisalhamento, além de outras fissuras secundárias no vão de corte.

As vigas com telas soldadas também apresentaram ruína por força cortante-tração, também com variações na inclinação da fissura principal. Essas vigas apresentaram uma ruína mais dúctil, com absorção de forças aplicadas, mesmo após o escoamento de alguns estribos verticais.

Apresenta-se a seguir a Tabela 8.1, informando sobre cada viga ensaiada pontos relevantes tais como: resistência à compressão do concreto, taxas de armadura transversal e lateral, idade, tipo de ruína e força cortante última.

Tabela 8.1 - Resumo dos resultados dos ensaios.

\begin{tabular}{|c|c|c|c|c|c|c|c|}
\hline \multirow[t]{2}{*}{ Série } & \multirow[t]{2}{*}{ Vigas } & $\mathbf{f}_{\mathrm{c}}$ & $\rho_{\mathrm{sw}}$ & $\rho_{\mathrm{s}, \mathrm{lat}}$ & $\begin{array}{c}\text { Força última } \\
\left(V_{\text {u,exp }}\right)\end{array}$ & \multirow[t]{2}{*}{$\begin{array}{l}\text { Tipo de } \\
\text { Ruptura }\end{array}$} & Idade \\
\hline & & (MPa) & $(\%)$ & $(\%)$ & $\mathbf{k N}$ & & (dias) \\
\hline \multirow{4}{*}{ A1 } & VQ-0 & 36,8 & --- & --- & 87,0 & $V-T D$ & 43 \\
\hline & VQ-1 & 36,8 & 0,185 & --- & 196,5 & V - TR & 44 \\
\hline & VQ-2 & 36,8 & 0,185 & 0,556 & 196,8 & $\mathrm{~V}-\mathrm{TR}$ & 45 \\
\hline & VQ-3 & 36,8 & 0,185 & 0,556 & 209,1 & $\mathrm{~V}-\mathrm{TR}$ & 48 \\
\hline \multirow{4}{*}{ B } & VQ-4 & 25,4 & 0,141 & 0,636 & 185,1 & V - TR & 30 \\
\hline & VQ-5 & 25,4 & 0,106 & 0,636 & 173,5 & $V-T R$ & 31 \\
\hline & VQ-6 & 25,8 & 0,071 & 0,636 & 145,4 & V - TR & 35 \\
\hline & VQ-1A & 25,8 & 0,185 & --- & 202,5 & $V-T R$ & 37 \\
\hline \multirow{4}{*}{$\mathrm{D}$} & VQ-7 & 25,1 & 0,185 & 0,556 & 213,5 & $\mathrm{~V}-\mathrm{TR}$ & 28 \\
\hline & VQ-8 & 25,1 & 0,185 & 0,556 & 225,4 & $\mathrm{~V}-\mathrm{TR}$ & 29 \\
\hline & VQ-9 & 26,8 & 0,185 & 0,556 & 206,7 & V - TR & 30 \\
\hline & VQ-10 & 26,8 & 0,185 & 0,556 & 228,5 & $V-T R$ & 31 \\
\hline \multirow{4}{*}{$\mathrm{A} 2$} & VS-0 & 17,6 & --- & --- & 161,1 & V - TD & 34 \\
\hline & VS-1 & 18,8 & 0,196 & --- & 366,3 & $V-T R$ & 40 \\
\hline & VS-2 & 17,6 & 0,196 & 1,176 & 358,8 & V - TR & 36 \\
\hline & VS-3 & 18,8 & 0,196 & 1,176 & 384,4 & V - TR & 41 \\
\hline \multirow{3}{*}{$\mathrm{C}$} & VS-4 & 24,9 & 0,196 & 0,523 & 434,8 & V - TR & 29 \\
\hline & VS-5 & 24,9 & 0,196 & 0,294 & 430,3 & $\mathrm{~V}-\mathrm{TR}$ & 28 \\
\hline & VS-6 & 21,0 & 0,196 & 0,131 & 413,9 & $V-T R$ & 28 \\
\hline
\end{tabular}


LEGENDA: V - força cortante; TD - tração diagonal.; TR - tração, com escoamento dos estribos verticais.

$$
\rho_{s, l a t}=\frac{A_{s, l a t}}{b_{w} \cdot s_{l a t}}
$$

\section{4 - DESLOCAMENTOS VERTICAIS}

Os deslocamentos verticais foram medidos no meio do vão (D3), nos pontos de aplicação das forças (D2 e D4) e nos apoios (D1 e D5). Os valores relativos dos deslocamentos no meio do vão foram obtidos pela expressão seguinte:

$$
v_{3}=D_{3}-\left(\left(D_{1}+D_{5}\right) / 2\right)
$$

As Figuras 8.20, 8.21, 8.22, 8.23 e 8.24 apresentam os diagramas força $x$ deslocamento dos ensaios das séries A1, B, D, A2 e C, respectivamente.

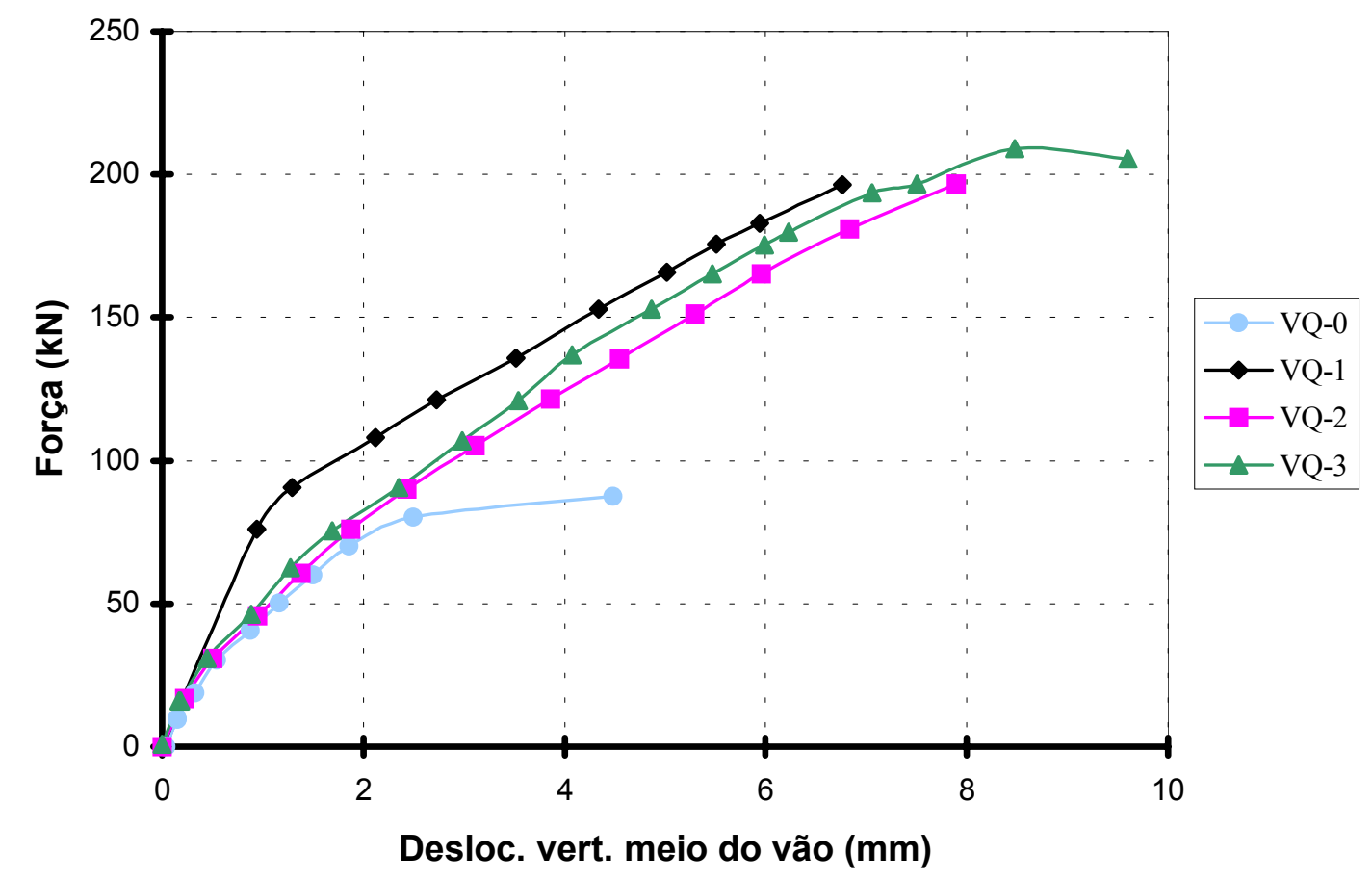

Figura 8.20 - Diagramas força x deslocamento - série A1. 


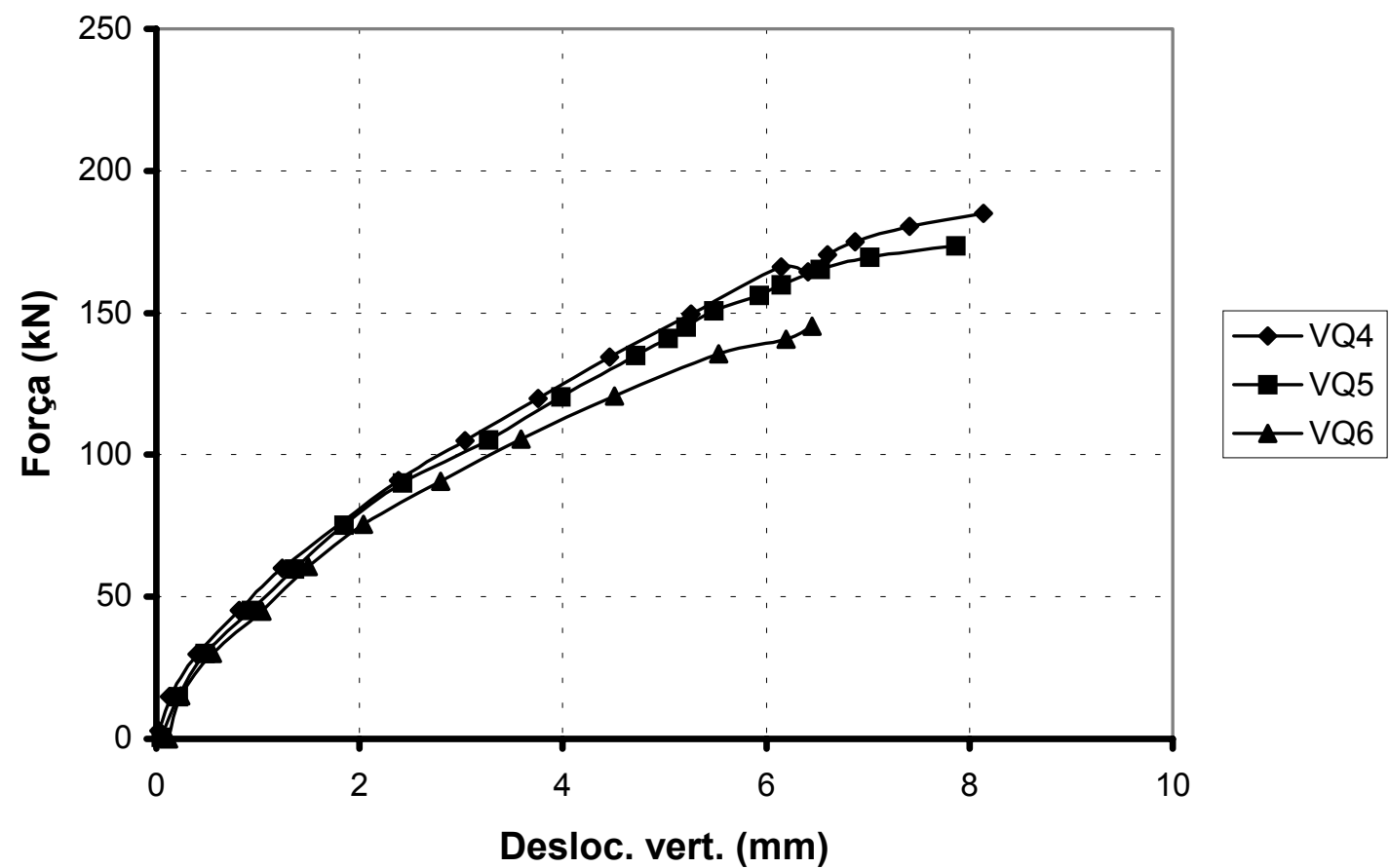

Figura 8.21 - Diagramas força x deslocamento - série B.

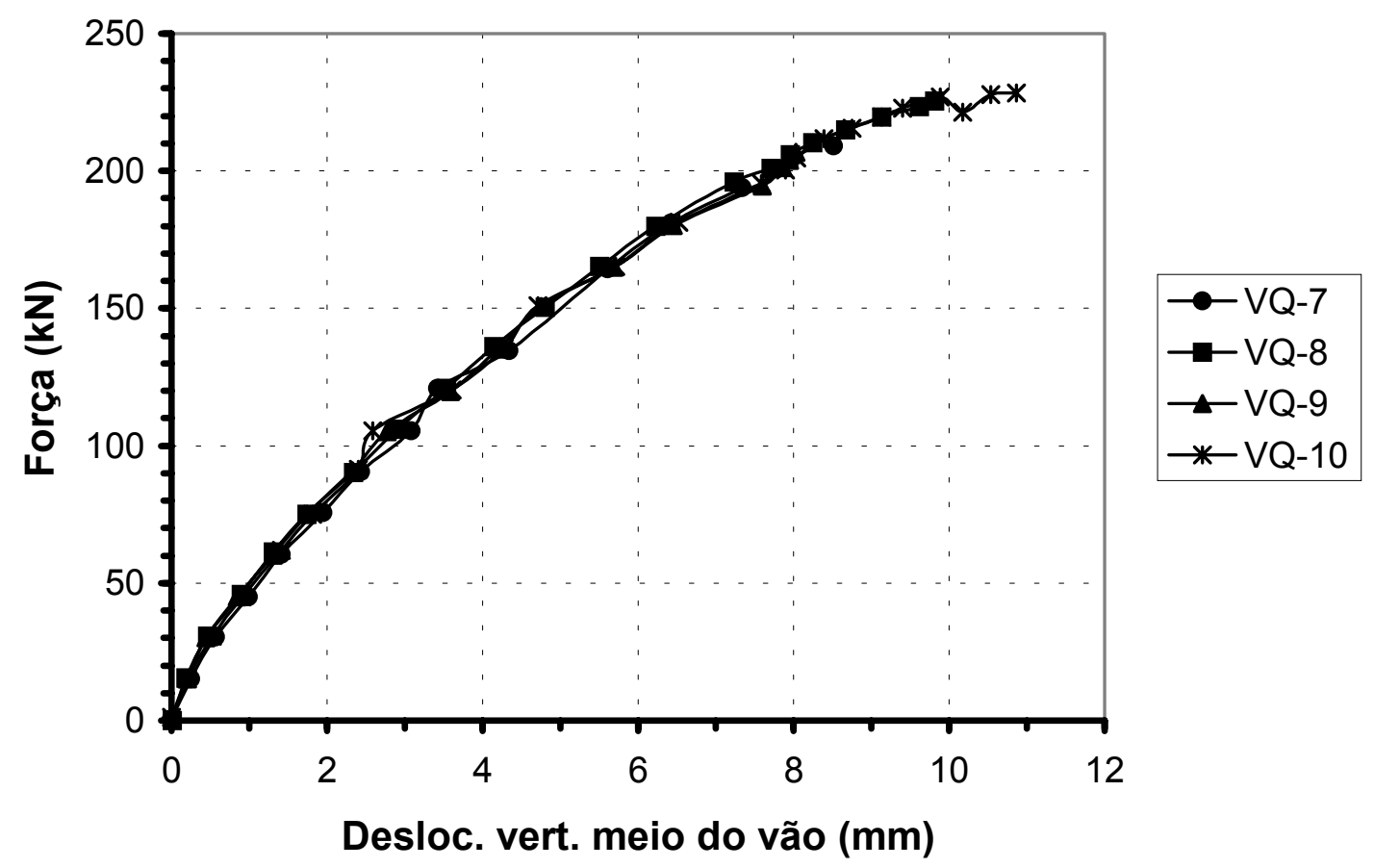

Figura 8.22 - Diagramas força $\mathrm{x}$ deslocamento - série D. 


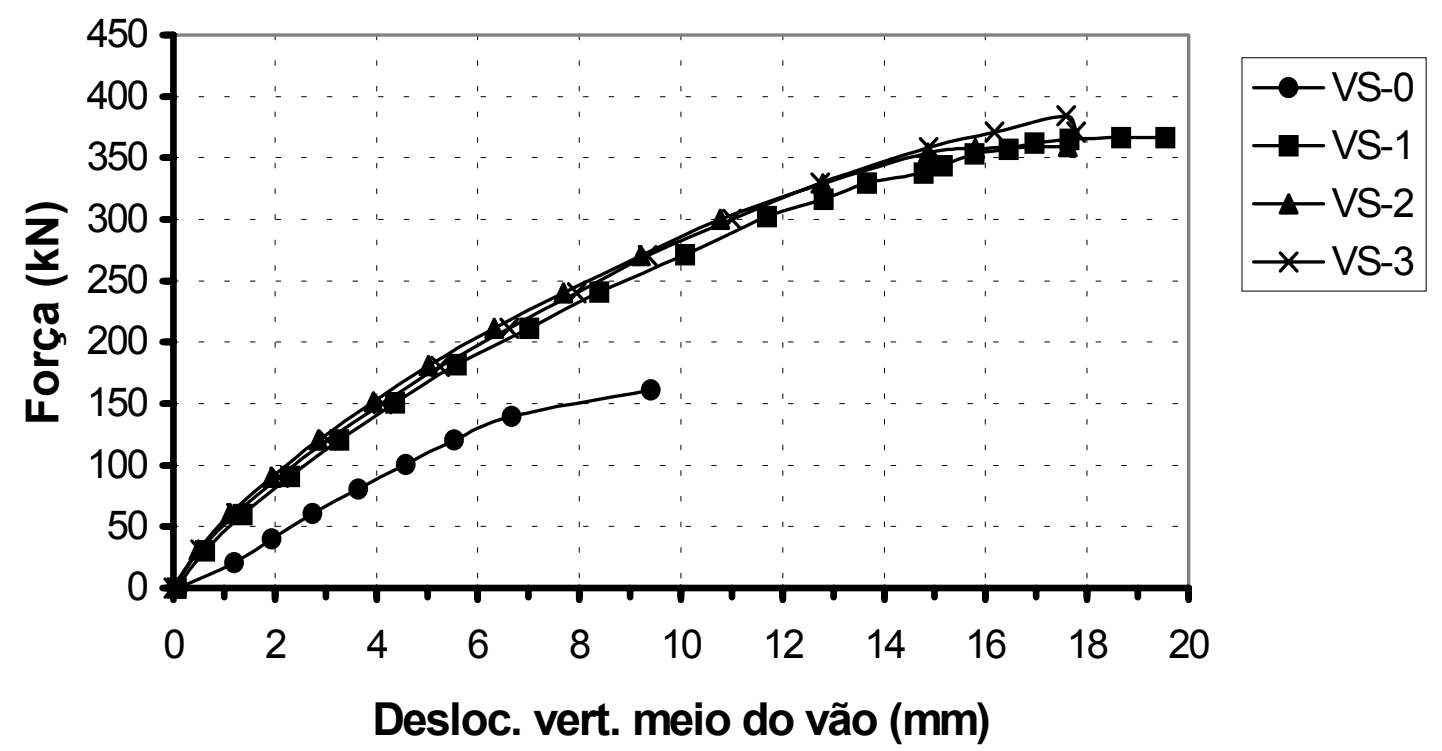

Figura 8.23 - Diagramas força x deslocamento - série A2.

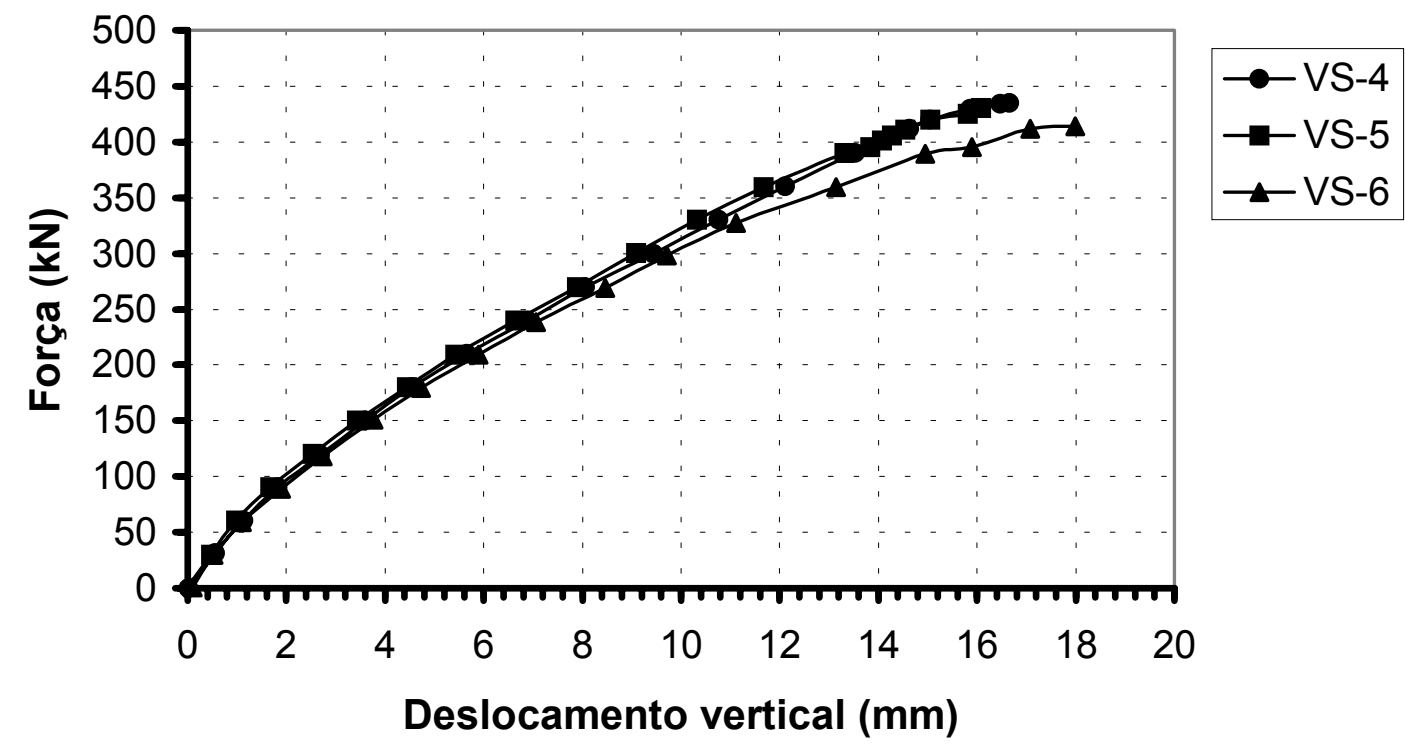

Figura 8.24 - Diagramas força x deslocamento - série C. 


\section{5-DEFORMAÇÕES ARMADURA LONGITUDINAL}

As Figuras $8.25,8.26,8.27,8.28$ e 8.29 apresentam os diagramas força $\mathrm{x}$ deformação na armadura longitudinal (meio do vão) dos ensaios das séries A1, B, D, A2 e C, respectivamente. Os valores mostrados são a média dos valores obtidos em duas barras instrumentadas.

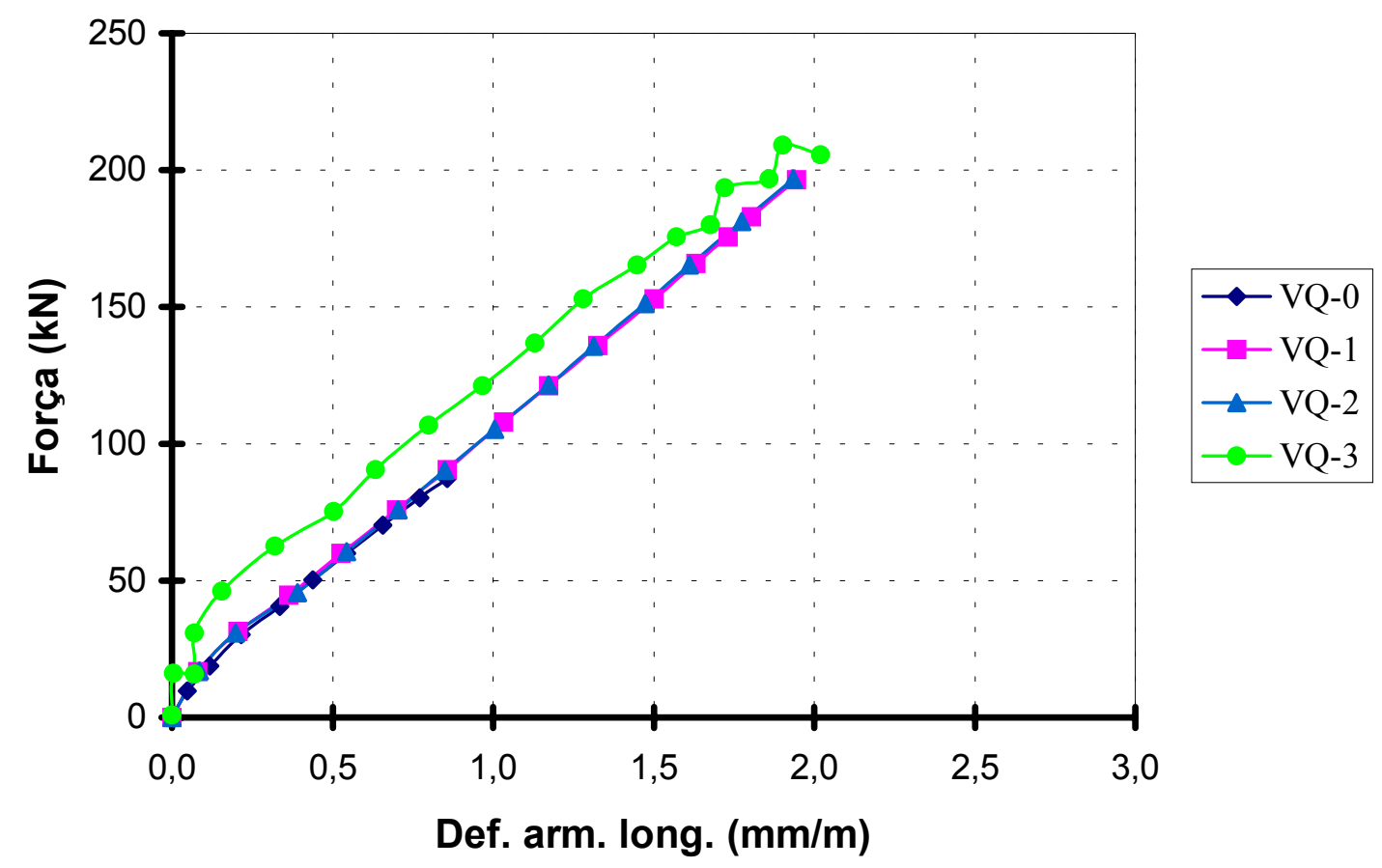

Figura 8.25 - Diagramas força x deformação na armadura longitudinal no meio do vão série A1. 


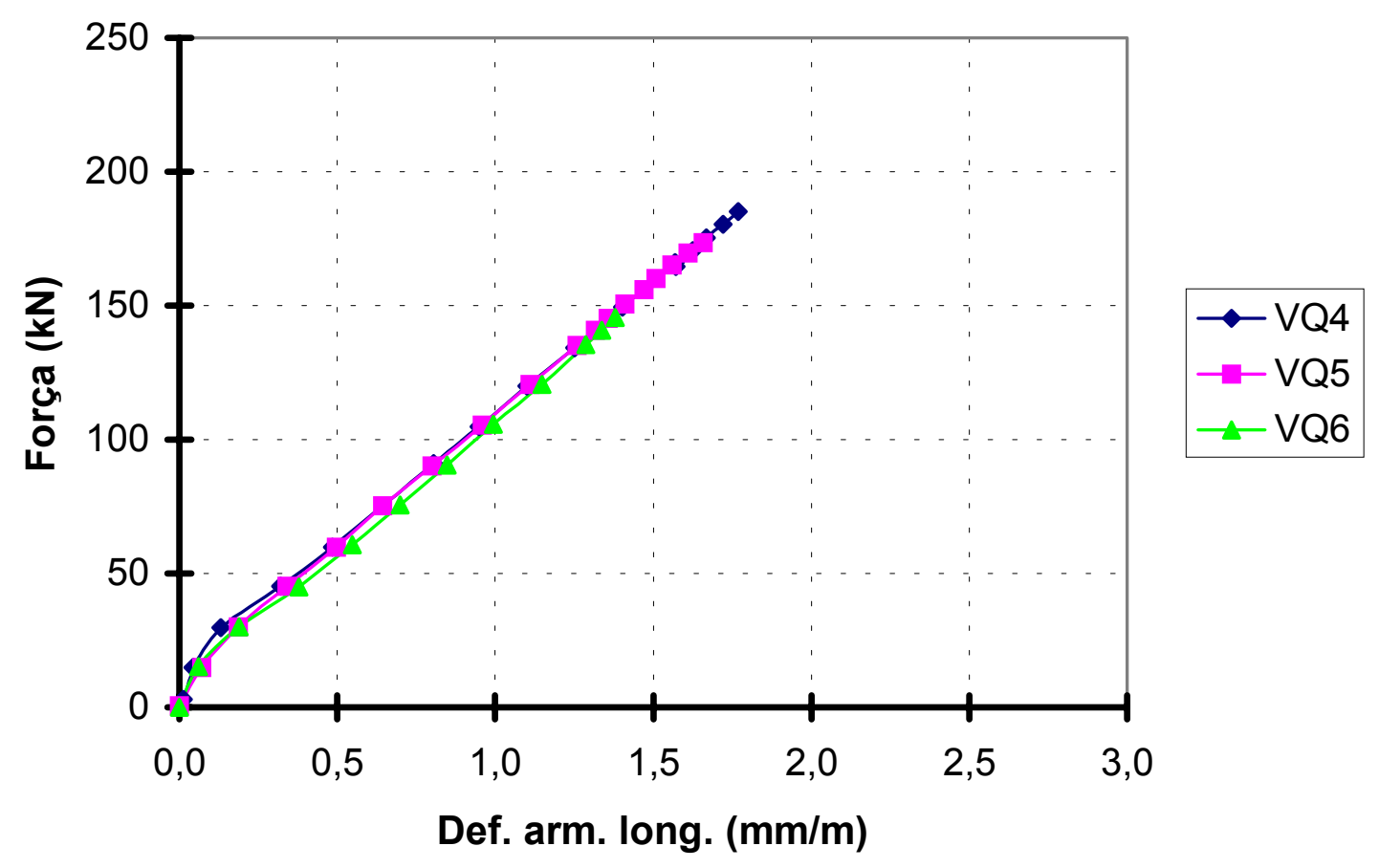

Figura 8.26 - Diagramas força x deformação armadura longitudinal (meio do vão) - série B.

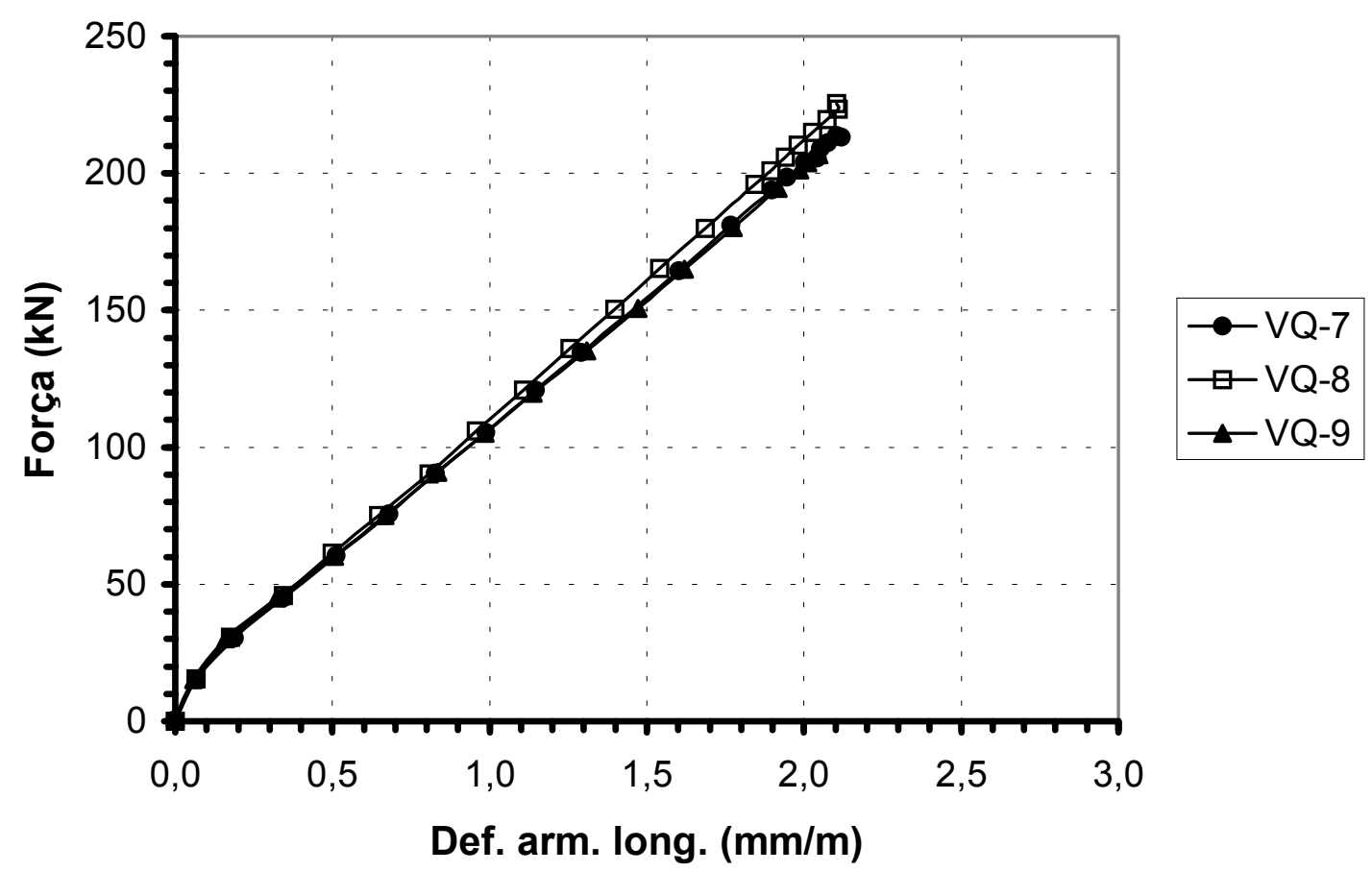

Figura 8.27 - Diagramas força x deformação armadura longitudinal (meio do vão)-série D. 


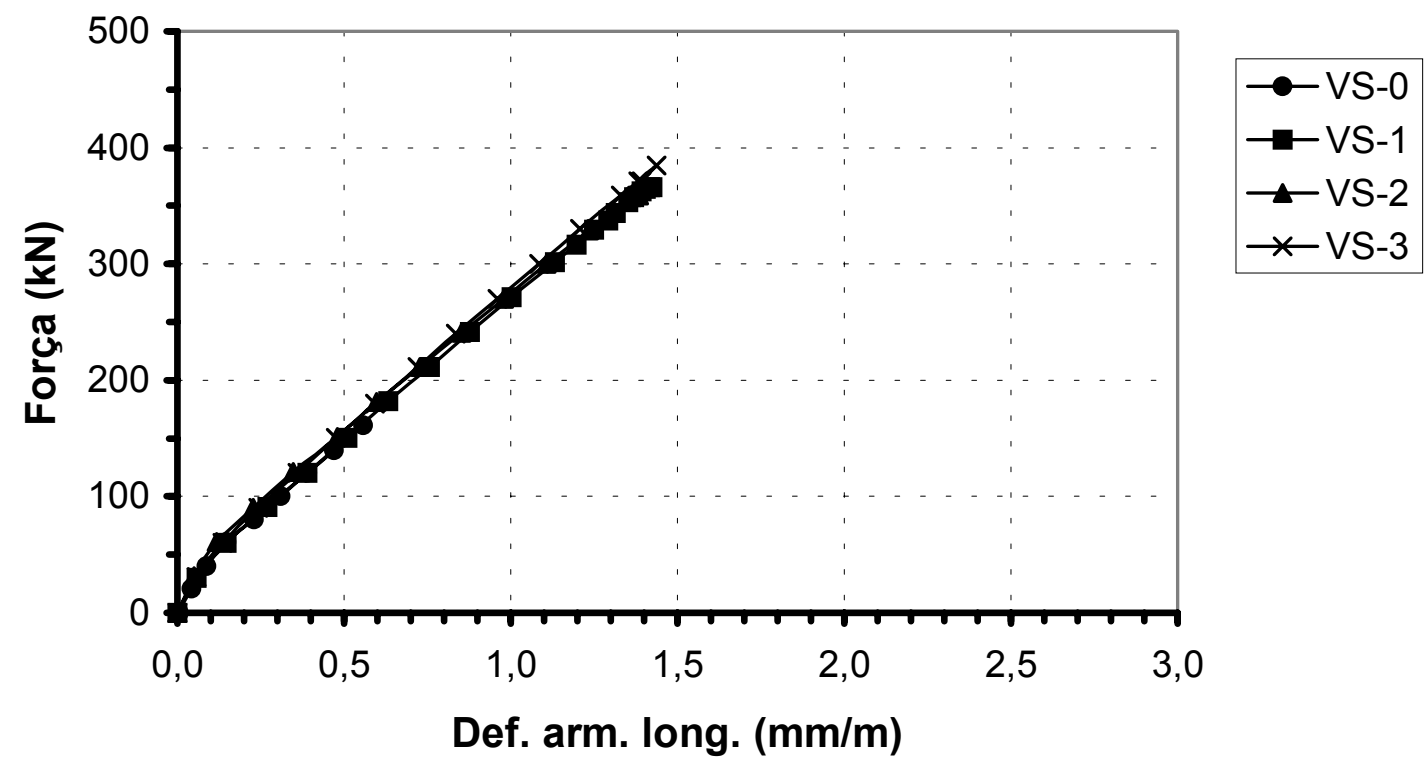

Figura 8.28 - Diagramas força x deformação armadura longitudinal (meio do vão)-série A2.

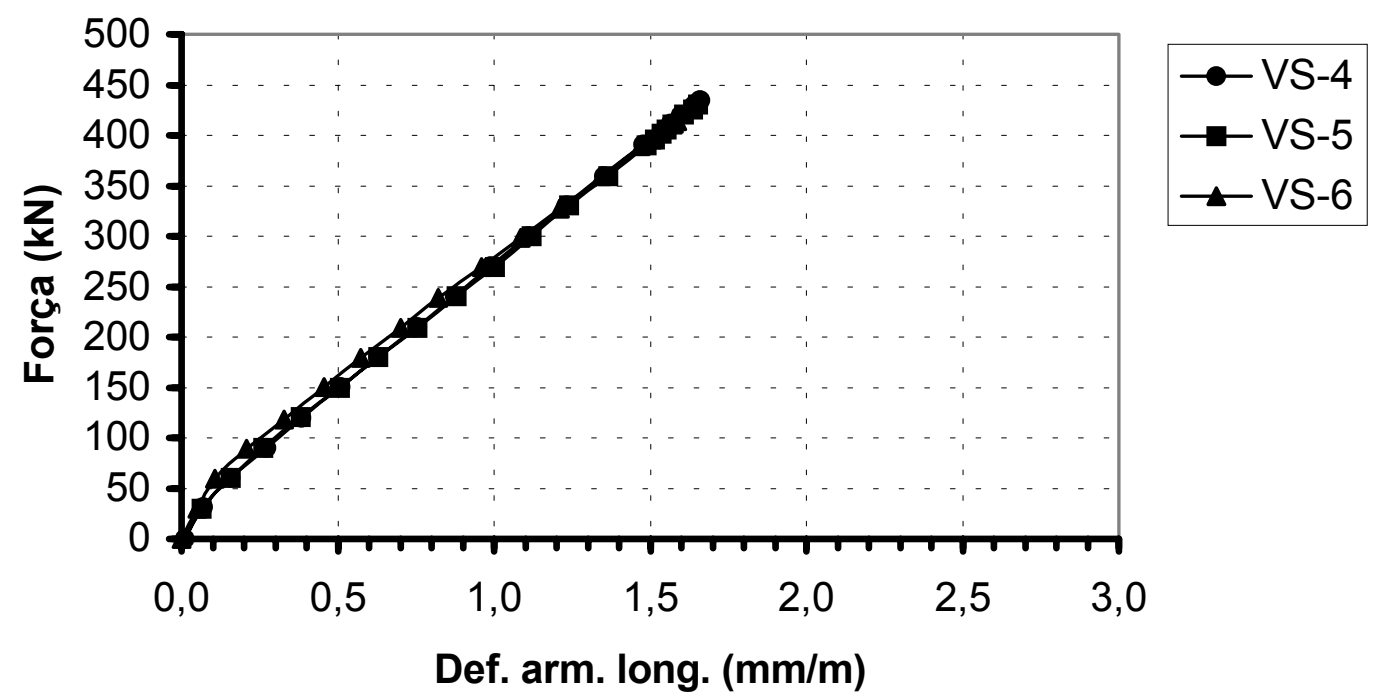

Figura 8.29 - Diagramas força x deformação armadura longitudinal (meio do vão) - série C. 


\section{6 - DEFORMAÇÕES NO CONCRETO COMPRIMIDO}

As Figuras $8.30,8.31,8.32,8.33$ e 8.34 apresentam os diagramas força $\mathrm{x}$ deformação no concreto comprimido (meio do vão) dos ensaios das séries A1, B, D, A2 e C, respectivamente. Os valores mostrados são a média dos valores obtidos nos dois pontos instrumentados.

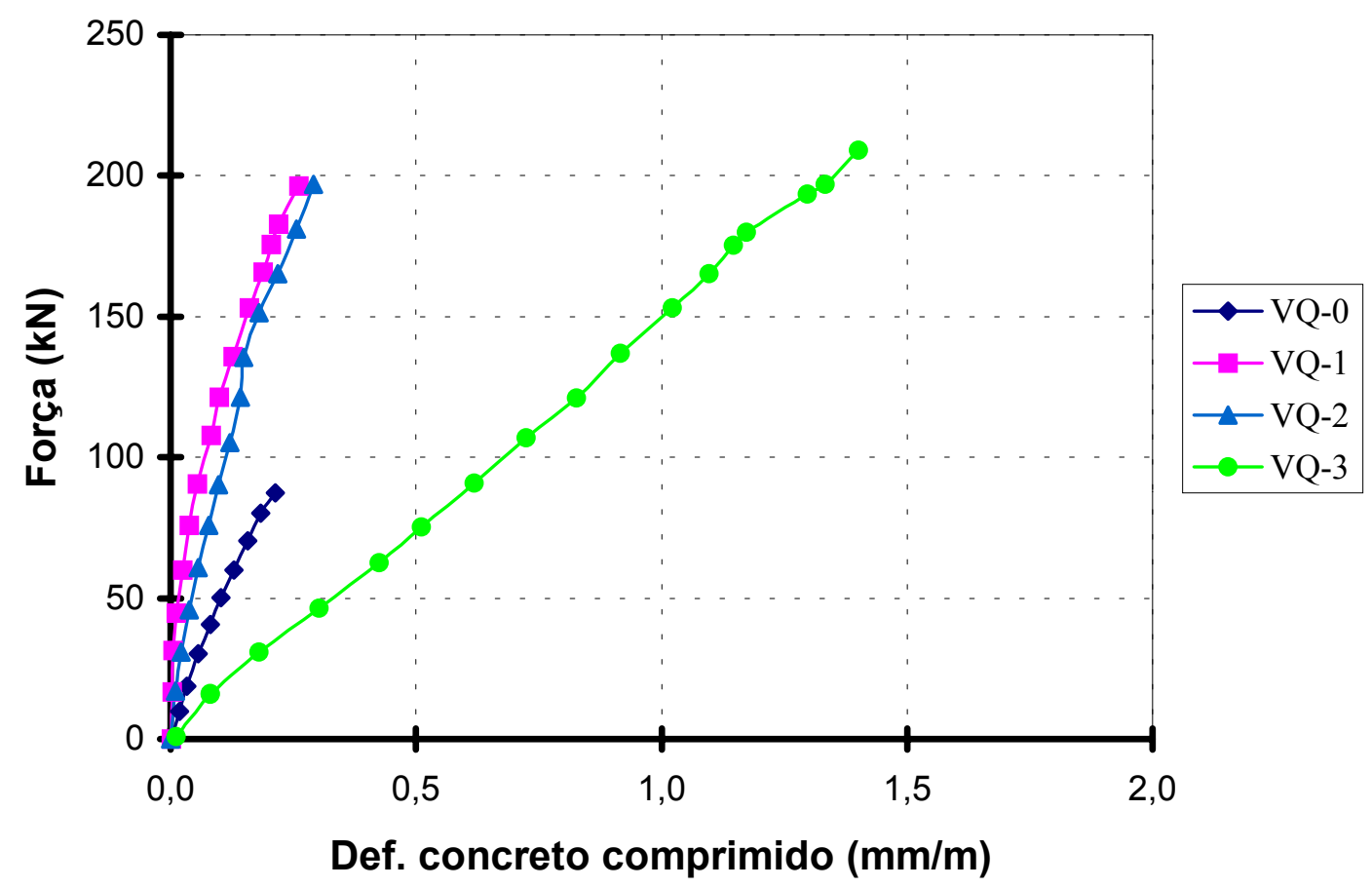

Figura 8.30 - Diagramas força x deformação concreto comprimido (meio do vão) - série A1. 


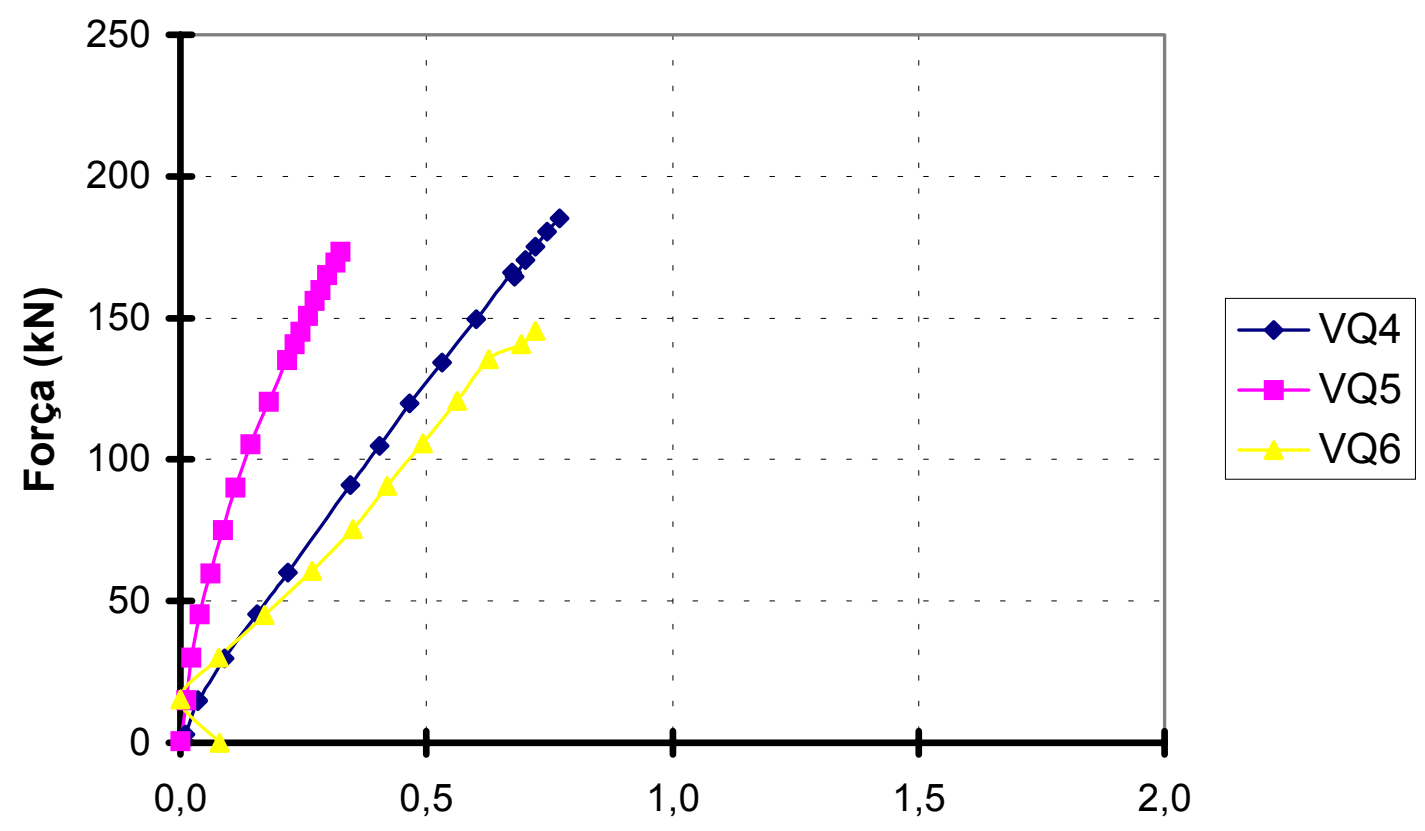

Def. concr. compr. $(\mathrm{mm} / \mathrm{m})$

Figura 8.31 - Diagramas força x deformação concreto comprimido (meio do vão) - série B.

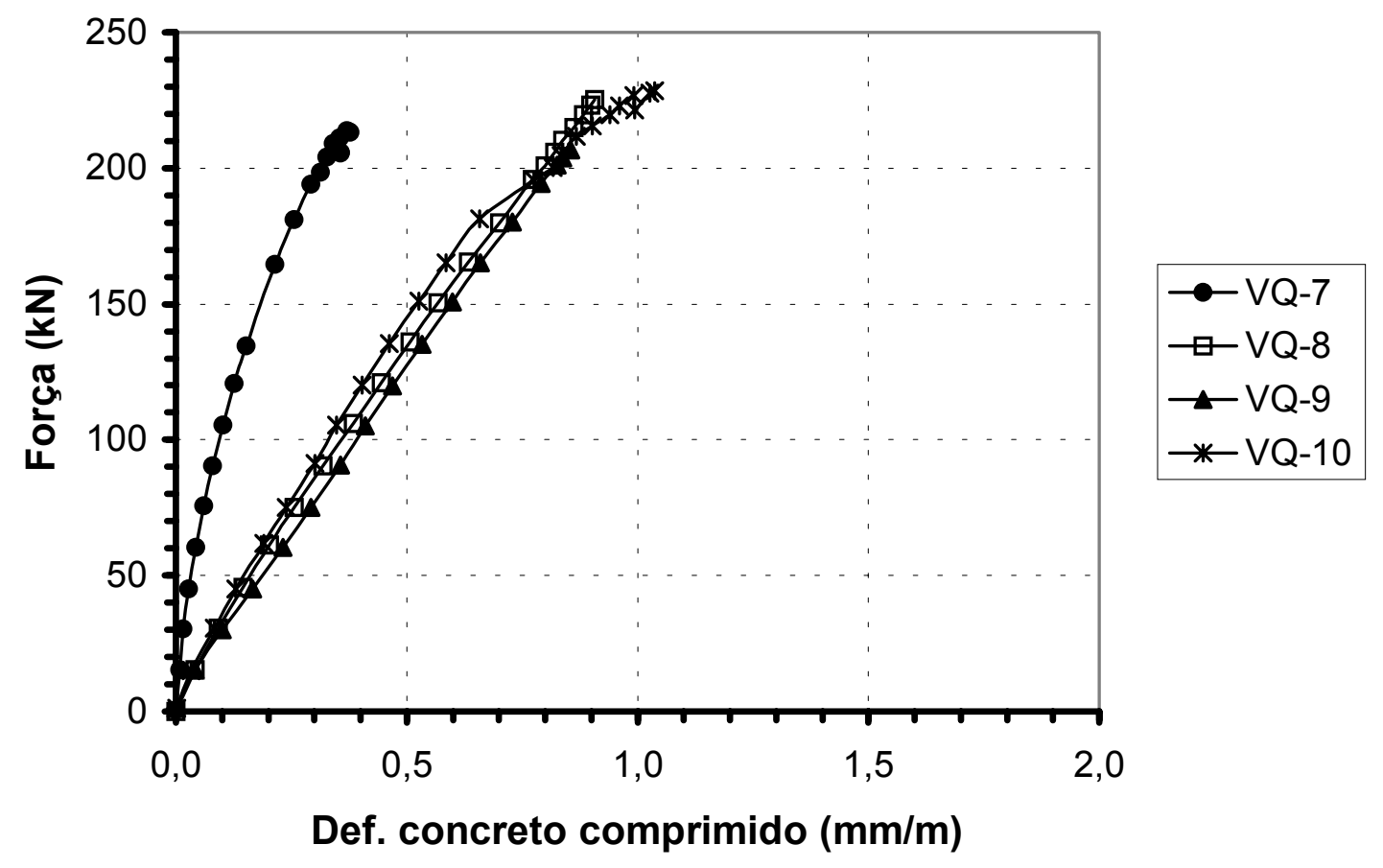

Figura 8.32 - Diagramas força x deformação concreto comprimido (meio do vão) - série D. 


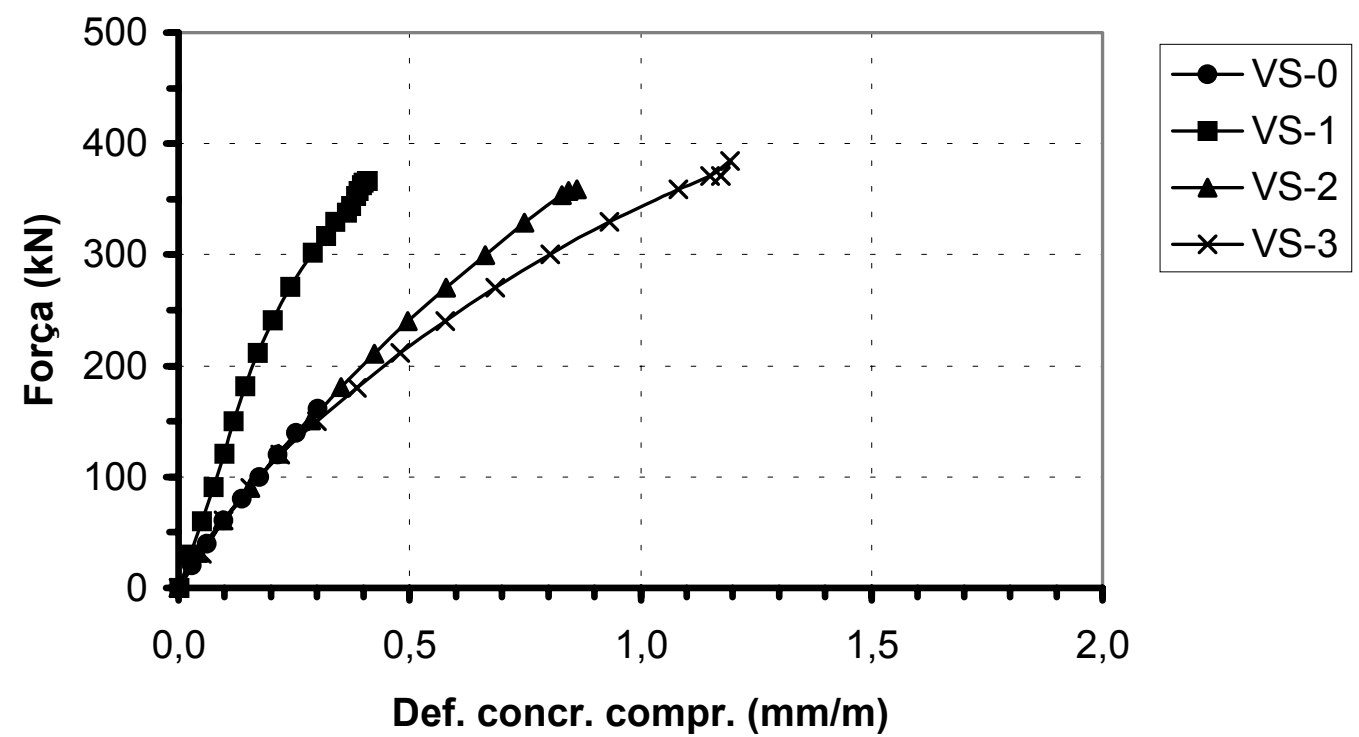

Figura 8.33 - Diagramas força x deformação concreto comprimido (meio do vão) - série A2.

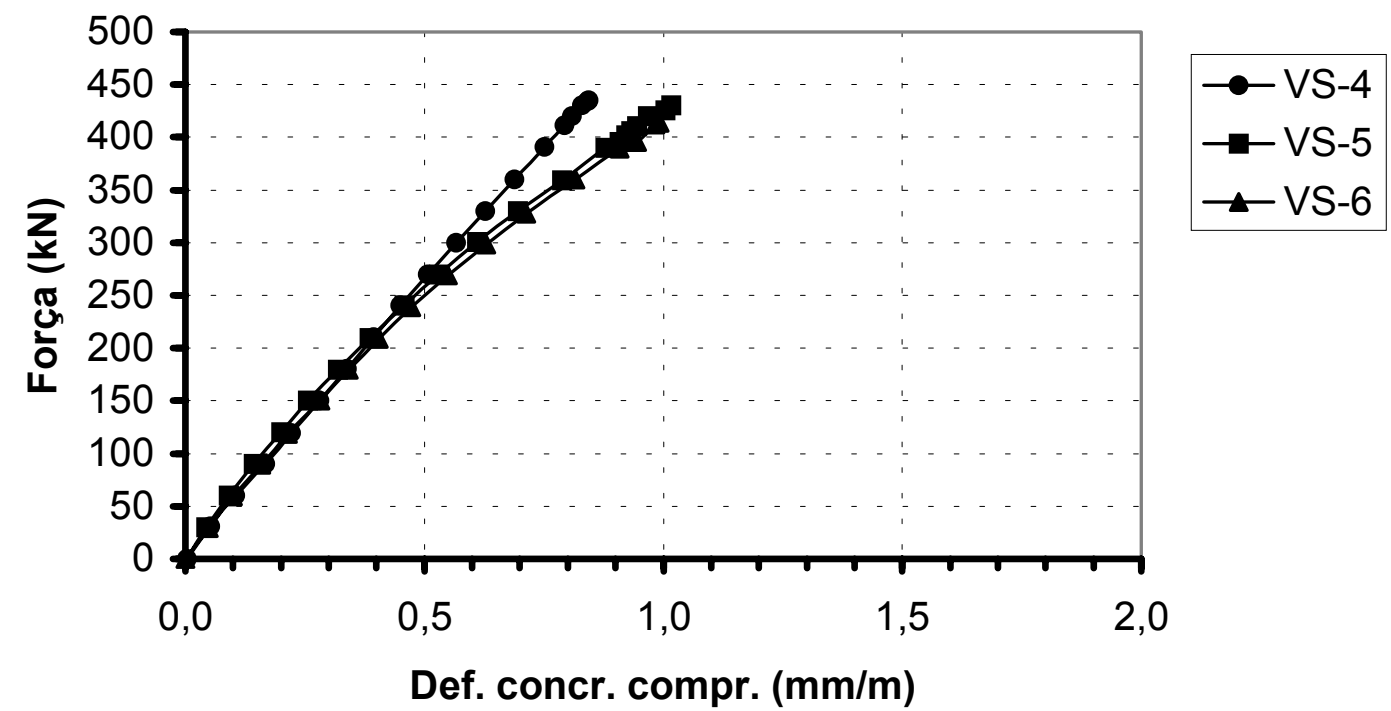

Figura 8.34 - Diagramas força x deformação concreto comprimido (meio do vão) - série C. 


\section{7 - DEFORMAÇÕES NOS ESTRIBOS VERTICAIS}

Nas vigas VQ das séries A1, B e D foram instrumentados 5 estribos verticais nos 2 ramos. Utilizou-se a seguinte nomenclatura: estribo 1 é o primeiro estribo instrumentado da direita para a esquerda, a partir do apoio direito, estribo 2 é o segundo e assim por diante, até o estribo 5 que é o último estribo instrumentado.

A Figura 8.35 ilustra o posicionamento dos estribos instrumentados nas vigas VQ.

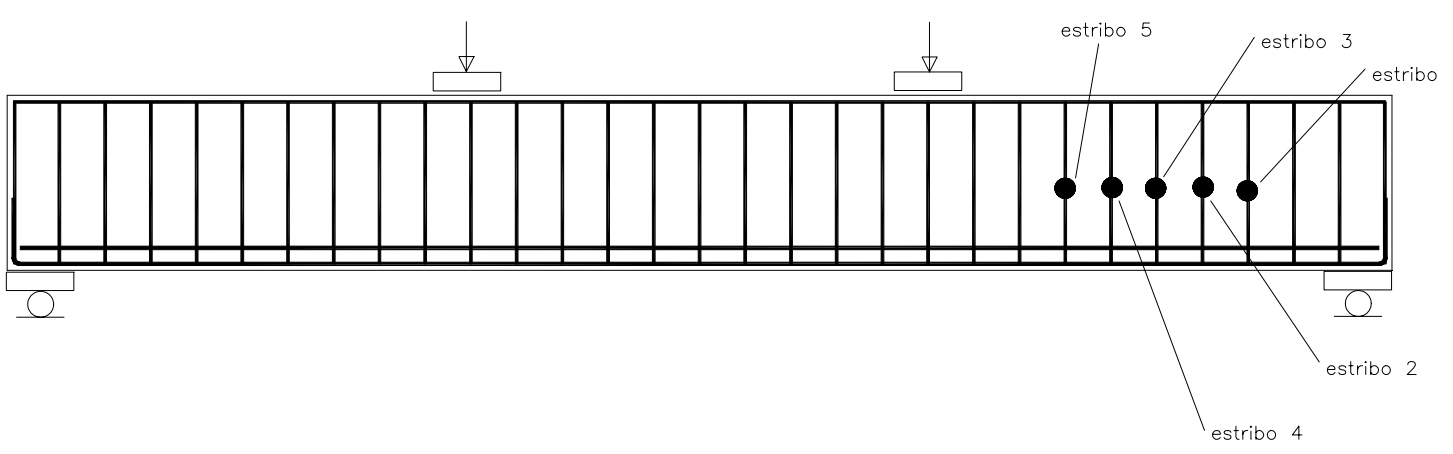

Figura 8.35 - Posicionamento dos estribos instrumentados nas vigas VQ.

Nas vigas VS das séries A2 e C foram instrumentados 5 estribos verticais em 1 ou 2 ramos. Utilizou-se a seguinte nomenclatura: estribo 1 é o primeiro estribo instrumentado da direita para a esquerda, a partir do apoio direito, estribo 2 é o segundo e assim por diante, até o estribo 5 que é o último estribo instrumentado.

A Figura 8.36 ilustra o posicionamento dos estribos instrumentados nas vigas VS.

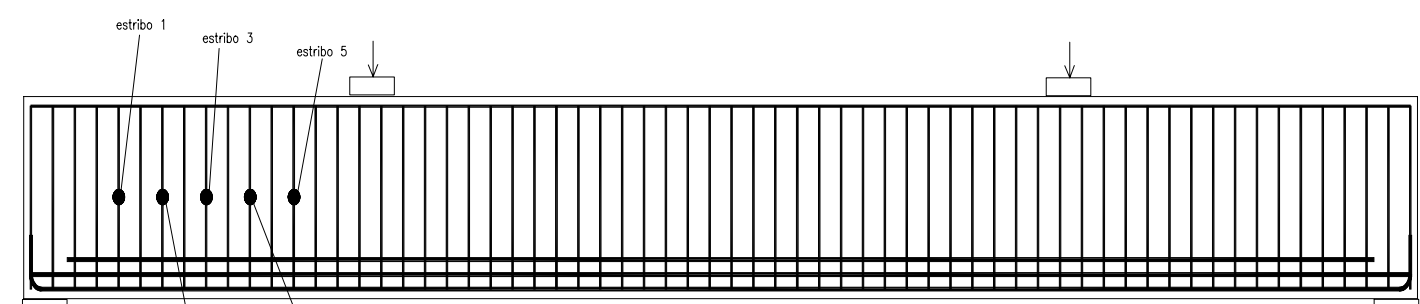

Figura 8.36 - Posicionamento dos estribos instrumentados nas vigas VS. 
As Figuras $8.37,8.38,8.39,8.40$ e 8.41 apresentam os diagramas força $\mathrm{x}$ deformação nos estribos verticais para os ensaios das vigas VQ-1, VQ-2 e VQ-3 da série A1. Os valores mostrados são a média dos valores obtidos nos dois ramos instrumentados.
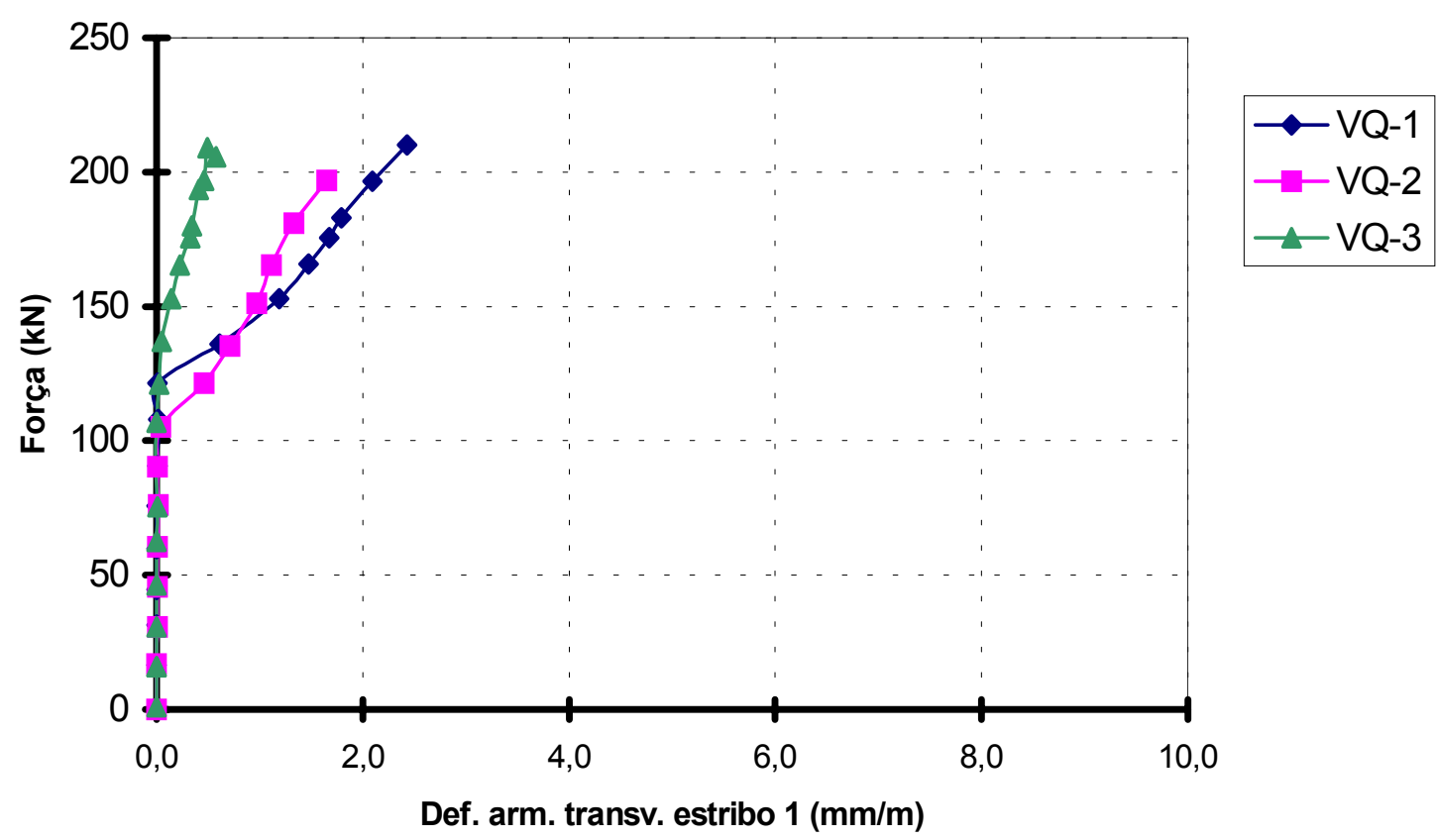

Figura 8.37 - Diagramas força x deformação nos estribos 1 (série A1).

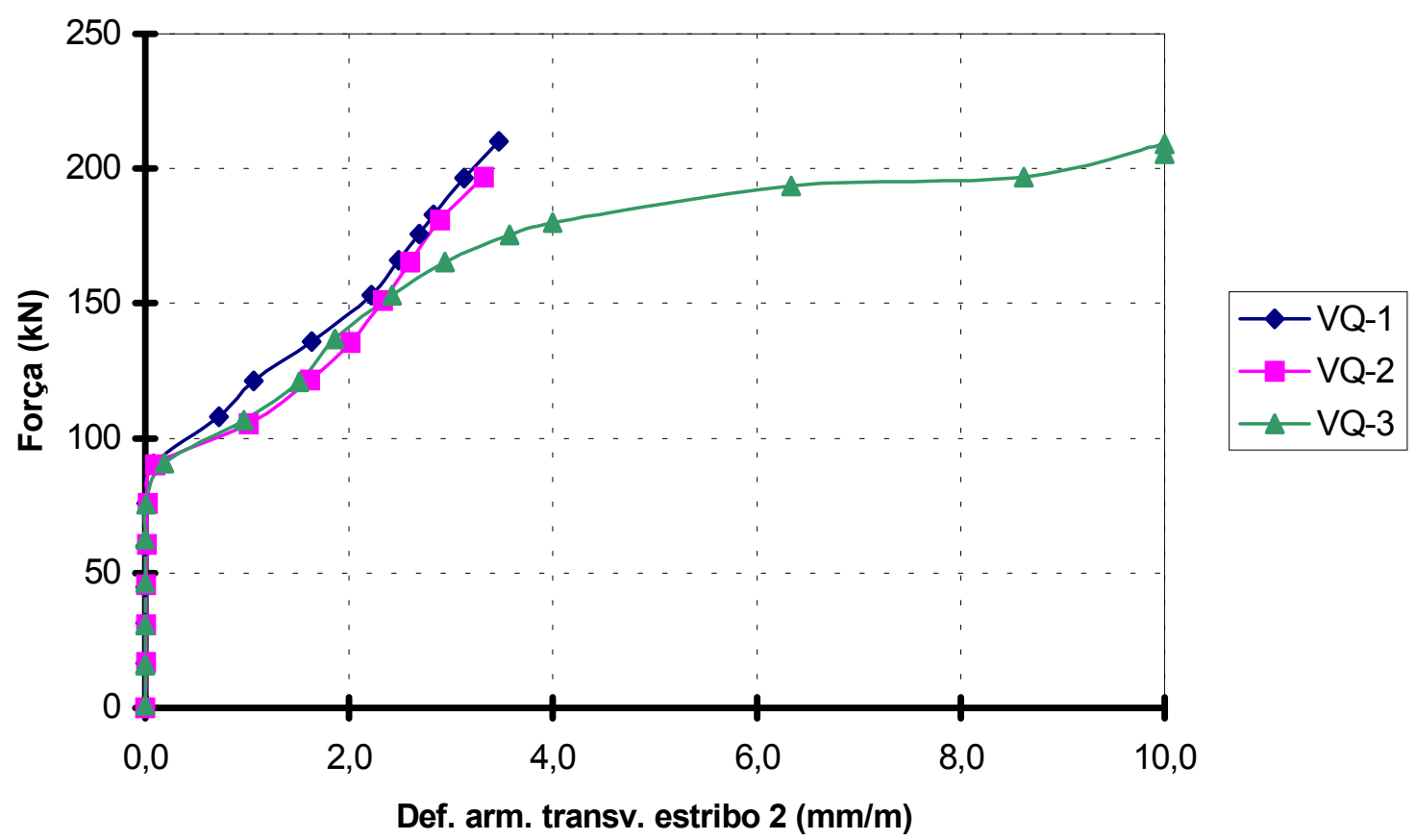

Figura 8.38 - Diagramas força $x$ deformação nos estribos 2 (série A1). 


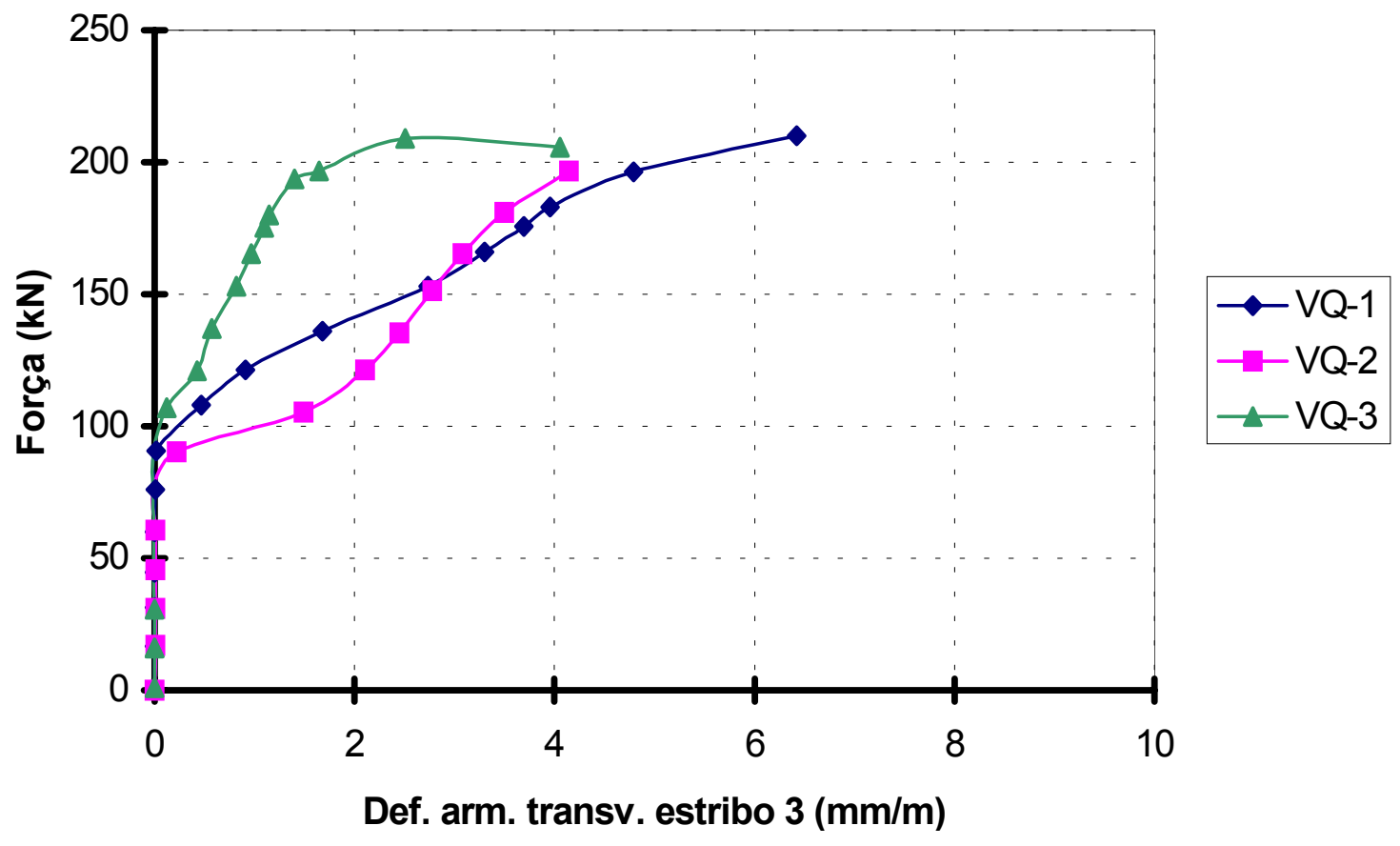

Figura 8.39 - Diagramas força x deformação nos estribos 3 (série A1).

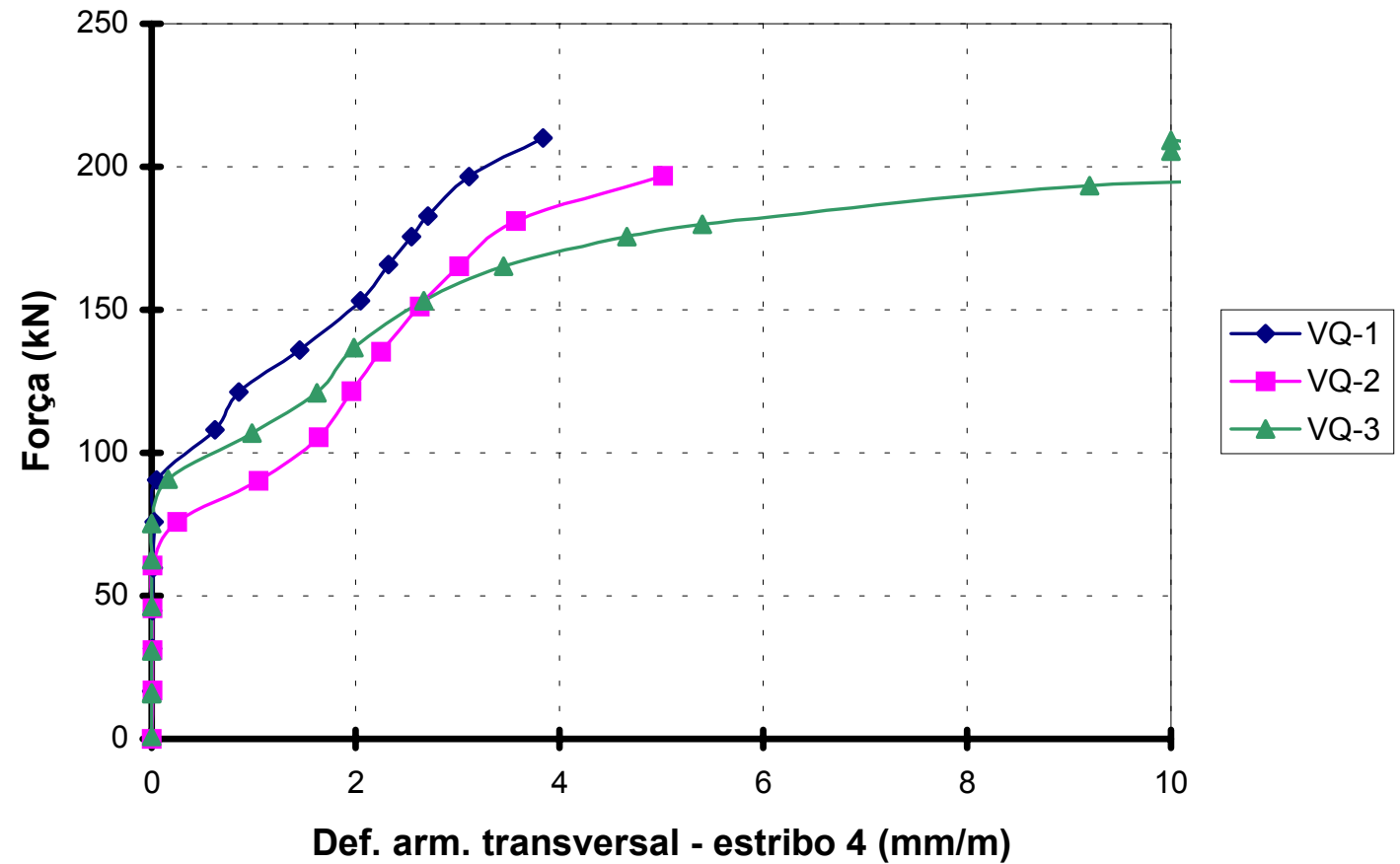

Figura 8.40 - Diagramas força x deformação nos estribos 4 (série A1). 


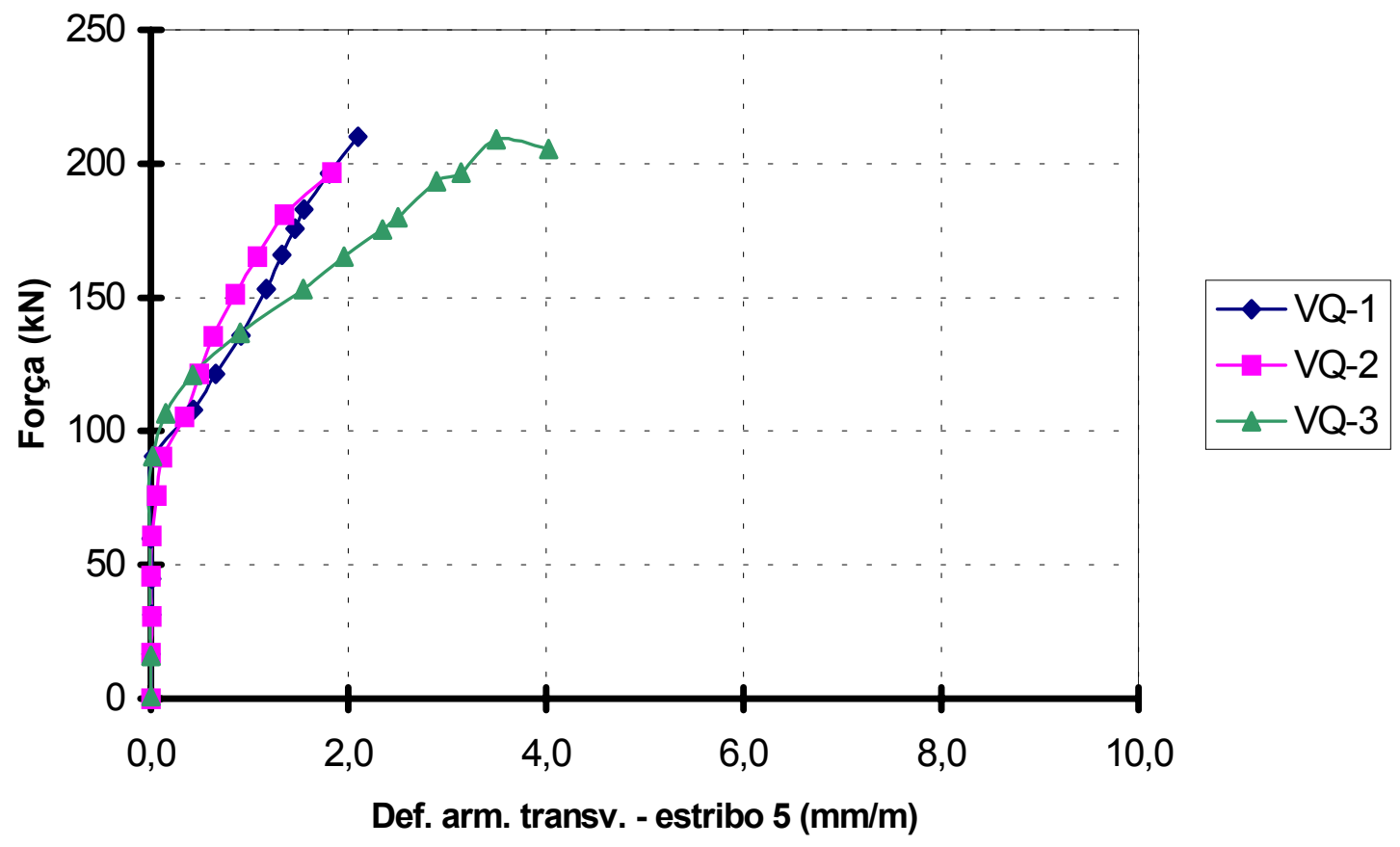

Figura 8.41 - Diagramas força x deformação nos estribos 5 (série A1).

As Figuras 8.42, 8.43 e 8.44 apresentam os diagramas força $\mathrm{x}$ deformação nos estribos verticais dos ensaios das vigas VQ-4, VQ-5 e VQ-6 da série B, respectivamente. 


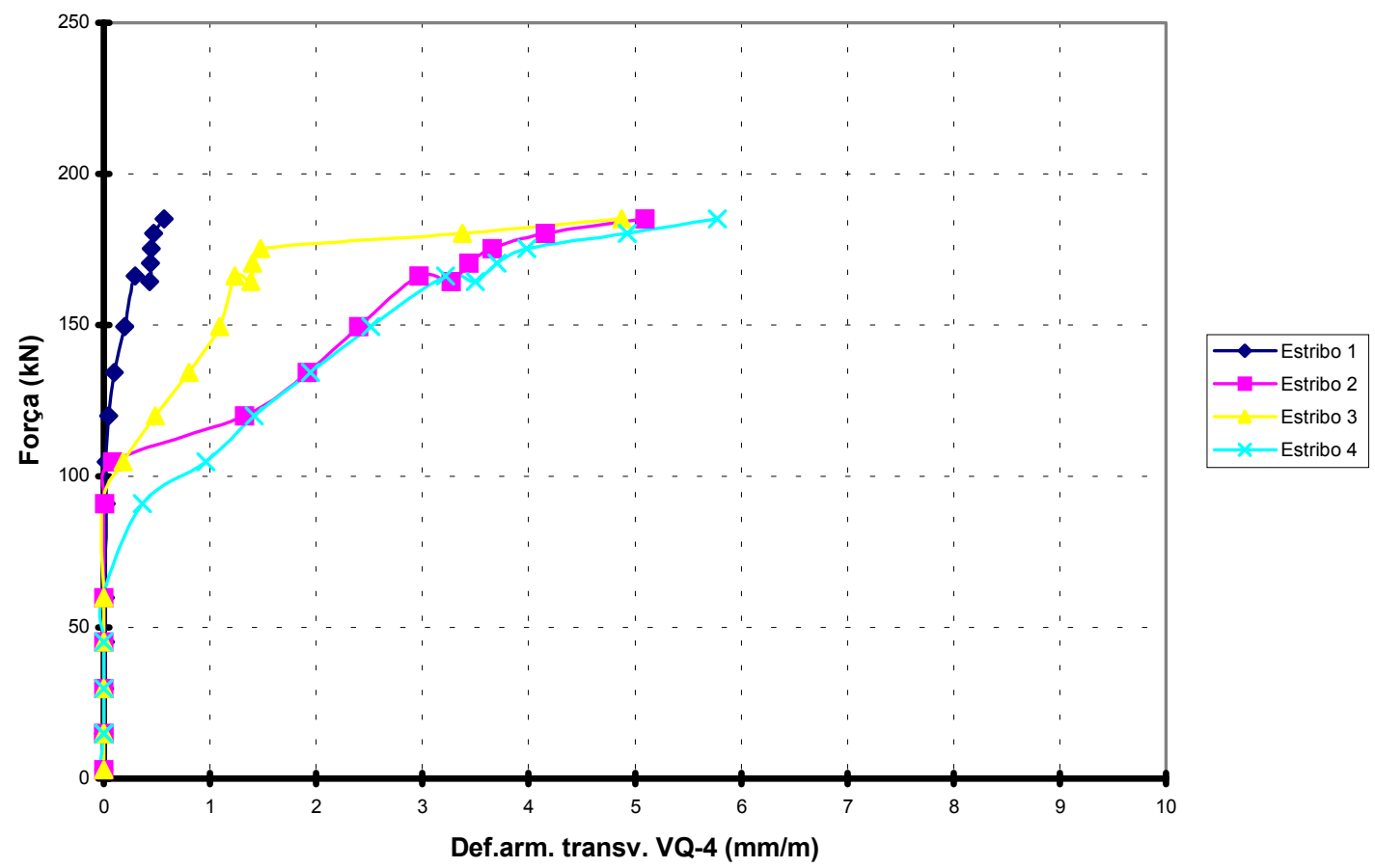

Figura 8.42 - Diagramas força x deformação nos estribos da viga VQ-4 (série B).

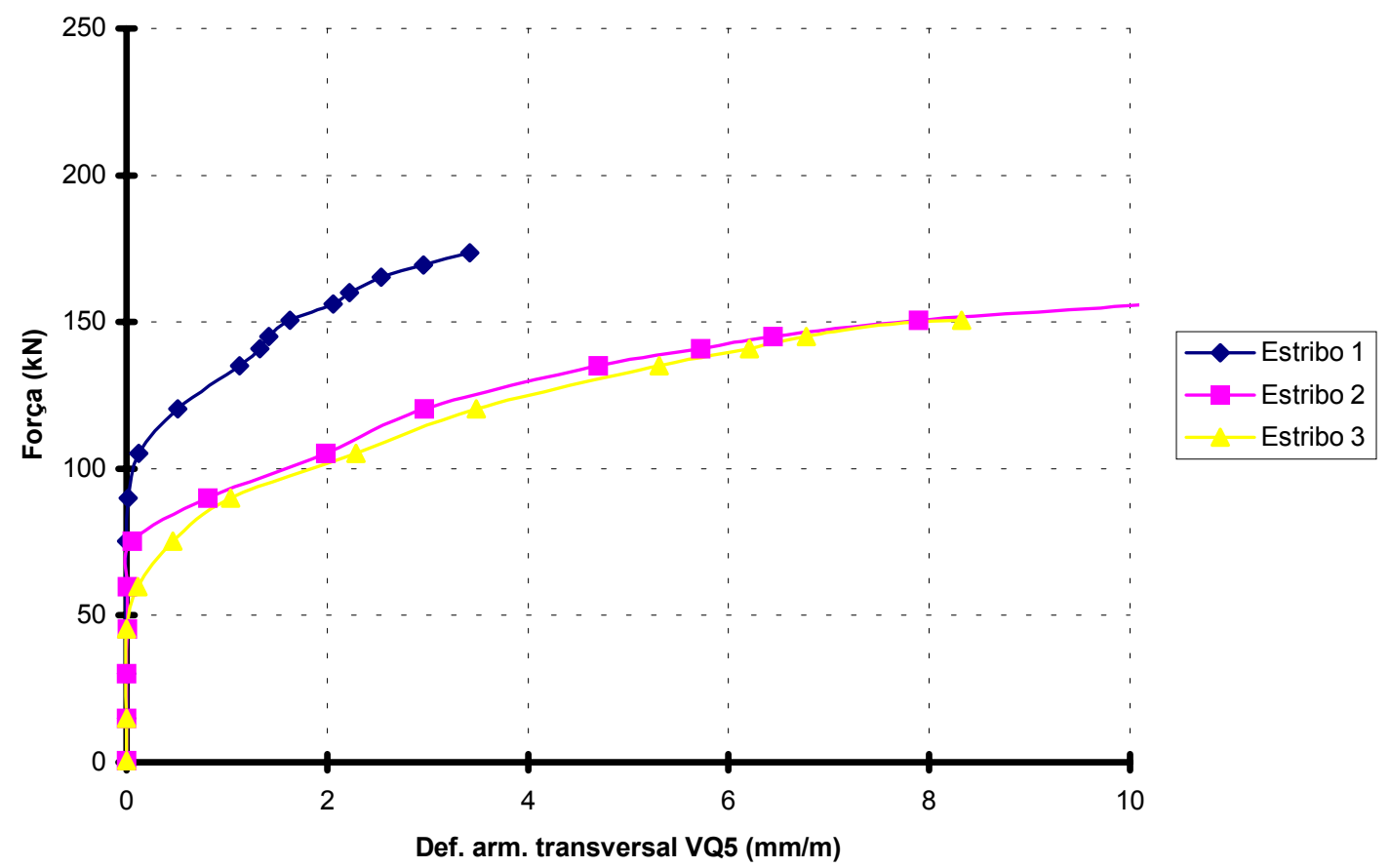

Figura 8.43 - Diagramas força x deformação nos estribos da viga VQ-5 (série B). 


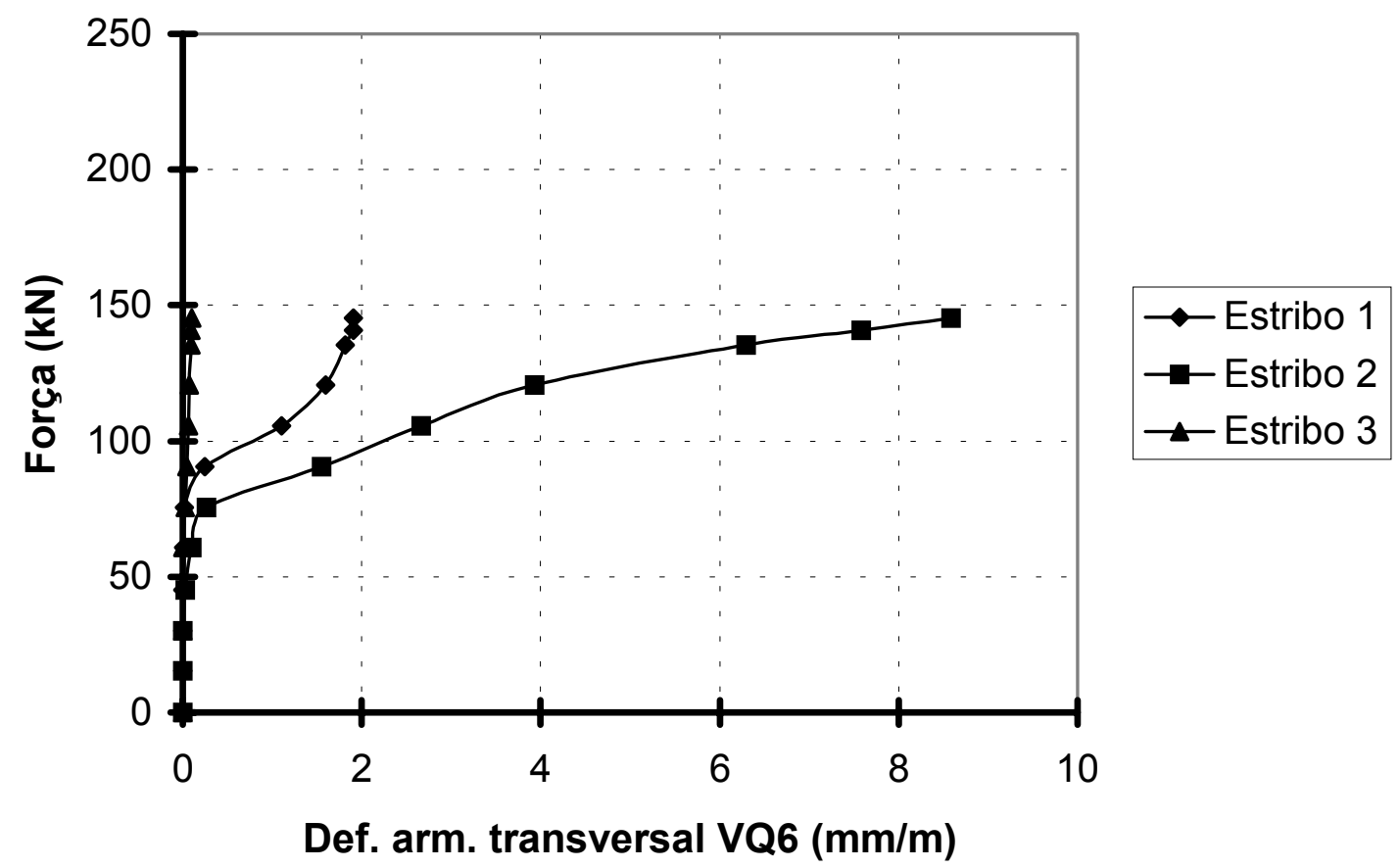

Figura 8.44 - Diagramas força x deformação nos estribos da viga VQ-6 (série B).

As Figuras 8.45, 8.46 e 8.47 apresentam, respectivamente, os diagramas força $\mathrm{x}$ deformação nos estribos verticais dos ensaios das vigas VQ-7, VQ-8 e VQ-9 da série D. Os valores mostrados são a média dos valores obtidos nos dois ramos instrumentados.

As Figuras 8.48, 8.49 e 8.50 apresentam os diagramas força $\mathrm{x}$ deformação nos estribos verticais das vigas VS-1, VS-2 e VS-3 da série A2, respectivamente. Os valores mostrados são a média dos valores obtidos nos dois ramos instrumentados.

As Figuras $8.51,8.52$ e 8.53 apresentam, respectivamente, os diagramas força $\mathrm{x}$ deformação nos estribos verticais das vigas VS-4, VS-5 e VS-6 da série C. 


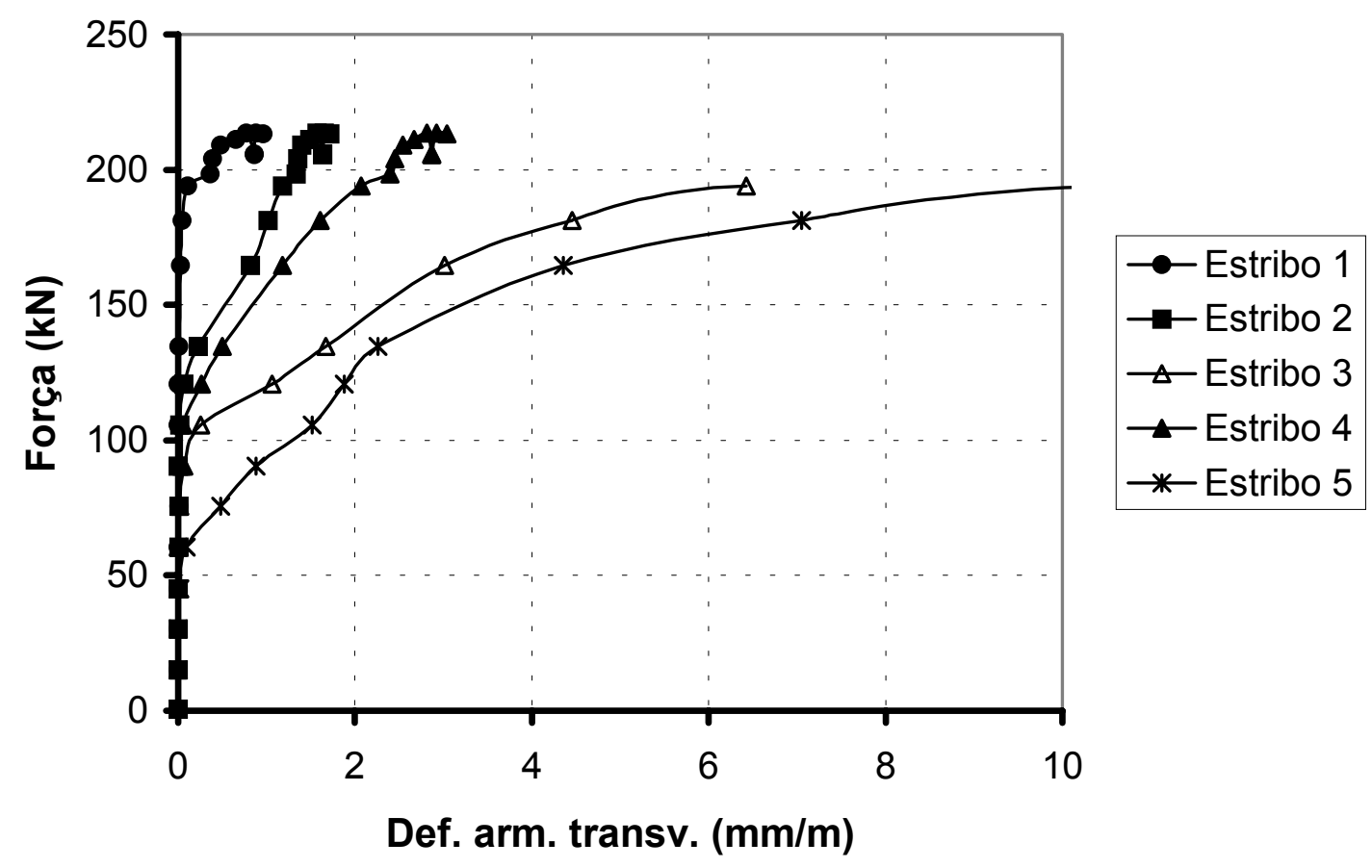

Figura 8.45 - Diagramas força x deformação nos estribos da viga VQ-7 (série D).

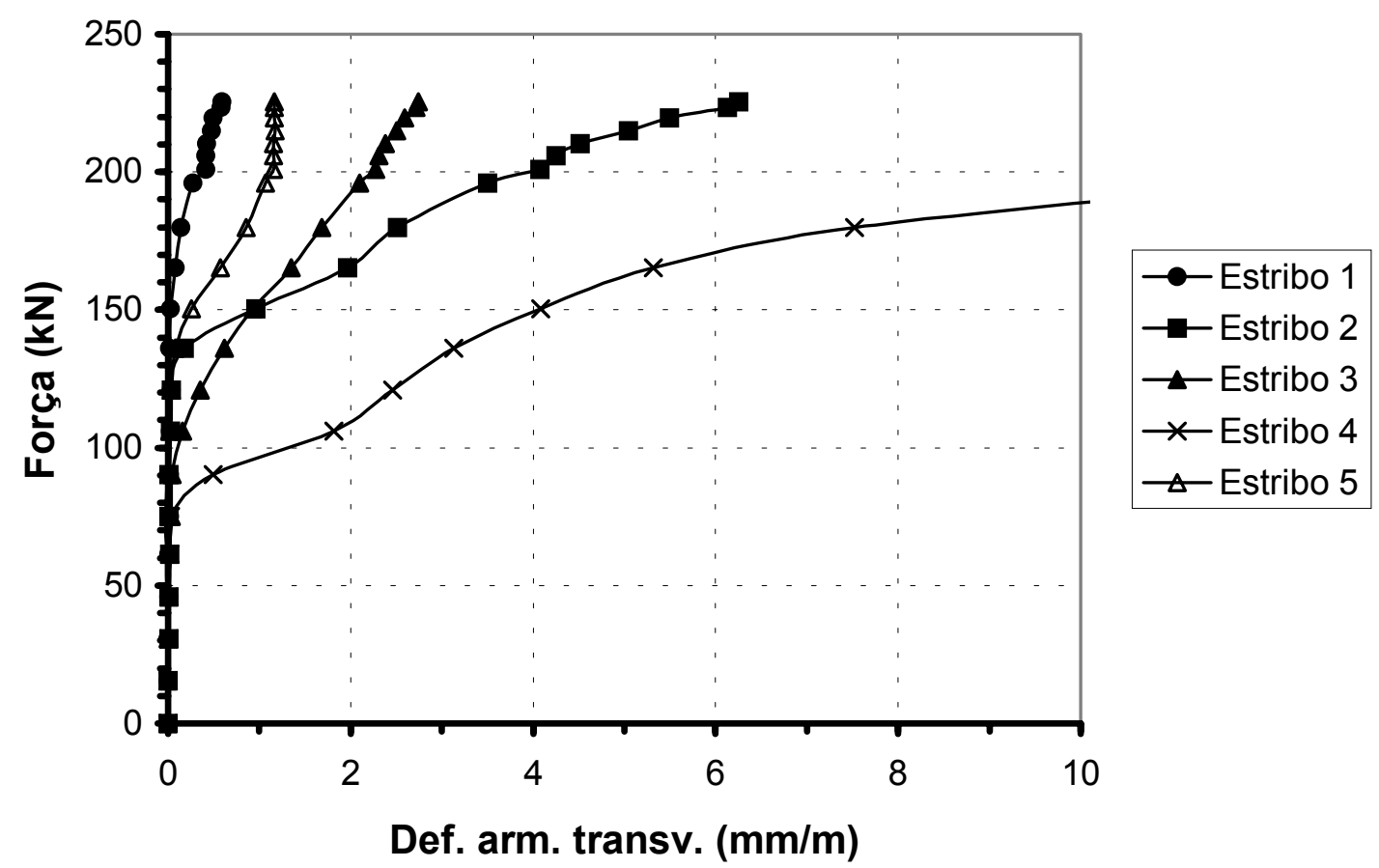

Figura 8.46 - Diagramas força x deformação nos estribos da viga VQ-8 (série D). 


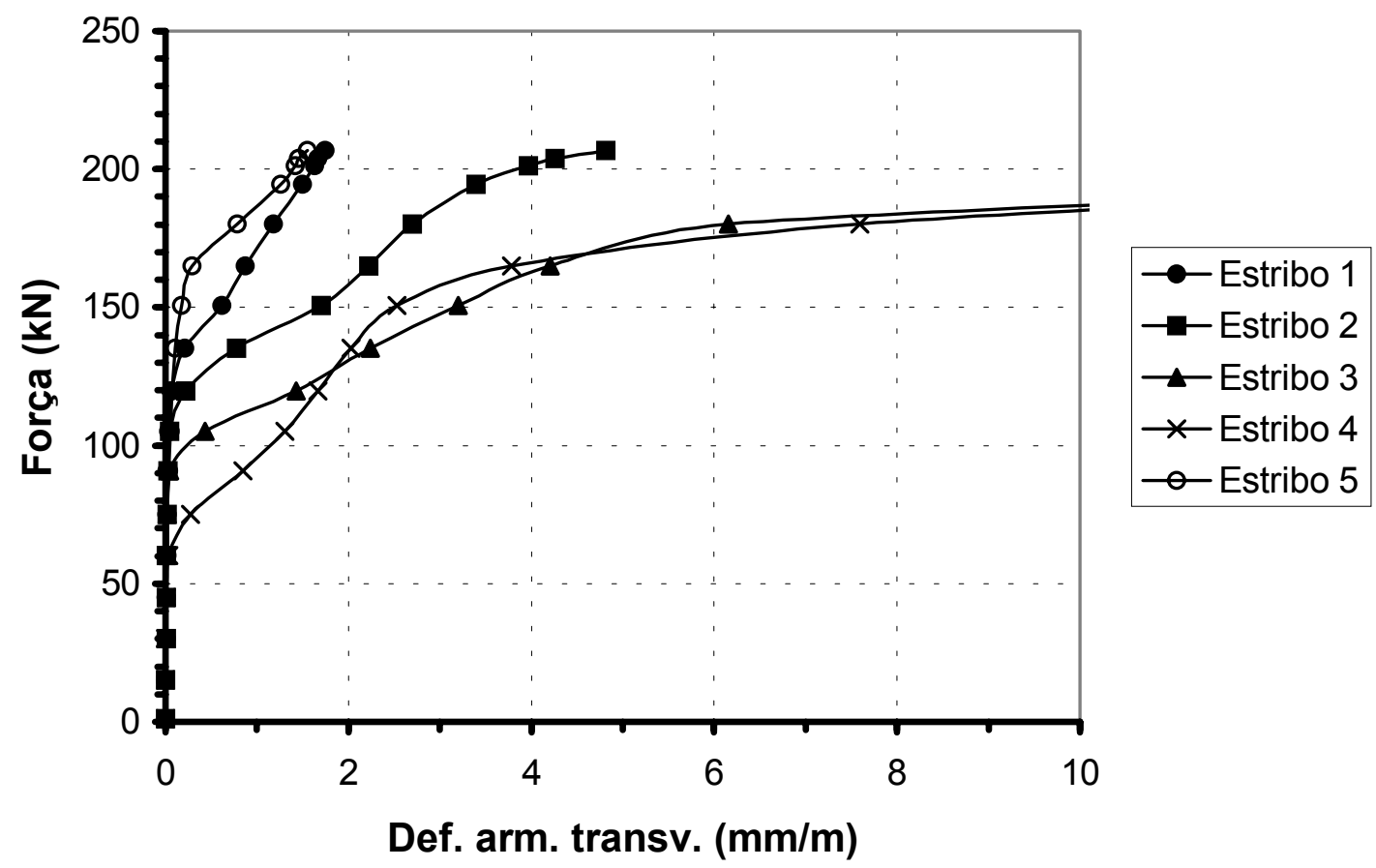

Figura 8.47 - Diagramas força x deformação nos estribos da viga VQ-9 (série D).

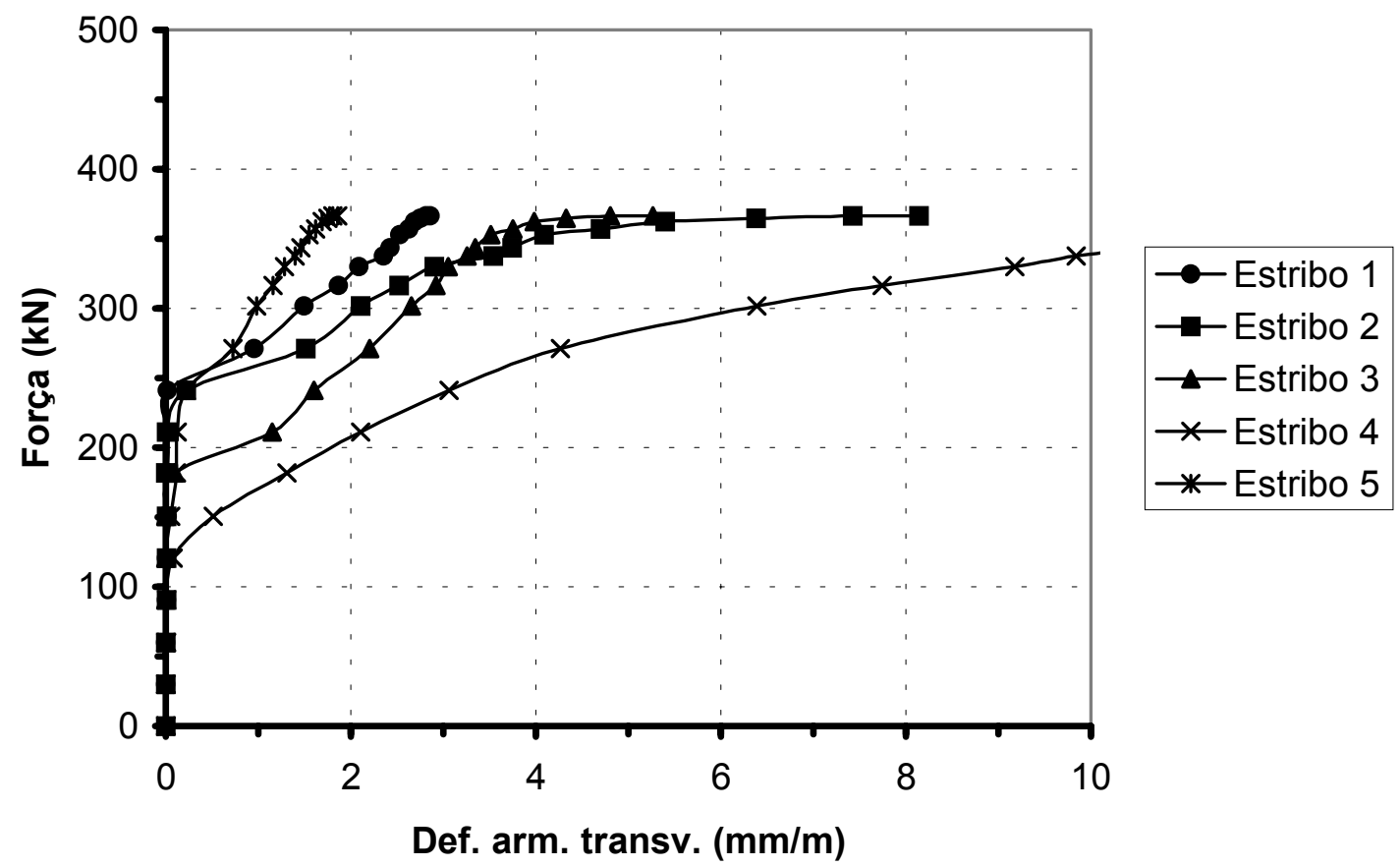

Figura 8.48 - Diagramas força x deformação nos estribos da viga VS-1 (série A2). 


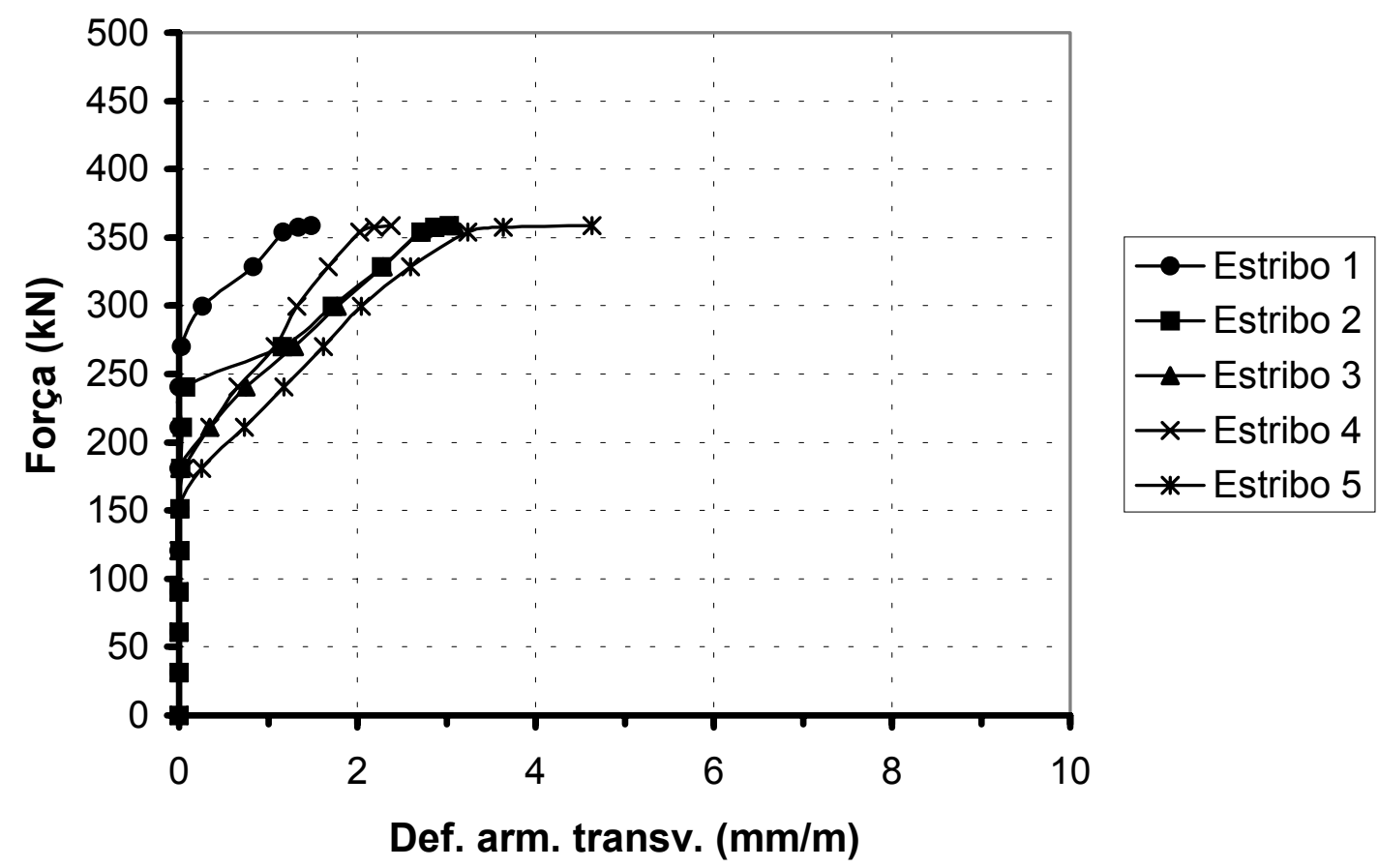

Figura 8.49 - Diagramas força x deformação nos estribos da viga VS-2 (série A2).

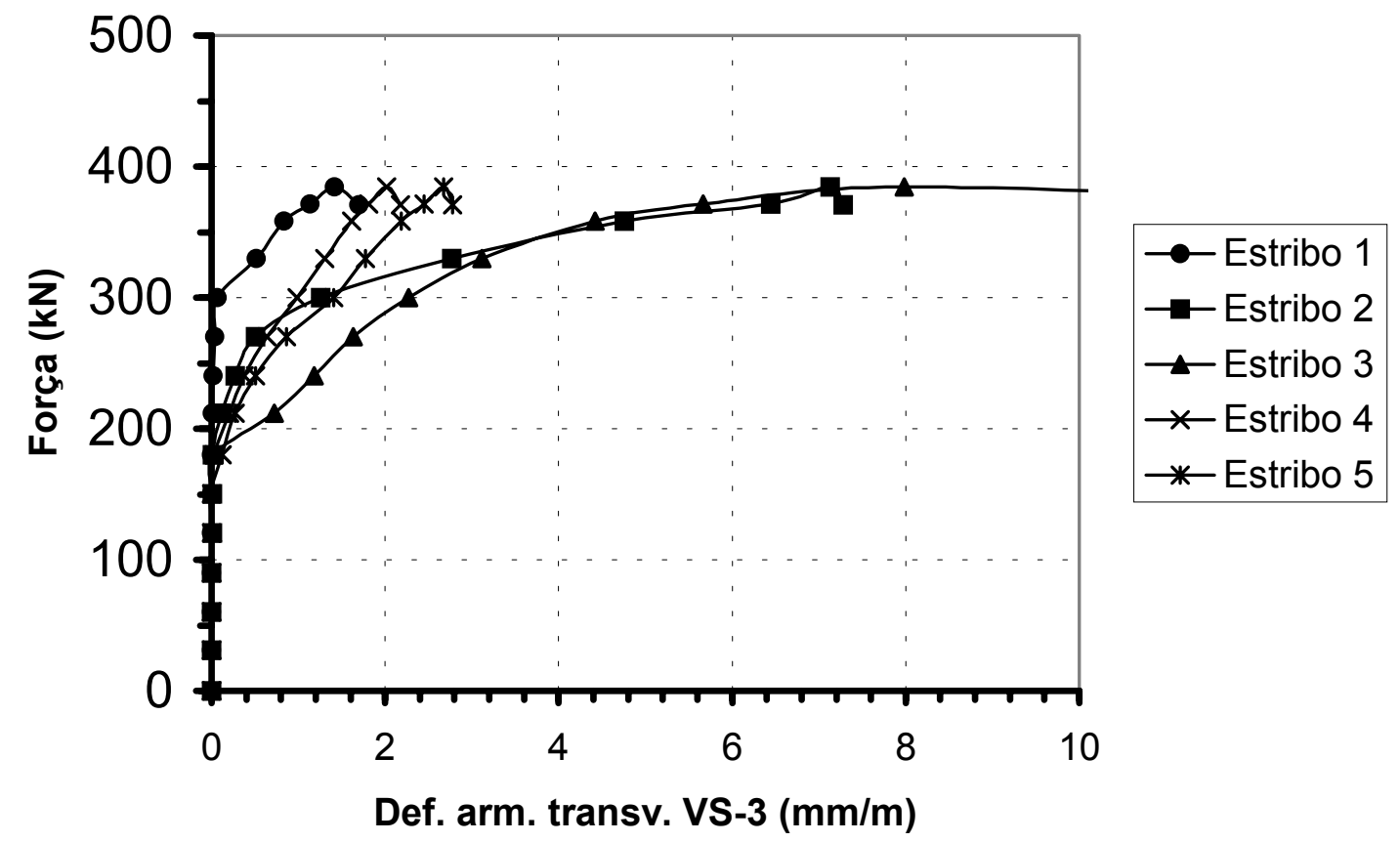

Figura 8.50 - Diagramas força x deformação nos estribos da viga VS-3 (série A2). 


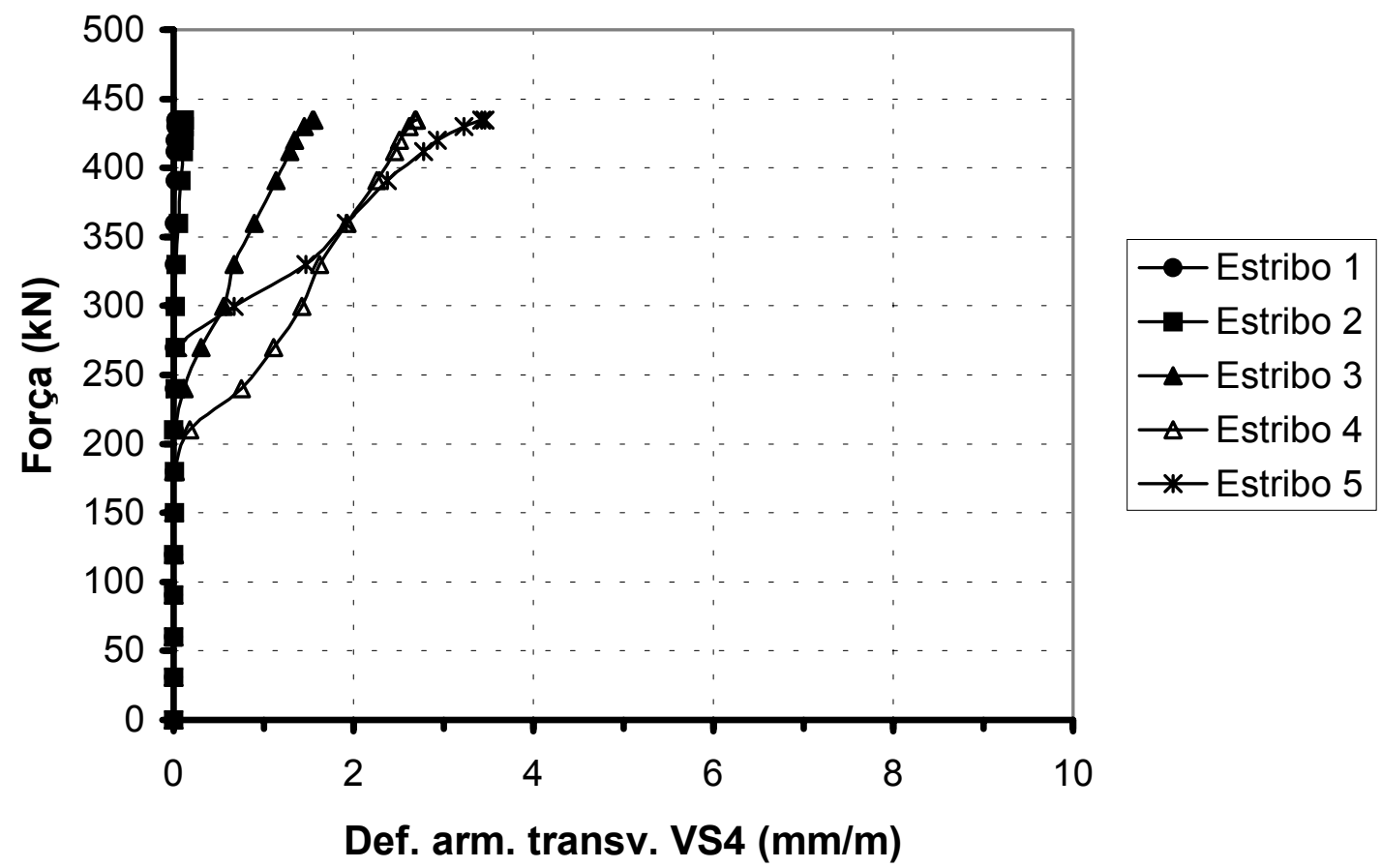

Figura 8.51 - Diagramas força x deformação nos estribos da viga VS-4 (série C).

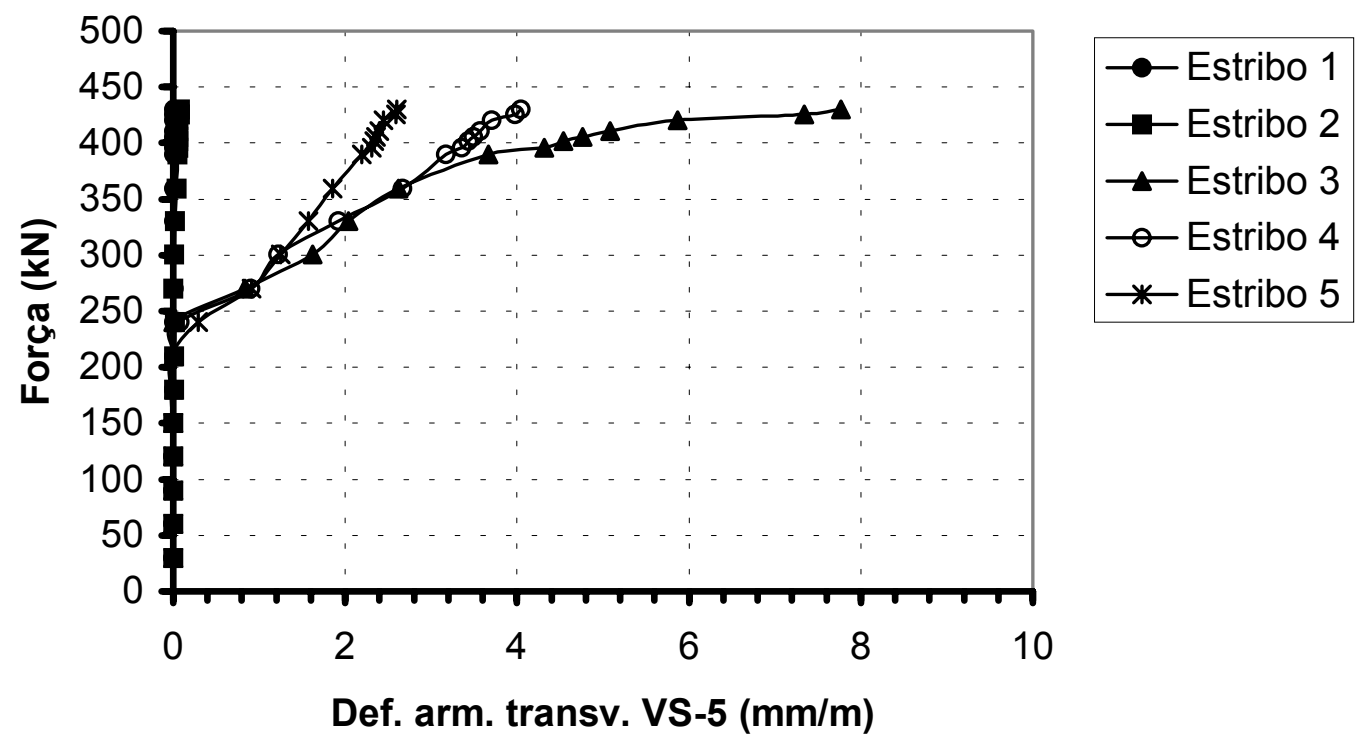

Figura 8.52 - Diagramas força x deformação nos estribos da viga VS-5 (série C). 


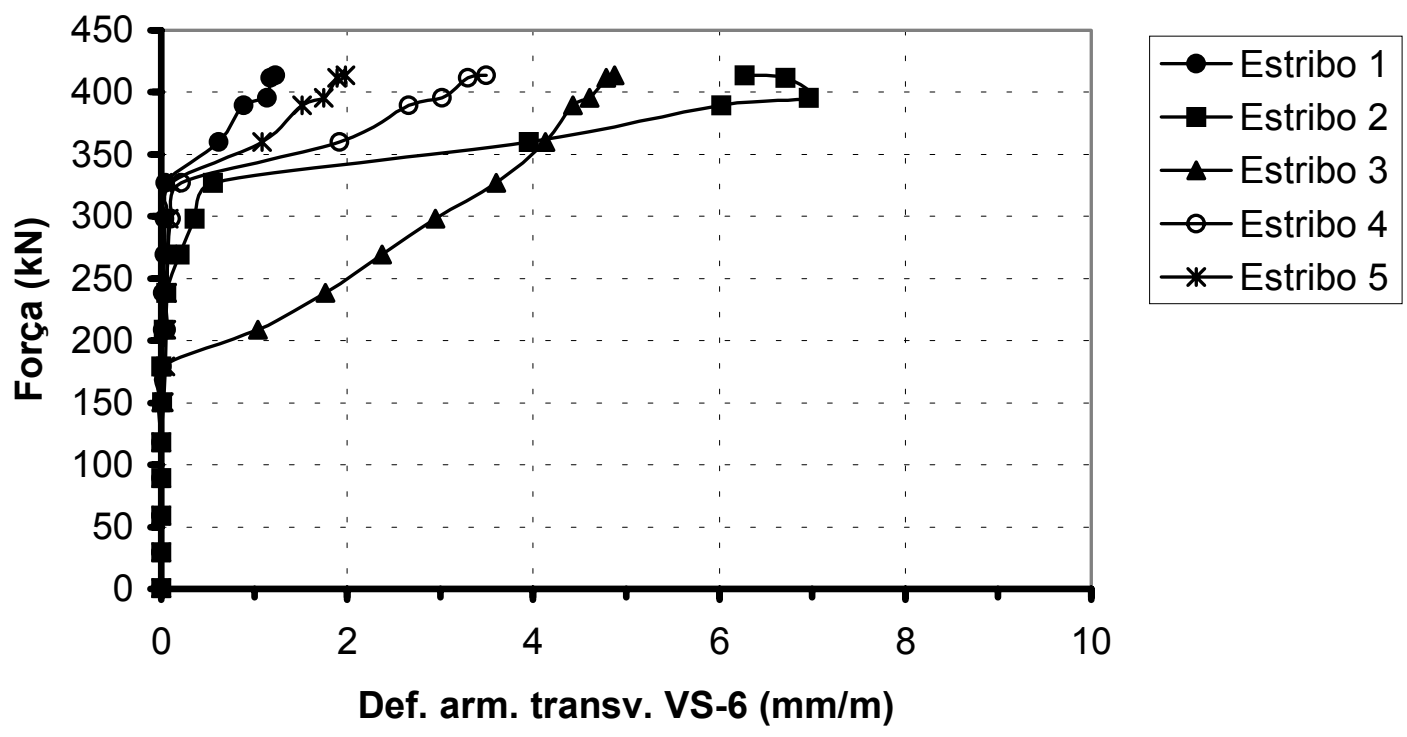

Figura 8.53 - Diagramas força x deformação nos estribos da viga VS-6 (série C).

\section{8 - DEFORMAÇÕES NAS ARMADURAS LATERAIS}

Nas vigas VQ-2 e VQ-3 da série A1 foram instrumentadas 4 barras de armadura lateral nos 2 lados. Os extensômetros foram posicionados a $40 \mathrm{~cm}$ (inferior e superior) da face externa do apoio e a $60 \mathrm{~cm}$ (inferior e superior).

A Figura 8.54 ilustra o posicionamento dos extensômetros nas barras da armadura horizontal lateral para as vigas da série A1. 


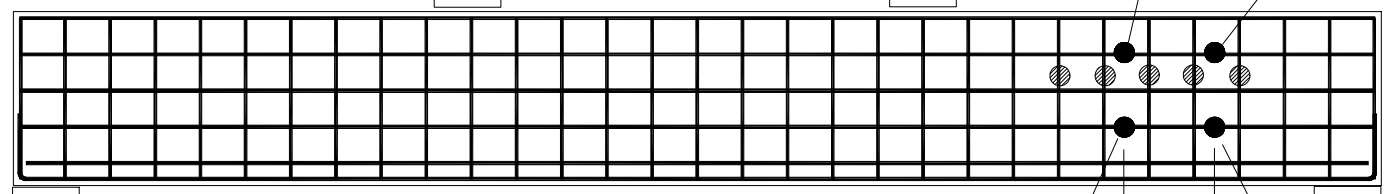

antos de instrumentaçõo dos estribos

Figura 8.54 - Posicionamento dos extensômetros nas barras da armadura lateral para as vigas da série A1.

As Figuras 8.55 e 8.56 apresentam os diagramas força x deformação nos fios da armadura lateral para os ensaios das vigas VQ-2 e VQ-3, respectivamente. Os valores mostrados são a média dos valores obtidos nos dois lados instrumentados.

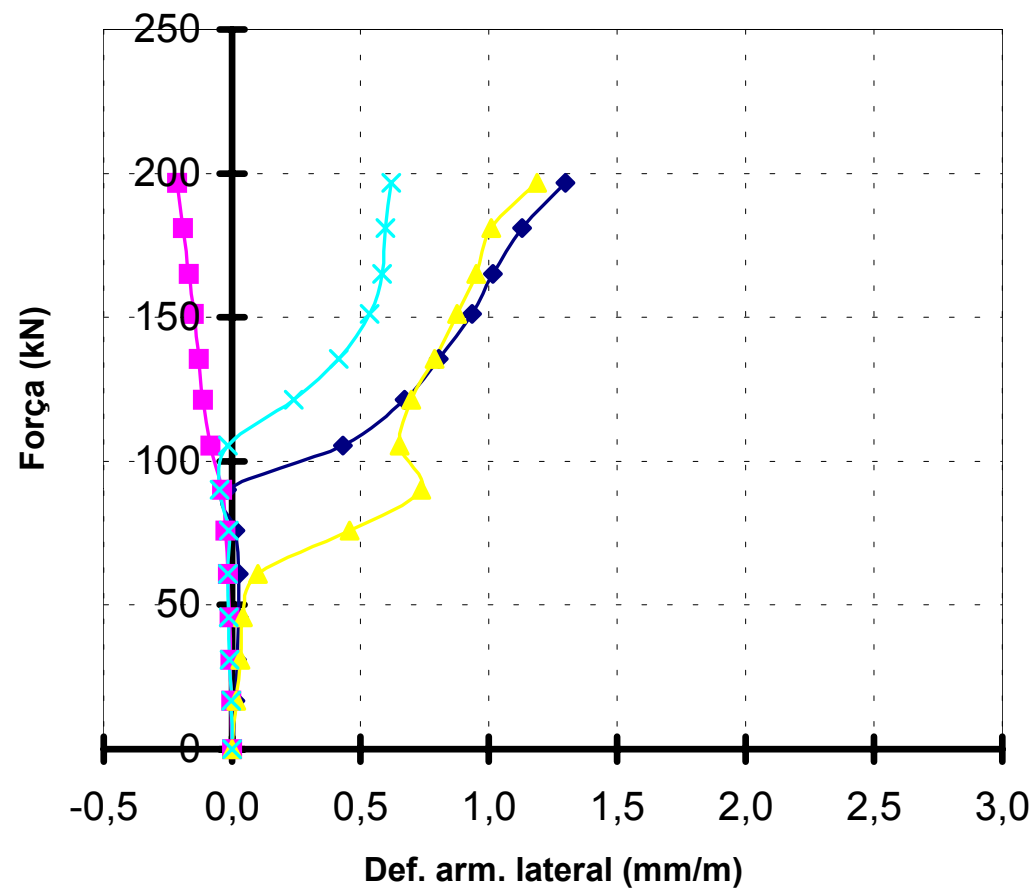

$\neg$ Inferior $40 \mathrm{~cm}$

- Superior a $40 \mathrm{~cm}$ - Inferior a $60 \mathrm{~cm}$ Superior a $60 \mathrm{~cm}$

Figura 8.55 - Diagramas força x deformação nos fios da armadura lateral (VQ-2). 


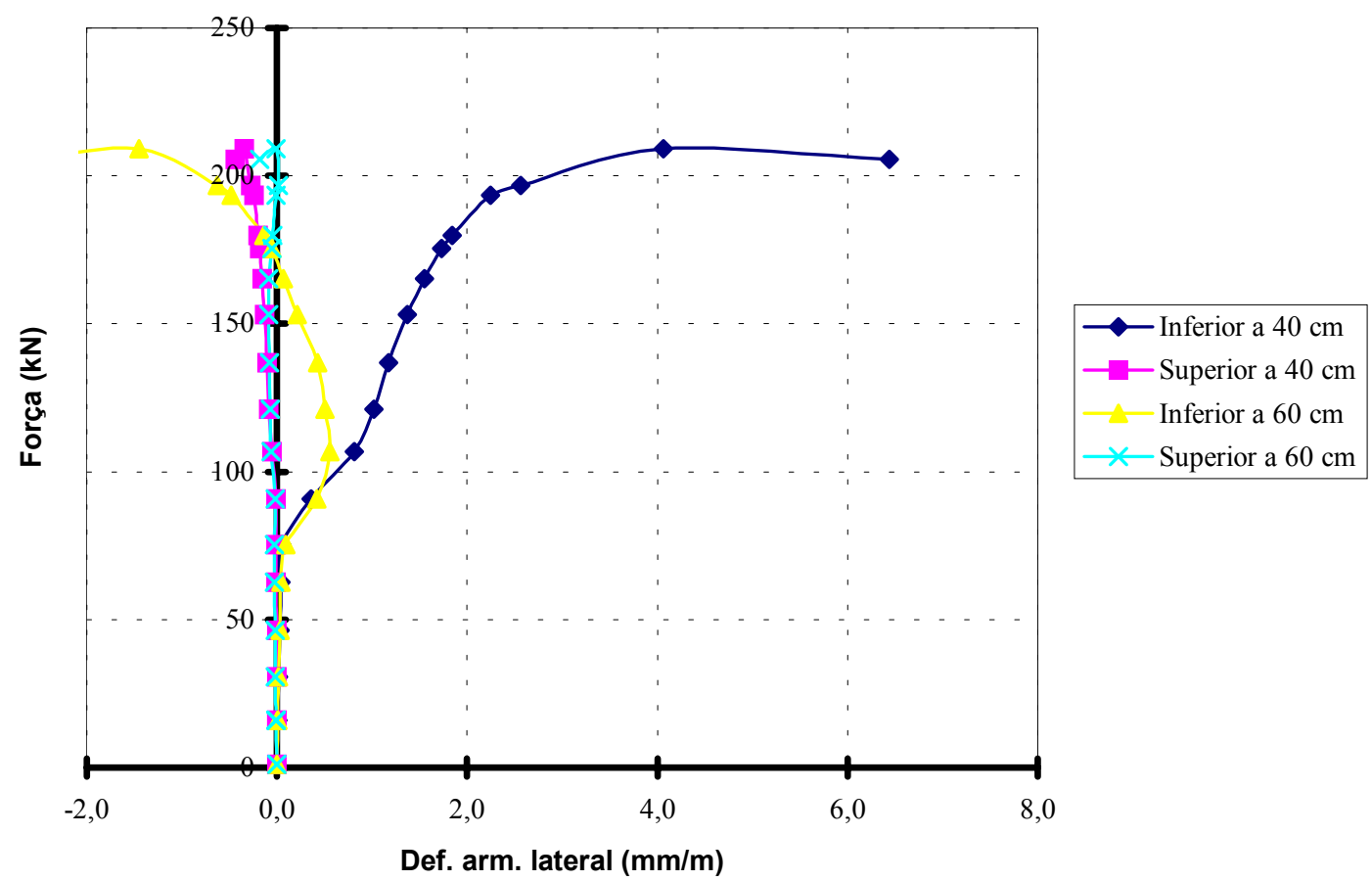

Figura 8.56 - Diagramas força x deformação nos fios da armadura lateral (VQ-3).

As Figuras 8.57, 8.58 e 8.59 apresentam os diagramas força x deformação nos fios da armadura lateral das vigas VQ-4, VQ-5 e VQ-6, respectivamente.

As Figuras 8.60 a 8.64 apresentam os diagramas força $x$ deformação nos fios da armadura lateral inferior das vigas das séries A2 (VS-2 e VS-3) e C (VS-4, VS-5 e VS-6). 


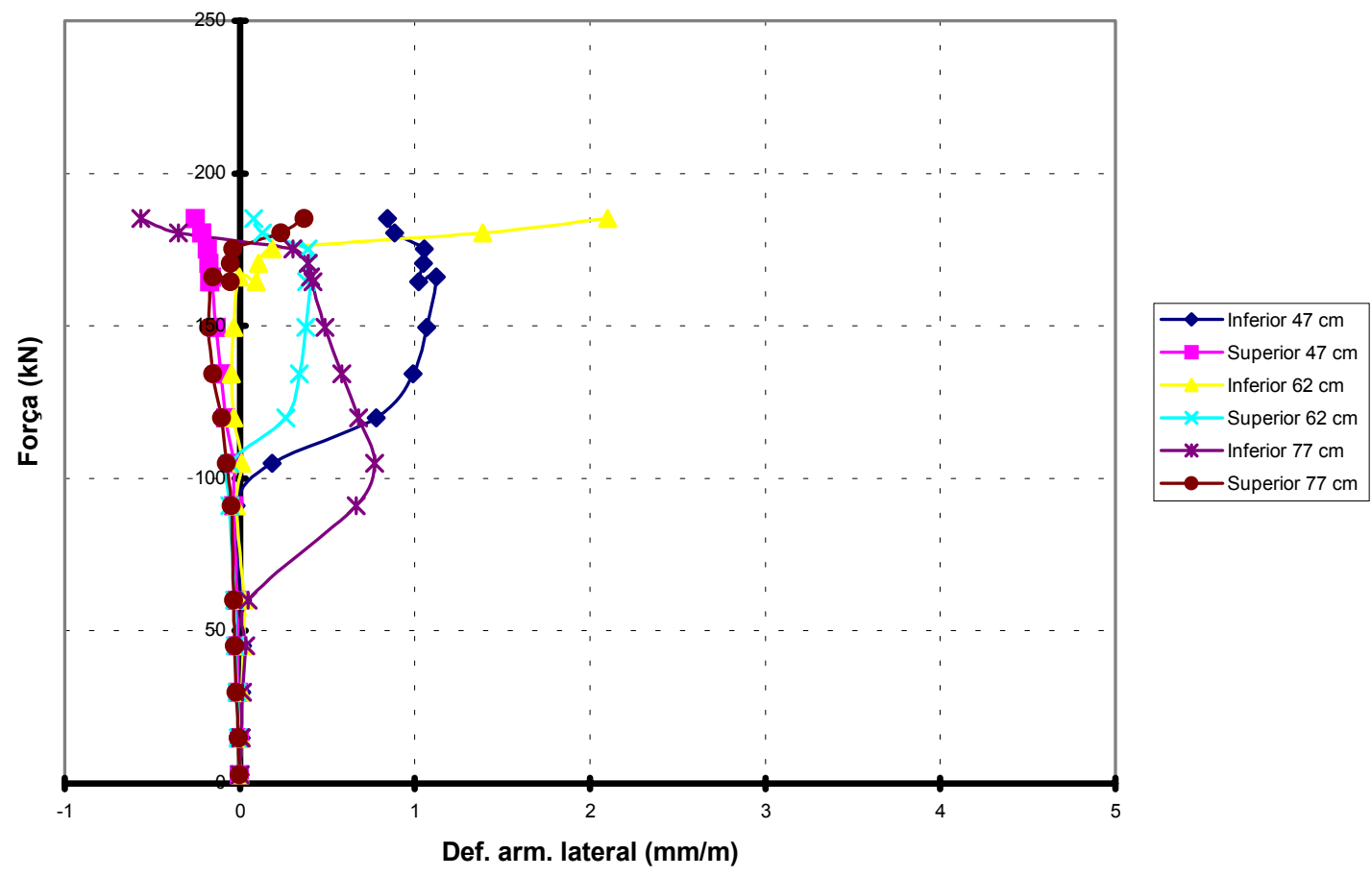

Figura 8.57 - Diagramas força x deformação nos fios da armadura lateral (VQ-4).

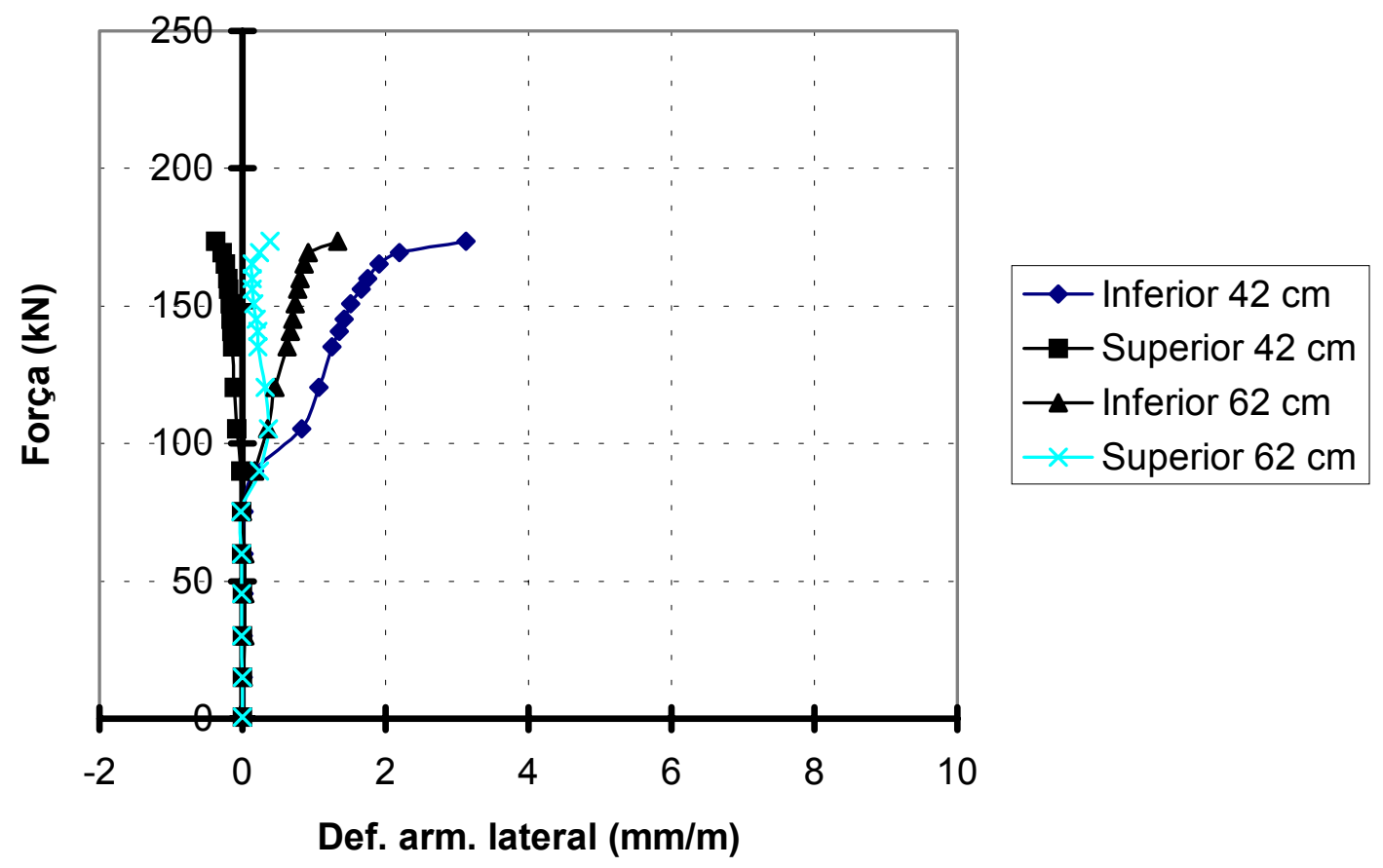

Figura 8.58 - Diagramas força x deformação nos fios da armadura lateral (VQ-5). 


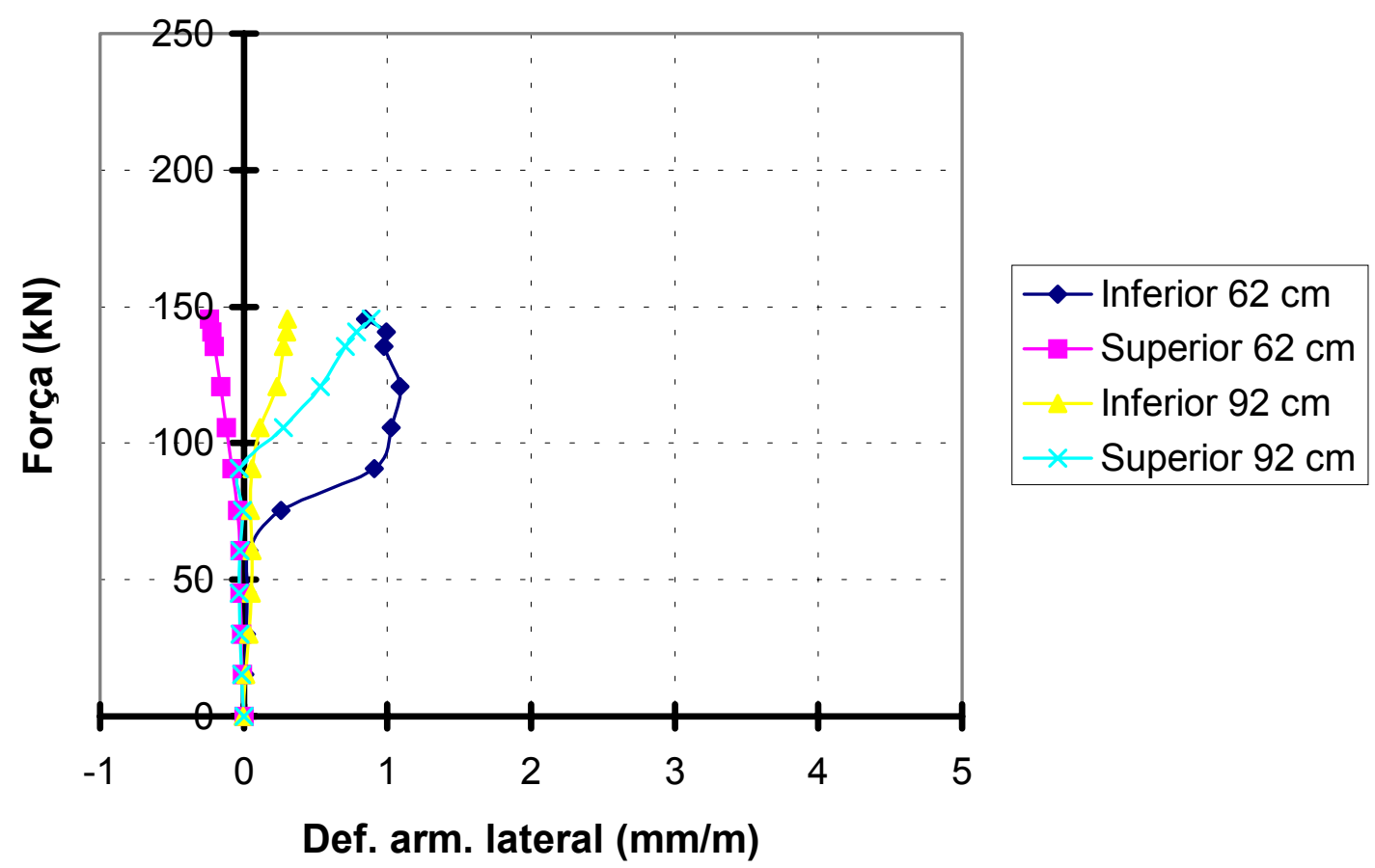

Figura 8.59 - Diagramas força x deformação nos fios da armadura lateral (VQ-6).

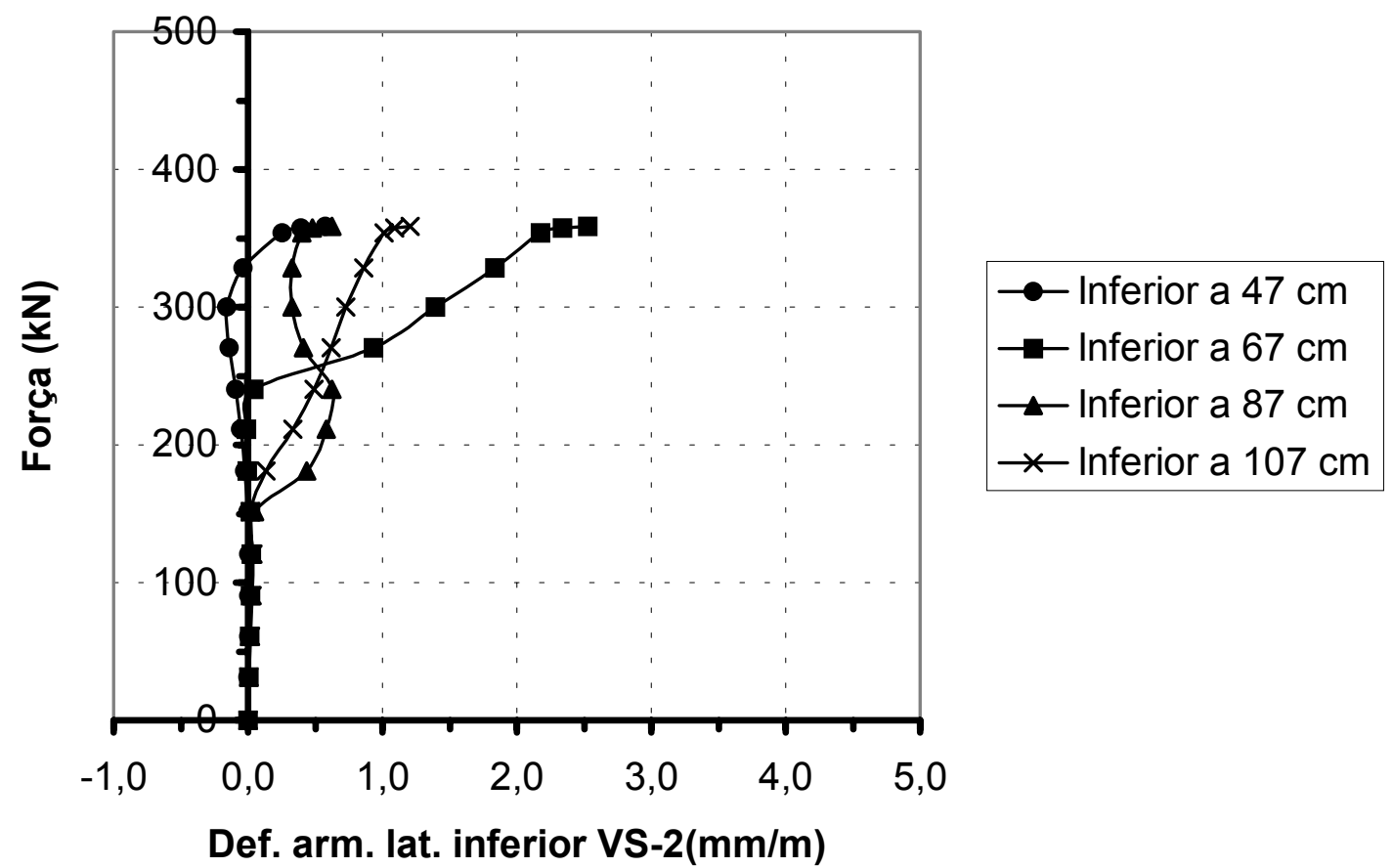

Figura 8.60 - Diagramas força $x$ deformação nos fios da armadura lateral inferior (VS-2). 


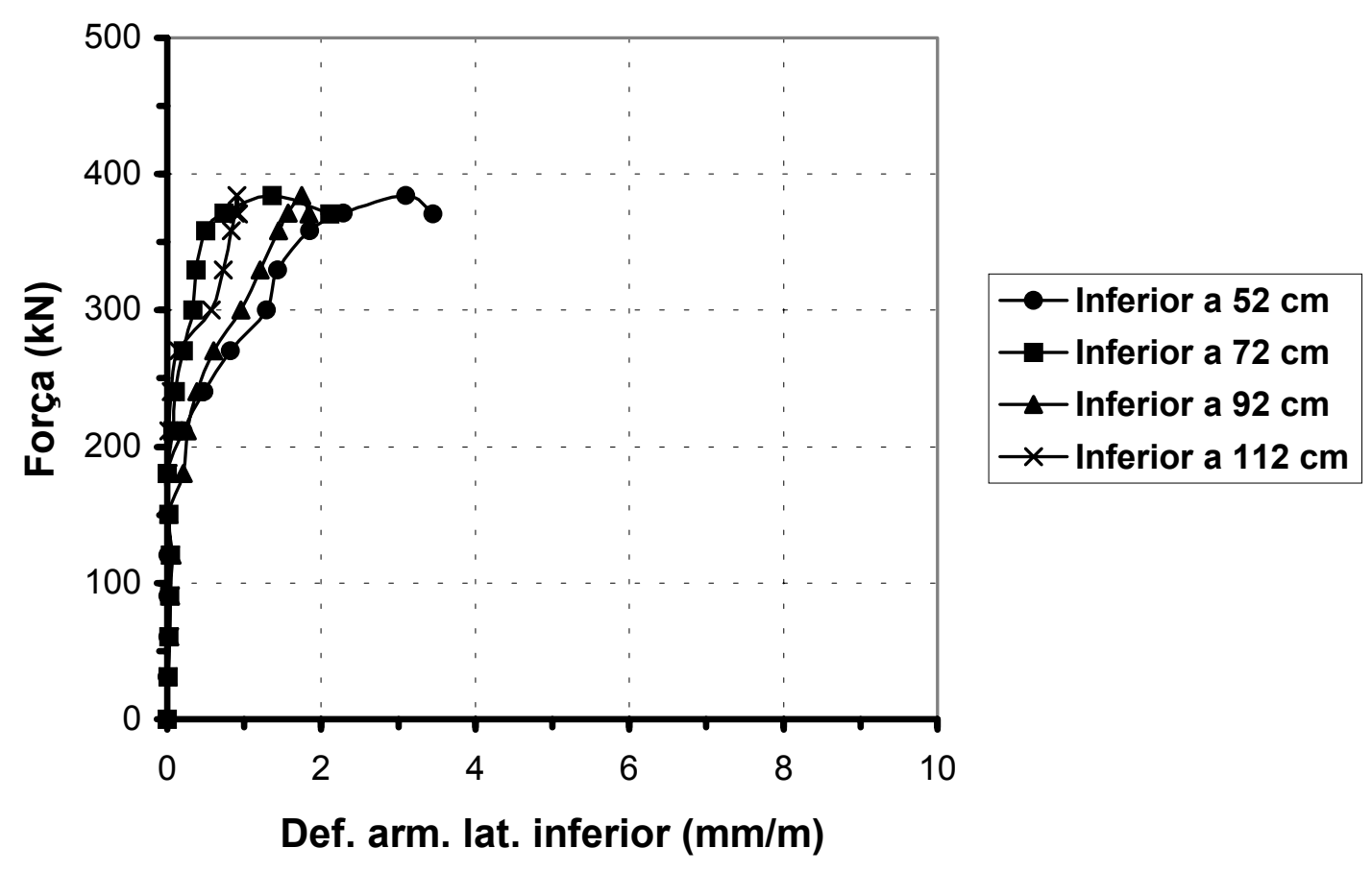

Figura 8.61 - Diagramas força x deformação nos fios da armadura lateral inferior (VS-3).

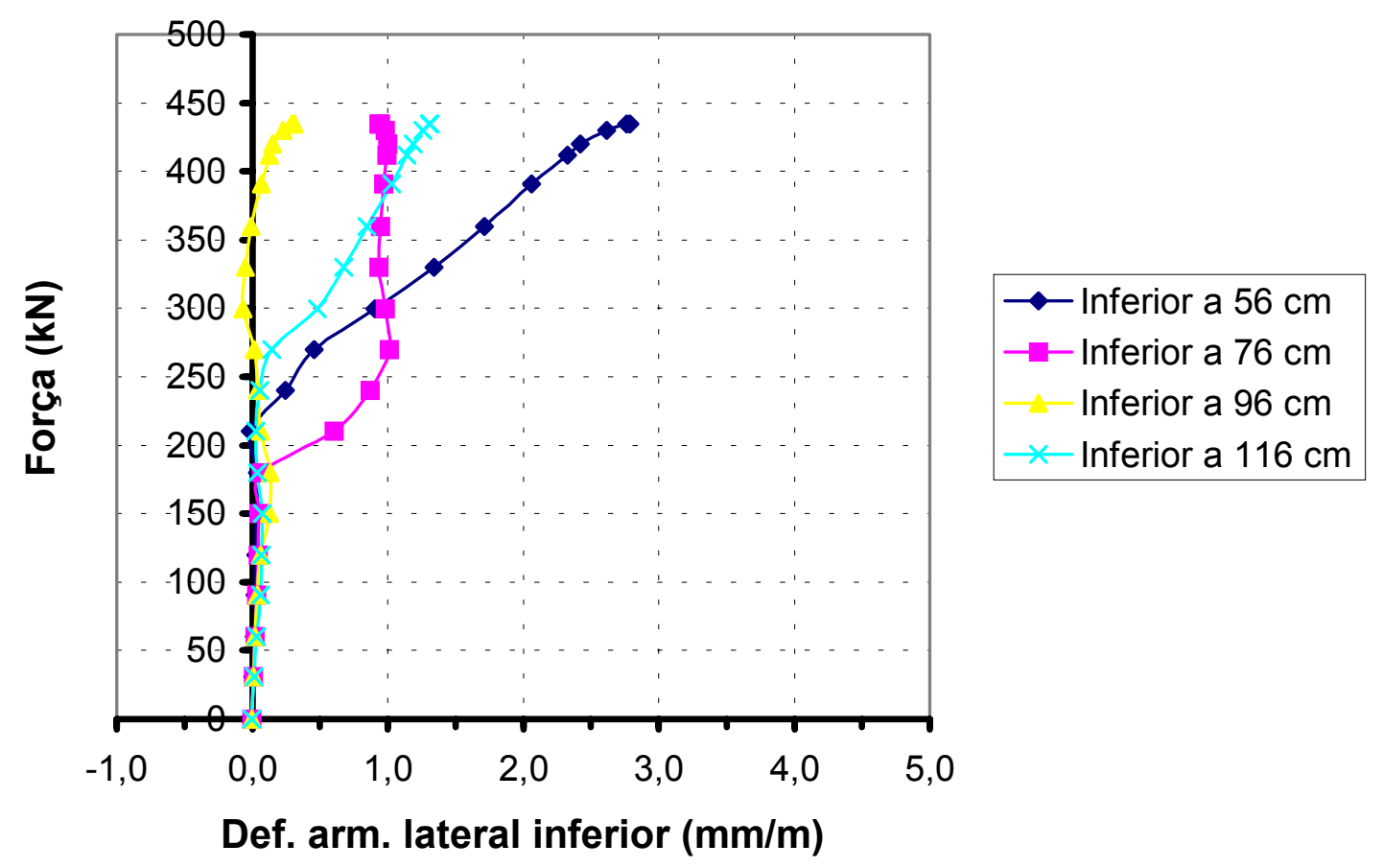

Figura 8.62 - Diagramas força x deformação nos fios da armadura lateral inferior (VS-4). 


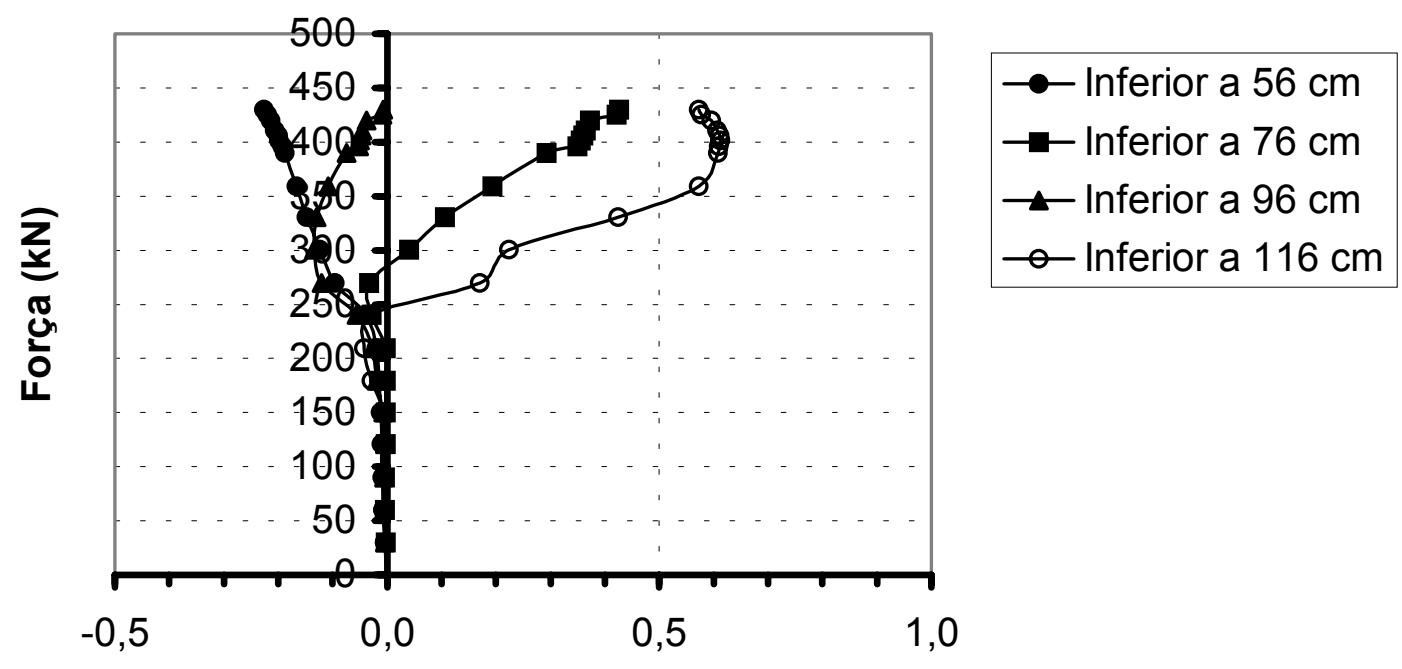

Def. arm. lat. inferior VS-5 (mm/m)

Figura 8.63 - Diagramas força x deformação nos fios da armadura lateral inferior (VS-5).

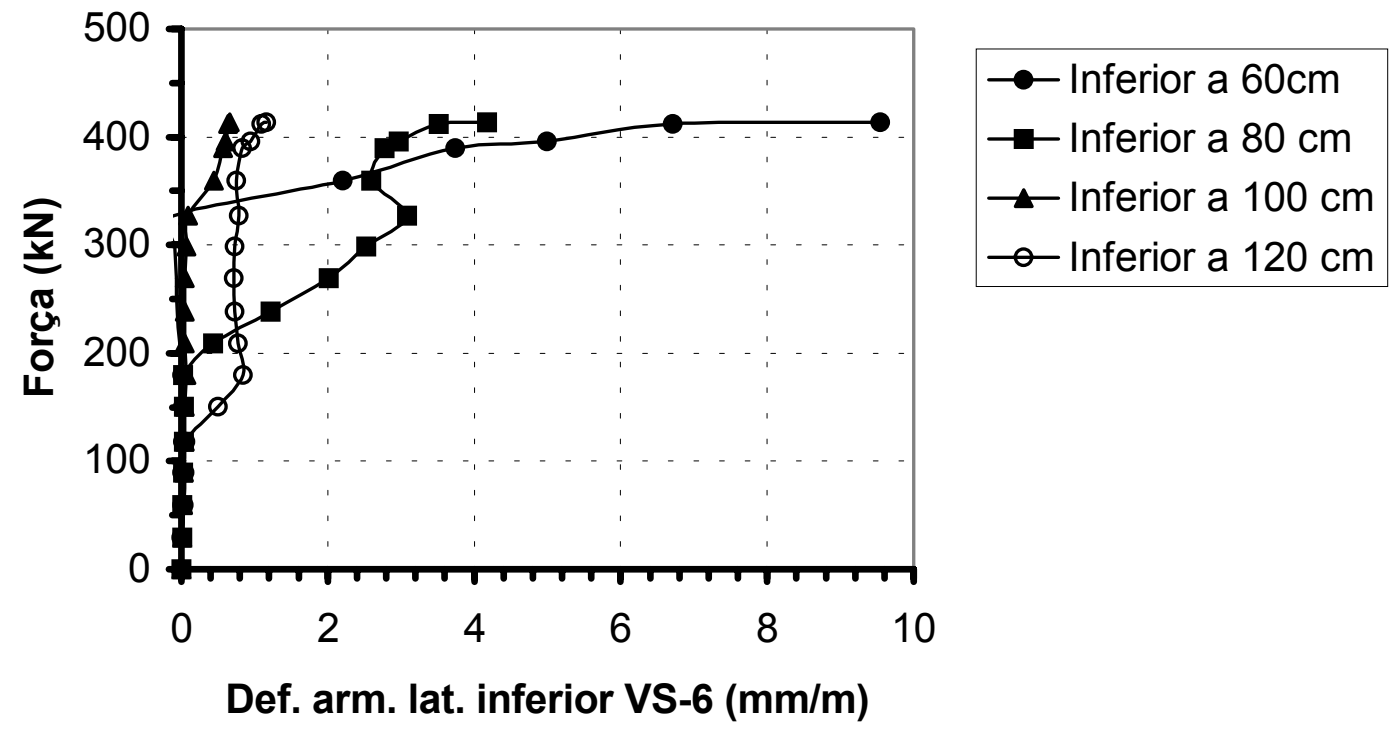

Figura 8.64 - Diagramas força $x$ deformação nos fios da armadura lateral inferior (VS-6). 


\section{9 - ABERTURAS E ESPAÇAMENTOS DAS FISSURAS}

As tabelas ímpares, C-1 a C-37, do Anexo C, apresentam os valores das aberturas de fissuras, desde a etapa em que se observou a primeira fissura até a etapa anterior à ruína. As estimativas dessas aberturas foram feitas ao longo dos eixos 1 e 2 (nervura tracionada) e eixo 3 (alma), como se pode observar na Figura 7.36.

As tabelas pares, C-2 a C-38, do Anexo C, indicam os espaçamentos entre fissuras medidos ao longo dos eixos 1, 2 e 3 , após o término dos ensaios. 


\section{ANÁLISE DOS RESULTADOS}

\section{1 - PRELIMINARES}

Neste capítulo apresenta-se a análise dos resultados experimentais obtidos, confrontando-os com os valores teóricos calculados segundo os critérios mostrados nos capítulos sobre resistência à força cortante e fissuração.

A formulação proposta pelo autor, utilizando a teoria do cisalhamento-atrito, para considerar a contribuição da armadura lateral na resistência à força cortante é validada pelos resultados dos ensaios.

Procede-se também à análise dos diversos parâmetros que influenciaram os resultados dos ensaios.

\section{2 - FORÇA CORTANTE ÚLTIMA}

\subsection{1 - NORMAS TÉCNICAS E PESQUISADORES}

Cabe esclarecer que as expressões das normas técnicas utilizadas neste item referemse às vigas usuais, com armadura transversal constituída por estribos verticais. Além disso, 
essas expressões são aplicáveis a projetos de estruturas, mas foram adaptadas com a utilização de coeficientes de segurança unitários.

A Tabela 9.1 apresenta os valores teóricos e experimentais da capacidade resistente à força cortante, calculados pelo Projeto de Revisão da NBR 6118: 2001 (modelos de cálculo I e II) e pelas expressões propostas por ZSUTTY (1968).

Tabela 9.1 - Valores teóricos e experimentais da capacidade resistente à força cortante obtidos pelo Projeto de Revisão da NBR 6118: 2001 e ZSUTTY (1968).

\begin{tabular}{|c|c|c|c|c|c|c|c|}
\hline \multirow[t]{2}{*}{ Viga } & \multicolumn{3}{|c|}{$V_{u, t e o}(k N)$} & \multirow{2}{*}{$V_{u, \exp }(k N$} & \multicolumn{3}{|c|}{$V_{u, \exp } / V_{u, t e o}$} \\
\hline & $\begin{array}{l}\text { NBR } \\
6118 \text { (I) }\end{array}$ & $\begin{array}{l}\text { NBR } \\
6118 \text { (II) }\end{array}$ & Zsutty & & \begin{tabular}{|l|} 
NBR \\
6118 (I)
\end{tabular} & $\begin{array}{l}\text { NBR } \\
6118 \text { (II) }\end{array}$ & Zsutty \\
\hline VQ-0 & 79,4 & 79,4 & 94,8 & 87,0 & 1,10 & 1,10 & 0,92 \\
\hline VQ-1 & 147,1 & 157,0 & 170,0 & 196,5 & 1,34 & 1,25 & 1,16 \\
\hline VQ-2 & 147,1 & 157,0 & 170,0 & 196,8 & 1,34 & 1,25 & 1,16 \\
\hline VQ-3 & 146,4 & 155,8 & 169,2 & 209,1 & 1,43 & 1,34 & 1,24 \\
\hline VQ-4 & 117,8 & 121,9 & 139,1 & 185,1 & 1,57 & 1,52 & 1,33 \\
\hline VQ-5 & 102,5 & 95,4 & 122,1 & 173,5 & 1,69 & 1,82 & 1,42 \\
\hline VQ-6 & 93,3 & 79,2 & 112,2 & 145,4 & 1,56 & 1,84 & 1,30 \\
\hline VQ-1A & 135,8 & 152,8 & 159,4 & 202,5 & 1,49 & 1,33 & 1,27 \\
\hline VQ-7 & 133,4 & 150,7 & 157,9 & 213,5 & 1,60 & 1,42 & 1,35 \\
\hline VQ-8 & 133,4 & 150,7 & 157,9 & 225,4 & 1,69 & 1,50 & 1,43 \\
\hline VQ-9 & 139,9 & 154,5 & 159,7 & 206,7 & 1,48 & 1,34 & 1,29 \\
\hline VQ-10 & 139,9 & 154,5 & 159,7 & 228,5 & 1,63 & 1,48 & 1,43 \\
\hline VS-0 & 124,8 & 124,8 & 182,6 & 161,1 & 1,29 & 1,29 & 0,88 \\
\hline VS-1 & 286,0 & 344,5 & 365,7 & 366,3 & 1,28 & 1,06 & 1,00 \\
\hline VS-2 & 286,0 & 345,8 & 361,7 & 358,8 & 1,25 & 1,04 & 0,99 \\
\hline VS-3 & 290,9 & 353,1 & 371,2 & 384,4 & 1,32 & 1,09 & 1,04 \\
\hline VS-4 & 335,0 & 382,8 & 395,2 & 434,8 & 1,30 & 1,14 & 1,10 \\
\hline VS-5 & 312,5 & 343,8 & 370,2 & 430,3 & 1,38 & 1,25 & 1,16 \\
\hline \multirow[t]{2}{*}{ VS-6 } & 296,3 & 344,0 & 366,9 & 413,9 & 1,40 & 1,20 & 1,13 \\
\hline & & & & média & 1,43 & 1,33 & 1,19 \\
\hline
\end{tabular}


Legenda:

NBR 6118 (I) - Projeto de Revisão da NBR 6118:2001-modelo I;

NBR 6118 (II) - Projeto de Revisão da NBR 6118:2001 - modelo II $\left(V_{S d}=0,6 \cdot V_{R d 2}\right.$ e $\left.\theta=30^{\circ}\right)$.

Na Tabela 9.1, observa-se que as relações $V_{u \text {,exp }} / V_{u, t e o}$ para as vigas com telas soldadas são superiores às relações para as vigas somente com estribos verticais. Os valores situam-se em torno de 1,50 para o Projeto de Revisão da NBR 6118: 2001 e 1,30 para as expressões propostas por ZSUTTY (1968). Analisando ainda os valores de $V_{u, \exp } / V_{u, \text { teo }}$ para as vigas da série A2, pode-se considerar os resultados suspeitos tendo em vista a baixa resistência à compressão do concreto.

A Tabela 9.2 mostra os valores teóricos e experimentais da capacidade resistente à força cortante calculados pelo ACI 318R (2002), Norma espanhola EHE (1999) e EUROCODE 2 (1992).

Observa-se novamente na Tabela 9.2 que as relações $V_{u, \exp } / V_{u, t e o}$ para as vigas com telas soldadas são superiores àquelas das vigas apenas com estribos verticais, e os valores excedem 1,50, ACI 318R (2002) e EHE (1999), para as vigas das séries B e D. 
Tabela 9.2 - Valores teóricos e experimentais da capacidade resistente à força cortante, obtidos segundo ACI 318R (2002), EHE (1999) e EUROCODE 2 (1992).

\begin{tabular}{|c|c|c|c|c|c|c|c|}
\hline \multirow{2}{*}{ Viga } & \multicolumn{3}{|c|}{$V_{u, \text { teo }}(k N)$} & \multirow{2}{*}{$V_{u, \text { exp }}(k N)$} & \multicolumn{3}{|c|}{$V_{u, \text { exp }} / V_{u, \text { teo }}$} \\
& ACI & EHE & EC-2 & & ACI & EHE & EC-2 \\
\hline VQ-0 & 58,0 & 70,4 & 104,2 & 87,0 & 1,50 & 1,24 & 0,83 \\
\hline VQ-1 & 133,2 & 138,1 & 171,9 & 196,5 & 1,47 & 1,42 & 1,14 \\
\hline VQ-2 & 133,2 & 126,4 & 171,9 & 196,8 & 1,48 & 1,56 & 1,14 \\
\hline VQ-3 & 132,4 & 125,7 & 171,2 & 209,1 & 1,58 & 1,66 & 1,22 \\
\hline VQ-4 & 105,4 & 101,6 & 139,1 & 185,1 & 1,76 & 1,82 & 1,33 \\
\hline VQ-5 & 88,4 & 86,3 & 123,8 & 173,5 & 1,96 & 2,01 & 1,40 \\
\hline VQ-6 & 78,4 & 77,4 & 114,6 & 145,4 & 1,85 & 1,88 & 1,27 \\
\hline VQ-1A & 125,6 & 119,8 & 157,0 & 202,5 & 1,61 & 1,69 & 1,29 \\
\hline VQ-7 & 124,3 & 118,6 & 154,2 & 213,5 & 1,72 & 1,80 & 1,38 \\
\hline VQ-8 & 124,3 & 118,6 & 154,2 & 225,4 & 1,81 & 1,90 & 1,46 \\
\hline VQ-9 & 125,6 & 119,8 & 162,7 & 206,7 & 1,65 & 1,73 & 1,27 \\
\hline VQ-10 & 125,6 & 119,8 & 162,7 & 228,5 & 1,82 & 1,91 & 1,40 \\
\hline VS-0 & 106,7 & 118,4 & 126,1 & 161,1 & 1,51 & 1,36 & 1,28 \\
\hline VS-1 & 288,5 & 262,0 & 287,3 & 366,3 & 1,27 & 1,40 & 1,27 \\
\hline VS-2 & 285,8 & 259,9 & 287,3 & 358,8 & 1,26 & 1,38 & 1,25 \\
\hline VS-3 & 294,0 & 267,0 & 292,3 & 384,4 & 1,31 & 1,44 & 1,32 \\
\hline VS-4 & 311,7 & 281,9 & 336,7 & 434,8 & 1,39 & 1,54 & 1,29 \\
\hline VS-5 & 286,7 & 259,5 & 314,3 & 430,3 & 1,50 & 1,66 & 1,37 \\
\hline VS-6 & 287,2 & 260,6 & 297,8 & 413,9 & 1,44 & 1,59 & 1,39 \\
\hline & & & & média & 1,57 & 1,63 & 1,28 \\
\hline
\end{tabular}

Legenda:

ACI - Código americano ACI 318R (2002);

EHE - Norma espanhola EHE (1999);

EC-2 - EUROCODE 2 (1999). 


\subsection{2 - PROPOSTA DE SILVA, RITA C. (1999)}

SILVA, Rita C. (1999), com base em ensaios de vigas com estribos verticais e armadura lateral (fios ou barras amarrados nos estribos), propõe uma formulação prática para estimar a contribuição da armadura lateral na resistência à força cortante. Adota-se uma área equivalente de estribos por unidade de comprimento da viga, que corresponde à soma das áreas de estribos verticais com a área da armadura lateral referida à altura útil.

A Tabela 9.3 compara os resultados dos ensaios executados com os valores teóricos calculados pela citada proposta, utilizando-se as demais prescrições do Projeto de Revisão da NBR 6118: 2001 (modelo de cálculo I). Ou seja, utilizam-se as mesmas expressões da referida norma, para vigas apenas com estribos verticais, tomando-se a área equivalente de estribos ao invés da área efetiva existente. Observa-se que os valores teóricos da força de ruína aproximaram-se bastante dos valores experimentais, obtendo-se um valor médio para a relação $V_{u, \exp } / V_{u, \text { teo }}$ igual a 1,17 .

A vantagem da proposta de SILVA, Rita C. (1999) é que sua utilização é bastante simples, adaptando-se aos critérios de normas correntes, desde que essas normas baseiem-se nas parcelas $\mathrm{V}_{\mathrm{c}}$ e $\mathrm{V}_{\mathrm{s}}$ no cálculo da resistência à força cortante.

$\mathrm{Na}$ opinião do autor, a referida proposta, apesar de os valores numéricos obtidos mostrarem-se adequados, é conceitualmente equivocada. A contribuição da armadura lateral, em virtude da influência em dois mecanismos resistentes alternativos, é tratada matematicamente como um acréscimo na parcela $V_{s}$ de contribuição da armadura transversal. Em outras palavras, utiliza-se uma formulação inconsistente com o fenômeno físico que efetivamente ocorre e que, em última instância, induz uma interpretação errônea. 
Tabela 9.3 - Valores teóricos e experimentais da capacidade resistente à força cortante, considerando-se a contribuição da armadura lateral pela proposta de SILVA, Rita C. (1999).

\begin{tabular}{|c|c|c|c|c|c|c|}
\hline Viga & $\begin{array}{c}A_{s w} / s \\
\left(\mathrm{~cm}^{2} / \mathbf{m}\right)\end{array}$ & $\begin{array}{c}A_{h} / d \\
\left(\mathbf{c m}^{2} / \mathbf{m}\right)\end{array}$ & $\begin{array}{c}A_{s e, e q} \\
\left(\mathbf{c m}^{2} / \mathbf{m}\right)\end{array}$ & $\begin{array}{l}V_{u, t e o} \\
(\mathbf{k N})\end{array}$ & $\begin{array}{l}V_{u, \exp } \\
(\mathbf{k N})\end{array}$ & $V_{u, \exp } / V_{u, t e c}$ \\
\hline VQ-2 & 2,78 & 1,54 & 4,32 & 184,6 & 196,8 & 1,07 \\
\hline VQ-3 & 2,78 & 1,54 & 4,32 & 183,5 & 209,1 & 1,14 \\
\hline VQ-4 & 2,12 & 1,77 & 3,89 & 159,4 & 185,1 & 1,16 \\
\hline VQ-5 & 1,59 & 1,77 & 3,36 & 140,9 & 173,5 & 1,23 \\
\hline VQ-6 & 1,06 & 1,77 & 2,83 & 135,5 & 145,4 & 1,07 \\
\hline VQ-7 & 2,78 & 1,54 & 4,32 & 170,6 & 213,5 & 1,25 \\
\hline VQ-8 & 2,78 & 1,54 & 4,32 & 170,6 & 225,4 & 1,32 \\
\hline VQ-9 & 2,78 & 1,54 & 4,32 & 177,0 & 206,7 & 1,17 \\
\hline VQ-10 & 2,78 & 1,54 & 4,32 & 177,0 & 228,5 & 1,29 \\
\hline VS-2 & 3,92 & 1,81 & 5,73 & 360,4 & 358,8 & 1,00 \\
\hline VS-3 & 3,92 & 1,81 & 5,73 & 367,7 & 384,4 & 1,05 \\
\hline VS-4 & 3,92 & 1,21 & 5,13 & 387,8 & 434,8 & 1,12 \\
\hline VS-5 & 3,92 & 1,21 & 5,13 & 358,4 & 430,3 & 1,20 \\
\hline \multirow[t]{2}{*}{ VS-6 } & 3,92 & 0,60 & 4,52 & 320,2 & 413,9 & 1,29 \\
\hline & & & & & média & 1,17 \\
\hline
\end{tabular}




\subsection{3 - FORMULAÇÃO PROPOSTA}

As hipóteses de cálculo admitidas e as expressões de cálculo deduzidas no capítulo sobre teoria do cisalhamento-atrito foram utilizadas para a validação da formulação proposta.

Para o cálculo dos valores mostrados nas Tabelas 9.4 e 9.5 foram utilizadas as expressões (4.20), (4.25), (4.30), (4.33), (4.34) e (4.37).

Tabela 9.4 - Variáveis auxiliares utilizadas para o cálculo de $V_{u, t e o}$ pela formulação proposta pelo autor.

\begin{tabular}{|c|c|c|c|c|c|c|c|}
\hline Viga & $d_{e v}$ & $\mathbf{k}$ & $V_{s 1}$ & $\mathbf{C}$ & $a_{r u p}$ & $\lambda$ & $\theta$ \\
\hline & $\mathbf{( c m )}$ & & $\mathbf{( k N )}$ & $\mathbf{( k N )}$ & $\mathbf{( m m )}$ & & (graus) \\
\hline VQ-2 & 34,32 & 0,4965 & 20,90 & 2208 & 95 & 0,5278 & 32,0 \\
\hline VQ-3 & 34,32 & 0,4965 & 20,68 & 2208 & 72 & 0,4000 & 35,2 \\
\hline VQ-4 & 34,20 & 0,5758 & 23,06 & 1524 & 120 & 0,6667 & 34,3 \\
\hline VQ-5 & 34,20 & 0,5758 & 21,29 & 1524 & 90 & 0,5000 & 35,5 \\
\hline VQ-6 & 34,20 & 0,5722 & 23,39 & 1548 & 40 & 0,2222 & 29,8 \\
\hline VQ-7 & 34,32 & 0,5786 & 20,68 & 1506 & 145 & 0,8056 & 28,7 \\
\hline VQ-8 & 34,32 & 0,5786 & 20,68 & 1506 & 115 & 0,6389 & 32,3 \\
\hline VQ-9 & 34,32 & 0,5636 & 20,68 & 1608 & 95 & 0,5278 & 38,0 \\
\hline VQ-10 & 34,32 & 0,5636 & 20,68 & 1608 & 85 & 0,4722 & 31,8 \\
\hline VS-2 & 64,00 & 0,6668 & 27,55 & 2464 & 270 & 0,8308 & 39,0 \\
\hline VS-3 & 64,00 & 0,6495 & 28,40 & 2632 & 115 & 0,3538 & 30,1 \\
\hline VS-4 & 64,00 & 0,5804 & 29,26 & 3486 & 115 & 0,3538 & 37,5 \\
\hline VS-5 & 64,00 & 0,5804 & 25,42 & 3486 & 195 & 0,6000 & 37,8 \\
\hline VS-6 & 64,00 & 0,6213 & 26,66 & 2940 & 85 & 0,2615 & 30,4 \\
\hline
\end{tabular}


Tabela 9.5 - Valores teóricos e experimentais da capacidade resistente à força cortante, considerando-se a contribuição da armadura lateral (formulação proposta pelo autor).

\begin{tabular}{|c|c|c|c|c|c|c|c|}
\hline Viga & $\begin{array}{c}A_{s, \text { lat }} \\
\left.\mathbf{( c m}^{\mathbf{2}}\right)\end{array}$ & $\begin{array}{c}f_{y, l a t} \\
\mathbf{( M P a )}\end{array}$ & $\begin{array}{c}R_{\text {s,lat }} \\
\mathbf{( k N )}\end{array}$ & $\begin{array}{c}R_{s t} \\
\mathbf{( k N )}\end{array}$ & $\begin{array}{c}V_{u, \text { teo }} \\
\mathbf{( k N )}\end{array}$ & $\begin{array}{c}V_{u, \text { exp }} \\
\mathbf{( k N )}\end{array}$ & $\begin{array}{l}V_{u, \text { exp }} \\
V_{u, \text { teo }}\end{array}$ \\
\hline VQ-2 & 0,834 & 751,96 & 62,71 & 222,18 & 167,63 & 196,8 & 1,17 \\
\hline VQ-3 & 0,834 & 744,00 & 62,05 & 312,53 & 178,03 & 209,1 & 1,17 \\
\hline VQ-4 & 0,954 & 725,00 & 69,17 & 152,57 & 149,86 & 185,1 & 1,24 \\
\hline VQ-5 & 0,954 & 669,50 & 63,87 & 142,78 & 124,30 & 173,5 & 1,40 \\
\hline VQ-6 & 0,954 & 735,50 & 70,17 & 229,32 & 95,94 & 145,4 & 1,52 \\
\hline VQ-7 & 0,834 & 744,00 & 62,05 & 128,10 & 144,84 & 213,5 & 1,47 \\
\hline VQ-8 & 0,834 & 744,00 & 62,05 & 181,12 & 160,04 & 225,4 & 1,41 \\
\hline VQ-9 & 0,834 & 744,00 & 62,05 & 251,16 & 182,24 & 206,7 & 1,13 \\
\hline VQ-10 & 0,834 & 744,00 & 62,05 & 245,88 & 161,89 & 228,5 & 1,41 \\
\hline VS-2 & 2,352 & 702,90 & 165,32 & 384,13 & 405,37 & 358,8 & 0,89 \\
\hline VS-3 & 2,352 & 724,50 & 170,40 & 785,82 & 334,56 & 384,4 & 1,15 \\
\hline VS-4 & 1,568 & 746,50 & 117,05 & 872,78 & 417,54 & 434,8 & 1,04 \\
\hline VS-5 & 1,176 & 648,50 & 76,26 & 519,01 & 423,23 & 430,3 & 1,02 \\
\hline VS-6 & 0,784 & 680,00 & 53,31 & 889,32 & 332,88 & 413,9 & 1,24 \\
\hline & & & & & & média & 1,23 \\
\hline
\end{tabular}

Com relação aos valores apresentados nas Tabelas 9.4 e 9.5, valem as seguintes observações:

- simplificadamente, para o cálculo do coeficiente experimental $\mathrm{k}$ foi usada a expressão (4.30) que levou em conta apenas a resistência à compressão do concreto;

- os valores de $a_{r u p}$ e $\theta$ foram medidos experimentalmente;

- os valores calculados de $V_{u, t e o}$ foram influenciados pelos valores medidos de $a_{r u p}$ e $\theta$;

- os valores obtidos da relação $V_{u, \exp } / V_{u, \text { teo }}$ apresentaram-se razoáveis tendo em vista o coeficiente empírico k utilizado e os possíveis erros nas medidas de $a_{r u p}$ e $\theta$. 
Com base nas observações anteriores, concluiu-se que a formulação proposta pelo autor poderia ser aperfeiçoada. Uma contribuição importante seria a obtenção de uma expressão teórica para o cálculo dos valores de $a_{\text {rup }}$ e $\theta$.

\section{3 - ANÁLISE DOS PARÂMETROS ENVOLVIDOS}

\subsection{1 - INFLUÊNCIA DA RESISTÊNCIA À COMPRESSÃO DO CONCRETO}

Durante o planejamento inicial do programa experimental, pretendia-se utilizar um concreto com resistência à compressão pouco variável. Por esse motivo foi solicitado à empresa fornecedora um concreto com o mesmo traço em todas as concretagens. Entretanto, esse objetivo não foi atingido, pois a resistência à compressão do concreto variou bastante. Os motivos que causaram esta variação estão listados a seguir:

- em função do cronograma do Laboratório de Estruturas, as vigas da série A1 foram ensaiadas com 45/48 dias e não aos 28 dias como previsto; assim, a resistência à compressão foi superior à pretendida;

- as vigas das séries seguintes foram ensaiadas em idades em torno dos 28 dias, visto que um adiamento dos ensaios poderia inviabilizar o cronograma da pesquisa;

- para as vigas da série A2 o concreto apresentou um valor alto para o abatimento do tronco de cone; era esperada uma redução na resistência à compressão, mas não tão drástica quanto efetivamente ocorreu;

- as concretagens foram realizadas em um período de aproximadamente um ano, nesse tempo deve ter ocorrido alteração nas propriedades dos materiais constituintes do concreto (granulometria dos agregados, tipo de agregados, tipo de cimento, etc.).

Pode-se, inclusive, suspeitar de possíveis erros na dosagem do concreto fornecido pela empresa Pela aparência das vigas após a desforma e pelo comportamento dos modelos durante os ensaios, ficou evidenciado que, nas vigas da série A2, a qualidade duvidosa do concreto afetou os resultados dos ensaios. 
Apresentam-se, na Figura 9.1, gráficos mostrando a variação da força de ruína experimental em função da resistência à compressão do concreto. São apresentados os valores de $f_{c}$ em MPa e da relação $V_{u, \exp } / b_{w} \cdot d$ em MPa.
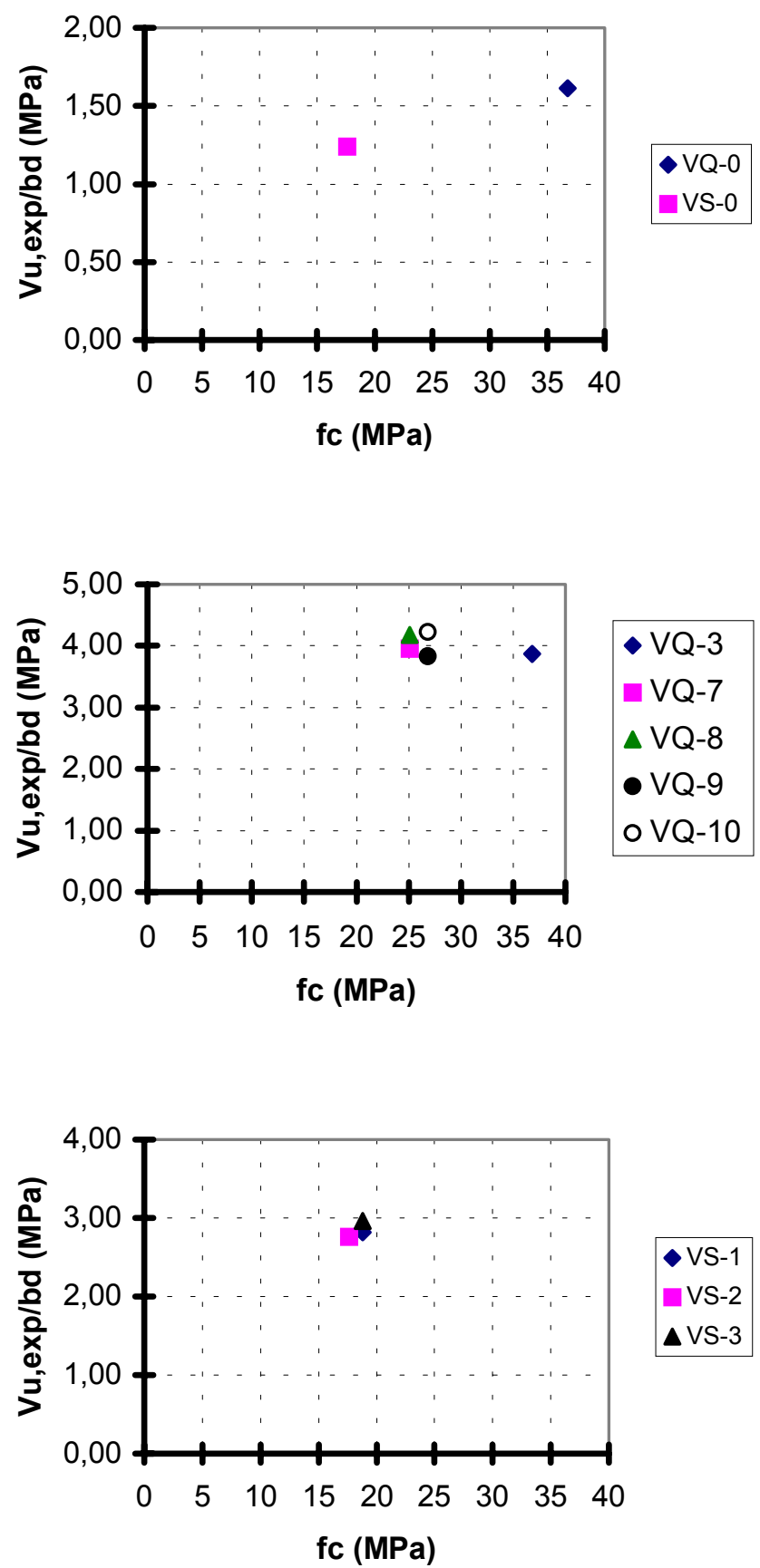

Figura 9.1 - Gráficos $\left(V_{u, \exp } / b_{w} \cdot d\right) \times f_{c}$ para as vigas ensaiadas. 
No primeiro gráfico da Figura 9.1 observa-se um aumento na relação $V_{u, \exp } / b_{w} \cdot d$ com o aumento da resistência à compressão do concreto. Lembra-se, todavia, que ocorreu diminuição da altura da viga (VQ- $0, d=36 \mathrm{~cm}$ e VS- $0, d=65 \mathrm{~cm}$ ). No segundo gráfico, no qual todas as vigas tinham taxas iguais de armaduras transversal e lateral, não se observou variação de $\mathrm{V}_{\mathrm{u}, \exp } / \mathrm{b}_{\mathrm{w}} \cdot \mathrm{d}$ com a resistência à compressão do concreto. $\mathrm{O}$ mesmo comentário pode ser feito com relação ao terceiro gráfico, sendo que apenas a viga VS-1 não tinha armadura lateral.

\subsection{2 - INFLUÊNCIA DA ALTURA DA VIGA}

Para análise da influência da altura da viga foram consideradas as vigas com altura útil d = $36 \mathrm{~cm}$ (VQ-3, VQ-7 a VQ-10) e a viga VS-4 com d = $65 \mathrm{~cm}$, por possuírem valores de taxas de armaduras transversal e lateral bastante próximos.

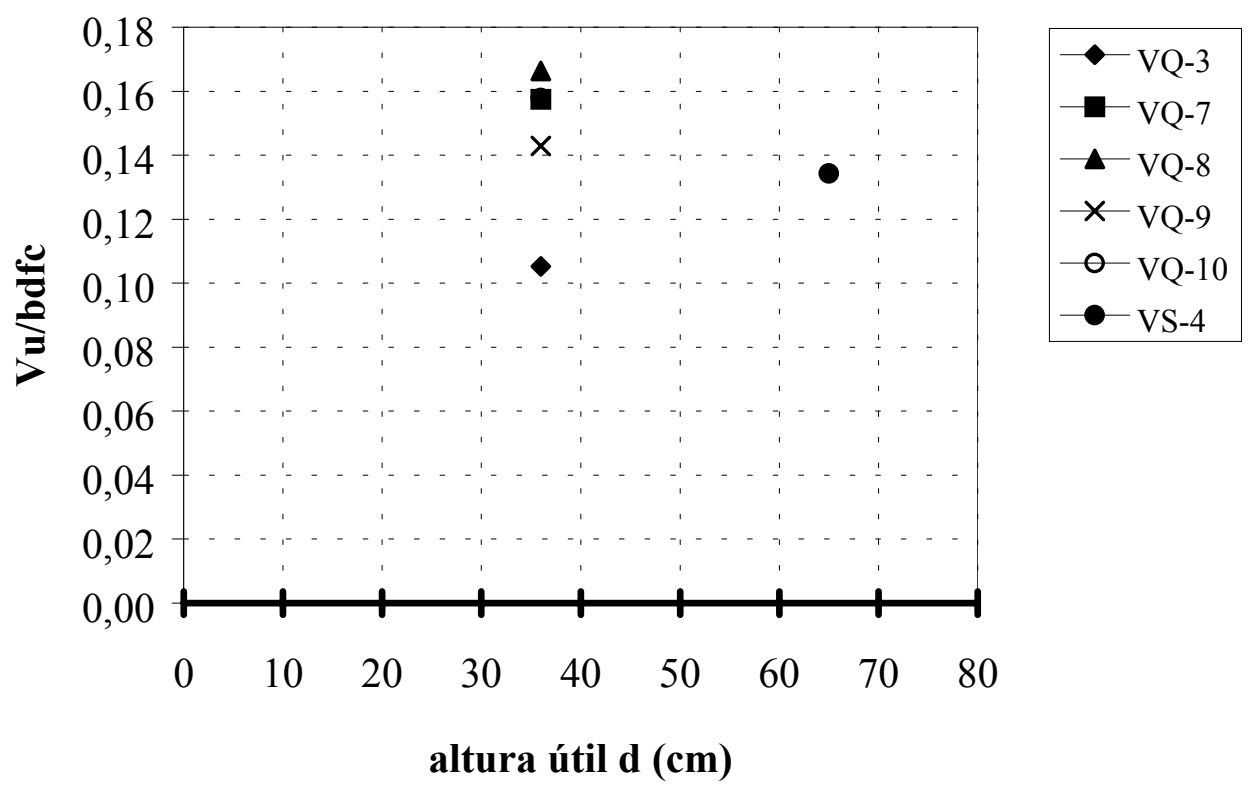

Figura 9.2 - Gráficos $\left(\mathrm{V}_{\mathrm{u}, \exp } / \mathrm{b}_{\mathrm{w}} \cdot\right.$ d. $\left.\mathrm{f}_{\mathrm{c}}\right) \times \mathrm{d}$ para as vigas ensaiadas.

Tomando-se os maiores valores obtidos de $\mathrm{V}_{\mathrm{u} \text {,exp }} / \mathrm{b}_{\mathrm{w}}$.d.f. $\mathrm{f}_{\mathrm{c}}$ (vigas VQ-7, VQ-8 e VQ-9) observa-se uma diminuição da resistência à força cortante com o aumento da altura útil d. 


\subsection{3 - INFLUÊNCIA DA TAXA DE ARMADURA LONGITUDINAL}

Utilizaram-se nas vigas de ensaio as seguintes taxas de armadura longitudinal: $\rho_{\mathrm{s} \ell}=$ $3,35 \%(\mathrm{VQ})$ ou $\rho_{\mathrm{s} \ell}=3,38 \%$ (VS). Essas taxas foram adotadas com o objetivo de induzir à ruína por força cortante, embora fossem muito altas para vigas usuais.

A diminuição da taxa de armadura longitudinal provocaria redução na resistência à força cortante da viga. Essa redução poderia acontecer em razão de uma maior abertura de fissuras (que reduziria o efeito de engrenamento dos agregados) e pela diminuição do efeito de pino.

A resistência à força cortante também poderia ser influenciada pela rigidez do banzo tracionado da viga. Nas vigas ensaiadas, vide o detalhamento das armaduras, as barras longitudinais, que não foram ancoradas no apoio com gancho a $90^{\circ}$, foram prolongadas pelo menos até a face interna do apoio.

\subsection{4 - INFLUENCIA DA TAXA DE ARMADURA TRANSVERSAL}

A capacidade resistente à força cortante é fortemente influenciada pela taxa de armadura transversal. Além disso, o tipo de armadura transversal, a ancoragem no banzo comprimido e o espaçamento dos estribos exercem sua parcela de influência.

Para as vigas ensaiadas com armadura transversal foram utilizados estribos verticais abertos com ancoragem na borda comprimida com gancho de $135^{\circ}$ (exceto as vigas da série D) e adotadas taxas de armadura transversal dentro do intervalo: $0,071 \% \leq \rho_{\mathrm{sw}} \leq 0,196 \%$.

Os gráficos mostrados na Figura 9.3 evidenciam o aumento da relação $\left(V_{u, \exp } / b_{w} \cdot d \cdot f_{c}\right)$ com o aumento de $\rho_{s w} . f_{y w}$, exceto para as vigas da série A2. 

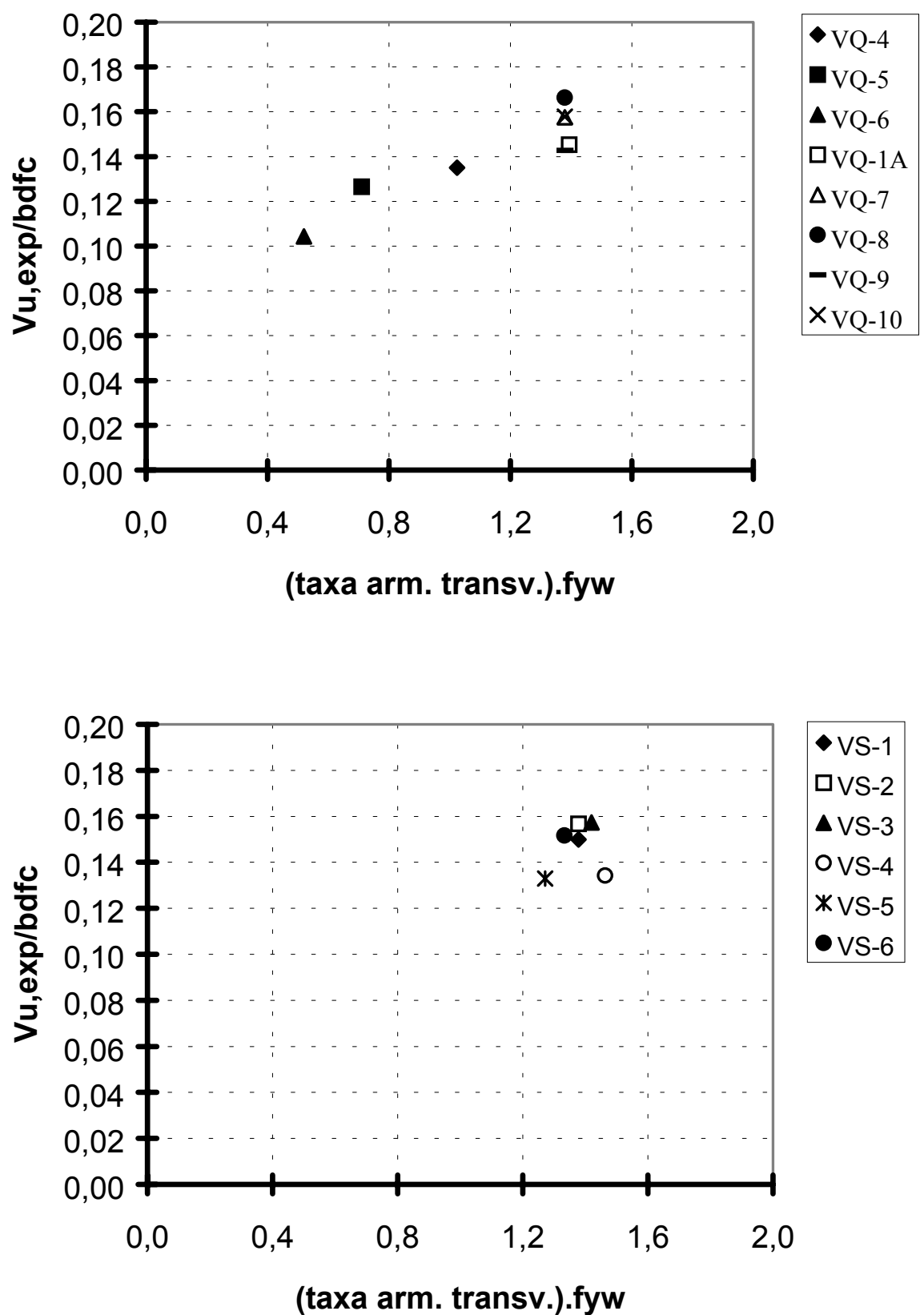

Figura 9.3 - Gráficos $\left(V_{u, \exp } / b_{w} \cdot d . f_{c}\right) \times \rho_{s w} \cdot f_{y w}$ para as vigas ensaiadas.

\subsection{5 - INFLUÊNCIA DA TAXA DE ARMADURA LATERAL}

Nas vigas foram adotadas taxas de armadura lateral no seguinte intervalo: $0,131 \% \leq$ $\rho_{\mathrm{s}, \text { lat }} \leq 1,176 \%$. 
O gráfico apresentado na Figura 9.4 indica o aumento da relação $\left(V_{u, \exp } / b_{w} \cdot d \cdot f_{c}\right)$ com o aumento de $\rho_{s, l a t} \cdot f_{y, l a t}$, exceto para a viga VS-6 da série C.

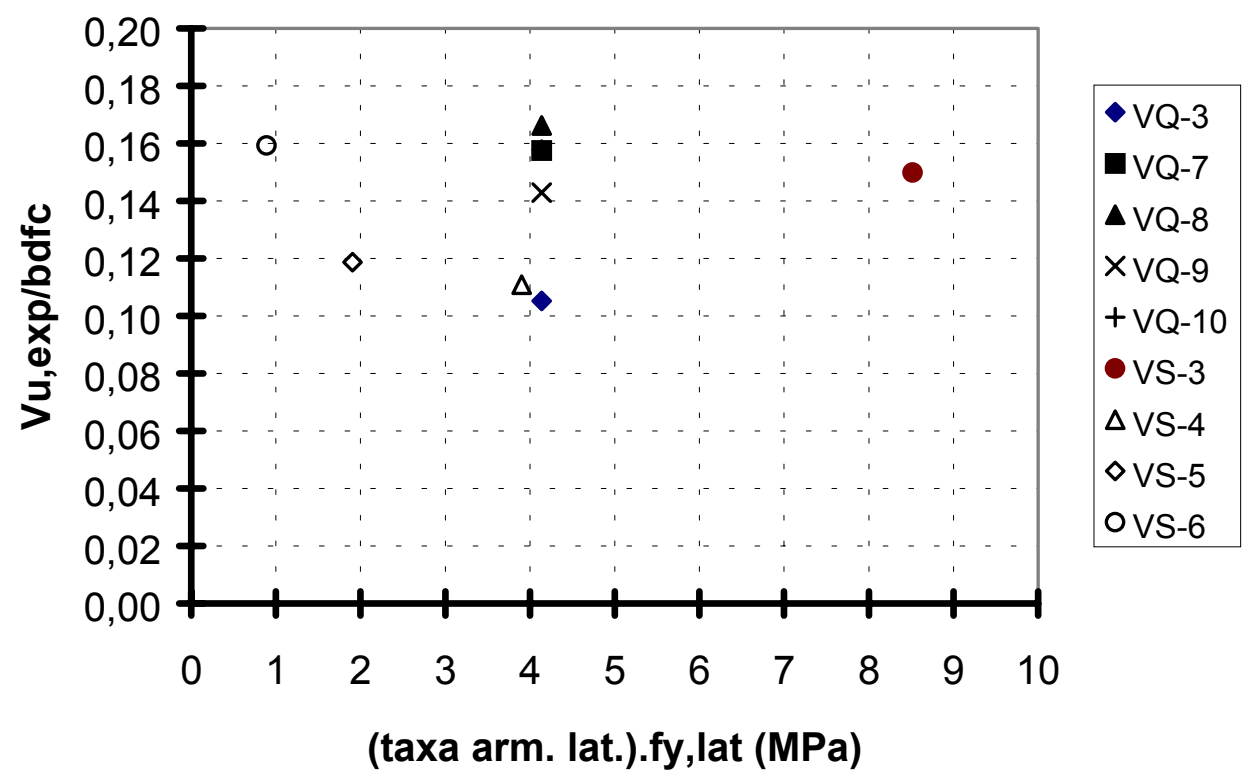

Figura 9.4 - Gráfico $\left(V_{u, \exp } / b_{w} \cdot d \cdot f_{c}\right) \times \rho_{s, \text { lat }} . f_{y, \text { lat }}$ para as vigas ensaiadas.

\subsection{6 - INFLUÊNCIA DO TIPO DE ANCORAGEM DA TELA NA BORDA COMPRIMIDA}

$\mathrm{Na}$ maior parte das vigas ensaiadas, utilizou-se ancoragem dos fios verticais da tela na borda comprimida com gancho de $135^{\circ}$. Entretanto, para as vigas da série D foram adotadas as ancoragens descritas na Tabela 9.6 e mostradas na Figura 9.4.

As normas ACI 318R (2002) e o EUROCODE 2 (1992) apresentam prescrições referentes a ganchos de $90^{\circ}$ e de $135^{\circ}$ e barras transversais soldadas de mesmo diâmetro dos estribos verticais (vide capítulo 2). Em termos construtivos, a ancoragem utilizada na viga VQ-9 é mais interessante, assim como usar barras transversais amarradas nos estribos e não soldadas.

Todas as vigas da série D, além de VQ-3, com taxas iguais de armadura transversal e lateral, apresentaram o mesmo comportamento durante o ensaio e modo de ruína (força cortante-tração), o que indica que o tipo de ancoragem na borda comprimida não afetou 
substancialmente os resultados. Entretanto, as vigas VQ-8 e VQ-10 apresentaram os maiores valores de força última experimental.

Os resultados indicaram que a utilização de barras transversais amarradas, e não soldadas, vigas VQ-7 e VQ-8, mostrou-se adequada. Entretanto, parece suficiente adotar $\phi_{\ell}=\phi_{\mathrm{t}}(\mathrm{VQ}-7)$ e não $\phi_{\ell}>1,4 \phi_{\mathrm{t}}(\mathrm{VQ}-8)$.

Tabela 9.6 - Tipos de ancoragem na borda comprimida da viga VQ-3 da série A1 e das vigas VQ-7, VQ-8, VQ-9 e VQ-10 da série D.

\begin{tabular}{|c|c|c|c|}
\hline Viga & Ancoragem na borda comprimida & $\begin{array}{c}V_{u, \exp } \\
\mathbf{( k N )}\end{array}$ & Tipo de ruína \\
\hline VQ-3 & ganchos a $135^{\circ}$ & 209,1 & força cortante-tração \\
\hline VQ-7 & duas barras transversais amarradas & 213,5 & força cortante-tração \\
& com $\phi=4,2 \mathrm{~mm}$ & & \\
\hline VQ-8 & duas barras transversais amarradas & 225,4 & força cortante-tração \\
& com $\phi=6,3 \mathrm{~mm}$ & & \\
\hline VQ-9 & ancoragem reta & 206,7 & força cortante-tração \\
\hline VQ-10 & ganchos de $90^{\circ}$ abertos para fora & 228,5 & força cortante-tração \\
\hline
\end{tabular}

Em vigas usuais de seção $T$, espera-se uma atuação conjunta da armadura negativa da laje e dos fios verticais da tela soldada, o que muito provavelmente ocorreu nos ensaios.

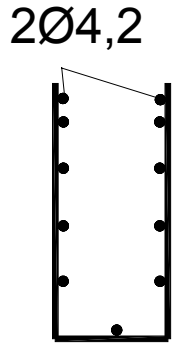

VQ-7

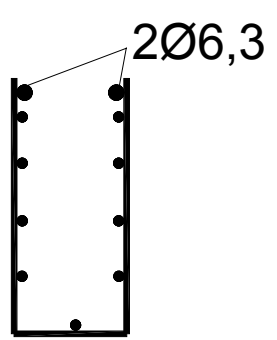

VQ-8

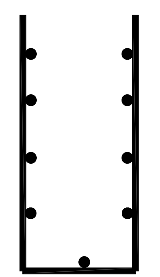

VQ-9

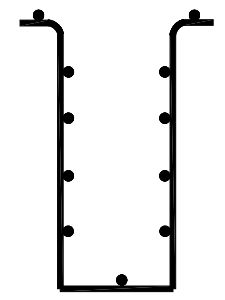

VQ-10

Figura 9.5 - Detalhes da ancoragem no bordo comprimido das vigas VQ-7, VQ-8, VQ-9 e VQ-10 da série D. 
Salienta-se que, a despeito do resultado obtido no ensaio da viga VQ-9, a ancoragem reta deve ser evitada em projetos usuais. Dependendo do ponto no qual o estribo é interceptado pela fissura de cisalhamento, ele não funciona efetivamente por falha de ancoragem, o que diminui a parcela de resistência da armadura transversal na resistência à força cortante.

\subsection{7 - ANÁLISE COMPARATIVA ARMADURA LATERAL (FIOS AMARRADOS X TELA SOLDADA)}

Nos ensaios apenas duas vigas foram executadas com armadura lateral, composta por fios amarrados nos estribos verticais. Essas vigas, VQ-2 da série A1 e VS-2 da série A2, tinham as mesmas características das vigas VQ-3 e VS-3, respectivamente, armadas com telas soldadas.

Os valores experimentais da força de ruína das vigas VQ-3 e VS-3 foram superiores aos das vigas VQ-2 e VS-2 (Tabela 8.1). Além disso, as duas vigas com telas soldadas apresentaram uma reserva de segurança nas proximidades do colapso, com absorção de forças aplicadas mesmo com o escoamento de alguns estribos verticais.

Pressupõe-se que este aumento na força última em VQ-3 e VS-3 ocorreu em virtude do aumento na parcela de engrenamento dos agregados, além do efeito favorável do nó soldado.

\section{4 - ESTADOS LIMITES DE SERVIÇO}

\subsection{1 - MOMENTO FLETOR DE FISSURAÇÃO}

O momento fletor de fissuração experimental refere-se à etapa de aplicação de ação na qual foi observada a primeira fissura de flexão visível. $\mathrm{O}$ valor foi confirmado pela observação dos diagramas força-deslocamento e força-deformação da armadura longitudinal, com a perda de rigidez dos modelos, caracterizado pela passagem do Estádio I para o Estádio II.

A Tabela 9.7 apresenta os valores experimentais e teóricos do momento fletor de fissuração de todas as vigas ensaiadas. Os valores de $M_{r, \text { teo }}$ foram calculados pelas expressões do Projeto de Revisão da NBR 6118:2001. 
Tabela 9.7 - Valores teóricos e experimentais do momento fletor de fissuração.

\begin{tabular}{|c|c|c|c|}
\hline Viga & $\begin{array}{c}M_{r, \text { teo }} \\
\mathbf{( k N . m )}\end{array}$ & $\begin{array}{c}M_{r, \text { exp }} \\
\mathbf{( k N . m )}\end{array}$ & $M_{r, \exp } / M_{r, \text { teo }}$ \\
\hline VQ-0 & 32,7 & 40,0 & 1,22 \\
\hline VQ-1 & 32,7 & 45,0 & 1,38 \\
\hline VQ-2 & 32,7 & 46,3 & 1,42 \\
\hline VQ-3 & 32,7 & 30,8 & 0,94 \\
\hline VQ-4 & 28,0 & 29,8 & 1,06 \\
\hline VQ-5 & 28,0 & 29,8 & 1,06 \\
\hline VQ-6 & 28,0 & 29,8 & 1,06 \\
\hline VQ-1A & 28,0 & 45,0 & 1,61 \\
\hline VQ-7 & 27,3 & 30,7 & 1,12 \\
\hline VQ-8 & 27,3 & 30,7 & 1,12 \\
\hline VQ-9 & 30,0 & 30,7 & 1,02 \\
\hline VQ-10 & 30,0 & 30,7 & 1,02 \\
\hline VS-0 & 87,7 & 80,4 & 0,92 \\
\hline VS-1 & 87,7 & 90,2 & 1,03 \\
\hline VS-2 & 87,7 & 90,2 & 1,03 \\
\hline VS-3 & 87,7 & 90,2 & 1,03 \\
\hline VS-4 & 115,0 & 120,6 & 1,05 \\
\hline VS-5 & 115,0 & 120,6 & 1,05 \\
\hline VS-6 & 98,6 & 118,4 & 1,20 \\
\hline & & $\mathbf{m e ́ d i a}$ & 1,12 \\
\hline
\end{tabular}

\subsection{2 - FORÇA CORTANTE DE FISSURAÇÃO}

A Tabela 9.8 apresenta os valores experimentais e teóricos da força cortante de fissuração das vigas ensaiadas. Os valores de $V_{c r, t e o}$ foram calculados pelas expressões do Código Modelo CEB-FIP (1990) e os valores experimentais foram anotados durante os ensaios, com o aparecimento da primeira fissura de cisalhamento visível. 
Tabela 9.8 - Valores teóricos e experimentais da força cortante de fissuração.

\begin{tabular}{|c|c|c|c|}
\hline Viga & $\begin{array}{l}V_{c r, t e o} \\
(\mathbf{k N})\end{array}$ & $\begin{array}{l}V_{c r, \exp } \\
(\mathbf{k N})\end{array}$ & $V_{c r, \exp } / V_{c r, t e o}$ \\
\hline VQ-0 & 72,2 & 60 & 0,83 \\
\hline VQ-1 & 72,2 & 60 & 0,83 \\
\hline VQ-2 & 72,2 & 75 & 1,04 \\
\hline VQ-3 & 72,2 & 75 & 1,04 \\
\hline VQ-4 & 63,8 & 75 & 1,18 \\
\hline VQ-5 & 63,8 & 75 & 1,18 \\
\hline VQ-6 & 64,1 & 75 & 1,17 \\
\hline VQ-1A & 64,1 & 75 & 1,17 \\
\hline VQ-7 & 63,6 & 90 & 1,42 \\
\hline VQ-8 & 63,6 & 90 & 1,42 \\
\hline VQ-9 & 65,0 & 90 & 1,38 \\
\hline VQ-10 & 65,0 & 75 & 1,15 \\
\hline VS-0 & 123,9 & 140 & 1,13 \\
\hline VS-1 & 126,7 & 120 & 0,95 \\
\hline VS-2 & 123,9 & 150 & 1,21 \\
\hline VS-3 & 126,7 & 120 & 0,95 \\
\hline VS-4 & 139,1 & 150 & 1,08 \\
\hline VS-5 & 139,1 & 180 & 1,29 \\
\hline \multirow[t]{2}{*}{ VS-6 } & 131,5 & 150 & 1,14 \\
\hline & & média & 1,13 \\
\hline
\end{tabular}

\subsection{3 - ABERTURAS DE FISSURAS DE CISALHAMENTO NA}

\section{ALMA}

\subsubsection{1 - Série A1}

A Tabela 9.9 apresenta os valores teóricos e experimentais das aberturas de fissuras de cisalhamento das vigas da série A1, para forças aplicadas aproximadamente entre $40 \% \mathrm{e}$ 
$60 \%$ da força última. Os valores teóricos foram calculados pelas expressões 5.24 a 5.30 do CEB (1978), sendo $w_{w}=k_{w} \cdot w_{m}$ e $k_{w}=1,2$ (estribos verticais).

Observa-se que a média dos valores $w_{w, t e o} / w_{w, \exp }$ para a viga VQ-3, com tela soldada, foi de 1,61, o que evidencia o controle da fissuração proporcionado pela tela soldada.

Tabela 9.9 - Valores teóricos e experimentais das aberturas de fissuras das vigas da série A1.

\begin{tabular}{|c|c|c|c|c|}
\hline Viga & $\mathbf{V}(\mathbf{k N})$ & $\frac{\mathrm{w}_{\mathrm{w}, \text { teo }}(\mathrm{mm})}{\text { CEB-78 }}$ & $\begin{array}{l}\mathbf{W}_{\mathrm{w}, \exp } \\
(\mathrm{mm})\end{array}$ & $\frac{\mathbf{W}_{\mathrm{w}, \mathrm{tee}} / \mathbf{w}_{\mathrm{w}, \mathrm{exp}}}{\text { CEB-78 }}$ \\
\hline \multirow{5}{*}{ VQ-1 } & 90 & 0,07 & 0,08 & 0,88 \\
\hline & 120 & 0,28 & 0,30 & 0,93 \\
\hline & 150 & 0,56 & 0,55 & 1,02 \\
\hline & $\mathrm{V}_{\mathrm{u}, \exp }=196,5$ & & & \\
\hline & & & média & 0,94 \\
\hline \multirow[t]{5}{*}{ VQ-2 } & 90 & 0,07 & 0,10 & 0,70 \\
\hline & 120 & 0,28 & 0,30 & 0,93 \\
\hline & 150 & 0,56 & 0,55 & 1,02 \\
\hline & $\mathrm{V}_{\mathrm{u}, \exp }=196,8$ & & & \\
\hline & & & média & 0,88 \\
\hline \multirow[t]{5}{*}{ VQ-3 } & 90 & 0,07 & 0,08 & 0,88 \\
\hline & 120 & 0,28 & 0,16 & 1,75 \\
\hline & 150 & 0,55 & 0,25 & 2,20 \\
\hline & $\mathrm{V}_{\mathrm{u}, \exp }=209,1$ & & & \\
\hline & & & média & 1,61 \\
\hline
\end{tabular}

O gráfico apresentado na Figura 9.6 indica claramente a ocorrência de menores aberturas de fissuras de cisalhamento na alma (região A1/C1) da viga VQ-3 (tela soldada) em relação às outras duas vigas da série $\mathrm{A} 1$. Tal fato não se repete na região $\mathrm{A} 2 / \mathrm{C} 2$, Figura 9.7. 


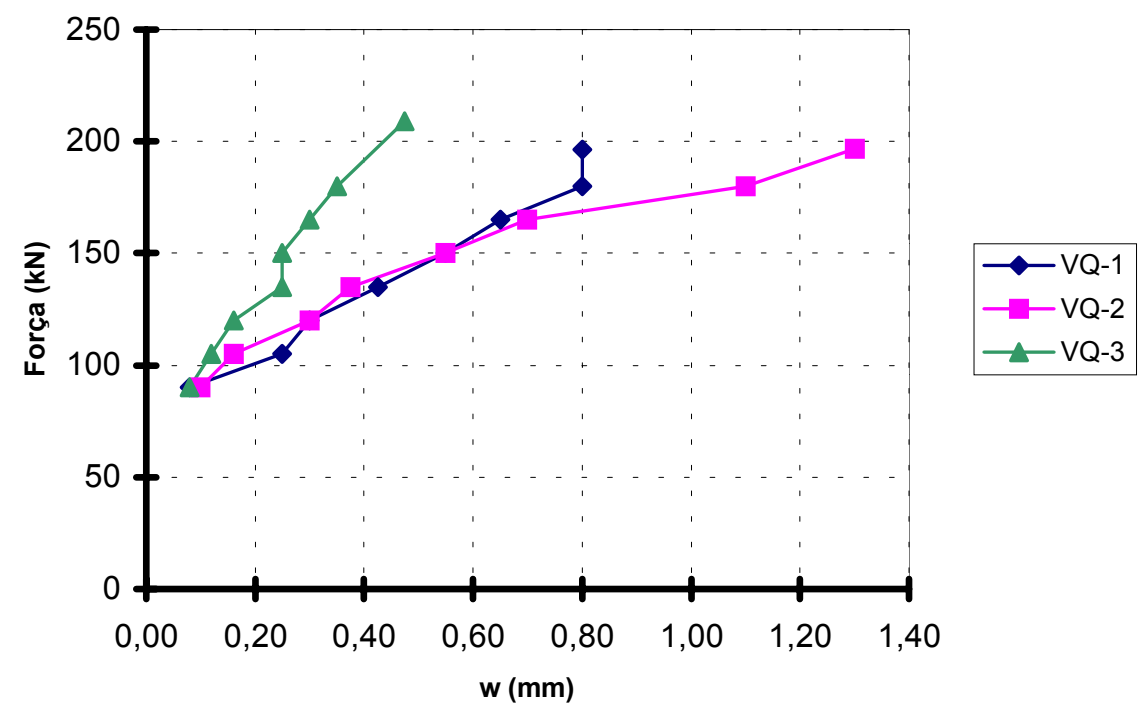

Figura 9.6 - Gráficos força aplicada x aberturas de fissuras na alma das vigas da série A1 (região A1/C1).

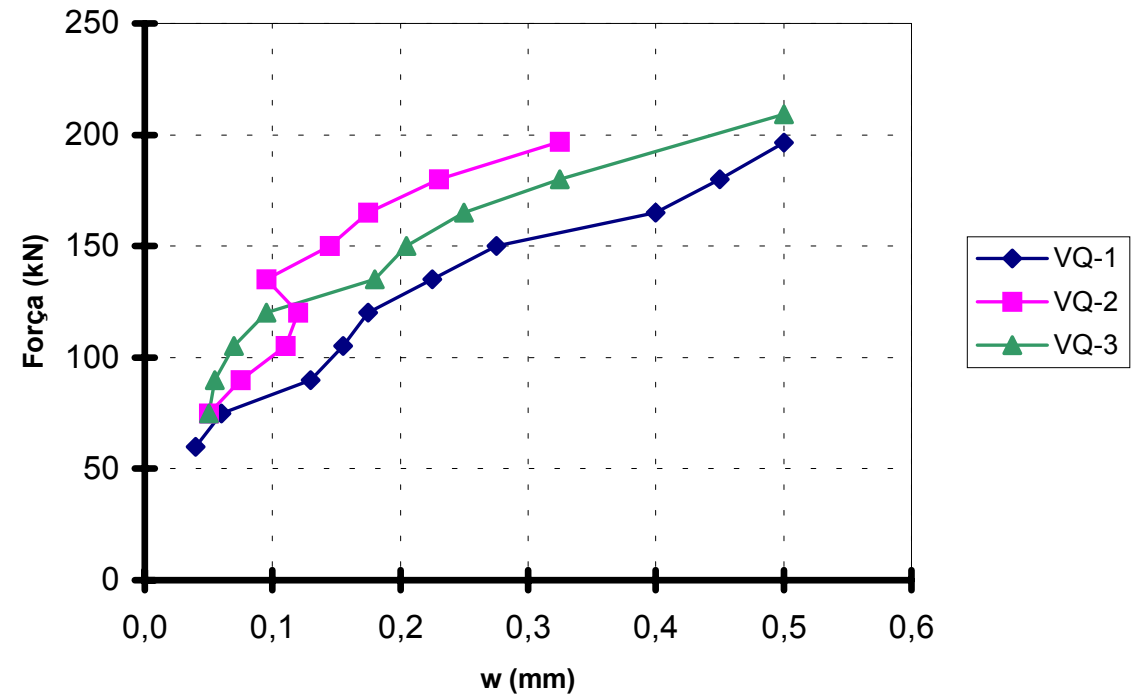

Figura 9.7 - Gráficos força aplicada x aberturas de fissuras na alma das vigas da série A1 (região $\mathrm{A} 2 / \mathrm{C} 2$ ). 


\subsubsection{2 - Série B}

A Tabela 9.10 mostra os valores teóricos e experimentais das aberturas de fissuras de cisalhamento das vigas da série B, para forças aplicadas aproximadamente entre $40 \%$ e $60 \%$ da força última. Observa-se que a média dos valores $w_{w, t e o} / w_{w, \exp }$ foram bastante altos variando de 2,50 para a viga VQ-6 até 3,49 para a viga VQ-4.

Tabela 9.10 - Valores teóricos e experimentais das aberturas de fissuras das vigas da série B.

\begin{tabular}{|c|c|c|c|c|}
\hline Viga & $\mathbf{V}(\mathbf{k N})$ & $\frac{\mathrm{w}_{\mathrm{w}, \text { teo }}(\mathrm{mm})}{\text { CEB-78 }}$ & $\begin{array}{l}\mathbf{W}_{\mathrm{w}, \exp } \\
(\mathrm{mm})\end{array}$ & $\frac{\mathbf{w}_{\mathrm{w}, \text { teo }} / \mathbf{w}_{\mathrm{w}, \mathrm{exp}}}{\text { CEB-78 }}$ \\
\hline \multirow[t]{4}{*}{ VQ-4 } & 90 & 0,17 & 0,04 & 4,25 \\
\hline & 120 & 0,53 & 0,15 & 3,53 \\
\hline & 150 & 0,94 & 0,35 & 2,69 \\
\hline & $\mathrm{V}_{\mathrm{u}, \exp }=185,1$ & & & \\
\hline & & & média & 3,49 \\
\hline \multirow[t]{3}{*}{ VQ-5 } & 90 & 0,24 & 0,08 & 3,00 \\
\hline & 120 & 0,75 & 0,20 & 3,75 \\
\hline & $V_{u, \exp }=173,5$ & & & \\
\hline & & & média & 3,38 \\
\hline \multirow[t]{3}{*}{ VQ-6 } & 90 & 0,40 & 0,16 & 2,50 \\
\hline & $\mathrm{V}_{\mathrm{u}, \exp }=145,4$ & & & \\
\hline & & & média & 2,50 \\
\hline \multirow[t]{5}{*}{ VQ-1A } & 90 & 0,12 & 0,09 & 1,33 \\
\hline & 120 & 0,37 & 0,18 & 2,06 \\
\hline & 150 & 0,65 & 0,30 & 2,17 \\
\hline & $V_{u, \exp }=202,5$ & & & \\
\hline & & & média & 1,85 \\
\hline
\end{tabular}

Nas vigas da série B, observa-se que mesmo com a diminuição da taxa de armadura transversal (variação do espaçamento dos estribos verticais), as aberturas das fissuras de cisalhamento na alma são controladas pela presença da armadura lateral. Assim, como pode ser visto nas Figuras 9.8 e 9.9, as aberturas das fissuras de cisalhamento na alma da viga VQ6 são pouco maiores que as aberturas das outras vigas da mesma série. 


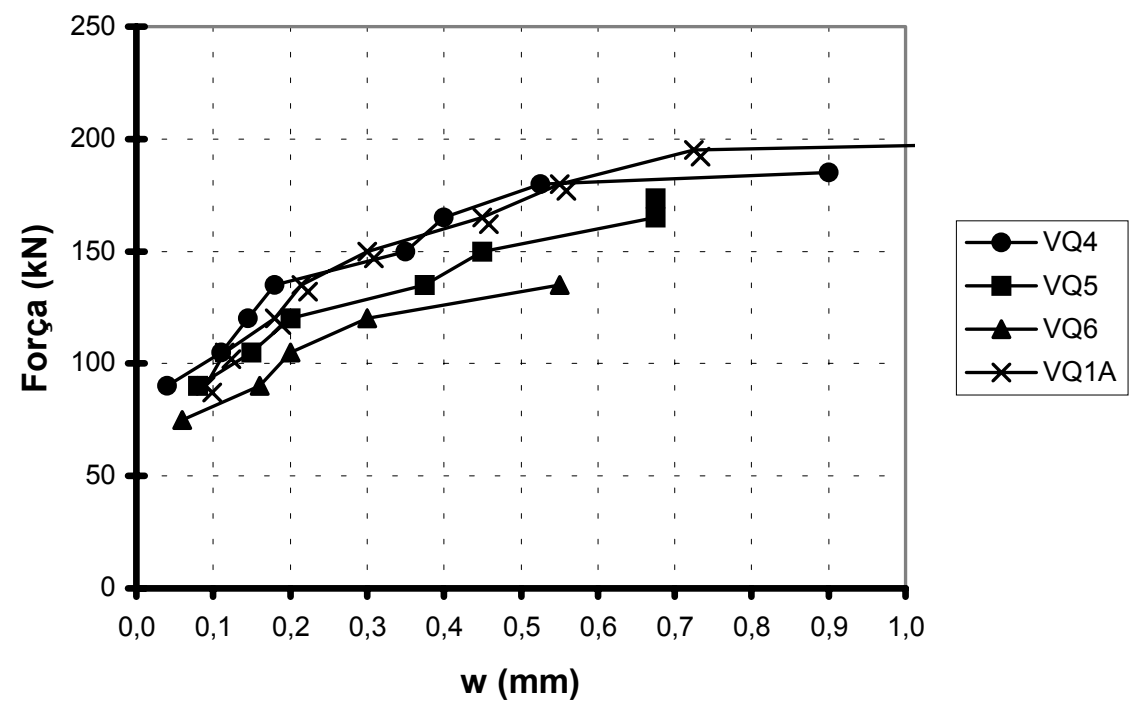

Figura 9.8 - Gráficos força aplicada $\mathrm{x}$ aberturas de fissuras na alma das vigas da série $\mathrm{B}$ (região A1/C1).

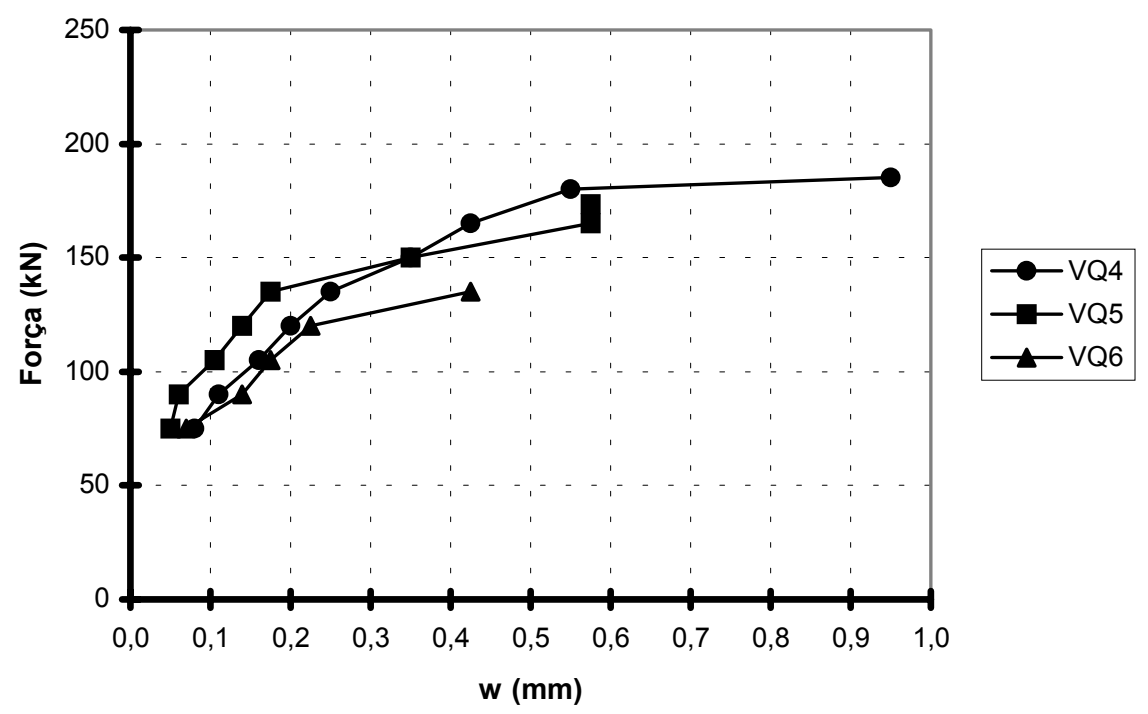

Figura 9.9- Gráficos força aplicada $\mathrm{x}$ aberturas de fissuras na alma das vigas da série $\mathrm{B}$ (região A2/C2).

\subsubsection{3 - Série D}

A Tabela 9.11 indica os valores teóricos e experimentais das aberturas de fissuras de cisalhamento das vigas da série $\mathrm{D}$, para forças aplicadas aproximadamente entre $40 \%$ e $60 \%$ 
da força última. A média dos valores $w_{w, \text { teo }} / w_{w, \exp }$ obtidos variaram de 3,28 para a viga VQ-10 até 4,44 para VQ-8.

Tabela 9.11 - Valores teóricos e experimentais das aberturas de fissuras das vigas da série D.

\begin{tabular}{|c|c|c|c|c|}
\hline Viga & $\mathrm{V}(\mathbf{k N})$ & $\begin{array}{c}\mathrm{w}_{\mathrm{w}, \text { teo }}(\mathrm{mm}) \\
\text { CEB-78 }\end{array}$ & $\begin{array}{l}\mathbf{W}_{\mathrm{w}, \exp } \\
(\mathbf{m m})\end{array}$ & $\begin{array}{c}\mathbf{w}_{\mathrm{w}, \text { teo }} / \mathbf{w}_{\mathrm{w}, \mathrm{exp}} \\
\text { CEB-78 }\end{array}$ \\
\hline \multirow[t]{5}{*}{ VQ-7 } & 90 & 0,12 & --- & --- \\
\hline & 120 & 0,38 & 0,10 & 3,80 \\
\hline & 150 & 0,66 & 0,19 & 3,47 \\
\hline & $\mathrm{V}_{\mathrm{u}, \exp }=213,5$ & & & \\
\hline & & & média & 3,64 \\
\hline \multirow[t]{5}{*}{ VQ-8 } & 90 & 0,12 & --- & --- \\
\hline & 120 & 0,38 & 0,10 & 3,80 \\
\hline & 150 & 0,66 & 0,13 & 5,08 \\
\hline & $\mathrm{V}_{\mathrm{u}, \exp }=225,4$ & & & \\
\hline & & & média & 4,44 \\
\hline \multirow[t]{5}{*}{ VQ-9 } & 90 & 0,11 & 0,04 & 2,75 \\
\hline & 120 & 0,36 & 0,08 & 4,50 \\
\hline & 150 & 0,64 & 0,12 & 5,33 \\
\hline & $V_{u, \exp }=206,7$ & & & \\
\hline & & & média & 4,19 \\
\hline \multirow[t]{5}{*}{ VQ-10 } & 90 & 0,11 & --- & -- \\
\hline & 120 & 0,36 & 0,12 & 3,00 \\
\hline & 150 & 0,64 & 0,18 & 3,56 \\
\hline & $V_{u, \exp }=228,5$ & & & \\
\hline & & & média & 3,28 \\
\hline
\end{tabular}

Analisando os gráficos das Figuras 9.10 e 9.11, para as vigas da série D, fica evidenciada a ocorrência de menores aberturas das fissuras de cisalhamento na alma em todas as vigas desta série, quando se compara com vigas sem armadura lateral (VQ-1 e VQ$1 \mathrm{~A})$. 


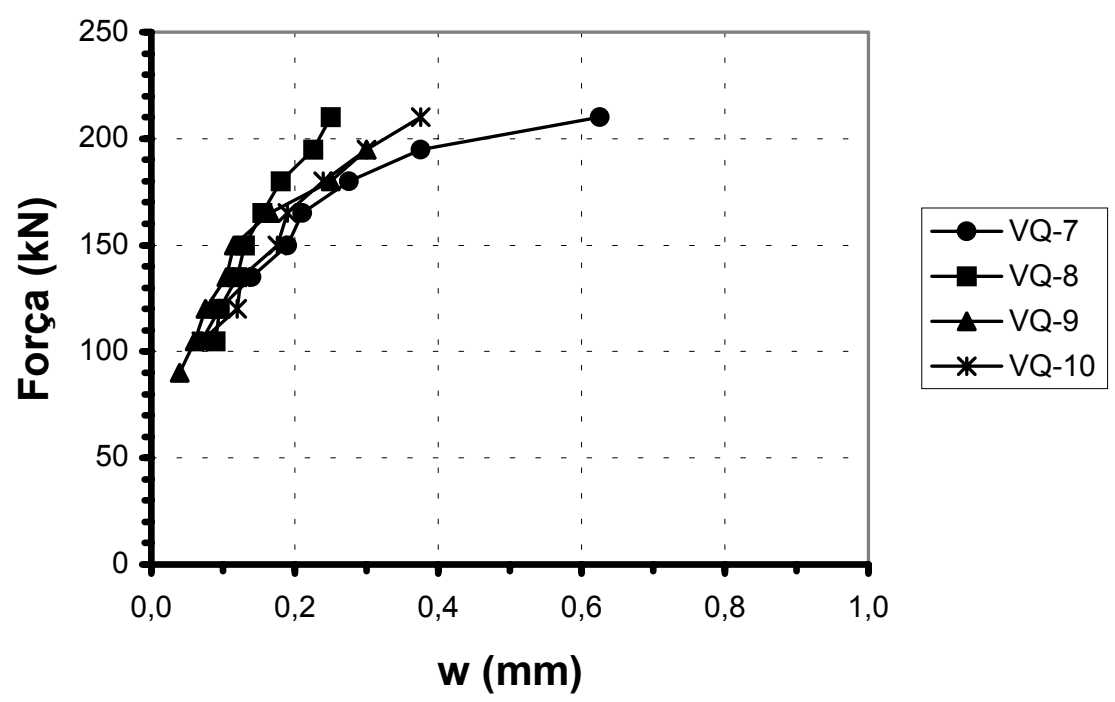

Figura 9.10 - Gráficos força aplicada $\mathrm{x}$ aberturas de fissuras na alma das vigas da série D (região A1/C1).

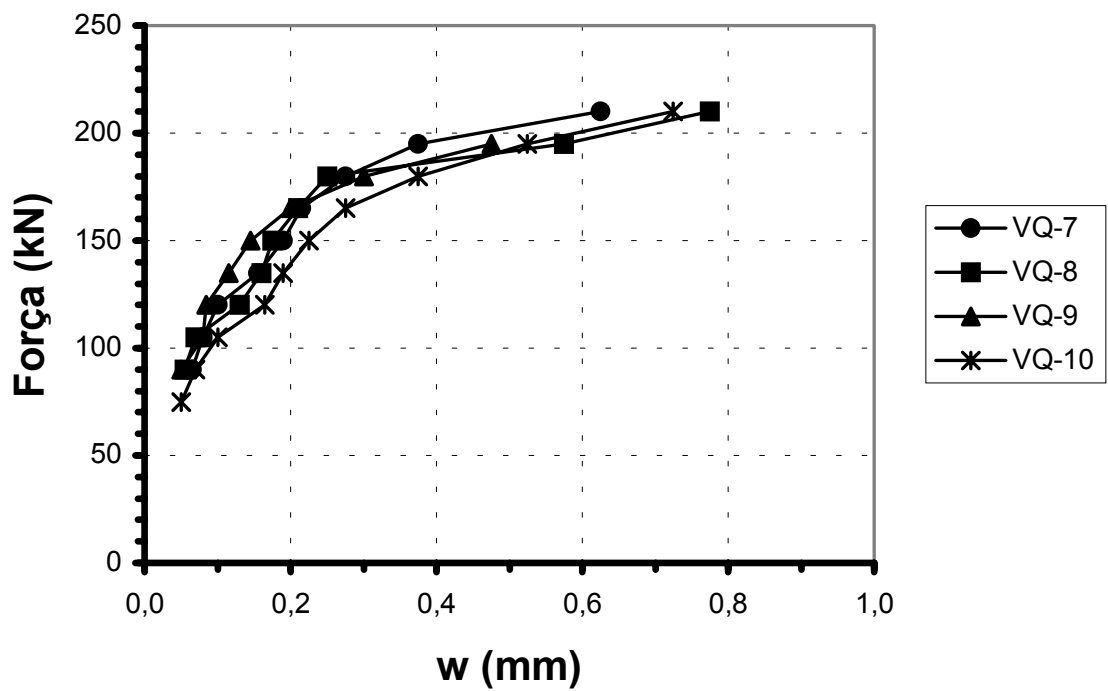

Figura 9.11- Gráficos força aplicada $\mathrm{x}$ aberturas de fissuras na alma das vigas da série $\mathrm{D}$ (região A2/C2).

\subsubsection{4 - Série A2}

A Tabela 9.12 apresenta os valores teóricos e experimentais das aberturas de fissuras de cisalhamento das vigas da série A2, para forças aplicadas aproximadamente entre $40 \% \mathrm{e}$ $60 \%$ da força última. Observa-se que a média dos valores $w_{w, t e o} / w_{w \text {,exp }}$ para as vigas VS-2 e 
VS-3 foram de 2,59 e 2,28, respectivamente. Isto indica que, para essas duas vigas, o controle da fissuração proporcionado pela tela soldada foi aproximadamente equivalente ao da armadura lateral composta por fios horizontais amarrados nos estribos verticais.

Tabela 9.12 - Valores teóricos e experimentais das aberturas de fissuras das vigas da série A2.

\begin{tabular}{|c|c|c|c|c|}
\hline Viga & $\mathrm{V}(\mathrm{kN})$ & $\frac{\mathbf{w}_{\mathrm{w}, \text { teo }}(\mathbf{m m})}{\text { CEB-78 }}$ & $\begin{array}{l}\mathbf{W}_{\mathbf{w}, \exp } \\
(\mathbf{m m})\end{array}$ & $\frac{\mathbf{w}_{\mathrm{w}, \text { teo }} / \mathbf{w}_{\mathrm{w}, \mathrm{exp}}}{\text { CEB-78 }}$ \\
\hline \multirow[t]{4}{*}{ VS-1 } & 180 & 0,11 & 0,07 & 1,57 \\
\hline & 240 & 0,33 & 0,20 & 1,65 \\
\hline & $V_{u, \exp }=366,3$ & & & \\
\hline & & & média & 1,61 \\
\hline \multirow[t]{4}{*}{ VS-2 } & 180 & 0,12 & 0,06 & 2,00 \\
\hline & 240 & 0,35 & 0,11 & 3,18 \\
\hline & $\mathrm{V}_{\mathrm{u}, \exp }=358,8$ & & & \\
\hline & & & média & 2,59 \\
\hline \multirow[t]{4}{*}{ VS-3 } & 180 & 0,11 & 0,05 & 2,20 \\
\hline & 240 & 0,33 & 0,14 & 2,36 \\
\hline & $V_{u, \exp }=384,4$ & & & \\
\hline & & & média & 2,28 \\
\hline
\end{tabular}

Os gráficos apresentados nas Figuras 9.12 e 9.13 indicam a ocorrência de menores aberturas de fissuras de cisalhamento na alma (regiões A1/C1 e A2/C2) nas vigas VS-2 e VS-3 em relação à viga VS-1 da mesma série. 


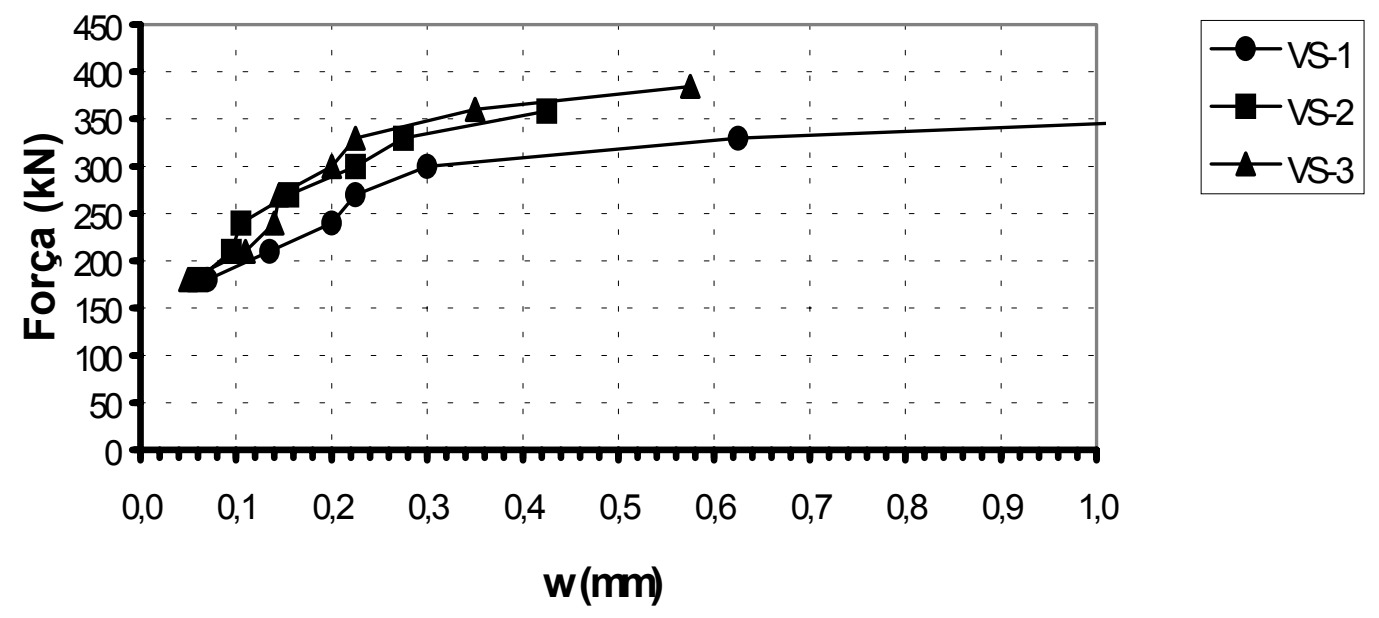

Figura 9.12 - Gráficos força aplicada $\mathrm{x}$ aberturas de fissuras na alma das vigas da série A2 (região A1/C1).

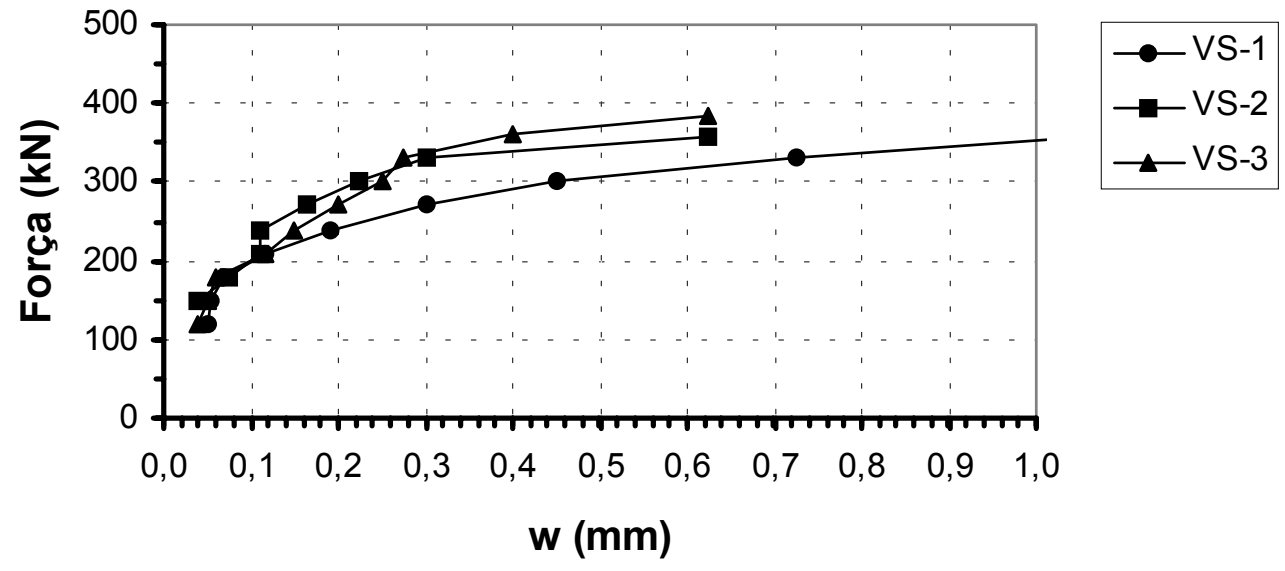

Figura 9.13- Gráficos força aplicada $\mathrm{x}$ aberturas de fissuras na alma das vigas da série A2 (região A2/C2). 


\subsubsection{5 - Série C}

A Tabela 9.13 indica os valores teóricos e experimentais das aberturas de fissuras de cisalhamento das vigas da série $\mathrm{C}$, para forças aplicadas aproximadamente entre $40 \%$ e $60 \%$ da força última. A média dos valores $w_{w, \text { teo }} / w_{w \text {,exp }}$ obtidos variaram de 2,69 para a viga VS6 até 4,44 para VS-5.

Tabela 9.13 - Valores teóricos e experimentais das aberturas de fissuras das vigas da série C.

\begin{tabular}{|c|c|c|c|c|}
\hline Viga & $\mathrm{V}(\mathrm{kN})$ & $\begin{array}{c}\mathrm{w}_{\mathrm{w}, \text { teo }}(\mathrm{mm}) \\
\text { CEB-78 }\end{array}$ & $\begin{array}{l}\mathbf{W}_{\mathrm{w}, \exp } \\
(\mathbf{m m})\end{array}$ & $\frac{\mathbf{W}_{\mathrm{w}, \text { tee }} / \mathbf{W}_{\mathrm{w}, \exp }}{\text { CEB-78 }}$ \\
\hline \multirow[t]{5}{*}{ VS-4 } & 180 & 0,06 & --- & --- \\
\hline & 240 & 0,26 & 0,11 & 2,36 \\
\hline & 300 & 0,50 & 0,18 & 2,78 \\
\hline & $\mathrm{V}_{\mathrm{u}, \exp }=434,8$ & & & \\
\hline & & & média & 2,57 \\
\hline \multirow[t]{5}{*}{ VS-5 } & 180 & 0,06 & --- & --- \\
\hline & 240 & 0,26 & 0,06 & 4,33 \\
\hline & 300 & 0,50 & 0,11 & 4,55 \\
\hline & $\mathrm{V}_{\mathrm{u}, \exp }=430,3$ & & & \\
\hline & & & média & 4,44 \\
\hline \multirow[t]{5}{*}{ VS-6 } & 180 & 0,09 & --- & --- \\
\hline & 240 & 0,30 & 0,11 & 2,73 \\
\hline & 300 & 0,53 & 0,20 & 2,65 \\
\hline & $\mathrm{V}_{\mathrm{u}, \exp }=413,9$ & & & \\
\hline & & & média & 2,69 \\
\hline
\end{tabular}

Observando os gráficos das Figuras 9.14 e 9.15, vigas da série C, nota-se o aumento nas aberturas das fissuras de cisalhamento na alma com o aumento do espaçamento entre os fios da armadura lateral ( $s_{\text {lat }}=30 \mathrm{~cm}$ para a viga VS-6). Pode-se afirmar então que o controle da fissuração por força cortante é mais efetivo para espaçamentos da armadura lateral no intervalo $10 \mathrm{~cm} \leq s_{\text {lat }} \leq 20 \mathrm{~cm}$. 


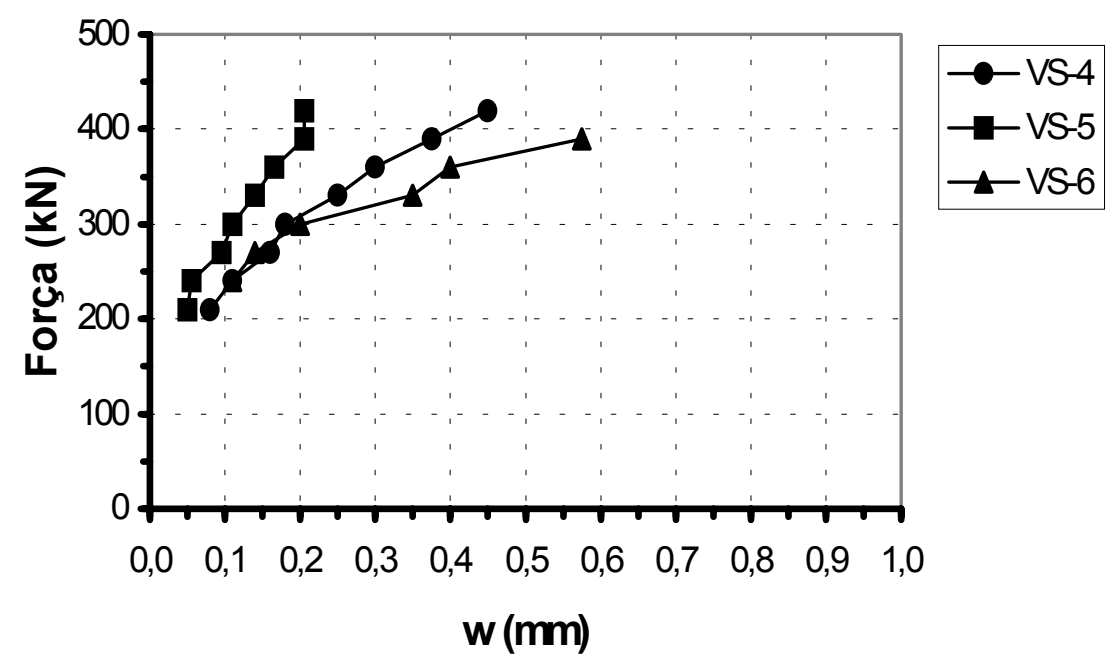

Figura 9.14 - Gráficos força aplicada $\mathrm{x}$ aberturas de fissuras na alma das vigas da série $\mathrm{C}$ (região A1/C1).

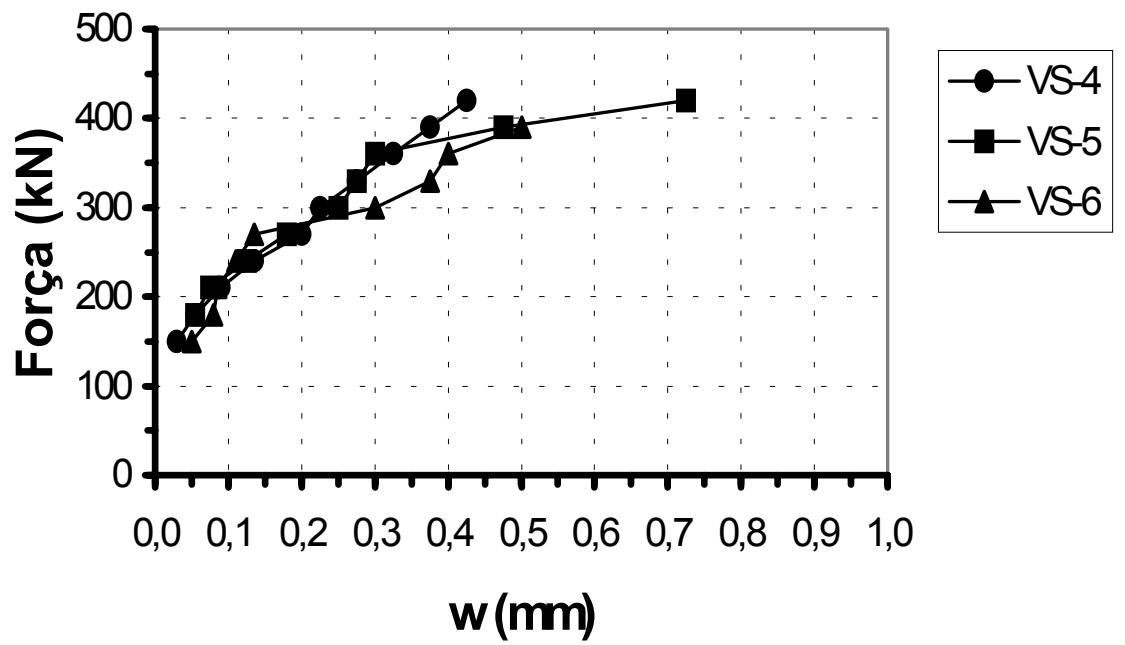

Figura 9.15- Gráficos força aplicada $\mathrm{x}$ aberturas de fissuras na alma das vigas da série $\mathrm{C}$ (região A2/C2).

Tendo em vista a média dos valores $w_{w, t e o} / w_{w, \exp }$ apresentados nas Tabelas 9.9 a 9.13, sugere-se utilizar o valor $k_{w}=0,8$ para vigas com armadura lateral composta por telas soldadas. 


\subsection{4 - ESTADO LIMITE DE DEFORMAÇÕES EXCESSIVAS}

Analisando-se os gráficos força $\mathrm{x}$ deslocamento apresentados no item 8.4, podem ser feitas as seguintes observações:

- as vigas VQ-2 e VQ-3 (série A1) apresentaram valores de deslocamentos verticais da mesma ordem de grandeza, assim como VS-2 e VS-3 (série A2). Assim, os resultados mostraram que as vigas com armadura lateral, sejam de telas soldadas ou não, apresentaram rigidez semelhante;

- para as vigas da série $\mathrm{B}$, os deslocamentos verticais de VQ-4 (maior taxa de armadura transversal) foram pouco inferiores aos deslocamentos de VQ-5. Idem, VQ-5 em relação a VQ-6;

- todas as vigas da série D apresentaram deslocamentos verticais muito próximos;

- em relação às vigas da série C, a viga VS-6 (menor taxa de armadura lateral) apresentou valores um pouco maiores de deslocamentos verticais.

\subsection{5 - ANÁLISE COMPARATIVA ARMADURA LATERAL (FIOS AMARRADOS X TELA SOLDADA)}

Observando-se nos gráficos das Figuras 9.12 (região A1/C1) e 9.13 (região A2/C2) os valores das aberturas das fissuras de cisalhamento nas vigas VS-2 (fios amarrados) e VS-3 (tela soldada) notam-se valores da mesma ordem de grandeza.

No gráfico da Figura 9.7 (região A1/C1), para as vigas VQ-2 (fios amarrados) e VQ3 (tela soldada), em alguns pontos as aberturas das fissuras de cisalhamento de VQ-2 são menores que as da viga VQ-3. Apenas no gráfico apresentado na Figura 9.6 (região A1/C1) observou-se a ocorrência de menores aberturas de fissuras de cisalhamento em VQ-3 em relação a VQ-2.

Assim, com relação às aberturas das fissuras de cisalhamento, os resultados obtidos mostraram um comportamento bastante próximo entre as vigas com telas soldadas e aquelas com fios amarrados. 


\section{5 - DEFORMAÇÕES NOS ESTRIBOS VERTICAIS E ARMADURAS LATERAIS}

Nas vigas VQ-1, VQ-2 e VQ-3 da série A1 as maiores deformações ocorreram nos estribos 2, 3 e 4. Na viga VQ-3 esses três estribos romperam, como pode ser observado nas Figuras $8.38,8.39$ e 8.40 .

De modo geral, as deformações da armadura lateral variaram, pois em algumas seções transversais apresentaram, no início do ensaio, deformações de compressão e, nas etapas intermediárias e finais, deformações de escoamento.

Nas vigas da série A1, as maiores deformações ocorreram em inf40 e inf60 da viga VQ-2 e inf40 de VQ-3, que atingiu o escoamento (Figuras 8.55 e 8.56). O fio da armadura lateral inf40 em VQ-3 atingiu o escoamento porque foi interceptado pela fissura principal de cisalhamento.

Na série B os estribos 2 e 3 da viga VQ-5 e o estribo 2 da viga VQ-6 romperam no colapso da viga, Figuras 8.43 e 8.44 . Na viga VQ-4 os estribos 2, 3 e 4 atingiram a deformação correspondente ao escoamento, Figura 8.42.

Para as vigas da série $B$ os fios laterais que atingiram as maiores deformações foram inf62 em VQ-4, inf42 em VQ-5 e VQ-6, Figuras 8.57, 8.58 e 8.59.

No colapso das vigas da série D alguns estribos romperam (estribo 5 em VQ-7, estribo 4 em VQ-8 e estribos 3 e 4 em VQ-9), enquanto outros escoaram (estribo 3 em VQ-7, estribo 2 em VQ-8 e VQ-9), Figuras 8.45, 8.46 e 8.47.

As armaduras laterais das vigas da série D não foram instrumentadas porque o comportamento esperado era semelhante ao da viga VQ-3.

Nos ensaios das vigas da série A2 ocorreu a ruptura dos estribos 2 e 4 em VS-1 e estribos 2 e 3 em VS-3, Figuras 8.48, 8.49 e 8.50. Os estribos que atingiram a deformação de escoamento foram os estribos 3 em VS-1 e 5 em VS-2. Os fios laterais que atingiram as maiores deformações foram inf67 em VS-2 e inf52 em VS-3, Figuras 8.60 e 8.61.

Para as vigas da série $\mathrm{C}$ ocorreu a separação das partes da viga pela fissura, provocando a ruptura de alguns estribos verticais. Com relação às armaduras laterais, ocorreu a ruptura do fio lateral inf60 em VS-6. Além disso, inf56 em VS-4 e inf80 em VS-6 atingiram as maiores deformações, Figuras 8.62, 8.63 e 8.64 . 


\section{CONCLUSÃO}

\section{1 - CONSIDERAÇÕES INICIAIS}

Apresentam-se neste capítulo as principais conclusões deste trabalho, além de sugestões para novas pesquisas sobre o tema.

Pelo levantamento bibliográfico realizado, constatou-se um número reduzido de pesquisas sobre a utilização de telas soldadas em vigas. Com relação ao controle da fissuração, os principais trabalhos publicados por outros autores enfatizavam as vantagens advindas do uso de telas soldadas. Por outro lado, praticamente não há consenso sobre a contribuição das armaduras laterais na resistência à força cortante. Em grande parte dos ensaios executados por outros pesquisadores a armadura lateral foi constituída por fios amarrados nos estribos e não telas soldadas.

Lembra-se que os modelos experimentais atenderam às seguintes características físicas e geométricas:

- resistência à compressão do concreto entre 17,6 e 36,8 MPa;

- relação a/d: 2,78 (vigas VQ) ou 2,66 (vigas VS);

- altura útil da viga: $\mathrm{d}=36 \mathrm{~cm}$ (vigas $\mathrm{VQ}$ ) ou $\mathrm{d}=65 \mathrm{~cm}$ (vigas $\mathrm{VS}$ ); 
- taxa de armadura longitudinal: $\rho_{\mathrm{s} \ell}=3,35 \%$ (VQ) ou $\rho_{\mathrm{s} \ell}=3,38 \%(\mathrm{VS})$

- taxa de armadura transversal: $0,071 \% \leq \rho_{\mathrm{sw}} \leq 0,196 \%$;

- taxa de armadura lateral: $0,131 \% \leq \rho_{\mathrm{s}, \text { lat }} \leq 1,176 \%$;

- vigas de seção $T$ com relação entre a largura da mesa e da nervura $b_{f} / b_{w}$ igual a 3,33 (vigas VQ) ou 2,50 (vigas VS).

Ressalta-se que, com a utilização de telas soldadas, além da economia de homenshora na montagem das armaduras das vigas, obtém-se rigoroso controle dimensional dos espaçamentos e cobrimentos das barras de aço.

\section{2 - FORÇA ÚLTIMA}

No desenvolvimento do trabalho experimental observou-se que os parâmetros que mais influenciaram a resistência à força cortante foram a resistência à compressão do concreto e a taxa de armadura transversal, mantidos os outros parâmetros constantes.

Os resultados dos ensaios realizados nesta pesquisa indicaram um aumento na resistência à força cortante com o aumento da taxa de armadura lateral, conforme visto no gráfico mostrado na Figura 9.4. Entretanto, a variabilidade dos resultados pode ser observada nesse mesmo gráfico.

A contribuição da armadura lateral da tela soldada na resistência à força cortante deve-se a dois mecanismos resistentes alternativos:

- aumento da contribuição da parcela relativa ao engrenamento dos agregados provocada pelas menores aberturas das fissuras por ação de força cortante na alma;

- efeito de pino dos fios da armadura lateral nos pontos em que são interceptados pelas fissuras diagonais.

Nos ensaios das vigas com telas soldadas (VQ-3 e VS-3) as forças últimas experimentais obtidas foram superiores àquelas das vigas similares com fios amarrados nos estribos (VQ-2 e VS-2), provavelmente pelo efeito adicional do nó soldado, além dos já citados mecanismos resistentes.

O código ACI 318R (2002) recomenda os seguintes valores de cálculo limites para a resistência de escoamento da armadura transversal: $f_{y w d} \leq 60.000 \mathrm{psi}=414 \mathrm{MPa}$ para estribos verticais e $f_{y w d} \leq 80.000 p s i=552 \mathrm{MPa}$ para tela soldada. O valor proposto para 
as vigas com telas soldadas foi inicialmente apresentado na edição de 1995 do código americano, embasado no trabalho conduzido por GRIEZIC et al. (1994).

O Projeto de Revisão da NBR 6118:2001 propõe o valor $f_{y w d} \leq 435 \mathrm{MPa}$ com o objetivo de limitar as aberturas das fissuras de cisalhamento por força cortante.

Com base nos resultados dos ensaios, principalmente aqueles referentes às aberturas das fissuras de cisalhamento, sugere-se a adoção do valor $f_{y w d} \leq f_{y d}$ para vigas com telas soldadas em que o espaçamento entre as barras da armadura lateral seja igual ou inferior a 20 $\mathrm{cm}$.

A formulação proposta pelo autor, com base na teoria do cisalhamento-atrito, para consideração da contribuição da armadura lateral na resistência à força cortante, deve ser considerada tendo em vista os aspectos seguintes:

- a formulação deve ser aperfeiçoada com a proposição de expressões teóricas para o cálculo de $a_{r u p} e \theta$;

- os valores experimentais de $a_{r u p} e \theta$ utilizados na validação da proposta afetam e muito os resultados obtidos;

- os valores do coeficiente experimental $\mathrm{k}$ devem ser melhor avaliados.

A partir dos resultados dos ensaios da série $\mathrm{D}$, pode-se indicar a utilização de barras transversais amarradas e não soldadas nos fios verticais para ancoragem na borda comprimida de telas soldadas dobradas em U. Sugere-se ainda evitar a utilização de ancoragem reta (alternativa utilizada na viga VQ-9) em projetos usuais, porque o estribo pode ser interceptado pela fissura de cisalhamento em um ponto próximo à borda superior, a partir do qual a ancoragem é insuficiente e seu funcionamento não é efetivo.

Nos ensaios as deformações medidas nos estribos verticais e na armadura lateral variaram dependendo da posição do ponto instrumentado em relação ao plano potencial de ruptura ou fissura principal de cisalhamento. Ocorreu a ruptura de 2 ou 3 estribos verticais e 1 fio da armadura lateral em praticamente todas as vigas de ensaio. Esses fios da armadura interceptavam a fissura principal de cisalhamento.

A armadura lateral, quando interceptada pela fissura de cisalhamento, apresenta deformações na ruína que comprovam seu funcionamento efetivo no aumento da resistência à força cortante. 


\section{3 - ESTADOS LIMITES DE SERVIÇO}

As vigas com armadura lateral, tanto as com telas soldadas quanto aquelas com fios amarrados nos estribos, apresentaram menores aberturas das fissuras de cisalhamento na alma em relação às vigas armadas apenas com estribos verticais.

Nas vigas da série B, com a diminuição da taxa de armadura transversal, as aberturas das fissuras de cisalhamento na alma foram controladas pela armadura lateral.

Nos ensaios das vigas da série $\mathrm{D}$, com variação do tipo de ancoragem da tela no banzo comprimido, não foram notadas alterações significativas nos valores das aberturas das fissuras de cisalhamento, o que era esperado.

Nos ensaios da série $\mathrm{C}$ evidenciou-se a importância da taxa de armadura lateral no controle da fissuração por força cortante.

Para as vigas armadas com telas soldadas sugere-se utilizar o coeficiente $\mathrm{k}_{\mathrm{w}}=0,8$ para o cálculo das aberturas das fissuras de cisalhamento pelo critério do CEB (1978). Essa proposta baseia-se nas relações entre valores teóricos e experimentais apresentados nas Tabelas 9.9 a 9.13 .

Observando-se os gráficos Força $\mathrm{x}$ Deslocamento conclui-se que as vigas com armadura lateral, sejam de telas soldadas ou não, apresentaram valores muito próximos de deslocamentos verticais, ou seja, rigidez semelhante.

Finalmente, relembra-se que a armadura lateral da tela soldada também controla as aberturas das fissuras de flexão que eventualmente propagam-se ao longo da altura na região central da viga.

\section{4 - CONTINUIDADE DA PESQUISA}

As principais sugestões para a continuidade deste trabalho são apresentadas a seguir:

- planejamento de novos ensaios utilizando concreto dosado em laboratório com rigoroso controle da resistência à compressão, relação água/cimento e granulometria do agregado graúdo;

- em vigas com ruína causada pela ruptura à compressão diagonal, deve ser investigado experimentalmente o aumento na resistência da diagonal comprimida causado pelo confinamento proporcionado pela tela soldada; 
- planejamento de ensaios específicos com o objetivo de propor uma expressão empírica simplificada para a estimativa da contribuição da armadura lateral $\Delta V_{c}$ em função de $\rho_{s, l a t}$;

- ensaios de vigas contínuas ou biapoiadas com balanços, utilizando tela soldada em U com armadura suplementar de fechamento (armadura negativa da laje). 


\section{REFERÊNCIAS BIBLIOGRÁFICAS}

ADORNO, A. L. C. (1996). Contribuição da armadura de pele na resistência ao cisalhamento na flexão em vigas de concreto armado. Brasília. Dissertação (Mestrado) Departamento de Engenharia Civil, Universidade de Brasília (UnB).

ADORNO, A. L. C. (1999). Resistência ao esforço cortante em vigas de concreto armado com armadura de pele. Goiânia, Universidade Federal de Goiás. / Relatório de Pesquisa de Desenvolvimento Científico Regional /

ADORNO, A. L. C.; CLÍMACO, J. C. T. S.; GOMES, R. B.(2000). Influência da armadura de pele na resistência ao esforço cortante em vigas de concreto armado. In: JORNADAS SUDAMERICANAS DE INGENIERIA ESTRUCTURAL, 29., Punta Del Este, Uruguay. Memórias [CD-ROM].

AMARAL, N. A. (1974). A resistência do concreto armado à força cortante. Dirigente Construtor, p. 49-64, out., p. 26-36, nov.

AMERICAN CONCRETE INSTITUTE (2002). ACI 318R/02 - Building code requirements for structural concrete. Detroit, Michigan.

AMERICAN SOCIETY FOR TESTING AND MATERIALS (1994). ASTM A185/94 Standard specification for steel welded wire fabric, plain, for concrete reinforcement (CD- ROM). Philadelphia.

AMERICAN SOCIETY FOR TESTING AND MATERIALS (1995). ASTM A497/95 Standard specification for steel welded wire fabric, deformed, for concrete reinforcement (CD-ROM). Philadelphia.

ANDERSON, N. S.; RAMIREZ, J. A. (1989). Detailing of stirrup reinforcement. $A C I$ Structural Journal, v. 86, n. 5, p. 507-515, Sep.-Oct.

ASSOCIAÇÃO BRASILEIRA DE NORMAS TÉCNICAS (1984). NBR 5738 - Moldagem e cura de corpos-de-prova de concreto, cilíndricos ou prismáticos. Rio de Janeiro.

ASSOCIAÇÃO BRASILEIRA DE NORMAS TÉCNICAS (1980). NBR 5739 - Ensaio de compressão de corpos-de-prova cilíndricos de concreto. Rio de Janeiro.

ASSOCIAÇÃO BRASILEIRA DE NORMAS TÉCNICAS (1990). NBR 5916 - Junta de tela de aço soldada para armadura de concreto - Ensaio de resistência ao cisalhamento. Rio de Janeiro.

ASSOCIAÇÃO BRASILEIRA DE NORMAS TÉCNICAS (1978). NBR 6118 - Projeto e execução de estruturas de concreto armado. Rio de Janeiro. 
ASSOCIAÇÃO BRASILEIRA DE NORMAS TÉCNICAS (2001). Projeto de revisão da NBR 6118 - Projeto de estruturas de concreto. Rio de Janeiro.

ASSOCIAÇÃO BRASILEIRA DE NORMAS TÉCNICAS (1992). NBR 6152 - Materiais metálicos - Determinação das propriedades mecânicas à tração. Rio de Janeiro.

ASSOCIAÇÃO BRASILEIRA DE NORMAS TÉCNICAS (1988). NBR 7187 - Projeto e execução de pontes de concreto armado e concreto protendido. Rio de Janeiro.

ASSOCIAÇÃO BRASILEIRA DE NORMAS TÉCNICAS (1983). NBR 7222 Argamassas e concretos - Determinação da resistência à tração por compressão diametral de corpos-de-prova cilíndricos. Rio de Janeiro.

ASSOCIAÇÃO BRASILEIRA DE NORMAS TÉCNICAS (1982). NBR 7223 - Concreto Determinação da consistência pelo abatimento do tronco de cone. Rio de Janeiro.

ASSOCIAÇÃO BRASILEIRA DE NORMAS TÉCNICAS (1996). NBR 7480 - Barras e fios de aço destinados a armaduras para concreto armado. Rio de Janeiro.

ASSOCIAÇÃO BRASILEIRA DE NORMAS TÉCNICAS (1990). NBR 7481 - Tela de aço soldada - Armadura para concreto. Rio de Janeiro.

BAZANT, Z. P.; SUN, H. H. (1987). Size effect in diagonal shear failure: influence of aggregate size and stirrups. ACI Materials Journal, v. 84, n. 4, p. 259-272, Jul.-Aug.

BURMAN, I. (1981). Fissuração no concreto armado: natureza do fenômeno e sua interferência no comportamento e durabilidade das estruturas. São Paulo. Dissertação (Mestrado) - Escola Politécnica, Universidade de São Paulo (USP).

CABRAL, K. C. (1998). Análise local e global da resistência ao esforço cortante de vigas com e sem apoios em dente. Brasília. Dissertação (Mestrado) - Departamento de Engenharia Civil , Universidade de Brasília (UnB).

CABRAL, K. C.; NAGATO, Y. (1999). Estudo experimental sobre componentes da resistência ao esforço cortante em vigas de concreto armado. In: CONGRESSO BRASILEIRO DO CONCRETO, 41., Natal , 1999. Anais.(CD-ROM). São Paulo, IBRACON.

CANADIAN STANDARDS ASSOCIATION (1994). CSA A23.3-94 -Design of concrete structures. Rexdale.

CASTRO, F. A. B. (1997). Cisalhamento em vigas de concreto armado - estudo paramétrico. Rio de Janeiro. Dissertação (Mestrado) - COPPE/UFRJ.

CHANA, P. S. (1987). Investigation of the mechanism of shear failure of reinforced concrete beams. Magazine of Concrete Research, v. 39, n. 141, p. 196-204, Dec.

CLÍMACO, J. C. T. S. ; ADORNO, A. L. C. (1995). Resistência ao esforço cortante em vigas de concreto armado com armadura longitudinal de pele. In: JORNADAS 
SUDAMERICANAS DE INGENIERIA ESTRUCTURAL, 27., Tucumán, Argentina. Memórias, v. 1, p. 419-428.

COMISIÓN PERMANENTE DEL HORMIGÓN (1999). Instrucción de Hormigón Estructural EHE. Ministerio de Fomento, 476 p., Madrid, Espãna.

COMITÉ EURO-INTERNATIONAL DU BÉTON (1978). Code modele CEB-FIP pour lês structures en béton. Bulletim D'Information, Paris, n. 124/125-F, v. 2.

COMITÉ EURO-INTERNATIONAL DU BÉTON (1978). CEB-FIP model code 1978 Shear and torsion. Bulletim D'Information, n. 126.

COMITÉ EURO-INTERNATIONAL DU BÉTON (1985). Industrialization of reinforcement in reinforced concrete structures. Bulletim D'Information, n. 164, Jan.

COMITÉ EURO-INTERNATIONAL DU BÉTON (1991). CEB-FIP model code 1990: final draft. Bulletim D'Information, n. 203-205, July.

EL METWALLY, A. ; LOOV, R. E. (2001). Shear strength of reinforced concrete beams with and without stirrups using shear-friction: a comparison with CSA-A23.3-94 simplified and general methods. In: ANNUAL CONFERENCE OF THE CANADIAN SOCIETY FOR CIVIL ENGINEERING, Victoria, British Columbia, Canada.

EUROPEAN COMMITTEE STANDARDIZATION (1992). Eurocode 2 - Design of concrete structures. Part 1: General rules and rules for buildings. London, BSI.

FAGURY, S. C.; LIBÓRIO, J. B. L. (2002). A utilização de concreto de elevado desempenho, com agregados de $\mathrm{d}_{\text {máx }} \leq 6,3 \mathrm{~mm}$, como material de reparo de estruturas de concreto. In: JORNADAS SUL-AMERICANAS DE ENGENHARIA ESTRUTURAL, 30., Brasília, Brasil, 2002. Anais [CD-ROM].

FÉDÉRATION INTERNATIONALE DU BÉTON (1999). FIB - Structural Concrete. Bulletins, n. 1-3.

FERNANDES., G. B. (1992). Cisalhamento em vigas de concreto de alta resistência. São Paulo. Tese (Doutorado) - Escola Politécnica, Universidade de São Paulo (USP).

FIORIN, E. (1998). Arranjos de armaduras em estruturas de concreto armado. São Carlos. Dissertação (Mestrado) - Escola de Engenharia de São Carlos (EESC), Universidade de São Paulo (USP).

FURLAN JR., S. (1995). Vigas de concreto com taxas reduzidas de armadura de cisalhamento: influência do emprego de fibras curtas e de protensão. São Carlos. Tese (Doutorado) - Escola de Engenharia de São Carlos (EESC), Universidade de São Paulo (USP).

FUSCO, P. B. (1984). Estruturas de concreto: solicitações tangenciais. São Paulo, EPUSP.

FUSCO, P. B. (1994). Técnicas de armar as estruturas de concreto. São Paulo, Editora 
Pini.

GRIEZIC, A.; COOK, W. D.; MITCHELL, D. (1994). Tests to determine performance of deformed welded wire fabric stirrups. ACI Structural Journal, v. 91, n. 2, p. 211-220, Mar.-Apr.

HERMANSEN, B. R.; COWAN, J. (1974). Modified shear-friction theory for bracket design. ACI Journal, v. 71, n. 7, p. 55-60, Feb.

INSTITUTO BRASILEIRO DE TELAS SOLDADAS (1990). Telas soldadas informações técnicas. São Paulo, IBTS.

INSTITUTO BRASILEIRO DE TELAS SOLDADAS (1996). Telas soldadas - ancoragem. São Paulo, IBTS. (Boletim Técnico n. 2).

JELIC, I.; PAVLOVIC, M. N.; KOTSOVOS, M. D (1999). A study of dowel action in reinforced concrete beams. Magazine of Concrete Research, v. 51, n. 2, p. 131-141, Apr.

KRISKI, W. ; LOOV, R. (1996). Strength of beams based on shear-friction. In: STRUCTURAL SPECIALTY CONFERENCE, 1., Edmonton, Alberta, Canada. Proceedings, p. 537-547.

LEONHARDT, F.; WALTHER, R. (1965). Geschweite Bewehrungsmatten als Bugelbewehrung Schubversuche an Plattenbalken und Verankerungsversuche (Telas soldadas como armaduras de estribos). Die Bautechnik, v. 42, n. 10, p. 329-341, Oct.

LEONHARDT, F. (1965). La réduction de la couture d'effort tranchant dans les structures en béton armé. CEB Bulletin d'Information, n. 49, Paris.

LEONHARDT, F. (1978). Shear in concrete structures. CEB Bulletin d'Information, n. 126, p. 66-124, Jun.

LEONHARDT, F. (1979). Construções de concreto: verificação da capacidade de utilização. Rio de Janeiro, Interciência. v.4.

LEONHARDT, F.; MÖNNIG, E. (1978a). Construções de concreto: princípios básicos do dimensionamento de estruturas de concreto armado. Rio de Janeiro, Interciência. v.1.

LEONHARDT, F.; MÖNNIG, E. (1978b). Construções de concreto: princípios básicos sobre a armação de estruturas de concreto armado. Rio de Janeiro, Interciência. v.3.

LÉPORE, P. F. (1998). Armadura longitudinal em almas de vigas altas. Campinas. Dissertação (Mestrado) - Faculdade de Engenharia Civil, UNICAMP.

LIN, C.-H.; PERNG, S.-M. (1998). Flexural behaviour of concrete beams with welded wire fabric as shear reinforcement. ACI Structural Journal, v. 95, n. 5, p. 540-546, Sep.-Oct.

LOOV, R. E. (1998). Review of A23.3-94 simplified method of shear design and comparison with results using shear friction. Canadian Journal of Civil Engineering, v. 25 , p. $437-450$. 
LOOV, R. E. (2000). Shear design of concrete - a simpler way. In: STRUCTURAL SPECIALTY CONFERENCE, 3., London, Ontario, Canada. Proceedings, p. 49-56.

LOOV, R. ; PENG, L. (1998). The influence of concrete strength on shear-friction based design of reinforced concrete beams. In: INTERNATIONAL CONFERENCE ON HPHSC, Perth Australia, Canada. Proceedings, p. 505-519.

LOOV, R. ; PENG, L. (1999). Shear strength of high-strength concrete - ACI 318-95 versus shear-friction. In: HIGH-PERFORMANCE CONCRETE - RESEARCH TO PRACTICE, American Concrete Institute, SP 189, p. 411-430.

LOOV, R. ; TOZSER, O. (1999). Shear-friction - a simpler approach to shear design. / Presented at Transportation research board, Washington, D. C., 1999. /

MACHADO, C. P. (1999). Consolos curtos e muito curtos de concreto armado. São Paulo. Tese (Doutorado) - Escola Politécnica, Universidade de São Paulo (USP).

MANSUR, M. A.; LEE, C. K.; LEE, S. L. (1986). Anchorage of welded wire fabric used as shear reinforcement in beams. Magazine of Concrete Research, v. 38, n. 134, p. 36-46, Mar.

MANSUR, M. A.; LEE, C. K.; LEE, S. L. (1987). Deformed wire fabric as shear reinforcement in concrete beams. ACI Structural Journal, v. 84, n.5, p. 392-399,SepOct.

MARTINS, C. O. ; SILVA, R. C. ; CLÍMACO, J. C. T.S. (2000). Shear strenghening of reinforced concrete beams by the addition of longitudinal web bars. In: IABSE CONGRESS, 16. Lucerne, Swiss, Paper 211, Sept.

MAST, R. F. (1968). Auxiliary reinforcement in concrete connections. Journal of the Structural Division (ASCE), v. 94, n. ST6, p. 1484-1504, Jun.

MATTOCK, A. H. (1976). Design proposals for reinforced concrete corbels. PCI Journal, p. 19--43, May-June.

MOLLICA JR., S. (1986). O uso da tela soldada no combate à fissuração. São Paulo, IBTS. 76 p.

MONTOYA, P. J.; MESEGUER, A. G.; CABRE, F. M. (1981). Hormigón armado. 11. ed. Barcelona, Editorial Gustavo Gili, Tomo 1, 696 p.

MORENO JR., A. L. (1996). Cisalhamento em vigas de concreto de alta resistência submetidas à flexo-compressão. São Paulo. Tese (Doutorado) - Escola Politécnica, Universidade de São Paulo (USP).

NOBRE, E. M. (1992). Argamassa armada: estudo experimental de vigas submetidas à força cortante. São Carlos. Dissertação (Mestrado) - Escola de Engenharia de São Carlos (EESC), Universidade de São Paulo (USP). 
OLIVEIRA, A. A. S.; NAGATO, Y.; MELO, G. S. S. A. (2001). Um estudo sobre o efeito de pino em vigas de concreto armado. In: CONGRESSO BRASILEIRO DO CONCRETO, 43., Foz do Iguaçu, 2001. Anais [CD-ROM].

PAES, J. L. R. (1994). Contribuição ao projeto de elementos pré-fabricados de argamassa armada com ênfase na durabilidade. Niterói. Dissertação (Mestrado) - Universidade Federal Fluminense (UFF).

PINCHEIRA, J. A.; RIZKALLA, S. H.; ATTIOGBE, E. K. (1989). Performance of welded wire fabric as shear reinforcement under cyclic loading. ACI Structural Journal, v. 86, n. 6, p. 728-735, Nov.-Dec.

PLACAS, A. ; REGAN, P. E. (1971). Shear failure of reinforced concrete beams. $A C I$ Journal, v. 68, p. 763-773, Oct.

RAMOS, R. F. (2001). Análise experimental de pilares de concreto armado sob ação centrada com resistência do concreto de $25 \mathrm{MPa}$. São Carlos. Dissertação (Mestrado) Escola de Engenharia de São Carlos (EESC), Universidade de São Paulo (USP).

REGAN, P. E. (1993). Research on shear: a benefit to humanity or a waste of time? The Structural Engineer, v. 71, n. 19/5, p. 337-346, Oct.

ROBERTSON, I. N.; DURRANI, A. J. (1987). Shear strength of prestressed concrete T beams with welded wire fabric as shear reinforcement. PCI Journal, p. 46-61, Mar.-Apr.

SALLES NETO, M. (2000). Comportamento ao cisalhamento de vigas " $T$ " de concreto armado reforçadas com compósitos de fibras de carbono. Brasília. Dissertação (Mestrado) - Departamento de Engenharia Civil e Ambiental, Faculdade de Tecnologia, Universidade de Brasília (UnB).

SILVA, Reginaldo C. (1991). Concreto armado: aplicações de modelos de bielas e tirantes. São Carlos. Dissertação (Mestrado) - Escola de Engenharia de São Carlos (EESC), Universidade de São Paulo (USP).

SILVA, R. C. ; GIONGO, J. S. (2000). Modelos de bielas e tirantes aplicados a estruturas de concreto armado. São Carlos, EESC/USP.

SILVA, R. C.; GIONGO, J. S. (2001). Industrialização das armaduras dos elementos estruturais de concreto armado. In: CONGRESSO BRASILEIRO DO CONCRETO, 43., Foz do Iguaçu, 2001. Anais [CD-ROM].

SILVA, R. C.; GIONGO, J. S. (2002a). Investigação experimental sobre o comportamento resistente ao esforço cortante de vigas de concreto armado com telas soldadas. In: JORNADAS SUL-AMERICANAS DE ENGENHARIA ESTRUTURAL, 30., Brasília, Brasil, 2002. Anais [CD-ROM].

SILVA, R. C.; GIONGO, J. S. (2002b). Vigas de concreto armado solicitadas ao esforço 
cortante dimensionadas pela teoria do cisalhamento-atrito: análise de resultados de ensaios. In: JORNADAS SUL-AMERICANAS DE ENGENHARIA ESTRUTURAL, 30., Brasília, Brasil, 2002. Anais [CD-ROM].

SILVA, R. C.; GIONGO, J. S. (2002c). Ancoragem no apoio extremo em vigas de concreto armado: análises teórica e experimental. In: CONGRESSO BRASILEIRO DO CONCRETO, 44., Belo Horizonte, 2002. Anais [CD-ROM].

SILVA, Rita C. (1999). Contribuição da armadura de pele na resistência ao cisalhamento na flexão em vigas de concreto armado com seção T. Brasília, Dissertação (Mestrado) Departamento de Engenharia Civil, Universidade de Brasília (UnB).

SILVA, R. C.; CLÍMACO, J. C. T. S. (2000). Contribuição da armadura de pele na resistência ao cisalhamento em vigas de concreto armado com seção T. In: JORNADAS SUDAMERICANAS DE INGENIERIA ESTRUCTURAL, 29., Punta Del Este , Uruguay, 2000. Memórias [CD-ROM].

TAYLOR, M. A.; EL-HAMMASI, S. (1980). Web cracking behavior of beams using welded wire fabric as shear reinforcement. ACI Journal, v. 77, n. 2, p. 12-17, Jan.-Feb.

THOMAZ, E. (1988). Fissuração. In: COLÓQUIO SOBRE COMPORTAMENTO E PROJETO DE ESTRUTURAS, 5., PUC/RJ, Rio de Janeiro. Anais.

TIETZ, W. (1979). Armadura transversal das vigas fletidas. Revista Estrutura, n. 86, p. 25 35.

TOMPOS, E. J.; FROSCH, R. J. (2002). Influence of beam size, longitudinal reinforcement, and stirrup effectiveness on concrete shear strength. ACI Structural Journal, v. 99, n. 5, p. 559-567, Sep.-Oct.

XUAN, X.; RIZKALLA, S.; MARUYAMA, K. (1988). Effectiveness of welded wire fabric as shear reinforcement in pretensioned concrete T beams. ACI Structural Journal, v. 85, n. 4, p. 429-436, Jul.-Aug.

VASCONCELOS, A. C. (2000). Engenheiro russo "cai do cavalo". TQS News, n. 14, p. $25-$ 26 , out.

VASCONCELOS, A. C.; GIAMMUSSO, S. E. (1993). Qual a diferença entre a $f_{c k}$ e a $f_{c}^{\prime}$ do ACI? Revista Engenharia, São Paulo, n. 498, p. 40-43.

WALRAVEN, J.; FRÉNAY, J.; PRUIJSSERS, A. (1987). Influence of concrete strength and load history on the shear friction capacity of concrete members. PCI Journal, v. 32, n. 1, Jan.-Feb.

WIRE REINFORCEMENT INSTITUTE (1981). Bending welded wire fabric for reinforced concrete. Manual WWF-400, Mclean, Virginia.

WIRE REINFORCEMENT INSTITUTE (1983). Structural welded wire fabric detailing 
manual. Subcommittee on Detailing Manual Structural Fabric Committee, WRI, Mclean, Virginia

ZSUTTY, T. C. (1968). Beam shear strength prediction by analysis of existing data. $A C I$ Journal, v. 65, n. 8, p. 943-951, Nov.

\section{BIBLIOGRAFIA COMPLEMENTAR}

ALMEIDA, M. C. F. ; LIMA, W. S. (2001). Verificação da eficiência das normas brasileira atual e proposta no controle da fissuração em vigas de concreto armado. Revista Engenharia: Estudo e Pesquisa, Juiz de Fora, v. 4, n. 2, p. 61-69, jul./dez.

ASSOCIAÇÃO BRASILEIRA DE NORMAS TÉCNICAS (1985). NBR 9062 - Projeto e execução de estruturas de concreto pré-moldado. Rio de Janeiro.

ASSOCIAÇÃO BRASILEIRA DE NORMAS TÉCNICAS (1992). NBR 8953 - Concreto para fins estruturais: classificação por grupos de resistência. Rio de Janeiro.

ASSOCIAÇÃO BRASILEIRA DE NORMAS TÉCNICAS (1996). NBR 12.655 - Concreto - Preparo, controle e recebimento. Rio de Janeiro.

BRANDÃO, A. M. S. ; PINHEIRO, L. M. (1997). Estados limites de utilização. São Carlos,EESC-USP.

CLÍMACO, J. C. T. S. (1975). Resistência ao esforço cortante em vigas curtas de concreto leve sem armadura transversal. Rio de Janeiro. Dissertação (Mestrado). COPPE-UFRJ.

COMITÉ EURO-INTERNATIONAL DU BÉTON (1985). CEB - Design manual on cracking and deformations. Bulletim D'Information, Lausanne, n. 158.

COZZA, E. (1986). Aço: pronto para usar. Revista Construção, São Paulo, n. 2508, p. 1011 ,mar.

FARIAS, M. L. R. ; SÁNCHEZ, E. (1995). Análise e dimensionamento ao cortante pelo Eurocode 2. In: JORNADAS SUDAMERICANAS DE INGENIERIA ESTRUCTURAL, 27., Tucuman, AR, 1995. Memória. Tucuman, LE/FCET/UNT. v. 1, p. 471-481.

FERrEiRA, C. A. T.; DUMÊT, T. B. ; ALMEIDA, P. A.; FUSCO, P. B. (1993). Verificação experimental da inclinação da biela de concreto. In: JORNADAS SUDAMERICANAS DE INGENIERIA ESTRUCTURAL, 26., Montevideo, Uruguay, 1993. Memórias, v. 3, p. 225-233.

FUSCO, P. B. (1990). As armaduras mínimas de tração no concreto estrutural. In: SIMPÓSIO EPUSP SOBRE ESTRUTURAS DE CONCRETO, 2., São Paulo. Anais, v. 
2, p. $665-700$.

INSTITUTO BRASILEIRO DE TELAS SOLDADAS (1989). Telas soldadas informações técnicas simplificadas. São Paulo, IBTS.

KOTSOVOS, M. D. (1984). Behavior of reinforced concrete beams with a shear span to depth ratio between 1.0 and 2.5. ACI Journal, v. 81, n. 3. p. 279-286, May-Jun.

KOTSOVOS, M. D. (1986). Behavior of beams with shear span-to-depth ratios greater than 2.5. ACI Journal, v. 83, n. 6. p. 1026-1034, Nov.-Dec.

LEONHARDT, F.; MÖNNIG, E. (1977). Construções de concreto: princípios básicos do dimensionamento de estruturas de concreto armado. Rio de Janeiro, Interciência. v.1, p. $175-218$.

LEVI, F.; MARRO, P. (1989). Shear tests up to failure of beams made with normal and high strength concrete. CEB Bulletin d'Information, n. 193, p. 12-23, Dec.

MACGREGOR, J. G. (1988). Reinforced concrete mechanics and design. Englewood Cliffs, Prentice Hall.

MARCOS NETO, N. (1997). Estruturas pré-moldadas de concreto para edificios de múltiplos pavimentos de pequena altura. São Carlos. Dissertação (Mestrado) - Escola de Engenharia de São Carlos (EESC), Universidade de São Paulo (USP).

MENDES, P. T. C. (1983). A influência da fissuração no comportamento das vigas de concreto armado. São Paulo. Dissertação (Mestrado) - Escola Politécnica, Universidade de São Paulo (USP).

MPHONDE, A. G. (1989). Use of stirrup efectiveness in shear design of concrete beams. ACI Structural Journal, v. 86, n. 5, p. 541-545, Sep.-Oct.

PARK, R. ; PAULAY, T. (1975). Reinforced concrete structures. New York, Wiley.

PINHEIRO, L. M. (1986). Concreto armado: tabelas e ábacos. São Carlos, EESC-USP.

PRESTRESSED CONCRETE INSTITUTE. Committee on Standardization of Welded Wire Fabric (1976). Standardization of welded wire fabric. PCI Journal, v. 21, n. 4, p. 30-37, Jul.-Aug.

PRESTRESSED CONCRETE INSTITUTE \& WIRE REINFORCEMENT INSTITUTE. Committee on Welded Wire Fabric for Shear Reinforcement (1980). Welded wire fabric for shear reinforcement. PCI Journal, v. 25, n. 4, p. 32-36, Jul.-Aug.

SHEHATA, I. A. M.; SHEHATA, L. C. D. ; VENTORINI, L. A. (1997). Avaliação das deformações das armaduras de estruturas de concreto armado a partir das características das fissuras. In: JORNADAS SULAMERICANAS DE ENGENHARIA ESTRUTURAL, 28., São Carlos, Brasil. Anais, v.1, p. 397-405.

SOLUÇÕES de alto desempenho (1998). Revista Téchne, Informe Técnico, n. 36, set.-out. 
TAKEYA, T. (2000). Análise experimental de estruturas - notas de aula. São Carlos,EESC-USP.

TAYLOR, H. P. J. (1978). Basic behavior in shear and the model code provisions for members without shear reinforcement. CEB Bulletin d'Information, n. 126, p.126-140, Jun.

VENTORINI, L. F. (1996). Fissuração de vigas de concreto armado. Rio de Janeiro. Dissertação (Mestrado) - COPPE/UFRJ.

ZSUTTY, T. C. (1971). Shear strength prediction for separate categories of simple beam tests. ACI Journal, v. 68, n. 2, p. 138-143, Feb. 
Tabela A.1 - Série A1

\begin{tabular}{|c|c|c|c|c|c|c|c|}
\hline Assunto: & Resultados e & saios corpo & -de-pro & a concreto & Série: A1 & $\begin{array}{l}\text { Data: } \\
\text { 14/08/01 }\end{array}$ & $\begin{array}{l}\text { Folha: } \\
\text { 01/07 }\end{array}$ \\
\hline $\mathrm{N}^{0} \mathrm{C} . \mathrm{P}$. & Moldagem & Ensaio & Idade & Ensaio & $\begin{array}{c}\text { Força } \\
\text { Última }\end{array}$ & $\mathbf{f}_{\mathrm{cj}}$ & $\mathbf{f}_{\mathrm{tj}}$ \\
\hline & & & (dias) & & $(\mathbf{k N})$ & (MPa) & (MPa) \\
\hline & & & & & & & \\
\hline 01 & $14 / 08 / 01$ & $17 / 08 / 01$ & 03 & compressão & 272,0 & 15,4 & \\
\hline 02 & $14 / 08 / 01$ & $17 / 08 / 01$ & 03 & compressão & 283,0 & 16,0 & \\
\hline 03 & $14 / 08 / 01$ & $21 / 08 / 01$ & 07 & compressão & 408,7 & 23,1 & \\
\hline 04 & $14 / 08 / 01$ & $21 / 08 / 01$ & 07 & compressão & 397,3 & 22,5 & \\
\hline 05 & $14 / 08 / 01$ & $11 / 09 / 01$ & 28 & compressão & 563,4 & 31,9 & \\
\hline 06 & $14 / 08 / 01$ & $11 / 09 / 01$ & 28 & compressão & 637,0 & 36,1 & \\
\hline 07 & $14 / 08 / 01$ & $11 / 09 / 01$ & 28 & compressão & 643,0 & 36,4 & \\
\hline 08 & $14 / 08 / 01$ & $11 / 09 / 01$ & 28 & compressão & 582,0 & 32,9 & \\
\hline 09 & $14 / 08 / 01$ & $11 / 09 / 01$ & 28 & compr. diam. & 153.5 & & 2,15 \\
\hline 10 & $14 / 08 / 01$ & $11 / 09 / 01$ & 28 & compr. diam. & 143,7 & & 2,05 \\
\hline 11 & $14 / 08 / 01$ & $28 / 09 / 01$ & 45 & comnressão & 6715 & 380 & \\
\hline 12 & $14 / 08 / 01$ & $28 / 09 / 01$ & 45 & compressão & 630,7 & 35,7 & \\
\hline 13 & $14 / 08 / 01$ & $28 / 09 / 01$ & 45 & compr. diam. & 177.9 & & 250 \\
\hline 14 & $14 / 08 / 01$ & $28 / 09 / 01$ & 45 & compr. diam. & 200,8 & & 2,85 \\
\hline 15 & $14 / 08 / 01$ & $01 / 10 / 01$ & 48 & compressão & 643,8 & 36,4 & \\
\hline 16 & $14 / 08 / 01$ & $01 / 10 / 01$ & 48 & compressão & 654,8 & 37,1 & \\
\hline & & & & & & & \\
\hline & & & & & & & \\
\hline & & & & & & & \\
\hline & & & & & & & \\
\hline & & & & & & & \\
\hline & & & & & & & \\
\hline & & & & & & & \\
\hline & & & & & & & \\
\hline & & & & & & & \\
\hline & & & & & & & \\
\hline & & & & & & & \\
\hline Observa & es: 1- veloc & des $5,3 \mathrm{kl}$ & (con & essão) e 2,11 & (compr & dian & \\
\hline $2-$ Corp & -de-prova & dricos 15 & & & & & \\
\hline
\end{tabular}


Tabela A.2 - Série B

\begin{tabular}{|c|c|c|c|c|c|c|c|}
\hline \multicolumn{5}{|c|}{ Assunto: Resultados ensaios corpos-de-prova concreto } & \multirow{2}{*}{\begin{tabular}{|c|} 
Série: B \\
$\begin{array}{r}\text { Força } \\
\text { Última }\end{array}$ \\
\end{tabular}} & \multirow{2}{*}{$\begin{array}{l}\text { Data: } \\
\frac{25 / 02 / 02}{f_{c j}}\end{array}$} & \multirow{2}{*}{$\begin{array}{l}\text { Folha: } \\
\text { 02/07 } \\
\mathbf{f}_{\mathrm{tj}}\end{array}$} \\
\hline No C. P. & $\begin{array}{c}\text { Moldage } \\
\text { m }\end{array}$ & Ensaio & Idade & Ensaio & & & \\
\hline & & & (dias) & & $(\mathbf{k N})$ & (MPa) & (MPa) \\
\hline 01 & $25 / 02 / 02$ & $05 / 03 / 02$ & 08 & compressão & 349,8 & 19,8 & \\
\hline 02 & $25 / 02 / 02$ & $05 / 03 / 02$ & 08 & compressão & 325,8 & 18,4 & \\
\hline 03 & $25 / 02 / 02$ & $25 / 03 / 02$ & 28 & compressão & 484.0 & 27.4 & \\
\hline 04 & $25 / 02 / 02$ & $25 / 03 / 02$ & 28 & compressão & 488,5 & 25,7 & \\
\hline 05 & $25 / 02 / 02$ & $25 / 03 / 02$ & 28 & compressão & 482,4 & 26,0 & \\
\hline 06 & $25 / 02 / 02$ & $25 / 03 / 02$ & 28 & compressão & 443,1 & 25,1 & \\
\hline 07 & $25 / 02 / 02$ & $25 / 03 / 02$ & 28 & compr. & 160,4 & & 2,30 \\
\hline 08 & $25 / 02 / 02$ & $25 / 03 / 02$ & 28 & $\begin{array}{l}\text { compr. } \\
\text { diam. }\end{array}$ & 171,0 & & 2,40 \\
\hline 09 & $25 / 02 / 02$ & $27 / 03 / 02$ & 30 & compressão & 459,4 & 27,3 & \\
\hline 10 & $25 / 02 / 02$ & $27 / 03 / 02$ & 30 & compressão & 460,3 & 26,1 & \\
\hline 11 & $25 / 02 / 02$ & $03 / 04 / 02$ & 37 & compressão & 454.5 & 27.6 & \\
\hline 12 & $25 / 02 / 02$ & $03 / 04 / 02$ & 37 & compressão & 469,0 & 26,5 & \\
\hline & & & & & & & \\
\hline & & & & & & & \\
\hline & & & & & & & \\
\hline & & & & & & & \\
\hline & & & & & & & \\
\hline & & & & & & & \\
\hline & & & & & & & \\
\hline & & & & & & & \\
\hline & & & & & & & \\
\hline & & & & & & & \\
\hline & & & & & & & \\
\hline & & & & & & & \\
\hline & & & & & & & \\
\hline & & & & & & & \\
\hline & & & & & & & \\
\hline & & & & & & & \\
\hline Observa & es: $1-$ vel & dades 5,3 & $\mathrm{~s}(\mathrm{co}$ & essão) e 2,1 & /s (com & diar & \\
\hline $2-$ Corp & -de-prov & líndricos & 30 & & & & \\
\hline
\end{tabular}


Tabela A.3 - Série D

\begin{tabular}{|c|c|c|c|c|c|c|c|}
\hline \multicolumn{5}{|c|}{ Assunto: Resultados ensaios corpos-de-prova concreto } & \multirow{2}{*}{\begin{tabular}{|r|} 
Série: D \\
$\begin{array}{c}\text { Força } \\
\text { Última }\end{array}$ \\
\end{tabular}} & \multirow{2}{*}{\begin{tabular}{|c|}
$\begin{array}{l}\text { Data: } \\
18 / 03 / 02\end{array}$ \\
$f_{c j}$
\end{tabular}} & \multirow{2}{*}{$\begin{array}{l}\text { Folha: } \\
\text { 03/07 } \\
\mathbf{f}_{\mathrm{tj}}\end{array}$} \\
\hline $\begin{array}{c}\text { No C. } \\
\text { P. }\end{array}$ & Moldagem & Ensaio & Idade & Ensaio & & & \\
\hline & & & (dias) & & $(\mathbf{k N})$ & (MPa) & (MPa) \\
\hline 01 & $18 / 03 / 02$ & $25 / 03 / 02$ & 07 & compressão & 360,5 & 20,4 & \\
\hline 02 & $18 / 03 / 02$ & $25 / 03 / 02$ & 07 & compressão & 379,6 & 21,5 & \\
\hline 03 & $18 / 03 / 02$ & $15 / 04 / 02$ & 28 & compressão & 450,2 & 25,5 & \\
\hline 04 & $18 / 03 / 02$ & $15 / 04 / 02$ & 28 & compressão & 482,8 & 27,3 & \\
\hline 05 & $18 / 03 / 02$ & $15 / 04 / 02$ & 28 & compr. diam. & 155,0 & & 2,20 \\
\hline 06 & $18 / 03 / 02$ & $15 / 04 / 02$ & 28 & compr. diam. & 162,3 & & 2,30 \\
\hline 07 & $18 / 03 / 02$ & $17 / 04 / 02$ & 30 & compressão & 515,8 & 29,2 & \\
\hline 08 & $18 / 03 / 02$ & $17 / 04 / 02$ & 30 & compressão & 480,2 & 27,2 & \\
\hline 09 & $18 / 03 / 02$ & $18 / 04 / 02$ & 31 & compr. diam. & 172,8 & & 2,45 \\
\hline 10 & $18 / 03 / 02$ & $18 / 04 / 02$ & 31 & compr. diam. & 180,1 & & 2,55 \\
\hline & & & & & & & \\
\hline & & & & & & & \\
\hline & & & & & & & \\
\hline & & & & & & & \\
\hline & & & & & & & \\
\hline & & & & & & & \\
\hline & & & & & & & \\
\hline & & & & & & & \\
\hline & & & & & & & \\
\hline & & & & & & & \\
\hline & & & & & & & \\
\hline & & & & & & & \\
\hline & & & & & & & \\
\hline & & & & & & & \\
\hline & & & & & & & \\
\hline Obsery & ões: 1- velo & idades 5,3 & $/ \mathrm{s}(\mathrm{com}$ & essão) e 2,1 k & (compr & liametr & \\
\hline $2-\mathrm{Co}$ & ss-de-prova & ilíndricos & $\mathrm{mm} \times$ & $0 \mathrm{~mm}$ & & & \\
\hline
\end{tabular}


Tabela A.4 - Série A2-1

\begin{tabular}{|c|c|c|c|c|c|c|c|}
\hline \multicolumn{5}{|c|}{ Assunto: Resultados ensaios corpos-de-prova concreto } & \multirow{2}{*}{\begin{tabular}{|c|}
$\begin{array}{l}\text { Série: } \\
\text { A2 - } 1\end{array}$ \\
$\begin{array}{c}\text { Força } \\
\text { Última }\end{array}$ \\
\end{tabular}} & \multirow{2}{*}{$\begin{array}{l}\text { Data: } \\
\frac{11 / 04 / 02}{f_{c j}}\end{array}$} & \multirow{2}{*}{\begin{tabular}{|r|}
$\begin{array}{l}\text { Folha: } \\
04 / 07\end{array}$ \\
$\mathbf{f}_{\mathrm{tj}}$
\end{tabular}} \\
\hline $\begin{array}{c}N^{0} \mathrm{C} . \\
\mathrm{P} .\end{array}$ & Moldagem & Ensaio & Idade & Ensaio & & & \\
\hline & & & (dias) & & $(\mathbf{k N})$ & (MPa) & (MPa) \\
\hline 01 & $11 / 04 / 02$ & $18 / 04 / 02$ & 07 & compressão & 239,5 & 13,6 & \\
\hline 02 & $11 / 04 / 02$ & $18 / 04 / 02$ & 07 & compressão & 263,5 & 14,9 & \\
\hline $03 *$ & $11 / 04 / 02$ & $18 / 04 / 02$ & 07 & compressão & 250,0 & 14,1 & \\
\hline $04 *$ & $11 / 04 / 02$ & $18 / 04 / 02$ & 07 & compressão & 252,0 & 14,3 & \\
\hline 05 & $11 / 04 / 02$ & $09 / 05 / 02$ & 28 & compressão & 328,5 & 18,6 & \\
\hline $06^{*}$ & $11 / 04 / 02$ & $09 / 05 / 02$ & 28 & compressão & 327.8 & 18.6 & \\
\hline $07 *$ & $11 / 04 / 02$ & $09 / 05 / 02$ & 28 & compressão & 350,4 & 19,8 & \\
\hline 08 & $11 / 04 / 02$ & $13 / 05 / 02$ & 32 & compressão & 328,2 & 18,6 & \\
\hline 09 & $11 / 04 / 02$ & $16 / 05 / 02$ & 35 & comnressão & 3275 & 185 & \\
\hline 10 & $11 / 04 / 02$ & $16 / 05 / 02$ & 35 & compressão & 323,7 & 18,3 & \\
\hline 11 & $11 / 04 / 02$ & $16 / 05 / 02$ & 35 & compressão & 328,7 & 18,6 & \\
\hline 12 & $11 / 04 / 02$ & $16 / 05 / 02$ & 35 & $\begin{array}{l}\text { compr. } \\
\text { diam. }\end{array}$ & 125,6 & & 1,80 \\
\hline 13 & $11 / 04 / 02$ & $16 / 05 / 02$ & 35 & $\begin{array}{l}\text { compr. } \\
\text { diam. }\end{array}$ & 128,3 & & 1,80 \\
\hline 14 & $11 / 04 / 02$ & $16 / 05 / 02$ & 35 & $\begin{array}{l}\text { compr. } \\
\text { diam. }\end{array}$ & 118,3 & & 1,65 \\
\hline $15^{* * *}$ & $23 / 04 / 02$ & $16 / 05 / 02$ & 23 & compressão & 82,6 & 42,1 & \\
\hline $16^{* *}$ & $23 / 04 / 02$ & $16 / 05 / 02$ & 23 & compressão & 88,0 & 44,8 & \\
\hline $17 * *$ & $23 / 04 / 02$ & $16 / 05 / 02$ & 23 & compressão & 84,9 & 43,3 & \\
\hline & & & & & & & \\
\hline & & & & & & & \\
\hline & & & & & & & \\
\hline & & & & & & & \\
\hline & & & & & & & \\
\hline & & & & & & & \\
\hline & & & & & & & \\
\hline & & & & & & & \\
\hline Obsery & oes: 1- velc & dades 5,3 & $/ \mathrm{s}(\mathrm{con}$ & ressão) e 2,1 & $\mathrm{~N} / \mathrm{s}(\mathrm{cor}$ & ssão di & ral) \\
\hline $2-\mathrm{Co}$ & s-de-prova & ilíndricos & $0 \mathrm{~mm} x$ & $0 \mathrm{~mm}$ & & & \\
\hline $3-* c$ & reto prepa & lo no LE-S & & & & & \\
\hline $4-* *$ & amassa de & aro (corp & & 50 & & & \\
\hline
\end{tabular}


Tabela A.5 - Série A2-2

\begin{tabular}{|c|c|c|c|c|c|c|c|}
\hline \multicolumn{5}{|c|}{ Assunto: Resultados ensaios corpos-de-prova concreto } & \multirow{2}{*}{\begin{tabular}{|c|}
$\begin{array}{l}\text { Série: } \\
\text { A2 - 2 }\end{array}$ \\
$\begin{array}{c}\text { Força } \\
\text { Última }\end{array}$ \\
\end{tabular}} & \multirow{2}{*}{$\begin{array}{l}\text { Data: } \\
08 / 05 / 02 \\
f_{c j}\end{array}$} & \multirow{2}{*}{$\begin{array}{l}\begin{array}{c}\text { Folha: } \\
05 / 07 \\
f_{\mathrm{tj}}\end{array}\end{array}$} \\
\hline $\begin{array}{c}\text { No C. } \\
\text { P. }\end{array}$ & Moldagem & Ensaio & Idade & Ensaio & & & \\
\hline & & & (dias) & & $(\mathbf{k N})$ & (MPa) & (MPa) \\
\hline 01 & $08 / 05 / 02$ & $15 / 05 / 02$ & 07 & compressão & 227,4 & 12,9 & \\
\hline 02 & $08 / 05 / 02$ & $15 / 05 / 02$ & 07 & compressão & 245,5 & 13,9 & \\
\hline 03 & $08 / 05 / 02$ & $06 / 06 / 02$ & 29 & compressão & 296,0 & 16,8 & \\
\hline 04 & $08 / 05 / 02$ & $06 / 06 / 02$ & 29 & compressão & 358,6 & 20,3 & \\
\hline 05 & $08 / 05 / 02$ & $18 / 06 / 02$ & 41 & compressão & 369,1 & 20,9 & \\
\hline 06 & $08 / 05 / 02$ & $18 / 06 / 02$ & 41 & compressão & 329,5 & 18,7 & \\
\hline 07 & $08 / 05 / 02$ & $18 / 06 / 02$ & 41 & compressão & 313,4 & 17,7 & \\
\hline 08 & $08 / 05 / 02$ & $18 / 06 / 02$ & 41 & compressão & 344,1 & 19,5 & \\
\hline 09 & $08 / 05 / 02$ & $18 / 06 / 02$ & 41 & $\begin{array}{l}\text { compr. } \\
\text { diam. }\end{array}$ & 124,4 & & 1,75 \\
\hline 10 & $08 / 05 / 02$ & $18 / 06 / 02$ & 41 & $\begin{array}{l}\text { compr. } \\
\text { diam. }\end{array}$ & 135,8 & & 1,90 \\
\hline 11 & $08 / 05 / 02$ & $18 / 06 / 02$ & 41 & $\begin{array}{l}\text { compr. } \\
\text { diam. }\end{array}$ & 119,9 & & 1,70 \\
\hline 12 & $08 / 05 / 02$ & $18 / 06 / 02$ & 41 & $\begin{array}{l}\text { tração na } \\
\text { flexão }\end{array}$ & 24,04 & & 3,21 \\
\hline 13 & $08 / 05 / 02$ & $18 / 06 / 02$ & 41 & $\begin{array}{l}\text { tração na } \\
\text { flexão }\end{array}$ & 27,19 & & 3,63 \\
\hline 14 & $08 / 05 / 02$ & $18 / 06 / 02$ & 41 & $\begin{array}{l}\text { tração na } \\
\text { flexão }\end{array}$ & 19,05 & & 2,54 \\
\hline & & & & & & & \\
\hline & & & & & & & \\
\hline & & & & & & & \\
\hline & & & & & & & \\
\hline & & & & & & & \\
\hline & & & & & & & \\
\hline & & & & & & & \\
\hline & & & & & & & \\
\hline & & & & & & & \\
\hline & & & & & & & \\
\hline & & & & & & & \\
\hline & & & & & & & \\
\hline & & & & & & & \\
\hline & & & & & & & \\
\hline & & & & & & & \\
\hline & & & & & & & \\
\hline Obser & ões: 1 - vel & ades 5,3 & $\mathrm{s}(\mathrm{co}$ & essão) e 2,1 & $\mathrm{~s}(\mathrm{cos}$ & $\tilde{\mu}$ & \\
\hline $2-\mathrm{Co}$ & s-de-prov & líndricos & $\times 30$ & & & & \\
\hline $3-\mathrm{En}$ & de tração & flexão: v & idad & t5 kN/ & & & \\
\hline
\end{tabular}


Tabela A.6 - Série C-1

\begin{tabular}{|c|c|c|c|c|c|c|c|}
\hline \multicolumn{5}{|c|}{ Assunto: Resultados ensaios corpos-de-prova concreto } & \multirow{2}{*}{$\begin{array}{l}\text { Série: } \\
\text { C - } 1 \\
\begin{array}{c}\text { Força } \\
\text { Última }\end{array} \\
\end{array}$} & \multirow{2}{*}{$\begin{array}{l}\text { Data: } \\
05 / 06 / 02 \\
f_{c j}\end{array}$} & \multirow{2}{*}{$\begin{array}{l}\begin{array}{c}\text { Folha: } \\
06 / 07\end{array} \\
f_{\mathrm{tj}}\end{array}$} \\
\hline $\begin{array}{c}\mathrm{N}^{\mathbf{0}} \mathrm{C} . \\
\mathrm{P} .\end{array}$ & Moldagem & Ensaio & Idade & Ensaio & & & \\
\hline & & & (dias) & & $(\mathbf{k N})$ & (MPa) & (MPa) \\
\hline 01 & $05 / 06 / 02$ & $12 / 06 / 02$ & 07 & compressão & 312,2 & 17,7 & \\
\hline 02 & $05 / 06 / 02$ & $12 / 06 / 02$ & 07 & compressão & 273,9 & 15,5 & \\
\hline 03 & $05 / 06 / 02$ & $12 / 06 / 02$ & 07 & compressão & 340,5 & 19,3 & \\
\hline 04 & $05 / 06 / 02$ & $03 / 07 / 02$ & 28 & compressão & 479,3 & 27,1 & \\
\hline 05 & $05 / 06 / 02$ & $03 / 07 / 02$ & 28 & compressão & 469,6 & 26,6 & \\
\hline 06 & $05 / 06 / 02$ & $03 / 07 / 02$ & 28 & compressão & 461,6 & 26,1 & \\
\hline 07 & $05 / 06 / 02$ & $03 / 07 / 02$ & 28 & compressão & 439,1 & 24,9 & \\
\hline 08 & $05 / 06 / 02$ & $03 / 07 / 02$ & 28 & tração na flexão & 26,22 & & 3,50 \\
\hline 09 & $05 / 06 / 02$ & $03 / 07 / 02$ & 28 & tração na flexão & 23,92 & & 3,19 \\
\hline 10 & $05 / 06 / 02$ & $03 / 07 / 02$ & 28 & tração na flexão & 23,30 & & 3,11 \\
\hline 11 & $05 / 06 / 02$ & $04 / 07 / 02$ & 29 & compr. diam. & 176,4 & & 2,50 \\
\hline 12 & $05 / 06 / 02$ & $04 / 07 / 02$ & 29 & compr. diam. & 152,3 & & 2,16 \\
\hline & & & & & & & \\
\hline & & & & & & & \\
\hline & & & & & & & \\
\hline & & & & & & & \\
\hline & & & & & & & \\
\hline & & & & & & & \\
\hline & & & & & & & \\
\hline & & & & & & & \\
\hline & & & & & & & \\
\hline & & & & & & & \\
\hline & & & & & & & \\
\hline & & & & & & & \\
\hline & & & & & & & \\
\hline & & & & & & & \\
\hline & & & & & & & \\
\hline & & & & & & & \\
\hline & & & & & & & \\
\hline & & & & & & & \\
\hline Observ & ões: $1-$ vel & dades 5,3 & s (cor & essão) e 2,1 kl & ompre & liametra & \\
\hline $2-\mathrm{Co}$ & s-de-prov & índricos & x 30 & & & & \\
\hline & & & idade & & & & \\
\hline
\end{tabular}


Tabela A.7 - Série C-2

\begin{tabular}{|c|c|c|c|c|c|c|c|}
\hline \multicolumn{5}{|c|}{ Assunto: Resultados ensaios corpos-de-prova concreto } & \multirow{2}{*}{\begin{tabular}{|l|}
$\begin{array}{l}\text { Série: } \\
\text { C - } 2\end{array}$ \\
Força \\
Última \\
\end{tabular}} & \multirow{2}{*}{$\begin{array}{l}\text { Data: } \\
\frac{27 / 06 / 02}{f_{c j}}\end{array}$} & \multirow{2}{*}{\begin{tabular}{|r|}
$\begin{array}{l}\text { Folha: } \\
\text { 07/07 }\end{array}$ \\
$\mathbf{f}_{\mathrm{tj}}$ \\
\end{tabular}} \\
\hline $\begin{array}{c}N^{0} \mathrm{C} . \\
\text { P. }\end{array}$ & Moldagem & Ensaio & Idade & Ensaio & & & \\
\hline & & & (dias) & & $(\mathbf{k N})$ & (MPa) & (MPa) \\
\hline 01 & $27 / 06 / 02$ & $04 / 07 / 02$ & 07 & compressão & 318,0 & 18,0 & \\
\hline 02 & $27 / 06 / 02$ & $04 / 07 / 02$ & 07 & compressão & 277,1 & 15,7 & \\
\hline 03 & $27 / 06 / 02$ & $25 / 07 / 02$ & 28 & compressão & 360,9 & 20,4 & \\
\hline 04 & $27 / 06 / 02$ & $25 / 07 / 02$ & 28 & compressão & 390,6 & 22,1 & \\
\hline 05 & $27 / 06 / 02$ & $25 / 07 / 02$ & 28 & compressão & 410,6 & 23,2 & \\
\hline 06 & $27 / 06 / 02$ & $25 / 07 / 02$ & 28 & compressão & 398,7 & 22,6 & \\
\hline 07 & $27 / 06 / 02$ & $25 / 07 / 02$ & 28 & compr. diam. & 126,9 & & 1,80 \\
\hline 08 & $27 / 06 / 02$ & $25 / 07 / 02$ & 28 & compr. diam. & 144,3 & & 2,05 \\
\hline 09 & $27 / 06 / 02$ & $25 / 07 / 02$ & 28 & compr. diam. & 154,3 & & 2,20 \\
\hline 10 & $27 / 06 / 02$ & $25 / 07 / 02$ & 28 & compr. diam. & 134,3 & & 1,90 \\
\hline & & & & & & & \\
\hline & & & & & & & \\
\hline & & & & & & & \\
\hline & & & & & & & \\
\hline & & & & & & & \\
\hline & & & & & & & \\
\hline & & & & & & & \\
\hline & & & & & & & \\
\hline & & & & & & & \\
\hline & & & & & & & \\
\hline & & & & & & & \\
\hline & & & & & & & \\
\hline & & & & & & & \\
\hline & & & & & & & \\
\hline & & & & & & & \\
\hline & & & & & & & \\
\hline & & & & & & & \\
\hline & & & & & & & \\
\hline & & & & & & & \\
\hline bser & ões: 1- velo & dades 5,3 & $\mathrm{~N} / \mathrm{s}(\mathrm{cc}$ & pressão) e 2,1 & s ( & ão di & ral) \\
\hline $2-\mathrm{Co}$ & ss-de-prova & líndricos & $50 \mathrm{~mm}$ & $00 \mathrm{~mm}$ & & & \\
\hline
\end{tabular}




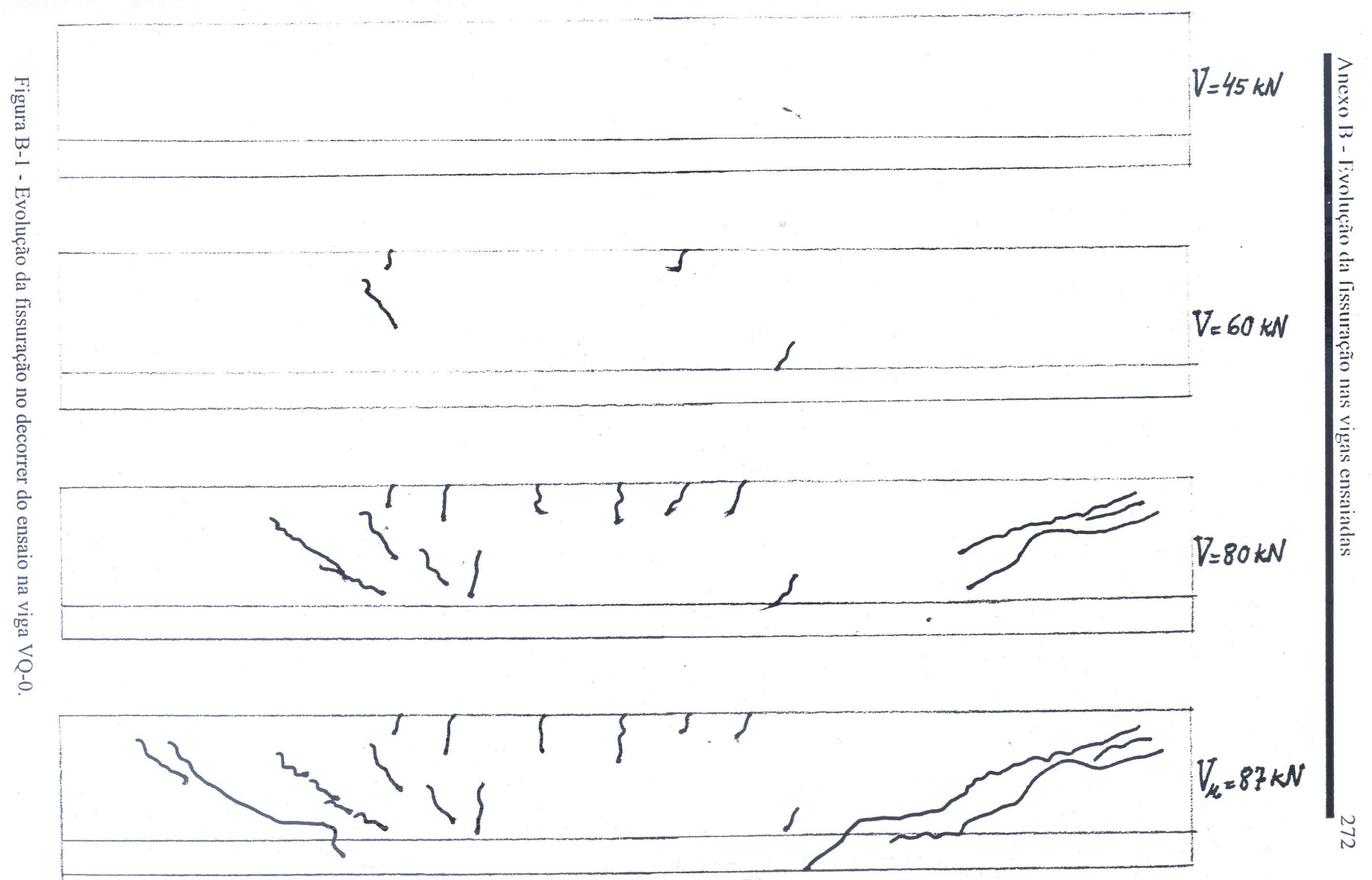




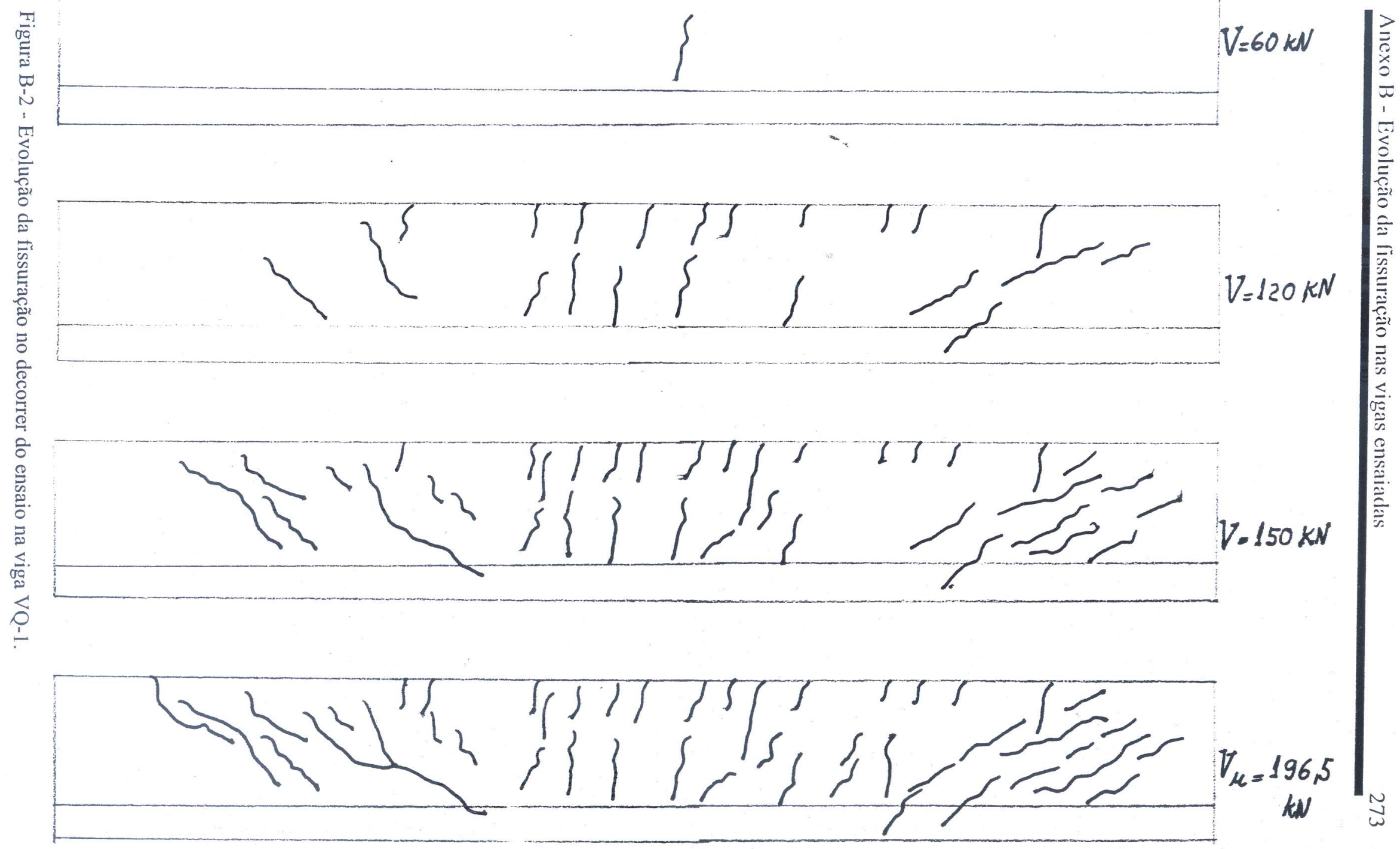




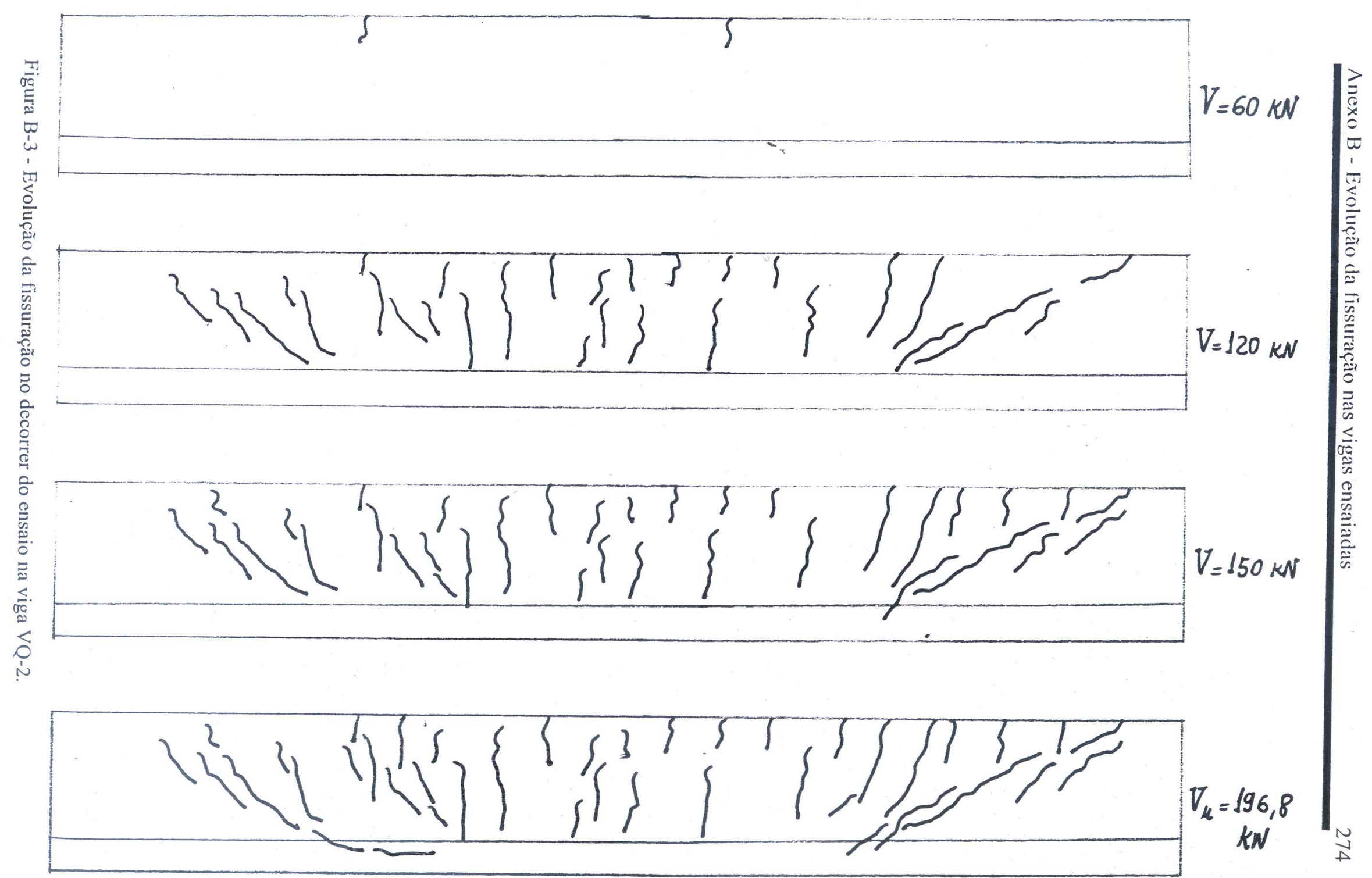




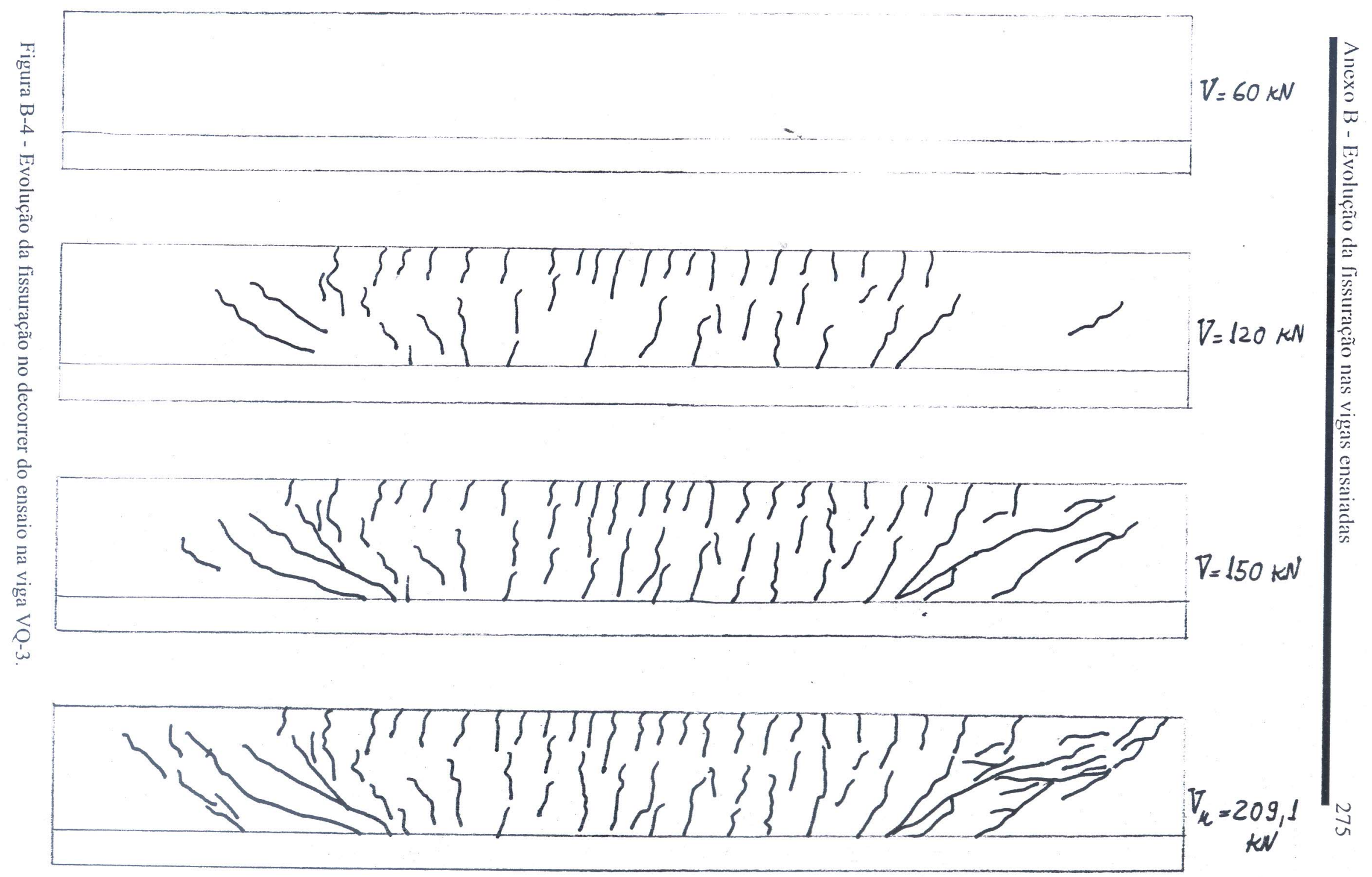




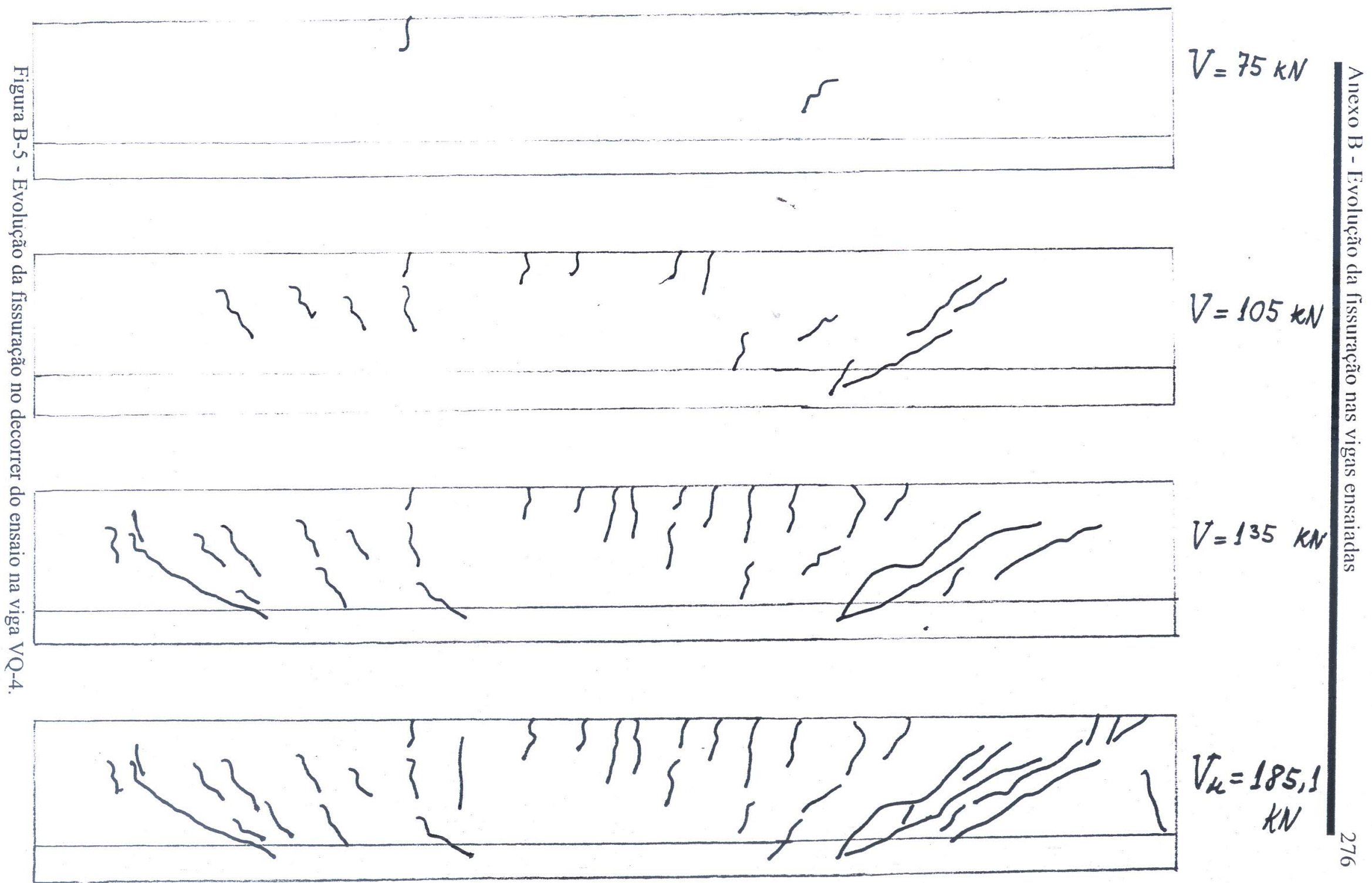




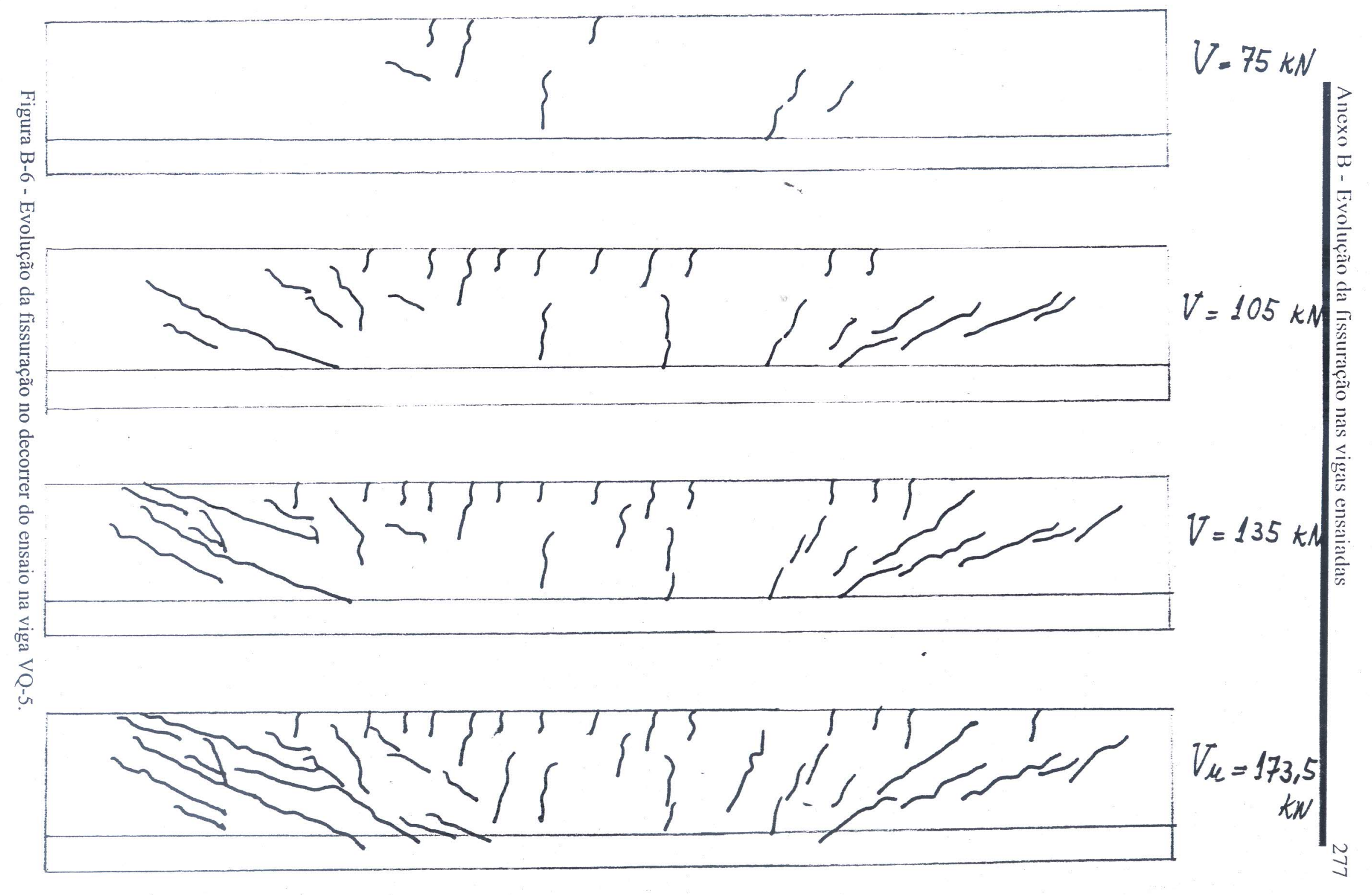




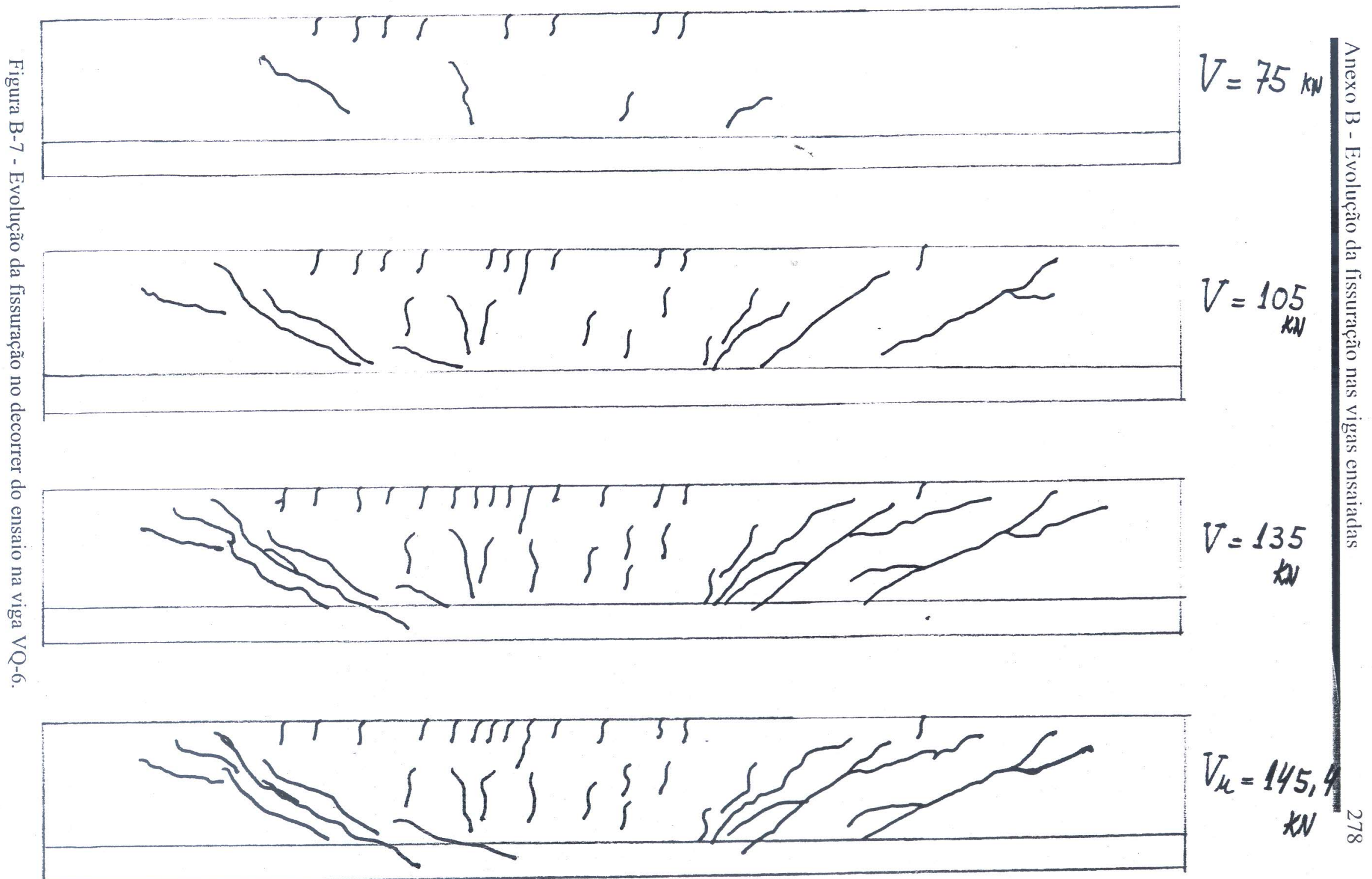




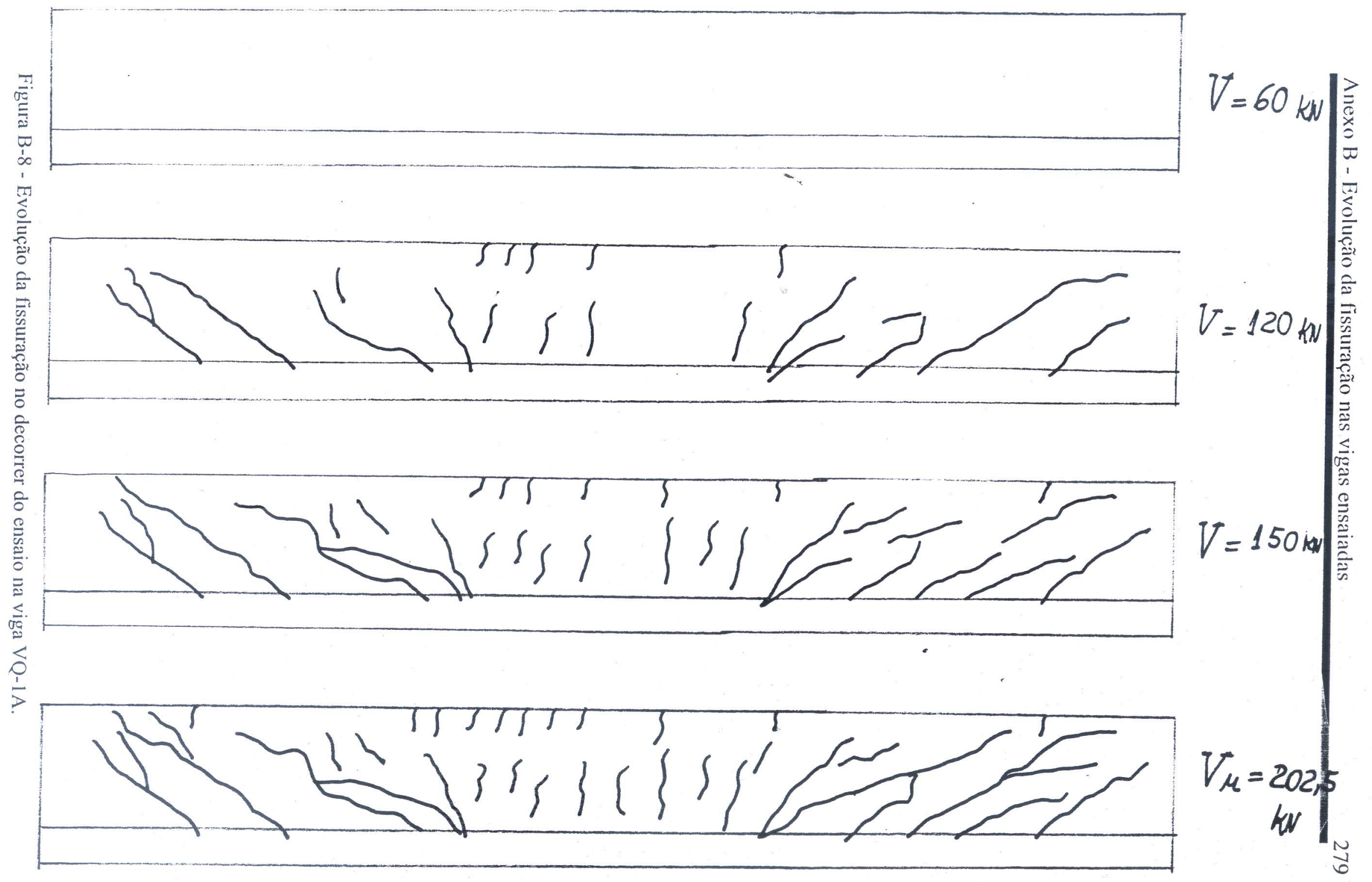




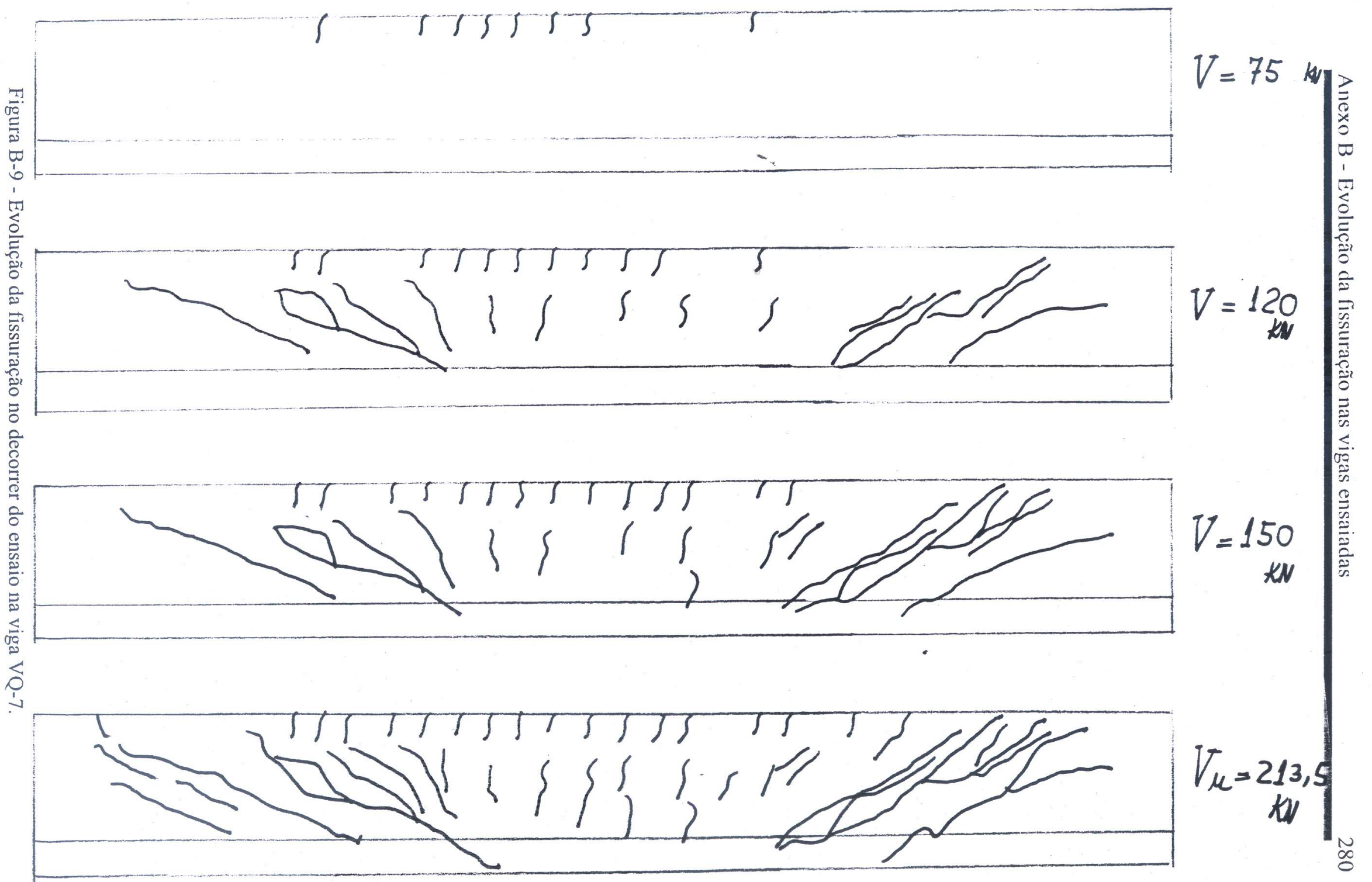




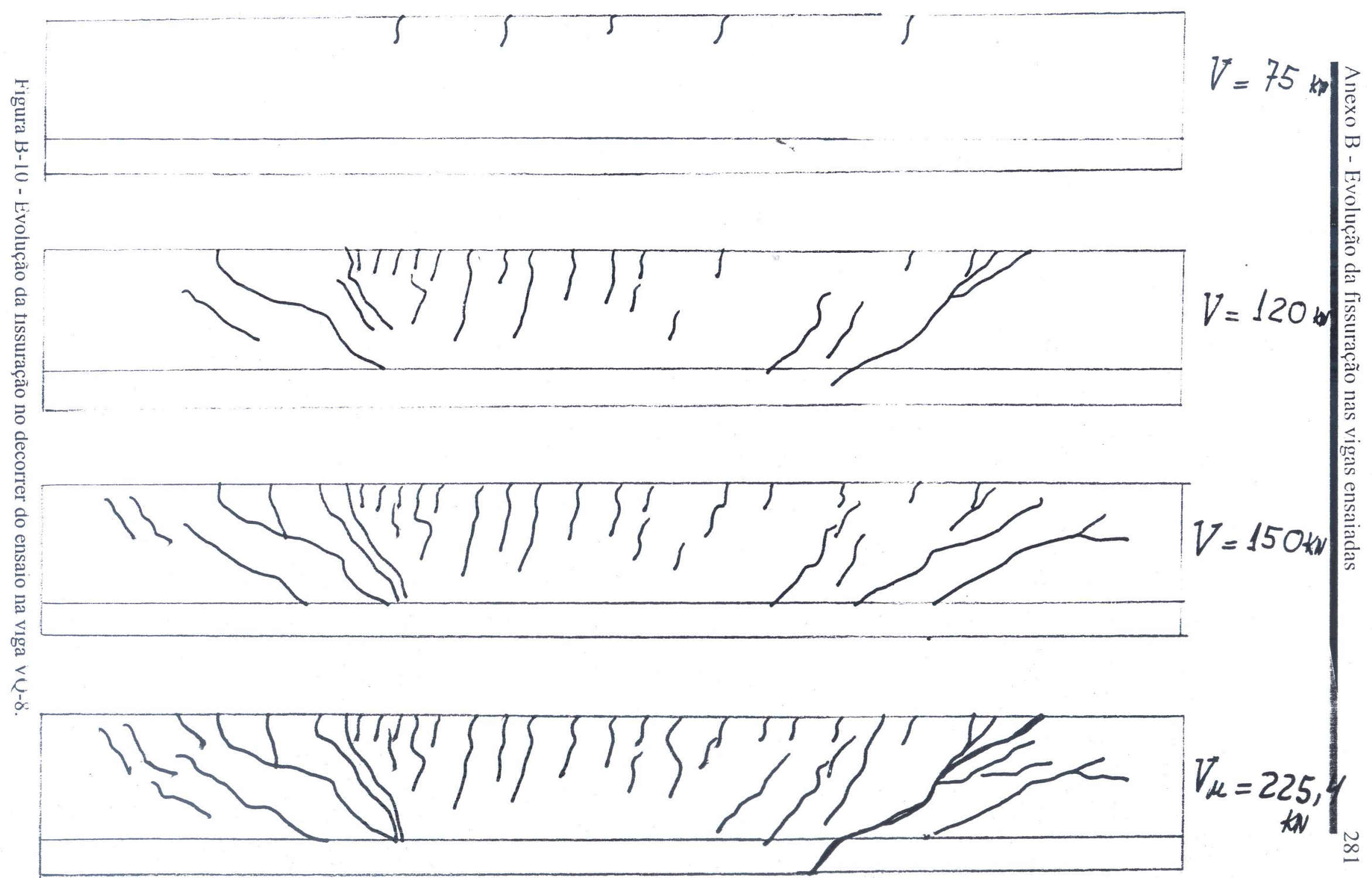




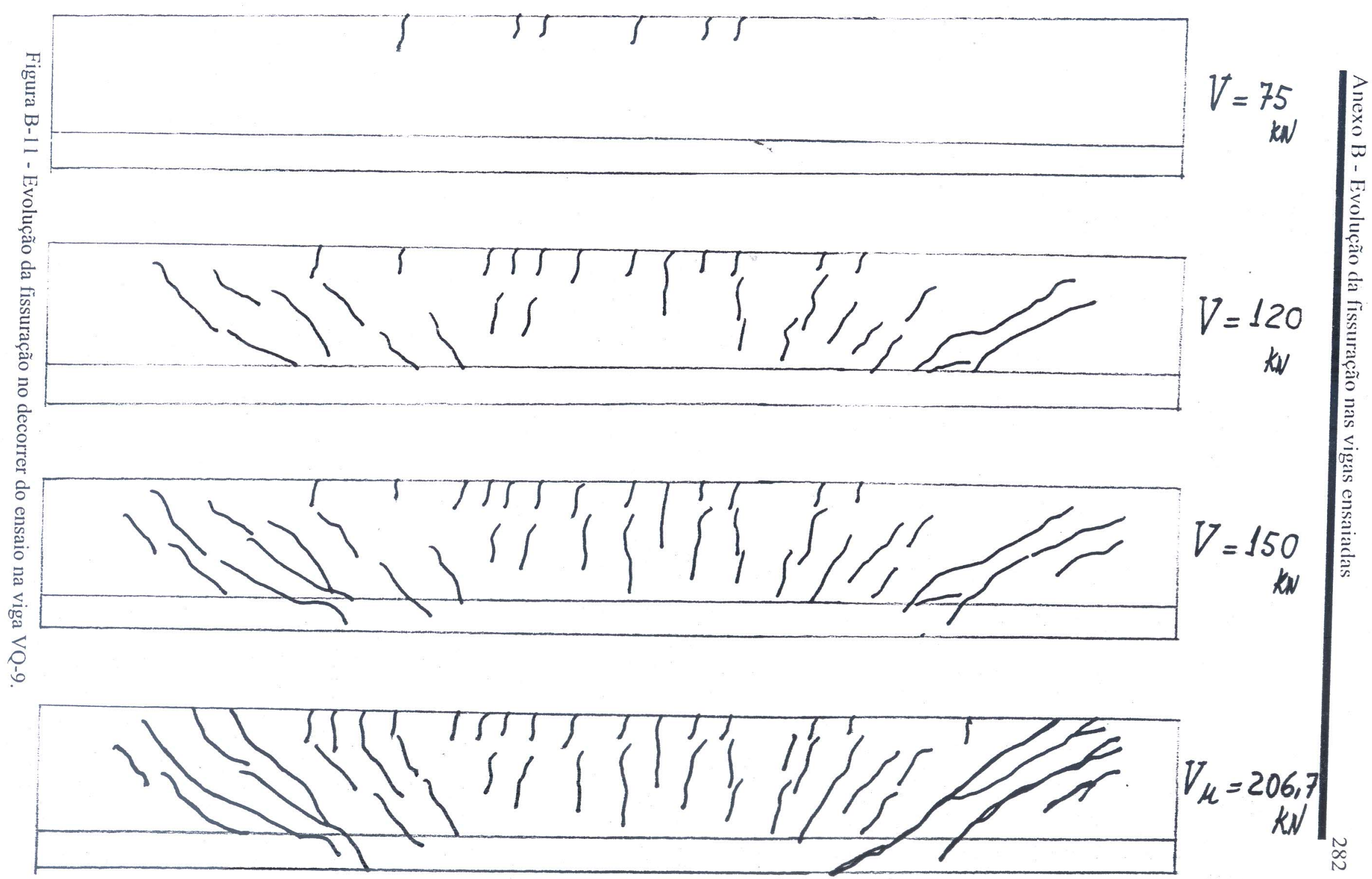




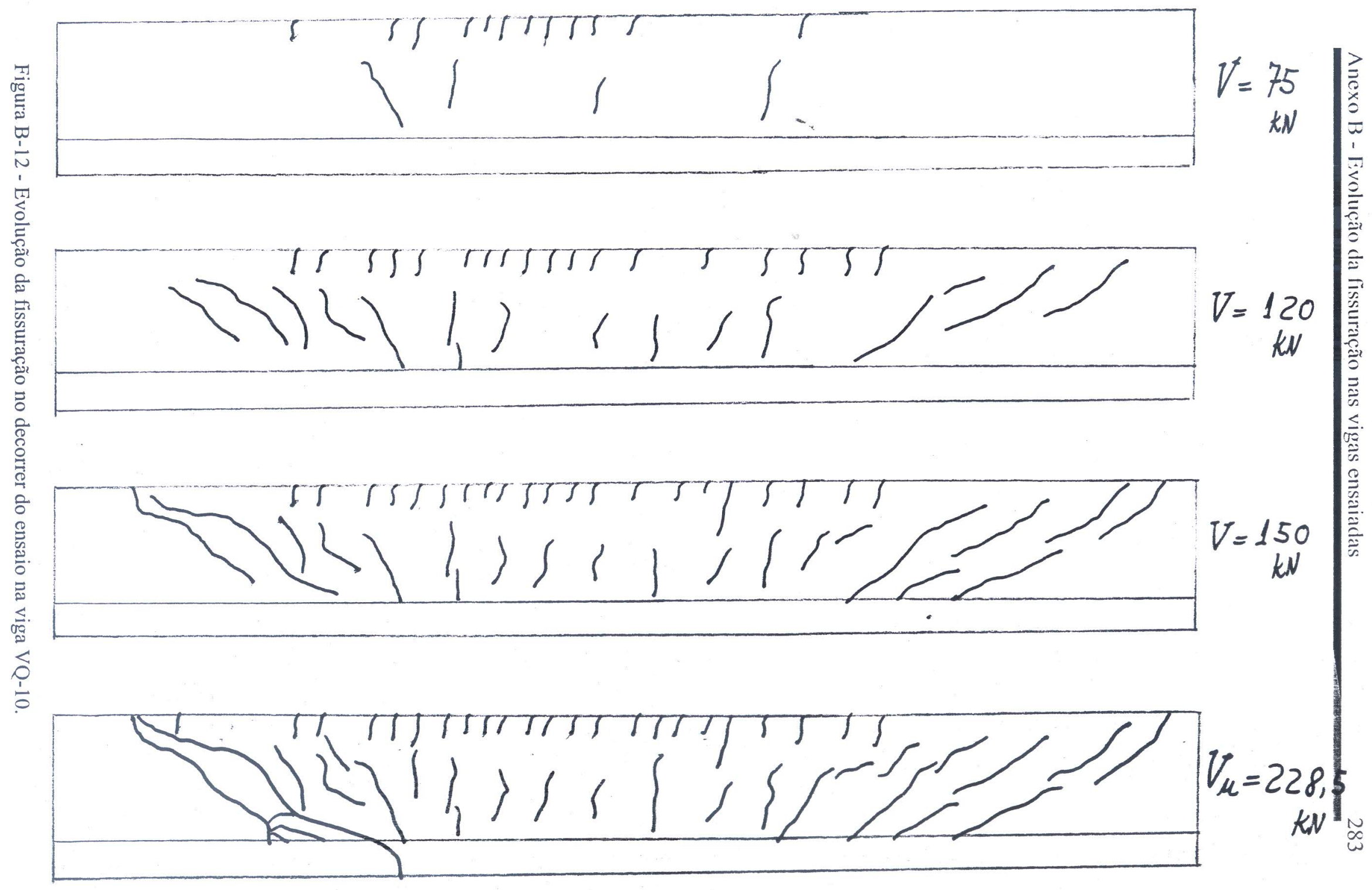




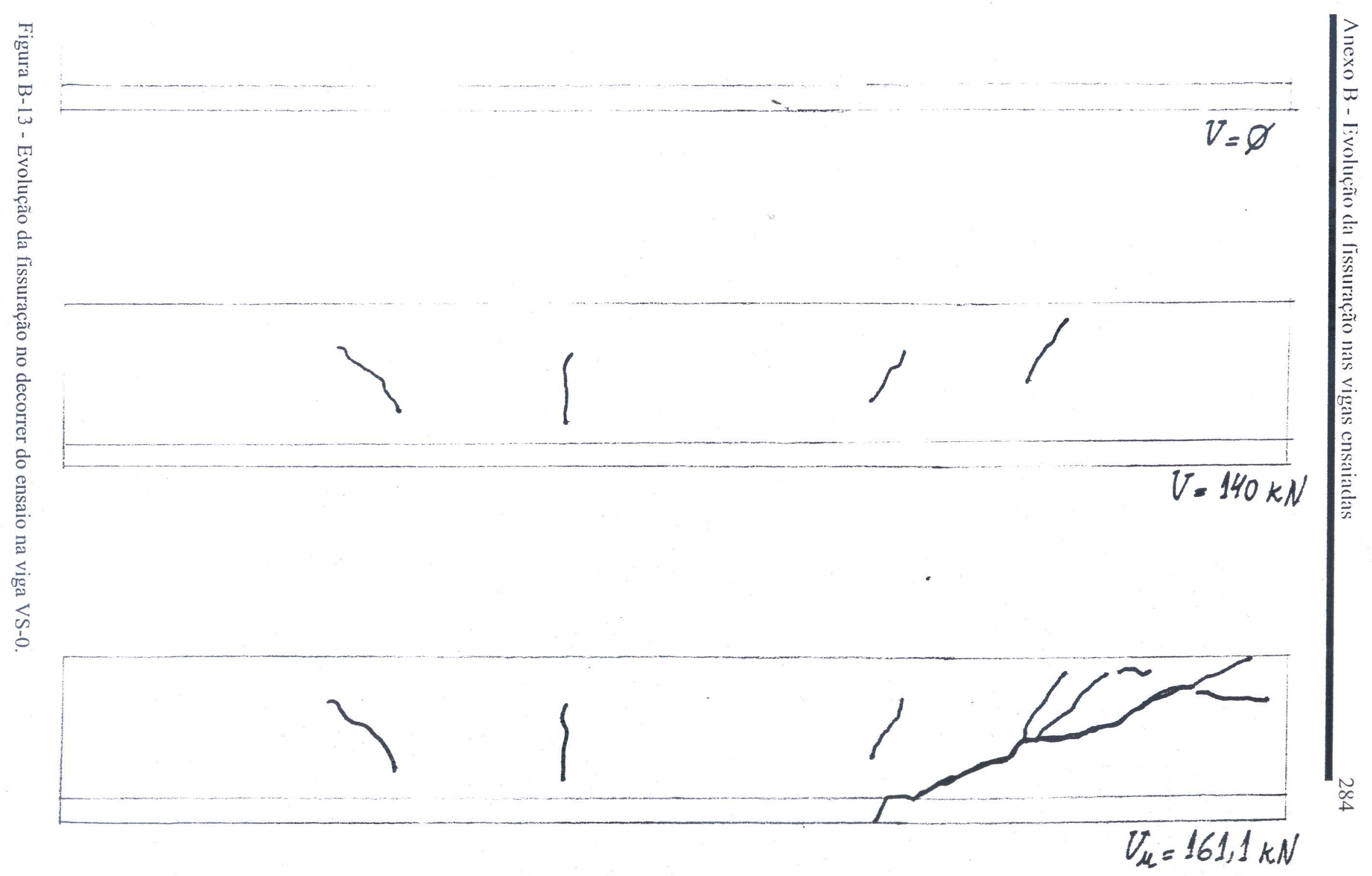




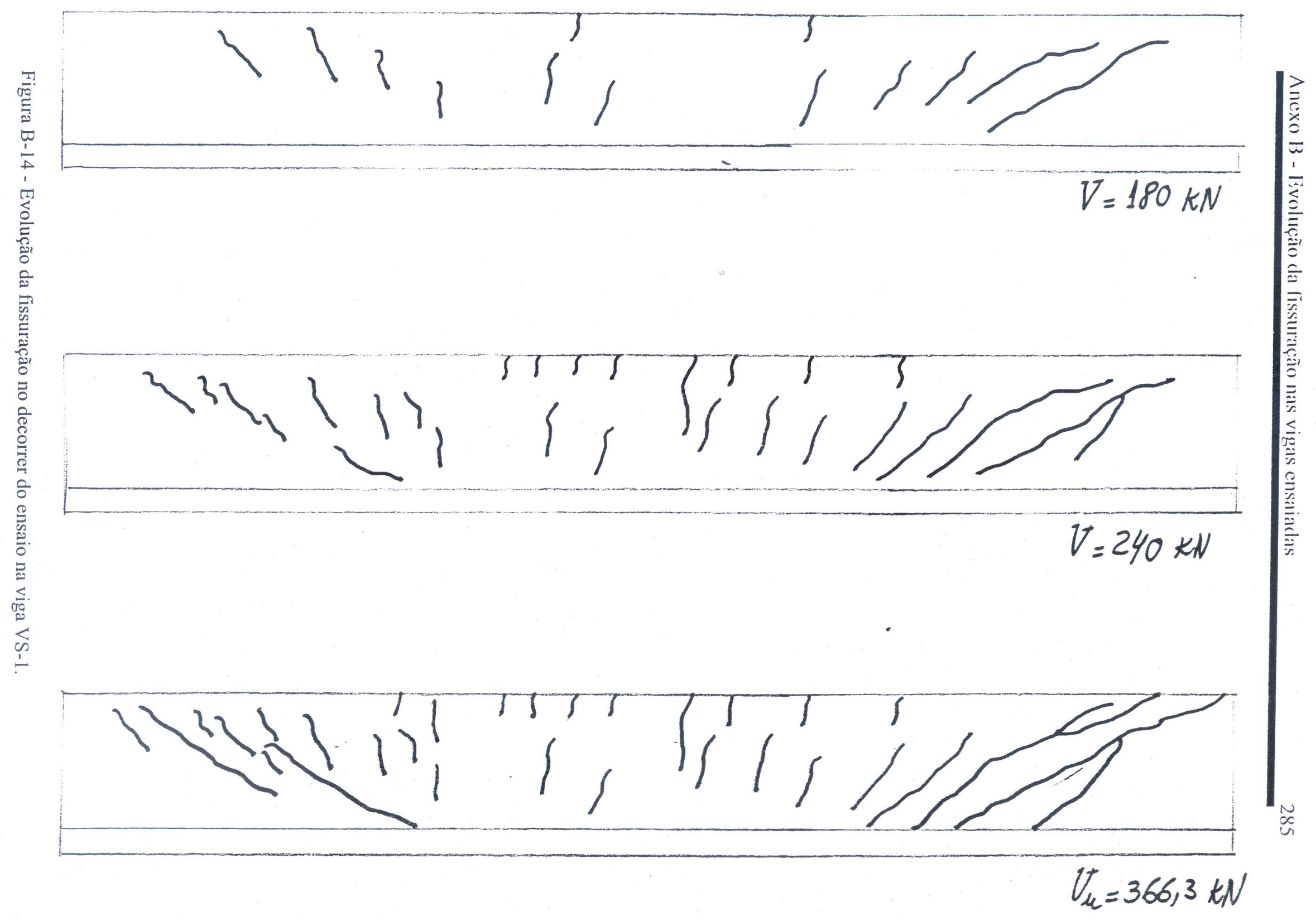




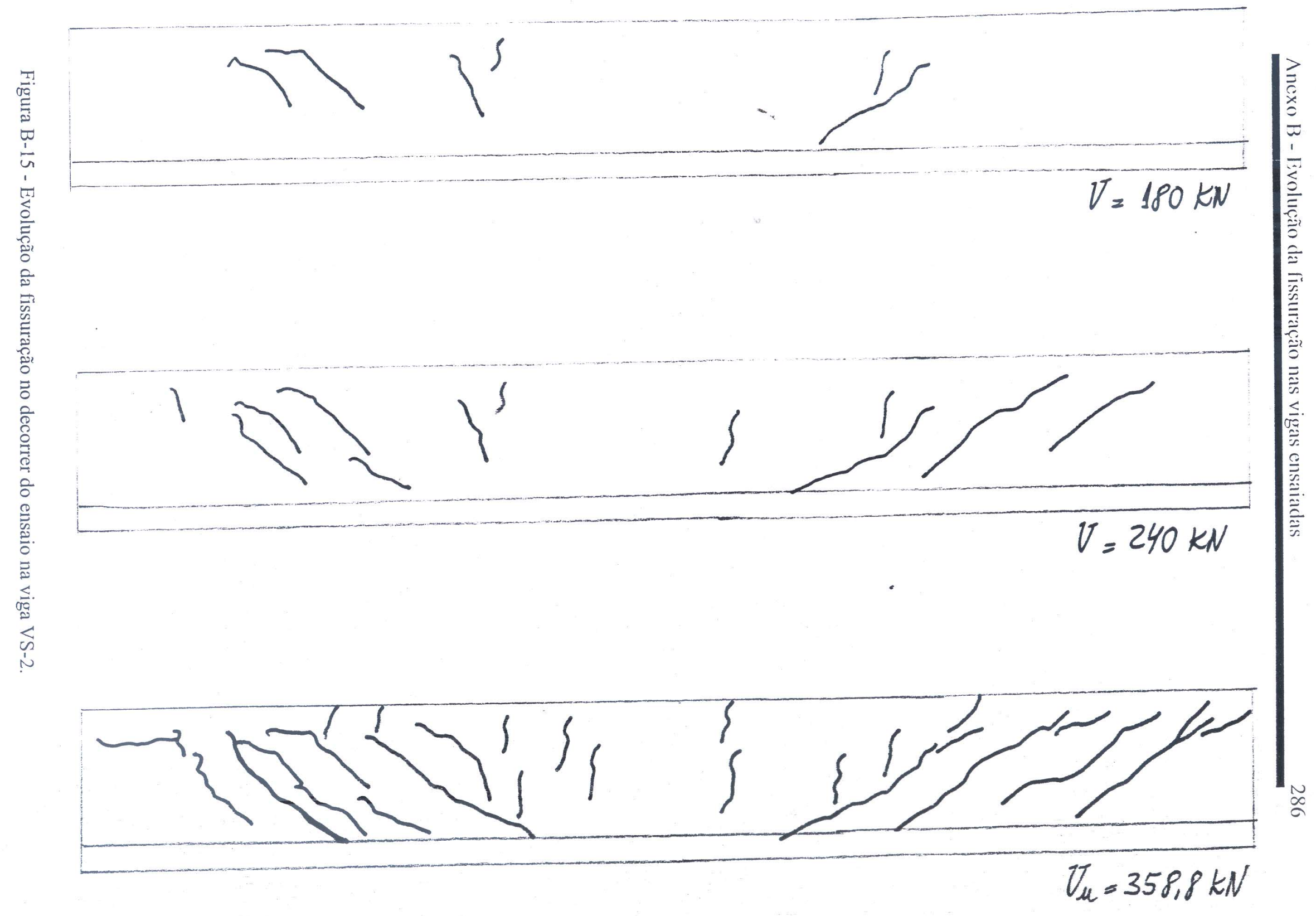




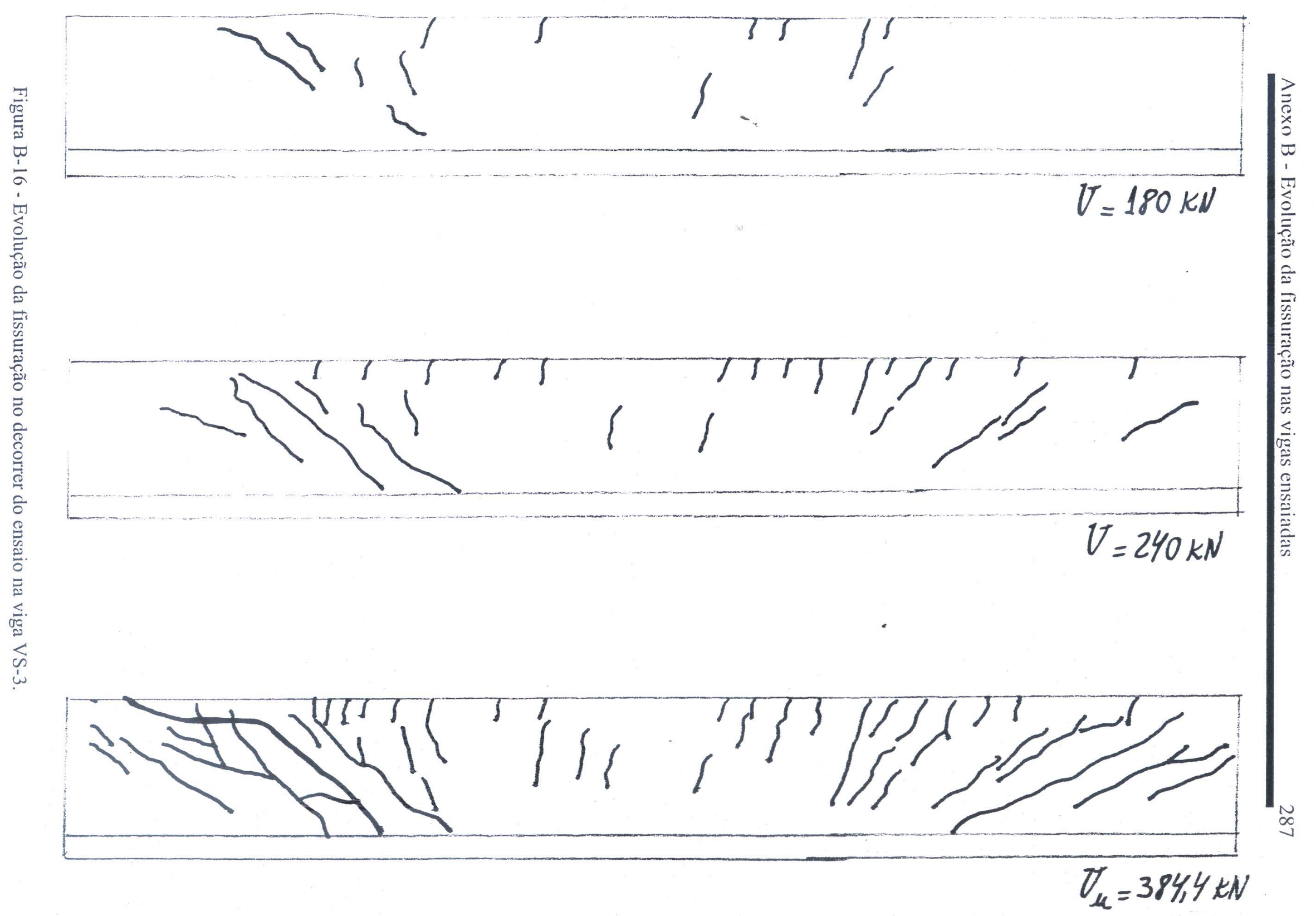




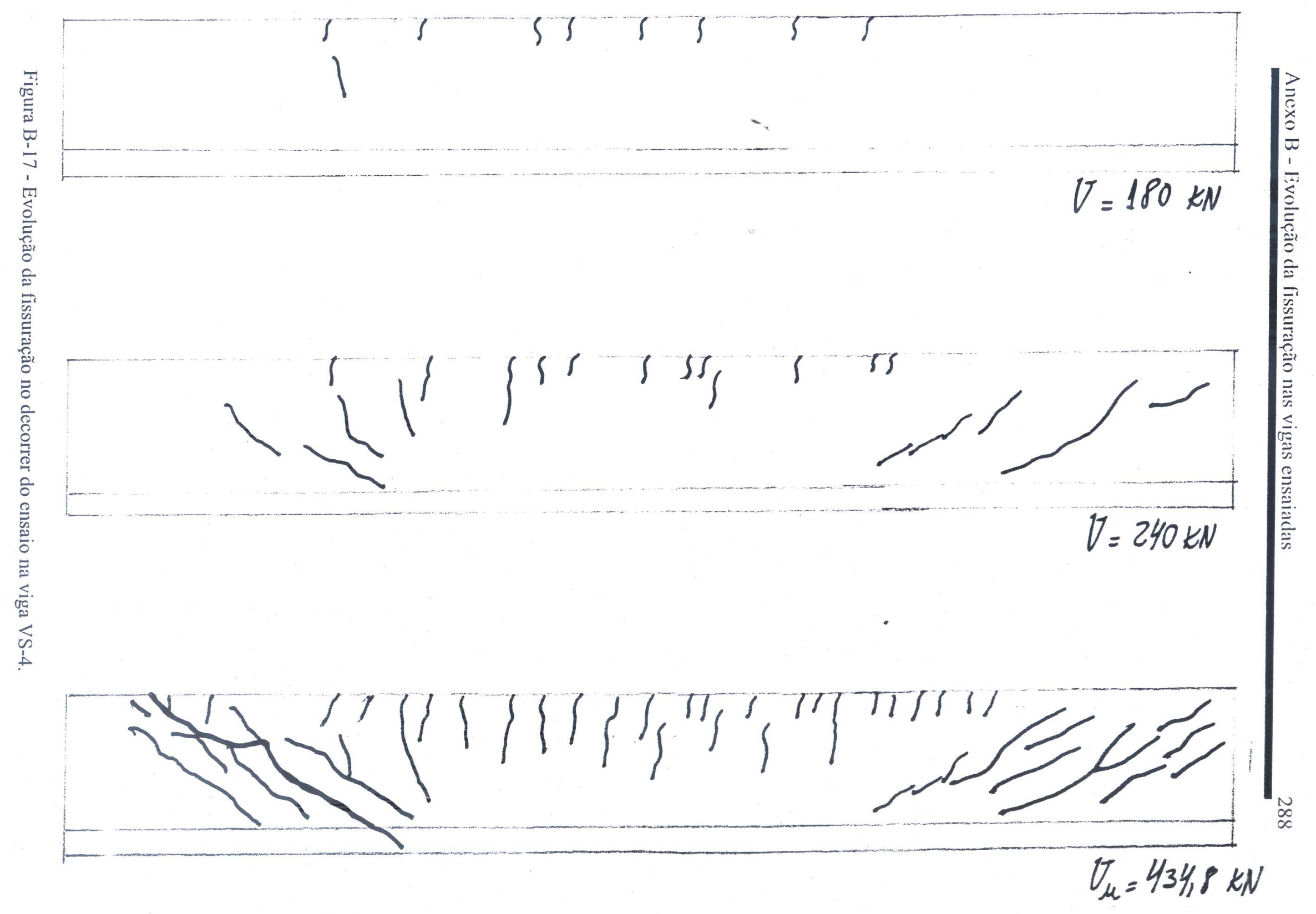




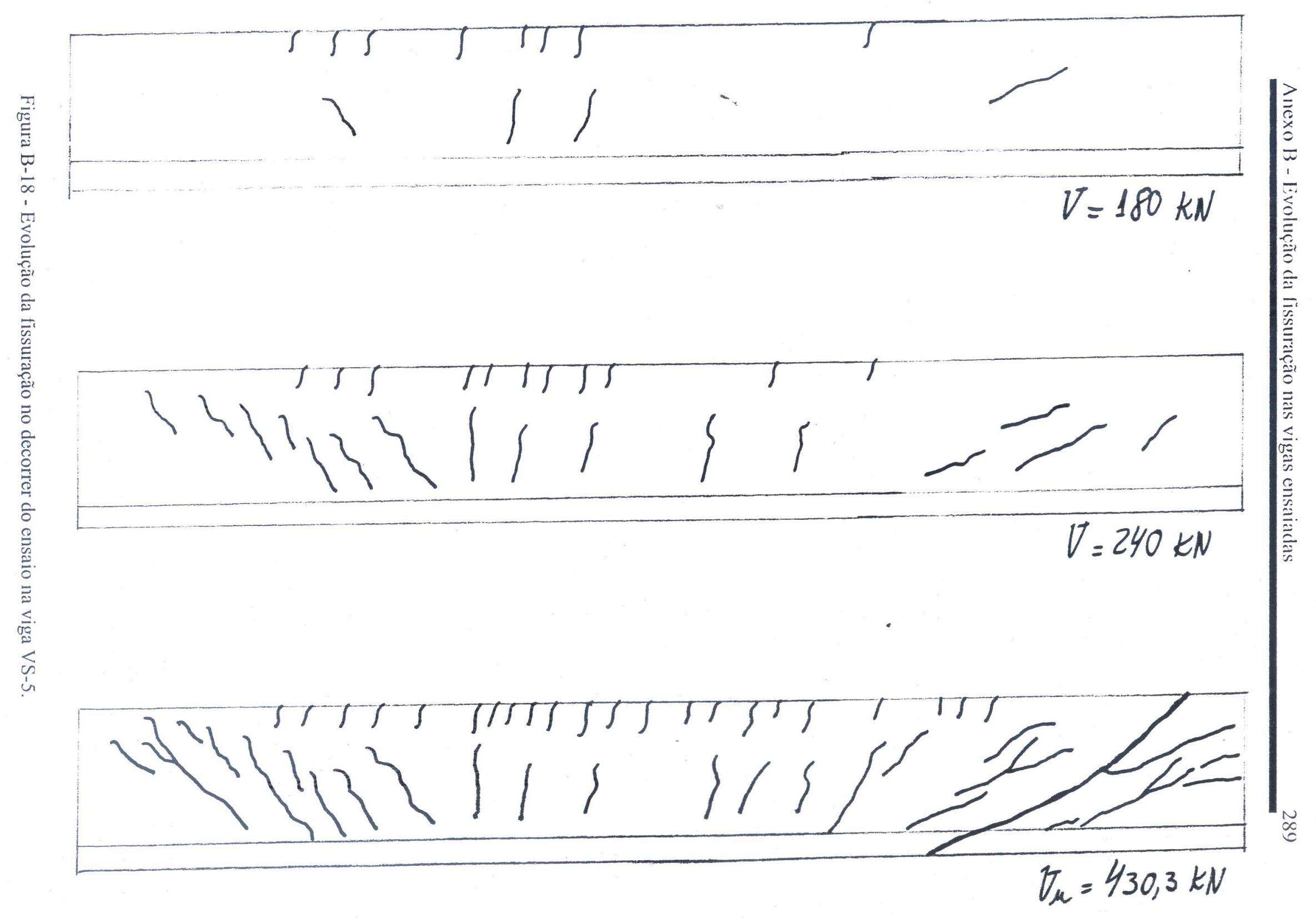




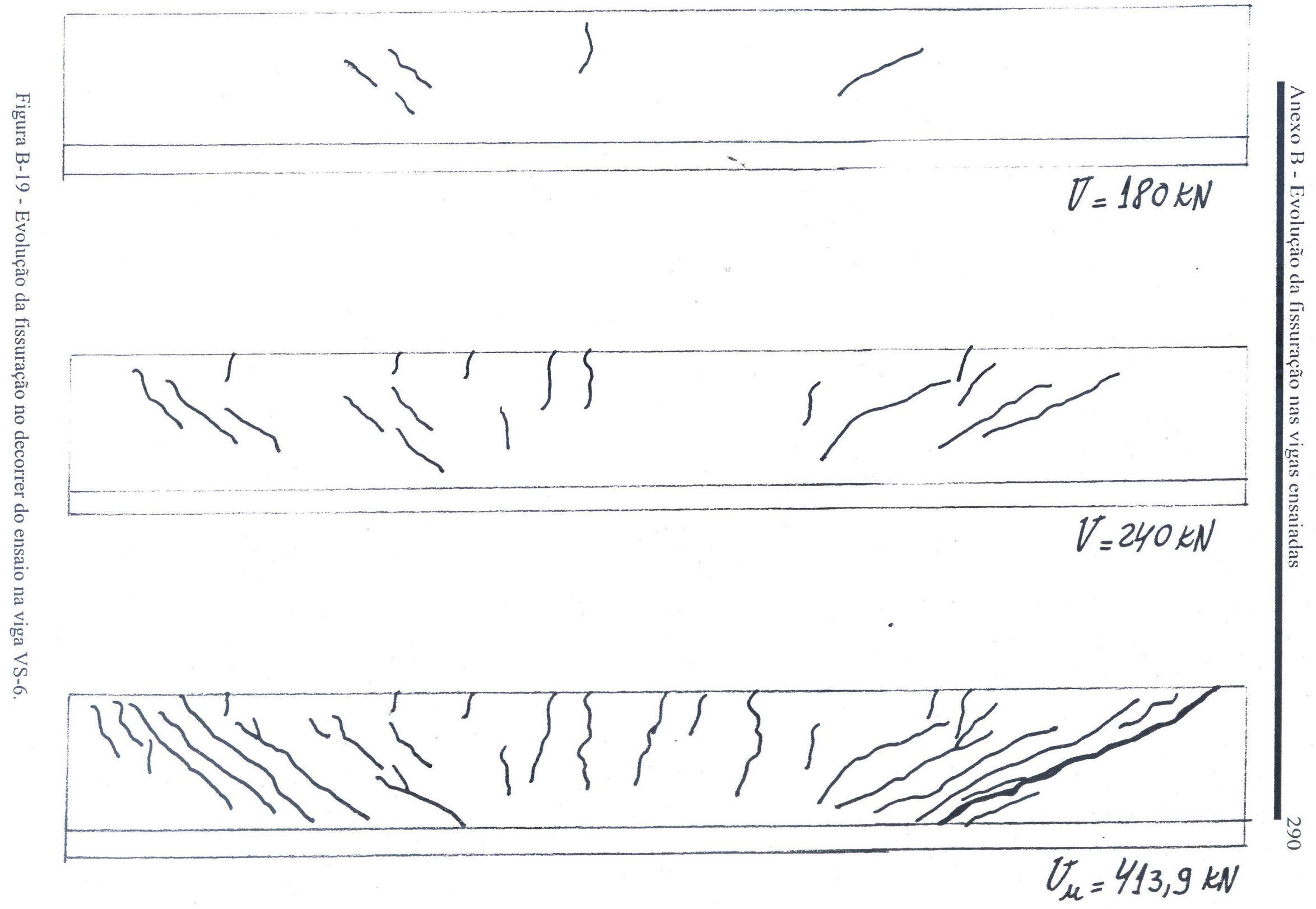


Tabela C-1 - Aberturas de fissuras na viga VQ-0.

\begin{tabular}{|c|c|c|c|c|c|c|c|}
\hline $\begin{array}{l}\text { VALOR } \\
\text { DE FISS } \\
\end{array}$ & $\begin{array}{l}\text { S DAS ABE } \\
\text { RAS (mm) }\end{array}$ & RAS & $\begin{array}{l}\text { NERVU } \\
\text { face infe }\end{array}$ & $\begin{array}{l}\text { ICIO } \\
\text { o 1) }\end{array}$ & & MODEI & \\
\hline Etapa & Força (kN) & A1 & $\mathrm{A} 2$ & B1 & B2 & $\mathrm{C} 2$ & $\mathrm{C} 1$ \\
\hline 0 & 0 & & & & & & \\
\hline 1 & -10 & & & & & & \\
\hline 2 & 0 & & & & & & \\
\hline 3 & 10 & & & & & & \\
\hline 4 & 20 & & & & & & \\
\hline 5 & 30 & & & & & & \\
\hline 6 & 40 & & 0,08 & 0,05 & & 0,05 & \\
\hline 7 & 50 & & 0,09 & 0,07 & & & \\
\hline 8 & 60 & & 0,10 & 0,08 & & & \\
\hline 9 & 70 & & 0,10 & 0,10 & & & \\
\hline 10 & 80 & & & & & & \\
\hline RUÍNA & 87 & & 0,10 & 0,10 & & 0,05 & \\
\hline
\end{tabular}

\begin{tabular}{|c|c|c|c|c|c|c|c|}
\hline $\begin{array}{l}\text { VALOR } \\
\text { DE FISS }\end{array}$ & $\begin{array}{l}\text { S DAS ABE } \\
\text { RAS (mm) }\end{array}$ & JRAS & $\begin{array}{l}\text { NERVU } \\
\text { face late }\end{array}$ & $\begin{array}{l}\mathrm{ACIO} \\
\text { 2) }\end{array}$ & & MODE & \\
\hline Etapa & Força $(\mathrm{kN})$ & A1 & $\mathrm{A} 2$ & B1 & B2 & $\mathrm{C} 2$ & $\mathrm{C} 1$ \\
\hline 0 & 0 & & & & & & \\
\hline 1 & -10 & & & & & & \\
\hline 2 & 0 & & & & & & \\
\hline 3 & 10 & & & & & & \\
\hline 4 & 20 & & & & & & \\
\hline 5 & 30 & & & & & & \\
\hline 6 & 40 & & & & & & \\
\hline 7 & 50 & & & & & & \\
\hline 8 & 60 & & & 0,06 & & 0,07 & \\
\hline 9 & 70 & & 0,07 & 0,08 & & 0,08 & \\
\hline 10 & 80 & & 0,08 & 0,08 & & & \\
\hline RUÍNA & 87 & & 0,08 & 0,09 & & 0,08 & \\
\hline
\end{tabular}

\begin{tabular}{|c|c|c|c|c|c|c|c|}
\hline \multicolumn{3}{|c|}{$\begin{array}{l}\text { VALORES DAS ABERTURAS } \\
\text { DE FISSURAS (mm) }\end{array}$} & \multicolumn{3}{|l|}{$\begin{array}{l}\text { ALMA } \\
\text { (eixo 3) }\end{array}$} & \multicolumn{2}{|c|}{ MODELO: VQ-0 } \\
\hline Etapa & Força $(\mathrm{kN})$ & A1 & A2 & B1 & $\mathrm{B} 2$ & $\mathrm{C} 2$ & $\mathrm{C} 1$ \\
\hline 0 & 0 & & & & & & \\
\hline 1 & -10 & & & & & & \\
\hline 2 & 0 & & & & & & \\
\hline 3 & 10 & & & & & & \\
\hline 4 & 20 & & & & & & \\
\hline 5 & 30 & & & & & & \\
\hline 6 & 40 & & & & & & \\
\hline 7 & 50 & & & & & & \\
\hline 8 & 60 & & & & & 0,06 & \\
\hline 9 & 70 & & 0,05 & & & 0,08 & \\
\hline 10 & 80 & & & & & & 0,30 \\
\hline RUÍNA & 87 & & $\mathbf{0 , 5 0}$ & & & 1,10 & \\
\hline
\end{tabular}


Tabela C-2 - Espaçamentos entre fissuras na viga VQ-0.

\begin{tabular}{|c|c|c|c|c|c|c|c|}
\hline \multicolumn{3}{|c|}{$\begin{array}{l}\text { ESPAÇAMENTO ENTRE } \\
\text { FISSURAS - valores médios }(\mathrm{mm})\end{array}$} & \multicolumn{3}{|c|}{$\begin{array}{l}\text { NERVURA TRACIONADA } \\
\text { face inferior (eixo 1) }\end{array}$} & \multicolumn{2}{|c|}{ MODELO: VQ-0 } \\
\hline Etapa & Força $(\mathrm{kN})$ & A1 & $\mathrm{A} 2$ & B1 & B2 & $\mathrm{C} 2$ & $\mathrm{C} 1$ \\
\hline 0 & 0 & & & & & & \\
\hline 1 & -10 & & & & & & \\
\hline 2 & 0 & & & & & & \\
\hline 3 & 10 & & & & & & \\
\hline 4 & 20 & & & & & & \\
\hline 5 & 30 & & & & & & \\
\hline 6 & 40 & & & & & & \\
\hline 7 & 50 & & & & & & \\
\hline 8 & 60 & & & & & & \\
\hline 9 & 70 & & & & & & \\
\hline 10 & 80 & & & & & & \\
\hline RUÍNA & 87 & & & & & & \\
\hline
\end{tabular}

\begin{tabular}{|c|c|c|c|c|c|c|c|}
\hline \multicolumn{3}{|c|}{$\begin{array}{l}\text { ESPAÇAMENTO ENTRE } \\
\text { FISSURAS - valores médios (mm) }\end{array}$} & \multicolumn{3}{|c|}{$\begin{array}{l}\text { NERVURA TRACIONADA } \\
\text { face lateral (eixo 2) }\end{array}$} & \multicolumn{2}{|c|}{ MODELO: VQ-0 } \\
\hline Etapa & Força $(\mathrm{kN})$ & A1 & A2 & B1 & B2 & $\mathrm{C} 2$ & $\mathrm{C} 1$ \\
\hline 0 & 0 & & & & & & \\
\hline 1 & -10 & & & & & & \\
\hline 2 & 0 & & & & & & \\
\hline 3 & 10 & & & & & & \\
\hline 4 & 20 & & & & & & \\
\hline 5 & 30 & & & & & & \\
\hline 6 & 40 & & & & & & \\
\hline 7 & 50 & & & & & & \\
\hline 8 & 60 & & & & & & \\
\hline 9 & 70 & & & & & & \\
\hline 10 & 80 & & & & & & \\
\hline RUÍNA & 87 & & & & & & \\
\hline
\end{tabular}

\begin{tabular}{|l|c|c|c|c|c|c|c|}
\hline $\begin{array}{l}\text { ESPAÇAMENTO ENTRE } \\
\text { FISSURAS - valores médios (mm) }\end{array}$ & $\begin{array}{l}\text { ALMA } \\
\text { (eixo 3) }\end{array}$ & \multicolumn{2}{l|}{ MODELO: VQ-0 } \\
\hline Etapa & Força (kN) & A1 & A2 & B1 & B2 & C2 & C1 \\
\hline 0 & 0 & & & & & & \\
\hline 1 & -10 & & & & & & \\
\hline 2 & 0 & & & & & & \\
\hline 3 & 10 & & & & & & \\
\hline 4 & 20 & & & & & & \\
\hline 5 & 30 & & & & & & \\
\hline 6 & 40 & & & & & & \\
\hline 7 & 50 & & & & & & \\
\hline 8 & 60 & & & & & & \\
\hline 9 & 70 & & & & & & \\
\hline 10 & 80 & & & & & & \\
\hline RUínA & $\mathbf{8 7}$ & & & & & & \\
\hline
\end{tabular}


Tabela C-3 - Aberturas de fissuras na viga VQ-1.

\begin{tabular}{|c|c|c|c|c|c|c|c|}
\hline \multicolumn{3}{|c|}{$\begin{array}{l}\text { VALORES DAS ABERTURAS } \\
\text { DE FISSURAS (mm) }\end{array}$} & \multicolumn{3}{|c|}{$\begin{array}{l}\text { NERVURA TRACIONADA } \\
\text { face inferior (eixo 1) }\end{array}$} & \multicolumn{2}{|c|}{ MODELO: VQ-1 } \\
\hline Etapa & Força $(\mathrm{kN})$ & A1 & $\mathrm{A} 2$ & B1 & B2 & $\mathrm{C} 2$ & $\mathrm{C} 1$ \\
\hline \multicolumn{8}{|l|}{0} \\
\hline 1 & 45 & & & & 0,04 & & \\
\hline 2 & 60 & & & & 0,04 & & \\
\hline 3 & 75 & & 0,03 & 0,04 & 0,05 & 0,05 & \\
\hline 4 & 90 & & 0,06 & 0,05 & 0,06 & 0,07 & \\
\hline 5 & 105 & & 0,06 & 0,07 & 0,07 & 0,05 & \\
\hline 6 & 120 & & 0,06 & 0,07 & 0,07 & 0,05 & \\
\hline 7 & 135 & 0,10 & 0,08 & 0,09 & 0,08 & 0,08 & 0,11 \\
\hline 8 & 150 & 0,10 & 0,13 & 0,13 & 0,15 & 0,10 & 0,13 \\
\hline 9 & 165 & 0,10 & 0,13 & 0,16 & 0,15 & 0,10 & 0,13 \\
\hline 10 & 180 & 0,10 & 0,13 & 0,18 & 0,17 & 0,10 & 0,13 \\
\hline RUÍNA & 196,5 & 0,10 & 0,13 & 0,20 & 0,18 & 0,10 & 0,13 \\
\hline
\end{tabular}

\begin{tabular}{|c|c|c|c|c|c|c|c|}
\hline \multicolumn{3}{|c|}{$\begin{array}{l}\text { VALORES DAS ABERTURAS } \\
\text { DE FISSURAS }(\mathrm{mm})\end{array}$} & \multicolumn{3}{|c|}{$\begin{array}{l}\text { NERVURA TRACIONADA } \\
\text { face lateral (eixo 2) }\end{array}$} & \multicolumn{2}{|c|}{ MODELO: VQ-1 } \\
\hline Etapa & Força $(\mathrm{kN})$ & A1 & A2 & B1 & B2 & $\mathrm{C} 2$ & $\mathrm{C} 1$ \\
\hline \multicolumn{8}{|l|}{0} \\
\hline 1 & 45 & & & & & & \\
\hline 2 & 60 & & & & & & \\
\hline 3 & 75 & & & & 0,05 & 0,04 & \\
\hline 4 & 90 & & & 0,06 & 0,05 & 0,09 & 0,09 \\
\hline 5 & 105 & & & 0,07 & 0,06 & 0,10 & 0,10 \\
\hline 6 & 120 & & & 0,07 & 0,06 & 0,10 & 0,10 \\
\hline 7 & 135 & & & 0,07 & 0,06 & 0,10 & 0,10 \\
\hline 8 & 150 & & & 0,07 & 0,09 & 0,10 & 0,10 \\
\hline 9 & 165 & & & 0,08 & 0,10 & 0,10 & 0,10 \\
\hline 10 & 180 & & & & & & \\
\hline RUÍNA & 196,5 & & & 0,08 & 0,10 & 0,10 & 0,10 \\
\hline
\end{tabular}

\begin{tabular}{|c|c|c|c|c|c|c|c|}
\hline \multicolumn{3}{|c|}{$\begin{array}{l}\text { VALORES DAS ABERTURAS } \\
\text { DE FISSURAS (mm) }\end{array}$} & \multicolumn{3}{|l|}{$\begin{array}{l}\text { ALMA } \\
\text { (eixo 3) }\end{array}$} & \multicolumn{2}{|c|}{ MODELO: VQ-1 } \\
\hline Etapa & Força $(\mathrm{kN})$ & A1 & A2 & B1 & B2 & $\mathrm{C} 2$ & $\mathrm{C} 1$ \\
\hline \multicolumn{8}{|l|}{0} \\
\hline 1 & 45 & & & & & & \\
\hline 2 & 60 & & 0,04 & & 0,04 & & \\
\hline 3 & 75 & & 0,06 & 0,04 & 0,04 & & \\
\hline 4 & 90 & 0,08 & 0,10 & 0,04 & 0,04 & 0,16 & \\
\hline 5 & 105 & 0,25 & 0,15 & 0,04 & 0,05 & 0,16 & 0,25 \\
\hline 6 & 120 & 0,30 & 0,15 & 0,05 & 0,05 & 0,20 & 0,30 \\
\hline 7 & 135 & 0,40 & 0,20 & 0,05 & 0,05 & 0,25 & 0,45 \\
\hline 8 & 150 & 0,55 & 0,30 & & & 0,25 & 0,55 \\
\hline 9 & 165 & 0,65 & 0,35 & 0,12 & & 0,45 & 0,65 \\
\hline 10 & 180 & 0,80 & 0,45 & & & 0,45 & 0,80 \\
\hline RUÍNA & 196,5 & $\mathbf{0 , 8 0}$ & $\mathbf{0 , 5 0}$ & 0,12 & 0,12 & $\mathbf{0 , 5 0}$ & $\mathbf{0 , 8 0}$ \\
\hline
\end{tabular}


Tabela C-4 - Espaçamentos entre fissuras na viga VQ-1.

\begin{tabular}{|c|c|c|c|c|c|c|c|}
\hline \multicolumn{3}{|c|}{$\begin{array}{l}\text { ESPAÇAMENTO ENTRE } \\
\text { FISSURAS - valores médios }(\mathrm{mm})\end{array}$} & \multicolumn{3}{|c|}{$\begin{array}{l}\text { NERVURA TRACIONADA } \\
\text { face inferior (eixo 1) }\end{array}$} & \multicolumn{2}{|c|}{ MODELO: VQ-1 } \\
\hline Etapa & Força (kN) & A1 & A2 & B1 & B2 & $\mathrm{C} 2$ & $\mathrm{C} 1$ \\
\hline \multicolumn{8}{|l|}{0} \\
\hline 1 & 45 & & & & & & \\
\hline 2 & 60 & & & & & & \\
\hline 3 & 75 & & 430 & 190 & 260 & & \\
\hline 4 & 90 & & 190 & 210 & 260 & 160 & \\
\hline 5 & 105 & & 190 & 90 & 115 & 100 & \\
\hline 6 & 120 & & 190 & 90 & 115 & 100 & \\
\hline 7 & 135 & 240 & 190 & 90 & 115 & 90 & 90 \\
\hline 8 & 150 & 60 & 190 & 80 & 115 & 90 & 90 \\
\hline 9 & 165 & & & & & & \\
\hline 10 & 180 & & & & & & \\
\hline RUÍNA & 196,5 & 60 & 190 & 80 & 115 & 90 & 90 \\
\hline
\end{tabular}

\begin{tabular}{|c|c|c|c|c|c|c|c|}
\hline \multicolumn{3}{|c|}{$\begin{array}{l}\text { ESPAÇAMENTO ENTRE } \\
\text { FISSURAS - valores médios }(\mathrm{mm})\end{array}$} & \multicolumn{3}{|c|}{$\begin{array}{l}\text { NERVURA TRACIONADA } \\
\text { face lateral (eixo 2) }\end{array}$} & \multicolumn{2}{|c|}{ MODELO: VQ-1 } \\
\hline Etapa & Força $(\mathrm{kN})$ & A1 & $\mathrm{A} 2$ & B1 & B2 & $\mathrm{C} 2$ & $\mathrm{C} 1$ \\
\hline \multicolumn{8}{|l|}{0} \\
\hline 1 & 45 & & & & & & \\
\hline 2 & 60 & & & & & & \\
\hline 3 & 75 & & & & & & \\
\hline 4 & 90 & & & & & & \\
\hline 5 & 105 & & & & & & \\
\hline 6 & 120 & & & & & & \\
\hline 7 & 135 & & & & & & \\
\hline 8 & 150 & & & & & & \\
\hline 9 & 165 & & & & & & \\
\hline 10 & 180 & & & & & & \\
\hline RUÍNA & 196,5 & & & & & & \\
\hline
\end{tabular}

\begin{tabular}{|c|c|c|c|c|c|c|c|}
\hline \multicolumn{3}{|c|}{$\begin{array}{l}\text { ESPAÇAMENTO ENTRE } \\
\text { FISSURAS - valores médios (mm) }\end{array}$} & \multicolumn{3}{|l|}{$\begin{array}{l}\text { ALMA } \\
\text { (eixo 3) }\end{array}$} & \multicolumn{2}{|c|}{ MODELO: VQ-1 } \\
\hline Etapa & Força $(\mathrm{kN})$ & A1 & A2 & B1 & B2 & $\mathrm{C} 2$ & $\mathrm{C} 1$ \\
\hline \multicolumn{8}{|l|}{0} \\
\hline 1 & 45 & & & & & & \\
\hline 2 & 60 & & & & & & \\
\hline 3 & 75 & & 180 & 120 & 330 & & \\
\hline 4 & 90 & 200 & 200 & 120 & 330 & 150 & \\
\hline 5 & 105 & 200 & 200 & 100 & 330 & 150 & 140 \\
\hline 6 & 120 & 150 & 200 & 100 & 330 & 150 & 140 \\
\hline 7 & 135 & 90 & 180 & 100 & 320 & 150 & 70 \\
\hline 8 & 150 & 90 & 180 & 100 & 120 & 150 & 70 \\
\hline 9 & 165 & 90 & 150 & 100 & 120 & 150 & 70 \\
\hline 10 & 180 & & & & & & \\
\hline RUÍNA & 196,5 & 90 & 150 & 100 & 120 & 150 & 70 \\
\hline
\end{tabular}


Tabela C-5 - Aberturas de fissuras na viga VQ-2.

\begin{tabular}{|c|c|c|c|c|c|c|c|}
\hline \multicolumn{3}{|c|}{$\begin{array}{l}\text { VALORES DAS ABERTURAS DE } \\
\text { FISSURAS (mm) }\end{array}$} & \multicolumn{3}{|c|}{$\begin{array}{l}\text { NERVURA TRACIONADA } \\
\text { face inferior (eixo 1) }\end{array}$} & \multicolumn{2}{|c|}{ MODELO: VQ-2 } \\
\hline Etapa & Força $(\mathrm{kN})$ & A1 & $\mathrm{A} 2$ & B1 & B2 & $\mathrm{C} 2$ & $\mathrm{C} 1$ \\
\hline \multicolumn{8}{|l|}{0} \\
\hline 1 & 45 & & & & & & \\
\hline 2 & 60 & & & 0,05 & 0,06 & 0,04 & \\
\hline 3 & 75 & & 0,07 & 0,05 & 0,08 & 0,04 & \\
\hline 4 & 90 & & 0,08 & 0,06 & 0,08 & 0,05 & \\
\hline 5 & 105 & & 0,08 & 0,06 & 0,08 & 0,07 & \\
\hline 6 & 120 & & 0,08 & 0,07 & 0,09 & 0,07 & \\
\hline 7 & 135 & & 0,08 & 0,09 & 0,11 & 0,08 & \\
\hline 8 & 150 & & 0,10 & 0,09 & 0,13 & 0,10 & \\
\hline 9 & 165 & & 0,10 & 0,10 & 0,15 & 0,10 & \\
\hline 10 & 180 & & 0,13 & 0,12 & 0,16 & 0,10 & \\
\hline RUÍNA & 196,8 & & $\overline{0,13}$ & 0,12 & 0,16 & 0,10 & \\
\hline
\end{tabular}

\begin{tabular}{|c|c|c|c|c|c|c|c|}
\hline \multicolumn{3}{|c|}{$\begin{array}{l}\text { VALORES DAS ABERTURAS DE } \\
\text { FISSURAS (mm) }\end{array}$} & \multicolumn{3}{|c|}{$\begin{array}{l}\text { NERVURA TRACIONADA } \\
\text { face lateral (eixo 2) }\end{array}$} & \multicolumn{2}{|c|}{ MODELO: VQ-2 } \\
\hline Etapa & Força $(\mathrm{kN})$ & A1 & $\mathrm{A} 2$ & B1 & B2 & $\mathrm{C} 2$ & $\mathrm{C} 1$ \\
\hline \multicolumn{8}{|c|}{ ב } \\
\hline 1 & 45 & & & & & & \\
\hline 2 & 60 & & & & 0,06 & & \\
\hline 3 & 75 & & 0,06 & & 0,07 & & \\
\hline 4 & 90 & & 0,08 & 0,06 & & & \\
\hline 5 & 105 & & & & & & \\
\hline 6 & 120 & & & & & & \\
\hline 7 & 135 & & & & & & \\
\hline 8 & 150 & & & & & & \\
\hline 9 & 165 & & & & & & \\
\hline 10 & 180 & & & & & & \\
\hline RUÍNA & 196,8 & & & & & & \\
\hline
\end{tabular}

\begin{tabular}{|c|c|c|c|c|c|c|c|}
\hline \multicolumn{3}{|c|}{$\begin{array}{l}\text { VALORES DAS ABERTURAS DE } \\
\text { FISSURAS (mm) }\end{array}$} & \multicolumn{3}{|l|}{$\begin{array}{l}\text { ALMA } \\
\text { (eixo 3) }\end{array}$} & \multicolumn{2}{|c|}{ MODELO: VQ-2 } \\
\hline Etapa & Força $(\mathrm{kN})$ & A1 & A2 & B1 & B2 & $\mathrm{C} 2$ & $\mathrm{C} 1$ \\
\hline \multicolumn{8}{|l|}{0} \\
\hline 1 & 45 & & & & & & \\
\hline 2 & 60 & & & & & & \\
\hline 3 & 75 & & 0,05 & 0,03 & 0,03 & & \\
\hline 4 & 90 & & 0,07 & 0,09 & 0,06 & 0,08 & 0,10 \\
\hline 5 & 105 & 0,16 & 0,07 & 0,06 & 0,09 & 0,15 & 0,16 \\
\hline 6 & 120 & 0,30 & 0,09 & 0,07 & 0,10 & 0,15 & 0,30 \\
\hline 7 & 135 & 0,35 & 0,09 & 0,08 & 0,07 & 0,10 & 0,40 \\
\hline 8 & 150 & 0,55 & 0,09 & 0,08 & 0,10 & 0,20 & 0,55 \\
\hline 9 & 165 & 0,70 & 0,10 & 0,08 & 0,09 & 0,25 & 0,70 \\
\hline 10 & 180 & 1,20 & 0,16 & 0,09 & 0,10 & 0,30 & 1,00 \\
\hline RUÍNA & 196,8 & 1,20 & 0,25 & 0,09 & 0,15 & 0,40 & 1,40 \\
\hline
\end{tabular}


Tabela C-6 - Espaçamentos entre fissuras na viga VQ-2.

\begin{tabular}{|c|c|c|c|c|c|c|c|}
\hline \multicolumn{3}{|c|}{$\begin{array}{l}\text { ESPAÇAMENTO ENTRE } \\
\text { FISSURAS - valores médios (mm) }\end{array}$} & \multicolumn{3}{|c|}{$\begin{array}{l}\text { NERVURA TRACIONADA } \\
\text { face inferior (eixo 1) }\end{array}$} & \multicolumn{2}{|c|}{ MODELO: VQ-2 } \\
\hline Etapa & Força $(\mathrm{kN})$ & $\mathrm{A} 1$ & $\mathrm{~A} 2$ & B1 & B2 & $\mathrm{C} 2$ & $\mathrm{C} 1$ \\
\hline \multicolumn{8}{|l|}{0} \\
\hline 1 & 45 & & & & & & \\
\hline 2 & 60 & & & & & & \\
\hline 3 & 75 & & 185 & 190 & 115 & & \\
\hline 4 & 90 & & 185 & 190 & 115 & & \\
\hline 5 & 105 & & 150 & 135 & 115 & & \\
\hline 6 & 120 & & 130 & 100 & 115 & & \\
\hline 7 & 135 & & & & & & \\
\hline 8 & 150 & & & & & & \\
\hline 9 & 165 & & & & & & \\
\hline 10 & 180 & & & & & & \\
\hline RUÍNA & 196,8 & & 130 & 100 & 115 & & \\
\hline
\end{tabular}

\begin{tabular}{|c|c|c|c|c|c|c|c|}
\hline \multicolumn{3}{|c|}{$\begin{array}{l}\text { ESPAÇAMENTO ENTRE } \\
\text { FISSURAS - valores médios (mm) }\end{array}$} & \multicolumn{3}{|c|}{$\begin{array}{l}\text { NERVURA TRACIONADA } \\
\text { face lateral (eixo 2) }\end{array}$} & \multicolumn{2}{|c|}{ MODELO: VQ-2 } \\
\hline Etapa & Força $(\mathrm{kN})$ & $\mathrm{A} 1$ & A2 & B1 & B2 & $\mathrm{C} 2$ & $\mathrm{C} 1$ \\
\hline \multicolumn{8}{|c|}{ 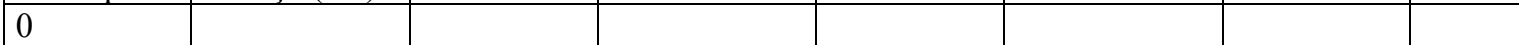 } \\
\hline 1 & 45 & & & & & & \\
\hline 2 & 60 & & & & & & \\
\hline 3 & 75 & & & & & & \\
\hline 4 & 90 & & & & & & \\
\hline 5 & 105 & & & & & & \\
\hline 6 & 120 & & & & & & \\
\hline 7 & 135 & & & & & & \\
\hline 8 & 150 & & & & & & \\
\hline 9 & 165 & & & & & & \\
\hline 10 & 180 & & & & & & \\
\hline RUÍNA & 196,8 & & & & & & \\
\hline
\end{tabular}

\begin{tabular}{|c|c|c|c|c|c|c|c|}
\hline \multicolumn{3}{|c|}{$\begin{array}{l}\text { ESPAÇAMENTO ENTRE } \\
\text { FISSURAS - valores médios (mm) }\end{array}$} & \multicolumn{3}{|l|}{$\begin{array}{l}\text { ALMA } \\
\text { (eixo 3) }\end{array}$} & \multicolumn{2}{|c|}{ MODELO: VQ-2 } \\
\hline Etapa & Força $(\mathrm{kN})$ & A1 & A2 & B1 & B2 & $\mathrm{C} 2$ & $\mathrm{C} 1$ \\
\hline \multicolumn{8}{|l|}{0} \\
\hline 1 & 45 & & & & & & \\
\hline 2 & 60 & & & & & & \\
\hline 3 & 75 & & & & & & \\
\hline 4 & 90 & & & & & & \\
\hline 5 & 105 & & & & & & \\
\hline 6 & 120 & 100 & 135 & 145 & 165 & 110 & \\
\hline 7 & 135 & 100 & 135 & 145 & 165 & 110 & \\
\hline 8 & 150 & 100 & 90 & 145 & 165 & 110 & \\
\hline 9 & 165 & 100 & 90 & 145 & 165 & 110 & \\
\hline 10 & 180 & 100 & 90 & 145 & 165 & 110 & 120 \\
\hline RUÍNA & 196,8 & 100 & 90 & 145 & 165 & 110 & 120 \\
\hline
\end{tabular}


Tabela C-7 - Aberturas de fissuras na viga VQ-3.

\begin{tabular}{|c|c|c|c|c|c|c|c|}
\hline \multicolumn{3}{|c|}{$\begin{array}{l}\text { VALORES DAS ABERTURAS } \\
\text { DE FISSURAS (mm) }\end{array}$} & \multicolumn{3}{|c|}{$\begin{array}{l}\text { NERVURA TRACIONADA } \\
\text { face inferior (eixo 1) }\end{array}$} & \multicolumn{2}{|c|}{ MODELO: VQ-3 } \\
\hline Etapa & Força $(\mathrm{kN})$ & A1 & A2 & B1 & B2 & $\mathrm{C} 2$ & $\mathrm{C} 1$ \\
\hline \multicolumn{8}{|l|}{0} \\
\hline 1 & 45 & & & & & & \\
\hline 2 & 60 & & & & & & \\
\hline 3 & 75 & & 0,05 & & 0,07 & 0,05 & \\
\hline 4 & 90 & & 0,07 & 0,06 & 0,07 & 0,05 & \\
\hline 5 & 105 & & 0,07 & 0,06 & 0,08 & 0,06 & \\
\hline 6 & 120 & 0,08 & 0,08 & 0,07 & 0,08 & 0,07 & 0,08 \\
\hline 7 & 135 & 0,08 & 0,09 & 0,09 & 0,08 & 0,09 & 0,08 \\
\hline 8 & 150 & 0,10 & 0,09 & 0,09 & 0,10 & 0,09 & 0,08 \\
\hline 9 & 165 & 0,15 & 0,12 & 0,13 & 0,12 & 0,09 & 0,13 \\
\hline 10 & 180 & 0,15 & 0,16 & 0,15 & 0,13 & 0,15 & 0,14 \\
\hline RUÍNA & 209,1 & 0,15 & 0,16 & 0,11 & 0,13 & 0,10 & 0,16 \\
\hline
\end{tabular}

\begin{tabular}{|c|c|c|c|c|c|c|c|}
\hline \multicolumn{3}{|c|}{$\begin{array}{l}\text { VALORES DAS ABERTURAS } \\
\text { DE FISSURAS (mm) }\end{array}$} & \multicolumn{3}{|c|}{$\begin{array}{l}\text { NERVURA TRACIONADA } \\
\text { face lateral (eixo 2) }\end{array}$} & \multicolumn{2}{|c|}{ MODELO: VQ-3 } \\
\hline Etapa & Força $(\mathrm{kN})$ & A1 & $\mathrm{A} 2$ & B1 & B2 & $\mathrm{C} 2$ & $\mathrm{C} 1$ \\
\hline \multicolumn{8}{|l|}{0} \\
\hline 1 & 45 & & & & & & \\
\hline 2 & 60 & & & & & & \\
\hline 3 & 75 & & 0,07 & 0,03 & 0,04 & & \\
\hline 4 & 90 & & & 0,06 & 0,07 & & \\
\hline 5 & 105 & & & & & & \\
\hline 6 & 120 & & & & & & \\
\hline 7 & 135 & & & & & & \\
\hline 8 & 150 & 0,05 & & & & & \\
\hline 9 & 165 & & & & & & \\
\hline 10 & 180 & & & & & & \\
\hline RUÍNA & 209,1 & & & & & & \\
\hline
\end{tabular}

\begin{tabular}{|c|c|c|c|c|c|c|c|}
\hline \multicolumn{3}{|c|}{$\begin{array}{l}\text { VALORES DAS ABERTURAS } \\
\text { DE FISSURAS }(\mathrm{mm}) \\
\end{array}$} & \multicolumn{3}{|l|}{$\begin{array}{l}\text { ALMA } \\
\text { (eixo 3) }\end{array}$} & \multicolumn{2}{|c|}{ MODELO: VQ-3 } \\
\hline Etapa & Força $(\mathrm{kN})$ & A1 & A2 & B1 & B2 & $\mathrm{C} 2$ & $\mathrm{C} 1$ \\
\hline \multicolumn{8}{|l|}{0} \\
\hline 1 & 45 & & & & & & \\
\hline 2 & 60 & & & & & & \\
\hline 3 & 75 & & 0,05 & 0,06 & 0,06 & & \\
\hline 4 & 90 & & 0,05 & 0,06 & 0,07 & 0,06 & 0,08 \\
\hline 5 & 105 & 0,12 & 0,07 & 0,06 & 0,07 & 0,07 & 0,12 \\
\hline 6 & 120 & 0,16 & 0,07 & 0,06 & 0,08 & 0,12 & 0,16 \\
\hline 7 & 135 & 0,25 & 0,20 & 0,08 & 0,09 & 0,16 & 0,25 \\
\hline 8 & 150 & 0,25 & 0,25 & 0,10 & 0,08 & 0,16 & 0,25 \\
\hline 9 & 165 & 0,30 & 0,30 & 0,10 & 0,09 & 0,20 & 0,30 \\
\hline 10 & 180 & 0,35 & 0,40 & 0,10 & 0,11 & 0,25 & 0,35 \\
\hline RUÍNA & 209,1 & 0,40 & $\mathbf{0 , 5 0}$ & $\mathbf{0 , 1 0}$ & $\mathbf{0 , 1 0}$ & $\mathbf{0 , 5 0}$ & $\mathbf{0 , 5 5}$ \\
\hline
\end{tabular}


Tabela C-8 - Espaçamentos entre fissuras na viga VQ-3.

\begin{tabular}{|c|c|c|c|c|c|c|c|}
\hline \multicolumn{3}{|c|}{$\begin{array}{l}\text { ESPAÇAMENTO ENTRE } \\
\text { FISSURAS - valores médios }(\mathrm{mm})\end{array}$} & \multicolumn{3}{|c|}{$\begin{array}{l}\text { NERVURA TRACIONADA } \\
\text { face inferior (eixo 1) }\end{array}$} & \multicolumn{2}{|c|}{ MODELO: VQ-3 } \\
\hline Etapa & Força (kN) & A1 & A2 & B1 & B2 & $\mathrm{C} 2$ & $\mathrm{C} 1$ \\
\hline \multicolumn{8}{|l|}{0} \\
\hline 1 & 45 & & & & & & \\
\hline 2 & 60 & & & & & & \\
\hline 3 & 75 & & & & & & \\
\hline 4 & 90 & & 100 & 80 & 85 & 80 & \\
\hline 5 & 105 & & & & & & \\
\hline 6 & 120 & & 96 & 80 & 78 & 68 & 195 \\
\hline 7 & 135 & & & & & & \\
\hline 8 & 150 & 100 & 96 & 68 & 55 & 64 & 71 \\
\hline 9 & 165 & & & & & & \\
\hline 10 & 180 & 100 & 96 & 68 & 55 & 64 & 71 \\
\hline RUÍNA & 209,1 & 100 & 96 & 68 & 55 & 64 & 71 \\
\hline
\end{tabular}

\begin{tabular}{|c|c|c|c|c|c|c|c|}
\hline \multicolumn{3}{|c|}{$\begin{array}{l}\text { ESPAÇAMENTO ENTRE } \\
\text { FISSURAS - valores médios (mm) }\end{array}$} & \multicolumn{3}{|c|}{$\begin{array}{l}\text { NERVURA TRACIONADA } \\
\text { face lateral (eixo 2) }\end{array}$} & \multicolumn{2}{|c|}{ MODELO: VQ-3 } \\
\hline Etapa & Força $(\mathrm{kN})$ & A1 & A2 & B1 & B2 & $\mathrm{C} 2$ & $\mathrm{C} 1$ \\
\hline \multicolumn{8}{|l|}{0} \\
\hline 1 & 45 & & & & & & \\
\hline 2 & 60 & & & & & & \\
\hline 3 & 75 & & & & & & \\
\hline 4 & 90 & & & & & & \\
\hline 5 & 105 & & & & & & \\
\hline 6 & 120 & & & & & & \\
\hline 7 & 135 & & & & & & \\
\hline 8 & 150 & & & & & & \\
\hline 9 & 165 & & & & & & \\
\hline 10 & 180 & & & & & & \\
\hline RUÍNA & 209,1 & & & & & & \\
\hline
\end{tabular}

\begin{tabular}{|c|c|c|c|c|c|c|c|}
\hline $\begin{array}{l}\text { ESPAÇ } \\
\text { FISSUR }\end{array}$ & $\begin{array}{l}\text { MENTO EN } \\
\text { S - valores n }\end{array}$ & os $(\mathrm{mm})$ & $\begin{array}{l}\text { ALMA } \\
\text { (eixo 3) }\end{array}$ & & & MODEI & \\
\hline Etapa & Força $(\mathrm{kN})$ & A1 & A2 & B1 & B2 & $\mathrm{C} 2$ & $\mathrm{C} 1$ \\
\hline 0 & & & & & & & \\
\hline 1 & 45 & & & & & & \\
\hline 2 & 60 & & & & & & \\
\hline 3 & 75 & & 175 & & & & \\
\hline 4 & 90 & & 130 & 200 & 120 & 230 & 160 \\
\hline 5 & 105 & & & & & & \\
\hline 6 & 120 & 115 & 120 & 190 & 108 & 120 & 160 \\
\hline 7 & 135 & & & & & & \\
\hline 8 & 150 & 115 & 120 & 110 & 103 & 90 & 140 \\
\hline 9 & 165 & & & & & & \\
\hline 10 & 180 & 110 & 120 & 110 & 103 & 90 & 130 \\
\hline RUÍNA & 209,1 & 110 & 120 & 110 & 103 & 90 & 130 \\
\hline
\end{tabular}


Tabela C-9 - Aberturas de fissuras na viga VQ-4.

\begin{tabular}{|c|c|c|c|c|c|c|c|}
\hline \multicolumn{3}{|c|}{$\begin{array}{l}\text { VALORES DAS ABERTURAS } \\
\text { DE FISSURAS (mm) }\end{array}$} & \multicolumn{3}{|c|}{$\begin{array}{l}\text { NERVURA TRACIONADA } \\
\text { face inferior (eixo 1) }\end{array}$} & \multicolumn{2}{|c|}{ MODELO: VQ-4 } \\
\hline Etapa & Força $(\mathrm{kN})$ & A1 & A2 & B1 & B2 & $\mathrm{C} 2$ & $\mathrm{C} 1$ \\
\hline \multicolumn{8}{|l|}{0} \\
\hline \multicolumn{8}{|l|}{1} \\
\hline \multicolumn{8}{|l|}{2} \\
\hline 3 & 75 & & 0,06 & & 0,06 & & \\
\hline 4 & 90 & & 0,06 & & 0,06 & 0,08 & \\
\hline 5 & 105 & 0,06 & 0,08 & 0,06 & 0,08 & 0,08 & 0,04 \\
\hline 6 & 120 & 0,06 & 0,12 & 0,08 & 0,10 & 0,09 & 0,07 \\
\hline 7 & 135 & 0,09 & 0,13 & 0,09 & 0,10 & 0,10 & 0,09 \\
\hline 8 & 150 & 0,15 & 0,14 & 0,10 & 0,12 & 0,12 & 0,11 \\
\hline 9 & 165 & 0,15 & 0,15 & 0,10 & 0,12 & 0,13 & 0,12 \\
\hline 10 & 180 & 0,15 & 0,16 & 0,11 & 0,13 & 0,14 & 0,14 \\
\hline RUÍNA & 185,1 & 0,15 & 0,16 & 0,11 & $\mathbf{0 , 1 3}$ & 0,14 & 0,14 \\
\hline
\end{tabular}

\begin{tabular}{|c|c|c|c|c|c|c|c|}
\hline \multicolumn{3}{|c|}{$\begin{array}{l}\text { VALORES DAS ABERTURAS } \\
\text { DE FISSURAS (mm) }\end{array}$} & \multicolumn{3}{|c|}{$\begin{array}{l}\text { NERVURA TRACIONADA } \\
\text { face lateral (eixo 2) }\end{array}$} & \multicolumn{2}{|c|}{ MODELO: VQ-4 } \\
\hline Etapa & Força $(\mathrm{kN})$ & A1 & A2 & B1 & B2 & $\mathrm{C} 2$ & $\mathrm{C} 1$ \\
\hline \multicolumn{8}{|l|}{0} \\
\hline \multicolumn{8}{|l|}{1} \\
\hline \multicolumn{8}{|l|}{2} \\
\hline 3 & 75 & & 0,06 & & & & \\
\hline 4 & 90 & & 0,06 & 0,06 & 0,06 & & \\
\hline 5 & 105 & & 0,08 & 0,08 & 0,06 & 0,08 & \\
\hline 6 & 120 & & 0,09 & 0,08 & 0,09 & 0,08 & \\
\hline 7 & 135 & & 0,11 & 0,08 & 0,09 & 0,10 & \\
\hline 8 & 150 & & 0,11 & 0,10 & 0,10 & 0,14 & \\
\hline 9 & 165 & & 0,12 & 0,12 & 0,12 & 0,14 & \\
\hline 10 & 180 & & 0,12 & 0,12 & 0,12 & 0,14 & \\
\hline RUÍNA & 185,1 & --- & 0,12 & 0,12 & 0,12 & 0,14 & --- \\
\hline
\end{tabular}

\begin{tabular}{|c|c|c|c|c|c|c|c|}
\hline \multicolumn{3}{|c|}{$\begin{array}{l}\text { VALORES DAS ABERTURAS } \\
\text { DE FISSURAS }(\mathrm{mm}) \\
\end{array}$} & \multicolumn{3}{|l|}{$\begin{array}{l}\text { ALMA } \\
\text { (eixo 3) }\end{array}$} & \multicolumn{2}{|c|}{ MODELO: VQ-4 } \\
\hline Etapa & Força $(\mathrm{kN})$ & A1 & A2 & B1 & B2 & $\mathrm{C} 2$ & $\mathrm{C} 1$ \\
\hline \multicolumn{8}{|l|}{0} \\
\hline \multicolumn{8}{|l|}{1} \\
\hline \multicolumn{8}{|l|}{2} \\
\hline 3 & 75 & & 0,08 & & & 0,08 & \\
\hline 4 & 90 & 0,04 & 0,10 & & & 0,12 & \\
\hline 5 & 105 & 0,10 & 0,16 & 0,04 & 0,04 & 0,16 & 0,12 \\
\hline 6 & 120 & 0,11 & 0,20 & 0,08 & 0,08 & 0,20 & 0,18 \\
\hline 7 & 135 & 0,16 & 0,25 & 0,09 & 0,09 & 0,25 & 0,20 \\
\hline 8 & 150 & 0,30 & 0,35 & 0,10 & 0,10 & 0,35 & 0,40 \\
\hline 9 & 165 & 0,35 & 0,45 & 0,12 & 0,12 & 0,40 & 0,45 \\
\hline 10 & 180 & 0,50 & 0,55 & 0,14 & 0,15 & 0,55 & 0,55 \\
\hline RUÍNA & 185,1 & $\mathbf{0 , 8 0}$ & 0,90 & 0,16 & 0,20 & 1,00 & 1,00 \\
\hline
\end{tabular}


Tabela C-10 - Espaçamentos entre fissuras na viga VQ-4.

\begin{tabular}{|c|c|c|c|c|c|c|c|}
\hline \multicolumn{3}{|c|}{\begin{tabular}{l|} 
ESPAÇAMENTO ENTRE \\
FISSURAS - valores médios (mm)
\end{tabular}} & \multicolumn{3}{|c|}{$\begin{array}{l}\text { NERVURA TRACIONADA } \\
\text { face inferior (eixo 1) }\end{array}$} & \multicolumn{2}{|c|}{ MODELO: VQ-4 } \\
\hline Etapa & Força $(\mathrm{kN})$ & A1 & A2 & B1 & B2 & $\mathrm{C} 2$ & $\mathrm{C} 1$ \\
\hline \multicolumn{8}{|l|}{0} \\
\hline \multicolumn{8}{|l|}{1} \\
\hline \multicolumn{8}{|l|}{2} \\
\hline 3 & 75 & & 160 & & & & \\
\hline 4 & 90 & & 100 & 150 & 200 & 120 & 80 \\
\hline 5 & 105 & & 100 & 90 & 100 & 120 & \\
\hline 6 & 120 & 280 & 100 & 75 & 100 & 120 & 80 \\
\hline 7 & 135 & 280 & 100 & & 100 & 120 & \\
\hline 8 & 150 & 140 & 80 & 75 & 80 & 100 & 80 \\
\hline 9 & 165 & 140 & 80 & & & & \\
\hline 10 & 180 & 140 & 80 & 75 & 80 & 100 & 80 \\
\hline RUÍNA & 185,1 & 140 & 80 & 75 & 80 & 100 & 80 \\
\hline
\end{tabular}

\begin{tabular}{|c|c|c|c|c|c|c|c|}
\hline \multicolumn{3}{|c|}{$\begin{array}{l}\text { ESPAÇAMENTO ENTRE } \\
\text { FISSURAS - valores médios }(\mathrm{mm})\end{array}$} & \multicolumn{3}{|c|}{$\begin{array}{l}\text { NERVURA TRACIONADA } \\
\text { face lateral (eixo 2) }\end{array}$} & \multicolumn{2}{|c|}{ MODELO: VQ-4 } \\
\hline Etapa & Força $(\mathrm{kN})$ & A1 & A2 & B1 & B2 & $\mathrm{C} 2$ & $\mathrm{C} 1$ \\
\hline \multicolumn{8}{|l|}{0} \\
\hline \multicolumn{8}{|l|}{1} \\
\hline \multicolumn{8}{|l|}{2} \\
\hline 3 & 75 & & & & & & \\
\hline 4 & 90 & & & 460 & & & \\
\hline 5 & 105 & & & & & & \\
\hline 6 & 120 & & & & 75 & & \\
\hline 7 & 135 & & & & & 120 & \\
\hline 8 & 150 & & & & & & \\
\hline 9 & 165 & & & & & & \\
\hline 10 & 180 & & & & & & \\
\hline RUÍNA & 185,1 & & & 460 & 75 & 120 & \\
\hline
\end{tabular}

\begin{tabular}{|c|c|c|c|c|c|c|c|}
\hline \multicolumn{3}{|c|}{$\begin{array}{l}\text { ESPAÇAMENTO ENTRE } \\
\text { FISSURAS - valores médios }(\mathrm{mm})\end{array}$} & \multicolumn{3}{|l|}{$\begin{array}{l}\text { ALMA } \\
\text { (eixo 3) }\end{array}$} & \multicolumn{2}{|c|}{ MODELO: VQ-4 } \\
\hline Etapa & Força $(\mathrm{kN})$ & A1 & A2 & B1 & B2 & $\mathrm{C} 2$ & $\mathrm{C} 1$ \\
\hline \multicolumn{8}{|l|}{0} \\
\hline \multirow{2}{*}{\multicolumn{8}{|c|}{$\frac{1}{2}$}} \\
\hline & & & & & & & \\
\hline 3 & 75 & & & & & 300 & \\
\hline 4 & 90 & 160 & 150 & 230 & 190 & 160 & \\
\hline 5 & 105 & 160 & 150 & 230 & 190 & 160 & \\
\hline 6 & 120 & 150 & 110 & 230 & 110 & 160 & 90 \\
\hline 7 & 135 & 150 & 110 & 230 & 110 & 160 & 90 \\
\hline 8 & 150 & 150 & 110 & 230 & 150 & 160 & 60 \\
\hline 9 & 165 & 150 & 110 & 230 & 150 & 160 & 60 \\
\hline 10 & 180 & 150 & 110 & 230 & 150 & 160 & 60 \\
\hline RUÍNA & 185,1 & 150 & 110 & 230 & 150 & 160 & 60 \\
\hline
\end{tabular}


Tabela C-11 - Aberturas de fissuras na viga VQ-5.

\begin{tabular}{|c|c|c|c|c|c|c|c|}
\hline \multicolumn{3}{|c|}{$\begin{array}{l}\text { VALORES DAS ABERTURAS } \\
\text { DE FISSURAS }(\mathrm{mm})\end{array}$} & \multicolumn{3}{|c|}{$\begin{array}{l}\text { NERVURA TRACIONADA } \\
\text { face inferior (eixo 1) }\end{array}$} & \multicolumn{2}{|c|}{ MODELO: VQ-5 } \\
\hline Etapa & Força $(\mathrm{kN})$ & A1 & A2 & B1 & B2 & $\mathrm{C} 2$ & $\mathrm{C} 1$ \\
\hline \multicolumn{8}{|l|}{0} \\
\hline \multicolumn{8}{|l|}{1} \\
\hline \multicolumn{8}{|l|}{2} \\
\hline \multicolumn{8}{|l|}{3} \\
\hline 4 & 75 & --- & 0,07 & 0,06 & 0,06 & ---- & \\
\hline 5 & 90 & --- & 0,07 & 0,06 & 0,07 & 0,05 & \\
\hline 6 & 105 & 0,05 & 0,08 & 0,08 & 0,09 & 0,08 & 0,07 \\
\hline 7 & 120 & 0,07 & 0,08 & 0,09 & 0,09 & 0,08 & 0,08 \\
\hline 8 & 135 & 0,09 & 0,08 & 0,10 & 0,10 & 0,08 & 0,08 \\
\hline 9 & 150 & 0,10 & 0,11 & 0,11 & 0,10 & 0,10 & 0,09 \\
\hline 10 & 165 & 0,10 & 0,12 & 0,11 & 0,10 & 0,10 & 0,09 \\
\hline RUÍNA & 173,5 & & & & & & \\
\hline
\end{tabular}

\begin{tabular}{|c|c|c|c|c|c|c|c|}
\hline \multicolumn{3}{|c|}{$\begin{array}{l}\text { VALORES DAS ABERTURAS } \\
\text { DE FISSURAS (mm) }\end{array}$} & \multicolumn{3}{|c|}{$\begin{array}{l}\text { NERVURA TRACIONADA } \\
\text { face lateral (eixo 2) }\end{array}$} & \multicolumn{2}{|c|}{ MODELO: VQ-5 } \\
\hline Etapa & Força $(\mathrm{kN})$ & A1 & A2 & B1 & B2 & $\mathrm{C} 2$ & $\mathrm{C} 1$ \\
\hline \multicolumn{8}{|l|}{0} \\
\hline \multicolumn{8}{|l|}{1} \\
\hline \multicolumn{8}{|l|}{2} \\
\hline \multicolumn{8}{|l|}{3} \\
\hline 4 & 75 & & 0,06 & --- & & & \\
\hline 5 & 90 & & 0,07 & 0,06 & & 0,06 & \\
\hline 6 & 105 & & 0,08 & 0,08 & & 0,07 & \\
\hline 7 & 120 & & 0,09 & 0,10 & 0,10 & 0,07 & --- \\
\hline 8 & 135 & & 0,10 & 0,10 & 0,10 & 0,08 & --- \\
\hline 9 & 150 & & 0,11 & 0,10 & 0,10 & 0,08 & 0,07 \\
\hline 10 & 165 & --- & 0,11 & 0,10 & 0,10 & 0,10 & 0,08 \\
\hline$\overline{\text { RUÍNA }}$ & 173,5 & --- & & & & & \\
\hline
\end{tabular}

\begin{tabular}{|c|c|c|c|c|c|c|c|}
\hline \multicolumn{3}{|c|}{$\begin{array}{l}\text { VALORES DAS ABERTURAS } \\
\text { DE FISSURAS }(\mathrm{mm}) \\
\end{array}$} & \multicolumn{3}{|l|}{$\begin{array}{l}\text { ALMA } \\
\text { (eixo 3) }\end{array}$} & \multicolumn{2}{|c|}{ MODELO: VQ-5 } \\
\hline Etapa & Força $(\mathrm{kN})$ & A1 & A2 & B1 & B2 & $\mathrm{C} 2$ & $\mathrm{C} 1$ \\
\hline \multicolumn{8}{|l|}{0} \\
\hline \multicolumn{8}{|l|}{1} \\
\hline \multicolumn{8}{|l|}{2} \\
\hline \multicolumn{8}{|l|}{3} \\
\hline 4 & 75 & --- & 0,05 & 0,05 & --- & 0,05 & --- \\
\hline 5 & 90 & 0,08 & 0,06 & 0,05 & --- & 0,06 & --- \\
\hline 6 & 105 & 0,14 & 0,14 & 0,07 & 0,06 & 0,07 & 0,16 \\
\hline 7 & 120 & 0,20 & 0,20 & 0,08 & 0,07 & 0,08 & 0,20 \\
\hline 8 & 135 & 0,40 & 0,25 & 0,08 & 0,08 & 0,10 & 0,35 \\
\hline 9 & 150 & 0,45 & 0,40 & 0,09 & 0,09 & 0,30 & 0,45 \\
\hline 10 & 165 & 0,70 & 0,50 & 0,10 & 0,10 & 0,65 & 0,65 \\
\hline RUÍNA & 173,5 & 0,70 & $\mathbf{0 , 5 0}$ & 0,12 & 0,11 & 0,65 & 0,65 \\
\hline
\end{tabular}


Tabela C-12 - Espaçamentos entre fissuras na viga VQ-5.

\begin{tabular}{|c|c|c|c|c|c|c|c|}
\hline \multicolumn{3}{|c|}{$\begin{array}{l}\text { ESPAÇAMENTO ENTRE } \\
\text { FISSURAS - valores médios }(\mathrm{mm})\end{array}$} & \multicolumn{3}{|c|}{$\begin{array}{l}\text { NERVURA TRACIONADA } \\
\text { face inferior (eixo 1) }\end{array}$} & \multicolumn{2}{|c|}{ MODELO: VQ-5 } \\
\hline Etapa & Força $(\mathrm{kN})$ & A1 & A2 & B1 & B2 & $\mathrm{C} 2$ & $\mathrm{C} 1$ \\
\hline \multicolumn{8}{|l|}{0} \\
\hline \multicolumn{8}{|l|}{1} \\
\hline \multicolumn{8}{|l|}{2} \\
\hline \multicolumn{8}{|l|}{3} \\
\hline 4 & 75 & & 160 & 110 & 180 & & \\
\hline 5 & 90 & & 160 & 110 & 95 & 90 & \\
\hline 6 & 105 & 280 & 160 & 110 & 95 & 90 & \\
\hline 7 & 120 & 280 & 150 & 100 & 95 & 90 & \\
\hline 8 & 135 & 280 & 150 & 100 & 95 & 90 & \\
\hline 9 & 150 & 280 & 150 & 100 & 90 & 90 & 150 \\
\hline 10 & 165 & 280 & 150 & 100 & 90 & 90 & 150 \\
\hline RUÍNA & 173,5 & 280 & 150 & 100 & 90 & 90 & 150 \\
\hline
\end{tabular}

\begin{tabular}{|c|c|c|c|c|c|c|c|}
\hline \multicolumn{3}{|c|}{$\begin{array}{l}\text { ESPAÇAMENTO ENTRE } \\
\text { FISSURAS - valores médios }(\mathrm{mm})\end{array}$} & \multicolumn{3}{|c|}{$\begin{array}{l}\text { NERVURA TRACIONADA } \\
\text { face lateral (eixo 2) }\end{array}$} & \multicolumn{2}{|c|}{ MODELO: VQ-5 } \\
\hline Etapa & Força $(\mathrm{kN})$ & A1 & A2 & B1 & B2 & $\mathrm{C} 2$ & $\mathrm{C} 1$ \\
\hline \multicolumn{8}{|l|}{0} \\
\hline \multicolumn{8}{|l|}{1} \\
\hline \multicolumn{8}{|l|}{2} \\
\hline \multicolumn{8}{|l|}{3} \\
\hline 4 & 75 & & 160 & & & & \\
\hline 5 & 90 & & 160 & 320 & 130 & 110 & \\
\hline 6 & 105 & & 160 & 155 & 130 & 110 & \\
\hline 7 & 120 & & 160 & 150 & 130 & 110 & \\
\hline 8 & 135 & & 115 & 150 & 130 & 95 & \\
\hline 9 & 150 & & 115 & 150 & 130 & 95 & \\
\hline 10 & 165 & & 115 & 150 & 130 & 95 & \\
\hline RUÍNA & 173,5 & --- & 115 & 150 & 130 & 95 & -- \\
\hline
\end{tabular}

\begin{tabular}{|c|c|c|c|c|c|c|c|}
\hline $\begin{array}{l}\text { ESPAÇA } \\
\text { FISSUR }\end{array}$ & $\begin{array}{l}\text { MENTO EN } \\
\text { S - valores n }\end{array}$ & $\mathrm{s}(\mathrm{mm})$ & \begin{tabular}{|l|} 
ALMA \\
(eixo 3)
\end{tabular} & & & MODEI & \\
\hline Etapa & Força $(\mathrm{kN})$ & A1 & A2 & B1 & B2 & $\mathrm{C} 2$ & $\mathrm{C} 1$ \\
\hline 0 & & & & & & & \\
\hline 1 & & & & & & & \\
\hline 2 & & & & & & & \\
\hline 3 & & & & & & & \\
\hline 4 & 75 & & 150 & & & 110 & \\
\hline 5 & 90 & 60 & 150 & 280 & & 110 & \\
\hline 6 & 105 & 60 & 120 & 280 & & 110 & 50 \\
\hline 7 & 120 & 60 & 120 & 280 & & 110 & 50 \\
\hline 8 & 135 & 60 & 120 & 280 & --- & 110 & 50 \\
\hline 9 & 150 & 75 & 160 & 115 & --- & 110 & 50 \\
\hline 10 & 165 & 75 & 160 & 115 & 190 & 110 & 50 \\
\hline RUÍNA & 173,5 & 75 & 160 & 115 & 190 & 110 & 50 \\
\hline
\end{tabular}


Tabela C-13 - Aberturas de fissuras na viga VQ-6.

\begin{tabular}{|c|c|c|c|c|c|c|c|}
\hline \multicolumn{3}{|c|}{$\begin{array}{l}\text { VALORES DAS ABERTURAS } \\
\text { DE FISSURAS (mm) }\end{array}$} & \multicolumn{3}{|c|}{$\begin{array}{l}\text { NERVURA TRACIONADA } \\
\text { face inferior (eixo 1) }\end{array}$} & \multicolumn{2}{|c|}{ MODELO: VQ-6 } \\
\hline Etapa & Força $(\mathrm{kN})$ & A1 & A2 & B1 & B2 & $\mathrm{C} 2$ & $\mathrm{C} 1$ \\
\hline \multicolumn{8}{|l|}{0} \\
\hline \multicolumn{8}{|l|}{1} \\
\hline \multicolumn{8}{|l|}{2} \\
\hline \multicolumn{8}{|l|}{3} \\
\hline 4 & 45 & & & 0,05 & & 0,05 & \\
\hline 5 & 60 & & 0,06 & 0,05 & 0,05 & 0,05 & \\
\hline 6 & 75 & & 0,06 & 0,06 & 0,05 & 0,05 & \\
\hline 7 & 90 & ---- & 0,10 & 0,10 & 0,08 & 0,08 & \\
\hline 8 & 105 & 0,12 & 0,12 & 0,11 & 0,11 & 0,09 & 0,09 \\
\hline 9 & 120 & 0,13 & 0,12 & 0,11 & 0,11 & 0,09 & 0,10 \\
\hline 10 & 135 & 0,15 & 0,13 & 0,11 & 0,11 & 0,11 & 0,12 \\
\hline RUÍNA & 145,4 & & & & & & \\
\hline
\end{tabular}

\begin{tabular}{|c|c|c|c|c|c|c|c|}
\hline \multicolumn{3}{|c|}{$\begin{array}{l}\text { VALORES DAS ABERTURAS } \\
\text { DE FISSURAS }(\mathrm{mm})\end{array}$} & \multicolumn{3}{|c|}{$\begin{array}{l}\text { NERVURA TRACIONADA } \\
\text { face lateral (eixo 2) }\end{array}$} & \multicolumn{2}{|c|}{ MODELO: VQ-6 } \\
\hline Etapa & Força $(\mathrm{kN})$ & A1 & $\mathrm{A} 2$ & B1 & B2 & $\mathrm{C} 2$ & $\mathrm{C} 1$ \\
\hline \multicolumn{8}{|l|}{0} \\
\hline \multicolumn{8}{|l|}{1} \\
\hline \multicolumn{8}{|l|}{2} \\
\hline \multicolumn{8}{|l|}{3} \\
\hline 4 & & & & 0,05 & & & \\
\hline 5 & 60 & & & 0,05 & 0,05 & & \\
\hline 6 & 75 & & 0,06 & 0,06 & 0,05 & & \\
\hline 7 & 90 & & 0,08 & 0,07 & 0,06 & 0,08 & \\
\hline 8 & 105 & & 0,09 & 0,08 & 0,09 & 0,08 & \\
\hline 9 & 120 & & 0,10 & 0,08 & 0,10 & 0,09 & \\
\hline 10 & 135 & --- & 0,10 & 0,10 & 0,11 & 0,09 & \\
\hline$\overline{\text { RUÍNA }}$ & 145,4 & & & & & & \\
\hline
\end{tabular}

\begin{tabular}{|c|c|c|c|c|c|c|c|}
\hline \multicolumn{3}{|c|}{$\begin{array}{l}\text { VALORES DAS ABERTURAS } \\
\text { DE FISSURAS (mm) }\end{array}$} & \multicolumn{3}{|l|}{$\begin{array}{l}\text { ALMA } \\
\text { (eixo 3) }\end{array}$} & \multicolumn{2}{|c|}{ MODELO: VQ-6 } \\
\hline Etapa & Força $(\mathrm{kN})$ & A1 & A2 & B1 & B2 & $\mathrm{C} 2$ & $\mathrm{C} 1$ \\
\hline \multicolumn{8}{|l|}{0} \\
\hline \multicolumn{8}{|l|}{1} \\
\hline \multicolumn{8}{|l|}{2} \\
\hline \multicolumn{8}{|l|}{3} \\
\hline \multicolumn{8}{|l|}{4} \\
\hline 5 & 60 & & & & & & \\
\hline 6 & 75 & 0,06 & 0,09 & & 0,04 & 0,05 & \\
\hline 7 & 90 & 0,16 & 0,18 & & 0,06 & 0,10 & --- \\
\hline 8 & 105 & 0,25 & 0,25 & 0,07 & 0,06 & 0,10 & 0,15 \\
\hline 9 & 120 & 0,35 & 0,30 & 0,10 & 0,09 & 0,15 & 0,25 \\
\hline 10 & 135 & 0,70 & 0,65 & 0,10 & 0,09 & 0,20 & 0,40 \\
\hline RUÍNA & 145,4 & & & & & & \\
\hline
\end{tabular}


Tabela C-14 - Espaçamentos entre fissuras na viga VQ-6.

\begin{tabular}{|c|c|c|c|c|c|c|c|}
\hline \multicolumn{3}{|c|}{$\begin{array}{l}\text { ESPAÇAMENTO ENTRE } \\
\text { FISSURAS - valores médios }(\mathrm{mm})\end{array}$} & \multicolumn{3}{|c|}{$\begin{array}{l}\text { NERVURA TRACIONADA } \\
\text { face inferior (eixo 1) }\end{array}$} & \multicolumn{2}{|c|}{ MODELO: VQ-6 } \\
\hline Etapa & Força $(\mathrm{kN})$ & A1 & A2 & B1 & B2 & $\mathrm{C} 2$ & $\mathrm{C} 1$ \\
\hline \multicolumn{8}{|l|}{0} \\
\hline \multicolumn{8}{|l|}{1} \\
\hline \multicolumn{8}{|l|}{2} \\
\hline \multicolumn{8}{|l|}{3} \\
\hline \multicolumn{8}{|l|}{4} \\
\hline 5 & 60 & & & & 120 & 220 & \\
\hline 6 & 75 & & 110 & 85 & 120 & 220 & \\
\hline 7 & 90 & & 100 & 85 & 80 & 130 & \\
\hline 8 & 105 & --- & 100 & 85 & 80 & 120 & \\
\hline 9 & 120 & --- & 100 & 80 & 80 & 120 & \\
\hline 10 & 135 & 200 & 100 & 80 & 100 & 120 & \\
\hline RUÍNA & 145,4 & 200 & 100 & 80 & 100 & 120 & -- \\
\hline
\end{tabular}

\begin{tabular}{|c|c|c|c|c|c|c|c|}
\hline \multicolumn{3}{|c|}{$\begin{array}{l}\text { ESPAÇAMENTO ENTRE } \\
\text { FISSURAS - valores médios (mm) }\end{array}$} & \multicolumn{3}{|c|}{$\begin{array}{l}\text { NERVURA TRACIONADA } \\
\text { face lateral (eixo 2) }\end{array}$} & \multicolumn{2}{|c|}{ MODELO: VQ-6 } \\
\hline Etapa & Força $(\mathrm{kN})$ & A1 & A2 & B1 & B2 & $\mathrm{C} 2$ & $\mathrm{C} 1$ \\
\hline \multicolumn{8}{|l|}{0} \\
\hline \multicolumn{8}{|l|}{1} \\
\hline \multicolumn{8}{|l|}{2} \\
\hline \multicolumn{8}{|l|}{3} \\
\hline \multicolumn{8}{|l|}{4} \\
\hline 5 & 60 & & & 170 & 110 & 200 & \\
\hline 6 & 75 & & 115 & 170 & 110 & 200 & \\
\hline 7 & 90 & & 115 & 170 & 110 & 130 & \\
\hline 8 & 105 & & 115 & 70 & 110 & 110 & \\
\hline 9 & 120 & & 100 & 70 & 110 & 110 & \\
\hline 10 & 135 & & 100 & 70 & 110 & 110 & \\
\hline RUÍNA & 145,4 & -- & 100 & 70 & 110 & 110 & \\
\hline
\end{tabular}

\begin{tabular}{|c|c|c|c|c|c|c|c|}
\hline \multicolumn{3}{|c|}{$\begin{array}{l}\text { ESPAÇAMENTO ENTRE } \\
\text { FISSURAS - valores médios }(\mathrm{mm})\end{array}$} & \multicolumn{3}{|l|}{$\begin{array}{l}\text { ALMA } \\
\text { (eixo 3) }\end{array}$} & \multicolumn{2}{|c|}{ MODELO: VQ-6 } \\
\hline Etapa & Força $(\mathrm{kN})$ & A1 & A2 & B1 & B2 & $\mathrm{C} 2$ & $\mathrm{C} 1$ \\
\hline \multicolumn{8}{|l|}{0} \\
\hline \multirow{2}{*}{\multicolumn{8}{|c|}{$\frac{1}{2}$}} \\
\hline \multicolumn{3}{|l|}{2} & & & & & \\
\hline \multicolumn{8}{|l|}{3} \\
\hline \multicolumn{8}{|l|}{4} \\
\hline 5 & 60 & --- & & & & & \\
\hline 6 & 75 & --- & 350 & & & & \\
\hline 7 & 90 & 130 & 180 & --- & 125 & 130 & \\
\hline 8 & 105 & 130 & 150 & 270 & 125 & 120 & 170 \\
\hline 9 & 120 & 100 & 150 & 130 & 125 & 120 & 170 \\
\hline 10 & 135 & 100 & 150 & 130 & 125 & 120 & 170 \\
\hline RUÍNA & 145,4 & 100 & 150 & 130 & 125 & 120 & 170 \\
\hline
\end{tabular}


Tabela C-15 - Aberturas de fissuras na viga VQ-1A.

\begin{tabular}{|c|c|c|c|c|c|c|c|}
\hline \multicolumn{3}{|c|}{$\begin{array}{l}\text { VALORES DAS ABERTURAS } \\
\text { DE FISSURAS (mm) }\end{array}$} & \multicolumn{3}{|c|}{$\begin{array}{l}\text { NERVURA TRACIONADA } \\
\text { face inferior (eixo 1) }\end{array}$} & \multicolumn{2}{|c|}{ MODELO: VQ-1A } \\
\hline Etapa & Força $(\mathrm{kN})$ & A1 & A2 & B1 & B2 & $\mathrm{C} 2$ & $\mathrm{C} 1$ \\
\hline 0 & 45 & & 0,05 & --- & 0,04 & 0,05 & \\
\hline 1 & 60 & & 0,06 & --- & 0,05 & 0,06 & \\
\hline 2 & 75 & & 0,07 & 0,04 & 0,06 & 0,07 & \\
\hline 3 & 90 & --- & 0,08 & 0,05 & 0,06 & 0,07 & \\
\hline 4 & 105 & 0,06 & 0,10 & 0,06 & 0,08 & 0,07 & 0,05 \\
\hline 5 & 120 & 0,06 & 0,13 & 0,06 & 0,08 & 0,13 & 0,06 \\
\hline 6 & 135 & 0,07 & 0,14 & 0,08 & 0,09 & 0,14 & 0,08 \\
\hline 7 & 150 & 0,08 & 0,15 & 0,10 & 0,10 & 0,15 & 0,08 \\
\hline 8 & 165 & 0,08 & 0,16 & 0,10 & 0,11 & 0,16 & 0,13 \\
\hline 9 & 180 & 0,09 & 0,16 & 0,10 & 0,13 & 0,16 & 0,13 \\
\hline 10 & 195 & 0,09 & 0,16 & 0,10 & 0,13 & 0,16 & 0,13 \\
\hline RUÍNA & 202,5 & & & & & & \\
\hline
\end{tabular}

\begin{tabular}{|c|c|c|c|c|c|c|c|}
\hline \multicolumn{3}{|c|}{$\begin{array}{l}\text { VALORES DAS ABERTURAS } \\
\text { DE FISSURAS (mm) }\end{array}$} & \multicolumn{3}{|c|}{$\begin{array}{l}\text { NERVURA TRACIONADA } \\
\text { face lateral (eixo 2) }\end{array}$} & \multicolumn{2}{|c|}{ MODELO: VQ-1A } \\
\hline Etapa & Força $(\mathrm{kN})$ & A1 & A2 & B1 & B2 & $\mathrm{C} 2$ & $\mathrm{C} 1$ \\
\hline \multicolumn{8}{|l|}{0} \\
\hline \multicolumn{8}{|l|}{1} \\
\hline 2 & 75 & & & 0,04 & & & \\
\hline 3 & 90 & & & 0,05 & & & \\
\hline 4 & 105 & & & 0,05 & & & 0,04 \\
\hline 5 & 120 & & & 0,06 & & 0,06 & 0,06 \\
\hline 6 & 135 & & & 0,06 & & 0,07 & 0,06 \\
\hline 7 & 150 & & & 0,07 & & 0,08 & 0,07 \\
\hline 8 & 165 & --- & --- & 0,08 & & 0,09 & 0,07 \\
\hline 9 & 180 & 0,08 & 0,08 & 0,09 & --- & 0,11 & 0,07 \\
\hline 10 & 195 & 0,08 & 0,08 & 0,09 & 0,07 & 0,11 & 0,07 \\
\hline RUÍNA & 202,5 & & & & & & \\
\hline
\end{tabular}

\begin{tabular}{|c|c|c|c|c|c|c|c|}
\hline \multicolumn{3}{|c|}{$\begin{array}{l}\text { VALORES DAS ABERTURAS } \\
\text { DE FISSURAS (mm) }\end{array}$} & \multicolumn{3}{|l|}{$\begin{array}{l}\text { ALMA } \\
\text { (eixo 3) }\end{array}$} & \multicolumn{2}{|c|}{ MODELO: VQ-1A } \\
\hline Etapa & Força $(\mathrm{kN})$ & A1 & $\mathrm{A} 2$ & B1 & B2 & $\mathrm{C} 2$ & $\mathrm{C} 1$ \\
\hline \multicolumn{8}{|l|}{0} \\
\hline \multicolumn{8}{|l|}{1} \\
\hline 2 & 75 & ---- & 0,05 & 0,04 & --- & 0,05 & --- \\
\hline 3 & 90 & 0,09 & 0,05 & 0,05 & 0,05 & 0,05 & --- \\
\hline 4 & 105 & 0,13 & 0,07 & 0,05 & 0,07 & 0,06 & 0,10 \\
\hline 5 & 120 & 0,20 & 0,10 & 0,06 & 0,08 & 0,07 & 0,16 \\
\hline 6 & 135 & 0,23 & 0,16 & 0,06 & 0,08 & 0,15 & 0,20 \\
\hline 7 & 150 & 0,30 & 0,25 & 0,09 & 0,10 & 0,25 & 0,30 \\
\hline 8 & 165 & 0,45 & 0,35 & 0,09 & 0,10 & 0,25 & 0,45 \\
\hline 9 & 180 & 0,55 & 0,50 & 0,09 & 0,10 & 0,45 & 0,55 \\
\hline 10 & 195 & 0,70 & 0,60 & 0,09 & 0,10 & 0,60 & 0,75 \\
\hline RUÍNA & 202,5 & 1,80 & 1,20 & & & & 1,80 \\
\hline
\end{tabular}


Tabela C-16 - Espaçamentos entre fissuras na viga VQ-1A.

\begin{tabular}{|c|c|c|c|c|c|c|c|}
\hline \multicolumn{3}{|c|}{$\begin{array}{l}\text { ESPAÇAMENTO ENTRE } \\
\text { FISSURAS - valores médios (mm) }\end{array}$} & \multicolumn{3}{|c|}{$\begin{array}{l}\text { NERVURA TRACIONADA } \\
\text { face inferior (eixo 1) }\end{array}$} & \multicolumn{2}{|c|}{ MODELO: VQ-1A } \\
\hline Etapa & Força $(\mathrm{kN})$ & A1 & A2 & B1 & B2 & $\mathrm{C} 2$ & $\mathrm{C} 1$ \\
\hline \multicolumn{8}{|l|}{0} \\
\hline \multicolumn{8}{|l|}{1} \\
\hline 2 & 75 & & & 90 & & & \\
\hline 3 & 90 & & 340 & 90 & 130 & & \\
\hline 4 & 105 & --- & 110 & 80 & 100 & 130 & \\
\hline 5 & 120 & 100 & 100 & 80 & 100 & 120 & \\
\hline 6 & 135 & 75 & 90 & 80 & 90 & 90 & 85 \\
\hline 7 & 150 & 75 & 90 & 80 & 90 & 90 & 85 \\
\hline 8 & 165 & 75 & 75 & 80 & 90 & 65 & 75 \\
\hline 9 & 180 & 75 & 75 & 80 & 90 & 65 & 75 \\
\hline 10 & 195 & 75 & 75 & 80 & 90 & 65 & 75 \\
\hline RUÍNA & 202,5 & 75 & 75 & 80 & 90 & 65 & 75 \\
\hline
\end{tabular}

\begin{tabular}{|c|c|c|c|c|c|c|c|}
\hline \multicolumn{3}{|c|}{$\begin{array}{l}\text { ESPAÇAMENTO ENTRE } \\
\text { FISSURAS - valores médios (mm) }\end{array}$} & \multicolumn{3}{|c|}{$\begin{array}{l}\text { NERVURA TRACIONADA } \\
\text { face lateral (eixo 2) }\end{array}$} & \multicolumn{2}{|c|}{ MODELO: VQ-1A } \\
\hline Etapa & Força $(\mathrm{kN})$ & A1 & A2 & B1 & B2 & $\mathrm{C} 2$ & $\mathrm{C} 1$ \\
\hline \multicolumn{8}{|l|}{0} \\
\hline \multicolumn{8}{|l|}{1} \\
\hline 2 & 75 & & & & & & \\
\hline 3 & 90 & & & 100 & & & \\
\hline 4 & 105 & & & 100 & & & \\
\hline 5 & 120 & & & 100 & & & \\
\hline 6 & 135 & & & 100 & & & \\
\hline 7 & 150 & & --- & 100 & --- & --- & \\
\hline 8 & 165 & & 240 & 75 & --- & --- & \\
\hline 9 & 180 & & 120 & 75 & 350 & 450 & \\
\hline 10 & 195 & --- & 120 & 75 & 350 & 450 & -- \\
\hline RUÍNA & 202,5 & --- & 120 & 75 & 350 & 450 & --- \\
\hline
\end{tabular}

\begin{tabular}{|c|c|c|c|c|c|c|c|}
\hline \multicolumn{3}{|c|}{$\begin{array}{l}\text { ESPAÇAMENTO ENTRE } \\
\text { FISSURAS - valores médios }(\mathrm{mm})\end{array}$} & \multicolumn{3}{|l|}{$\begin{array}{l}\text { ALMA } \\
\text { (eixo 3) }\end{array}$} & \multicolumn{2}{|c|}{ MODELO: VQ-1A } \\
\hline Etapa & Força $(\mathrm{kN})$ & A1 & A2 & B1 & B2 & $\mathrm{C} 2$ & $\mathrm{C} 1$ \\
\hline \multicolumn{8}{|l|}{0} \\
\hline 1 & & & & & & & \\
\hline 2 & 75 & & & & & & \\
\hline 3 & 90 & & 110 & & & --- & --- \\
\hline 4 & 105 & 150 & 100 & --- & & 190 & 150 \\
\hline 5 & 120 & 150 & 100 & 150 & --- & 120 & 140 \\
\hline 6 & 135 & 150 & 100 & 100 & 220 & 120 & 140 \\
\hline 7 & 150 & 140 & 100 & 100 & 105 & 120 & 140 \\
\hline 8 & 165 & 140 & 100 & 100 & 100 & 120 & 70 \\
\hline 9 & 180 & 140 & 100 & 100 & 100 & 120 & 70 \\
\hline 10 & 195 & 140 & 100 & 100 & 100 & 120 & 70 \\
\hline RUÍNA & 202,5 & $\overline{140}$ & 100 & 100 & $\mathbf{1 0 0}$ & 120 & $\overline{70}$ \\
\hline
\end{tabular}


Tabela C-17 - Aberturas de fissuras na viga VQ-7.

\begin{tabular}{|c|c|c|c|c|c|c|c|}
\hline \multicolumn{3}{|c|}{$\begin{array}{l}\text { VALORES DAS ABERTURAS } \\
\text { DE FISSURAS (mm) }\end{array}$} & \multicolumn{3}{|c|}{$\begin{array}{l}\text { NERVURA TRACIONADA } \\
\text { face inferior (eixo 1) }\end{array}$} & \multicolumn{2}{|c|}{ MODELO: VQ-7 } \\
\hline Etapa & Força $(\mathrm{kN})$ & A1 & A2 & B1 & B2 & $\mathrm{C} 2$ & $\mathrm{C} 1$ \\
\hline 0 & 60 & & & 0,04 & --- & --- & \\
\hline 1 & 75 & --- & --- & 0,06 & 0,06 & 0,05 & \\
\hline 2 & 90 & 0,06 & 0,07 & 0,08 & 0,08 & 0,06 & --- \\
\hline 3 & 105 & 0,06 & 0,07 & 0,09 & 0,08 & 0,06 & 0,05 \\
\hline 4 & 120 & 0,06 & 0,07 & 0,09 & 0,09 & 0,07 & 0,06 \\
\hline 5 & 135 & 0,08 & 0,09 & 0,10 & 0,10 & 0,09 & 0,06 \\
\hline 6 & 150 & 0,09 & 0,10 & 0,10 & 0,10 & 0,10 & 0,07 \\
\hline 7 & 165 & 0,09 & 0,11 & 0,10 & 0,11 & 0,11 & 0,08 \\
\hline 8 & 180 & 0,10 & 0,11 & 0,10 & 0,11 & 0,11 & 0,09 \\
\hline 9 & 195 & & & & & & \\
\hline 10 & 210 & & & & & & \\
\hline RUÍNA & 213,5 & & & & & & \\
\hline
\end{tabular}

\begin{tabular}{|c|c|c|c|c|c|c|c|}
\hline \multicolumn{3}{|c|}{$\begin{array}{l}\text { VALORES DAS ABERTURAS } \\
\text { DE FISSURAS (mm) }\end{array}$} & \multicolumn{3}{|c|}{$\begin{array}{l}\text { NERVURA TRACIONADA } \\
\text { face lateral (eixo 2) }\end{array}$} & \multicolumn{2}{|c|}{ MODELO: VQ-7 } \\
\hline Etapa & Força $(\mathrm{kN})$ & A1 & A2 & B1 & B2 & $\mathrm{C} 2$ & $\mathrm{C} 1$ \\
\hline 0 & 60 & & & 0,05 & & --- & \\
\hline 1 & 75 & & 0,05 & 0,05 & & 0,05 & \\
\hline 2 & 90 & & 0,07 & 0,06 & & 0,06 & \\
\hline 3 & 105 & & 0,07 & 0,08 & --- & 0,06 & \\
\hline 4 & 120 & & 0,07 & 0,08 & 0,08 & 0,06 & \\
\hline 5 & 135 & & 0,08 & 0,08 & 0,09 & 0,08 & \\
\hline 6 & 150 & & 0,09 & 0,10 & 0,09 & 0,09 & \\
\hline 7 & 165 & & 0,10 & 0,10 & 0,10 & 0,09 & \\
\hline 8 & 180 & & & & & & \\
\hline 9 & 195 & & & & & & \\
\hline 10 & 210 & & & & & & \\
\hline RUÍNA & 213,5 & --- & & & & & --- \\
\hline
\end{tabular}

\begin{tabular}{|c|c|c|c|c|c|c|c|}
\hline \multicolumn{3}{|c|}{$\begin{array}{l}\text { VALORES DAS ABERTURAS } \\
\text { DE FISSURAS (mm) }\end{array}$} & \multicolumn{3}{|l|}{$\begin{array}{l}\text { ALMA } \\
\text { (eixo 3) }\end{array}$} & \multicolumn{2}{|c|}{ MODELO: VQ-7 } \\
\hline Etapa & Força $(\mathrm{kN})$ & A1 & A2 & B1 & B2 & $\mathrm{C} 2$ & $\mathrm{C} 1$ \\
\hline 0 & 60 & & & & & & \\
\hline 1 & 75 & & --- & --- & ---- & --- & --- \\
\hline 2 & 90 & --- & 0,08 & 0,05 & 0,05 & 0,05 & ---- \\
\hline 3 & 105 & 0,06 & 0,09 & 0,06 & 0,06 & 0,07 & 0,08 \\
\hline 4 & 120 & 0,09 & 0,11 & 0,06 & 0,06 & 0,09 & 0,10 \\
\hline 5 & 135 & 0,14 & 0,16 & 0,07 & 0,07 & 0,15 & 0,14 \\
\hline 6 & 150 & 0,18 & 0,20 & 0,09 & 0,09 & 0,18 & 0,20 \\
\hline 7 & 165 & 0,22 & 0,23 & 0,10 & 0,10 & 0,20 & 0,20 \\
\hline 8 & 180 & 0,30 & 0,30 & 0,10 & 0,10 & 0,25 & 0,25 \\
\hline 9 & 195 & 0,40 & 0,45 & 0,10 & 0,10 & 0,30 & 0,35 \\
\hline 10 & 210 & 0,75 & 0,75 & & & 0,50 & 0,50 \\
\hline RUÍNA & 213,5 & 0,90 & 0,90 & & & 0,60 & 0,60 \\
\hline
\end{tabular}


Tabela C-18 - Espaçamentos entre fissuras na viga VQ-7.

\begin{tabular}{|c|c|c|c|c|c|c|c|}
\hline \multicolumn{3}{|c|}{$\begin{array}{l}\text { ESPAÇAMENTO ENTRE } \\
\text { FISSURAS - valores médios }(\mathrm{mm})\end{array}$} & \multicolumn{3}{|c|}{$\begin{array}{l}\text { NERVURA TRACIONADA } \\
\text { face inferior (eixo 1) }\end{array}$} & \multicolumn{2}{|c|}{ MODELO: VQ-7 } \\
\hline Etapa & Força $(\mathrm{kN})$ & A1 & A2 & B1 & B2 & $\mathrm{C} 2$ & $\mathrm{C} 1$ \\
\hline 0 & 60 & & & & & & \\
\hline 1 & 75 & & 135 & 120 & 115 & & \\
\hline 2 & 90 & & 135 & 120 & 115 & & \\
\hline 3 & 105 & & 165 & 120 & 115 & --- & \\
\hline 4 & 120 & --- & 165 & 120 & 115 & 145 & --- \\
\hline 5 & 135 & --- & 165 & 120 & 115 & 145 & 110 \\
\hline 6 & 150 & 100 & 165 & 120 & 110 & 95 & 110 \\
\hline 7 & 165 & 100 & 165 & 120 & 110 & 95 & 110 \\
\hline 8 & 180 & 95 & 110 & 110 & 110 & 85 & 80 \\
\hline 9 & 195 & 95 & 110 & 110 & 110 & 85 & 80 \\
\hline 10 & 210 & 95 & 110 & 110 & 110 & 85 & 80 \\
\hline RUÍNA & 213,5 & 95 & 110 & 110 & 110 & 85 & 80 \\
\hline
\end{tabular}

\begin{tabular}{|c|c|c|c|c|c|c|c|}
\hline $\begin{array}{l}\text { ESPAÇ } \\
\text { FISSUR }\end{array}$ & $\begin{array}{l}\text { MENTO EN } \\
\text { S - valores n }\end{array}$ & $\mathrm{s}(\mathrm{mm})$ & $\begin{array}{l}\text { NERVU } \\
\text { face late }\end{array}$ & $\begin{array}{l}\text { CIC } \\
\text { 2) }\end{array}$ & & MODEI & \\
\hline Etapa & Força $(\mathrm{kN})$ & A1 & A2 & B1 & B2 & $\mathrm{C} 2$ & $\mathrm{C} 1$ \\
\hline 0 & 60 & & & & & & \\
\hline 1 & 75 & & 250 & 90 & & & \\
\hline 2 & 90 & & 250 & 90 & & & \\
\hline 3 & 105 & & 250 & 90 & --- & & \\
\hline 4 & 120 & & 160 & 90 & 95 & --- & \\
\hline 5 & 135 & & 160 & 90 & 95 & 110 & \\
\hline 6 & 150 & & 110 & 90 & 85 & 110 & \\
\hline 7 & 165 & & 110 & 90 & 85 & 110 & \\
\hline 8 & 180 & & 80 & 90 & 85 & 110 & \\
\hline 9 & 195 & & 80 & 90 & 85 & 110 & \\
\hline 10 & 210 & & 80 & 90 & 85 & 110 & \\
\hline RUÍNA & 213,5 & --- & 80 & 90 & 85 & 110 & -- \\
\hline
\end{tabular}

\begin{tabular}{|c|c|c|c|c|c|c|c|}
\hline \multicolumn{3}{|c|}{$\begin{array}{l}\text { ESPAÇAMENTO ENTRE } \\
\text { FISSURAS - valores médios (mm) }\end{array}$} & \multicolumn{3}{|l|}{$\begin{array}{l}\text { ALMA } \\
\text { (eixo 3) }\end{array}$} & \multicolumn{2}{|c|}{ MODELO: VQ-7 } \\
\hline Etapa & Força $(\mathrm{kN})$ & $\mathrm{A} 1$ & $\mathrm{~A} 2$ & B1 & B2 & $\mathrm{C} 2$ & $\mathrm{C} 1$ \\
\hline 0 & 60 & & & & & & \\
\hline 1 & 75 & & --- & --- & & & \\
\hline 2 & 90 & & 230 & 400 & --- & --- & \\
\hline 3 & 105 & --- & 145 & 200 & 220 & 130 & --- \\
\hline 4 & 120 & 150 & 140 & 200 & 220 & 130 & 130 \\
\hline 5 & 135 & 150 & 140 & 200 & 220 & 130 & 130 \\
\hline 6 & 150 & 130 & 140 & 200 & 220 & 105 & 110 \\
\hline 7 & 165 & 130 & 140 & 200 & 220 & 105 & 110 \\
\hline 8 & 180 & 115 & 90 & 165 & 150 & 75 & 110 \\
\hline 9 & 195 & 115 & 90 & 165 & 150 & 75 & 110 \\
\hline 10 & 210 & 115 & 90 & 165 & 150 & 75 & 110 \\
\hline RUÍNA & 213,5 & 115 & 90 & 165 & 150 & 75 & 110 \\
\hline
\end{tabular}


Tabela C-19 - Aberturas de fissuras na viga VQ-8.

\begin{tabular}{|c|c|c|c|c|c|c|c|}
\hline \multicolumn{3}{|c|}{$\begin{array}{l}\text { VALORES DAS ABERTURAS } \\
\text { DE FISSURAS (mm) }\end{array}$} & \multicolumn{3}{|c|}{$\begin{array}{l}\text { NERVURA TRACIONADA } \\
\text { face inferior (eixo 1) }\end{array}$} & \multicolumn{2}{|c|}{ MODELO: VQ-8 } \\
\hline Etapa & Força $(\mathrm{kN})$ & A1 & A2 & B1 & B2 & $\mathrm{C} 2$ & $\mathrm{C} 1$ \\
\hline 0 & 60 & & --- & --- & & & \\
\hline 1 & 75 & & 0,04 & 0,04 & 0,04 & --- & --- \\
\hline 2 & 90 & & 0,05 & 0,05 & 0,05 & 0,04 & --- \\
\hline 3 & 105 & & 0,06 & 0,06 & 0,05 & 0,05 & --- \\
\hline 4 & 120 & --- & 0,07 & 0,08 & 0,06 & 0,06 & 0,05 \\
\hline 5 & 135 & 0,05 & 0,07 & 0,08 & 0,08 & 0,06 & 0,06 \\
\hline 6 & 150 & 0,05 & 0,07 & 0,09 & 0,08 & 0,08 & 0,07 \\
\hline 7 & 165 & 0,06 & 0,08 & 0,09 & 0,08 & 0,08 & 0,08 \\
\hline 8 & 180 & 0,07 & 0,08 & 0,09 & 0,09 & 0,08 & 0,08 \\
\hline 9 & 195 & 0,07 & 0,09 & 0,10 & 0,10 & 0,09 & 0,08 \\
\hline 10 & 210 & & & & & & \\
\hline RUÍNA & 225,4 & & & & & & \\
\hline
\end{tabular}

\begin{tabular}{|c|c|c|c|c|c|c|c|}
\hline \multicolumn{3}{|c|}{$\begin{array}{l}\text { VALORES DAS ABERTURAS } \\
\text { DE FISSURAS (mm) }\end{array}$} & \multicolumn{3}{|c|}{$\begin{array}{l}\text { NERVURA TRACIONADA } \\
\text { face lateral (eixo 2) }\end{array}$} & \multicolumn{2}{|c|}{ MODELO: VQ-8 } \\
\hline Etapa & Força $(\mathrm{kN})$ & A1 & A2 & B1 & B2 & $\mathrm{C} 2$ & $\mathrm{C} 1$ \\
\hline 0 & 60 & & & & & & \\
\hline 1 & 75 & & 0,04 & 0,04 & 0,05 & 0,04 & --- \\
\hline 2 & 90 & & 0,05 & 0,05 & 0,05 & 0,05 & 0,04 \\
\hline 3 & 105 & & 0,06 & 0,06 & 0,07 & 0,06 & 0,05 \\
\hline 4 & 120 & & 0,07 & 0,07 & 0,08 & 0,07 & 0,06 \\
\hline 5 & 135 & & 0,07 & 0,08 & 0,09 & 0,07 & 0,07 \\
\hline 6 & 150 & --- & 0,08 & 0,08 & 0,09 & 0,07 & 0,07 \\
\hline 7 & 165 & 0,05 & 0,09 & 0,09 & 0,10 & 0,08 & 0,07 \\
\hline 8 & 180 & 0,06 & 0,09 & 0,09 & 0,10 & 0,08 & 0,09 \\
\hline 9 & 195 & 0,07 & 0,11 & 0,10 & 0,11 & 0,08 & 0,09 \\
\hline 10 & 210 & & & & & & \\
\hline RUÍNA & 225,4 & & & & & & \\
\hline
\end{tabular}

\begin{tabular}{|c|c|c|c|c|c|c|c|}
\hline \multicolumn{3}{|c|}{$\begin{array}{l}\text { VALORES DAS ABERTURAS } \\
\text { DE FISSURAS (mm) }\end{array}$} & \multicolumn{3}{|l|}{$\begin{array}{l}\text { ALMA } \\
\text { (eixo 3) }\end{array}$} & \multicolumn{2}{|c|}{ MODELO: VQ-8 } \\
\hline Etapa & Força $(\mathrm{kN})$ & A1 & A2 & B1 & B2 & $\mathrm{C} 2$ & $\mathrm{C} 1$ \\
\hline 0 & 60 & & & & & & \\
\hline 1 & 75 & & --- & --- & & --- & \\
\hline 2 & 90 & & 0,06 & 0,05 & --- & 0,05 & --- \\
\hline 3 & 105 & --- & 0,07 & 0,06 & 0,06 & 0,07 & 0,09 \\
\hline 4 & 120 & 0,05 & 0,10 & 0,06 & 0,06 & 0,16 & 0,14 \\
\hline 5 & 135 & 0,10 & 0,14 & 0,07 & 0,08 & 0,18 & 0,14 \\
\hline 6 & 150 & 0,11 & 0,15 & 0,08 & 0,09 & 0,20 & 0,15 \\
\hline 7 & 165 & 0,15 & 0,20 & 0,08 & 0,09 & 0,22 & 0,16 \\
\hline 8 & 180 & 0,16 & 0,25 & 0,09 & 0,10 & 0,25 & 0,20 \\
\hline 9 & 195 & 0,20 & 0,40 & 0,10 & 0,11 & 0,75 & 0,25 \\
\hline 10 & 210 & 0,20 & 0,65 & 0,11 & 0,12 & 0,90 & 0,30 \\
\hline RUÍNA & 225,4 & & & & & & \\
\hline
\end{tabular}


Tabela C-20 - Espaçamentos entre fissuras na viga VQ-8.

\begin{tabular}{|c|c|c|c|c|c|c|c|}
\hline \multicolumn{3}{|c|}{$\begin{array}{l}\text { ESPAÇAMENTO ENTRE } \\
\text { FISSURAS - valores médios (mm) }\end{array}$} & \multicolumn{3}{|c|}{$\begin{array}{l}\text { NERVURA TRACIONADA } \\
\text { face inferior (eixo 1) }\end{array}$} & \multicolumn{2}{|c|}{ MODELO: VQ-8 } \\
\hline Etapa & Força $(\mathrm{kN})$ & A1 & A2 & B1 & B2 & $\mathrm{C} 2$ & $\mathrm{C} 1$ \\
\hline 0 & 60 & & & & & & \\
\hline 1 & 75 & & 230 & 90 & & & \\
\hline 2 & 90 & & 230 & 90 & 250 & & \\
\hline 3 & 105 & & 230 & 90 & 175 & 140 & \\
\hline 4 & 120 & & 80 & 90 & 90 & 140 & \\
\hline 5 & 135 & --- & 65 & 90 & 90 & 140 & \\
\hline 6 & 150 & 180 & 65 & 90 & 90 & 140 & -- \\
\hline 7 & 165 & 90 & 65 & 90 & 90 & 100 & 120 \\
\hline 8 & 180 & 90 & 65 & 90 & 90 & 100 & 120 \\
\hline 9 & 195 & 90 & 65 & 90 & 90 & 100 & 70 \\
\hline 10 & 210 & 90 & 65 & 90 & 90 & 100 & 70 \\
\hline RUÍNA & 225,4 & 90 & 65 & 90 & 90 & 100 & 70 \\
\hline
\end{tabular}

\begin{tabular}{|c|c|c|c|c|c|c|c|}
\hline $\begin{array}{l}\text { ESPAÇ } \\
\text { FISSUR }\end{array}$ & $\begin{array}{l}\text { MENTO EN } \\
\text { S - valores n }\end{array}$ & os (mm) & $\begin{array}{l}\text { NERVU } \\
\text { face late }\end{array}$ & $\begin{array}{l}\text { CIO } \\
\text { 2) }\end{array}$ & & MODEI & \\
\hline Etapa & Força $(\mathrm{kN})$ & A1 & A2 & B1 & B2 & $\mathrm{C} 2$ & C1 \\
\hline 0 & 60 & & & & & & \\
\hline 1 & 75 & & 190 & 310 & 360 & & \\
\hline 2 & 90 & & 85 & 200 & 360 & & \\
\hline 3 & 105 & & 85 & 200 & 360 & & -- \\
\hline 4 & 120 & & 65 & 120 & 180 & --- & 90 \\
\hline 5 & 135 & & 65 & 120 & 180 & 400 & 90 \\
\hline 6 & 150 & & 70 & 120 & 180 & 205 & 90 \\
\hline 7 & 165 & & 70 & 120 & 180 & 205 & 90 \\
\hline 8 & 180 & --- & 70 & 120 & 180 & 130 & 90 \\
\hline 9 & 195 & 100 & 70 & 120 & 115 & 100 & 80 \\
\hline 10 & 210 & 100 & 70 & 120 & 115 & 100 & 80 \\
\hline RUÍNA & 225,4 & 100 & 70 & 120 & 115 & 100 & 80 \\
\hline
\end{tabular}

\begin{tabular}{|c|c|c|c|c|c|c|c|}
\hline \multicolumn{3}{|c|}{$\begin{array}{l}\text { ESPAÇAMENTO ENTRE } \\
\text { FISSURAS - valores médios }(\mathrm{mm})\end{array}$} & \multicolumn{3}{|c|}{$\begin{array}{l}\text { ALMA } \\
\text { (eixo 3) }\end{array}$} & \multicolumn{2}{|c|}{ MODELO: VQ-8 } \\
\hline Etapa & Força $(\mathrm{kN})$ & A1 & $\mathrm{A} 2$ & B1 & B2 & $\mathrm{C} 2$ & $\mathrm{C} 1$ \\
\hline 0 & 60 & & & & & & \\
\hline 1 & 75 & & & & & & \\
\hline 2 & 90 & & 80 & & & 150 & \\
\hline 3 & 105 & & 80 & --- & & 150 & \\
\hline 4 & 120 & & 70 & 125 & 145 & 150 & --- \\
\hline 5 & 135 & & 70 & 125 & 145 & 150 & 130 \\
\hline 6 & 150 & --- & 70 & 125 & 145 & 150 & 130 \\
\hline 7 & 165 & 135 & 70 & 125 & 145 & 150 & 130 \\
\hline 8 & 180 & 135 & 70 & 125 & 145 & 150 & 130 \\
\hline 9 & 195 & 135 & 70 & 125 & 145 & 140 & 85 \\
\hline 10 & 210 & 135 & 70 & 125 & 145 & 140 & 85 \\
\hline RUÍNA & 225,4 & 135 & 70 & 125 & 145 & 140 & 85 \\
\hline
\end{tabular}


Tabela C-21 - Aberturas de fissuras na viga VQ-9.

\begin{tabular}{|c|c|c|c|c|c|c|c|}
\hline \multicolumn{3}{|c|}{$\begin{array}{l}\text { VALORES DAS ABERTURAS } \\
\text { DE FISSURAS (mm) }\end{array}$} & \multicolumn{3}{|c|}{$\begin{array}{l}\text { NERVURA TRACIONADA } \\
\text { face inferior (eixo 1) }\end{array}$} & \multicolumn{2}{|c|}{ MODELO: VQ-9 } \\
\hline Etapa & Força $(\mathrm{kN})$ & A1 & A2 & B1 & B2 & $\mathrm{C} 2$ & $\mathrm{C} 1$ \\
\hline \multicolumn{8}{|l|}{0} \\
\hline 1 & 60 & & 0,04 & --- & 0,04 & & \\
\hline 2 & 75 & & 0,04 & 0,04 & 0,04 & & \\
\hline 3 & 90 & --- & 0,05 & 0,05 & 0,05 & --- & --- \\
\hline 4 & 105 & 0,05 & 0,05 & 0,06 & 0,06 & 0,05 & 0,05 \\
\hline 5 & 120 & 0,06 & 0,07 & 0,07 & 0,07 & 0,05 & 0,05 \\
\hline 6 & 135 & 0,07 & 0,08 & 0,08 & 0,08 & 0,06 & 0,06 \\
\hline 7 & 150 & 0,09 & 0,09 & 0,09 & 0,09 & 0,07 & 0,06 \\
\hline 8 & 165 & 0,09 & 0,09 & 0,10 & 0,09 & 0,07 & 0,06 \\
\hline 9 & 180 & 0,09 & 0,09 & 0,10 & 0,09 & 0,08 & 0,07 \\
\hline 10 & 195 & & & & & & \\
\hline RUÍNA & 206,7 & & & & & & \\
\hline
\end{tabular}

\begin{tabular}{|c|c|c|c|c|c|c|c|}
\hline \multicolumn{3}{|c|}{$\begin{array}{l}\text { VALORES DAS ABERTURAS } \\
\text { DE FISSURAS (mm) }\end{array}$} & \multicolumn{3}{|c|}{$\begin{array}{l}\text { NERVURA TRACIONADA } \\
\text { face lateral (eixo 2) }\end{array}$} & \multicolumn{2}{|c|}{ MODELO: VQ-9 } \\
\hline Etapa & Força $(\mathrm{kN})$ & A1 & A2 & B1 & B2 & $\mathrm{C} 2$ & $\mathrm{C} 1$ \\
\hline \multicolumn{8}{|l|}{0} \\
\hline 1 & 60 & & 0,04 & --- & 0,04 & & \\
\hline 2 & 75 & & 0,04 & 0,04 & 0,04 & & \\
\hline 3 & 90 & & 0,05 & 0,05 & 0,05 & --- & \\
\hline 4 & 105 & & 0,05 & 0,06 & 0,06 & 0,05 & \\
\hline 5 & 120 & & 0,05 & 0,06 & 0,06 & 0,06 & \\
\hline 6 & 135 & & 0,06 & 0,06 & 0,07 & 0,06 & \\
\hline 7 & 150 & ---- & 0,09 & 0,07 & 0,07 & 0,07 & \\
\hline 8 & 165 & 0,05 & 0,09 & 0,08 & 0,08 & 0,08 & --- \\
\hline 9 & 180 & 0,05 & 0,10 & 0,09 & 0,09 & 0,09 & 0,05 \\
\hline 10 & 195 & & & & & & \\
\hline RUÍNA & 206,7 & & & & & & \\
\hline
\end{tabular}

\begin{tabular}{|c|c|c|c|c|c|c|c|}
\hline \multicolumn{3}{|c|}{$\begin{array}{l}\text { VALORES DAS ABERTURAS } \\
\text { DE FISSURAS (mm) }\end{array}$} & \multicolumn{3}{|l|}{$\begin{array}{l}\text { ALMA } \\
\text { (eixo 3) }\end{array}$} & \multicolumn{2}{|c|}{ MODELO: VQ-9 } \\
\hline Etapa & Força $(\mathrm{kN})$ & A1 & A2 & B1 & B2 & $\mathrm{C} 2$ & $\mathrm{C} 1$ \\
\hline \multicolumn{8}{|l|}{0} \\
\hline 1 & 60 & & & & & & \\
\hline 2 & 75 & --- & --- & --- & --- & --- & \\
\hline 3 & 90 & 0,04 & 0,05 & 0,05 & 0,05 & 0,05 & --- \\
\hline 4 & 105 & 0,07 & 0,07 & 0,05 & 0,05 & 0,09 & 0,05 \\
\hline 5 & 120 & 0,09 & 0,08 & 0,05 & 0,05 & 0,09 & 0,06 \\
\hline 6 & 135 & 0,12 & 0,11 & 0,06 & 0,06 & 0,12 & 0,09 \\
\hline 7 & 150 & 0,13 & 0,14 & 0,06 & 0,06 & 0,15 & 0,10 \\
\hline 8 & 165 & 0,18 & 0,20 & 0,08 & 0,07 & 0,20 & 0,15 \\
\hline 9 & 180 & 0,25 & 0,25 & 0,08 & 0,07 & 0,35 & 0,25 \\
\hline 10 & 195 & 0,30 & 0,35 & 0,08 & 0,07 & 0,60 & 0,30 \\
\hline RUÍNA & 206,7 & 0,35 & $\mathbf{0 , 5 5}$ & & & $\mathbf{0 , 8 0}$ & 0,40 \\
\hline
\end{tabular}


Tabela C-22 - Espaçamentos entre fissuras na viga VQ-9.

\begin{tabular}{|c|c|c|c|c|c|c|c|}
\hline \multicolumn{3}{|c|}{$\begin{array}{l}\text { ESPAÇAMENTO ENTRE } \\
\text { FISSURAS - valores médios }(\mathrm{mm})\end{array}$} & \multicolumn{3}{|c|}{$\begin{array}{l}\text { NERVURA TRACIONADA } \\
\text { face inferior (eixo 1) }\end{array}$} & \multicolumn{2}{|c|}{ MODELO: VQ-9 } \\
\hline Etapa & Força $(\mathrm{kN})$ & A1 & A2 & B1 & B2 & $\mathrm{C} 2$ & $\mathrm{C} 1$ \\
\hline \multicolumn{8}{|l|}{0} \\
\hline 1 & 60 & & 130 & & & & \\
\hline 2 & 75 & & 130 & 160 & 90 & & \\
\hline 3 & 90 & & 130 & 105 & 90 & & \\
\hline 4 & 105 & & 130 & 105 & 90 & 150 & \\
\hline 5 & 120 & --- & 70 & 65 & 90 & 110 & \\
\hline 6 & 135 & 110 & 70 & 65 & 90 & 90 & \\
\hline 7 & 150 & 110 & 70 & 65 & 75 & 70 & \\
\hline 8 & 165 & 65 & 70 & 65 & 75 & 70 & \\
\hline 9 & 180 & 65 & 70 & 65 & 75 & 70 & \\
\hline 10 & 195 & 65 & 70 & 65 & 75 & 70 & --- \\
\hline RUÍNA & 206,7 & 65 & 70 & 65 & 75 & 70 & --- \\
\hline
\end{tabular}

\begin{tabular}{|c|c|c|c|c|c|c|c|}
\hline $\begin{array}{l}\text { ESPAÇ } \\
\text { FISSUR }\end{array}$ & $\begin{array}{l}\text { MENTO EN } \\
\text { S - valores n }\end{array}$ & $\mathrm{s}(\mathrm{mm})$ & $\begin{array}{l}\text { NERVU } \\
\text { face late }\end{array}$ & $\begin{array}{l}\text { CIC } \\
\text { 2) }\end{array}$ & & MODE & \\
\hline Etapa & Força $(\mathrm{kN})$ & A1 & A2 & B1 & B2 & $\mathrm{C} 2$ & $\mathrm{C} 1$ \\
\hline 0 & & & & & & & \\
\hline 1 & 60 & & & & & & \\
\hline 2 & 75 & & & 85 & 145 & & \\
\hline 3 & 90 & & 290 & 85 & 145 & & \\
\hline 4 & 105 & & 290 & 85 & 95 & 95 & \\
\hline 5 & 120 & & 290 & 85 & 95 & 95 & \\
\hline 6 & 135 & & 290 & 80 & 95 & 95 & \\
\hline 7 & 150 & --- & 290 & 80 & 95 & 95 & \\
\hline 8 & 165 & 50 & 140 & 80 & 95 & 95 & \\
\hline 9 & 180 & 50 & 90 & 80 & 95 & 95 & \\
\hline 10 & 195 & 50 & 90 & 80 & 95 & 95 & -- \\
\hline RUÍNA & 206,7 & 50 & 90 & 80 & 95 & 95 & -- \\
\hline
\end{tabular}

\begin{tabular}{|c|c|c|c|c|c|c|c|}
\hline \multicolumn{3}{|c|}{$\begin{array}{l}\text { ESPAÇAMENTO ENTRE } \\
\text { FISSURAS - valores médios }(\mathrm{mm})\end{array}$} & \multicolumn{3}{|l|}{\begin{tabular}{|l|} 
ALMA \\
(eixo 3)
\end{tabular}} & \multicolumn{2}{|c|}{ MODELO: VQ-9 } \\
\hline Etapa & Força $(\mathrm{kN})$ & A1 & A2 & B1 & B2 & $\mathrm{C} 2$ & $\mathrm{C} 1$ \\
\hline \multicolumn{8}{|l|}{0} \\
\hline 1 & 60 & & & & & & \\
\hline 2 & 75 & & & & & & \\
\hline 3 & 90 & 140 & 160 & 95 & & 280 & \\
\hline 4 & 105 & 120 & 160 & 95 & 210 & 180 & \\
\hline 5 & 120 & 120 & 160 & 95 & 210 & 140 & 100 \\
\hline 6 & 135 & 100 & 160 & 115 & 100 & 90 & 100 \\
\hline 7 & 150 & 100 & 160 & 115 & 100 & 90 & 100 \\
\hline 8 & 165 & 100 & 160 & 115 & 100 & 90 & 100 \\
\hline 9 & 180 & 100 & 160 & 115 & 100 & 90 & 60 \\
\hline 10 & 195 & 100 & 160 & 115 & 100 & 90 & 60 \\
\hline RUÍNA & 206,7 & 100 & 160 & 115 & 100 & 90 & 60 \\
\hline
\end{tabular}


Tabela C-23 - Aberturas de fissuras na viga VQ-10.

\begin{tabular}{|c|c|c|c|c|c|c|c|}
\hline \multicolumn{3}{|c|}{$\begin{array}{l}\text { VALORES DAS ABERTURAS } \\
\text { DE FISSURAS (mm) }\end{array}$} & \multicolumn{3}{|c|}{$\begin{array}{l}\text { NERVURA TRACIONADA } \\
\text { face inferior (eixo 1) }\end{array}$} & \multicolumn{2}{|c|}{ MODELO: VQ-10 } \\
\hline Etapa & Força $(\mathrm{kN})$ & A1 & A2 & B1 & B2 & $\mathrm{C} 2$ & $\mathrm{C} 1$ \\
\hline 0 & 60 & & 0,04 & 0,05 & 0,05 & & \\
\hline 1 & 75 & & 0,04 & 0,06 & 0,05 & & \\
\hline 2 & 90 & & 0,06 & 0,06 & 0,05 & 0,05 & \\
\hline 3 & 105 & 0,05 & 0,06 & 0,08 & 0,07 & 0,06 & \\
\hline 4 & 120 & 0,07 & 0,08 & 0,08 & 0,09 & 0,08 & \\
\hline 5 & 135 & 0,07 & 0,09 & 0,08 & 0,09 & 0,08 & \\
\hline 6 & 150 & 0,09 & 0,09 & 0,08 & 0,10 & 0,08 & \\
\hline 7 & 165 & 0,10 & 0,09 & 0,09 & 0,10 & 0,08 & \\
\hline 8 & 180 & 0,12 & 0,09 & 0,09 & 0,10 & 0,09 & \\
\hline 9 & 195 & 0,14 & 0,11 & 0,10 & 0,10 & 0,09 & --- \\
\hline 10 & 210 & & & & & & \\
\hline RUÍNA & 228,5 & & & & & & \\
\hline
\end{tabular}

\begin{tabular}{|c|c|c|c|c|c|c|c|}
\hline \multicolumn{3}{|c|}{$\begin{array}{l}\text { VALORES DAS ABERTURAS } \\
\text { DE FISSURAS (mm) }\end{array}$} & \multicolumn{3}{|c|}{$\begin{array}{l}\text { NERVURA TRACIONADA } \\
\text { face lateral (eixo 2) }\end{array}$} & \multicolumn{2}{|c|}{ MODELO: VQ-10 } \\
\hline Etapa & Força $(\mathrm{kN})$ & A1 & $\mathrm{A} 2$ & B1 & B2 & $\mathrm{C} 2$ & $\mathrm{C} 1$ \\
\hline 0 & 60 & & 0,04 & 0,05 & 0,05 & & \\
\hline 1 & 75 & & 0,05 & 0,05 & 0,06 & 0,04 & \\
\hline 2 & 90 & & 0,06 & 0,07 & 0,07 & 0,05 & \\
\hline 3 & 105 & & 0,06 & 0,07 & 0,08 & 0,05 & \\
\hline 4 & 120 & & 0,06 & 0,08 & 0,08 & 0,05 & \\
\hline 5 & 135 & & 0,07 & 0,08 & 0,08 & 0,06 & \\
\hline 6 & 150 & & 0,08 & 0,08 & 0,09 & 0,06 & \\
\hline 7 & 165 & 0,05 & 0,08 & 0,08 & 0,09 & 0,06 & \\
\hline 8 & 180 & 0,06 & 0,08 & 0,08 & 0,09 & 0,07 & \\
\hline 9 & 195 & 0,07 & 0,08 & 0,09 & 0,11 & 0,07 & --- \\
\hline 10 & 210 & & & & & & \\
\hline RUÍNA & 228,5 & & & & & & \\
\hline
\end{tabular}

\begin{tabular}{|c|c|c|c|c|c|c|c|}
\hline \multicolumn{3}{|c|}{$\begin{array}{l}\text { VALORES DAS ABERTURAS } \\
\text { DE FISSURAS }(\mathrm{mm})\end{array}$} & \multicolumn{3}{|l|}{$\begin{array}{l}\text { ALMA } \\
\text { (eixo 3) }\end{array}$} & \multicolumn{2}{|c|}{ MODELO: VQ-10 } \\
\hline Etapa & Força $(\mathrm{kN})$ & $\mathrm{A} 1$ & $\mathrm{~A} 2$ & B1 & B2 & $\mathrm{C} 2$ & $\mathrm{C} 1$ \\
\hline 0 & 60 & & & & & & \\
\hline 1 & 75 & & 0,05 & 0,04 & & 0,05 & \\
\hline 2 & 90 & & 0,07 & 0,06 & 0,05 & 0,07 & \\
\hline 3 & 105 & & 0,10 & 0,08 & 0,07 & 0,10 & 0,07 \\
\hline 4 & 120 & --- & 0,18 & 0,08 & 0,08 & 0,15 & 0,12 \\
\hline 5 & 135 & 0,10 & 0,20 & 0,08 & 0,08 & 0,18 & 0,15 \\
\hline 6 & 150 & 0,15 & 0,25 & 0,09 & 0,08 & 0,20 & 0,20 \\
\hline 7 & 165 & 0,16 & 0,30 & 0,09 & 0,09 & 0,25 & 0,22 \\
\hline 8 & 180 & 0,18 & 0,40 & 0,09 & 0,10 & 0,35 & 0,30 \\
\hline 9 & 195 & 0,25 & 0,60 & 0,10 & 0,11 & 0,45 & 0,35 \\
\hline 10 & 210 & 0,25 & 0,85 & 0,10 & 0,11 & 0,60 & 0,50 \\
\hline RUÍNA & 228,5 & & & & & & \\
\hline
\end{tabular}


Tabela C-24 - Espaçamentos entre fissuras na viga VQ-10.

\begin{tabular}{|c|c|c|c|c|c|c|c|}
\hline \multicolumn{3}{|c|}{$\begin{array}{l}\text { ESPAÇAMENTO ENTRE } \\
\text { FISSURAS - valores médios (mm) }\end{array}$} & \multicolumn{3}{|c|}{$\begin{array}{l}\text { NERVURA TRACIONADA } \\
\text { face inferior (eixo 1) }\end{array}$} & \multicolumn{2}{|c|}{ MODELO: VQ-10 } \\
\hline Etapa & Força $(\mathrm{kN})$ & A1 & A2 & B1 & B2 & $\mathrm{C} 2$ & $\mathrm{C} 1$ \\
\hline 0 & 60 & & & & & & \\
\hline 1 & 75 & & 320 & 155 & & & \\
\hline 2 & 90 & & 115 & 115 & 60 & 175 & \\
\hline 3 & 105 & & 100 & 115 & 60 & 175 & \\
\hline 4 & 120 & 205 & 100 & 100 & 60 & 85 & \\
\hline 5 & 135 & 205 & 80 & 100 & 60 & 75 & \\
\hline 6 & 150 & 205 & 80 & 100 & 60 & 65 & \\
\hline 7 & 165 & 90 & 80 & 100 & 55 & 60 & 60 \\
\hline 8 & 180 & 90 & 80 & 100 & 55 & 60 & 60 \\
\hline 9 & 195 & 80 & 80 & 100 & 55 & 60 & 60 \\
\hline 10 & 210 & 80 & 80 & 100 & 55 & 60 & 60 \\
\hline RUÍNA & 228,5 & 80 & 80 & 100 & 55 & 60 & 60 \\
\hline
\end{tabular}

\begin{tabular}{|c|c|c|c|c|c|c|c|}
\hline $\begin{array}{l}\text { ESPAÇ } \\
\text { FISSUR }\end{array}$ & $\begin{array}{l}\text { MENTO EN } \\
\text { S - valores n }\end{array}$ & $\mathrm{s}(\mathrm{mm})$ & $\begin{array}{l}\text { NERVU } \\
\text { face late }\end{array}$ & $\begin{array}{l}\text { CIC } \\
\text { 2) }\end{array}$ & & MODE & \\
\hline Etapa & Força $(\mathrm{kN})$ & A1 & A2 & B1 & B2 & $\mathrm{C} 2$ & $\mathrm{C} 1$ \\
\hline 0 & 60 & & & 90 & & & \\
\hline 1 & 75 & & 200 & 70 & & & \\
\hline 2 & 90 & & 80 & 70 & & 100 & \\
\hline 3 & 105 & & 80 & 70 & 230 & 70 & \\
\hline 4 & 120 & & 80 & 70 & 230 & 70 & \\
\hline 5 & 135 & & 65 & 70 & 165 & 70 & \\
\hline 6 & 150 & & 65 & 70 & 95 & 70 & \\
\hline 7 & 165 & 80 & 65 & 70 & 95 & 70 & \\
\hline 8 & 180 & 80 & 65 & 70 & 70 & 70 & \\
\hline 9 & 195 & & & & & & \\
\hline 10 & 210 & & & & & & \\
\hline RUÍNA & 228,5 & 55 & 65 & 70 & 70 & 70 & \\
\hline
\end{tabular}

\begin{tabular}{|c|c|c|c|c|c|c|c|}
\hline \multicolumn{3}{|c|}{$\begin{array}{l}\text { ESPAÇAMENTO ENTRE } \\
\text { FISSURAS - valores médios }(\mathrm{mm})\end{array}$} & \multicolumn{3}{|l|}{$\begin{array}{l}\text { ALMA } \\
\text { (eixo 3) }\end{array}$} & \multicolumn{2}{|c|}{ MODELO: VQ-10 } \\
\hline Etapa & Força $(\mathrm{kN})$ & $\mathrm{A} 1$ & $\mathrm{~A} 2$ & B1 & B2 & $\mathrm{C} 2$ & $\mathrm{C} 1$ \\
\hline 0 & 60 & & & & & & \\
\hline 1 & 75 & & 150 & & & & \\
\hline 2 & 90 & & 130 & 250 & 170 & 320 & \\
\hline 3 & 105 & & 130 & 250 & 170 & 230 & \\
\hline 4 & 120 & & 130 & 250 & 170 & 230 & \\
\hline 5 & 135 & & 130 & 250 & 170 & 140 & 70 \\
\hline 6 & 150 & 120 & 130 & 125 & 145 & 140 & 70 \\
\hline 7 & 165 & 110 & 90 & 125 & 145 & 140 & 70 \\
\hline 8 & 180 & 110 & 90 & 125 & 145 & 140 & 70 \\
\hline 9 & 195 & & & & & & \\
\hline 10 & 210 & & & & & & \\
\hline RUÍNA & 228,5 & 85 & 90 & 125 & 145 & 140 & 70 \\
\hline
\end{tabular}


Tabela C-25 - Aberturas de fissuras na viga VS-0.

\begin{tabular}{|c|c|c|c|c|c|c|c|}
\hline \multicolumn{3}{|c|}{$\begin{array}{l}\text { VALORES DAS ABERTURAS } \\
\text { DE FISSURAS (mm) }\end{array}$} & \multicolumn{3}{|c|}{$\begin{array}{l}\text { NERVURA TRACIONADA } \\
\text { face inferior (eixo 1) }\end{array}$} & \multicolumn{2}{|c|}{ MODELO: VS - 0} \\
\hline Etapa & Força $(\mathrm{kN})$ & A1 & A2 & B1 & B2 & $\mathrm{C} 2$ & $\mathrm{C} 1$ \\
\hline \multicolumn{8}{|l|}{0} \\
\hline \multicolumn{8}{|l|}{1} \\
\hline \multicolumn{8}{|l|}{2} \\
\hline \multicolumn{8}{|l|}{3} \\
\hline \multicolumn{8}{|l|}{4} \\
\hline \multicolumn{8}{|l|}{5} \\
\hline \multicolumn{8}{|l|}{6} \\
\hline \multicolumn{8}{|l|}{7} \\
\hline 8 & 120 & & & & & & \\
\hline 9 & 140 & & 0,04 & & & & \\
\hline 10 & 160 & & & & & & \\
\hline RUÍNA & 161,1 & & & & & & \\
\hline
\end{tabular}

\begin{tabular}{|c|c|c|c|c|c|c|c|}
\hline \multicolumn{3}{|c|}{$\begin{array}{l}\text { VALORES DAS ABERTURAS } \\
\text { DE FISSURAS (mm) }\end{array}$} & \multicolumn{3}{|c|}{$\begin{array}{l}\text { NERVURA TRACIONADA } \\
\text { face lateral (eixo 2) }\end{array}$} & \multicolumn{2}{|c|}{ MODELO: VS - 0} \\
\hline Etapa & Força $(\mathrm{kN})$ & A1 & $\mathrm{A} 2$ & B1 & B2 & $\mathrm{C} 2$ & $\mathrm{C} 1$ \\
\hline \multicolumn{8}{|l|}{0} \\
\hline \multicolumn{8}{|l|}{1} \\
\hline \multicolumn{8}{|l|}{2} \\
\hline \multicolumn{8}{|l|}{3} \\
\hline \multicolumn{8}{|l|}{4} \\
\hline \multicolumn{8}{|l|}{5} \\
\hline \multirow{2}{*}{\multicolumn{8}{|c|}{$\frac{6}{7}$}} \\
\hline & & & & \multicolumn{4}{|c|}{7} \\
\hline 8 & 120 & & & & & & \\
\hline 9 & 140 & & & & & & \\
\hline 10 & 160 & & & & & & \\
\hline RUÍNA & 161,1 & & & & & & \\
\hline
\end{tabular}

\begin{tabular}{|c|c|c|c|c|c|c|c|}
\hline \multicolumn{3}{|c|}{$\begin{array}{l}\text { VALORES DAS ABERTURAS } \\
\text { DE FISSURAS }(\mathrm{mm}) \\
\end{array}$} & \multicolumn{3}{|l|}{$\begin{array}{l}\text { ALMA } \\
\text { (eixo 3) }\end{array}$} & \multicolumn{2}{|c|}{ MODELO: VS - 0} \\
\hline Etapa & Força $(\mathrm{kN})$ & A1 & A2 & B1 & B2 & $\mathrm{C} 2$ & $\mathrm{C} 1$ \\
\hline \multicolumn{8}{|l|}{0} \\
\hline \multicolumn{8}{|l|}{1} \\
\hline \multicolumn{8}{|l|}{2} \\
\hline \multicolumn{8}{|l|}{3} \\
\hline \multicolumn{8}{|l|}{4} \\
\hline \multicolumn{8}{|l|}{5} \\
\hline \multirow{2}{*}{\multicolumn{8}{|c|}{$\frac{6}{7}$}} \\
\hline \multicolumn{6}{|l|}{7} & & \\
\hline 8 & 120 & & & & & & \\
\hline 9 & 140 & & 0,06 & 0,05 & --- & 0,04 & \\
\hline 10 & 160 & & & & & & \\
\hline RUÍNA & 161,1 & & & & & 3,00 & $\mathbf{3 , 0 0}$ \\
\hline
\end{tabular}


Tabela C-26 - Espaçamentos entre fissuras na viga VS-0.

\begin{tabular}{|c|c|c|c|c|c|c|c|}
\hline \multicolumn{3}{|c|}{$\begin{array}{l}\text { ESPAÇAMENTO ENTRE } \\
\text { FISSURAS - valores médios (mm) }\end{array}$} & \multicolumn{3}{|c|}{$\begin{array}{l}\text { NERVURA TRACIONADA } \\
\text { face inferior (eixo 1) }\end{array}$} & \multicolumn{2}{|c|}{ MODELO: VS - 0} \\
\hline Etapa & Força $(\mathrm{kN})$ & A1 & $\mathrm{A} 2$ & B1 & B2 & $\mathrm{C} 2$ & $\mathrm{C} 1$ \\
\hline \multicolumn{8}{|l|}{0} \\
\hline \multicolumn{8}{|l|}{1} \\
\hline \multicolumn{8}{|l|}{2} \\
\hline \multicolumn{8}{|l|}{3} \\
\hline \multicolumn{8}{|l|}{4} \\
\hline \multicolumn{8}{|l|}{5} \\
\hline \multicolumn{8}{|l|}{6} \\
\hline \multicolumn{8}{|l|}{7} \\
\hline 8 & 120 & & & & & & \\
\hline 9 & 140 & & & & & & \\
\hline 10 & 160 & & & & & & \\
\hline RUÍNA & 161,1 & & & & & & \\
\hline
\end{tabular}

\begin{tabular}{|c|c|c|c|c|c|c|c|}
\hline \multicolumn{3}{|c|}{$\begin{array}{l}\text { ESPAÇAMENTO ENTRE } \\
\text { FISSURAS - valores médios (mm) }\end{array}$} & \multicolumn{3}{|c|}{$\begin{array}{l}\text { NERVURA TRACIONADA } \\
\text { face lateral (eixo 2) }\end{array}$} & \multicolumn{2}{|c|}{ MODELO: VS - 0} \\
\hline Etapa & Força $(\mathrm{kN})$ & A1 & A2 & B1 & B2 & $\mathrm{C} 2$ & $\mathrm{C} 1$ \\
\hline \multicolumn{8}{|l|}{0} \\
\hline \multicolumn{8}{|l|}{1} \\
\hline \multicolumn{8}{|l|}{2} \\
\hline \multicolumn{8}{|l|}{3} \\
\hline \multicolumn{8}{|l|}{4} \\
\hline \multicolumn{8}{|l|}{5} \\
\hline \multicolumn{8}{|l|}{6} \\
\hline \multicolumn{8}{|l|}{7} \\
\hline 8 & 120 & & & & & & \\
\hline 9 & 140 & & & & & & \\
\hline 10 & 160 & & & & & & \\
\hline RUÍNA & 161,1 & & & & & & \\
\hline
\end{tabular}

\begin{tabular}{|c|c|c|c|c|c|c|c|}
\hline $\begin{array}{l}\text { ESPAÇ } \\
\text { FISSUR }\end{array}$ & $\begin{array}{l}\text { UENTO EN } \\
\text { S - valores n }\end{array}$ & os (mm) & $\begin{array}{l}\text { ALMA } \\
\text { (eixo 3) }\end{array}$ & & & MODE & \\
\hline Etapa & Força $(\mathrm{kN})$ & A1 & $\mathrm{A} 2$ & B1 & B2 & $\mathrm{C} 2$ & $\mathrm{C} 1$ \\
\hline 0 & & & & & & & \\
\hline 1 & & & & & & & \\
\hline 2 & & & & & & & \\
\hline 3 & & & & & & & \\
\hline 4 & & & & & & & \\
\hline 5 & & & & & & & \\
\hline 6 & & & & & & & \\
\hline 7 & & & & & & & \\
\hline 8 & 120 & & & & & & \\
\hline 9 & 140 & & & & & & \\
\hline 10 & 160 & & & & & & \\
\hline RUÍNA & 161,1 & & & & & & \\
\hline
\end{tabular}


Tabela C-27 - Aberturas de fissuras na viga VS-1.

\begin{tabular}{|c|c|c|c|c|c|c|c|}
\hline \multicolumn{3}{|c|}{$\begin{array}{l}\text { VALORES DAS ABERTURAS } \\
\text { DE FISSURAS (mm) }\end{array}$} & \multicolumn{3}{|c|}{$\begin{array}{l}\text { NERVURA TRACIONADA } \\
\text { face inferior (eixo 1) }\end{array}$} & \multicolumn{2}{|c|}{ MODELO: VS - 1} \\
\hline Etapa & Força $(\mathrm{kN})$ & A1 & A2 & B1 & B2 & $\mathrm{C} 2$ & $\mathrm{C} 1$ \\
\hline \multicolumn{8}{|l|}{0} \\
\hline \multicolumn{8}{|l|}{1} \\
\hline 2 & 120 & & & & & & \\
\hline 3 & 150 & & --- & 0,04 & & & \\
\hline 4 & 180 & & 0,06 & 0,05 & & & \\
\hline 5 & 210 & & 0,06 & 0,06 & 0,07 & & \\
\hline 6 & 240 & & 0,06 & 0,07 & 0,07 & & \\
\hline 7 & 270 & & 0,07 & 0,08 & 0,08 & 0,07 & \\
\hline 8 & 300 & & 0,08 & 0,08 & 0,08 & 0,08 & \\
\hline 9 & 330 & & 0,08 & 0,08 & 0,08 & 0,08 & \\
\hline 10 & 360 & & & & & & \\
\hline RUÍNA & 366,3 & --- & & & & & --- \\
\hline
\end{tabular}

\begin{tabular}{|c|c|c|c|c|c|c|c|}
\hline \multicolumn{3}{|c|}{$\begin{array}{l}\text { VALORES DAS ABERTURAS } \\
\text { DE FISSURAS }(\mathrm{mm})\end{array}$} & \multicolumn{3}{|c|}{$\begin{array}{l}\text { NERVURA TRACIONADA } \\
\text { face lateral (eixo 2) }\end{array}$} & \multicolumn{2}{|c|}{ MODELO: VS - 1} \\
\hline Etapa & Força $(\mathrm{kN})$ & A1 & $\mathrm{A} 2$ & B1 & B2 & $\mathrm{C} 2$ & $\mathrm{C} 1$ \\
\hline \multicolumn{8}{|l|}{0} \\
\hline \multicolumn{8}{|l|}{1} \\
\hline 2 & 120 & & & & & & \\
\hline 3 & 150 & & & 0,04 & 0,04 & & \\
\hline 4 & 180 & & --- & 0,05 & 0,05 & & \\
\hline 5 & 210 & & 0,05 & 0,05 & 0,05 & 0,05 & \\
\hline 6 & 240 & & 0,06 & 0,06 & 0,07 & 0,07 & \\
\hline 7 & 270 & & 0,07 & 0,07 & 0,07 & 0,07 & \\
\hline 8 & 300 & & 0,08 & 0,08 & 0,09 & 0,09 & \\
\hline 9 & 330 & & 0,08 & 0,08 & 0,09 & 0,09 & \\
\hline 10 & 360 & & & & & & \\
\hline$\overline{\text { RUÍNA }}$ & 366,3 & --- & & & & & -- \\
\hline
\end{tabular}

\begin{tabular}{|c|c|c|c|c|c|c|c|}
\hline \multicolumn{3}{|c|}{$\begin{array}{l}\text { VALORES DAS ABERTURAS } \\
\text { DE FISSURAS (mm) }\end{array}$} & \multicolumn{3}{|l|}{$\begin{array}{l}\text { ALMA } \\
\text { (eixo 3) }\end{array}$} & \multicolumn{2}{|c|}{ MODELO: VS - 1} \\
\hline Etapa & Força $(\mathrm{kN})$ & A1 & $\mathrm{A} 2$ & B1 & B2 & $\mathrm{C} 2$ & $\mathrm{C} 1$ \\
\hline \multicolumn{8}{|l|}{0} \\
\hline \multicolumn{8}{|l|}{1} \\
\hline 2 & 120 & & --- & & & 0,05 & \\
\hline 3 & 150 & & 0,05 & --- & & 0,06 & --- \\
\hline 4 & 180 & --- & 0,06 & 0,05 & 0,07 & 0,08 & 0,07 \\
\hline 5 & 210 & 0,14 & 0,10 & 0,07 & 0,07 & 0,13 & 0,13 \\
\hline 6 & 240 & 0,20 & 0,20 & 0,07 & 0,07 & 0,18 & 0,20 \\
\hline 7 & 270 & 0,20 & 0,30 & 0,07 & 0,07 & 0,30 & 0,25 \\
\hline 8 & 300 & 0,30 & 0,45 & 0,07 & 0,08 & 0,45 & 0,30 \\
\hline 9 & 330 & 0,80 & 0,75 & 0,09 & 0,09 & 0,70 & 0,45 \\
\hline 10 & 360 & 1,80 & 0,80 & & & 1,40 & 0,95 \\
\hline RUÍNA & 366,3 & & & & & 3,00 & \\
\hline
\end{tabular}


Tabela C-28 - Espaçamentos entre fissuras na viga VS-1.

\begin{tabular}{|c|c|c|c|c|c|c|c|}
\hline \multicolumn{3}{|c|}{$\begin{array}{l}\text { ESPAÇAMENTO ENTRE } \\
\text { FISSURAS - valores médios }(\mathrm{mm})\end{array}$} & \multicolumn{3}{|c|}{$\begin{array}{l}\text { NERVURA TRACIONADA } \\
\text { face inferior (eixo 1) }\end{array}$} & \multicolumn{2}{|c|}{ MODELO: VS - 1} \\
\hline Etapa & Força $(\mathrm{kN})$ & A1 & A2 & B1 & B2 & $\mathrm{C} 2$ & $\mathrm{C} 1$ \\
\hline \multicolumn{8}{|l|}{0} \\
\hline \multicolumn{8}{|l|}{1} \\
\hline 2 & 120 & & & & & & \\
\hline 3 & 150 & & & & & & \\
\hline 4 & 180 & & & 140 & & & \\
\hline 5 & 210 & & & 140 & & & \\
\hline 6 & 240 & & 480 & 140 & 160 & & \\
\hline 7 & 270 & & 240 & 140 & 160 & & \\
\hline 8 & 300 & & 210 & 140 & 160 & & \\
\hline 9 & 330 & & 210 & 140 & 160 & & \\
\hline 10 & 360 & & 210 & 140 & 160 & & \\
\hline RUÍNA & 366,3 & --- & 210 & 140 & 160 & --- & --- \\
\hline
\end{tabular}

\begin{tabular}{|c|c|c|c|c|c|c|c|}
\hline \multicolumn{3}{|c|}{$\begin{array}{l}\text { ESPAÇAMENTO ENTRE } \\
\text { FISSURAS - valores médios }(\mathrm{mm})\end{array}$} & \multicolumn{3}{|c|}{$\begin{array}{l}\text { NERVURA TRACIONADA } \\
\text { face lateral (eixo 2) }\end{array}$} & \multicolumn{2}{|c|}{ MODELO: VS - 1} \\
\hline Etapa & Força $(\mathrm{kN})$ & A1 & A2 & B1 & B2 & $\mathrm{C} 2$ & $\mathrm{C} 1$ \\
\hline \multicolumn{8}{|l|}{0} \\
\hline \multicolumn{8}{|l|}{1} \\
\hline 2 & 120 & & & & & & \\
\hline 3 & 150 & & & & & & \\
\hline 4 & 180 & & & & & & \\
\hline 5 & 210 & & & 120 & 450 & & \\
\hline 6 & 240 & & & 120 & 225 & & \\
\hline 7 & 270 & & 230 & 120 & 225 & & \\
\hline 8 & 300 & & 230 & 120 & 225 & & \\
\hline 9 & 330 & & 230 & 120 & 225 & & \\
\hline 10 & 360 & & 230 & 120 & 225 & & \\
\hline RUÍNA & 366,3 & --- & 230 & 120 & 225 & --- & -- \\
\hline
\end{tabular}

\begin{tabular}{|c|c|c|c|c|c|c|c|}
\hline \multicolumn{3}{|c|}{$\begin{array}{l}\text { ESPAÇAMENTO ENTRE } \\
\text { FISSURAS - valores médios }(\mathrm{mm})\end{array}$} & \multicolumn{3}{|l|}{$\begin{array}{l}\text { ALMA } \\
\text { (eixo 3) }\end{array}$} & \multicolumn{2}{|c|}{ MODELO: VS - 1} \\
\hline Etapa & Força $(\mathrm{kN})$ & A1 & A2 & B1 & B2 & $\mathrm{C} 2$ & $\mathrm{C} 1$ \\
\hline \multicolumn{8}{|l|}{0} \\
\hline \multicolumn{8}{|l|}{1} \\
\hline 2 & 120 & & & & & & \\
\hline 3 & 150 & & & & & & \\
\hline 4 & 180 & & 340 & 240 & & 160 & \\
\hline 5 & 210 & & 280 & 240 & 230 & 160 & \\
\hline 6 & 240 & & 280 & 240 & 160 & 160 & \\
\hline 7 & 270 & 240 & 280 & 240 & 160 & 160 & \\
\hline 8 & 300 & 240 & 280 & 240 & 160 & 160 & \\
\hline 9 & 330 & 210 & 280 & 240 & 160 & 160 & 90 \\
\hline 10 & 360 & 210 & 280 & 240 & 160 & 160 & 90 \\
\hline RUÍNA & 366,3 & 210 & 280 & 240 & 160 & 160 & 90 \\
\hline
\end{tabular}


Tabela C-29 - Aberturas de fissuras na viga VS-2.

\begin{tabular}{|c|c|c|c|c|c|c|c|}
\hline \multicolumn{3}{|c|}{$\begin{array}{l}\text { VALORES DAS ABERTURAS } \\
\text { DE FISSURAS (mm) }\end{array}$} & \multicolumn{3}{|c|}{$\begin{array}{l}\text { NERVURA TRACIONADA } \\
\text { face inferior (eixo 1) }\end{array}$} & \multicolumn{2}{|c|}{ MODELO: VS - 2} \\
\hline Etapa & Força $(\mathrm{kN})$ & A1 & A2 & B1 & B2 & $\mathrm{C} 2$ & $\mathrm{C} 1$ \\
\hline \multicolumn{8}{|l|}{0} \\
\hline \multirow{2}{*}{\multicolumn{8}{|c|}{$\frac{1}{2}$}} \\
\hline \multicolumn{6}{|l|}{2} & & \\
\hline 3 & 120 & & & & & & \\
\hline 4 & 150 & & ---- & 0,04 & & & \\
\hline 5 & 180 & & 0,04 & 0,05 & & & \\
\hline 6 & 210 & & 0,05 & 0,05 & & & \\
\hline 7 & 240 & & 0,05 & 0,06 & 0,04 & 0,04 & \\
\hline 8 & 270 & & 0,05 & 0,06 & 0,06 & 0,05 & \\
\hline 9 & 300 & & 0,06 & 0,07 & 0,06 & 0,06 & \\
\hline 10 & 330 & & 0,08 & 0,07 & 0,06 & 0,06 & \\
\hline RUÍNA & 358,8 & --- & 0,08 & $\mathbf{0 , 0 7}$ & $\mathbf{0 , 0 7}$ & 0,07 & \\
\hline
\end{tabular}

\begin{tabular}{|c|c|c|c|c|c|c|c|}
\hline \multicolumn{3}{|c|}{$\begin{array}{l}\text { VALORES DAS ABERTURAS } \\
\text { DE FISSURAS (mm) }\end{array}$} & \multicolumn{3}{|c|}{$\begin{array}{l}\text { NERVURA TRACIONADA } \\
\text { face lateral (eixo 2) }\end{array}$} & \multicolumn{2}{|c|}{ MODELO: VS - 2} \\
\hline Etapa & Força $(\mathrm{kN})$ & A1 & $\mathrm{A} 2$ & B1 & B2 & $\mathrm{C} 2$ & $\mathrm{C} 1$ \\
\hline \multicolumn{8}{|l|}{0} \\
\hline \multicolumn{8}{|l|}{1} \\
\hline \multicolumn{8}{|l|}{2} \\
\hline 3 & 120 & & & & & & \\
\hline 4 & 150 & & & & & & \\
\hline 5 & 180 & & & & & & \\
\hline 6 & 210 & & & & & & \\
\hline 7 & 240 & & & & & & \\
\hline 8 & 270 & & 0,06 & & & & \\
\hline 9 & 300 & & 0,07 & 0,05 & 0,05 & 0,06 & \\
\hline 10 & 330 & & 0,07 & 0,05 & 0,05 & 0,07 & \\
\hline$\overline{\text { RUÍNA }}$ & 358,8 & & & & & & \\
\hline
\end{tabular}

\begin{tabular}{|c|c|c|c|c|c|c|c|}
\hline \multicolumn{3}{|c|}{$\begin{array}{l}\text { VALORES DAS ABERTURAS } \\
\text { DE FISSURAS (mm) }\end{array}$} & \multicolumn{3}{|l|}{$\begin{array}{l}\text { ALMA } \\
\text { (eixo 3) }\end{array}$} & \multicolumn{2}{|c|}{ MODELO: VS - 2} \\
\hline Etapa & Força $(\mathrm{kN})$ & A1 & A2 & B1 & B2 & $\mathrm{C} 2$ & $\mathrm{C} 1$ \\
\hline \multicolumn{8}{|l|}{0} \\
\hline \multicolumn{8}{|l|}{1} \\
\hline \multicolumn{8}{|l|}{2} \\
\hline 3 & 120 & & & & & & \\
\hline 4 & 150 & & & & & 0,04 & \\
\hline 5 & 180 & 0,06 & 0,06 & 0,05 & & 0,09 & \\
\hline 6 & 210 & 0,09 & 0,09 & 0,06 & 0,05 & 0,13 & 0,10 \\
\hline 7 & 240 & 0,09 & 0,09 & 0,07 & 0,05 & 0,13 & 0,12 \\
\hline 8 & 270 & 0,11 & 0,13 & 0,07 & 0,06 & 0,20 & 0,20 \\
\hline 9 & 300 & 0,20 & 0,20 & 0,07 & 0,06 & 0,25 & 0,25 \\
\hline 10 & 330 & 0,25 & 0,30 & 0,08 & 0,06 & 0,30 & 0,30 \\
\hline RUÍNA & 358,8 & $0,35 / 0,80$ & $0,75 / 2,50$ & & & $0,50 / 0,70$ & $0,50 / 0,80$ \\
\hline
\end{tabular}


Tabela C-30 - Espaçamentos entre fissuras na viga VS-2.

\begin{tabular}{|c|c|c|c|c|c|c|c|}
\hline \multicolumn{3}{|c|}{$\begin{array}{l}\text { ESPAÇAMENTO ENTRE } \\
\text { FISSURAS - valores médios (mm) }\end{array}$} & \multicolumn{3}{|c|}{$\begin{array}{l}\text { NERVURA TRACIONADA } \\
\text { face inferior (eixo 1) }\end{array}$} & \multicolumn{2}{|c|}{ MODELO: VS - 2} \\
\hline Etapa & Força $(\mathrm{kN})$ & A1 & A2 & B1 & B2 & $\mathrm{C} 2$ & $\mathrm{Cl}$ \\
\hline \multicolumn{8}{|l|}{0} \\
\hline \multicolumn{8}{|l|}{1} \\
\hline \multicolumn{8}{|l|}{2} \\
\hline 3 & 120 & & & & & & \\
\hline 4 & 150 & & & & & & \\
\hline 5 & 180 & & & & & & \\
\hline 6 & 210 & & & & & & \\
\hline 7 & 240 & & & & 340 & & \\
\hline 8 & 270 & & 100 & 140 & 200 & 145 & \\
\hline 9 & 300 & & 100 & 140 & 200 & 95 & \\
\hline 10 & 330 & & 100 & 115 & 150 & 95 & \\
\hline RUÍNA & 358,8 & --- & 100 & 115 & 120 & 95 & --- \\
\hline
\end{tabular}

\begin{tabular}{|c|c|c|c|c|c|c|c|}
\hline \multicolumn{3}{|c|}{$\begin{array}{l}\text { ESPAÇAMENTO ENTRE } \\
\text { FISSURAS - valores médios (mm) }\end{array}$} & \multicolumn{3}{|c|}{$\begin{array}{l}\text { NERVURA TRACIONADA } \\
\text { face lateral (eixo 2) }\end{array}$} & \multicolumn{2}{|c|}{ MODELO: VS - 2} \\
\hline Etapa & Força $(\mathrm{kN})$ & A1 & A2 & B1 & B2 & $\mathrm{C} 2$ & $\mathrm{C} 1$ \\
\hline \multicolumn{8}{|l|}{0} \\
\hline \multicolumn{8}{|l|}{1} \\
\hline \multicolumn{8}{|l|}{2} \\
\hline 3 & 120 & & & & & & \\
\hline 4 & 150 & & & & & & \\
\hline 5 & 180 & & & & & & \\
\hline 6 & 210 & & & & & & \\
\hline 7 & 240 & & & & & & \\
\hline 8 & 270 & & 290 & & & & \\
\hline 9 & 300 & & & & & & \\
\hline 10 & 330 & & & 250 & & & \\
\hline RUÍNA & 358,8 & --- & & & & & \\
\hline
\end{tabular}

\begin{tabular}{|c|c|c|c|c|c|c|c|}
\hline \multicolumn{3}{|c|}{$\begin{array}{l}\text { ESPAÇAMENTO ENTRE } \\
\text { FISSURAS - valores médios }(\mathrm{mm})\end{array}$} & \multicolumn{3}{|l|}{$\begin{array}{l}\text { ALMA } \\
\text { (eixo 3) }\end{array}$} & \multicolumn{2}{|c|}{ MODELO: VS - 2} \\
\hline Etapa & Força $(\mathrm{kN})$ & A1 & A2 & B1 & B2 & $\mathrm{C} 2$ & $\mathrm{C} 1$ \\
\hline \multicolumn{8}{|l|}{0} \\
\hline \multirow{2}{*}{\multicolumn{8}{|c|}{$\frac{1}{2}$}} \\
\hline 2 & & & & & & & \\
\hline 3 & 120 & & & & & & \\
\hline 4 & 150 & & & & & & \\
\hline 5 & 180 & & 230 & & & 300 & \\
\hline 6 & 210 & & 230 & & & 240 & \\
\hline 7 & 240 & 180 & 230 & & & & \\
\hline 8 & 270 & 130 & 150 & & & & 200 \\
\hline 9 & 300 & 130 & 150 & & 370 & 240 & \\
\hline 10 & 330 & 130 & 130 & 150 & 370 & 240 & \\
\hline RUÍNA & 358,8 & 130 & 130 & 150 & 370 & 220 & 200 \\
\hline
\end{tabular}


Tabela C-31 - Aberturas de fissuras na viga VS-3.

\begin{tabular}{|c|c|c|c|c|c|c|c|}
\hline \multicolumn{3}{|c|}{$\begin{array}{l}\text { VALORES DAS ABERTURAS } \\
\text { DE FISSURAS (mm) }\end{array}$} & \multicolumn{3}{|c|}{$\begin{array}{l}\text { NERVURA TRACIONADA } \\
\text { face inferior (eixo 1) }\end{array}$} & \multicolumn{2}{|c|}{ MODELO: VS - 3} \\
\hline Etapa & Força $(\mathrm{kN})$ & A1 & A2 & B1 & B2 & $\mathrm{C} 2$ & $\mathrm{C} 1$ \\
\hline \multicolumn{8}{|l|}{0} \\
\hline \multicolumn{8}{|l|}{1} \\
\hline 2 & 120 & & & --- & --- & & \\
\hline 3 & 150 & & --- & 0,05 & 0,05 & --- & \\
\hline 4 & 180 & & 0,05 & 0,05 & 0,06 & 0,05 & \\
\hline 5 & 210 & & 0,07 & 0,06 & 0,06 & 0,06 & --- \\
\hline 6 & 240 & & 0,07 & 0,07 & 0,08 & 0,07 & 0,06 \\
\hline 7 & 270 & ---- & 0,08 & 0,07 & 0,08 & 0,08 & 0,07 \\
\hline 8 & 300 & 0,06 & 0,08 & 0,07 & 0,08 & 0,08 & 0,07 \\
\hline 9 & 330 & 0,07 & 0,08 & 0,09 & 0,09 & 0,08 & 0,08 \\
\hline 10 & 360 & 0,10 & 0,08 & 0,09 & 0,09 & 0,10 & 0,09 \\
\hline RUÍNA & 384,4 & & & & & & \\
\hline
\end{tabular}

\begin{tabular}{|c|c|c|c|c|c|c|c|}
\hline \multicolumn{3}{|c|}{$\begin{array}{l}\text { VALORES DAS ABERTURAS } \\
\text { DE FISSURAS (mm) }\end{array}$} & \multicolumn{3}{|c|}{$\begin{array}{l}\text { NERVURA TRACIONADA } \\
\text { face lateral (eixo 2) }\end{array}$} & \multicolumn{2}{|c|}{ MODELO: VS - 3} \\
\hline Etapa & Força $(\mathrm{kN})$ & A1 & $\mathrm{A} 2$ & B1 & B2 & $\mathrm{C} 2$ & $\mathrm{C} 1$ \\
\hline \multicolumn{8}{|l|}{0} \\
\hline \multicolumn{8}{|l|}{1} \\
\hline 2 & 120 & & --- & --- & --- & --- & \\
\hline 3 & 150 & & 0,05 & 0,05 & 0,05 & 0,05 & \\
\hline 4 & 180 & & 0,06 & 0,06 & 0,06 & 0,06 & \\
\hline 5 & 210 & & 0,06 & 0,07 & 0,07 & 0,07 & --- \\
\hline 6 & 240 & --- & 0,06 & 0,07 & 0,07 & 0,07 & 0,05 \\
\hline 7 & 270 & 0,05 & 0,06 & 0,07 & 0,08 & 0,07 & 0,06 \\
\hline 8 & 300 & 0,05 & 0,06 & 0,08 & 0,08 & 0,08 & 0,06 \\
\hline 9 & 330 & 0,06 & 0,07 & 0,09 & 0,08 & 0,08 & 0,06 \\
\hline 10 & 360 & 0,06 & 0,08 & 0,09 & 0,08 & 0,09 & 0,07 \\
\hline RUÍNA & 384,4 & & & & & & \\
\hline
\end{tabular}

\begin{tabular}{|c|c|c|c|c|c|c|c|}
\hline \multicolumn{3}{|c|}{$\begin{array}{l}\text { VALORES DAS ABERTURAS } \\
\text { DE FISSURAS }(\mathrm{mm})\end{array}$} & \multicolumn{3}{|l|}{$\begin{array}{l}\text { ALMA } \\
\text { (eixo 3) }\end{array}$} & \multicolumn{2}{|c|}{ MODELO: VS - 3} \\
\hline Etapa & Força $(\mathrm{kN})$ & A1 & A2 & B1 & B2 & $\mathrm{C} 2$ & $\mathrm{C} 1$ \\
\hline \multicolumn{8}{|l|}{0} \\
\hline \multicolumn{8}{|l|}{1} \\
\hline 2 & 120 & & --- & & 0,04 & 0,04 & \\
\hline 3 & 150 & --- & 0,05 & & 0,05 & 0,05 & \\
\hline 4 & 180 & 0,05 & 0,06 & & 0,06 & 0,06 & --- \\
\hline 5 & 210 & 0,12 & 0,11 & -- & 0,07 & 0,12 & 0,10 \\
\hline 6 & 240 & 0,15 & 0,15 & 0,04 & 0,07 & 0,15 & 0,13 \\
\hline 7 & 270 & 0,16 & 0,20 & 0,05 & 0,07 & 0,20 & 0,13 \\
\hline 8 & 300 & 0,20 & 0,25 & 0,05 & 0,08 & 0,25 & 0,20 \\
\hline 9 & 330 & 0,20 & 0,30 & 0,05 & 0,08 & 0,25 & 0,25 \\
\hline 10 & 360 & 0,30 & 0,40 & 0,07 & 0,08 & 0,40 & 0,40 \\
\hline RUÍNA & 384,4 & 0,65 & 0,75 & & & $\mathbf{0 , 5 0}$ & 0,50 \\
\hline
\end{tabular}


Tabela C-32 - Espaçamentos entre fissuras na viga VS-3.

\begin{tabular}{|c|c|c|c|c|c|c|c|}
\hline \multicolumn{3}{|c|}{$\begin{array}{l}\text { ESPAÇAMENTO ENTRE } \\
\text { FISSURAS - valores médios (mm) }\end{array}$} & \multicolumn{3}{|c|}{$\begin{array}{l}\text { NERVURA TRACIONADA } \\
\text { face inferior (eixo 1) }\end{array}$} & \multicolumn{2}{|c|}{ MODELO: VS - 3} \\
\hline Etapa & Força $(\mathrm{kN})$ & A1 & A2 & B1 & B2 & $\mathrm{C} 2$ & $\mathrm{C} 1$ \\
\hline \multicolumn{8}{|l|}{0} \\
\hline \multicolumn{8}{|l|}{1} \\
\hline 2 & 120 & & & & & & \\
\hline 3 & 150 & & & & 290 & & \\
\hline 4 & 180 & & 260 & & 290 & & \\
\hline 5 & 210 & & 260 & 190 & 145 & & \\
\hline 6 & 240 & & 210 & 115 & 145 & 310 & \\
\hline 7 & 270 & & 175 & 115 & 145 & 310 & \\
\hline 8 & 300 & 120 & 155 & 100 & 145 & 310 & \\
\hline 9 & 330 & 120 & 155 & 100 & 145 & 140 & \\
\hline 10 & 360 & 120 & 155 & 100 & 145 & 140 & \\
\hline RUÍNA & 384,4 & 120 & 155 & 100 & 145 & 140 & --- \\
\hline
\end{tabular}

\begin{tabular}{|c|c|c|c|c|c|c|c|}
\hline \multicolumn{3}{|c|}{$\begin{array}{l}\text { ESPAÇAMENTO ENTRE } \\
\text { FISSURAS - valores médios (mm) }\end{array}$} & \multicolumn{3}{|c|}{$\begin{array}{l}\text { NERVURA TRACIONADA } \\
\text { face lateral (eixo 2) }\end{array}$} & \multicolumn{2}{|c|}{ MODELO: VS - 3} \\
\hline Etapa & Força $(\mathrm{kN})$ & A1 & A2 & B1 & B2 & $\mathrm{C} 2$ & $\mathrm{C} 1$ \\
\hline \multicolumn{8}{|l|}{0} \\
\hline \multicolumn{8}{|l|}{1} \\
\hline 2 & 120 & & & & & & \\
\hline 3 & 150 & & & & 160 & 160 & \\
\hline 4 & 180 & & & & 160 & 160 & \\
\hline 5 & 210 & & & & 125 & 160 & \\
\hline 6 & 240 & & 185 & 270 & 125 & 160 & \\
\hline 7 & 270 & & 145 & 270 & 125 & 160 & \\
\hline 8 & 300 & & 115 & 270 & 125 & 130 & \\
\hline 9 & 330 & & 115 & 270 & 125 & 130 & \\
\hline 10 & 360 & & 115 & 270 & 125 & 130 & \\
\hline RUÍNA & 384,4 & --- & 115 & 270 & 125 & 130 & -- \\
\hline
\end{tabular}

\begin{tabular}{|c|c|c|c|c|c|c|c|}
\hline \multicolumn{3}{|c|}{$\begin{array}{l}\text { ESPAÇAMENTO ENTRE } \\
\text { FISSURAS - valores médios (mm) }\end{array}$} & \multicolumn{3}{|l|}{$\begin{array}{l}\text { ALMA } \\
\text { (eixo 3) }\end{array}$} & \multicolumn{2}{|c|}{ MODELO: VS - 3} \\
\hline Etapa & Força $(\mathrm{kN})$ & A1 & A2 & B1 & B2 & $\mathrm{C} 2$ & $\mathrm{C} 1$ \\
\hline \multicolumn{8}{|l|}{0} \\
\hline \multicolumn{8}{|l|}{1} \\
\hline 2 & 120 & & & & & & \\
\hline 3 & 150 & & & & & & \\
\hline 4 & 180 & & & & & & \\
\hline 5 & 210 & 350 & 160 & & & & 150 \\
\hline 6 & 240 & 140 & 160 & & & & 150 \\
\hline 7 & 270 & 140 & 160 & & & 300 & 150 \\
\hline 8 & 300 & 100 & 160 & 135 & & 280 & 150 \\
\hline 9 & 330 & 100 & 160 & 135 & & 280 & 150 \\
\hline 10 & 360 & 100 & 160 & 135 & & 280 & 150 \\
\hline RUÍNA & 384,4 & 100 & 160 & 135 & -- & 280 & 150 \\
\hline
\end{tabular}


Tabela C-33 - Aberturas de fissuras na viga VS-4.

\begin{tabular}{|c|c|c|c|c|c|c|c|}
\hline \multicolumn{3}{|c|}{$\begin{array}{l}\text { VALORES DAS ABERTURAS } \\
\text { DE FISSURAS (mm) }\end{array}$} & \multicolumn{3}{|c|}{$\begin{array}{l}\text { NERVURA TRACIONADA } \\
\text { face inferior (eixo 1) }\end{array}$} & \multicolumn{2}{|c|}{ MODELO: VS - 4} \\
\hline Etapa & Força $(\mathrm{kN})$ & A1 & A2 & B1 & B2 & $\mathrm{C} 2$ & $\mathrm{C} 1$ \\
\hline \multicolumn{8}{|l|}{0} \\
\hline 1 & 150 & & --- & 0,04 & 0,04 & 0,04 & \\
\hline 2 & 180 & & 0,04 & 0,06 & 0,06 & 0,05 & \\
\hline 3 & 210 & & 0,06 & 0,06 & 0,08 & 0,05 & \\
\hline 4 & 240 & & 0,06 & 0,07 & 0,08 & 0,06 & \\
\hline 5 & 270 & --- & 0,08 & 0,09 & 0,10 & 0,08 & \\
\hline 6 & 300 & 0,05 & 0,08 & 0,09 & 0,10 & 0,08 & \\
\hline 7 & 330 & 0,06 & 0,09 & 0,10 & 0,10 & 0,11 & \\
\hline 8 & 360 & 0,06 & 0,09 & 0,10 & 0,11 & 0,11 & \\
\hline 9 & 390 & 0,06 & 0,11 & 0,12 & 0,11 & 0,12 & --- \\
\hline 10 & 420 & & & & & & \\
\hline RUÍNA & 4434,8 & & & & & & \\
\hline
\end{tabular}

\begin{tabular}{|c|c|c|c|c|c|c|c|}
\hline \multicolumn{3}{|c|}{$\begin{array}{l}\text { VALORES DAS ABERTURAS } \\
\text { DE FISSURAS }(\mathrm{mm})\end{array}$} & \multicolumn{3}{|c|}{$\begin{array}{l}\text { NERVURA TRACIONADA } \\
\text { face lateral (eixo 2) }\end{array}$} & \multicolumn{2}{|c|}{ MODELO: VS - 4} \\
\hline Etapa & Força $(\mathrm{kN})$ & A1 & $\mathrm{A} 2$ & B1 & B2 & $\mathrm{C} 2$ & $\mathrm{C} 1$ \\
\hline \multicolumn{8}{|l|}{0} \\
\hline 1 & 150 & & --- & 0,05 & 0,04 & 0,04 & \\
\hline 2 & 180 & & 0,04 & 0,06 & 0,05 & 0,05 & \\
\hline 3 & 210 & & 0,05 & 0,07 & 0,07 & 0,05 & \\
\hline 4 & 240 & & 0,06 & 0,08 & 0,08 & 0,06 & \\
\hline 5 & 270 & & 0,07 & 0,10 & 0,09 & 0,08 & \\
\hline 6 & 300 & & 0,07 & 0,10 & 0,09 & 0,08 & \\
\hline 7 & 330 & & 0,09 & 0,10 & 0,10 & 0,10 & \\
\hline 8 & 360 & & 0,09 & 0,10 & 0,11 & 0,10 & \\
\hline 9 & 390 & --- & 0,11 & 0,13 & 0,11 & 0,10 & --- \\
\hline 10 & 420 & & & & & & \\
\hline RUÍNA & 434,8 & & & & & & \\
\hline
\end{tabular}

\begin{tabular}{|c|c|c|c|c|c|c|c|}
\hline $\begin{array}{l}\text { VALOR } \\
\text { DE FIS: }\end{array}$ & $\begin{array}{l}\text { S DAS ABE } \\
\text { RAS (mm) }\end{array}$ & URAS & $\begin{array}{l}\text { ALMA } \\
\text { (eixo 3) }\end{array}$ & & & MODEI & \\
\hline Etapa & Força $(\mathrm{kN})$ & A1 & $\mathrm{A} 2$ & B1 & B2 & $\mathrm{C} 2$ & $\mathrm{C} 1$ \\
\hline 0 & & & & & & & \\
\hline 1 & 150 & & --- & & & 0,03 & \\
\hline 2 & 180 & & 0,05 & & & 0,06 & --- \\
\hline 3 & 210 & --- & 0,08 & --- & & 0,10 & 0,08 \\
\hline 4 & 240 & 0,10 & 0,15 & 0,06 & --- & 0,12 & 0,12 \\
\hline 5 & 270 & 0,14 & 0,20 & 0,06 & 0,07 & 0,20 & 0,18 \\
\hline 6 & 300 & 0,16 & 0,20 & 0,07 & 0,08 & 0,25 & 0,20 \\
\hline 7 & 330 & 0,25 & 0,25 & 0,08 & 0,08 & 0,30 & 0,25 \\
\hline 8 & 360 & 0,30 & 0,30 & 0,08 & 0,10 & 0,35 & 0,30 \\
\hline 9 & 390 & 0,40 & 0,40 & 0,10 & 0,12 & 0,35 & 0,35 \\
\hline 10 & 420 & 0,50 & 0,45 & & & 0,40 & 0,40 \\
\hline RUÍNA & 434,8 & & & & & & \\
\hline
\end{tabular}


Tabela C-34 - Espaçamentos entre fissuras na viga VS-4.

\begin{tabular}{|c|c|c|c|c|c|c|c|}
\hline \multicolumn{3}{|c|}{$\begin{array}{l}\text { ESPAÇAMENTO ENTRE } \\
\text { FISSURAS - valores médios (mm) }\end{array}$} & \multicolumn{3}{|c|}{$\begin{array}{l}\text { NERVURA TRACIONADA } \\
\text { face inferior (eixo 1) }\end{array}$} & \multicolumn{2}{|c|}{ MODELO: VS - 4} \\
\hline Etapa & Força $(\mathrm{kN})$ & A1 & A2 & B1 & B2 & $\mathrm{C} 2$ & $\mathrm{C} 1$ \\
\hline \multicolumn{8}{|l|}{0} \\
\hline 1 & 150 & & & 180 & 410 & & \\
\hline 2 & 180 & & 255 & 165 & 410 & & \\
\hline 3 & 210 & & 255 & 165 & 240 & 360 & \\
\hline 4 & 240 & & 170 & 140 & 175 & 360 & \\
\hline 5 & 270 & & 170 & 140 & 140 & 240 & \\
\hline 6 & 300 & 200 & 140 & 120 & 140 & 240 & \\
\hline 7 & 330 & 180 & 120 & 100 & 115 & 175 & \\
\hline 8 & 360 & 140 & 115 & 90 & 115 & 130 & \\
\hline 9 & 390 & 140 & 115 & 90 & 115 & 130 & \\
\hline 10 & 420 & 140 & 115 & 90 & 115 & 130 & \\
\hline RUÍNA & 4434,8 & 140 & 115 & 90 & 115 & 130 & \\
\hline
\end{tabular}

\begin{tabular}{|c|c|c|c|c|c|c|c|}
\hline \multicolumn{3}{|c|}{$\begin{array}{l}\text { ESPAÇAMENTO ENTRE } \\
\text { FISSURAS - valores médios (mm) }\end{array}$} & \multicolumn{3}{|c|}{$\begin{array}{l}\text { NERVURA TRACIONADA } \\
\text { face lateral (eixo 2) }\end{array}$} & \multicolumn{2}{|c|}{ MODELO: VS - 4} \\
\hline Etapa & Força $(\mathrm{kN})$ & A1 & A2 & B1 & B2 & $\mathrm{C} 2$ & $\mathrm{C} 1$ \\
\hline \multicolumn{8}{|l|}{0} \\
\hline 1 & 150 & & & 215 & & & \\
\hline 2 & 180 & & 400 & 215 & 420 & & \\
\hline 3 & 210 & & 400 & 215 & 420 & & \\
\hline 4 & 240 & & 400 & 215 & 260 & 150 & \\
\hline 5 & 270 & & 400 & 215 & 105 & 150 & \\
\hline 6 & 300 & & 400 & 215 & 105 & 150 & \\
\hline 7 & 330 & & 200 & 150 & 105 & 120 & \\
\hline 8 & 360 & & 130 & 150 & 105 & 115 & \\
\hline 9 & 390 & & 80 & 150 & 105 & 115 & \\
\hline 10 & 420 & & 80 & 150 & 105 & 115 & \\
\hline RUÍNA & 434,8 & & 80 & 150 & 105 & $\overline{115}$ & \\
\hline
\end{tabular}

\begin{tabular}{|c|c|c|c|c|c|c|c|}
\hline $\begin{array}{l}\text { ESPAÇ } \\
\text { FISSUR }\end{array}$ & $\begin{array}{l}\text { MENTO EN } \\
\text { S - valores n }\end{array}$ & $\begin{array}{l}\mathrm{E} \\
\mathrm{os}(\mathrm{mm})\end{array}$ & \begin{tabular}{|l|} 
ALMA \\
(eixo 3)
\end{tabular} & & & MODE & \\
\hline Etapa & Força $(\mathrm{kN})$ & A1 & $\mathrm{A} 2$ & B1 & B2 & $\mathrm{C} 2$ & $\mathrm{C} 1$ \\
\hline 0 & & & & & & & \\
\hline 1 & 150 & & & & & & \\
\hline 2 & 180 & & & & & & \\
\hline 3 & 210 & & 225 & & & & \\
\hline 4 & 240 & & 225 & & & 450 & \\
\hline 5 & 270 & & 150 & 450 & & 450 & \\
\hline 6 & 300 & 200 & 150 & 350 & 260 & 170 & \\
\hline 7 & 330 & 200 & 150 & 350 & 260 & 170 & \\
\hline 8 & 360 & 200 & 150 & 350 & 260 & 170 & \\
\hline 9 & 390 & 200 & 150 & 350 & 260 & 170 & \\
\hline 10 & 420 & 200 & 150 & 350 & 260 & 170 & \\
\hline RUÍNA & 434,8 & 200 & 150 & 350 & 260 & 170 & \\
\hline
\end{tabular}


Tabela C-35 - Aberturas de fissuras na viga VS-5.

\begin{tabular}{|c|c|c|c|c|c|c|c|}
\hline \multicolumn{3}{|c|}{$\begin{array}{l}\text { VALORES DAS ABERTURAS } \\
\text { DE FISSURAS (mm) }\end{array}$} & \multicolumn{3}{|c|}{$\begin{array}{l}\text { NERVURA TRACIONADA } \\
\text { face inferior (eixo 1) }\end{array}$} & \multicolumn{2}{|c|}{ MODELO: VS - 5} \\
\hline Etapa & Força $(\mathrm{kN})$ & A1 & A2 & B1 & B2 & $\mathrm{C} 2$ & $\mathrm{C} 1$ \\
\hline \multicolumn{8}{|l|}{0} \\
\hline 1 & 150 & & --- & 0,04 & & & \\
\hline 2 & 180 & & 0,04 & 0,04 & 0,04 & 0,04 & \\
\hline 3 & 210 & & 0,06 & 0,06 & 0,05 & 0,05 & \\
\hline 4 & 240 & & 0,06 & 0,06 & 0,06 & 0,06 & \\
\hline 5 & 270 & & 0,08 & 0,06 & 0,06 & 0,06 & \\
\hline 6 & 300 & & 0,10 & 0,09 & 0,08 & 0,08 & \\
\hline 7 & 330 & & 0,10 & 0,09 & 0,08 & 0,08 & \\
\hline 8 & 360 & & 0,12 & 0,10 & 0,10 & 0,10 & \\
\hline 9 & 390 & & 0,14 & 0,12 & 0,11 & 0,11 & \\
\hline 10 & 420 & --- & 0,14 & 0,13 & 0,11 & 0,11 & \\
\hline RUÍNA & 430,3 & & & & & & \\
\hline
\end{tabular}

\begin{tabular}{|c|c|c|c|c|c|c|c|}
\hline \multicolumn{3}{|c|}{$\begin{array}{l}\text { VALORES DAS ABERTURAS } \\
\text { DE FISSURAS }(\mathrm{mm})\end{array}$} & \multicolumn{3}{|c|}{$\begin{array}{l}\text { NERVURA TRACIONADA } \\
\text { face lateral (eixo 2) }\end{array}$} & \multicolumn{2}{|c|}{ MODELO: VS - 5} \\
\hline Etapa & Força $(\mathrm{kN})$ & A1 & $\mathrm{A} 2$ & B1 & B2 & $\mathrm{C} 2$ & $\mathrm{C} 1$ \\
\hline \multicolumn{8}{|l|}{0} \\
\hline 1 & 150 & & --- & --- & & & \\
\hline 2 & 180 & & 0,04 & 0,04 & --- & 0,04 & \\
\hline 3 & 210 & & 0,06 & 0,05 & 0,05 & 0,05 & \\
\hline 4 & 240 & & 0,08 & 0,05 & 0,05 & 0,05 & \\
\hline 5 & 270 & & 0,09 & 0,06 & 0,07 & 0,06 & \\
\hline 6 & 300 & & 0,11 & 0,08 & 0,07 & 0,08 & \\
\hline 7 & 330 & & 0,11 & 0,09 & 0,08 & 0,08 & \\
\hline 8 & 360 & & 0,14 & 0,10 & 0,08 & 0,08 & \\
\hline 9 & 390 & & 0,15 & 0,10 & 0,09 & 0,09 & \\
\hline 10 & 420 & --- & 0,15 & 0,10 & 0,10 & 0,10 & -- \\
\hline RUÍNA & 430,3 & & & & & & \\
\hline
\end{tabular}

\begin{tabular}{|c|c|c|c|c|c|c|c|}
\hline $\begin{array}{l}\text { VALOR } \\
\text { DE FIS: }\end{array}$ & $\begin{array}{l}\text { S DAS ABE } \\
\text { RAS (mm) }\end{array}$ & URAS & $\begin{array}{l}\text { ALMA } \\
\text { (eixo 3) }\end{array}$ & & & MODE & \\
\hline Etapa & Força $(\mathrm{kN})$ & A1 & $\mathrm{A} 2$ & B1 & B2 & $\mathrm{C} 2$ & $\mathrm{C} 1$ \\
\hline 0 & & & & & & & \\
\hline 1 & 150 & & --- & --- & & --- & \\
\hline 2 & 180 & & 0,06 & 0,05 & --- & 0,05 & --- \\
\hline 3 & 210 & --- & 0,09 & 0,05 & 0,05 & 0,06 & 0,05 \\
\hline 4 & 240 & 0,04 & 0,13 & 0,06 & 0,05 & 0,12 & 0,07 \\
\hline 5 & 270 & 0,10 & 0,20 & 0,06 & 0,06 & 0,16 & 0,09 \\
\hline 6 & 300 & 0,12 & 0,25 & 0,07 & 0,07 & 0,25 & 0,10 \\
\hline 7 & 330 & 0,18 & 0,30 & 0,07 & 0,08 & 0,25 & 0,10 \\
\hline 8 & 360 & 0,18 & 0,30 & 0,08 & 0,08 & 0,30 & 0,15 \\
\hline 9 & 390 & 0,25 & 0,35 & 0,09 & 0,09 & 0,60 & 0,16 \\
\hline 10 & 420 & 0,25 & 0,40 & 0,09 & 0,09 & 1,05 & 0,16 \\
\hline RUÍNA & 430,3 & & & & & & \\
\hline
\end{tabular}


Tabela C-36 - Espaçamentos entre fissuras na viga VS-5.

\begin{tabular}{|c|c|c|c|c|c|c|c|}
\hline \multicolumn{3}{|c|}{$\begin{array}{l}\text { ESPAÇAMENTO ENTRE } \\
\text { FISSURAS - valores médios }(\mathrm{mm})\end{array}$} & \multicolumn{3}{|c|}{$\begin{array}{l}\text { NERVURA TRACIONADA } \\
\text { face inferior (eixo 1) } \\
\end{array}$} & \multicolumn{2}{|c|}{ MODELO: VS - 5} \\
\hline Etapa & Força (kN) & $\mathrm{A} 1$ & A2 & B1 & B2 & $\mathrm{C} 2$ & $\mathrm{C} 1$ \\
\hline \multicolumn{8}{|l|}{0} \\
\hline 1 & 150 & & & & & & \\
\hline 2 & 180 & & & 150 & & & \\
\hline 3 & 210 & & 200 & 130 & 230 & & \\
\hline 4 & 240 & & 135 & 95 & 140 & & \\
\hline 5 & 270 & & 135 & 95 & 140 & 200 & \\
\hline 6 & 300 & & 135 & 95 & 110 & 200 & \\
\hline 7 & 330 & & 100 & 95 & 110 & 140 & \\
\hline 8 & 360 & & 100 & 95 & 100 & 140 & \\
\hline 9 & 390 & & 100 & 95 & 100 & 140 & \\
\hline 10 & 420 & & 100 & 95 & 100 & 140 & \\
\hline RUÍNA & 430,3 & & 100 & 95 & 100 & 140 & \\
\hline
\end{tabular}

\begin{tabular}{|c|c|c|c|c|c|c|c|}
\hline \multicolumn{3}{|c|}{$\begin{array}{l}\text { ESPAÇAMENTO ENTRE } \\
\text { FISSURAS - valores médios (mm) }\end{array}$} & \multicolumn{3}{|c|}{$\begin{array}{l}\text { NERVURA TRACIONADA } \\
\text { face lateral (eixo 2) }\end{array}$} & \multicolumn{2}{|c|}{ MODELO: VS - 5} \\
\hline Etapa & Força $(\mathrm{kN})$ & A1 & A2 & B1 & B2 & $\mathrm{C} 2$ & $\mathrm{C} 1$ \\
\hline \multicolumn{8}{|l|}{0} \\
\hline 1 & 150 & & & & & & \\
\hline 2 & 180 & & 150 & & & & \\
\hline 3 & 210 & & 150 & 130 & & & \\
\hline 4 & 240 & & 150 & 130 & & & \\
\hline 5 & 270 & & 140 & 130 & 390 & & \\
\hline 6 & 300 & & 140 & 130 & 180 & 240 & \\
\hline 7 & 330 & & 140 & 130 & 180 & 155 & \\
\hline 8 & 360 & & 140 & 100 & 180 & 155 & \\
\hline 9 & 390 & & 140 & 100 & 140 & 155 & \\
\hline 10 & 420 & & 140 & 100 & 140 & 155 & \\
\hline RUÍNA & 430,3 & & 140 & 100 & 140 & 155 & \\
\hline
\end{tabular}

\begin{tabular}{|c|c|c|c|c|c|c|c|}
\hline \multicolumn{3}{|c|}{$\begin{array}{l}\text { ESPAÇAMENTO ENTRE } \\
\text { FISSURAS - valores médios (mm) }\end{array}$} & \multicolumn{3}{|l|}{$\begin{array}{l}\text { ALMA } \\
\text { (eixo 3) }\end{array}$} & \multicolumn{2}{|c|}{ MODELO: VS - 5} \\
\hline Etapa & Força $(\mathrm{kN})$ & A1 & A2 & B1 & B2 & $\mathrm{C} 2$ & $\mathrm{C} 1$ \\
\hline \multicolumn{8}{|l|}{0} \\
\hline 1 & 150 & & & & & & \\
\hline 2 & 180 & & & 240 & & & \\
\hline 3 & 210 & & & 240 & 490 & & \\
\hline 4 & 240 & & 195 & 240 & 490 & 450 & \\
\hline 5 & 270 & 200 & 180 & 240 & 240 & 280 & \\
\hline 6 & 300 & 200 & 180 & 240 & 240 & 280 & \\
\hline 7 & 330 & 200 & 180 & 240 & 240 & 280 & \\
\hline 8 & 360 & 200 & 180 & 240 & 240 & 280 & \\
\hline 9 & 390 & 200 & 180 & 240 & 240 & 280 & \\
\hline 10 & 420 & 200 & 180 & 240 & 240 & 280 & \\
\hline RUÍNA & 430,3 & 200 & 180 & 240 & 240 & 280 & \\
\hline
\end{tabular}


Tabela C-37 - Aberturas de fissuras na viga VS-6.

\begin{tabular}{|c|c|c|c|c|c|c|c|}
\hline \multicolumn{3}{|c|}{$\begin{array}{l}\text { VALORES DAS ABERTURAS } \\
\text { DE FISSURAS (mm) }\end{array}$} & \multicolumn{3}{|c|}{$\begin{array}{l}\text { NERVURA TRACIONADA } \\
\text { face inferior (eixo 1) }\end{array}$} & \multicolumn{2}{|c|}{ MODELO: VS - 6} \\
\hline Etapa & Força $(\mathrm{kN})$ & A1 & A2 & B1 & B2 & $\mathrm{C} 2$ & $\mathrm{C} 1$ \\
\hline \multicolumn{8}{|l|}{0} \\
\hline \multicolumn{8}{|l|}{1} \\
\hline 2 & 150 & & & --- & 0,04 & 0,04 & \\
\hline 3 & 180 & & --- & 0,04 & 0,05 & 0,05 & \\
\hline 4 & 210 & --- & 0,05 & 0,05 & 0,05 & 0,05 & \\
\hline 5 & 240 & 0,04 & 0,05 & 0,06 & 0,08 & 0,06 & \\
\hline 6 & 270 & 0,05 & 0,06 & 0,06 & 0,08 & 0,07 & \\
\hline 7 & 300 & 0,05 & 0,08 & 0,08 & 0,09 & 0,08 & \\
\hline 8 & 330 & 0,05 & 0,08 & 0,10 & 0,10 & 0,08 & \\
\hline 9 & 360 & 0,06 & 0,11 & 0,10 & 0,12 & 0,09 & \\
\hline 10 & 390 & 0,07 & 0,11 & 0,10 & 0,12 & 0,10 & --- \\
\hline RUÍNA & 413,9 & & & & & & \\
\hline
\end{tabular}

\begin{tabular}{|c|c|c|c|c|c|c|c|}
\hline \multicolumn{3}{|c|}{$\begin{array}{l}\text { VALORES DAS ABERTURAS } \\
\text { DE FISSURAS (mm) }\end{array}$} & \multicolumn{3}{|c|}{$\begin{array}{l}\text { NERVURA TRACIONADA } \\
\text { face lateral (eixo 2) }\end{array}$} & \multicolumn{2}{|c|}{ MODELO: VS - 6} \\
\hline Etapa & Força $(\mathrm{kN})$ & A1 & $\mathrm{A} 2$ & B1 & B2 & $\mathrm{C} 2$ & $\mathrm{C} 1$ \\
\hline \multicolumn{8}{|l|}{0} \\
\hline \multicolumn{8}{|l|}{1} \\
\hline 2 & 150 & & & --- & & & \\
\hline 3 & 180 & & --- & 0,04 & & & \\
\hline 4 & 210 & --- & 0,05 & 0,04 & --- & --- & \\
\hline 5 & 240 & 0,04 & 0,05 & 0,06 & 0,06 & 0,05 & \\
\hline 6 & 270 & 0,05 & 0,06 & 0,07 & 0,06 & 0,06 & \\
\hline 7 & 300 & 0,05 & 0,07 & 0,08 & 0,08 & 0,07 & \\
\hline 8 & 330 & 0,05 & 0,08 & 0,08 & 0,09 & 0,08 & \\
\hline 9 & 360 & 0,06 & 0,09 & 0,08 & 0,10 & 0,08 & \\
\hline 10 & 390 & 0,07 & 0,09 & 0,10 & 0,10 & 0,09 & --- \\
\hline RUÍNA & 413,9 & & & & & & \\
\hline
\end{tabular}

\begin{tabular}{|c|c|c|c|c|c|c|c|}
\hline $\begin{array}{l}\text { VALOR } \\
\text { DE FISS }\end{array}$ & $\begin{array}{l}\text { S DAS ABE } \\
\text { RAS (mm) }\end{array}$ & URAS & $\begin{array}{l}\text { ALMA } \\
\text { (eixo 3) }\end{array}$ & & & MODEI & \\
\hline Etapa & Força $(\mathrm{kN})$ & A1 & $\mathrm{A} 2$ & B1 & B2 & $\mathrm{C} 2$ & $\mathrm{C} 1$ \\
\hline 0 & & & & & & & \\
\hline 1 & & & & & & --- & \\
\hline 2 & 150 & & --- & --- & & 0,05 & \\
\hline 3 & 180 & & 0,07 & 0,05 & & 0,09 & \\
\hline 4 & 210 & --- & 0,08 & 0,05 & & 0,09 & --- \\
\hline 5 & 240 & 0,08 & 0,08 & 0,06 & --- & 0,14 & 0,14 \\
\hline 6 & 270 & 0,13 & 0,13 & 0,06 & 0,07 & 0,14 & 0,15 \\
\hline 7 & 300 & 0,20 & 0,30 & 0,07 & 0,07 & 0,30 & 0,20 \\
\hline 8 & 330 & 0,30 & 0,35 & 0,09 & 0,08 & 0,40 & 0,40 \\
\hline 9 & 360 & 0,40 & 0,40 & 0,09 & 0,08 & 0,40 & 0,40 \\
\hline 10 & 390 & 0,65 & 0,50 & 0,09 & 0,09 & 0,50 & 0,50 \\
\hline RUÍNA & 413,9 & & & & & & \\
\hline
\end{tabular}


Tabela C-38 - Espaçamentos entre fissuras na viga VS-6.

\begin{tabular}{|c|c|c|c|c|c|c|c|}
\hline \multicolumn{3}{|c|}{$\begin{array}{l}\text { ESPAÇAMENTO ENTRE } \\
\text { FISSURAS - valores médios }(\mathrm{mm})\end{array}$} & \multicolumn{3}{|c|}{$\begin{array}{l}\text { NERVURA TRACIONADA } \\
\text { face inferior (eixo 1) }\end{array}$} & \multicolumn{2}{|c|}{ MODELO: VS - 6} \\
\hline Etapa & Força (kN) & A1 & A2 & B1 & B2 & $\mathrm{C} 2$ & $\mathrm{C} 1$ \\
\hline \multicolumn{8}{|l|}{0} \\
\hline \multicolumn{8}{|l|}{1} \\
\hline 2 & 150 & & & & & & \\
\hline 3 & 180 & & & 170 & 170 & 180 & \\
\hline 4 & 210 & & 280 & 170 & 170 & 180 & \\
\hline 5 & 240 & & 280 & 170 & 110 & 180 & \\
\hline 6 & 270 & & 280 & 130 & 110 & 180 & \\
\hline 7 & 300 & & 260 & 130 & 110 & 180 & \\
\hline 8 & 330 & & 160 & 110 & 100 & 120 & \\
\hline 9 & 360 & & 160 & 110 & 95 & 120 & \\
\hline 10 & 390 & & 130 & 110 & 95 & 120 & \\
\hline RUÍNA & 413,9 & & 130 & 110 & 95 & 120 & \\
\hline
\end{tabular}

\begin{tabular}{|c|c|c|c|c|c|c|c|}
\hline \multicolumn{3}{|c|}{$\begin{array}{l}\text { ESPAÇAMENTO ENTRE } \\
\text { FISSURAS - valores médios (mm) }\end{array}$} & \multicolumn{3}{|c|}{$\begin{array}{l}\text { NERVURA TRACIONADA } \\
\text { face lateral (eixo 2) }\end{array}$} & \multicolumn{2}{|c|}{ MODELO: VS - 6} \\
\hline Etapa & Força $(\mathrm{kN})$ & A1 & A2 & B1 & B2 & $\mathrm{C} 2$ & $\mathrm{C} 1$ \\
\hline \multicolumn{8}{|l|}{0} \\
\hline \multicolumn{8}{|l|}{1} \\
\hline 2 & 150 & & & & & & \\
\hline 3 & 180 & & & & & & \\
\hline 4 & 210 & & & & & & \\
\hline 5 & 240 & & & 220 & & & \\
\hline 6 & 270 & & & 220 & 220 & & \\
\hline 7 & 300 & & & 220 & 220 & & \\
\hline 8 & 330 & & & 220 & 220 & 190 & \\
\hline 9 & 360 & & & 220 & 220 & 190 & \\
\hline 10 & 390 & & & 220 & 220 & 190 & \\
\hline RUÍNA & 413,9 & & & 220 & 220 & 190 & \\
\hline
\end{tabular}

\begin{tabular}{|c|c|c|c|c|c|c|c|}
\hline $\begin{array}{l}\text { ESPAÇ } \\
\text { FISSUR }\end{array}$ & $\begin{array}{l}\text { MENTO EN } \\
\text { S - valores n }\end{array}$ & $\mathrm{ss}(\mathrm{mm})$ & $\begin{array}{l}\text { ALMA } \\
\text { (eixo 3) }\end{array}$ & & & MODE & \\
\hline Etapa & Força $(\mathrm{kN})$ & A1 & A2 & B1 & B2 & $\mathrm{C} 2$ & $\mathrm{C} 1$ \\
\hline 0 & & & & & & & \\
\hline 1 & & & & & & & \\
\hline 2 & 150 & & & & & & \\
\hline 3 & 180 & & 210 & & & & \\
\hline 4 & 210 & & 210 & & & 220 & \\
\hline 5 & 240 & 90 & 210 & 135 & & 220 & \\
\hline 6 & 270 & 90 & 210 & 135 & 330 & 220 & \\
\hline 7 & 300 & 80 & 150 & 135 & 330 & 210 & 180 \\
\hline 8 & 330 & 80 & 150 & 135 & 330 & 210 & 180 \\
\hline 9 & 360 & 80 & 150 & 135 & 330 & 210 & 180 \\
\hline 10 & 390 & 80 & 150 & 135 & 330 & 120 & 180 \\
\hline RUÍNA & 413,9 & 80 & 150 & 135 & 330 & $\overline{120}$ & 180 \\
\hline
\end{tabular}

